$R B 208292$

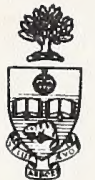

Presented to the

\section{LIBRARY of the}

\section{UNIVERSITY OF TORONTO}

by

William Johnston 

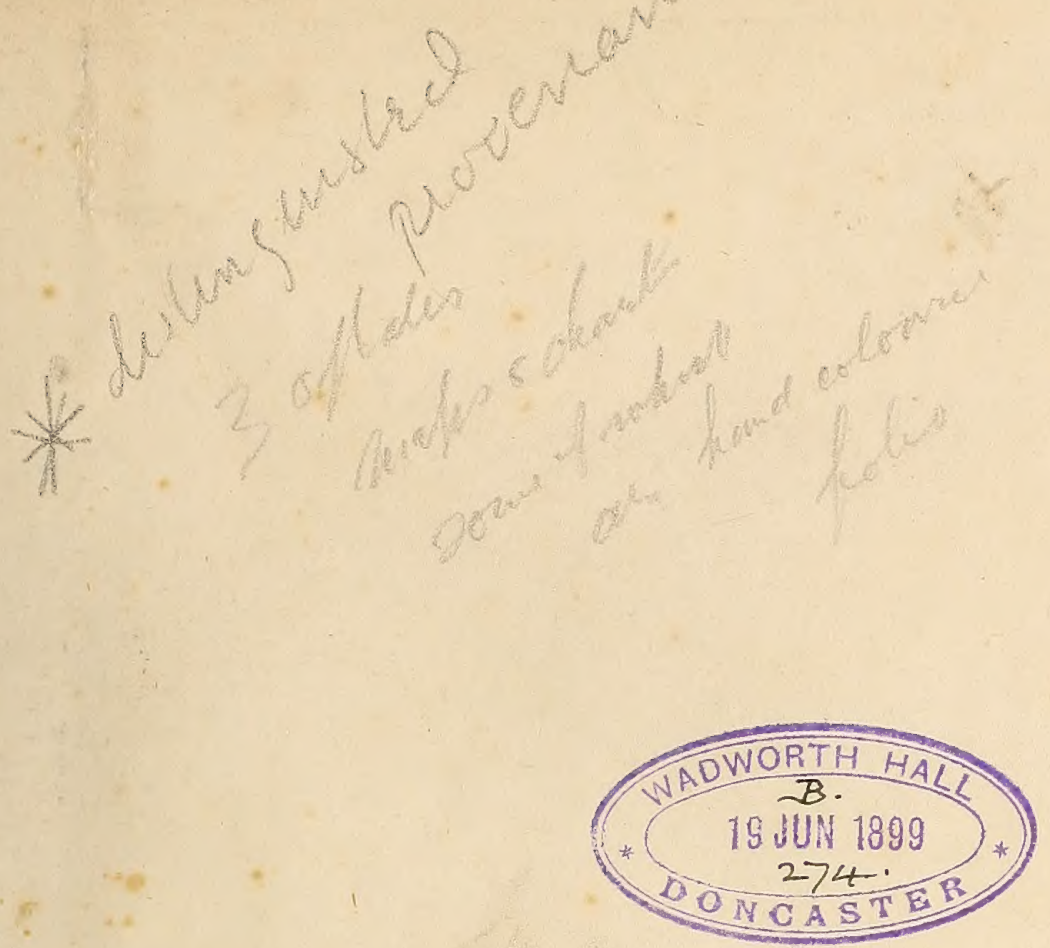

REV. JAMES C. Ross, dedaworth 5all, DONCASTER.

REV. JAMES C. Ross,

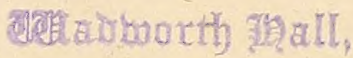
DONCASTER.

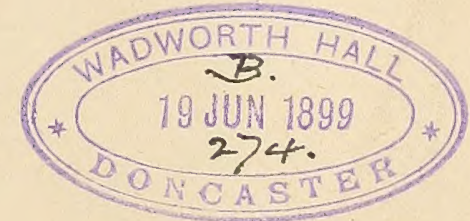


Digitized by the Internet Archive in 2015

https://archive.org/details/narrativeofsecon00ross_1 



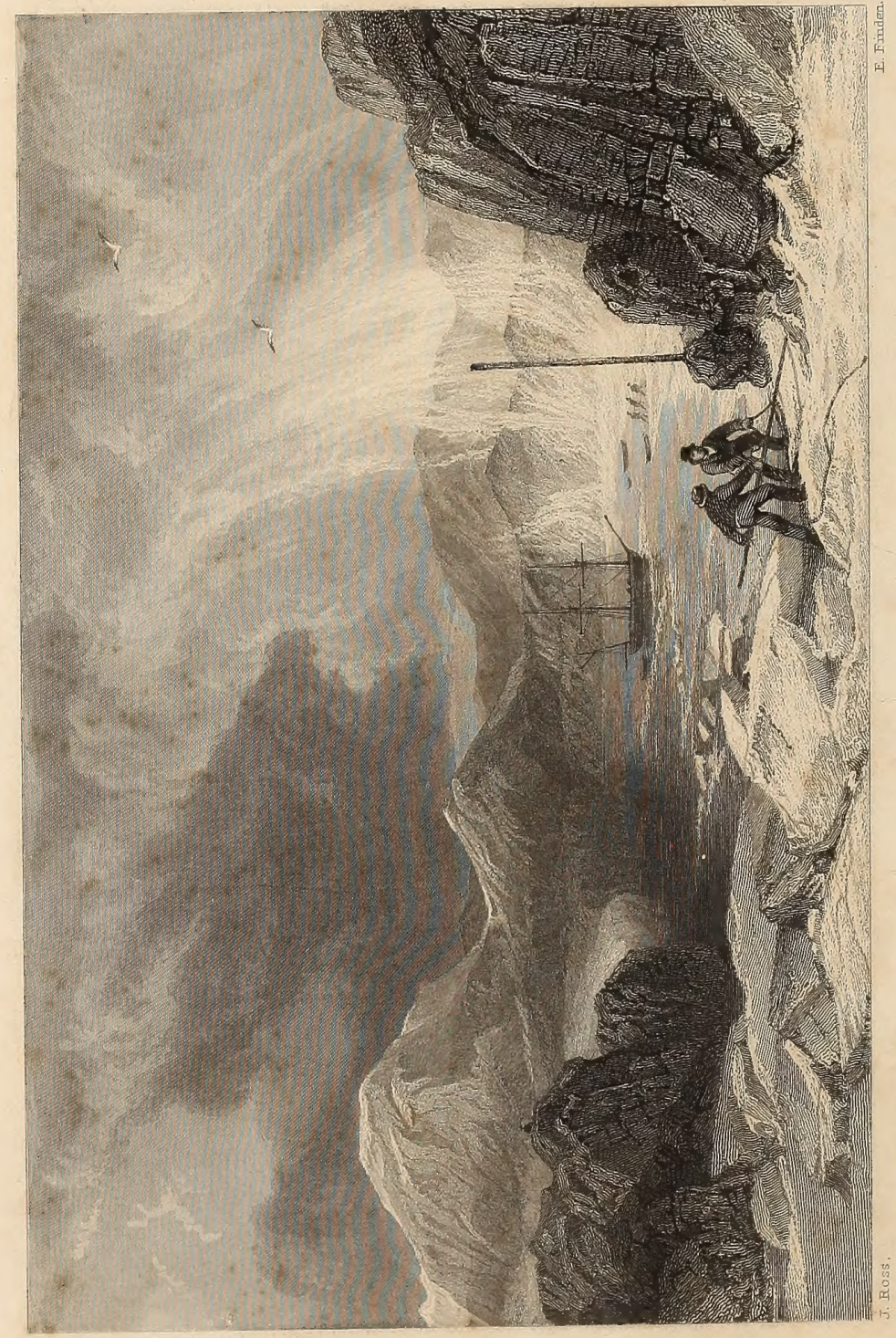

0
5
0
0
0
0
0
0
0
0 


\title{
NARRATIVE
}

OF A

\author{
SECOND VOYAGE IN SEARCH OF
}

A

\section{NORTH-WEST PASSAGE, AND OF A}

\section{RESIDENCE IN THE ARCTIC REGIONS}

DURING THE YEARS 1829, 1830, 1831, 1832, 1833.

BY

SIR JOHN ROSS, C.B., K.S.A., K.C.S., \&c. \&c. CAPTAIN IN THE ROYAL NAVY.

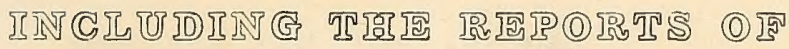

COMMANDER, Now CAPTAIN, JAMES CLARK ROSS, R.N., F.R.S., F.L.S., \&C. A N D

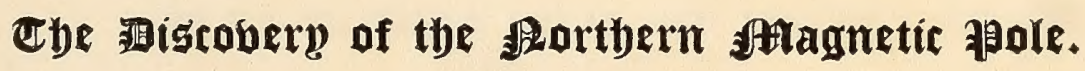

$$
\text { L O N D O N : }
$$

A. W. W EBSTER, 156, REGENT STREET.

1835.

REV. JAMES C. ROBS, dellavmortb 政all, DONCASTER.

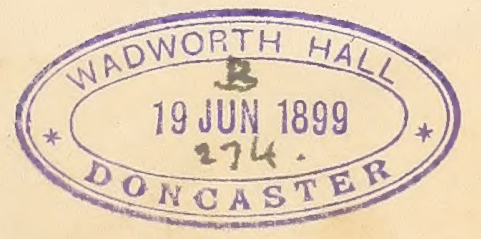

REV. J.MES \&. ROBS,

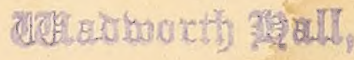
DONCASTER: 


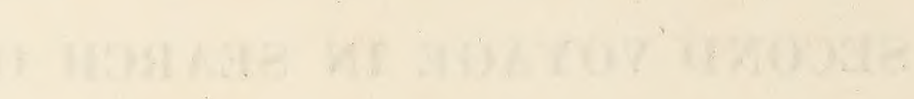

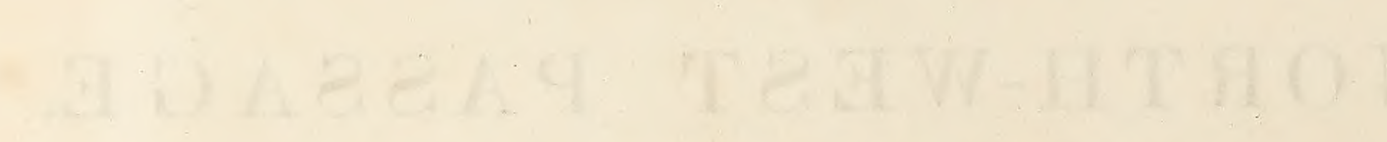


TO

HIS MOST EXCELLENT MAJESTY, WILLIAM IV.

KING OF GREAT BRITAIN, IRELAND, \&c.

\section{THIS NARRATIVE}

OF THE

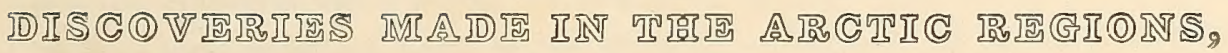
IN THE YEARS

$1829,1830,1831,1832$, AND 1833 ,

IS DEDICATED WITH HIS MAJESTY'S GRACIOUS PERMISSION,

BY HIS MAJESTY'S LOYAL AND DEVOTED SUBJECT,

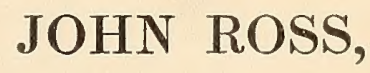

CAPTAIN IN THE ROYAL NAVY. 
| 


\section{A DVERT IS EME NT.}

THE Author is sensible that he owes his numerous and generous Subscribers some apology for the delay which has occurred in the publication of his work : a delay, as vexatious to him as it must have been wearisome to them. But they who know the troubles connected with printing, and still more with engraving, will not be surprised; while to those causes he must add his absence from England during many months of the last year. Trusting in this, he subscribes himself,

Their most obedient humble Servant, 



\section{INTRODUCTION.}

Tнат the public should expect some introduction to the journal of a voyage which has attracted so much notice, is natural; but having placed at the commencement of the narrative, all those matters which relate to the original project, to the financial arrangements under which the expedition was undertaken, to the fitting out of the ship, and the selection of the officers and crew, I have anticipated, if I may so say, in the work itself, much of that which is generally referred to an introduction, in books of this nature.

That in giving an account of the last voyage which has been undertaken for the discovery of a north-west passage, and of the last which will probably be attempted for some years to come, I ought to have sketched, at least, the history of the endeavours made to find such a passage to the westward round the northern shores of America, has been the opinion of many of my friends, and of him in particular on whom I have most relied.

But so much has been published on this subject, and by so many writers, long before my first voyage, and still more during the years which have intervened between that and the present one, that I cannot but believe that all who interest themselves in this question, must be as fully informed respecting it as they could desire ; while perhaps every reader of this journal is sufficiently acquainted with the subject, either from the intermediate voyages, the public journals and reviews, or that work of Barrow which has long been in circulation, to render such a sketch superfluous; as it could also be nothing 
more than an abridged compilation, prolonging a work which has already extended to a much greater length than $I$ at first foresaw.

I have thought it best, therefore, to refer to Purchas, Harris, Churchill, Barrington, to works in many hands, and always easy of access, but above all to Barrow's Chronological History, published in 1818, for such fuller information as I might have extracted from those writers, had I thought it expedient. Yet not willing to leave entirely in the dark on this subject, those to whom such reading may be neither familiar nor accessible, I will here give a condensed list sufficient for such a general purpose, from the writers above named. It will thus be the easier for those who are desirous of extending their knowledge of this question, to refer to any author or any voyage which they may fancy; though I imagine that Barrow's sketch will be sufficient to satisfy most readers.

It was in the ninth century that this problem seems to have been first proposed: and the first northern expedition by sea, of which we know, was that of Othervie, who sailed from Drontheim to the White Sea. Iceland was also discovered about the same period, and subsequently, Greenland, by means of a voyage from that island in the year 970 .

1496 John Cabot, sailed, and made an unsuccessful voyage in the same quarter; and in 1498 Sebastian Cabot went to the west coast of Greenland, and reached the latitude of $56^{\circ}$, but without effecting the particular object in view.

1500-1502 Gaspar and Michael Cotreal made two voyages to Greenland, and affirm that they reached the sixtieth degree of latitude. They discovered the straits of Gaspar and several islands, together with the strait which was called Anian, by them.

1508-1535 Jacque and Aubert Cartier made several voyages for the purpose of exploring a new passage to the countries from which Spain derived her treasure, and they discovered the Gulf of St. Lawrence.

1524 Estevan Gomez was employed by Spain for the same purpose, but was unsuccessful; having only reached Labrador.

1542 Mendoza Coronada tried to find the supposed strait of Anian, but saw nothing to satisfy him respecting its existence.

1527 Robert Thorne, of Bristol, is said, in Hakluyt's Collection, to have sailed for the discovery of the North Pole; but there is no account of his voyage. 
1553 Sir Hugh Willoughby sailed from England, and is said to have discovered Nova Zembla; but, on his return, he was frozen to death in Lapland, with all his crew.

1555-1557 Steven Burough and Richard Chancelor made two voyages, in which they reached the Island of Weigatts, and Nova Zembla, but without effecting a northeast passage, which was the object these navigators had in view.

1576 Martin Frobisher made his first voyage, discovering the strait which bears his name, which was at one time supposed to have divided or cut off a portion of old Greenland: but this expectation was afterwards proved to be fallacious, while it is now concluded that this imaginary passage is probably nothing more than one of the openings on the west coast of Davis's strait.

1577 The same navigator made a second voyage, and named Mount Warwick, to the southward of what has since been called Frobisher strait; but it does not appear that he made any advance towards the discovery of a passage.

1578 In this year he made a third voyage, which was unsuccessful. After this, two brothers of the same name sailed to discover a north-west passage, but they never returned, nor is there any conjecture respecting their fate.

1579 Edward Fenton sailed to discover a north-west passage, by the way of the Pacific; but he returned, without having even proceeded towards the object which he had in view, in consequence of his fear of the Spaniards, by whom he expected to be taken or intercepted.

1580 Mercator, Pet, and Jackman tried, without success, to penetrate through Weigatz strait, and returned with much difficulty.

1583 Sir Humphrey Gilbert, intending to discover the north-west passage, sailed to Newfoundland.

1585 John Davis made his first voyage, and discovered the strait which bears his name. On the eastern side of this wide sea, so improperly termed a strait, he discovered and named what has retained his appellative of Cape Desolation, and, on the western shore, Mount Raleigh, Cape Walsingham, Exeter Sound, and some other places still bear the names which he gave them.

1586 In his second voyage, this enterprising and persevering seaman examined the coast on the west side of the strait between Cumberland island and the latitude of $66 \frac{10}{2}$ north.

1587 Not discouraged, however, by his want of success, this navigator made a third 
voyage, and affirms that he reached the $73 \mathrm{~d}$ degree of latitude. In this, he examined the coast which he had seen before, giving names to some other places, but made no advance towards the solution of the problem which he had in view. The discoveries, however, which he made in the course of his three voyages proved of great commercial importance: since, to him more than any preceding or subsequent navigator, has the whale fishery been indebted. Let not his name be slightly passed over. In talent he has not had many rivals : and it is ignorance, probably, rather than ingratitude, which fails to thank him for the debts owed him by British commerce.

1588 The voyage of Maldonado has been so strictly canvassed, and so utterly discredited in consequence, that if I name him in this chronological list, it is but for the sake of those who may have heard of his voyage but not of the criticisms which it has justly received. He did not make the north-west passage to which he pretends; beyond this I need not say what it was that he asserted himself to have done.

1592 Juan de Fuca was sent to discover the supposed strait of Anian. By his own account he followed the coast until he discovered an opening, up which he sailed in various directions during twenty days, after which he entered into the North Sea; when finding it to be so wide for 30 or 40 leagues within the strait as to make him suppose that it really would afford that passage of which he was in search, he conceived that he had discharged his duty, and therefore returned.

1594-1596 William Barentz, in company with three others, made three voyages; in the last of which he and half his crew perished: but these voyages were all directed to the north-east. passage, and he advanced no further than Weigatz strait, and the north-west end of Nova Zembla.

1602 George Weymouth sailed from England, but he reached no latitude higher than $64^{\circ}$, and therefore made no discoveries.

1605 James Hall sailed to Greenland with two ships, and coasted the land up to $63^{\circ}$, but made no discovery.

1606-1607 In these years he made two more voyages to the same coast, but he only reached $66^{\circ}$, and returned without success.

1606 John Knight sailed to discover that same north-west passage which seems to have occupied the dreams of half the navigating and commercial portion of mankind, 
at this time, and during so many previous and subsequent years: but he only reached the coast of Labrador, and returned, abandoning the enterprise.

1607 Henry Hudson's first voyage was to the east coast of Greenland, and he returned by the way of Spitzbergen and Cherry island.

1608-1610 In these years, this commander, whose name has had the good fortune of being perpetuated in no common manner, by the results which gave rise to the incorporation of so opulent a mercantile company as that which bears his name, and by the enormous territory which has fallen under their sway, made two other voyages. He then discovered the bay which bears his name, but made no other discovery.

1611 In his fourth voyage his men mutinied, and he lost his life, after he had penetrated to $73^{\circ}$ north.

1609-1611 James Poole made two voyages, and reached the 73d degree of latitude in Davis's straits, which was the nearest approach to the Pole that had been made down to that period.

1611 Sir Thomas Button made a voyage for the discovery of a north-west passage, but it was without the expected success : his voyage was never published.

1612 James Hall sailed on a fourth voyage for the discovery of a north-west passage. He reached Ramelsford, in Greenland, in $67^{\circ}$, and was there killed by a savage. The new master decided on returning, without making any further effort.

1614 Captain Gibbons sailed to discover a passage, but having been entangled in the ice, he took shelter in a creek about the latitude of $57^{\circ}$, where he remained five months; after which, contriving to escape, yet not without considerable damage, he returned to England.

1615 In this voyage Robert Bylot was master, and Wm. Baffin acted as the mate and pilot. Their success was not great, since they only reached as far as $65^{\circ}$ north, examining the coast of Davis's strait, and tracing the coast thence to Resolution island, where they abandoned their pursuits, returning to England in September.

1616 Bylot and Baffin again sailed, and circumnavigated the bay which now bears the name of the latter, until they came to a sound which was named Sir James Lancaster's sound, in lat. $74^{\circ} 20^{\prime}$. The narration of this voyage is very imperfect, while there is a reference to a chart which is not given by Purchas, and as far as I now know, is not to be found at present. There are charts, however, which 
probably give these discoveries in the exact manner in which they were laid down by Baffin: but as I have had occasion to remark at some length at the end of this Introduction, it is exceedingly incorrect in the longitudes, though sufficiently true in the latitudes, while the consequences of the former error are of such importance as to have led me into a detailed criticism on the question of this geography.

1614-1616 Fotherby made a voyage for the discovery of a north-west passage, but without success.

1619 Jans Munk, entered Hudson's bay, in this year, and visited Thorfield inlet, returning without success.

1630-1631 Luke Fox (commonly called north-west Fox), made an attempt to penetrate by Hudson's bay, but he added nothing to former discoverers, and returned unsuccessful.

1601 James sailed from Bristol, and asserted that he discovered that now well-known island to which he gave his name. Since my own voyage, in 1818, there have been doubts respecting this "James's island ;" and the subject is so remarkable, not less than complicated, that I must refer it to the end of this Introduction, where I have attempted to elucidate this somewhat troublesome piece of geography, and, as I trust, with some success.

1633 Seven Russian sailors, who appear to have been shipwrecked at Spitzbergen, remained there one year.

1636 The Russians discovered the Lena and other rivers in the north of Europe and Asia, the account of which will be found in Churchill's collection of voyages.

1640 Bernarda, a Spaniard, affirms that by a coasting voyage he sailed from the Pacific through a strait, and reached an isthmus which divides the west from the east sea at Baffin's bay, where he could see the sea on each side from the high land, which he ascended.

1646 Forty-two persons were wrecked at Spitzbergen, and remained there a year.

1719-1722 There are voyages recorded to have been performed between these years, by Knight, Barlow, Vaughan, and Scroggs; but very little is known of these navigators, except that they sailed to discover a north-west passage. As no account of them was ever received, it must be presumed that they were lost.

1719 John Munk sailed on a voyage of discovery to the north, but his men all died 
excepting two, and he was unsuccessful, as far as any record of him has arrived to our days.

1722 Behring's strait was discovered by the navigator of that name: he was afterwards wrecked on Behring's island, which he had discovered, and there he died.

1741 Christopher Middleton sailed to Hudson's bay in the Furnace, for the discovery of a north-west passage; his failure led to a controversy between him and Dobbs, and also with the Admiralty, on which I need not here enter.

1743 Six Russian sailors were left at Spitzbergen, and remained there six years.

1740-1746 The Russian government employed several officers, and traced, by land, nearly the whole coast of Europe and Asia, between Nova Zembla and Behring's strait.

1746 William Moor and Francis Smith made an unsuccessful attempt in this wearisome pursuit by the way of Repulse bay; this being one of the speculations, the execution of which has since been repeated in our own times, and, as all know, without success.

1769-1772 Hearne discovered Hearne river, by means of a journey by land, which has been so often quoted as to be familiar to every one.

1773 Phipps (afterwards Lord Mulgrave) made an unsuccessful attempt to reach the Pole; this voyage' is equally familiar, and is often quoted, the more so, perhaps, on account of its style, and of the honours conferred on his name.

1776 The justly celebrated Captain Cook (accompanied by Captain James Clerke), who had already performed two voyages round the world, attempted to discover the north-west passage, by Behring's strait, which he entered in August, 1779, and penetrated to a point which he named Icy Cape, in latitude $70^{\circ} 29^{\prime} \mathrm{N}$, and in longitude $198^{\circ} 20^{\prime} \mathrm{W}$, where he found the ice impenetrable, being a solid mass ten feet thick and extending across to the coast of Asia, aground in twenty-seven fathoms. He returned to the Sandwich islands, and there, as is well known, he lost his life in a contest with the natives.

1780 Captains Clerke and King made another unsuccessful attempt in the same quarter; but the furthest point to which they proceeded was lat. $70^{\circ} 33^{\prime} \mathrm{N}$, in $194^{\circ}$ west longitude.

1776 Lieutenant Pickersgill was sent out in the Lion brig to meet Captain Cook, by Baffin's bay: he reached the latitude of $68^{\circ} 10^{\prime}$, and bore up for Labrador, returning unsuccessful. 
1777 Lieutenant Young, in the same ship, was sent for the same purpose: he reached $72^{\circ} 45^{\prime}$ (Woman's islands), and returned without making any further progress.

1786-1787 The Danish Admiral Lowenorn, sailed to " re-discover" (as the phrase is), East Greenland, but his vessels being damaged by the ice, he returned to Denmark unsuccessful.

1789 Alexander Mackenzie, afterwards knighted, discovered the Mackenzie river by a land journey, and traced it to the Frozen Sea. His tediously-written journey has been read by every one conversant with voyages and travels.

$1790 \mathrm{Mr}$. Duncan examined Chesterfield inlet : his men mutinied, and he returned, in consequence, without success.

1815-1818 Lieutenant Kotzebue, in a vessel named the Rurik, fitted out for discovery at the expense of the Russian Count Romanzoff, proceeded round Cape Horn, and attempted the discovery of the north-west passage, by the way of Behring's strait. This he passed, and entered on the sea which washes the northern shore of the American continent; discovering also the sound which bears his name, and which had been passed unobserved by Captain Cook. He returned unsuccessful, as far as even the slightest attempt at a passage is concerned, since he did not succeed in reaching Icy Cape.

1818 In this year I circumnavigated Baffin's bay, and by this means restored to our charts, whence they had been expunged, the valuable discoveries of that great navigator, whose name it bears: correcting them only where the imperfection, of his means, and other circumstances, had left errors, of small importance compared to what he had effected. I need not name here, what else in its consequences to commerce, was the result of this my first voyage.

1818 Buchan made a fruitless attempt to reach the Pole; having failed, from circumstances beyond his control, he returned in consequence of the damage sustained by his ship.

1819-1820 Parry in his first voyage, between latitude $74^{\circ} \mathrm{N}$, and $113^{\circ} \mathrm{W}$, discovered Melville island, North Georgian, now called Parry's islands, and Prince Regent's inlet, and was the first to winter in these regions.

1820-1821 Franklin, in his first journey from Hudson's bay, by land, for this purpose, traced the coast of America between Hearne river and Point Turnagain.

1821-1822 Parry, in his second voyage, discovered the land which he has termed Melville peninsula, together with the strait which he has named after his ships the Fury and Hecla. 
1822-1823 Franklin, in his second journey, traced the coast of America between Mackenzie river and Cape Back; while Dr. Richardson, separating from him for this purpose, surveyed the coast between Hearne and Mackenzie rivers.

1822-1825 Parry, in his third voyage, penetrated down Prince Regent's inlet as far as latitude $72^{\circ} 30^{\prime}$ in longitude $91^{\circ} \mathrm{W}$. In this voyage the Fury was lost, and he, in consequence, returned unsuccessful.

1823-1826 Beechy, in a voyage which occupied the period denoted in these dates, passed through Behring's strait, and attempted to penetrate to the eastward; he reached the $71^{\circ} 23 \frac{1}{2}^{\prime}$ latitude and the $156^{\circ} 21 \frac{1}{2}^{\prime}$ west longitude, leaving about 150 miles unexplored between his own and Franklin's discoveries.

1827 Parry, in this year, made an unsuccessful attempt to reach the North Pole; it having been imagined that a free passage to the equator might possibly be made in that direction.

The results of all these voyages show that the discovery and survey of the land between Greenland and Asia had gradually advanced: so that when my voyage was undertaken in 1829, there were only 150 miles on the west side, near Behring's strait, and 500 miles on the east side, between Cape Garry and Cape Turnagain, unexplored, Davis may be said to have made the first important advance towards a passage, and Baffin the second. The latter was found to be correct in his latitudes, but his longitudes were proved to be the reverse. The last of these statements on his part seems to have led to the unjust supposition that he was equally incorrect in every thing; whence it happened, under some criticisms which I have now no intention to examine, that all which he had done was asserted to be incorrect and false. Hence was James's island expunged from our charts, as I have remarked in a former note on his voyage; but far more uncharitably as well as improperly, the bay which had so long and so justly borne his name, was equally obliterated: as if this great navigator had seen nothing and done nothing. It is not thus that men will be tempted to sacrifice their time, their comforts, their fortunes, and their lives, in the service of mankind: but if fame must hereafter be allotted or withheld by any one who may assume the office of a judge, then let the men of ability and enterprise withdraw, unless they are of that better spirit which finds its reward in an approving conscience.

If the name of Baffin was restored to its exalted place, as I trust it was by my voyage in 1818 , I may now proceed to remark, that the results of my late expedition 
consist in the Discovery of King William's land; the isthmus and peninsula of Boothia Felix; the gulf of Boothia: the western sea of King William, and the true position of a northern magnetic pole; and in regard to the question of a north-west passage, it is fully established that there is none through Prince Regent's inlet, or to the southward of the latitude of $74^{\circ}$ north. Besides this, many important and interesting facts regarding Magnetism and other branches of science and natural knowledge in the conclusion of the voyage. The banks of the Isabella and Alexander were restored to their former position in the chart, and the line of coast fully verified; and several harbours surveyed and discovered.

There remains, therefore, still the 150 miles to the westward, and to the eastward the space between Cape Turnagain and the coast seen by Sir Edward Parry, which may be estimated at 400 miles.

It is not generally known that the question of " a north-west passage," which had been lying dormant since the voyage of Captain Phipps, was, in 1817, revived by Mr. William Scoresby, a highly gifted and talented navigator, who then commanded a ship on the Greenland fishery, but now a respectable and useful member of the Church of England, at Exeter. This gentleman, in a well penned letter to Sir Joseph Banks, represented that so great a change had taken place in the seasons and the position of the ice in the Arctic Regions; that the time had probably arrived when the longagitated problem might be solved.

His object was, no doubt, employment on this arduous service, that as he had been the proposer he might share in the glory of the enterprise. Why his services were rejected does not appear, but I have his own authority for saying that he would have accepted "any situation in the expedition which a gentleman could hold." He cannot, however, be deprived of the merit of being the promoter of all the attempts which have been made since that time. Sir Joseph Banks's high recommendation of his proposal to the Government was attended to, and a circular was written to discover what officer of the navy had served most among ice. In the mean time ships were purchased, and were not only in a great state of forwardness before I was selected to command them, but all the junior officers were appointed. The purser and my nephew, then only seventeen years of age, being the only individuals of my own selection.

I believe there is no instance on record where an officer was appointed to command such an enterprise without his having been consulted as to the qualities of the ships he 
was to conduct; but with me it was not the case, and when I arrived in London I was concerned to discover that the ships (by that time half finished), were totally unfit for such a service; but my remonstrances were too late, and I was told that if I did not choose to accept the command some one else would; and as I had left the Driver, it was the only chance I had for promotion. I must here remark, however, that I throw no blame on the late Admiralty on this account; their lordships consulted, before I was selected, people well qualified to give them information; but these people had ships to sell or strengthen, and the temptation of gaining 6 or $7000 l$,, was sufficient to turn the scale; and I alone, who had the whole responsibility, was doomed to be the sufferer. The truth of my assertion is fully demonstrated in the narrative of my first voyage, and in the employment, subsequently, of ships of a totally different class. The officers were all, certainly, as seamen and navigators, well qualified, but none had ever wintered, or had any considerable experience among ice; the service was entirely new to them, and for this reason ice masters and mates were appointed, whose opinions of course had much the more weight, but if I had had officers of my own selection, I could have found those who combined those qualities with experience among ice, even more than my own; and I would certainly have employed Mr. Scoresby. As the results of my first expedition have been long before the public, and as it has been alluded to in the course of this narrative, I need only remark that it, as well as the subsequent voyages which precede my last, proves how much, or rather how entirely our humble endeavours depend on Divine Providence, which has wisely put less within our power than in any other kind of navigation. Added to the disadvantages which $I$ have mentioned, there were others which were beyond our control, which seemed to combine against the success of the enterprise, and the disappointment created a feeling towards the commander, against which nothing but a consciousness that he had always done his duty, could have supported him ; and which he now confesses made him anxious to prove that he could treat with a far different feeling all the abuse which has been so unsparingly, and he must add unjustly attached to his name. The expeditions subsequent to my first were closely watched by myself, with the view of correcting errors from whatever cause they might arise, and I soon discovered that the ships which had been employed since 1817, had been far too large; for while they carried provisions only in the same proportions to their crews, as a vessel half the size does to her crew, they drew such an increased depth of water, viz., eighteen feet instead of eight, 
as to render navigation in them much more unsafe, as in the instance of the Fury, which ship was damaged because her depth was greater than that of the ice, and when damaged had to be unloaded and hove down, and during this process that occupied several days, she was wrecked; whereas the Victory was actually laid on the ground, with all her stores, and when the tide fell she was dry (for she drew only seven feet), and her leak was stopped. Like the Fury, she carried two and a half years' provisions, besides coals for 1000 hours; and had the boiler and other parts of the machinery not given way, there can be no doubt but the services might have been performed, as far as the navigation was concerned, in fifteen months instead of four years and a half. Baffin's ship, though only thirty tons, was far more fit than either the Isabella, Fury, or Hecla. Sir Edward Parry's two voyages in that direction, and Sir John Franklin's journeys to the Polar Sea, had directed the eyes of the scientific world to Prince Regent's inlet, and with the exception of the late Major Rennell, there was no one that I conversed with on the subject, who did not say, that if no passage was found between Cape Garry and Point Turnagain there could be none at all. The Major was indeed of opinion that there was none there, and his reasons for it were well founded. It was, however, obvious that it became my duty, in undertaking this enterprise, to decide that question in the first place, and then turn my attention to the next opening further north, and it was an extraordinary fact that the first discovery we made was, that Cresswell bay was at least thirty miles deeper than where the land had been laid down on the preceding voyage, even after it had been seen from both the ship and the shore for several days, and it was not until we actually walked round it that we were certain that no passage existed in that direction; proving how very deceiving the appearance of ice in a bay or passage is, by its having deceived all the officers of both Hecla and Fury, after, too, an experience of eight years, just as it had myself and the pilots of the Isabella, in 1818. Nevertheless I determined to follow my first plan, which was also that approved of by Commander Ross, and Mr. Thom, the second and third in the direction. I shall leave the remainder of my proceedings for the reader of my narrative, which is carried on in the shape of a journal, which was written by myself daily. The ship was fitted out in a manner far superior to any other, as she combined every improvement which had previously been made, and the provisions were of the very best quality; and although the feeling was against her qualities, in consequence of the lamentable failure of the machinery, she proved 
to be the very best vessel that was ever employed on such a service. The instruments were chiefly my own; the transit was 36 inches, and the theodolite 9 inches, both by Jones; and several instruments were lent by the Admiralty and Colonial Secretary, all of which were lost, excepting a dipping needle, now in the possession of Captain J. C. Ross, belonging to the Admiralty; two of the chronometers were my own, one the property of Messrs. Parkinson and Frodsham, and three belonged to Mr. Murray : all of these performed well, but four of them were lost with the ship. Commander, now Captain J. C. Ross, who was second in command, had during the whole time the charge of the transit, and to him belong all the observations made with it, and with a sixty-six inch telescope of $3 \frac{1}{2}$ object glass, belonging to me; but these observations must, with the Natural History, also by him, form a part of an appendix, which will be published separate from the narrative, in which are only the abstracts, which would concern the general reader. The sketches from which the drawings were made were taken by Mr. Ronald's invaluable perspective instrument, and therefore must be true delineations: these, although they have been partly redrawn by Harding and Rowbotham, and engraved on steel by the first engravers, whose names will be found on the plates, were originally my own sketches, but they are only offered to the public as faithful illustrations of the work, being well aware that I do not possess such talents in that art as could embellish it, were the scenery even more favourable. The Meteorological Table, which is given in abstract, will be in full in the Appendix, as well as the Diurnal Variation, and a new theory of the Aurora Borealis: indeed, the length of the narrative has so much exceeded what I expected, that I have not been able to give any of the scientific observations at full length; as I have preferred giving Commander Ross's journeys, in which will be found the most remote and extended part of our discovery; and also that of the present position of the Magnetic Pole. The methods which necessity pointed out for the preservation of the health and discipline of the crew will be found in full; and at the end will be found an Addenda, comprehending the conclusion of our proceedings after our happy return.

In short, our whole voyage, from its commencement until its conclusion, will be found a wonderful chain of providential circumstances, affording an evident proof that those who "go down into the sea in ships," \&c., are, of all others, the most dependent on the Divine aid, and the most short-sighted of mortals; while it must be no less manifest, that if men rusting in "Him who cannot err," will only make 
use of the means mercifully put within their power, there are no difficulties which cannot be overcome, and no case too desperate!

It is not necessary that I should, in this Introduction, enter into a formal discussion respecting the probability that yet remains of finding a "North-west Passage," to the northward of the 74th degree of latitude. Such remarks as I have had occasion to make on this subject, will be found in the course of the following narrative, wherever occasion for them chanced to arise: while, even had I aught more to say on this great question than I have done, any such dissertation has been long superseded by that of Sir Edward Parry, to which I gladly refer.

Let no one suppose that I do not estimate the merits of that officer, both as a writer and a navigator, as highly as the public has agreed to do. We were once partners in the same pursuit, and have together undergone the same dangers and the same anxieties; we have since, if separately, carried on the same warfare with ocean and ice, with storms and toils; each still pursuing one object and endeavouring after one fame. If we have thus been as rivals, it has been a rivalry in which neither jealousy nor dislike could ever have intermingled: as well might it be supposed that La Perouse should hate the memory of Cook, or that this great man, had he then lived, should have sickened at the success of the bold and intelligent French navigator. Brothers in the Service, we have been such also in one track of discovery. If there are men who please themselves with imagining or exciting jealousies and dislikes among those who pursue a common object, their just punishment will be to know that they have failed.

But although I do not think it needful to discuss the question of this passage, I may here make a few remarks on the subject which might not very readily occur to my readers; or, not at least, to those who have not familiarized themselves with this great point in geography, by previous reading.

Before I left England on the present expedition, various hypotheses were afloat respecting the probable place of the expected passage. All these were justifiable, in some manner or other, or in a greater or less degree; as hypotheses must ever be when they pretend to no more, or when, at least, the evidences on which they rest, fall short of proof. On the asserted, or imaginary, indications of such a passage, in one direction or in another, I had never, myself, laid any stress; though willing to listen to all, and desirous, rather than otherwise, to leave every one to the indulgence of his own speculations or fancies. 
If also I had then no hypothesis of my own, I think I may now safely say that I have not gained any knowledge by this voyage, which would justify me in forming one; assuredly at least, not in proposing a new scheme for the discovery of a north-west passage. Of the imagined, or hoped for, or possible, passage through Lancaster strait and by the way of Melville islands, I know nothing more than was known before; nor have I any conjectures, nor any hopes or doubts, to offer respecting it, which I could add to what has already been amply discussed. It was a portion of this region to which we never gained any access, inasmuch as the scheme which I had determined to follow was a different one, leading me in another direction, and because we could never afterwards extricate ourselves from the place where we had been imprisoned, from the very day, I almost say, when we first trusted ourselves to this barbarous shore.

Thus also, whether the impossibility of passing northward by the way of the Pole, is now fully admitted, or not, since the failure of Parry's bold attempt, this too is a question respecting which the course of my own navigation did not allow me to form any additional conjectures.

If now, the attempt which I carried on, of which, as far as a passage is concerned, the failure is now before the public, has given me no new hypothesis to offer, nor any firesh scheme to propose, and if all, therefore, of a positive nature, as hope is concerned, remains as it was, the negative result is of much value on this question, independently of all the other knowledge in geography or whatever else, which has been gained by this laborious voyage, under the hard-earned honours which may be assigned to it, or, possibly, refused.

That point on which our own attempt was made, had formed one of the places of hope: I may call it one of the hypotheses, or rather a basis for one of those to which I have just alluded. In this direction, and with a vague, but justifiable and natural hope of succeeding, was the last effort of Parry made, as the preceding one had been, though under a different plan, and by taking a very different course from mine. How he failed in both, from causes beyond human prudence to avert or control, is well known; and that hope, or that possibility, still therefore remained.

This hope is now extinguished; and if it be, on all occasions of life as in this, a gain to demolish those hopes which only tend to delusion, the merit of this result at least belongs to our present voyage. We navigated, or examined by travelling on shore, the 
only part of these lands where the possible passage in question might have existed : and by means of our journeys the examination was made complete.

How complete it was, the journal, but, still more clearly, the appended chart will show: yet the result, though it was but to fail in finding this problematical opening, is highly interesting; while it was very tantalizing to us, and, as I really may say, without more temper than the event justifies, proved in the end mortifying. It is mortifying to labour hard and suffer much, under hopes so often held out, to be ever on some anticipated brink of the discovery which should indemnify us for all those toils, and place the crown of success on our labours, and then at length to find that we have not missed that reward by having indulged in absurd or groundless expectations, have not been striving against those obstacles, the utterly insurmountable nature of which may console us for the disappointment, but have been, in reality, nearly within reach of the expected object, yet as far from attaining it, for ever, as if mountains had intervened.

It will be seen, on examining those documents, that the tract of land which separates Prince Regent's inlet from the northern sea of America westward, at the place of our investigations, is not only very narrow, but is largely occupied by lakes, by which the length of the land itself which separates the two seas, is reduced to three miles. How little, therefore, nature has here done towards preventing such a passage between the eastern and western sea, or otherwise, how nearly she has approached towards permitting it, is apparent; while no one can be surprised if we had often indulged in hopes that it actually existed.

Thus has it proved that there was some justification of the beliefs or hypotheses of those who had expected a passage somewhere in this quarter, though they had no grounds on which to point out its probable place. Yet I must not be supposed to say, that even had we found an opening through this low and narrow tract, it ever could have been a "north-west passage" in the actual sense of that phrase, or ever could have been turned to purposes of communication or commerce. The state of the inlets by which we reached it, and not less the nature and condition of those seas or openings through which Sir Edward Parry might have reached it had he been more favoured by fortune, is such, as he and I have shown, that all utility of this kind would be a wild hope, not only at any given period, but for ever.

It remains, therefore, to say, since I need not longer dwell on this subject, that 
while my voyage and its results have demolished all hypotheses and hopes but those which may still be entertained respecting Lancaster strait, and the Pole, if, indeed, the latter has still an advocate remaining, there are now fewer temptations than ever to make any fresh attempt for solving this problem.

This at least is true, as far as an actual or practical communication round the north coast of America is concerned : yet how is it more true now, than when the problem was first proposed (I will not say by the early navigators), but by those who again brought forward this scheme before my first voyage, in 1818, and caused it to be put into action during so many successive seasons, under a course of expenditure so heavy?

It did not require more than my first voyage, it scarcely required that to show, that no commerce could ever be attempted in this direction, even had some singular good fortune proved that the American continent did not extend further north than Hecla and Fury strait, or had terminated much short of this : even, I may say, had the actual passage been effected by some lucky ship. Merchants risk much on commerce, it is true, but they are not given to hazard every thing, in opposition to the dictates of common sense, or in equal defiance of experience and probability. They have a test, also, by which their united body judges of every thing in cases of this nature; and that barometer is stationed at Lloyd's Coffee-house, to be consulted by all. On what terms could such an insurance be effected; on what premium, even under the favourable circumstances which I have thus supposed? Where the sum, and therefore the hazard for each man is small, men will go very far, under very slight hopes; but it is to be doubted if a premium, even to the value of the entire ship and cargo, would have filled the list handed to those who, bold and liberal as they are, or hopeful as they may be, are men of acute understandings, and of more information than is sometimes suspected. Commanders there are, it is certain, who would have tried, and tried any thing; for in such men, thank heaven, England has never been deficient, and, I hope, never will. As to our seamen, there is nothing which they will not undertake: or at least, in my younger days, there is nothing which they would not have undertaken, throwing all their cares, as they ever do, on him by whom they are conducted. May it so continue under this new era of rising light and spreading knowledge! But more than this would have been wanted; and that, I verily believe, would never have been obtained. 
With respect to any future attempt of this nature, my opinion, I presume, may be easily extracted from the general tenour of the following journal, and from various remarks made as occasion gave rise to them, as well as from what I have just said; since the conclusions from this are almost too obvious to require a distinct statement.

If there are now no hopes of a useful passage, as these ought to have ceased long ago, I am aware that it would be a matter of just boast to Britain, could its navigators, who have already effected so much for geography, complete the navigation and survey of the northern shores of America. Still more may this be a justifiable, as a desired object, when it is to their spirit of enterprise and ability that the world owes nearly all that is yet known respecting this long obscure and difficult piece of geography. Surely also it is right, that this bold spirit should not flag for want of the means of exertion, nor these abilities and experience and science lie dormant, or cease to be cultivated for want of objects capable of rousing ambition, and of occupations which may tempt men to make or maintain themselves what men can be, when inducements are held out to them.

Where economy is put into the balance against all this, it is a contemptible economy indeed; too much as such false economy has become the rule of an age which has rendered our once liberal, and splendidly liberal country, a far other Britain than it once was. Alas, that men cannot see how miserable is the spirit of money making and money saving, how wretchedly debased man becomes when this forms his sole pursuit, when all his notions of moral conduct are confined within the base code of Franklin's "Poor Richard;" to produce the effects which it has done in the country to which he preached his_-" religion," I may call it, not merely its morality. Not such is the spirit of my noble-minded friend, to whom the world is now indebted for the products of the present voyage: may this example teach Englishmen what they may be again; for such as he is, have Englishmen been.

Let me be excused a remark into which gratitude and justice, not less than pure and disinterested admiration have led me: while I must conclude these observations with a repetition of the suggestions which I have offered in the commencement of my journal. If I was unfortunate in my own steam vessel, this was not the misfortune of the plan, but of the vessel itself: yet no, not of the ship, its size or construction, but of its wretched and discreditable machinery. My opinion remains unaltered: a vessel intended for discoveries in these regions ought not to 
draw more than ten feet of water; she ought to be strong, as our own was, and handy also in point of rigging: and she ought further to have a steam engine, for occasional services, the reasons for which I have assigned in the beginning of the following narrative.

I have not, in these miscellaneous remarks on the question of a "north-west passage," given such sketches of my gengraphical discoveries as I ought perhaps to condense, in some form, in this Introduction, since no opportunity for it has offered in the journal, and since a connected view of the facts might not, possibly, be easily extracted from it, by readers not previously acquainted with the subject, and above all with the preceding discoveries, made by myself and my successors.

It is impossible, indeed, to do this in words alone, and without reference to a chart, to a picture of facts which saves many words, and also presents to the eye what no length or detail of language ever can do. Let the reader at least turn to that chart, as it is here given, and, with its aid, a few words will effect all that is necessary.

It will thence be seen that the last point in Prince Regent's inlet which Sir Edward Parry had been able to attain, was Cape Garry; and hence my own discoveries may be marked as commencing at this place. If not very extensive in point of space, they are minute and accurate: under our extraordinary detention for so long a time, in so narrow a tract, they could not indeed have been enlarged, over a country where travelling by land was so completely restricted by its mountainous, or rather hilly form, and far more by the ice and snow with which it was almost eternally covered, as not less by the very short season of a few weeks when alone any travelling was possible. This minuteness and this accuracy are indeed far greater than the subject required; so that it may be but a worthless boast to say, that they exceed in this respect any thing ever yet done by navigators. In New South Wales, such work would have had a value which it never can possess here; but we had little else to do, and no harm at least was produced by this superfluous eare.

The chart will show that from the point which I have named, our survey of this shore extended to the 69 th degree of latitude, and between the longitudes of 89 and 99 , terminating at the place to which I have given the name of Point Franklin. Hence it 
extended through this portion of the Northern American continent, so as to give a correct draught of the interior land, with its multifarious lakes and rivers, over a space for which the chart must be consulted, since it cannot be defined by words. Thus, further reacling to the western shore of that isthmus to which I have given the name Boothia, it has defined that portion of the coast between the latitudes $72^{\circ} 30^{\prime}$, and $69^{\circ}$, and under longitudes lying between $89^{\circ}$ and $99^{\circ}$ west.

What it has thus effected for the geography of this part of the continent of America is therefore obvious; but I must further note in what manner these discoveries conduce to that general problem, to which an interest, next at least to that of a "north-west passage" has been attached; namely, the completion of the coast line of the Northern American continent, from Behring's strait to Baffin's bay, as it had been determined by the several navigators employed on this inquiry, under the more recent as more remote voyages.

If, in the catalogue with which I have commenced this introduction, I have mentioned the several distant and unconnected points which had been noted, or the coasts which had been more extensively examined, by Hearne and Mackenzie, by those who had preceded them in coming from the eastward through Behring's strait, and by the navigators and travellers who were employed on these services after my first voyage, namely, Parry, Franklin, and Beechy, so may I now say that the line of the American northern shore which has thus been traced by their joint labours, is the following. The chart indeed shows it; but for those to whom the examination and measuring of charts is a matter of some effort, and for whom especially it is difficult to trace an extent in miles, under the ratio which these bear to degrees of longitude in those northern latitudes, the following verbal explanations will be of use.

Commencing at Behring's strait and from the Cape Barrow of Beechy, the coast has now been marked, by means however of nautical surveys only, and those of course far from minute, while also not always boasting of much accuracy, thence to Point Back of Franklin. Here, and as far as the mouth of Mackenzie river, being the only discovery of that traveller, it is again laid down by Richardson to the exit of the Copper-mine river, being Hearne's sole discovery on the coast. Thence to Point Turnagain, lie the discoveries of Franklin; after which, in the progress eastward as far as Point Jane Franklin, there is a blank of 222 miles, which we hope will be filled up by Captain Back. Should this expectation be gratified, the discoveries which I have thus traced 
will be united to our own; when all that will be wanted to complete our knowledge of the northern coast of America will be the space between the Banks's land of Parry, and Boothia Felix. Thus the progress and connexion of these several discoveries brings us to Cape Turnagain, being the nearest point toward which we had protracted our own investigations: and hence it appears that the blank which now remains on the chart between that point and the westernmost land which we had either touched, or inferred by the usual modes of observation, amounts, in English miles, to 500. I have elsewhere said, how much I regretted that Commander Ross was prevented from extending the journeys which he undertook toward the west, so far as to have completed this connexion, which would thus have left nothing for future examination between this point and Behring's strait, but the other spaces already mentioned. I must, however, admit his plea, grounded on the difficulty of carrying or procuring provisions, rather than on any impediments offered by the country or the climate; unavoidably regretting, nevertheless, that we could not command the means of completing this very short portion of the coast, and of thus drawing on our chart that line, of which perhaps the only satisfaction that can ever be derived would be, that there is, on a piece of paper, a black line instead of a blank. But of such imaginary joys does human happiness full often consist : and what matter, if even less than this, the anatomy of a fly's toe, or whatever else, will serve to make men happy, and proud of themselves?

On what else remains unknown of the American coast, from the northernmost point on this western shore which our voyage had ascertained, I need say nothing, since I have not undertaken to analyze or describe the whole of this yet unsettled line. The chart itself can be consulted for what remains hence to Lancaster strait; of the continuity of which coast I presume there can be no doubt, since this may be inferred from that of the eastern shores examined by Sir Edward Parry and myself. Of the exceedingly uncertain and obscure nature of that land termed Melville islands, I have not the smallest right to speak: and although I circumnavigated Baffin's bay in my first voyage, thus restoring to that able and extraordinary man the honours of which it had been attempted to rob him, I will not say that there may not be in it an opening to the northward, and possibly at more points than one, and will therefore not offer any conjectures respecting the nature of all this tract from Melville islands even to Greenland, its insularity, or rather insularities, or on what the extent, nature, and connexions of these islands may be, if, as is presumed, they form a group of this kind, so defined 
and restricted too, as to leave a wide and clear ocean about the northern pole of the earth; if not a "polar basin" in the sense of one of the well-known speculations on this subject.

But the results of the present voyage, and a comparison of that of Baffin with my original one, which I could not have made at that time with the same confidence as I now do, added to some further investigations into this subject which I could not then have ventured on, and might probably not have had the confidence to propose without the new grounds of judgment which I have now acquired, have led to some conclusions which I must now state. To myself, they seem of considerable moment, not merely as they concern the accuracy, or otherwise, of the ancient navigators of the seas in question, but as they relate to the true geography of those regions, so long obscure, and so long the source of error and obscurity to more modern voyagers, as to geographers and their labours; with the consequence of producing confusion and doubt in all that relates to the charts of these seas, and to the true forms and relations of the land in this part of the world. If, in any manner, the examination and analysis in question may seem, to the ignorant, to attack the reputation of any of our modern discoverers, let me assure them that there are no such thoughts in my mind; as it is not my own opinion, that any thing on which I can defend the discoveries of the ancient navigators, ought, in the slightest manner, to interfere with the claims or diminish the merits of those who have recently followed in the same career.

No one, of those at least who are acquainted with the theory of navigation, or with the sciences on which it depends, can be ignorant of the difficulty which the ancient navigators found in determining their longitudes. I need scarcely say how little was then known even of practical magnetism, of such simple facts as the variation and the dip of the needle; and still less need I here notice how uncertain were the means of determining " the longitude."

That Baffin should but have shared in this general difficulty, is no cause for surprise; and thence it is that I have traced those errors of his which I am about to note, not to such observations as he might have made during a run of a few days across the head of the bay bearing his name, but to the distance and length of time which was passed over and occupied during his voyage thither from England; the latter amounting to some months, and the former being only a few days. 
In consequence of this more than suspicion, since it was the unquestionable source of all his subsequent errors, I have commenced by laying down the true longitude of the east coast of this bay, as determined by those modern methods which leave but the slightest error; thence assuming this as the basis, or "point of departure," for all the subsequent determinations which he has made, and which I have here undertaken to correct.

Having first determined this, and thence assuming that the distance estimated by him in his short passage across the bay is correct, since I do not see how he could here have committed an error of any possible moment, it must follow that he had seen all that land to the east of Melville islands and the north of Fury strait, which we have supposed to have been first discovered by our recent navigators.

The consequence of this becomes very remarkable on an inspection of our present and new charts. The strait of the Hecla and Fury, as laid down by Parry, thus proves to be the Baffin's strait of this navigator; while the land now laid down by us as lying to the eastward of Prince Regent's inlet, will turn out to be James's island, as named by James. Further, that land to the southward of this island, of which we have traced the eastern coast, but of which we have not examined the inlets, should be the "three islands" of Baffin and his Cumberland island : while it is to be hoped that future examination will verify his assertions. On the same grounds, our Barrow's strait will be the Lancaster sound of Baffin, as our coast of North Somerset, thus named by Parry, will prove to be that which Baffin termed Prince William's land. The opposed shore, therefore, which has been called North Devon, will equally be the west side of James's island.

Let it now be supposed that these views are incorrect, and we will then see the consequences which will follow; as these, if I mistake not, will confirm the criticisms which I am here making. Though Baffin's longitude is incorrect on the east side of his bay, which he has placed nearly four degrees too far to the eastward, it has been found, on the west side, to be so coincident with the observations of modern navigators at that place which I formerly considered the entrance of Lancaster sound, and have thus named in my chart of 1818, that the result would be to exterminate James's island altogether : which cannot be, without considering James's account to be false.

Having thus passed such geographical criticism on this subject, as my voyages and the deductions I have since made from them seem amply to justify, I must now turn to 
the western portion of these northern shores, that I may compare the really puzzling and obscure account of Bernarda and Juan de Fuca with the recent examinations, or discoveries, as they have not unnaturally been termed, which my followers and coadjutors have made on this part of the northern coast of America : still, however, disclaiming all intention to deprive them of their well-merited and hard-earned honours.

I think I have good reasons to suppose that these very early navigators effected their voyages by pure coasting, as was the practice in the far more remote times of the ancients, and, for the most part, of our Scandinavian ancestors, without any regard to observations, for which they did not much care, as they had little means of making those. Thus do I believe it possible that they passed through Behring's strait, and held on their course even as far as that part of this coast which I have termed the isthmus of Boothia; while I find, in their accounts, a sufficient congruity with those of our modern discoverers to justify this belief. This is especially remarkable in the fact which I noted in a former part of this Introduction, namely, that Bernarda had sailed towards the east, to a certain longitude, and had there ascended a land, not far from Davis's strait or Baffin's bay, which I have concluded, on good grounds, as it seems to me, to have been the isthmus of Boothia. Supposing now that my views of the voyages of these two navigators are correct, it is plain that they had long ago effected, in some manner at least, what has since been performed by Kotzebue, Beechy, Hearne, Mackenzie and Franklin; doing even more, since the last point to the eastward which they reached was that isthmus which $I$ have just named.

This subject, however, is so obscure in itself, while the novelty of this criticism, added to that obscurity, is such as to render all verbal explanations insufficient, that I have constructed a chart, here appended, for the purpose of rendering it more intelligible. It will require some attention, even to consult and understand that chart; but the following explanation will, I hope, render it intelligible to every reader, and at the same time adequate to the appreciation of this piece of geographical criticism. It will be seen that it also serves to illustrate those remarks on Baffin which I have just made; while having nothing of the same nature to discuss respecting Bernarda and De Fuca, I must entirely trust to this chart, and the following explanations of it. 



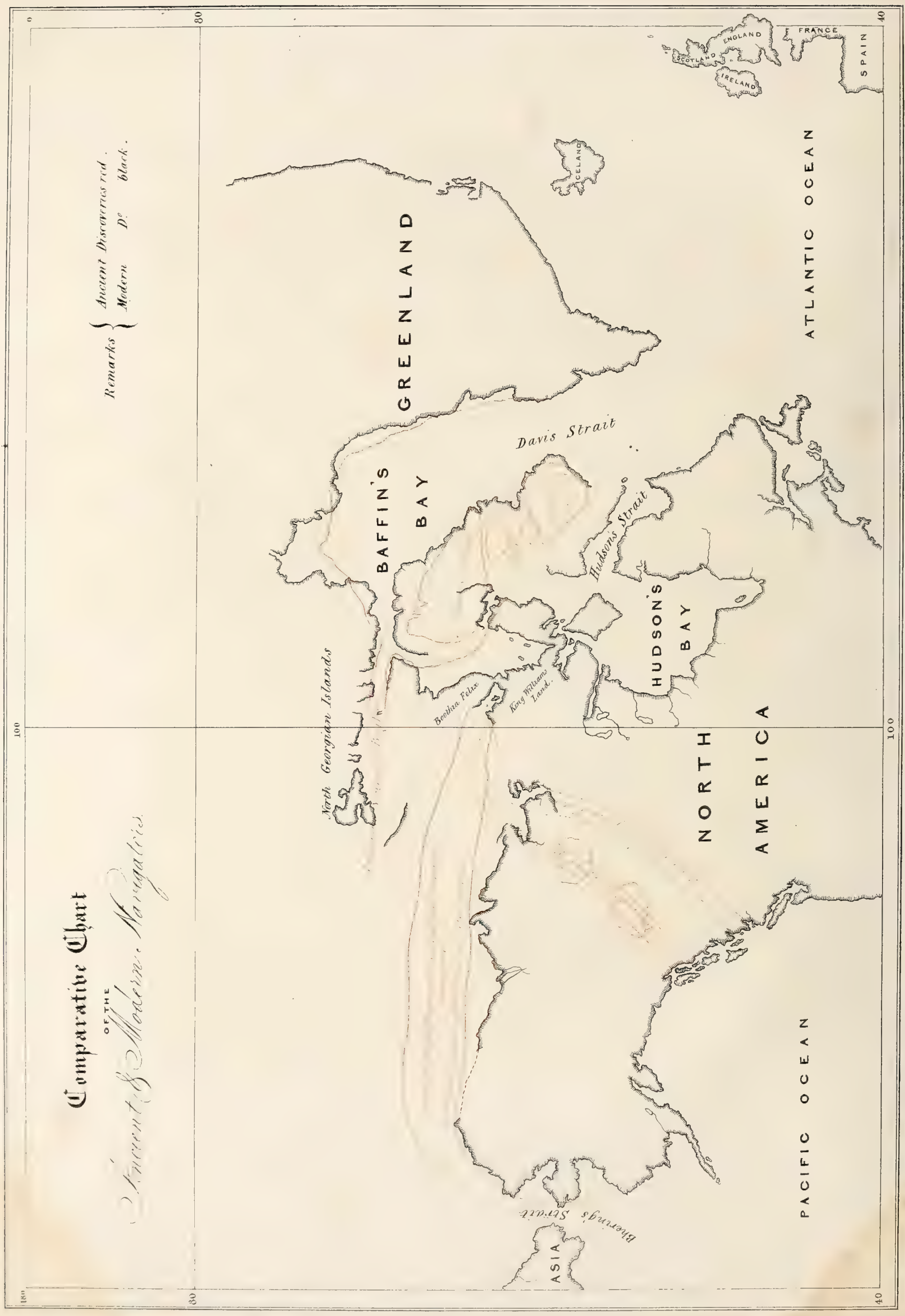




\section{Explanation of the Chart.}

This draught, which I have constructed from a comparison of our modern knowledge with the records of the old navigators in question, presents at one view the space which extends from Britain to Behring's strait.

The black and shaded outline shows the form of the land as it is now known by the researches of modern navigators.

The dotted line denotes the coast which was erroneously laid down in longitude by Baffin; and the difference between this line and the shaded coast on the east side of his bay, is the great error in his longitude of this shore which I have noticed in the preceding remarks.

The red line, where it reaches along the eastern shore of Baffin's bay, represents his draught of that shore, but it is transferred further westward according to the real longitude; while the same lines to the westward exhibit his notions of the land on this side, according to the difference of longitude which he has himself given: thus denoting the breadth of his bay in longitude, together with the position of James's island, Baffin's three islands, and Cumberland island.

Again, the two lower pairs of red lines to the westward, represent the tracts of De Fuca and De Fonte, as drawn in their charts. But as there is no opening on this part of the coast, they must have gone through Behring's strait, if they ever made such a passage as they relate: and the two upper lines are therefore meant to represent the track they must have made to reach the isthmus of Boothia, which I have reason to believe they did, from the conformity of their descriptions to what we saw. Bernarda must have equally passed through Behring's strait; and thence the same lines may serve to represent his track also. 



\section{EXPLANATION OF SEA AND TECHNICAL TERMS USED IN ICY SEAS.}

Iceberg, an insulated mountain of ice.

A field, a piece of ice so large that its extent cannot be seen.

$A$ floe, a piece of ice of considerable size, but the extent of which can be distinguished.

A patch, a number of pieces of ice overlapping and joining each other.

A stream, a number of pieces of ice joining each other in a ridge or in any particular direction.

Loose ice, a number of pieces of ice near each other, but through which the ship can make way.

Suiling ice, a number of pieces of ice at a distance sufficient to enable a ship to beat to windward among it.

Brash ice, ice in a broken state, and in such small preces that the ship can easily force through.

Cake ice, ice formed in the early part of the season.

Bay ice, newly-formed ice having the colour of the water.

Hummocks of ice, lumps thrown up by some pressure or force, on a field or floe.

Heavy ice, that which has a great depth in proportion, and not in a state of decay.

A lane or vein, a narrow channel between two floes or fields, or between the ice and the shore.

Beset, surrounded with ice so as to be obliged to remain immovable.

Nipt, caught and jammed between two pieces of ice.

A tongue, a piece of ice projecting from an iceberg or floe, which is under water.

$A$ calf, a piece of ice which breaks from the lower part of a field or berg, and rises with violence to the surface of the water. 
A barrier, ice stretching from the land ice to the sea ice, or across a channel so as to be impassable.

Land ice, ice attached to the shore, within which there is no channel.

Sea ice, ice within which there is a separation from the land.

$A$ lead, a channel in a direct line through the sea.

Pancake ice, ice formed after a fall of snow.

$A$ patch of ice, separate masses of ice joined, but of small extent.

$A$ pack, masses of ice joined by pressure, the extent of which cannot be seen.

Sludge, ice having the appearance of snow just thrown in the water, which scarcely impedes the ship.

$A$ bight, a bay in a floe of ice.

To bore, or boring, pressing the ship through small ice or young ice, under sail.

$A$ crow's nest, a cylindrical house at the mast-head, to protect the look-out man from cold.

A blink, ice blink, peculiar white appearance of the sky in the direction of the ice; or over distant ice.

A blink, land blink, peculiar yellow appearance of the sky over the distant land.

Water sky, a dark appearance of the sky indicating clear water in that direction.

Young ice, ice which has been formed during the day or night.

Drift ice, pieces of ice less than floes of various shapes and sizes.

Hummocky ice, ice so uneven and rough as to be impassable or nearly so on foot.

Fresh-water ice, ice formed on a lake or fresh water, and which is transparent.

Fire hole, a hole in the ice, kept open in order to obtain water to extinguish fire.

Scupper, holes through the side or gunwale to let water out.

Jigger mast, a small mast at the stern, with a sail resembling a lug sail.

Krang, the body of a whale after the blubber is taken off. 


\section{O N T E N T S.}

CHAPTER I.

The Project of the Expedition and its Outfit, p. 1.

CHAPTER II.

Leave the River-Detention at the Isle of Man-Accident to the Engineer-Landing at Port Logan-Arrival in Loch Ryan-Meeting of the John Tender, p. 8.

CHAPTER III.

Leave Loch Ryan-Gale of Wind off Ireland and Loss of the Fore Topmast-First Sight of the Iceblinks-Entrance of Davis's Straits, p. 30.

\section{CHAPTER IV.}

Off Cape Farewell-First Iceberg seen-Abreast of Baal's River-Sight of Sukkertop-Land and Islands near. Wideford seen-A Codbank discovered-Mountain called Old Woman's Hood-Arrival at an Anchorage, p. 43.

\section{CHAPTER V}

Visit of the Danish Governor of the Settlement at Holsteinborg-Residence there and Purchase of Stores from the Wreck of the Rookwood-Departure from Holsteinborg, p. 59.

\section{CHAPTER VI.}

Disco Island-Enter on the First of August-Reach our furthest intended Point north-Steer for Lancaster Sound-Enter the Sound-Remarks on the former Discovery of this Spot, p. 78.

CHAPTER VII.

Progress down Lancaster Sound-Sight of Catharine and Elizabeth Mountains-Pass Cape York and steer for Prince Regent's Inlet-Cape Elwin and Elwin Bay-The Compasses cease to traverse-Discover Adelaide Bay-Approach to Fury Beach-First Sight of the Tent Poles left at the time of the Wreck-The Victory moored, p. 93.

\section{CHAPTER VIII.}

Examination of the Fury's Stores-Embarkation of those which we intended to take-Departure and Progress down this Shore-Several new Discoveries made and named-Obstructed by the Ice, and moored, p. 107.

\section{CHAPTER IX.}

Attempts to Work along Shore-Discovery of Port Logan-Land there-Traces of Esquimaux -Labouring among the Ice-Discovery of Elizabeth Harbour, p. 125.

\section{CHAPTER X.}

Attempt to quit Elizabeth Harbour-Slow Progress along Shore-Critical Position of the Ship among the Ice, and Escape through Perilous Passage-Discovery of Eclipse HarbourFurther Discoveries-Cape St. Catherine and Lax Harbour, p. 143. 


\section{CHAPTER XI.}

A heavy Gale: Succession of Tempestuous Weather, with Snow-Partial clearing of the Ice, and extrication from it-Discover the Island of Andrew Ross, Cape Margaret, Best Harbour, and Martin Islands-A new Bay-End of September-General Remarks on the progress of the Ship and the mode of navigating among Ice, p. 157.

\section{CHAPTER XII.}

Remarks on the present condition of the Ship, and preparations to reduce the encumbrance of the Engine-Unrigging of the Ship-A successful Bear Hunt--Ascertain that we are truly frozen in for the Winter-A Powder Magazine erected on shore-Provisions examined-The Guns and parts of the Engine hoisted out, p. 181.

\section{CHAPTER XIII.}

Remarks on the actual Temperature and on that of Sensation-Proceed in lightening the Ship - The Engine finally landed, and the Krusenstern secured - Roofing of the Ship completed-Remarks on the Temperature-Abolition of the use of Spirits on Board-Contrivances for Warming and Ventilating the Vapour between Decks-Description of the several arrangements made for Wintering, as relating both to the Ship and the Crew, p. 196.

\section{CHAPTER XIV.}

The Month commences Stormy and Cold-Improvement in its progress-Remarks on the Thermometer and Barometer-Occurrence of a splendid Aurora Borealis-Summary of the Month, p. 216.

\section{CHAPTER XV.}

Repeated occurrence of Aurora Borealis-Christmas-day-Summary of the Month-Remarks at the termination of the Year 1829, p. 227.

\section{CHAPTER XVI.}

Commencement of the Year 1830-First meeting with the Esquimaux on this Coast-Description of their Village, and of their Society and Manners-They are entertained on BoardCommunicate some Geographical Information, and promise more, p. 239.

\section{CHAPTER XVII.}

Receive more Geographical Information from one of the Natives called Ikmallik-Continue our Communications with them-Pure Mercury freezes at length, at minus $39^{\circ}$ - The first Sunrise of the Year-Death of the Armourer-End of the Month, and Summary, p. 259.

\section{CHAPTER XVIII.}

Pilfering on the part of the Natives-The first fall of Snow of this Year- Native DanceSummary of the Month of February, p. 279.

\section{CHAPTER XIX.}

Purchase of Dogs from the Natives-Commander Ross departs on an Expedition to the Native Huts, for information-Process of building Snow Huts-Summary of the Month of March, p. 289. 
CHAPTER XX.

Proceedings to the Tenth of April-Journey and Narrative of Commander Ross, p. 301.

\section{CHAPTER XXI.}

Narrative of Commander Ross, p. 304.

\section{CHAPTER XXII.}

Proceedings in the Ship, and with the Natives, p. 320.

\section{CHAPTER XXIII.}

Commander Ross's Second Journey and Narrative, p. 326.

\section{CHAPTER XXIV.}

Departure of Commander Ross on a Third Expedition-Threatening of a Rupture with the Natives-Commander Ross's Return, p. 333.

\section{CHAPTER XXV.}

Narrative of Commander Ross, p. 338.

\section{CHAPTER XXVI.}

Repetition of heavy Snow-Another Expedition by Commander Ross-Another Expedition under my own charge--Summary of the Month of April, p. 372.

\section{CHAPTER XXVII.}

Expedition commenced-Narrative of our Journey-Return to the Ship-Observations made to obtain the difference of the Elevation of the Eastern and Western Seas-The Dip of the Needle, and intensity of Magnetic Force, p. 381.

\section{CHAPTER XXVIII.}

Proceedings in the Ship from the First of June-Commander Ross's Return, p. 398. =

CHAPTER XXIX.

Commander Ross's Narrative, p. 401.

\section{CHAPTER XXX.}

Continuation of the Journal-Summary of the Month, p. 436.

\section{CHAPTER XXXI.}

An Expedition to Fish for the supply of Fish for the Crew, undertaken by Myself and PartyNarrative and Return, p. 443.

\section{CHAPTER XXXII.}

Journal of the Month of July-Summary of the Month-Transactions during August, and its Summary, p. 454.

\section{CHAPTER XXXIII.}

Warping out, Unloading, and final Escape from our Harbour-Ineffectual Movements among the Ice-Become fixed in the Attempt to find a new Harbour for the Winter-Summary of September, p. 466. 


\section{CHAPTER XXXIV.}

Labour in Cutting through the Ice-Become fixed for the Winter-Summary of the Month, p. 476 .

\section{CHAPTER XXXV.}

Transactions in November-Summary of that Month-Proceedings in December, with a Summary, p. 484.

\section{CHAPTER XXXVI.}

Transactions on Board the Ship in January, 1831-Summary of that Month. February: with its Summary. March : its Summary, p. 500.

\section{CHAPTER XXXVII.}

April-An Expedition undertaken-Account of this Journey-Summary of the Month, p. 510.

\section{CHAPTER XXXVIII.}

May-Commander Ross's Journey, p. 519.

\section{CHAPTER XXXIX.}

Narrative of Commander Ross, p. 521.

\section{CHAPTER XL.}

Journal of May-A Journey in company with the Natives, p. 528.

\section{CHAPTER XLI.}

Transactions in June-Return of Commander Ross from his Expedition, p. 543.

\section{CHAPTER XLII.}

Commander Ross's Narrative-His Journey for ascertaining the Place of the North Magnetic Pole-Observations for the Purpose of assigning its Place, and Deductions from those, p. 549.

\section{CHAPTER XLIII.}

Remarks on the Assignment of the Magnetic Pole, p. 567.

\section{CHAPTER XLIV.}

Transactions during the remainder of June-The Journal and the Summary of July, p. 572.

\section{CHAPTER XLV.}

Proceedings in July, August, and September, with the Summaries of those respective Months, p. 577 .

\section{CHAPTER XLVI.}

Journal of August-The Victory moved out of her Harbour-Attempts to proceed along the Shore-The Ship forced by the Ice into another Harbour-Summary of the Month-Journal of September, and its Summary, p. 588.

CHAPTER XLVII.

Journal of October-The Journals of November and December, and the end of the Year, p. 609 .

\section{CHAPTER XLVIII.}

The Journals of January, February, and March, p. 624. 
CHAPTER XLIX.

April-Commence the operation of carrying forward Boats, Sledges, and Provisions, with the view of abandoning the Ship-May-Continuation of the same work-The Ship is abandoned, p. 632.

\section{CHAPTER L.}

June-Our Journey with the Sledges and Boats-Arrival at Fury Beach-Transactions and Detentions during July, p. 645.

\section{CHAPTER LI.}

August-Departure from Fury Beach in the Boats-Detention and Difficulties on the CoastSummary of August-Transactions in September-Baffled in our attempts to proceedReturn towards Fury Beach-Summary of September, p. 656.

\section{CHAPTER LII.}

Attempt to Proceed in the Boats-Obstructions by the Ice-Proposal to Return to Fury Beach -Renew our Attempt-Put ashore near Batty Bay-Land the Stores-Summary of August -Abandonment of the Mineral Specimens, p. 665.

\section{CHAPTER LIII.}

Continuation of our Travelling Southward in October-Return to Fury Beach-Establish ourselves at Somerset House for the Winter-Summary of this Month-Journal and Summary of November and December, p. 677.

\section{CH APTER LIV.}

The Journals of January, February, and March, with their respective Summaries-Death and Funeral of the Carpenter, p. 689.

\section{CHAPTER LV.}

April : the Journal and Summary-May : the commencement of the Journeys intended for the future Expedition-June : the continuance of these advancing Journeys-July : the abandonment of the Winter House, and arrival at the Boats-Summary, p. 697.

\section{CHAPTER LVI.}

August-Detention at Batty Bay-The Ice breaks-Departure in the Boats-Reach the Eastern Coast of Prince Regent's Inlet-Meet with the Isabella, and are received on Board, p. 713.

\section{CHAPTER LVII.}

Proceedings on Board of the Isabella-Survey of the Coast-Departure-Arrival at Hull, and in London, p. 724. 


\section{PLATES PAGED FOR THE BINDER.}

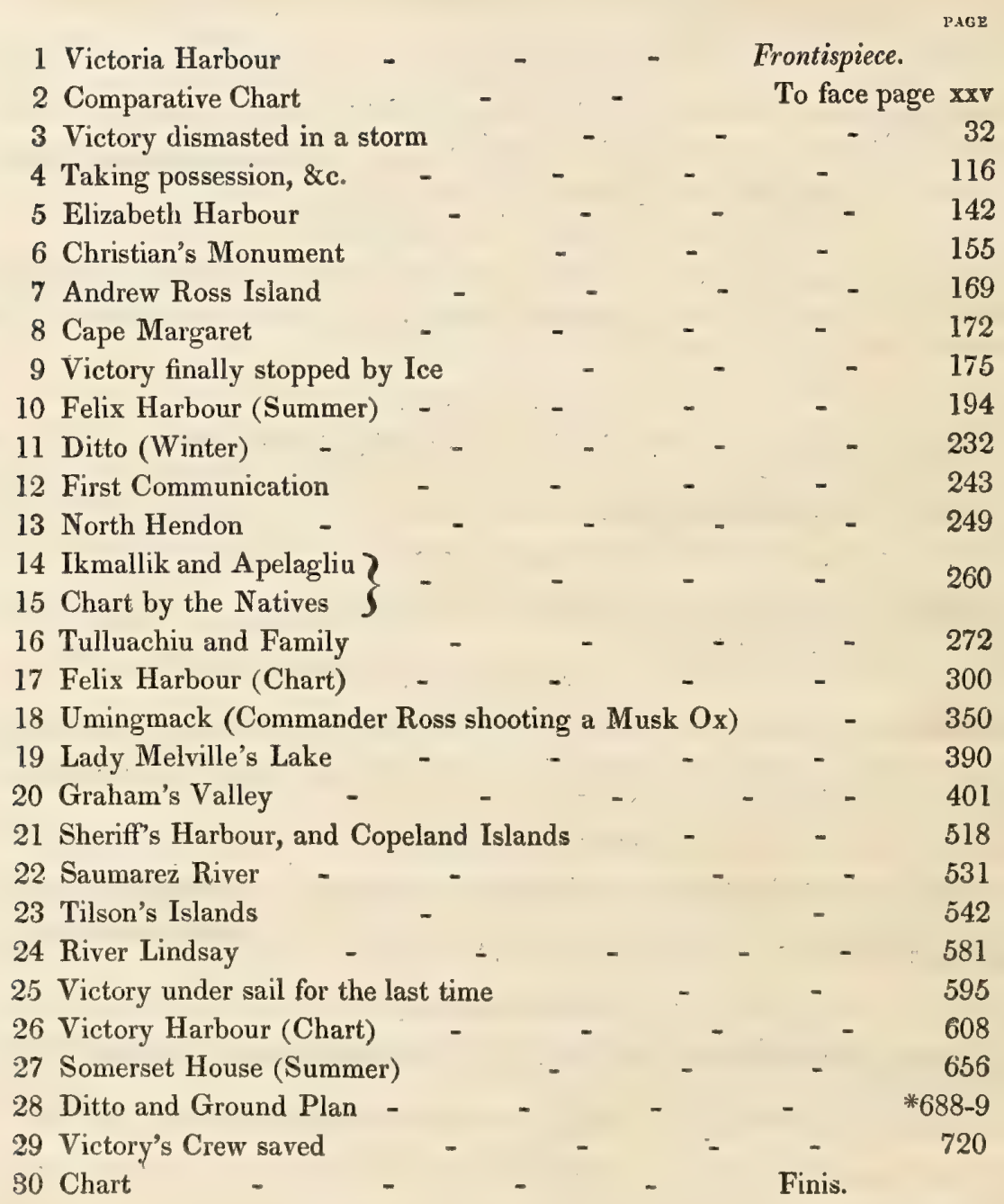




\section{S E C O N D}

\section{VOYAGE OF DISCOVERY}

TO

\section{THE ARCTIC REGIONS.}

\section{CHAPTER I.}

THE PROJECT OF THE EXPEDITION AND ITS OUTFIT.

A FTER the return of that expedition which had attempted to reach the Pole in 1827, I submitted, to the Lords Commissioners of the Admiralty, and, subsequently, to the Lord High Admiral, the plan of the voyage which I am now about to relate. I had long been convinced that the navigation of the arctic sea would prove more easy to a steam vessel than to any merely sailing ship, and for reasons which will, I believe, be fully appreciated by all to whom this navigation is familiar. When the ice is open, or the sea navigable, it is either calm, or the wind is adverse, since it is to northerly winds that this state of things is owing: so that the sailing vessel is stopped exactly where every thing else is in her favour, while the steam boat can make a valuable progress. Tne small draught of water in these vessels is another advantage; their power can also 
drive them through bay ice where, except in a fresh and favourable breeze, a sailing ship would be entirely impeded: while to add to all, the facility with which they can be moved, without wind, or in spite of it, must render it comparatively easy for them to avoid the masses of ice, and also to find places of shelter, where other vessels would fail.

This proposal was not, however, accepted: but being satisfied that the possibility of the expected route to the westward, through Prince Regent's inlet, might thus be established, or otherwise, and the question, therefore, as far as related to a north-west passage by this strait, be set at rest, I resolved not to abandon my design, without making some further trials, in another manner.

I therefore laid the scheme which I had formed, before Mr. Sheriff Booth, an old and intimate friend, with whose liberality and spirit I was well acquainted: but as, at that time, the parliamentary reward of $20,000 l$. was still held out to the discoverer of a north-west passage, he declined embarking in what might be deemed, by others, a mere mercantile speculation.

In 1828, I again submitted my plan to the Admiralty, with some improvements; but the answer which I received was, that government did not intend to send out any more expeditions on this inquiry.

I was then persuaded to apply to Mr. Thornton, of Old Swan, a well-known London merchant: pointing out to him, as a temptation, the value of the promised reward, and that of the Fury's stores, which I could not fail to reach. My answer was delayed for three months; and, at the end of that time, it was a refusal. 
Soon after, it was with some surprise I heard that a bill had been brought into parliament and passed ; of which, while abolishing the board of Longitude, the effect also was to repeal that which had held out the above named reward for the discovery of a northwest passage.

Whatever else might be my thoughts on this subject, it had the advantage of at least removing the scruples of Mr. Sheriff Booth : and $I$ accordingly received from him, in the most liberal and disinterested manner, entire power to provide on his account, all that I deemed necessary for the expedition.

After examining various steam ships that were advertised for sale, I purchased, at Liverpool, the Victory, which had been once employed as a packet between that port and the Isle of Man, and replaced the old paddles by the superior ones of Mr. Robertson's construction: arriving with her in London, on the second of November.

Here she was put into the hands of Mr. Fearnall, to be raised on, and to be strengthened in the usual manner, which I need not describe. Her original tonnage was 85 ; but by raising five feet and a half on her, she became capable of carrying a hundred and fifty tons, including the engine with the necessary complement of provisions.

The engine was made by Braithwaite and Erickson, being a patent contrivance; and the paddle wheels were so constructed that they could be hoisted out of the water in a minute. There was no flue; instead of which, the fires were kept in action by bellows, and it was, of course, a high pressure engine, the boilers 
of which were heated by pipes passing through them, in a manner now sufficiently familiar.

The stores of provision and fuel were for a thousand days: the former being of the best quality, and containing a proportion of preserved meats: while all the usual necessaries which experience had taught us to provide for such voyages as this, were supplied in the same liberal manner.

With instruments we were well furnished: having every thing that could be really wanted. Besides two chronometers of my own, there was one lent by Messrs. Parkinson and Frodsham, and three were intrusted to us by Mr. Murray. I had a transit instrument of three feet radius, a theodolite of nine inches, and a powerful telescope by Tulley; with five sextants, two altitude instruments, four barometers, twelve thermometers, two dipping needles, and several compasses: besides which H. M. Government lent me several valuable instruments and books which had been used in the former expeditions.

Having at length brought every thing to a state of forwardness, I signified my intentions to the Admiralty; and soon after made them public. On this, applications to serve in the expedition under me, came from many quarters, even from officers of my own rank; some of whom also offered to bear a share in the expenses, so strong was the interest which had been excited. They were not less numerous from men who wished to serve as sailors: but my officers had already been chosen, and the list of men was soon filled up.

As my second in command, I had chosen my nephew, Com- 
mander Ross, who had been on every one of the northern voyages : while my former Purser in the Isabella, Mr. Thom, volunteered as third; both of these officers undertaking, like myself, to serve without pay. A Surgeon, Mr. Macdiarmid, was procured some time afterwards.

Among the petty officers were three mates : and our crew consisted of a carpenter and his mate, two engineers, three stokers, a steward, a cook, and nine seamen; the names of the ship's company were as follow:

John Ross, Captain, R.N.

James Clark Ross, Commander, ditto.

William Thom, Purser, ditto.

George Macdiarmid, Surgeon.

Thomas Blanky, first Mate.

Thomas Abernethy, second ditto.

George Taylor, third ditto.

Chimham Thomas, Carpenter.

Alexander Brunton, first Engineer.

Allan Macinnes, second ditto.

William Light, Steward.

Henry Eyre, Cook.

Richard Wall, Harpooner.

James Curtis; ditto.

John Park, Seaman.

Anthony Buck, ditto.

John Wood, ditto. 
David Wood, Seaman.

Robert Shreeve, Carpenter's Mate.

James Marslin, Armourer.

James Dixon, Stoker,

George Baxter, ditto,

William Hardy, ditto, afterwards, in consequence of the loss of his arm, replaced at Port Logan, by

Barnard Laughy, ditto.

Thus were the arrangements of our ship completed: but this did not constitute the whole of the plan.

It being necessary to carry stores and provisions for several years, to which our own tonnage was unequal, it had been intended to take a consort storeship for this purpose: on the supposition that while carrying to Prince Regent's inlet whatever was thought necessary, she might also fish by the way, and further, bring away some of the stores of the Fury; so as to compensate, to the liberal fitter-out of this expedition, for such additional expense as might thus be incurred,

A whaler, built of teak, and in every way adapted to such a service, was therefore purchased at Greenock; by name the John, manned with a crew of fifty-four men, and commanded by the master, Coombe, under whom she had formerly sailed in the whale fishery. Her appointed rendezvous was Loch Ryan, and she was under the charge of Mr. Thom. The event of this arrangement, which proved a failure, will appear but too soon in the following journal.

It being also thought expedient to have a secondary vessel of 
as large a tonnage as our own could conveniently manage, we obtained, by the kindness of the Admiralty, the decked vessel of sixteen tons burden which had accompanied a former expedition intended for the Pole; giving her the name of Krusenstern: and we were provided with two boats which had been used by Captain Franklin.

In March 1829, I addressed letters to the several learned societies, signifying my intentions, and requesting to know in what manner I could aid them in their several objects of pursuit; receiving from each, such answers as they thought proper.

My last application was to the different foreign ambassadors, with a request to be considered neutral in case of war; on which passports were readily granted: while the Treasury issued an order for the remission of duties on such articles embarked in the vessel, as were subject to impost.

I may end by saying, that the ship was visited before our departure, by the Lords of the Admiralty and several persons of rank and science; and that I had the honour of receiving the best wishes of his present Majesty for the success of my enterprise. 


\section{CHAPTER II.}

LEAVE THE RIVER-DETENTION AT THE ISLE OF MAN-ACCIDENT TO THE ENGINEER-LANDING AT PORT LOGAN-ARRIVAL IN LOCH RYAN-MEETING OF THE JOHN TENDER.

THE twenty-third of May having been at length fixed on for our departure, I attended at the Admiralty, and took my leave: the official engagements of Lord Melville and Sir George Cockburn not permitting them to pay a final visit to the ship, as had been intended. A rriving at Woolwich, I found my excellent friend Sir Byam Martin, Comptroller of the Navy, and Sir John Franklin, on board; and we were afterwards honoured by the visit of the Duke of Orleans (his present Majesty of France), attended by the (then) Duke of Chartres and a numerous suite.

If the inspection of the arrangements was a source of gratification to our visitors, my friends were as little satisfied as myself with what I had long anticipated, if not to so great an extent; and which, while it was to be a cause of hourly torment and vexation to us for many weeks, was at length to lead to the abandonment of one of our chief hopes, in addition to all the waste of time and money, consequent on the grossly negligent conduct of our engine- 
makers. The ship had been brought by her steam power from the upper part of Galleon's reach, to the buoy opposite to the dock; but her progress was so slow as to promise nothing but disappointment; while, even thus early, a part of her machinery had become displaced, so as to be an additional source of delay.

Receiving here the materials of the boats which had been lent us by the Government, together with a spare foreyard which had been made for us, we were also joined by Mr. Thomas Abernethy, Gunner of the Blossom, and Mr. Chimham Thomas, Carpenter of the Eurydice, who had both volunteered; the former on the preceding day, and the latter but a few hours before. Abernethy had been leading man on two former expeditions, and Thomas was also accustomed to the northern seas; while both had been promoted for good conduct. If I had reason to consider these two men as forming a valuable acquisition, so have I especially cause to be grateful to the Admiralty for the prompt and handsome manner in which they were discharged on my application; leave of absence having been given, and their names placed on the cheque at Woolwich.

At three o'clock, my deservedly esteemed friend Mr. Booth, with his nephew and two more gentlemen, came on board, with the intention of accompanying us to Margate, and we sailed at six, with our boat the Krusenstern in tow, after taking in our gunpowder at the lower buoy; Captain Beaufort, the Admiralty hydrographer, with Mr. and Mrs. Fearnall, having been the last to quit us. We arrived at Gravesend, under our steam, at eleven o'clock, anchoring to stay the tide and wait for a pilot; and here 
the constructors of our execrable machinery, Messrs. Braithwaite May 24. and Erickson left us. The river pilot being discharged, and the new one coming on board, we weighed at 6 A. M., with a light breeze from the west, through which, although aided by the engine, we did not reach Margate under twelve hours, though by the inner channel; our rate of going varying from $3 \frac{1}{2}$ to $4 \frac{1}{2}$ miles per hour. Hailing a fishing boat at seven, our best friend, with his companions, took leave of us; little foreseeing at that time the length of our separation, and the doubts hereafter to arise whether we should ever meet again on this side of eternity.

Whatever my former fears or suspicions might have been, the defects of the machinery, now that we were fairly embarked on our voyage, began to weigh very seriously on my mind; as I now also discovered much more imperfection than our former opportunities had afforded the means of even conjecturing. The boilers leaked so much, that the additional forcing pump which had been placed in the engine room to be worked by hand, was kept constantly going; while the fresh water necessary to compensate that loss could not be spared, even on the passage to Scotland. It was moreover impossible for the men to remain, for any length of time, at this work, in a place where the temperature was above $95^{\circ}$ : while, although they performed it without murmuring, they soon became exhausted, as I was fully convinced by the fainting of one of them, whom it therefore became necessary to bring on deck before he could be recovered. How much more painfully I was yet to be convinced of this, will shortly be seen.

Nevertheless, we had no resource but to persist; when, about 
eight o'clock, while rounding the north Foreland, a breeze sprung up from the north-east, which induced us to heave our paddles out of the water and trust to our sails; under which, passing the Downs in company with several vessels, we discharged our pilot and proceeded to sea. But as the wind increased, and with it the swell, we soon had the mortification of finding, that in addition to the evils of our vexatious machinery, the ship was so leaky as to require the constant use of two pumps: though I hoped that this would prove but a temporary inconvenience, as such effects are very apt to follow the doubling of vessels, and had actually occurred in the Isabella on a former occasion, and moreover, to such a degree, in the Trent, that it became necessary to heave her down in Shetland, during the expedition of 1818.

The wind however continuing fair, it was some consolation to find that our vessel sailed, with the wind free, as well as any ship in company; and in the morning we were off Beachyhead, with the wind ENE, and comparatively smooth water, which accompanied us in our passage of the Isle of Wight the same evening. At midnight, being off the Bill of Portland, the wind and sea had increased so much, that we ran some risk of losing the Krusenstern, in consequence of her being driven against the quarter during our plunges in this detestable Race, while we were endeavouring to secure her by another rope. In the following evening, however, May 26. we again reached smooth water under the Bolthead, where she was effectually secured.

The wind continuing in the same quarter, but being more moderate, we passed close to the Lizard, cleared the Rundlestone 
May 27. a little before daybreak, and hauled up for the Longships, the wind being now directly against us. These last days had been employed by the engineer in examining the machinery, and it was thus discovered that one of the guide wheels of the piston rod on the starboard side was so much worn, as to require a piece to be brazed to it, to restore its thickness, while the connecting keys of the main shaft were also found to be loose. It was plain that these defects were or ought to have been known to the manufacturer, who had nevertheless omitted to inform us of them, and his concealing his negligence in not supplying spare keys, or any mode of remedying the impending evil, of which he must or ought to have been fully aware, was in my opinion most unjustifiable.

May 28. Holding on, we, on the 28th, passed between the Longships and the $W$ olf rock, and standing to the westward, observed the latiMay 29. tude at noon in $50^{\circ} 24^{\prime} \mathrm{N}$. On the 29 th, another observation at the same hour gave us $50^{\circ} 21^{\prime} \mathrm{N}$ : and as we were nearly in the same longitude, we found, that during the last twenty-four hours, we had lost three miles in beating against a steady foul wind. The engine being however supposed capable of being again used, we put on the steam, and as the wind had shifted to the ENE, began to make some way to the north. In the night, however, it was repeatedly stopped, by the keys of the main shaft becoming May 30. loose; and on the 30th at 4 A.M., the principal one on the starboard side broke, so as to render the whole machine useless. On examination, it was found to have been formed of a bad piece of steel; and there being none on board sufficiently large to make a new one, we constructed one from iron, which, as 
might have been expected, gave way very shortly; so that it was not till after two days, and having made three new keys, that we were enabled to replace the machinery in what we hoped to prove a workable condition.

By our observations we now found that we had gained twenty miles against the wind, and on this day spoke a fishing boat from Kinsale, from which we procured a supply of fish. The thirtieth, being Sunday, was made a day of rest by us, as it had been made such by nature herself, since it was an absolute calm; our latitude being $50^{\circ} 43^{\prime}$, and our longitude, west, by the chronometer, 7 degrees.

The three new iron keys being ready, and the weather moderate, June 1. the fires were lighted and the engine again set to work; but each of them broke after about an hour's trial, so that we were obliged to give up our hopes fiom such expedients, with all further attempts at repairing the evil in our present situation. Independently of this, the performance of the engine was most unsatisfactory. Even with a pressure of forty-five pounds on the inch, we could never obtain more than fifteen strokes in the minute; and as it thence followed, that the outer edge of the paddles had no greater velocity than five miles in the hour, that of the vessel could not possibly exceed three. The boilers also continued to leak, though we had put dung and potatoes in them, by Mr. Erickson's direction. The men were moreover so fatigued by the work required at the extra pump, for the supply of the boiler, that I contrived to get it wrought from the lower deck; though, even with this alteration, the labour continued too severe to be endured. 
This however did not include the whole of our nearly fruitless attempts to remedy the evil inflicted on us by the discreditable conduct of our engine manufacturers. Finding, further, that the condensing apparatus was defective, inasmuch as the air pump always drew a quantity of water, and the feeding pump was insufficient to supply the boiler, we disconnected the whole apparatus, except the latter, which we proceeded to supply by a cock; and having led the steam from the eduction pipe, by tubes and hose to the upper deck, we put the engine in motion, and thus, by means of a pressure of forty-seven pounds on the inch, obtained a velocity of sixteen strokes in the minute; being one more than when the condensing apparatus was in action. It was thus shown that power had been wasted, partly in this part of the contrivance, and partly through the vacuum pump; but whatever our correction was, it could have availed us nothing at sea, from the great loss of water to which it gave rise.

In addition to these unproductive corrections, we next tried the effect of disengaging the great bellows; yet though we saved considerable power in this manner, we found that it did not last, and that the small one was quite incapable of maintaining the requisite heat : while it was now also plain, that they were wearing so fast as to threaten to become utterly useless in no long time. Every thing in fact was imperfect; since even the cylinders were too small to perform the duties required of them : so that, if I had not been satisfied of it before, I was now convinced that we had little to expect from the assistance of an engine which, at the best, could, if acting alone, scarcely move our ship three miles in the 
hour, and was therefore utterly inadequate to aid us in taking in tow our consort the $\mathbf{J}$ ohn, as had been contemplated in planning this expedition; or could not at least have towed her faster than her own boats.

In blaming the execution and workmanship of this engine, I must however do justice to the principle, which was judicious, and, under a careful execution, might have rendered this machinery of great service to us on many of the occasions which occurred in our voyage. The diminution of weight, and the removal of inconvenience, caused by the omission of a funnel, constituted a manifest advantage; and a still greater one was the reduced consumption of fuel involved in the plan of this newly contrived engine. And while the plan of lifting the paddles out of the water, and thus out of the reach of eventual ice, was well suggested, so was the execution of this part of the machinery correct, even to superfluity; since we were enabled to take away the counterpoises and guide rods, and thus to diminish both the weight and the trouble. The pieces of timber placed to keep out the sea, above and below the shaft, succeeded perfectly: but finding that the scuppers on the lower deck would not let out the water from that and from the pumps, without also letting in the sea, we were obliged to invent a remedy by carrying a pipe from the pump to the scupper, which proved effectual.

The ship, as I had expected, had now become less leaky, and was easily kept clear by one pump; but the engine, I need not now say, being perfectly useless, we were compelled to trust to our sails, under which we had the mortification to find, not only a 
steadily adverse breeze, but that we were beaten by every vessel that we saw, so ill did we sail upon a wind. Our passage thus June 2. promised to be as tedious as it was irksome; but, on the second of June, we saw the Small's light, found ourselves off Wicklow on June 3. the same day, and on the third, it then blowing fresh, fetched the Calf of Mann, in time to get under its lee and shelter ourselves from the increasing gale.

June 4. On this morning we came to anchor in Douglas bay; when still desirous to make another attempt with our engine, I here procured proper materials, so as to construct two new keys for the shaft; writing also to London and to Liverpool for a supply of other spare ones, in case we should at all succeed in carrying this machinery further on our destination. We were here detained two days; yet losing nothing by the detention, since it blew a storm from the north-west the whole time, while we were thus also enabled to lay in a supply of beef, vegetables, and water.

As we had had good opportunities of observing the efficacy of our rigging during our passage, we found that our present method of managing the after sails admitted of some improvement. I therefore purchased some spars, together with some canvas, to replace the square sail, which we had lost during our voyage; here also receiving the visits of many friends, and others, all more

June 5. or less interesting themselves in our success. Every thing being completed on the evening of the fifth, we waited for a change of weather, which accordingly took place with a shift of wind on the June b. following morning; enabling us to weigh our anchor at six o'clock, with a breeze from the north-east. We stood towards the Calf of 
Mann; but, the wind falling light, made little progress, though working the engine, as we had attempted to do before, without the condensing apparatus. Yet, even thus, succeeding in obtaining only fifteen strokes in the minute, and being unable to make some intended repairs while the engine was at work, we had once more to depend on our sails alone, and against a wind which was now adverse.

On Sunday we were off the harbour of Peel, when by taking June 7. advantage of the tides, and carrying a press of sail, we made considerable progress, and soon saw the Mull of Galloway to windward. Early on Monday morning, the engine being once more ready, such as it was, we let down the lee paddle wheel, keeping the weather one out of water, with the expectation of advantages in which we were not disappointed. Instead of fifteen, we now found that we could easily make eighteen strokes in the minute, and that we could thus beat to windward as well as any of the vessels in company; even gaining on them, very shortly, as much as they had gained on us before.

Thus were we flattered with the hopes of soon reaching Loch Ryan; but an accident, as miserable as it was unforeseen, soon occurred to destroy the pleasure resulting from this new and unexpected success. We had just tacked close to the Mull of Galloway, after having made about thirty miles during the night, and were getting fast to windward, with the tide in our favour, when, at ten in the morning, our principal stoker, William Hardy, came up from the engine room on the deck, unassisted, and alone, and though without complaint or exclamation, presenting his left arm, 
shattered, and nearly severed, above the elbow. It appeared on inquiry, that his foot had slipped in consequence of the motion of the vessel, while examining a part of the machinery near the piston rod; thus causing him to fall in such a manner as to entangle his arm between the guide wheels and the frame, so that it was crushed, during the back stroke, in the horrible manner which it now exhibited. The bone being splintered as well as fractured, and the muscles and skin so bruised and torn that the two parts of the limb scarcely held together, there could be no hesitation in determining that it demanded amputation, and as far as my opportunities of surgical reading had extended, that no time ought to be lost in performing this operation. Unfortunately, our surgeon, Mr. M'Diarmid had not yet joined us, being on board the John, our intended consort; so that it became my duty to apply to this unfortunate case such knowledge as the sight of amputations in my naval service, added to my limited reading on such subjects, could supply. It was well that the instruments for the surgeon were on board, together with the medicine chest; and a berth having been prepared for our unlucky patient, I have only to say that I did, as well as I could, what seemed necessary, as far as my want of experience enabled me to do it; applying the tourniquet first, and then securing, with the tenaculum and ligatures, the only two arteries which I could find, while I cut off the injured muscles and skin in such a way as I hoped sufficient to remove the dead and hazardous parts, and to leave materials for producing a decent stump. Unfortunately, the amputation saw was not to be found, so that I was not only unable to remove as much of the bone as I 
ought, but was compelled to leave the broken extremity in a splintery state, to the further care of the surgeon whom I expected to find on shore before a day was over. And that I may not return to this case, I may now add, that as we reached the land so as to put our patient under proper surgical care before any material inflammation had occurred, that which I could not finish was completed without difficulty; so as to leave, in the end, a stump, which though not such as to have done much credit to a surgeon, is not worse than hundreds occurring under better auspices, and has not finally prevented this mutilated engineer from returning to his original employment in the establishment whence we procured him.

If I need not say that I should have been much more at my ease in cutting away half a dozen masts in a gale than in thus " doctoring” one arm, I could not but be gratified as well as interested by the effect which this occurrence, vexatious and painful as it was to me, produced on the men. The arrangements of the medical chest and instruments, the neatness of every thing, and the abundance of the supply, with, I hope, the further conviction that there was a good will to apply them all to their security and use, and that good will to be rendered more effectual as soon as the proper medical officer should join us, seemed to give them a confidence that nothing which could conduce to their comfort had been neglected: as, in this feeling, I found an ample confirmation of what I had long before read in the work of Monsieur Larrey, respecting the effect of his excellent medical arrangements on the troops of the farsighted soldier under whom his system was organized. 
Anxious as we were for our progress, we were now even more impatient on account of our unfortunate engineer; and we thus viewed with pleasure the progress which we were now making by the new help of our lee paddle wheel. We thus calculated that June 8. we should make Port Logan, then about nine miles off, before the end of the tide; but at noon all our hopes were destroyed by the breaking of the teeth which turned the fly wheel of the small bellows. On a sudden they gave way with a loud crash, so that this instrument became useless, and although, as the steam was then high, we hoped that this failure would not have much effect, it was shortly reported that the boilers had burst: as if it had been predetermined that not a single atom of all this machinery should be aught but a source of vexation, obstruction, and evil. This report did not indeed prove quite accurate; but some of the joints had so far given way, that the water was pouring out of the furnace door; and with such effect, that in ten minutes the fire was extinguished, and the engine stopped.

During these few hours the tide had changed against us; and as the wind was done, there remained no prospect of gaining either Port Logan or any other harbour on that day. Nevertheless, towards the end of the tide, we made a tack toward the Irish shore, in hopes that the wind would shift more to the westward. These however were not realized; and we had the further mortification of seeing all the vessels which we had passed, repass us; so as to convince us of the necessity of improving our own sailing qualities, by some change in our rigging, if that should indeed prove competent to such an end. 
On this morning we contrived to fetch within four miles of the June 9. harbour ; and the tide being in our favour, reached Port Logan at eight o'clock; finding sufficient water at the end of the pier, though it was now three quarters ebb. This, formerly called Port Nessock, is a safe and commodious pier harbour, constructed at the expense of Colonel M'Douall, of Logan, on the south side of a spacious bay, situated nine miles north of the Mull of Galloway. It is easily known by a remarkable building on the hill to the north of the bay, and by the watchhouse and flagstaff on that to the south, forming the station of the coastguard at this place. There is good holding ground in the bay; and ships may choose their depth of water, since it shoals from thirty to three fathoms. It is secure to the south-west, but is open to the north-west winds. It is a great advantage here, that ships can run for the pier, though at half tide; since, even at low water, it has seven feet, as, in the former case, there are fourteen, which at spring tides is increased to eighteen. There is no danger in entering, as every thing is visible; and as the tide sets outwards during eight hours, on the north side, a vessel has no difficulty in beating out. This is decidedly the best harbour of refuge, even in its present state, on this part of the coast; deriving advantage also from the proximity of the lighthouse on the Mull of Galloway. It has been computed that a breakwater might be erected within the bay, at an expense of $80,000 \mathrm{l}$; and should this ever be effected, it will become one of the most safe and commodious harbours in Scotland.

Before entering the pier, we were boarded by Mr. Harvey, the officer of the coastguard, with an offer of his services; and it was 
here, on landing, that we procured a spring car for the conveyance of our patient to my house at Stranraer, where he was put under the care of our own surgeon, Mr. M'Diarmid, and that of Mr. Wilson and Dr. Ritchie, who completed the operation which I was obliged to leave imperfect, and attended him kindly to a cure. I must not however quit the history of this spirited fellow, seaman though he was not, without adding, that while he found his way up the two ladders of the engine room without help, and made no complaint at any time, the only regret he expressed was, that he should " now not be able to go on the expedition." I might well regret, myself, being obliged to leave behind such a man as this.

Having followed Hardy to my house, that I might see him properly disposed of, I sent for Mr. Thom, to whom I had confided the management of the John; when I had the vexation to learn from him, that her officers and men were in a state approaching to mutiny, having taken advantage of our delay in joining that ship. It was soon easy to see in the looks of the officers and men, that Mr. Thom's report of their unwillingness to go on this expedition was but too true; the latter appearing disorderly and dirty, as they skulked and sneaked about the ship. Judging it therefore necessary to come to an immediate explanation, I went on board the John, and ordered all hands to be called. I then expressed my regret at finding there was dissatisfaction among them; but as I dared not suppose that it proceeded from fear, I trusted that a little explanation would rectify this misunderstanding. Having myself sailed from Greenock, I had desired 
that Greenock men should share with me the honours and advantages of this expedition; and of the advantages there could be no doubt, under the knowledge which I possessed and the plans which I had adopted. It was true, that the season might appear to them somewhat advanced; but, independently of the advantages our steam power might give us, I knew so well where to find abundance of fish, that there could be no question of our success, and that we should not, in the end, prove a day too late. I therefore expressed my trust that they would return to their duties, and not proceed in a mode of conduct which would bring disgrace both on themselves and their native port.

On this, a pause took place, when, after some interchange of significant looks and whisperings between the mates and the men, the boatswain stepped forward, and after calling on some others to join him, observed, that as the season was so far advanced, they were not willing to go without a fresh agreement; a resolution in which he was joined by the majority of the crew. On inquiring into the nature of this new demand, I was answered that they would not go, unless I would ensure them, in writing, the same shares as if they had returned with a full ship. It would not have been easy to frame a much more unreasonable request, when such a promise would necessarily deprive them of all inducement to exert themselves in fishing. I could not hesitate therefore in answering to so absurd a proposal, that I would ensure finding them fish in abundance, but that, to take them and fill the ship, must be their own business. I was answered, however, that nothing less would satisfy them than an absolute promise of 
200 tons of oil, with a further guarantee, in writing, that they were not to be detained on the expedition, but returned home in the usual time.

I now, therefore, began to suspect that the real motive of their present conduct was the fear of being detained beyond the summer; but I was soon convinced that their fears were even deeper than this, since it was in vain that I represented to them the egregious folly I should commit in taking them out with only six months' provisions, had I intended to keep them out longer, or even did I foresee the possibility of such an event as their detention. The best policy therefore now seemed to be that of shortening the stay of the Victory at Port Logan as much as possible; while I hoped that when we should join, and they were made to comprehend the advantages arising from the presence of a steam ship to aid the John in towing, this feeling would subside and they would return to their duties under our agreement.

I returned therefore to Port Logan without loss of time; and the remainder of this day, June 9, was employed in landing the small boiler, together with the apparatus intended for cutting the ice, which, it was now evident, exceeded the power of the engine to work. We thus got rid of six or seven tons of what was now mere June 10. lumber; replacing it by three tons of water. On the following day I was visited by my friend, Colonel $\mathbf{M}$ 'Douall, accompanied by others, relations and friends : nor did he part with us without a substantial present to furnish our next Christmas dinner, in the shape of one of the best Galloway cattle from his own estate. At six in the evening we cast off from the pier; and, with the assistance of the 
coastguard, were towed round the point of Logan, under a. light air from the south-east. At eight it fell calm, and we were obliged to stop the tide off Port Kale, under our kedge; and though weighing again the following morning at six, with a June 11 . light breeze from the north-east, we were unable to round Corswall point, so that we were again compelled to stop the tide in the same manner.

These delays allowed us to examine into the nature of the damage already mentioned as having been indicated in our boilers; when we found that the failure consisted chiefly in that of the iron cement which had been used in securing some of the joints; while the engineer had neither been informed of this, nor provided with the materials for replacing it in case of need. The small bellows, with the machinery belonging to it, was also in need of a thorough repair, as was the large one more partially; but I must be excused from dwelling on this endless and provoking subject at present, further than to say, that every day convinced us still more that we must consider ourselves in future, as dependent on our sails for such progress as it should be our good fortune to make.

We now weighed anchor once more at half-past five in the afternoon, rounded the point of Corswall, and bore up for Loch Ryan; but, as it fell calm, were obliged to come to anchor until the next morning, when, favoured by the breeze and a flowing June 12. tide, we ran alongside the John, having taken Mr. Thom on board the evening before, on making the Loch.

The Victory being now alongside of the John, and her crew 
ranged on the deck, I again went on board. When the hands were called, I explained at considerable length the advantages they would obtain, and that I did not entertain an intention of keeping them out a second year. But seeing that all I said was without effect, I addressed my own crew, by remarking that such cowards as the men of the John were not worthy to accompany such gallant fellows as themselves, even to the edge of the ice. Yet as it was also necessary that I should prove a positive act of disobedience, I desired Mr. Coombe, the master, to order his crew to assist ours in removing the coke. This was refused at once by the men, who at the same time called on those of the Victory to join them in "standing up for seamen's rights," as they expressed it. But the appeal, as I expected, was received by my own people with indignation; upon which I returned on board, and after praising them as they well merited, both for this and all their other good conduct, proposed that we should sail by ourselves, and leave the cowardly Juhn to her own proceedings. This proposal was received with three cheers; entirely disconcerting the mutineers, who had believed that I could not do without their assistance, and that they might therefore make any terms they pleased.

It was still necessary, however, that I should muster the John's crew, so as to ascertain the feelings of each individual; and this therefore was done by the master, at my instance. It commenced with the first mate, Muirhead, who declared that he would not abide by his agreement, nor go on the voyage, without a guarantee for 150 tons of oil and the immediate return of the ship : a specimen of the rest, at which I was exceedingly surprised, as he was 
the son of the worthy commander of the Larkins whaler, from whom I harl formerly received both kindness and services. The answers of the second mate, Robb, were the same; and it was not difficult to see that the master was kept in awe by these two men. The boatswain and the harpooners being next asked if they would assist in weighing the anchor, joined in refusing, while some added to their refusal, impertinence; and this example was followed by the whole crew, with the exception of the cook, the cooper, and two men, the latter of whom both entered with us afterwards for the expedition.

A disgraceful scene of confusion soon followed, in the attempts of the discontented men to leave the ship; that being opposed by the master, whether from a wish to conciliate my favour by a pretence, or from real repentance for his conduct, I could not be sure. Be that as it may, he proposed to lower down the boats and tow them on shore, that he might deprive the men of the means of quitting the vessel; but no sooner was this done, than several of them were taken possession of by the mutineers, who at the same time removed their chests from the ship, with the most insulting language, attended by the hisses of the Victory's crew and the reproaches of the coastguard, and a crowd of spectators who had collected to witness this scene. It was completed, as far as we could see of their proceedings, by their beginning to sell their clothes, to get drunk, and to fight, as soon as they were landed; thus proving that their mutinous conduct was but a part of a general character from which we could have expected no good. The number which thus left the John in the course of the day, amounted to thirty-eight; those who remained, including the 
master, some officers, and the apprentices, being eleven. In the course of these scuffles two boats had been stove, and one man had fallen overboard; but no lives were lost nor any known injury sustained.

'This drama having thus terminated, including an attempt to seduce four of the Victory's men by inviting them on board the John to make them drunk, which however failed, it remained for me to make a legal call on the master to perform his contract, and to leave him a written order to sail before the first of July, if he could reman the ship; failing which, he was to proceed to Greenock and deliver her over to the agent, Mr. Oughterson. It became necessary also for me to write an account of these proceedings to Mr. Booth, to which I added letters on the same subject to Sir Byam Martin, Captain Beaufort, and the Honourable Hugh Lindsay, in case any false reports, injurious to myself and my officers, or to the expedition, should be circulated, after my departure, by the people or officers of the John.

I cannot now, however, transcribe this narrative from my journal, without communicating to my readers what only came to my knowledge, after my return from this long banishment. Whatever else it may prove, to those who are but too ready to pronounce on that justice which it becomes no mortal to distribute, even in imagination, it served to satisfy us that we had lost nothing by the defection of our intended consort, and had perhaps escaped far greater evils than those which ultimately befel us : teaching us too, that the events, which in our shortsightedness we are so apt to view as evils, are full often intended as blessings. 
It was but in the following year, that the John, under the same master and officers, and with the same crew, barring one or two exceptions, sailed to Baffin's bay on a whaling expedition. From causes which have never come to light, a mutiny took place on board, attended by the death of the master, Coombe, but under circumstances which have not yet been rightly explained, as far as I can understand. The mate, with a boat's crew, were expelled at the same time; and having never since been heard of, are supposed to have perished in the ice. The ship, then put under the command of the Spikesoneer, was afterwards lost on the western coast, when most of the crew were drowned; the remainder being saved by a whaler which was accidentally passing. 


\section{CHAPTER III.}

LEAVE LOCH RYAN-GALE OF WIND OFF IRELAND AND LOSS OF THE FORE TOPMAST-FIRST SIGHT OF THE ICEBLINKS-ENTRANCE OF DAVIS'S STRAITS.

1829.

N the same day that we had got rid of the John and her mutinous crew, I returned on board the Victory, where the crew were occupied in removing the coke and some other stores which had been intrusted to the John as our consort and storeship. This occupied the best part of the following day; and, at six in the evening, all being ready, I cast off and stood to sea with a light breeze from the south-west; having taken leave of all our friends on shore and settled respecting the future management of our patient Hardy; receiving the cheers of Captain Sharpe and his men, whose countenance and aid had been of great service to us

June 14. during the troubles of the preceding day. On the morning of Sunday it was calm, and at noon the Mull of Cantyre bore north, the Craig of Ailsa bearing east; when a fresh breeze from the south-west, with a favourable tide, carried us rapidly through the north Channel.

It was at the first moment that we found ourselves settled and 
at peace after the disturbances of the preceding days, that I took the opportunity of expressing to my officers and crew the gratitude I felt for the support which all had afforded me, and of declaring iny entire confidence in them through the future voyage, whatever troubles we might be destined to contend with. Assembling them for this purpose, and also thanking them for the confidence which they had placed in me, it became further my duty to state to them that the defection of the John must now, as they could not fail to be sensible, affect their pecuniary interests; since no prize allowances, under the term of oil money, could now accrue to them, as there could be no fishery carried on by ourselves alone, for want of stowage. As it was therefore no less just than necessary for us to commence under a right mutual understanding on the subject of wages, I proposed that their pay should be settled according to their rating, as had been done in the former voyages of discovery. This was agreed to without hesitation, and with expressions of perfect satisfaction; the surgeon leaving it to myself to settle the compensation due to him on this score.

While our experience on the voyage to Loch Ryan had itself convinced me that our crew was deficient in the requisite number, the defection of the John rendered it still more imperious on me to increase our strength. For this purpose, after having taken an Irish labourer from Logan as a fire stoker, to replace the loss of Hardy, I also enlisted a third man from the John's crew, in addition to the two formerly mentioned; thus giving us an increase of three men, all volunteers, and immediately coalescing in harmony with the remainder of our people. 
We had no sooner passed the island of Rachlin, than we found a heavy swell setting in from the north-west; the apparent consequence of the long series of gales from that quarter which had recently occurred. Thus at least we at first thought : but we were soon undeceived, since it proved the forerunner of a storm still more severe than any which had yet occurred. It assailed us in a moment, when we were in hopes that we had at length overcome all our difficulties; and as the gale continued to increase rapidly, we were obliged to reduce our canvas without delay. The topsail had just been reefed, and there were two seamen on the topgallant yard, furling its sail, when the head of the foremast gave way with a terrible crash. Fortunately, however, the topmast did not fall immediately into the sea, but hung suspended by the rigging in a diagonal position; thus giving the two men time to escape from their perilous place, and to us, the opportunity of taking steps for saving the sails and rigging. We found the mast broken so close to the rigging, that it was only held in its place by the splinters; yet it seemed possible to frapp the shrouds and stays in such a way as to secure it from going overboard.

Having determined on this, no time was lost in putting it into execution, so as to preserve both the mast and rigging without discontinuing our voyage; while substituting such sails as we could contrive to carry on the crippled mast. Nor could any thing exceed the exertions and the enthusiasm of our men, whom if it is but justice to praise without exception, so must I especially notice the active and energetic conduct of my nephew, Commander Ross. It was highly gratifying to me, at this early stage of our career, to 


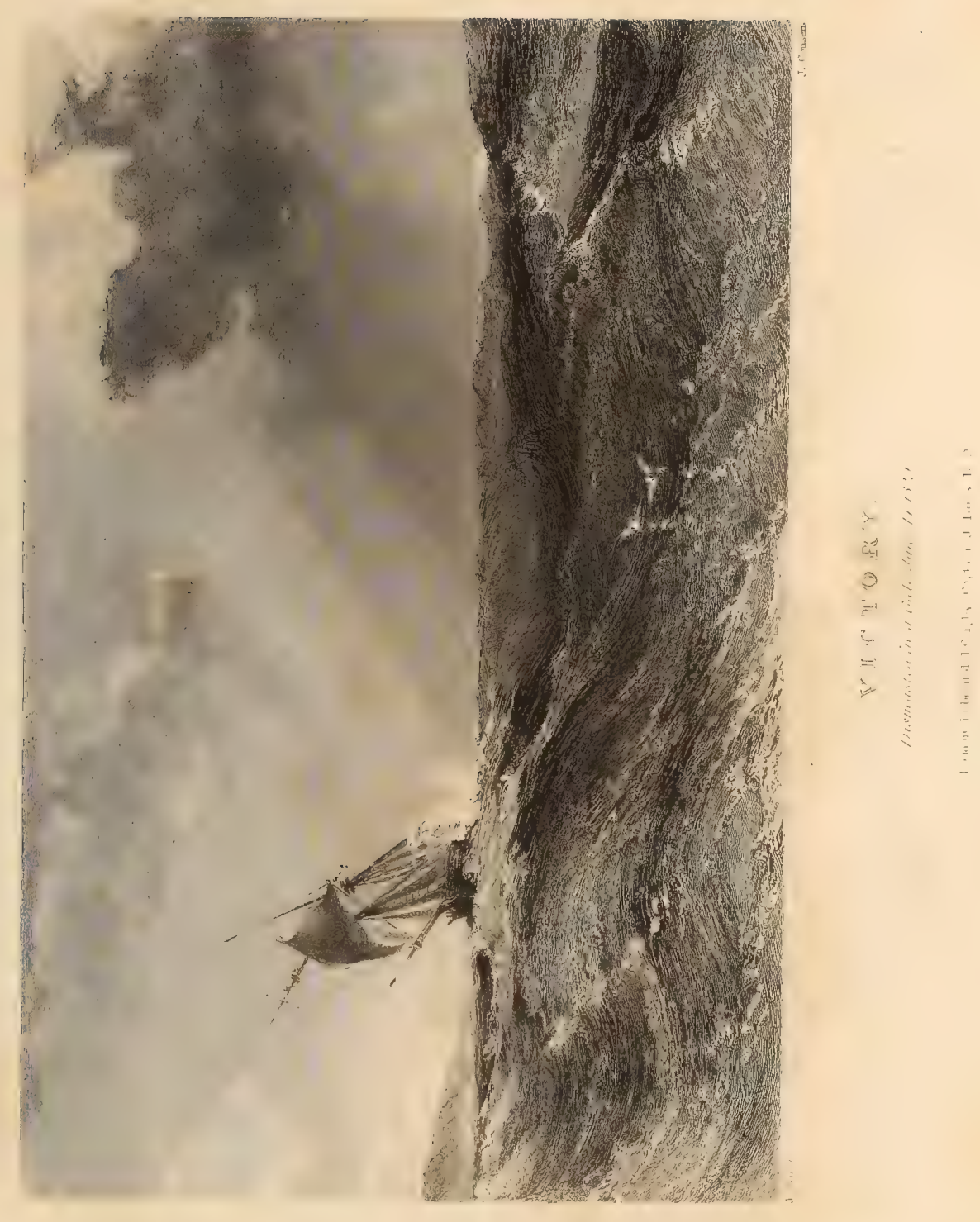



find in them all, the true spirit of seamen, since it taught me that I could depend on them in any emergencies; ready obedience, cheerful looks, and a general effort in every man to distinguish himself among his messmates and companions in this undertaking.

Before the night had quite closed in, the storm sails were consequently all set, and the Krusenstern was secured by an additional rope. At midnight, the lights on Insterhull bore west, and those of the Rinns of Isla nearly east; showing that our accident had occurred in the middle of this channel. The gale now seemed to moderate a little; but it was only to return with double violence, though more from the westward; while the sea was so heavy as to assure us that we could make no progress through it.

Thus did it continue to blow on Monday, yet with some intervals more moderate; during one of which we ventured to cross the topsail yard for a foreyard, setting on the reefed topsail for a foresail : our situation among the islands of this dangerous coast, rendering it necessary to set all the sail possible. Thus, although we were constantly obliged to wear the ship with great caution, in consequence of our having the Krusenstern in tow, we found that we at least kept our ground. At midnight we split the jib; and on searching for the storm jib to replace it, we found nothing but the rope; the canvas having been cut off and stolen by some plunderer, before we had left the Thames.

On Tuesday the gale rose to its height, and obliged us to lie June 16. to under the close-reefed mainsail; but the wind having veered considerably to the north-west, our drift was to the southward, in which direction there was plenty of sea room between us and the 
Irish coast. We were therefore able to maintain our westing; and shortly after noon the gale began to break, when, by the chronometers, we ascertained our longitude to be $7^{\circ}$ west; the latitude observed at noon being $56^{\circ} 23^{\prime} \mathrm{N}$. In the evening we were enabled to add the reefed foresail; but as the sea was very heavy, we made little progress. During the night we stood to the northward, in consequence of the wind having backed to the west; June 17. but in the morning of the 17th it became northerly, and we again wore. At seven we saw the Bishop's isles, together with Tirey at a great distance to the north-east.

The gale had gradually decreased; but the swell continued, and the ship laboured so much as to prevent us from taking any steps about our crippled mast. At midnight it fell calm; and the June 18. swell having abated on the eighteenth we contrived to secure the rigging on the foremast head somewhat better. The topmast, which had been broken off above the fid hole, and thus reduced in length, was pointed up; and the heel being secured by a lashing to the lower mast, about six feet below the rigging, there was sufficient length remaining to set the topgallant sail as a topsail. No sail could however be set on the pole, which was sprung about halfway up. At noon Malin head was in sight to the south-east, and the observed latitude was $55^{\circ} 57^{\prime} 14^{\prime \prime} \mathrm{N}$, the longitude by the chronometer being $7^{\circ} 40^{\prime} \mathrm{W}$. On this day the carpenters were employed in making a trunk to carry the water from the pumps to the scuppers, owing to the circumstances stated in the account of our passage down the river. It was satisfactory to find that one pump had been sufficient to keep the ship clear, during the whole 
of this gale, though we were obliged to have that one constantly going; but as this labour became less imperious as the wind moderated, we were convinced that the principal leak must be somewhere above the water line.

On this day the wind was still adverse; and as we had every June 19. prospect of a long passage, I began to entertain serious thoughts of putting in to Loch Swilly, which was now in view, and which we could just fetch, in order to take in an additional supply of water and provisions, and either to get a new foremast, or to cause the old one to be stepped on the lower deck, and to procure a new mast-head to be fitted on it. With this intention I stood to the southward, and at noon we were within 18 miles from the entrance, being in latitude $55^{\circ} 32^{\prime}$, longitude $7^{\circ} 55^{\prime} \mathrm{W}$, with Malin head in sight. A boat now came off which we believed to be a pilot vessel, but it proved to be a Dublin fishing boat, from which we obtained a good supply of fresh fish. The wind, which was now variable, died away entirely at 6 P. м., when we were ten miles from the entrance of the loch ; but at nine, a fresh breeze unexpectedly springing up from the south-south-west, we changed our plan, and bore up under all sail to continue our voyage.

As it was now evident that we had not water and hay enough to feed both the bullocks in our possession as far as the edge of the ice, one was killed. At midnight the breeze had increased, and the sea had also once more risen, so that we had again a fair prospect before us. Both increased as the day advanced; but we could June 20 . entertain no doubt, that it was nothing more than the sea occasioned by the late gales, though, as it crossed the course of the present 
breeze, it made our vessel labour violently. Notwithstanding this, and our course being to the north-west, the Krusenstern shipped very little water, which, as we were situated, was a fortunate circumstance; and, by midnight, having completely cleared the channel, we were all in high spirits, hoping that we had now left the chief of our troubles behind us.

June 21. The wind was from the south-east both on Saturday and Sunday, and we found that we had made about 200 miles. Divine service was performed on this last day, being the 21st, at eleven o'clock, and we trusted that our thanks to the Providence which had hitherto protected us through a series of troubles, which, though not extreme, were by no means light, were accepted.

June 22. On Monday the wind came to the north-east, being much more moderate; and at an early hour in the morning we passed the spot marked in the chart as that where Pickersgill sounded in 300 fathoms. The state of the weather did not, however, permit us to repeat this trial at so great a depth. The distance we had thus run was 103 miles, the latitude being $56^{\circ} 52^{\prime} \mathrm{N}$, and the longitude $19^{\circ} 3^{\prime} \mathrm{W}$; and we here saw a strange sail, which we took to be a vessel from the Baltic bound for America.

June 23. The wind being still fair, we made 113 miles, but had no observations. The tow ropes of the Krusenstern appearing to be chafed, we shortened sail and secured them, after which we held on our course. We were here surrounded by shearwaters, but there was too much swell to allow us to hoist out a boat in this pursuit. On

June 24. the twenty-fourth we were enabled to make observations; and, finding ourselves to the southward of our reckoning, altered our 
course to north-west by west, so as to make a true west by north course. In the afternoon of this day we got up our proper foreyard, and set the foresail with the lower and topmast studding sails. The swell had considerably abated, and the wind was now much more moderate.

Though we had some small rain on this day, the wind and the June 25 . sea continued to decrease, and we employed the carpenters in fitting up a dispensary for the surgeon. The engineers and armourer were also enabled to go on with the repairs of the engine and boiler, while the bellows were further put into the best condition in our power. We began also to prepare sails for the altered masts; that we might waste no time, when it was uncertain how long we might enjoy our present tranquillity.

On this morning there sprung up a fine fresh breeze, but towards June 26 . noon the weather became calm and foggy, so that no observation was procured. The carpenters and engineers continued their work of yesterday, and in the afternoon we picked up a piece of drift wood, which, with the animals attached to it, was preserved by Commander Ross (our naturalist in addition to all else); as were afterwards some specimens of the shearwater (procellaria puffinus) which we contrived to shoot.

A fresh and fair breeze sprung up once more at midnight; and at half-past three on the morning of the 27 th, a strange schooner June 27 . was seen standing to the north-east. The boilers having been at length repaired, they were now filled with water, and found to be water tight; on which the engineers were set to work to connect the forcing pump to the small engine, in hopes of saving the 
trouble which our men had formerly experienced in working this machinery. The little skiff was now taken in to be repaired and strengthened, and the new topmast was also finished.

A smart breeze of wind now enabled us to keep all our sails set, and we found a considerable swell coming from the south-west. There were some shearwaters and mollemokes about the ship, being the first time that we had yet fallen in with the latter. Our June 28. latitude on the following day, Sunday, was $57^{\circ} \mathrm{7}^{\prime} \mathrm{N}$, and the longitude by the chronometer $35^{\circ} \mathrm{W}$. The ship's company was mustered, and divine service performed. The wind was now variable, and tending to a calm; and, towards the evening, the little breeze of the day was quite done, and the sea smooth. We therefore took this favourable opportunity to set up the new topmast in place of the jury one which we had made out of the fragment of the former ; and having lashed and cleeted the heel about ten feet below the lower rigging, we found it sufficiently high to allow us to set the proper topsail on it, close reefed. This was accordingly done; and our topgallant sail, which had been used as a topsail since the accident, was also set in its proper place.

These arrangements were no sooner finished than a fine breeze arose, but it unfortunately lasted only a few hours. We had shot some of the shearwaters that had attended us, and now determined to try whether this bird was not eatable, in spite of its bad reputation, since it might be important for us hereafter to increase our resources of this nature, and to know to what we might trust in case of our coming to short allowance. We found them excellent, even in a pie, though the most supicious mode of cookery for meat 
of such a nature, and were glad to find that we need not even be forced by hunger to adopt a food which, if it never did more, would at least afford us variety. And I will now make this remark for the benefit of all who may be situated as we have often been, whatever use it may be turned to by those who, not knowing want, may find in the sea birds a source of variety or luxury. It has been overlooked by every one, that the fishy flavour of all these animals is confined to the fat; the whole of which also is lodged immediately under the skin, and is chiefly situated on the haunches. The muscles are always free of any oily, or rancid, or fishy taste; so that nothing more is requisite than to skin the animals, and especially on the back, to render them undistinguishable from a land bird. In this way even the cormorant and the puffin, strongtasted as they are, can be cooked in any manner, without the possibility of being recognised for seafowl. In fact this is equally true of many land birds; and in Sweden, where the cock of the wood and the black cock feed on junjper and fir, especially in winter, they are often scarcely eatable, from the flavour of turpentine; while that is entirely removed by the same mode of treatment, so as to render them a very acceptable game for the table. I believe, however, that I must except the mollemoke (fulmar peterel); since, in this bird, the fat is so mixed with the muscles, that no contrivance can rid them of their detestable flavour.

It being daylight soon after three in the morning of this day, June 29. a light air came from the eastward, and we set all our sails. We had seen an iceland hawk last night, and now observed two 
finners running to the north-east. The carpenters were again set to work on the skiff, it being Monday, and were also employed in making a jigger-mast. We had made but twenty miles in the last twenty-four hours; being the worst run we had had since quitting the Irish coast; but, in the evening, a breeze came from the eastward, which continued during the night, and served to help us on considerably. At sunset there was a shower of rain ; after which we saw an iceblink bearing north-north-west, the coast of Greenland being computed to be about 220 miles off in that direction. We also saw at this time many of the birds called boatswains, besides our former attendants the shearwaters and mollemokes.

June 30. On the thirtieth we had fresh breezes and cloudy weather, with the wind from the north. All sail was set; and the carpenters finished their work on the boat and the jigger-mast. The fresh beef of the bullock which we had killed was this day exhausted: but we decided on keeping the other animal, if possible, until we arrived at the ice, as we might then contrive to use the whole, by means of the cold, in a fresh state. The boilers seemed to continue tight, and the pump was in considerable progress; the bellows being also finished; so that we had a prospect of being again able to use our steam, to some extent at least, should the necessity for other aid than our sails arise, as indeed could not fail to be the case.

suly 1. The leaks which had now required us to keep our pumps going for at least an hour during every watch, in fine weather, and without cessation when it blew hard, were this day discovered 
to be the produce of three treenail holes on the larboard side, abreast of the engine room. The largest of these, which was about three feet below the water line, was easily stopped, and this gave immediate relief to the pump. The other two, though less in size, were situated near the floor-heads, so that we could not get at them till an opportunity should offer for laying the ship aground : it was, however, satisfactory to have found out the real nature of these two leaks, which also, in point of effect, were of little consequence.

The landblink was now very perceptible; $a n d$ in the evening we discerned the land itself, which we conceived to be Cape Farewell. The latitude and longitude of this point are $59^{\circ} 38^{\prime} \mathbf{N}$, and $42^{\circ} 45^{\prime} \mathrm{W}$, while our own, at the time that we saw it, were $58^{\circ} 8^{\prime}$, and $42^{\circ} 30^{\prime}$; so that, presuming these several things to be correct, our distance from it must have been about 31 leagues. During this day the temperature of the air and of the sea fell three degrees; the air being $46^{\circ}$ and the water $47^{\circ}$, at sunset.

On this day we began to keep our regular register of the thermometer every two hours, though unfortunately losing one at the very first trial, through the unhandiness of the mate. The wind was from the eastward, but there were evident signs of a change about to happen before no long time should be past.

We had, on this day, completed a fortnight of fair wind, and July 2. with it, our run from the point of our last departure, Loch Swilly, to Cape Farewell. Towards the evening, as we had foreseen, the wind veered to the northward, and our vessel could no longer lie her course. We now passed the spot where the Hecla and Griper 
had been on the thirteenth of June, 1819, after having left Fair island on the nineteenth of May; and as we had taken our own departure from Loch Swilly on the eighteenth of June, it followed that we had gained eleven days on that expedition, in nearly the same run of 1300 miles.

We had served out to the men, on the first of July, an allowance of clothes calculated for the climate we were now to encounter. This consisted of a blue jacket and trousers, a flannel shirt, a comfortable, a pair of wadmal hose, a pair of flannel drawers, a Welsh wig, a pair of sea boots, and another of carpet boots. The jackets of the officers and petty officers were slightly distinguished, so that our equipage had altogether a very uniform and orderly appearance. These clothes, with exception of the boots, were a present to the men; and a reserve set for each was kept in store, in case of need.

July 3. Our new jigger-mast had been got ready on the second (yesterday), together with two beams at the stern to support it and the out-rigger; and, after examining our run, we found it to be ninety-six miles, but unfortunately on only a south-west course. Thus, on this day, we found ourselves in latitude $57^{\circ} \mathbf{4 7 ^ { \prime }}$, and in longitude by account, $46^{\circ} 53^{\prime}$. The temperature of the air at midnight had been $41^{\circ}$, and that of the sea $43^{\circ}$. After making a board to the south-west, we tacked at 8 P. M., and stood all night to the July 4. northward; so that at noon on the next day, we found ourselves in latitude, by observation, $57^{\circ} 59^{\prime}$, and longitude $47^{\circ} 31^{\prime}$. The weather was hazy, and the winds light and variable. 


\section{CHAPTER IV.}

OFF CAPE FAREWELL-FIRST ICEBERG SEEN-ABREAST OF BAAL'S RIVER-SIGHT OFF SUKKERTOP-LAND AND ISLANDS NEAR WIDEFORD SEEN-A CODBANK DISCOVERED-MOUNTAIN CALLED OLD WOMAN'S HOOD-ARRIVAL AT AN ANCHORAGE.

THIS day, being Sunday, it was calm during the whole morning. At half-past ten the ship's company was mustered, as we were then just entering Davis's straits, being off Cape Farewell. The weather being cold, and the men in their warm dresses, we for a moment forgot that we were now in the very midst of summer and in its hottest period; scarcely even thinking of the contrast between our own situation and sensations and those of the friends we had left behind. After divine service, a fine fair breeze soon sprung up, and we secured a piece of fir timber which was passing us; the fragment of some ship, since it was full of treenail holes. It was covered by different marine animals, and was therefore a prize to Commander Ross.

At eight o'clock this evening we were going at the rate of six miles an hour, and our rate increased during the night so rapidly, that we were at length obliged to shorten sail, chiefly on account of the Krusenstern, which we could not conveniently tow along when 
under any considerable velocity. We now distinctly saw the land, which we supposed to be Cape Farewell, about thirty leagues distant, and near it a number of icebergs, bearing north-east by north.

July 6. The breeze continuing favourable, we had a prospect of making ourselves amends for the former two baffling days, and now passed many pieces of drift wood, but under too rapid a motion to allow of our securing any. Our latitude at noon was $59^{\circ} 33^{\prime}$, and longitude by the chronometer $50^{\circ} 54^{\prime}$; so that we found that we had made 140 miles in the last twenty-four hours. The temperature of the air was $48^{\circ}$, and that of the water $44^{\circ}$; and there was now no land in sight.

July 7. The breeze still eontinued till three in the afternoon of this day; and we found by the $\log$, at noon, that we had run 138 miles since the preceding one; but as the haziness of the weather prevented us from taking any observations for the chronometer, we could not form a more accurate computation. As the latitude, however, which was $61^{\circ} 33^{\prime}$, gave four miles more of northing on a northwest course, we attributed this increase of westing to a swell from the south-south-east. In consequence of this swell we were obliged, in the evening, to shorten sail, by taking in the mainsail, gaff topsail, and topgallant sail. We however set the latter again at daylight on the next day; replacing the mainsail also by the studding sails on each side.

At nine this morning we had altered the course to north-west half north, true meridian; having found this to be north-east by north according to our compasses, which, including the variation 
and the deviation, differed, on this course, four points and a half from the true bearings. Some shearwaters were still seen, and the mollemokes increased in numbers, as did the pieces of floating drift wood. After three, this fair breeze gradually fell off; and at midnight we were not making more than two miles and a half in the hour, with the weather still somewhat hazy.

On the whole of this day there were light airs with intervals of July 8 . calm, and with cat's paws coming gradually to the north-east. We accordingly wore, and stood to the eastward. A little before noon we picked up a tree which measured twenty-one feet in length and three feet in circumference near the root. It was without branches or bark, and proved to be larch, perfectly sound. 'The root fortunately contained a natural knee exactly suited to one of our wants, which was that of a boat's davit: and it was accordingly converted into one, as was a part of the other end; so that with these two, when completed, we found that we should be enabled to carry another boat over the quarter. Some shearwaters were shot, and a small fish taken; a drawing of which was made for our collection of natural history, while the specimen itself was preserved in spirit of wine. At midnight the temperature of the air was $39^{\circ}$, and that of the water $42^{\circ}$.

On the ninth, having observed for the latitude, we found it to be $62^{\circ} 36^{\prime}$, and the longitude by the chronometer $54^{\circ} 31^{\prime}$. The whole day was passed between light airs and calms; but as the swell set from the southward, we contrived to keep steerage way on the ship. A quantity of shearwaters and boatswains were shot by Commander Ross, who kept the best for specimens, the rest being 
added to our usual commons : and we also found that a gannet pie was preferred to the best piece of corned beef which we could produce, confirming the remark I have already made. Many more shearwaters were afterwards seen, so that I might safely call their numbers immense. Two finners also came alongside; and one of them was struck in the shoulder by a musket ball, without however being killed, as far as we could discover.

July 10. This day was perfectly calm during the whole twenty-four hours, with the exception of some cats paws that lasted only a few minutes. The ship's head was generally to the north and north-east, and I now had occasion to regret that the engine was not so ready for use as I had anticipated a few days before. The gear of the forcing pump had taken much more time than was expected, though the engineers and armourer had been steadily at work. The carpenters, however, contrived to fix the new davits, and we got out one of the six-oared boats and hoisted it up on the larboard gangway. We took this opportunity also of getting out of the Krusenstern five casks of salt provisions which had been left in her for ballast, together with a log of oak which we wanted for present use. A great many shearwaters, boatswains, and kittiwakes, were killed for use; but on this day we were unable to get any observations on account of the haze, which was very thick.

July 11 .

This morning the wind sprung up from the north by west, being directly against us, so that we began to be fearful lest our passage should be delayed. We stood to the eastward; and at three, picked up a piece of an American cedar-tree, sound and convertible to use. We killed as many birds as would suffice for the men's Sunday 
dinner, and accordingly served out to them flour enough to make crusts for their pies. We could get no observation at noon ; and the wind increased, as did the cold, the air and water being both at $43^{\circ}$. At ten in the evening the temperature of the latter suddenly fell to $38^{\circ}$; which, indicating the approach of ice in some form, induced us to tack and stand to the westward. We had seen the coast of Greenland at intervals, and had therefore little doubt that we were approaching the land ice. It blew too fresh to use the engine, even had it been completed; but we still hoped that we might be able to take advantage of it on Monday.

On Sunday the weather was thick and foggy, and it was blowing July 12. fresh. At daylight we saw a strange sail standing to the eastward; she seemed a brig, but we were at too great a distance to make out exactly what she was. There was too much swell to admit of divine service, so that we could but muster the men. We had an indifferent observation immediately after noon, and found the latitude to be $63^{\circ} 15^{\prime}$, and the longitude $54^{\circ} 23^{\prime}$. Much drift wood, and many birds, passed by us; the kittiwakes becoming much more numerous. As on the preceding evening the water fell in temperature, but again rose shortly after; the lowest being $37 \frac{1}{2}^{\circ}$, and the highest $43^{\circ}$ : whence we concluded that we had again approached some ice. At eight in the evening we fell into a strong. rippling current, which made the ship very uneasy, and seemed to indicate the set of a stream out of Davis's strait. The temperature of the water was then $39^{\circ}$ and $40^{\circ}$, but it afterwards rose to $41^{\circ}$, though we were nearest to the eastern land, and, as we computed, not more than fifty miles from it. 
July 13. We had stood first to the eastward last night, and then to the westward after midnight, the wind gradually decreasing; and on this day it fell calm at noon. We had tacked at three in the morning, when we found ourselves in the ripple, and as it cleared up about ten, we concluded that we were within fifteen leagues of the land near the exit of Baal's river; discovering then also the first iceberg which we had seen since entering the straits. We could not help noticing it as a remarkable coincidence, if it was no more, that this berg was nearly in the same latitude and longitude as the second one which we had seen from the Isabella eleven years before. It is indeed not to be conceived that it could be the same; yet, having in my possession a correct drawing of that one, it was even more remarkable that the resemblance between the forms of the two should have been so great as.we found it.

We sent a boat to it for the purpose of procuring ice which might furnish us with water, and she returned in three hours with two tons on board. The officer reported that he saw several whales, and many seals near this iceberg, which was covered with birds; and he found no difficulty in landing. The brig which we had seen on Sunday morning was also in sight, nine miles to the north of us; and when the breeze sprung up about five, we saw her steer for Baal's river, whence we concluded that she was a Danish vessel. We saw more birds to-day, including dovekies, than we remembered to have ever seen together before, as well as a quantity of seaweed from which many small fishes and other marine animals were procured, and preserved by Commander Ross. Of these, I may say once for all, that they have been reserved for the Appendix 
on Natural History which this officer has furnished; since descriptions of them would not only interrupt the narrative of our proceedings, but be of less distinctness and utility to the reader, than as they now stand in a regular approximation.

Another large piece of useful American cedar was also picked up to-day; and the carpenters were employed in fitting an oak mast-head to the foremast, that we might be ready to fix it on at the first convenient opportunity. The engineer having also finished his work, consisting in the repairs and improvements of the engine which we had planned, it was tried so far as to ascertain how the feeding pump would act, and whether the boiler could now be trusted. The former was found, or thought to have been, a successful piece of work; but though the principal leak of the latter was stopped, the small one at the foremost end was not cured. The engine was not, however, set going, because the springing up of a breeze rendered it unnecessary.

On the same evening we were abreast of Baal's river, and shaped our course to the north-north-west, that we might gain a little more offing, as the wind was to the south-west. 'The weather remained cloudy all day; and, judging by the land, we thought ourselves carried by a current to the northward. This indeed was made manifest by our observations, which gave us $63^{\circ} 39^{\prime}$ of latitude, or about nine miles more than the latitude by account. The breeze went on increasing, so that at midnight we were going three knots.

On Tuesday at daylight, which was now about two o'clock in the July 14. morning, the weather was foggy, and continued so till eight, when it cleared away; and the breeze at the same time began to fall off, 
so as to subside into a calm at six in the evening. Nevertheless, we were able to keep steerage way on the ship, as there was a swell from the southward. We had a good observation at noon, by which we found ourselves in latitude $64^{\circ} 48^{\prime}$, and in longitude $53^{\circ} 45^{\prime}$. We obtained on this day a fine view of the remarkable mountain Sukkertop (the sugar loaf), of which I was enabled to make two drawings; the one bearing east-north-east and the other due east. It appeared to be about twelve leagues distant, and far overtopped all the surrounding mountains.

The carpenters continued to be employed upon the new mast-head; and as we had replenished our water, we served out an allowance for washing, together with a quantity of soap to each man. Some rain fell about six in the evening, and the swell increased so much as to be very troublesome; while a breeze also sprung up from the north-east by north, our true course being north by west. At nine it cleared away, when we had another view of the magnificent mountains near Cockin Sound, and saw the land as high as Queen Anne's Cape. But one iceberg was seen to-day, and that a very small one; and we continued to meet with birds, seaweed, and drift wood. During the calm, the ship's head being to the eastward, we found that we had neared the land considerably; but after the wind was up, we found ourselves within about twelve leagues of it, the Kin of Sael bearing east by north, and Sukkertop south-east by east-half-east.

July 15. The swell continued all night, and this prevented us from using the engine, which, as far as our yesterday's trial had gone, seemed at last ready for use. The ice which we had seen in the morning 
had been left behind, and we saw no more this day, but, as usual, passed many birds and some drift wood. It being clear at noon we succeeded in getting an observation, by which we found ourselves in latitude $65^{\circ} 20^{\prime}$, and longitude $54^{\circ} 20^{\prime}$. In the morning, at eight, the temperature of the air and water were at $48^{\circ}$, and it rose to $49^{\circ}$ at noon. In the evening, the wind advanced to the north-west; and, at half-past ten, we tacked and stood to the eastward. We, on this day, crossed the track of the Isabella on the 30th of June, 1818, and were as far north as the Hecla and Griper had been on the 2d of July, 1824; and in the evening had a fine view of the striking range of mountains on this coast; Queen Anne's Cape bearing east-north-east at ten o'clock, and the land being seen to a great distance. The carpenters had been fully employed the whole of the day in forwarding their work.

The wind was against us all this day, and attended by so much July 16 . swell that we could neither attempt to employ the engine nor make any progress by our sails, At noon we were in latitude $65^{\circ} 34^{\prime}$, and in longitude, by the chronometer, $55^{\circ} 21^{\prime}$. We stood to the eastward till four in the morning, and found ourselves nine leagues from the land; standing to the westward after this till four in the afternoon, when we again wore. We soon lost sight of the land, in consequence of a fog which came on about six; but it cleared away about ten, after which we saw no more land, nor any ice. The temperature both of the air and water was $40^{\circ}$. We saw a few loons and shearwaters; but we believed that we had yesterday eaten the last allowance we should get of the latter, as we had always found that they ceased to frequent the sea further north. 
July 17. The wind was more moderate this day, and the swell so much abated that we set the lee paddle of the engine to work. We found that it made seventeen revolutions in the minute, and assisted us very much in plying to windward. In fact we could now keep the ship one point nearer the wind, with a velocity also of three and a half miles, instead of two and a half, and without making more than the half of our former leeway. In the morning watch, a good many whales and seals were seen, with numerous flocks of shearwaters asleep on the surface of the sea. Land was also seen a little to the northward of that which we had noted yesterday, yet only for a few minutes between seven and eight o'clock; while a fog that attended us cleared away. At eleven in the morning, the engine not having been at work more than three hours, one of the boilers began to leak. The fire was therefore immediately put out in it, when the other was found not to have sufficient power to keep the wheel going. Every thing was therefore stopped, and the fires extinguished, that we might endeavour once more to get the damage repaired. On examination, it was found that the largest and the larboard pipe, which are placed within the boiler, had been pressed flat, and that the outer edges of each had rent; thus accounting for the escape of the water, which was found to have made its way out at seven points in the larger, and at three in the smaller one.

We immediately set to work to replace the large, and to repair the small pipe: but found this to be both a tedious and a difficult undertaking. The screwholes in the flaunches did not correspond to each other, so that we were obliged to make new ones, after 
plugging up the old. Neither did the flaunches themselves meet as they ought to have done; thus materially increasing the trouble of the workmen; while we regretted every hour the loss of the valuable time which was slipping away. Thus did we labour till midnight, when on trying the pipes by forcing water into them, we still found further alterations necessary, as, eventually, we had to fit two new pipes, so as to occupy us the whole of this, the 17th day of July.

Our latitude by observation this day at noon, was $65^{\circ} 37^{\prime}$, and the longitude by the chronometer, $50^{\circ}$; showing that we had made ten miles northing. The temperature of the air and the sea had not changed, and the wind had rather increased, without however any sensible augmentation of the swell.

The engineers and armourer were still employed on the engine; July 18. my own anxiety also causing me to pass nearly all my time in the engine room, since I found that this repetition of adverse winds might materially obstruct our passage to Whale islands. By noon, consequently, we had only made four miles northing; and it was not till five in the afternoon that the work was reported to be ready. After an hour's labour in getting up the steam, the engine was thus at last set to work on the lee paddles; but they had not been quite half an hour in motion when the main key of the shaft gave way, and we were once more obliged to stop, under greater provocation to the patience of all of us than it would be easy to describe. There seemed indeed no end to the vexations produced by this accursed machinery; since the larboard boiler also was again found to have sprung a leak. Nevertheless we took the opportunity of screwing up the flaunches, though they were still warm; and the workmen set to 
work immediately to make a new key, though we could not hope to be ready for Monday. The paddle was consequently also hove up; when, as if we were not sufficiently troubled already, the tackle block gave way, and it came down, but, fortunately, without doing any damage. We however fitted a new tackle, and thus got it out of the water.

July 19. During the last night the wind and weather remained without alteration, nor was there any change in the temperature of the sea or the air. 'This morning, being Sunday, the weather was foggy, and the wind in the same direction, but more moderate: we consequently made little progress. At noon, as usual, the men were mustered in good health and spirits, and divine service performed. We saw the first walrus this day, with a good many whales, and abundance of birds. We stood off the land till noon, and then tacked; our latitude being $65^{\circ} 42^{\prime}$, and longitude $55^{\circ} 12^{\prime}$ with the temperature of both the air and sea $42^{\circ}$, and the same at midnight as in the day.

July 20. This day commenced with a calm, which continued till about eight, when a light breeze sprang up from the southward, and continued so as to give us a run of about fifteen miles during these twenty-four hours. Every one that could work was employed on the engine; and having fitted a new key on the shaft with all possible care, it was ready for use by the evening; even the boilers now seeming less likely to leak than they had done before. The breeze, however, was such as to render it unnecessary; so that we delayed a trial, which was perhaps only destined to disappoint us once $\mathrm{m}$ ore. 
We had now been beating about for fourteen days, in a situation little calculated to make much progress, from the various misfortunes which had beset us; and I had therefore determined, should the wind continue so unfavourable but one day longer, to look for some convenient anchorage on the coast, where we could fish or tongue the foremast, and make such other alterations as would enable us to carry more sail. With this view the anchors were got ready; but the occurrence of this last favourable breeze suspended the execution of this design, and gave us hopes that some better fortune was now in store for us.

We now sounded with the deepsea lead every two hours, and found from 38 to 50 fathoms, bringing up shells and small stones; while the nature of the bottom and the depth of water showed that we were probably on a fishing bank. We therefore tried our lines, and caught some excellent cod and halibut, which proved very acceptable as a change from our salt provisions. A large iceberg was seen this evening at a considerable distance, with many whales and birds. We still continued to shoal the water, which diminished from 39 to 35 fathoms by midnight; continuing to sound and fish during the whole night.

At four on the following morning it shoaled to 23, after which the water became suddenly deep, and we found no bottom at 70 fathoms by six o'clock. When on the shallowest part, we judged ourselves to be in the latitude of the rock on which the Victorious man-of-war struck during the last war, being $66^{\circ} 21^{\prime}$ : and though we conjectured that this shoal might be a continuation of the same ridge, our time would not admit of a closer examination. 
The land and islands near Wideford were now seen bearing east by north, about ten leagues distant; but we could not see the sun so as to obtain any observation. At three in the morning we passed the iceberg which we had seen the day before yesterday, being but the third one we had seen since our arrival in Davis's straits. The carpenters were employed in fitting up a lugyard to our jigger-mast; and the iron hoops for the foremast head were now also finished, with every thing else necessary for repairing this damage as soon as a convenient harbour should be found. We were even in hopes of getting to Whalefish islands this week. At noon the land about Wideford bore east: but our fair wind gradually fell off in the afternoon, and the engine being supposed to be now serviceable, we put on the steam and stood to the eastward, with the intention of clearing some rocks which appeared above water much further west than any which are laid down in the chart.

We had been swept towards the shore, either by the tide or a current; but at midnight we had made considerable way from the land by the aid of the engine and our sails. The former, however, was but of partial use. Owing to the leaky state of the boilers, we could employ but one, under which we could make no quicker progress than a mile within the hour. We therefore stopped it at four o'clock, to clear the furnaces; renewing the attempt at eight, but with no better success. In compensation, we had the continued advantage of enduring these endless trials of our patience; and whatever rewards may be allotted to the exertions of this virtue, we had assuredly a fair claim to them. 
It being calm this morning, the steam was continued till nine, July 22. when a breeze sprung up from the north-north-west, being right ahead, and so strong, that the engine, as it was now acting, was quite useless. It was therefore stopped. We had fished on the bank as long as it was calm, in depths varying from 14 to 36 fathoms; but on standing to the west, we dropped suddenly into fifty, and then into seventy. As the sinall engine had been unable to work the bellows, this duty fell on the men, who had consequently undergone abont twelve hours of this disagreeable labour, and were much fatigued; so that we were obliged to give them a turn of four hours' rest. The wind increasing in the course of the day, the weather became foggy, and we stood to the westward. At eight in the evening we renewed our attempt with the engine, using only the lee paddle; when it proved that the average of revolutions in the minute was but ten, no effort of the engineer having been able to carry them beyond sixteen, though the ship received so much aid from the sails as considerably to diminish the resistance of the water against the wheel.

The quantity of fish which we had caught, consisting of cod and halibut, was found to weigh 453 pounds; so that we were able to serve the crew with an allowance of two pounds each, a variation in their food not less conducive to their health than it was acceptable. In the afternoon the swell increased so much, that the engine was no longer of use. It was therefore stopped, and the wheel hoisted up; while the engineers took the opportunity of renewing their never-ending repairs. At five we made the land; and as it was then blowing fresh, with every appearance of a con- 
tinued adverse wind, I determined to look for a convenient harbour where I might repair our damages.

We accordingly stood in for the entrance of a large inlet; and when as near as we could approach with safety, Commander Ross was despatched in a boat to look for an anchorage. In the mean time, having passed to the southward of some small islands, I stood off with the ship, waiting with much anxiety for the appointed signal to bear up. I continued to sound as we stood on, and found the water deepen from thirty-five fathoms till there was no bottom at seventy. A stream, which was either the tide or a current, I could not be sure which, appeared setting here toward the north, and a creek was seen at the entrance of an inlet between the land and an island with a beacon on it. The land itself was very remarkable; bearing a high mountain with a sharp peak on it, quite unlike in character to that by which it was surrounded; the mountain itself is called the old wonan's hood: and there is also among the charts a draught of the harbour which it serves to mark.

We could not help once more observing from this point in our present voyage, what had already struck us so forcibly, in the rarity, almost the absence of icebergs, namely, that all the visible land was peculiarly free from ice. This led us to hope, as we had in reality believed likely before our departure from England, that the preceding winter had been peculiarly mild, and that the temptation under which it was, chiefly, that we had determined not to lose the present summer, late as we had been in setting out, would be followed by better success than we had expected under some of our recent disappointments. 


\section{CHAPTER $V$.}

VISIT OF THE DANISH GOVERNOR OF THE SETTLEMENT AT HOLSTEINBORG-RESIDENCE THERE AND PURCHASE OF STORES FROM THE WRECK OF THE ROOKWOOD-DEPARTURE FROM HOLSTEINBORG.

ON the morning of Thursday we continued in expectation of our boat, which made her appearance about one o'clock; coming out to the southward of the island with the appointed signal flying, to signify that she had discovered a harbour. We therefore bore up for it under all sail, as the wind had now much moderated On approaching the high land, we found it nearly calm, though there was a strong breeze still in the offing; and at two o'clock Commander Ross came on board. His report was, that he had discovered a cove at the east side of the beacon island, appearing to be perfectly safe, and with four fathoms a little after high water; being at the same time so small that it would be necessary to moor the ship both head and stern. Admitting that the water might ebb another fathom, there would be still enough for a ship of so moderate a draught as ours; so that we determined to make for it at once. 
Proceeding, we first passed a round island, and afterwards a rock above water, resembling a dead whale, situated to the right hand of the island. There appeared to be a good channel, however, on each side of it; and standing on till we approached the island, we found it to be about two hundred yards in length. It was between this and the beacon island that our intended harbour lay, which was thus defended from the north by the main land and the islands near, as, to the south, it was covered by many others, situated at various distances. The boats soon towed us round, and we entered from the south, mooring by ropes from each bow and quarter.

It was during this attempt that we first saw the moon since we had quitted the coast of Scotland on the fourteenth of June. The consequence was, that we had been unable to procure a single lunar observation during the whole passage. It was now most brilliant; and being seen between the peaks of the lofty and picturesque mountains of this coast, the effect was splendid in the highest degree; the rugged sides and peaks of all these hills appearing in all their distinctness through an atmosphere which seemed as if it had never known a vapour.

At five o'clock the tide had ebbed considerably, so as to leave us only twelve feet water. We found no inhabitants on the beacon island; but the presence of three Esquimaux dogs assured us that we were not far from some settlement. Ascending to the beacon, I gained a view of two magnificent inlets, surrounded by mountains of a very striking character; far more striking now than they had appeared on entering the harbour, as the view which I obtained 
was more extensive. Being entirely clear of snow, while broken into precipices, and shooting upwards their sharp and rugged peaks, their aspect was very different indeed from what had occurred to us in our former voyage, when the season was earlier, and the presence of snow on them not only obscured their forms in many places, but, by bringing them near to the eye, destroyed all atmospheric perspective; all keeping and all landscape effect. It was truly a splendid and a striking scene, well worthy of the pencil of a very different artist, as it defied the little power which I possessed.

The sight of numerous rocks and breakers, both to the north and the south, now proved that we had chosen the right passage, or rather the only navigable one; guided more by good fortune than by observations which we had not in reality the power of making. The island itself was a far finer object than our former experience at an earlier, and perhaps in a worse season, had given us reason to expect on this icy coast, and reminded us in a lively manner of the far fairer lands which we had quitted but a month before, and the summer which we believed we had left behind. Every practicable part of the surface, even the smallest spot which was not a pure precipice or a sea rock, was covered with verdure; while a profusion of wild plants, now in full and luxuriant blossom, rendered that a summer garden which we expected to find what we had often done before, a chaos of rugged rocks and cold snow. We no longer, therefore, wondered at those who had given the name of Greenland to a country, which others as well as ourselves had long thought to have been ridiculed by such a denomination. It was in truth a 
green land, as far as our present situation was concerned; and that green the more striking from the long absence of all but sea and sky, and the desolation of ice and rocks which, if we did not see at this moment, we knew full well lay all around us, as we had amply witnessed it on former occasions. Nor was it free of the usual accompaniments of a hot climate, the especial torments of a northern summer, in the crowds, swarms, of mosquitoes, which pursued us with a virulence even greater than many of us had often experienced in the West Indies.

Returning on board at eight o'clock, I found that the water had continued to fall, so that we had but a few inches between our keel and the ground. There were in fact but eight feet six inches at low water, though it was somewhat deeper astern: but as there was no swell, nor any prospect of one, we were satisfied to remain as we were.

The approach of any boat from the inlet could not here be seen, from the position of the island; so that we were taken by surprise at the arrival of a Danish flag, shortly after I had returned on board, accompanied by a multitude of canoes. They were alongside almost as soon as they were seen; and we were pleased to find that there were two Europeans in the crowd, which at first seemed to consist of Esquimaux alone; being dressed in the usual clothing of the natives. They introduced each other as the governor and clergyman of the district of Holsteinborg, saying that they had come to know who we were, and whether we were in want of any assistance. They had not seen us enter, but had observed our masts appearing over the rocks, so that they supposed us to be a wrecked vessel, since no ship had ever been seen in this creek. 
We found this governor, named Kall, a person of very prepossessing manners and appearance. He seemed about thirty years of age, and had been resident during six, with the charge of this district under the title of Colonies Bestyrere, subject to the Governor of Leifly, who has the rank of Major in the Danish Navy. The clergyman, named Kijer, seemed to be about the same age, with the manners and language of a well educated and intelligent man. He had been resident during the same time, with a wife and small family.

They informed us that the harbour of Holsteinborg, instead of being in the great inlet to the south of us, lay in the smaller one, only three miles distant, and entreated us to move our ship to it, as we should then be in a place of greater security: offering us at the same time any aid that we might require, whether in the way of supplies, or aught else, and expressing a desire to show us such hospitality as was in their power. We learned from them, that the Rookwood whaler, belonging to Mr. Mellish, and from London, had struck on a rock near Woman's islands, on the fourth of June, and had proceeded hither to repair her damages. It was found, however, that her main keel was broken in three places, so that she now lay a wreck in the harbour; the master, Flett, having consequently landed all his stores and provisions, and sold a part to the Danish government; leaving the remainder under the governor's charge, together with the hull and rigging.

I informed them of the nature and object of our enterprise, and requested permission to purchase such provisions and stores, with spars or whatever else might be needful and suitable to us, of those 
which remained under his custody from the wreck. To this he readily consented; assuring us that he took much interest in the success of our undertaking, and also repeating his offer of furnishing us from his own stores with whatever else we might want. It occurred to me immediately, among other things, that the mizen mast of the Rookwood, which had once been the Rattler sloop of war, must be about the size of our foremast, and that by taking it, instead of tonguing our own, we should not only save much time, but get a far more secure and suitable mast. In reality, this mast was already proved to have been two feet too short; and the projected repair to which we had been driven, would increase this deficiency to three feet and a half.

The governor having, on my announcing my consequent desire to see the wreck, kindly offered me a passage in his boat, I embarked together with Commander Ross, that we might inspect the mast in question, and determine on our proceedings respecting it. In the way, these gentlemen, who spoke English, communicated to us the names of the several islands, rocks, mountains, and inlets which we saw in passing, as I shall have occasion to notice in the place appropriated to those circumstances. 'To this useful information was added the most agreeable news which we had heard since we had left home; confirming what we had already been led to believe from the absence of ice, and the more gratifying that it still more completely justified us in having determiner to prosecute our expedition this summer, notwithstanding all the untoward circumstances by which it had been obstructed and delayed. 
We were assured that the present season was the mildest which had been known during the memory of the oldest person in this settlement, and that the preceding one had also been unusually mild. With this, they declared their conviction, that if ever the north-west passage was discovered, it would be in the present summer. In detail, they stated that there were only three days during all the latter part of the preceding year, in which the harbour might not have been crossed by a boat, that the thermometer had only been for one day as low as minus $18^{\circ}$, and that since that time it had never stood beneath $9^{\circ}$ below zero (both) of Reaumur. This was a great contrast to the five preceding years, during which it had often, and for a considerable time, been as low as $32^{\circ}$ below zero of the same scale. They also added, that although there had been a good deal of snow during the winter, there had been very little frost in comparison with the usual course of things; every particular confirming the general assertion respecting the mildness of the present summer.

Having proceeded about three miles up the inlet, we gained sight of the Alagstaff and the town. This opens to the north-west; being on an elevated spot about five hundred yards from the landing-place, which is situated at the head of a little creek, that by its curvature towards the south-west is hid from the sea, and forms a secure basin for boats or small vessels, which are also easily taken in at high water.

We found the Rookwood lying close to this landing-place, heeled to starboard, but with her topmasts still standing; and though it was not at that time low water, it was evident that she was com- 
pletely stranded. We landed under a salute; an honour which I did not expect, but which we returned afterwards, of course, as soon as an opportunity occurred. We were received by Mrs. Kijer, who was in waiting to conduct us to their hospitable mansion; and in both, Commander Ross was delighted to recognise two old acquaintances, having known them during a former voyage, at the Whale islands. Fortunately, knowing the Danish myself, I was enabled to converse with this lady also, as her knowledge did not, like her husband's, extend to the English language. We were treated with what we might here consider an elegant repast of venison and other things, and served by Esquimaux females in their native costumes, but far surpassing in cleanliness those with whom we had been in communication on former occasions, and moreover decorated with a profusion of beads, while their hair was bound with pink handkerchiefs.

After dinner we inspected the settlement, which consisted of the governor's and clergyman's houses, a church, two storehouses, a bakehouse, and about forty Esquimaux huts. The two houses were built of wood, having a ground story containing a commodious diningroom, a good bedroom, a small parlour, and a kitchen; the governor's having an extra room adjoining, for the accommodation of his two boats' crews and two pilots. The apartments were low, and having cross beams in the ceiling, resembled the fore cabin of a 50 gun ship. The upper story contained only bedrooms for servants, being a species of attic. To the church there is a small steeple somewhat surmounting the building; the inside being neat and plain, with an organ at one extremity and the altar at the other, though the former was not 
seen, as it had been sent home to be repaired. The church is capable of containing two hundred persons, and is well attended; the sermon and prayers being in the Esquimaux and in the Danish language on the alternate Sundays. I need not say that the Danish form is the Lutheran; nor need I repeat the praise so well deserved, and so often bestowed on the Danish government for their attention to the spiritual welfare of the Greenlanders; and as little need I notice the well-known success which has attended the labours of the worthy clergymen who have undertaken this office, under such a banishment and such privations.

The storehouse at the landing-place is the receptacle of all heavy articles; and at the other, higher up, some of the people reside. There is no view of the sea from the town, the harbour alone being visible. It is defended from the east by high rocks, and also from the west by others, so as to be well sheltered: while it is covered from the south, though at a greater distance, by the huge mountain called the Old Woman's Hood, and has also a prospect of a range of lofty hills fronting the harbour. It is thus a really interesting, and almost a romantic spot; being, nevertheless, scarcely endurable as a residence, were even a tolerable portion of the year such as it chanced to be at our visit. From an eminence a little way beyond it, we obtained a fine view of the sea and its countless islands; forming an interesting maritime landscape, out of the power of our pencils at least, if not of better ones than ours; and, from the same point, we could also discern our own floating home, lying snug in her little cove. The Esquimaux name of this town is Tirieniak Pudlit, meaning, as we understood, the "foxes' holes." 
Proceeding, after our return, to examine the Rookwood, I soon found that some of her stores would be a valuable acquisition to us; so that besides the pleasure which we were here enjoying, in the only day of comfort which we had met with since our departure from Woolwich, we had also fallen on what was as good to us at least, considering our few wants, as an English dockyard. The mizen mast suited us as well as if it had been made on purpose for our foremast; and the provisions which remained unsold, were sufficient to make our own up again, to our needful complement. It thus gave great satisfaction to our hospitable friends to find that I should lose no time in bringing the Victory into their harbour; and having promised to dine with the governor on the following day, we took one of his pilots on board in his boat.

On my return, I found that Mr. Thom, whom I had left on board to superintend the necessary operations, had already got out the foremast, and was in the act of doing the same for the mizen mast. These things being finished, I prepared to run up the harbour, by hoisting a topsail upon the sheers which had been set up, the wind being fortunately quite fair, and by the aid of warps; under which we soon reached the town, and made fast to rings on the rocks, by means of whale lines; our situation being within a hundred yards from the shore on the east side.

We immediately proceeded to get the mizen mast out of the Rookwood; and about nine on the same evening; the Victory was hauled alongside of the wreck, it being then high water. The mast was soon hoisted out by means of our own mainmast; when we again hauled to our moorings, and the carpenters were set to 
work; the men being sent to take their four hours' rest at one o'clock. The next day they were employed in getting up the July 24 . foremast and foretopmast; and $\mathrm{Mr}$. Thom went on shore to take an account of the provisions, which were shipped off in the Krusenstern, together with some other stores that we had selected.

In the mean time, I proceeded, in company with Commander Ross and the surgeon, to an eminence on the shore near to the ship, which commanded a complete view of the rocks, shoals, and entrance of this place; when sights were taken for the chronometers, together with a meridian altitude of the sun by the artificial horizon. A series of angles were further observed, for the purpose of determining the positions of several places in view; but under an annoyance from the mosquitoes, which far exceeded the persecutions of the former day, and under which my nephew suffered in a most extraordinary manner. Who is it that abuses Acerbi for his eternal repetition of the sufferings he endured from these pestilent animals, which, in these climates, render every moment a torment, so as to occupy the entire attention, and to make it almost as impossible to act as to enjoy? Let them try the experiment, not of a whole summer, but of a single day in Sweden, or even here in Greenland; and I am mistaken if they do not justify the accumulated complaints of all the travellers that ever annoyed their readers with the records of what they had endured from this most incredible, and never to be forgotten generation of worse than vipers.

Having nevertheless completed our observations, in despite of this 
army of ruthless devils, we proceeded to dine with the governor; meeting also the clergyman and his amiable wife, and being regaled with fare and wines that would have done credit to a very different land from this most unpromising of all the regions on earth. Peace and happiness are of no country or situation; and here at least, while they seemed to exist in perfection, we had no wish to think that it was ever otherwise than as we now saw it in this narrow, but apparently contented circle.

In the mean time, the Esquimaux natives, who had crowded round us in their canoes from the moment of our arrival, gave their assistance in hauling on the ropes, or doing any other work which chanced to be in hand; showing their good will at least, and in reality giving us some useful help. Many also brought for sale such articles as they had for disposal; and thus our men furnished themselves with boots and gloves, in exchange for cotton handkerchiefs and old clothes. Few of them seemed to be acquainted with the value of money : and one, who had proposed a pair of handsome gloves to Mr. Thom, preferred an old handkerchief to either a shilling or a sovereign, which were successively tendered to him in exchange.

After dinner I proceeded on board to superintend the work; and Mr. Thom, by means of the Krusenstern, continued to ship the provisions, sails, and cordage which we had purchased. Commander Ross, with Mr. M'Diarmid, took a walk to collect specimens of plants, or whatever else might offer itself; after which we all met at supper at the governor's house. At table, we were entertained with an account of the manner in which they spent their time; the 
principal occupations being hunting wild animals for their skins, and catching whales, seals, and fish, as the seasons chanced to permit. We understood that the annual number of reindeer skins exported to Denmark was three thousand, and that the quantity of whale and seal oil, which varied much according to the seasons, might be estimated from the capture of the former ranging between two and twelve. It was in the mildest seasons that the least number was taken.

We further understood that Mr. Kijer had the pastoral charge of the districts of Holsteinborg and Sukkertop, under the established church, and that he visited the latter during the spring; baptizing and confirming the natives as they were born and as they grew up to years of discretion. He further informed us, that a regular account of the population is transmitted to the Danish government. If I myself witnessed nothing but the most perfect good order during our short stay here, so I was informed that there were very few instances of immorality, and that the general character of the Greenlanders was so mild and pacific as to afford no instances even of common fighting; as, in no case, were they the aggressors when contests took place between them and the Danish settlers or other Europeans.

I have placed in the Appendix correct accounts of the population of the settlements which were kindly furnished to me by Mr. Kijer.

No one expects to hear that there were trees in the governor's garden, when even the Shetland islands are reputed to contain but one; but we found it cultivated, with sallad, radishes, and turnips. 
Here, as in Lapland, the wild angelica abounds, as do the wellknown scurvygrass and sorrel, so useful to a people consuming such quantities of the grossest animal food. The winter is reputed the healthiest season; and it is in summer that their chief diseases, being pulmonary or catarrhal, prevail. Whether these are to be amended by physic or not, it was for our surgeon, not for me, to determine; but the patients cannot at least suffer much from medicine, since the nearest medical person is two hundred miles off, at Baal's river; and even there, his practice is not extensive enough to afford him the means of doing much harm.

The stepping of the foremast was finished this evening, and the crew were allowed six hours' rest, after a day of very hard labour. In truth, with all that had happened to us, and all that had occurred to tease and provoke them, besides the real hard work which they had undergone, mine was a crew whose duties had been as little of a sinecure as will easily be found, either in the naval or the merchant service; while if they had had a right to expect a far easier and better passage, and a voyage of no more than the usual maritime toils and troubles up to this point, so, in having been thus unexpectedly harassed and disappointed, they were sensible that what might have been their comparative holiday was now at an end, and that henceforward nothing but labour and risk was to be expected. Yet there was neither murmur nor regret. Their zeal was unwearied, and their enthusiasm as lively as ever; while I could not too much praise their steadiness and sobriety, nor be otherwise than pleased at the amicable and good-tempered manner with which they conducted themselves towards the natives. I do them 
but bare justice to praise them, even now : with but little exception, and that proceeding from the most unexpected and severe sufferings and disappointments, I found far more reason to admire them in the coming years which none of us could then have foreseen.

When I came on deck this morning at six, the crew being still July 25. asleep, I found a poor Esquimaux waiting in his canoe alongside, with an oar which had been lost from one of the boats, and which he had picked up. He was of course handsomely rewarded for his honesty; showing at the same time that he had no expectation of the present by which he was so delighted. I know not how far the exertions of the worthy clergyman deserve to share in the merit of this and the other good conduct which we witnessed; but be this as it may, I do but justice to the natural character of this race, almost every where within our experience, to say that they are among the most worthy of all the rude tribes yet known to our voyagers, in whatever part of the world.

Here also, I must not forget to notice, we procured six Esquimaux dogs; a portion of our moving force that we were likely to want before the winter had long arrived, and might not obtain when we desired. Eventually, they proved of essential use to us. The payment for the articles which we had procured was of a somewhat complicated nature, but by the kindness of the governor, was made very light. He would take no return for the greater part of what he had furnished, the dogs being also his present: and as far as the stores taken from the wreck of the Rookwood were concerned, all that we had to do was to send a list to $\mathrm{Mr}$. Mellish, with a reference to Mr. Booth. 
After breakfast we went on shore to renew our operations for determining the exact situation of Holsteinborg, and found the latitude to be $66^{\circ} 58^{\prime} \mathrm{N}$, and the longitude $53^{\circ} 54^{\prime} \mathrm{W}$, by the means of five chronometers. The governor and the clergyman's party dined with us, and gave us an opportunity of showing them our present arrangements, together with those which we should be obliged to adopt in the future, adding to this whatever else might gratify their curiosity about an expedition in which they seemed to take an interest equally friendly and anxious, and not less than that shown by our own countrymen. Our ship was still however in great confusion, as could not fail to be the case; and it was not till late in the evening that we could expect to be in readiness to proceed.

Taking the boat, I therefore landed on the small spot called Lines island, which afforded the best view of this settlement, making a sketch of it and of the magnificent screen of mountains by which it was backed; after which, having written the last letters to England which I was now likely to write for many a day, I joined the whole party at the governor's house at nine, that we might take our probable farewell, and, accordingly equally to northern and maritime custom, shake hands over a "parting glass." There was every appearance of a favourable change in the wind, and the letters were forwarded to Baal's river, to the charge of the Danish ship that had on board the master and crew of the Rookwood, through whom we could be sure of their being carried on to England.

July 26. This day, being Sunday, it was quite calm in the morning, and 
as the launch, which had been on shore for coals, was aground, we could have no prospect of sailing before two o'clock. I therefore attended the church with the governor, and should have been surprised at the singing of the Esquimaux females, had I not long known of their musical talents, and the great facility with which they learn to sing even the more refined sacred music of the German school; as those talents also had been widely cultivated by the missionaries, even on the American shore, under the directions of Mr. Latrobe and others.

This is a subject on which my opinion and experience are, equally, of no value; and it is of no moment therefore, that, both in this and the former voyage, the tribes with which I communicated seemed quite indifferent to music, or insensible to it, as we thought. The authority of such a musician as the one whom I have named, is paramount : and when the Moravian missionaries in Labrador, under his charge, have found, not only that their converts could be rapidly taught, in addition to their accurate singing, to play on the violin, and not only this, but to construct their own instruments, no one can question the inherent musical talents of this race, though the faculty may not belong to every tribe. I presume it to be pretty well known that these worthy missionaries have not treated this subject as a mere matter of amusement or curiosity, but that, in their enlightened practice, it has been rendered a powerful auxiliary in religious instruction and civilization, as far as civilization is possible under such circumstances as those under which these tribes exist. The phrenologists may here seek to confirm their theory, as far at 
least as the existence of this single faculty can assist them : but whatever this, and the parallel case of the Hottentots under the same tuition, may prove, it must not at least be forgotten that the Moravians have been the instructors in each case, and that, possibly, more merit is due to the instructor than the pupil.

The clergyman afterwards presented me with a hymn in the Esquimaux language, which I subjoin for the sake of the few who may take an interest in this wide-spread tongue.

\section{KONGIVTINIK.}

ERIN.-Nallunakau tokoviksara.

1.

Amèrdlarsorsoangortikit

Atàtak! Kongim udloee!

Tamasa pillèe attatikit

Paralugo kotsinguerme

Tussàrkit tuksiautivut

Sajmangiuglo Kongerput !

2.

Tennitarpin opèrnarsusek

Arsûtigeïnarliuk

Tamàtigudlo sajmarsusek

Illigut nœllunòeliuk

Tussàrkin-à! Kenutivut

Sajmaugiuglo Kongerput!

The translation will be found in the Appendix. 
The breeze being at last fair, and our vessel afloat, it was necessary to take our departure, as we could not now afford to lose even a single day, nay, scarcely an hour; so far was the season advanced and so much ground lay yet before us, between our present place and that in which, wherever it might prove to be, we should be compelled to winter. Our kind friends accompanied us on board, and we immediately weighed anchor, under a salute from the fort, which we of course returned. They attended us to the entrance of the inlet, and we there parted, with final and cordial adieus on each side.

Whether the two kind and worthy men with whom we had thus parted, and whom we were little likely to see again, may ever read this testimony of gratitude to them, is unknown to me, but I am happy in the opportunity of recording their benevolence. To their disinterested generosity we could not find the means of making any return, beyond the simple keepsakes which they were willing to receive; refusing every thing in the nature of remuneration. I thought it however incumbent on me, as an officer in the King of England's service, to write a letter of thanks to the governor, which I accompanied by one to the Danish Court: a simple testimony in favour of one, to whom no recommendation from me could be of any service in that quarter. 


\title{
CHAPTER VI.
}

\begin{abstract}
DISCO ISLAND-ENTER ON THE FIRST OF AUGUST-REACH OUR FURTHEST INTENDED POINT NORTH-STEER FOR LANCASTER SOUND-ENTER THE SOUND-REMARKS ON THE FORMER DISCOVERY OF THIS SPOT.
\end{abstract}

THE pilot having quitted us, Commander Ross continued to take the angles necessary for determining the positions of the surrounding islands, of which he had given us the names, as well as those of the several mountains and promontories. We understood from him, that Lieutenant Graaf had set out on a very interesting expedition to East Greenland, and that Captain Holboll had removed to the district of Baal's river. Having finished our angles, the breeze continued to freshen in our favour, and we passed through an excellent channel inside the Reef islands, holding our course to the uorthward between them and Wâroe. The Holsteinborg mountains were soon out of sight ; but we gained a view of others not less grand though much less romantic in picturesque character. We then shaped our course for Disco island, and thus were gradually carried to a considerable distance from the land. 
It being no longer necessary to call at Whale islands, that inten- July 27. tion was abandoned; and as I had no desire to meet the John, our intended consort and tender, supposing, as was not very likely, that she had sailed, I held on our course in pursuit of our main object. The wind continued to favour us all Monday, and at midnight it had increased to a smart gale, which made us regret that we had not taken time to clear the Krusenstern of part of her cargo. The land about Wild islands, and near South bay, was seen at a distance; and, like what we had already passed, was remarkably clear of snow. We also now passed many icebergs, all of which seemed to be in a state of dissolution, while the temperature of the air was $40^{\circ}$, and that of the sea $39^{\circ}$.

We contrived to carry all our sail during the day, in spite of the force of the breeze, until one of the tow-ropes of the Krusenstern broke, which obliged us to take in some of our canvas. The mate, Blanky, had got on board of her to fasten a new hawser, when a violent sea caused her to strike against our stern, doing some damage to her stem, and one of the seamen, John Wood, then jumping into her, was so unfortunate as to break his leg. This obliged us to heave to, that we might get him on board the ship and put him under the surgeon's care. Just at this time, she gave a heavy lurch, which earried away the temporary topmast, its rigging having been rather slack, as it was, itself, sprung at the head. The topsail however happened to be just then lowered down, and we soon contrived to clear away the wreck, and to set up a spar which we had, for a substitute. The boat was also again secured, and we once more made all sail. Our latitude at noon was $69^{\circ} 33^{\prime}$, and the longitude $54^{\circ} 58^{\prime}$. 
As we proceeded towards the shallow water of Reefkol, the icebergs increased in number, but they were in general smaller and in a more decayed state, being also often surrounded by fragments. We passed Cape Chidley; but, being as we were, nine or ten leagues to the westward of it, could make no use of it for verifying our chronometers; which we might otherwise have done, because this was one of the places, the longitude of which we had ascertained in our former voyage. Neither could we approach Whalefish islands, without losing more time than we could now spare; especially as the wind was fair for us. Even among the icebergs, the temperature of the sea was $41^{\circ}$ at noon, and at midnight not lower than $40^{\circ}$; a fact agreeing with all that we had hitherto experienced and heard, to prove the mildness of the season.

July 23. On the twenty-eighth the fair wind still continued; but the lofty mountains of Disco were concealed by the haze till we were within a few miles of it. The place then nearest us was Godhavn bay, the residence of the Governor-general of the Danish settlements in Greenland, and it was here that the master of the John, supposing that we had proceeded, was to land the spare fuel. I was not, however, in want of any; and as it was moreover nearly impossible that this ship could have reached it, though she had made up a new crew, I considered that to stop there was a purposeless waste of time; not to be sacrificed when the wind was so fair as it still continued.

At ten o'clock in the morning the stupendous mountains of this island burst through the clouds, forming a splendid sight; and we 
could see that the range next to the sea was as clear of snow as the more southern land which we had already passed. Even the interior hills were but very partially covered; so that every thing continued to favour our hopes of making a useful progress this season, in spite of all the detention we had suffered. As we passed along the land, we took angles, in order to ascertain our distance from it, and also to compare these with our former observations at Hare island, that we might determine our true position.

This latter island was seen in the evening, its centre bearing due north. At first, it seemed entirely clear of snow; and it was not till a nearer approach, that we saw there was some remaining in the ravine. Our latitude at noon was $70^{\circ} 12^{\prime}$, and the longitude $55^{\circ} 45^{\prime}$; being then a few miles northward of Disco, and about twelve miles west of it. The wind held on fair; so that besides Hare island, we also obtained at length a good view of Four island point, and, before midnight, caught a sight of Unknown island also; carrying on our triangles as far as Hare island. Forty icebergs were here counted; and it becoming calm for an hour, we got near to one of them, and were tempted to get up our steam. This however was scarcely done, when the fair wind returned, and we were pleased to have lost our labour. All these icebergs were in the same state of waste as those which we had seen before, and as soon as we had passed them, the temperature of the water increased from $36^{\circ}$ to $42^{\circ}$ and that of the air to $44^{\circ}$.

The wind was light all this day, and we therefore took the July 29. opportunity of getting out of the Krusenstern the capstan which we had obtained from the Rookwood, together with some other 
articles, in order that she might be towed with more ease. At noon we were in latitude $71^{\circ} 1^{\prime}$ and longitude $56^{\circ}$, the Black rock bearing north. The land towards the sea was here also clear of snow, but the high mountains in the interior, both here and beyond Jacob's bay, were for the most part covered with it. The temperature of the water was $41^{\circ}$ at noon; having ranged, during the day, from $39^{\circ}$ to $42^{\circ}$.

The moon had risen at one in the afternoon, but there being now little wind, we attempted to take advantage of the engine; and in some manner or other, it continued to work all night. The breeze freshened nevertheless at midnight, though the weather remained, as it had been all day, beautifully clear. Our new mainsail was bent, and seemed to fit well; and the carpenters having worked for these last two days, all the new davits for the boats were finished, and they were hung on the larboard side. The temperature of the water rose to $46^{\circ}$. In the middle of the day a ship was reported to me, coming down on us with all sail set, nor was there any doubt about the nature of the object, either with the officer of the watch or Mr. Thom, as indeed the same opinion was entertained by every one on deck. My telescope, however, soon discovered it to be an iceberg, being one of a very few that were in sight at that time.

We stopped the engine when the breeze had sufficiently freshened, and passed the Black rock under all sail; having a beautiful view of the land, which was clear of snow near the sea, and only exhibited its white covering on the tops of the loftiest mountains in the interior. As we left the land during our pro- 
gress, the icebergs diminished in number, and we passed a blubber cask marked Jane, with some pieces of painted wood that seemed to indicate the loss of a whaler in this quarter. It became suddenly calm at four o'clock, making us have recourse to the engine; and at midnight, Sanderson's hope bore north-east, showing very little snow; the temperature of the air and sea being both at $42^{\circ}$.

There was a breeze to-day, which continued to increase till July 30. noon, when it moderated, and the engine was put into preparation. It soon, however, revived; so as not only to render our machinery unnecessary, but in a short time to become a pretty smart gale, commencing in the north-east, but shortly shifting to the eastward. The swell was also very considerable; thus indicating that there was no field ice near us : and though the weather was thick for a short time, it was not sufficient to prevent us from standing on and taking advantage of this fair wind.

As had been the case in all former voyages at this season of the year, we now expected to meet with the ice, being on the spot where the Hecla and Griper had found it at nearly the same date, and not far from that where the Hecla and Fury were beset a month later, in 1824. To our delight, not less than our surprise, there was none of any kind to be seen; and it was not till some hours had elapsed that we discerned even an iceberg. A land bird unknown to us flew on board, and was taken; and being left to Commander Ross to describe, as he had preserved it, I need not anticipate that department of this narrative which has been left to him. If the sailors called it a turtle dove, and hailed it as an auspicious omen, we were well pleased to encourage any of the 
nautical superstitions which served to keep up their spirits and furnish them with subjects of discussion.

In the night we passed a berg, on which there were many of the birds named Xeme, which I had discovered in my former voyage, together with some others. The temperature of the sea had been $42^{\circ}$ at noon, and the latitude $73^{\circ} 56^{\prime}$, with a longitude of $66^{\circ}$.

August 1. We commenced a new month with a clear morning, and nothing in sight but a solitary iceberg. We would gladly have sent to it for some water, of which we were beginning to be in want, but the swell was too great to permit our landing on it. At noun the latitude was $73^{\circ} 53^{\prime}$, and the longitude $65^{\circ} 50^{\prime}$, the temperature of the sea and the air being equally $40^{\circ}$; and that continued unchanged at midnight. It was, in every thing else, a summer day; the sea and sky resembling more what we should have expected in the Mediterranean than in such regions as Baffin's bay. The wind at length came gradually to the westward, and then died away, so that the engine was again made ready. To no purpose, however, as a breeze soon sprung up again; while, as one of the boilers appeared to leak once more, we were well pleased that we were not called on to use it, and thus took the opportunity of repairing it.

August 2. The wind freshening in the same direction, we stood toward the north, with one iceberg in sight; and as Sunday rose on us, it proved a beautiful day, with a sky of the utmost serenity; the atmosphere transparent, and the sea so smooth, as almost to leave us without motion. But for one iceberg that was in sight, we might have imagined ourselves in the summer seas of England, though the air was only at $45^{\circ}$ as the water was at $43^{\circ}$. The lati- 
tude at noon was $74^{\circ} 18^{\prime}$, and the longitude $66^{\circ} 49^{\prime}$. There was not an hour during the whole day that we could not see twenty leagues all round us. Divine service was performed, and the remainder of it was made what we always wished, a period of rest. On this day a large spot was seen near the centre of the sun; and two bottles were thrown overboard containing our description with the latitude and longitude.

Like the preceding, this was a summer's day; and as there was August 3. a gentle breeze from the north, we were enabled to make some progress to the westward. Both the new topmasts were now fidded; and so warm did the weather feel to the seamen, that they were glad to throw off their jackets and work in their shirts. During this delay, which prevented us for twelve hours from using our sails, the engine was kept at work; being only stopped at last, partly to repair the feeding pump, and partly because the breeze began to freshen.

Our latitude being $74^{\circ} 14^{\prime}$, and longitude $68^{\circ} 13^{\prime}$, being the furthest north that we were likely to be, a bottle was thrown overboard to commemorate the day, and I prepared letters for England, under the possibility of falling in with some whaler. At noon the air was $44^{\circ}$ and the sea $42^{\circ}$; while both subsided to $40^{\circ}$ at midnight; a midnight as lovely as the day had been, and which he who desires to know what an arctic night can be, should take a voyage to Baffin's bay to enjoy.

Had we been in the West Indies, I could but have found the August 4. men as I did this morning at six, scrubbing the decks withont shoes or stockings. The pump of the engine was completed before 
nine, but the starboard boiler began to leak again so soon after it had been set going, that we were obliged to make use of the other by itself; so that we could only obtain ten revolutions in the minute, and that with but one wheel. Thus, although it was a dead calm, we could make but a mile and a quarter in the hour; yet this was better than nothing at all, though our debt to the engine was assuredly as small as it well could be.

Though the sea was smooth, the sky was cloudy, so that we could obtain no observation; and the temperature of the sea was one degree higher than that of the air, which was $40^{\circ}$. We passed between two icebergs, but did not choose, under the present circumstances, to deviate from our course for the purpose of getting water from them. The never-ending engine was again set to work as soon as we had stopped the leak in the boiler; and, about five o'clock, we contrived to make somewhat more than a mile and a half in the hour, by the aid of both boilers, but with only one paddle, of which we could thus command nearly fourteen revolutions. 'The people were employed in fitting the new

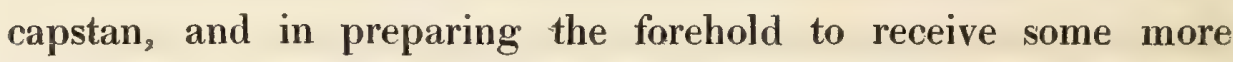
stores: and one of the stokers was nearly suffocated by inhaling some sulphurous gas at the furnace mouth. A few mollemokes were shot for the dogs, and we found some shrimps of a species new to us. About eleven, there being a small iceberg ahead, Commander Ross went in the boat to fetch some ice for water, as that which we had taken in at Holsteinborg was expended. We had not calculated on being so long without the means of renewing it, since we had always met abundance of field ice in our 
former voyages. About midnight, a smart shower of rain came; being much more welcome than the snow, which would have been a substitute for it in our preceding voyages.

At one o'clock this day we got pretty near the iceberg, when August 5. the boat returned with three tons of excellent ice. It had been found to be in a state of decay; and it was not long before we saw it fall to pieces. The wind becoming fair in a short time, the fires were put out after the engine had been working interruptedly about fourteen hours. For the present, the boilers had given over leaking. But this wind did not last long, and at length inclined to the south-west; so that it was again set to work and kept in action about twelve hours, being the longest period during which it had yet worked without accident or interruption. The weather was clear and pleasant, and the wind varying more to the northward. At noon the latitude was $73^{\circ} 43^{\prime}$ and the longitude $73^{\circ} 30^{\prime}$ : and at six, we had increased this to $74^{\circ}$, being about sixty miles to the east of Cape Byam Martin. We saw the land looming, but the view was not such as to enable us to recognise it. At eight a fog came on, but the temperature of the air and sea continued at $40^{\circ}$, just as it had been at noon.

The carpenters having finished the platform for the new capstan between the main and fore hatchway, it was shipped into its place. Two icebergs were in sight before the fog set in, but we soon lost sight of them and of every thing else. Some advantageous changes were made in the machinery, in consequence of which we made fully thirteen revolutions in a minute, with a velocity of more than a mile and a half in the hour. The fog thickened much at mid- 
night; but, as the temperature was $43^{\circ}$, it did not freeze on our rigging, as had happened in the former voyage.

August 6. Being nearly calm to-day, the topgallant sail was furled at one, and the topsail lowered; but we could not make more than a mile an hour with the engine. At three the fog suddenly cleared away, and the land became at once visible, as if bursting out of the clouds; Cape Byam Martin being distinguished from the rest by the grandeur of its form. All the high lands, and this among the rest, were covered with snow, with but little exception; and we attributed this difference between the present coast and that which we had quitted, to the circumstance of the former being exposed to the north-east. Possession bay bore due west, about fourteen leagues distant.

A light breeze now came from the westward, so as to oblige us to stand north; but we still kept the steam on, while the engine had conducted itself so far beyond all its former doings as to have been at work for twenty-four hours. Towards noon the land was covered by a haze, and we saw no more of it at this time. The latitude was $73^{\circ} 33^{\prime}$, being nearly that of Possession bay, and the longitude $\mathbf{7 4 ^ { \circ }} \mathbf{4 2 ^ { \prime }}$, being about thirteen leagues to the eastward of this part of the coast.

Three icebergs appeared, one of a very remarkable appearance, since it resembled a bridge with a castle perched on its summit. The other two seemed in a crazy state, and we afterwards saw one of them fall to pieces. Some of the krang of a whale had been seen in the morning; and, in the evening, that of a very large fish came near us, so that we sent out the boat and procured a supply. 
for the dogs. A piece of ship timber was also picked up, with a few shellfish adhering to it. In the evening the wind was directly against us, and the engine was stopped; as it was then of little use, and as the feeding pump had again gone wrong. The temperature of the air and sea was $40^{\circ}$.

On entering Lancaster sound, I was naturally reminded of the same period in my former voyage, and being now near the spot at which we had then decided to return, under the firm belief that we could penetrate no further westward in this direction, I could not help making in my journal the remarks which I now transcribe from that entry; though I have carefully reviewed this subject, in the sketch of the whole series of attempts to discover a north-west passage, which I have given in the introductory chapter to the present work.

'Sir Edward Parry remarks that Lancaster sound had " obtained a degree of notoriety beyond what it might otherwise have been considered to possess, from the very opposite opinions which have been held with regard to it." This language is somewhat ambiguous, at least; and either from this cause, or others, it has been inferred by some of those persons who took an interest in the discoveries and proceedings of that voyage, that Sir Edward's opinion was opposed to mine, when we were employed together on that first expedition. Under such a conclusion, the same persons ought also to have perceived, that as a matter of course, he must have then expressed that difference of opinion to me, since this was his duty, as my associated though junior officer; and thence, I presume, they will have further determined, that, in acting as I did, I proceeded in opposition to his declared opinion. 
'If this be the case, it is necessary that those persons should be undeceived; for he did not at that time make any such opinion known to me, and I am therefore bound to conclude that he did not entertain it. He could not have believed that there was a passage through Lancaster sound, or he would have told me that he thought so ; for it would be to suppose him capable of gross misconduct as an officer, were $\mathbf{I}$ to imagine that when he was my second in command, he suppressed any opinion that could concern the duty in which we were both engaged; above all, that he concealed an opinion which, on account of its very high importance, it was the more strongly his duty to have communicated. Nor is there a single officer belonging to either of the ships, who, if he now says that he differed from me in opinion at that time, is not equally censurable; since it was incumbent on all to have stated to me what they believed or thought on that leading object of the expedition.

' It is possible that I may not, even now, influence or alter the conclusions to which I have thus alluded, since it is in human nature to adhere to judgments once formed, and so long uncontradicted; but I can here, on the very spot itself, where every recollection seems but that of yesterday, reassert with the most perfect confidence, that no officer then expressed any belief that there was a passage through this opening, or even suggested a hint to that effect. So far from this, I was led to infer, by the general remarks on board of my own ship, and by the expressions of those who considered that they had more especially a right to be consulted, that I had, according to their opinions, already proceeded, not merely far enough, but too far. 
'It is further true, and I must repeat it in this place, that even if the opinion of my second in command had been, what by many it has been supposed, the reverse of my own, which it was not, I was perfectly justified, by my instructions, and by the circumstances in which the expedition found itself, in acting as I did. Those orders were clear and decisive: not only was the season passed for penetrating further through the ice, but it was my imperative duty, as it is with every officer in command, even if I had not received the orders to which I have referred, to attend to the preservation of the ships and their gallant crews.

' It is unquestioned, at the same time, that the whole space to the westward of the ship, at that period, was filled with ice, so that we could have penetrated but a few miles further, even had we made the attempt. Nor do I think it in the least probable, from the appearance of the distant land, as it is at this moment lying before me, that my judgment respecting the nature of this opening would have been different from what it was at the time we resolved to give up this pursuit, even had I then approached nearer to the edge of the ice. It is well known that the appearance of the land in the icy seas is often very deceptive; and when Cook himself had formed wrong judgments of it, on more than one occasion, it is a sufficient proof that the difficulty of judging truly must often be very great, if not insuperable. But, in reality, the whole history of navigation abounds with similar errors or false conclusions ; they might be collected in hundreds by any one who chooses to search for this purpose. He must be little conversant, indeed, in this kind of reading, who cannot recollect instances in abundance, even without 
the trouble of a search ; and instances, of course, where the error has been only detected by the better fortune or greater success of subsequent navigators.

' I might have said all this long ago, and I would have done so, had I felt that I was in justice called on for a defence of my opinions and proceedings. Knowing myself to be right, I adopted that course which, although the most difficult, is ever the best. Nor should I have broken that silence now, or have recurred to this history of times long past, but that the spot recals a lively recollection of the various trying emotions of which it has been the parent, and at the same time gives me more than hopes, that the effort which I am once more making to solve the important problem before me may, if ever I return to England, be received in a very different manner.' 


\section{CHAPTER VII.}

PROGRESS DOWN LANCASTER SOUND-SIGHT OF CATHARINE AND ELIZABETH MOUNTAINS-PASS CAPE YORK AND STEER FOR PRINCE REGENT'S INLET-CAPE ELWIN AND ELWIN BAY-THE COMPASSES CEASE TO TRAVERSE-DISCOVER ADELAIDE BAY-APPROACH TO FURY BEACH-FIRST SIGHT OF THE TENT POLES LEFT AT THE TIME OF THE WRECK-THE VICTORY MOORED.

THE ship made about four miles of northing in the morning, Augnst 7. after which it fell quite calm, with the vessel's head to the northward. Several icebergs were in sight, and a boat was sent for another load of ice, with which she returned about one o'clock. The boilers were then filled; and the engine being clean and ready, was set on about three. We only obtained ten revolutions in a minute, propelling the ship against a light air, at the rate of a mile and a quarter in an hour; not being able to raise the pressure of the steam beyond thirty pounds on the inch.

At noon we were in latitude $\mathbf{7 3 ^ { \circ }} \mathbf{5} 0^{\prime}$, having made twenty miles northing; and we estimated the longitude to be the same as yesterday, as we had no sights for the chronometers. More krang, with some blubber, was picked up for the dogs. The land was seen or 
each side of Lancaster sound, and our course was about midway between the two coasts. The day was cloudy, and a few drops of rain fell; the temperature being $40^{\circ}$, both at noon and midnight, for the air and the water alike. It was so warm, that although we received none of the heat from the steam engine into the cabin, we found it agreeable to dine without a fire, and with the skylight half off. It is true, that the thermometer did not indicate a summer temperature for England; yet, to our sensations, the weather was as mild as it would have seemed there, with a heat of sixty degrees. Many mollemokes had been seen during this and the preceding day; collected, doubtless, by the fragments of the whale that were floating about.

August 8. As the whole of this day was perfectly calm, the engine was in constant use; with exception of some interruptions in cleaning out the furnaces, and some other causes of hindrance which I am now weary of repeating. Eleven revolutions, which were all that we could produce, gave us a mile and a half in the hour. As it was cloudy at noon, we did not obtain a meridian altitude, nor did we see the land until after a very early hour in the morning, and then but indistinctly. In the forenoon, we procured a boat's load of ice, and cleared the Krusenstern of twenty-eight bags of coals and some timber. The air was at $40^{\circ}$, and the water $39^{\circ}$; but the latter became $40^{\circ}$ also at midnight, though, for a short time in the evening, it had been at $36^{\circ}$, in consequence probably of the vicinity of some icebergs.

The forehold was restowed, and made ready for receiving additional provisions, and we also obtained some more water in the 
evening. As the sun declined to the northward, there was an appearance of wind in the clouds; and, at ten, a light air arose, so as to induce us to set all our canvas. The remains of whales were still seen, in various directions, covered with mollemokes, and we also observed a flock of ducks, and some of the ivory gulls. The water seemed crowded with minute marine animals, and afforded us some specimens by means of the gauze nets.

During all the last week the utmost anxiety was expressed by all on board for a fair wind; and our impatience to profit by the fine weather made the miserable performance of the engine more grievous. That it was a frequent subject of execration, I might guess, if I did not hear it; and if the constructor received his share also, no one could have expressed much surprise. It required constant and minute attention to persuade it to work at all ; as even with all the goodwill of the workmen, my presence was for ever required in the engine room, insomuch that I was scarcely allowed to sleep. It may well then be believed that the appearance of a breeze from the eastward was looked for with the utmost solicitude. Every hand was held up to feel if a wind was coming, every cloud and fogbank watched, and all prophesied according to their hopes or fears, till they were fairly driven off the deck by the necessity of turning in to sleep. Had we been less anxious ourselves, we might have been more amused by observing how the characters of the men influenced their conduct on this occasion. Those of an eager disposition were continually watching the eastern sky, to discover, in the changes of the clouds, or whatever 
else might occur, the first promise of a fair wind; while the desponding characters occupied the bows, looking in gloomy silence at the dark sea and sky before them, and marking, even without a word, their despair of our ultimate success, or their fears that our voyage was about to come to an end at even this early day. At midnight, however, every symptom of a wind from the east began to show itself; the despairing few recovered their spirits, and the satisfaction of the hopeful was at length diffused throughout the ship.

August 9. This welcome wind which had at last arrived, gradually increased: all sail was set, and the engine kept in action till three o'clock, though by considerable exertions of the men at the bellows. The weather still felt mild, though the wind was east; and as the men had undergone much fatigue, they were sent to rest after divine service. The latitude was observed at $74^{\circ} 1^{\prime}$, and the longitude by the chronometer was $77^{\circ}$. No ice of any kind was in sight; but the snowy tops of the mountains, and particularly of the two remarkable ones formerly named Catharine and Elizabeth, were seen rising above the clouds. The course steered by the compass was here north-north-east, which under a variation of $114^{\circ}$, led us directly up the sound; making thus a course nearly west. In the evening, Cape Liverpool was also seen above the clouds. At noon the temperature of the air and the sea equally, were at $40^{\circ}$, and at midnight it subsided but one degree. That the present cheeriness of the crew might want nothing that we could add to it, they were served with a dinner of fresh beef from our Galloway bullock : though the warmth of the weather now began 
to make us fear that we should not long preserve the remainder in this state.

During the night both the northern and southern sides of the August 10. sound were in sight, though obscurely; but as the morming advanced the wind freshened, and it became so thick that we lost sight of them, and were unable to obtain any observations at noon. The sights, however, for the chronometer being near the prime vertical, our longitude was pretty well ascertained. At eleven we had passed Cape Charles Yorke on one side, and Cape Warrender on the other; and as it was sufficiently clear to see two miles from the ship, and no land was discernible, we hauled in to the southward, to make Cape Crawford, intending to run along shore.

At five it was actually seen on the starboard bow about two miles off, which compelled us to haul immediately to the northward; and, when it had cleared a little more, we found ourselves nearly embayed, and surrounded with fragments of icebergs and land ice. We sounded, and at first had fifty fathoms; but in a quarter of an hour it shoaled to twenty-five, with sand and shells, our ship being then but a mile from the nearest projecting point. The swell had much increased; and as we neared the land, which was now seen to be mountainous, the wind failed us; while, owing to the heavy motion of the vessel, she carried away her main boom, breaking it into three pieces. Our situation was indeed at one time very uncomfortable; as we were taken aback three several times, and were carried by the swell much nearer to the shore than was at all desirable. We were indeed preparing to anchor, as the only 
alternative left, when the wind suddenly returned to the old quarter, and we weathered the point.

To aid us through these difficulties, we got the steam up in an unusually short time; but this unexpected breeze rendered it unnecessary to have recourse to the engine. As the temperature of the water had fallen to $32^{\circ}$, we had warning to keep a good look out; and I must not forget to record the good conduct and activity of the crew, in this as in all the previous situations in which we had been in a hazardous position.

The mainsail was soon set again, without its boom, and we thus got entirely clear; when we bore up along shore, with a fine breeze from the east-south-east, but edging off a little to the northward till eight, when we had gradually gained a sufficient offing to enable us to steer according to the trending of the land to the westward. At three we saw Cape Yorke bearing north-north-east: An examination of the engine at this time, showed that a quantity of coke dust had been deposited in the airpipes, and that both the feeding pumps were again out of order. The cleaning and ordering of these things occupied us for six hours, and by midnight the breeze was fast increasing.

August 11. The weather this day, although foggy, was not such as to prevent us from keeping sight of the land, and at six, while passing Cape Yorke, a peaked hill was recognised by Commander Ross. We now met with a stream of heavy ice, but found a good passage through it; and, before noon, had passed through the openings of three others, much larger than the first. At the same time, it fortunately became sufficiently clear to enable us to see our 
way, and also to get a good observation at noon; when we found the latitude to be $73^{\circ} 40^{\prime}$, and the longitude $84^{\circ} 23^{\prime}$. After this, we found no more ice of any consequence, and were able to make a direct course for the south side of Prince Regent's inlet.

Accordingly, at two in the afternoon, we made the land between Cape Seppings and Elwin bay; bearing up, and sailing along shore, as soon as we had approached it within three leagues. The wind, which had been gradually increasing for some time, became so hard a gale at four o'clock, as to reduce us to a close-reefed topsail, under which we were now compelled to scud. The sea, which had been comparatively smooth among the ice, rose also as high as we had seen it during any part of the voyage; and as the wind, being now from the north-north-east, blew directly down the inlet, the land afforded us no shelter. We therefore prepared our storm sails, and made ready to lie to under them for the night.

When about ten miles to the north of the place where the Fury was wrecked, and near Elwin bay, we obtained some good observations. In running down, we perceived some of the land ice still fast in the bays; but, except a small iceberg, there were no outstanding masses on the shore. At nine we passed Batty bay, after which we met ice of a very different character from that in Baffin's bay, being much more uneven, and, generally, thicker; and from its appearance we concluded, that not only this, but most of what we had just passed was the produce of the previous year, and had been now broken off from the shores north of Prince Regent's inlet. As soon as we had passed the streams of ice already noticed, the temperature of the water at the surface rose from $31^{\circ}$ to $33^{\circ}$, giving 
us hopes that we should now see no more of this kind; while, although we had the prospect of being obliged to lie to for moderate weather, we considered this gale to be much in our favour.

After running under very little sail till midnight, at which time we had fetched from the furthest point of our progress in 1818 to the head of Prince Regent's inlet, in thirty-six hours, we brought to under the storm traysail and storm fore-staysail; the topsail having been previously handed, and the topgallant yard down.

It is now important to remark, on another subject, that while we were off Cape Yorke, and when the motion of the vessel became considerable, our compasses ceased to be of any use. Pope's, Gilbert's, and Alexander's, each of which had been used on the voyage, all ceased to traverse about the same time; and we were consequently obliged to shape our courses by means of astronomical bearings, deduced from the sun in the manner which I had practised in my first voyage. Thus, when we had ascertained the bearing of any object ahead, we steered for it without regard to the now useless needle; though when the weather became thick, and the sea heavy, this mode of proceeding either became difficult or required extreme caution.

The ice soon appeared to leeward in detached pieces, and the weather became thicker after midnight, but there was no appearance of any danger; so that Commander Ross and myself were enabled to take some rest, after the fatigues of the last forty-eight hours, leaving the charge of the vessel to our experienced and excellent mate, Blanky.

August 12. If we had ever doubted his care and ability, the event of this, 
following, day fully justified our confidence in him. At two o'clock in the morning a heavy pack of ice, which had been concealed from us by the fog, suddenly made its appearance at only three cables' length under our lee, being then only recognised by the tremendous breakers that were surging over it. Deciding at once, that the only chance for us was, to weather the end next the land, he let fly the storm traysail sheet, and putting the helm up, gave us notice of the danger, immediately proceeding to hoist the storm jib and reefed boom-foresail, which had been kept in readiness for such an emergency.

We found it nevertheless impossible to keep clear of a piece of ice in wearing; yet, though it gave us a violent shock on the larboard bow, it assisted in bringing the ship's head the right way. It was still doubtful whether we could clear the end of the pack of ice which was now on our lee bow, with the sea breaking over it. We therefore set all the sail that we could carry, and at last weathered it only by the ship's length; finding suddenly the most delightful relief, in quitting a turbulent sea for one that was as smooth as glass; a quiet retreat in which we could venture to finish our night's rest. We were indeed perfectly sheltered from the gale by this great mass, which was hourly gaining in size and solidity, by attaching the smaller pieces that were floating near it.

At six the weather began to moderate; and, venturing to set the mainsail, we passed the ice and stood towards the land. In half an bour we saw the place where the Fury was wrecked, with the poles of the tents standing; but we could not discern the ship, though we were sometimes willing to think that she was distin- 
guishable. To our great mortification, however, we could not reach the spot; and we now saw that a strong southerly current or tide was hurrying us away from this unlucky place. A thick fog obliged us to wear, and return to our shelter under the ice we had just quitted.

During the day, it being more moderate, with clearer weather, we made several tacks toward the land, but always found that we were losing ground. We therefore put on the steam at four o'clock; but, as the feeding pump went immediately out of order, it was to no purpose. At five, nevertheless, we had reached a point about five miles to leeward, or to the south of Fury point, at which time the wind and weather had both improved. Commander Ross immediately set out in the whale boat to look for an anchorage, and we followed, with the ship, now under steam and sail both, into the bay as it appeared to us, but inlet as it afterwards proved, which takes a direction due east from this part of the coast. He had found a place, as he judged, which would afford us security for the night; but we had discovered in the mean time that there was an eddy current setting along shore to the north-east, in the direction that we wished to go, and that there was a clear line of water inside the masses of ice, which seemed to be aground. We therefore stood towards this place, and found that we had just sufficient water to pass within musket-shot of the land.

The shore here was at first sloping; but, further to the northward, we found that the land rose from the sea in perpendicular cliffs from two to three hundred feet in height. We easily ascertained that they consisted of limestone, presenting the appearance of 
a horizontal stratification ; but as to any other details, our geological opportunities extended no further. A very large white bear came down to the beach, as if to gratify some curiosity respecting us; but it did not follow long, nor come within gunshot of the ship. It soon became quite calm; but between the eddy and the steam we were carried at the rate of two miles an hour.

It was quite clear to-day, and it was now we discovered that our August $1 \%$ supposed bay was an inlet. It appeared to be very deep, since we could see no land according to its direction, and we concluded that it proceeded far to the westward. As this chanced to be the birthday of the Duchess of Clarence, the bay, which constituted the first point of our discoveries in the present voyage, was named Adelaide bay, and the anchorage which Commander Ross had selected, Adelaide harbour.

At two o'clock we had made eight miles; when observing that the tide had changed, we made fast for the night, estimating that we were five or six miles from Fury point. Our ship was secure inside of some large pieces of ice which were in a state of decay, while that on the outside was setting fast to the southward. The more we saw of this coast, the higher the cliffs were found; while in some places projecting into horizontal shelves, and at others putting on an aspect of walls, castles, and turrets, with shapes even more fantastical, as is not uncommon in some of the deposits of this rock in other parts of the world. At short intervals also they were intersected by deep ravines, conveying streams of water, or showing the marks of former torrents.

At seven the wind appeared to come from the westward; and 
the tide, which had fallen, rose with great rapidity, so as to carry off the ice which obstructed while it protected us; thus leaving an open passage to the northward. The land now began to trend in this direction, and we accordingly made sail; but had not proceeded above a quarter of a mile, when the wind and the current came against us, and we were obliged to make fast to a piece of ice which lay aground.

In the mean time the steam was got up; and the wind being light, we cast off a second time, but made little progress, owing to the feeble action of the engine, and the defects in the feeding pump, which we could not here take time to repair. In fact, the wheels could make but eight revolutions; giving us but a mile an hour. We therefore were obliged again to moor to a piece of ice.

On further examination of the working of the engine, I now however found that it was possible to procure as much steam in fifteen minutes as would keep the engine in action for about an equal period, and with thirteen or fourteen revolutions of the wheels; I therefore adopted a new plan for converting it to some use. A whale line was carried out as a warp about two cables' length ahead; when the engine being stopped so as to allow the steam to accumulate, the vessel was warped on by it; and this being done, the steam was again set on. Thus, alternately steaming and warping, we proceeded along shore against the wind and the current; though sometimes compelled by the ice to haul in so close, that we were within a pistol-shot of the beach, with only a few inches water to spare beyond our draught of seven feet six inches. 
During all this period of extraordinary and laborious exertion, lasting from six in the morning till two in the afternoon, the utmost anxiety prevailed among the men throughout the space of five miles, and especially whenever we expected to turn the successive points which one after the other obstructed our view along the shore. Every one that could be spared from the work below was at the mast-head as soon as he could get there; and endless were the conjectures respecting the wreck of the Fury for which we were searching. At three, Commander Ross, who had then been her lieutenant, recognised a high projecting precipice, as being one which was about three miles to the northward of her place; and as we advanced, we saw at four, the tents themselves. One only seemed entire, and the rest, being common camp tents, displayed only their poles and ropes, with a few tattered remains dangling from their tops.

Commander Ross was then detached with a boat to seek for a safe anchorage, and soon returned with the welcome intelligence of an excellent harbour formed by a large iceberg and two small ones, situated about a quarter of a mile to the southward of the mound where the stores had been deposited. We therefore laboured with fresh spirit and energy, in spite of a new difficulty which obliged us to keep outside of the ice that was aground on Fury point. The water was so shallow within it as to be quite insufficient for us; the stones appearing above it within half the breadth of the ship, so as to show that there was a wall of rock here, by the side of which we were obliged to creep within a few yards, lest we should be swept away by the current, which, but a few fathoms 
further out, ran very strong against us. Here we were also much perplexed by the floating pieces of ice which it was impossible to avoid. But this also served at last to show us the peculiar advantage of the construction devised for our paddles. By turning off the ice they escaped all damage; and, at half after eight, the ship was moored in the ice harbour, which had sixteen feet at low water. 


\section{CHAPTER VIII.}

EXAMINATION OF THE FURY'S STORES-EMBARKATION OF THOSE WHICH WE INTENDED TO TAKE-DEPARTURE AND PROGRESS DOWN THIS SHORE-SEVERAL NEW DISCOVERIES MADE AND NAMED-OBSTRUCTED BY THE ICE, AND MOORED.

THE Victory being now securely moored in a good ice harbour, 1829. within a quarter of a mile of the place where the Fury's stores were landed, we were anxious to examine the spot; and having ordered the men a good meal, with the rest to which they were so well entitled, I landed at nine with Commander Ross, Mr. Thom, and the surgeon. We found the coast almost lined with coal, and it was with no common interest that we proceeded to the only tent which remained entire. This had been the mess tent of the Fury's officers; but it was too evident that the bears had been paying it frequent visits. There had been a pocket near the door where Commander Ross had left his memorandum book and specimens of birds; but it was torn down, without leaving a fragment of what it contained. The sides of the tent were also in many places torn out of the ground, but it was in other respects entire.

$$
\text { P } 2
$$


Where the preserved meats and vegetables had been deposited, we found every thing entire. The canisters had been piled up in two heaps; but though quite exposed to all the chances of the climate, for four years, they had not suffered in the slightest degree. There had been no water to rust them, and the security of the joinings had prevented the bears from smelling their contents. Had they known what was within, not much of this provision would have come to our share, and they would have had more reason than we to be thankful for Mr. Donkin's patent. On examining the contents, they were not found frozen, nor did the taste of the several articles appear to have been in the least degree altered. This was indeed no small satisfaction; as it was not our luxury but our very existence and the prospect of success, which were implicated in this most gratifying discovery. The wine, spirits, sugar, bread, flour, and cocoa, were in equally good condition, with exception of a part of the latter which had been lodged in provision casks. The lime-juice and the pickles had not suffered much; and even the sails, which had been well made up, were not only dry, but seemed as if they had never been wetted. It was remarkable, however, that while the spun yarn was bleached white, all appearance and smell of tar had vanished from it.

We proceeded now to the beach where the Fury had been abandoned, but not a trace of her hull was to be seen. There were many opinions; but all were equally at liberty to conjecture what had become of the wreck. Having often seen, however, what the moving masses of ice could do on this coast, it was not difficult to 
guess in general what we could not explain in detail. She had been carried bodily off, or had been ground to atoms and floated away to add to the drift timber of these seas. At any rate, she was not to be found; we had seen no appearance of her during the ten miles that we had coasted within pistol-shot of the shore to the southward of this place, and we now examined it for two miles to the northward with no better success.

We therefore returned on board, and made preparations for embarking a sufficiency of stores and provisions to complete our equipment for two years and three months; being what we expected to want on the one hand, and to obtain on the other. I need not say that it was an occurrence not less novel than interesting, to find in this abandoned region of solitude and ice, and rocks, a ready market where we could supply all our wants, and, collected in one spot, all the materials for which we should have searched the warehouses of Wapping and Rotherhithe: all ready to be shipped when we chose, and all free of cost ; since it was the certainty of this supply, and a well-grounded one it proved, that had formed the foundation of the present expedition.

A list of our wants was accordingly made out by Mr. 'Thom, who remained on board to receive the stores, together with the leading mate and a few hands. On shore, the rest of the crew were ready with the boats to receive and transport whatever was to be taken; and the steward together with the surgeon were employed in selecting whatever appeared to be of the best quality. Yet all that we could possibly stow away seemed scarcely to diminish the piles of canisters, of which we embarked whatever we could, together with 
such flour, cocoa, and sugar, as we wanted; all that we took being in excellent condition.

August 14. We continued our embarkations this day, including ten tons of coals; and, after allowing the men some rest, we contrived to get these, together with all the provisions and a part of the stores, on board before dinner time. We had found the spare mizen topmast of the Fury; and this was selected by the carpenter for a new boom, in place of the one that we had lost. We also got some anchors and hawsers, together with some boatswain's and carpenter's stores to make up our deficiencies. Some of the best of the sails were taken to make housings ; having found that belonging to the Fury damaged from having been ill made up, and from having lain in a situation which prevented the melted snow from running off. A skreen lined with fearnought was also found in tolerable condition; but the bears had overset the harness cask, and devoured nearly the whole of the contents. We found that some of the candle boxes had been entered, either by ermines or mice; one of them being entirely emptied, and the others partially. Though bleached, and especially on the upper side, as I already remarked of the spun yarn, none of the ropes were rotten, while the cables seemed perfect; and thence we concluded that the canvas of the tents had merely been blown away by the wind, after the bears had loosened the cloths at the foot in attempting an entrance.

The chain cable and the carronades were more or less covered by the small stones on the beach, and except being slightly rusted, were just as they had been left. The powder magazine, detached from the rest of the store, was unroofed, and the waterproof cloth 
of it in tatters; but the patent cases had kept the gunpowder itself perfectly dry. We selected from it what we thought we should require; and then in compliance with Sir Edward Parry's request and our own sense of what was right, caused the remainder to be destroyed, lest it should prove a source of injury to any Esquimanx who might hereafter chance to visit this spot. And with this we ended our new outfit: storing ourselves, somewhat like Robinson Crusoe, with whatever could be of use to us in the wreck; yet if thus far greedy, having in view but the execution of our plan, and precluded by our limited means of stowage from encumbering ourselves with superfluities.

In the evening we obtained sights for the chronometers, and found that they gave a difference of $40^{\prime}$ in longitude from that which had been laid down in the chart. And as this was the first place of verification which we had obtained since leaving England, we carried on both sets of longitudes in our proceedings, till it should be ascertained by a series of observations which was nearest the truth.

The tides were found to be very irregular; but not so much at the time of low or high water as during the rise and fall. On the first night, the tide rose seven feet, the flood being all the while from the northward; but the following two were three feet less, though, in consequence of the approaching full moon, they ought to have increased. In the offing, both during the flood and the ebb, the stream took the direction of the wind. Several whales were seen this day, and shoals of the white whale were observed running up and down the coast. 
It had been nearly calm for two days; but at eight in the afternoon a fresh breeze sprung up from the northward, and the ice harbour that we lay in began to break up. A dogkennel for which we had no use, was landed above high water-mark, and two bottles were left in it, containing an account of our proceedings up to that date. The boats were then hoisted up and secured, as was the Krusenstern in the usual manner; and casting off the ship from the ice we made sail for Cape Garry. It is true that the opening which we had seen leading to the westward held out the appearance of a passage, but it was less clear of ice, and had a much more feeble current than that to the southward. It was this also which seemed likely to lead us soonest to the American continent; while, in addition to all these reasons, we had the temptation of a fair wind in this direction.

At midnight the weather became thick, and soon after it rained in torrents, when we lost sight of land. As I formerly remarked, our compasses had ceased to traverse whenever the ship had any motion ; and, as we had no means therefore of ascertaining the true course, we steered by the wind, the direction of which we had observed before it became thick, and by the bearing of a stream of ice which we had noted: under which guidance, and using the pieces of ice as marks, we contrived to make Cape Garry very well.

August 15. It was about four miles from us at eight o'clock in the morning; and, at nine, we sounded at about a quarter of a mile, in twelve fathoms water.

The land here was comparatively low, but apparently of the same limestone; and, as this was the furthest extremity of the coast which 
had yet been discovered, our voyage now began to acquire its peculiar interest, since as yet we had seen nothing that was not more or less known. It had also been conjectured that there was an open sea between this point and the American continent: but this we soon found to be erroneous; since, after turning a little to the westward, the land, as far as we could judge, extended in a southsouth-west direction, and appeared to be continuous.

At a quarter of a mile from the beach we found bottom from ten to twelve fathoms, and continued to run in this depth, and at the same distance from the shore, at the rate of three miles and a half in the hour, passing through many pieces of heavy ice, which, while they kept the sea smooth, assured us that the water continued sufficiently deep for our ship. The greatest danger therefore which we had to apprehend, was that of being suddenly embayed; and we therefore kept ourselves in readiness to haul off or to anchor as might prove to be necessary. Though the risk too was considerable, we could not afford to lose the fair wind while the sea was sufficiently open.

At ten we came to a fine bay; and, sailing round it, found it to be about a mile in length and in breadth; and as, by a singular coincidence, this proved to be the birthday of our worthy builder, Mr. Fearnall, I conferred his name on it, and those of two members of a family to whose kindnesses when fitting out we were much indebted, on the capes by which it was formed. Near the bottom of this bay, that, which at a distance appeared to be sand, proved to be limestone; and fragments of the same rock were also brought up by sounding. The land was here quite clear of snow and ice. 
At eleven we passed the southern point, and, a little before noon, came to the entrance of a river discharging itself by a multitude of channels; exhibiting a deposit of alluvium which is far from common on these northern shores, and appearing to flow through a considerable space inland. It was named Lang river, after my friend of Woolwich yard who had so much exerted himself for our former expedition: after passing this, the land trended a point more to the westward. At two we passed another similar, but much smaller stream; and, two miles further, a remarkable peaked hill which I named Mount Oliver. The other names of this part will be found in the chart.

A point appeared shortly, jutting out here to the eastward, about which were collected a number of icebergs aground, indicating the presence of a shoal, extending about a mile off; and a narrow inlet opened to the northward of it, which appeared to be full of ice, and was probably shallow throughout, considering that there were but ten fathoms water on the outside. This opinion was confirmed by finding that there was here no appearance of any current, either into or out of it, though there was a very strong one running outside. I named this inlet Hazard inlet.

Round this point we found a very small island, to which I gave the name of Ditchburn, and to the land within it Boothia, being at the distance of a mile, and appearing to be continuous in the general direction already visible. It now fell nearly calm; but while the ice became thicker and heavier towards four in the afternoon, the fog cleared away, and there broke on our view a range of 
mountains rising beyond the land that we had been coasting, which we now saw clearly to be a low and flat tract, continuous eastward with this elevated region, and consisting, not of an uninterrupted plain, but of a series of low grounds and islets, among which we could but ill discern what was a real island and what was connected by an isthmus with the shore.

Many whales of a light colour came close to us; appearing to be quite indifferent to the presence of the ship; and if this proved that they had no experience of the fishery, so was it evident that here the whalers might find an easy prey, if it could be expedient for them to make the trial, and such trials should be as successful as ours. The mainland now appeared quite blue as the sky continued to brighten, being as clear of snow as the lower grounds. Pursuing our course, we observed a low island surrounded by icebergs, and subsequently a low point, from the end of which several islets and rocks stretched out, appearing to cover a large bay formed in the high blue land and full of close-packed ice. A low tract was also visible to the southward of this; beyond which the mountain range extended, as far as the eye could reach, in a southsouth-east direction as far as we could judge.

We could not here, however, approach nearer, on account of a tract of closely-packed ice, which formed a crescent extending from the shore round to the east and north-east. This was the first time that our progress had been entirely obstructed; and it was only now we found that we were still too early in the season to explore this passage; a discovery that consoled us for all our delays, in spite of which we were now convinced that we had made a greater 
progress than we could originally have expected in a single season, as we should also have gained nothing by being earlier.

At eight in the evening the wind came fresh from the north-west, which gave us an opportunity of examining more minutely the possibility of penetrating further; but no opening was to be found, neither was there any clear water visible over the ice, in any direction south of the east or west. We were therefore obliged to haul off and beat the whole night among the drift ice, which was streaming from the north-west, out of the different bays and creeks. Our estimated distance was about thirty miles south of Cape Garry.

August 16. The wind continued about north-west, and we kept on beating to gain the weather shore, near the last point we had passed, which now bore north-west by west. At two in the morning we got near to the land, and made fast to an iceberg about musket-shot from the beach, in three and a half fathoms water, being at the common entrance of two beautiful little harbours. By the time we were secured and the sails furled, it was too late for the usual church service; and as the men had undergone great fatigue, they were allowed the hours for rest. I went on shore with all the officers, to take formal possession of the new-discovered land; and at one o'clock, being a few minutes after seven in London, the colours were displayed with the usual ceremony, and the health of the King drunk, together with that of the founder of our expedition, after whom the land was named.

On exploring this spot it was found to be the southern extremity of the low land that we had traced, and that it joined the hill tract 


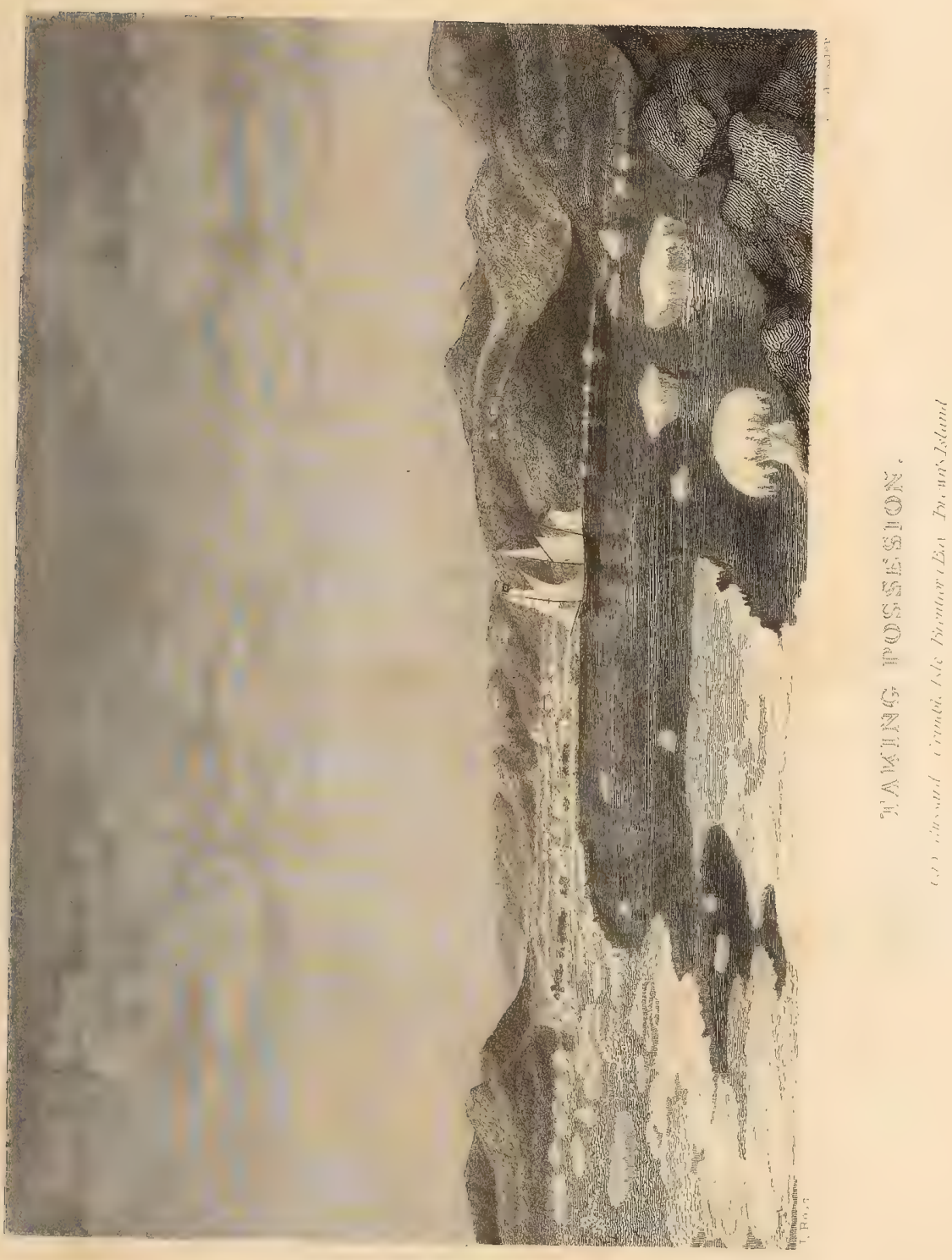



by an isthmus. Though formed of limestone, it was covered by scattered blocks of granite, indicating the probable nature of the mountainous country beyond. On the east side the rock was quite bare, but the west displayed some vegetation, with plants in flower, that were collected for the hortus siccus. An old Esquimaux grave proved that it had been visited by some of this wandering tribe; and we found the bones of foxes, and teeth of the musk ox. A bird resembling a sand lark was the only living animal we saw.

From the highest part of this land, which was upwards of a hundred feet above the level of the sea, we obtained a good view of the bay and the adjoining shores, and had the satisfaction to find that the ice was in motion and fast clearing away. We therefore resolved to wait patiently till we could see an opening; and proceeded to the northern quarter of this spot to make some observations on the dip of the magnetic needle. Here we found two Esquimaux huts, but empty, together with a fox-trap, containing some of the bones of this animal; we went afterwards on board to survey the northernmost harbour, which was found to have sufficient water for us, and to be sheltered from both wind and current. The tide rose four feet in the day, and five and a half in the night; high water being at twelve o'clock on the second day after the full moon. Though the wind was unaltered, the clouds continued to cover the sun so as to prevent any observation. The sea abounded in small marine animals, of which some were added to our collection. To this place I gave the name, Brown island, after the amiable sister of Mr. Booth; the inlet was named Brentford bay, and the islands Grimble islands. 
lngust 17. The sun appearing for the first time this morning, sights were obtained for the chronometers and the variation. The observations here made on the dip of the magnetic needle, gave $89^{\circ}$, being the greatest that had yet been observed, and an increase of one degree since we left the Fury's beach. As the variation also was westerly, we expected that we should find, or pass over the magnetic pole, which, under such a dip, could not be far distant.

Before noon we had a perfect view of the land, the point which we had next to pass being due south of our present anchorage; and it was a promising sight to observe that the ice still continued to separate and dissolve, so as to justify our attempting to work through it. The latitude observed at noon gave $71^{\circ} 59^{\prime}$, and the longitude by chronometer, corrected to Fury point, $93^{\circ} 32^{\prime}$; making the place where the flag was hoisted, exactly $73^{\circ} \mathrm{N}$, and $93^{\circ} 40^{\prime} \mathrm{W}$. We had here left a bottle containing an account of our proceedings, and had well secured it by means of a cairn of stones, on which was placed a post.

The tide having risen during the night, and floated the iceberg to which we were fast, we were obliged to cast off and let go our anchor in ten fathoms, about two cables' length nearer the point of the island than before. The steam was then got ready; and, there being a light air of wind, we took advantage of this and of the tide, weighed, and stood out for the opening that seemed to lead to the southern point, which was ten or twelve leagues distant. It soon, however, fell calm, and the engine acting very badly, we made little progress.

At six we were to the eastward of a large rock which seemed to 
be part of a reef extending between the points of the inlet in view to the westward, and which was full of ice. Near this rock there were many whales, apparently feeding and enjoying themselves in perfect security, and one large one came very near the ship. Whenever also the paddles were in motion, the seals were roused up, and seemed to be very abundant.

At eight o'clock a breeze sprung up from the northward, enabling us to approach the land, which was tolerably clear of ice till midnight; but the engine working to little purpose it was stopped, and the paddle hoisted up. Unfortunately, the weather became thick at ten, so that we could only shape our course by the wind: a hazardous guide, as it might shift, without our being able to perceive it, for want of marks or compass, and thus lead us into peril. Still it was a risk worth venturing; since it was by working to the southward, that we might get hold of the land which we presumed to be the American continent.

We continued to run at the rate of three and a half miles in the August 18. hour, among pieces of heavy ice, against some of which we could not avoid striking; receiving many hard blows, but no damage. At four, however, it became so thick, and the ice so close, that we could penetrate no further, and therefore made fast to a floe which we supposed to be near the point in question, since we had run about twenty miles. The depth of water was at first twenty-two fathoms; but we soon increased it to thirty-three by drifting. There were sufficient indications that the wind had continued true north, and therefore that we had steered south and a little easterly. About ten the weather cleared, so as to enable us to see our way 
to the westward; and we cast off from the floe to which we had made fast when we had first stopped, since it still continued drifting to the north-east.

We then stood to the westward through ice which was often so thick as entirely to stop our progress; and, after much labour by warping, got within sight of the land, which was low and encumbered by a continuation of the reef of rocks which we had previously seen. As it was, however, possible that there might be a deep channel near the land, I determined to cross this reef, which we accordingly attempted in a depth of four fathoms, at first, which gradually shoaled into two, thus leaving us little more water than we could venture to stay in. Here we made fast to a floe, and sent the boat forward to sound; thus discovering that there was no passage near the land, and being compelled to return by the way that we had attempted.

We were favoured in this by the wind shifting a little more to the westward, and were enabled to reach the deep water by six o'clock. We could not, however, discover how far we had proceeded since yesterday, since we had no observations at noon. Holding on, nevertheless, we forced our way through the lanes of water and the loose ice before us; receiving many other severe rubs, but no damage either to the ship or the boat, and, before midnight, succeeded in getting into some clear water that seemed to lead along the land to the southward. Here the temperature of the sea was $32^{\circ}$, the wind being due north.

We continued to stand to the southward without interruption, till four o'clock on this morning, when, in attempting to pass 
between two large pieces of ice, they suddenly closed, so as to give us a considerable squeeze, but without any injury; while we ultimately forced our way between them. Soon after this it was evident that the clear water was nearly at an end; and as the wind had freshened, we had no choice but to make fast for protection, to the largest piece we could find. This was done at five o'clock; and the weather becoming clear a little before eight, we found that the land bore from north-north-west to south by east, and the nearest point, which was about three miles off, west by north. There were now forty-five fathoms water; but we were closely beset by the ice, which, as it was drifting down on the piece to which we were fastened, carried this on the next to leeward. The Krusenstern was now cast off and placed in a natural dock near us; and towards noon we found that we had drifted several miles along the land to the southward.

We had here thirty fathoms; and the shore nearest us was a flat, smooth land, with a low cape, which I named Charlotte. Behind this was a range of hills, of no very great apparent height, but blue, and clear of snow, while extending further south than the lower land. The ice, too, seemed to be all drifting in that direction. Some sights obtained for the chronometer gave the longitude $94^{\circ} 40^{\prime}$; but we were obliged to estimate the latitude at $71^{\circ} 20^{\prime}$, as we could obtain no meridian altitude of the sun.

Before noon the ice, which was the heaviest we had yet seen, came down on us with great pressure, and the rudder was barely, yet but partially, unshipped in time to save it. We continued to 
drift to the southward, pretty smoothly, together with the ice, until eight; when it slackened a little, so as to give us the means of entirely extricating the rudder, which was then hoisted up and laid across the stern. Not long after, some fresh masses of ice lifted the Krusenstern nearly out of the water, and turned our own head to the shore; but after this we lay quiet all night, in depths varying from fifty-five to thirty-two fathoms; while, by the marks on the land, we could see that we were drifting southward with the whole body of ice. At midnight the temperature of the air was $36^{\circ}$, and that of the water $30^{\circ}$; the nearest land being about four miles off.

August 20. The weather was more clear this morning than it had been since Sunday, and we had a good view of this newly-discovered land, which extended from north $25^{\circ}$ west to south $20^{\circ}$ east. We had been drifted so close to the low point nearest us, that carrying the characters of the preceding in our eye, we could see that this consisted of the same limestone. It was a smooth tract, as far as it was visible, which was over an extent of ten miles, without either depressions or rising grounds. That behind it offered, as it had done before, a complete contrast of character; having the ruggedness and irregularity of surface which marks the granite or analogous rocks, and the atmospheric colouring making it appear of a dark blue.

The coast was broken and hollowed into little bays, and skirted by rocks and small islands; one of which appeared about a mile in length, elevated at the western side, and terminating in a low point to the eastward; whence we concluded that such was 
the general elevation and tendency of the limestone, flat as it might have appeared to us when seen in a different direction. The latitude observed here at noon was $70^{\circ} 59^{\prime}$, and the longitude $93^{\circ} 2^{\prime}$.

The ice still continued closely packed and drifting, with several lanes of water among it. Many whales were seen, together with some seals; but we could not contrive to take any of the latter. The soundings exhibited fiagments of granite and limestone; and the temperature of the air and water were, respectively, $39^{\circ}$ and $32^{\circ}$. We aired the small sails and the people's clothes; and several matters were done in the ship in the carpenter's department, and in that of the engineer; especially in clearing the pipes of the coke dust by which they were choked.

The wind was variable during the day; and, by the marks on the shore, we could see that we drifted, sometimes to the northward and at others to the southward, as the ice moved; invariably deepening the water in the latter direction, and finding it vary from 42 to 69 fathoms, with a calcareous muddy bottom and stones. The motion and state of the ice formed an anxious subject to those especially to whom this region was new: we, who were experienced, were easily consoled for such detention as this, by recollecting how much further we had already penetrated than former expeditions, though under the many disadvantages by which we had been attended. There was not, indeed, any immediate prospect of a release; and even we who had acquired experience from other voyages in these regions, were somewhat disconcerted by finding that a formation of new ice was commencing on the holes near 
the ship's side; the thermometer, for the first time, falling as low as $29^{\circ}$ in the water, while the air was only $30^{\circ}$. Still we thought that the clear water near the land was increasing in dimensions, and the great packs of ice becoming slacker. 


\section{CHAPTER IX.}

ATTEMPTS TO WORK ALONG SHORE-DISCOVERY OF PORT LOGAN-

LAND THERE-TRACES OF ESQUIMAUX-LABOURING AMONG THE ICE-DISCOVERY OF ELIZABETH HARBOUR.

$\mathrm{N}$ this day there was a great and sudden change of that threatening temperature. It was again, to the feelings, like a summer day in England, and the thermometer rose to $38^{\circ}$, as that of the sea did to $31^{\circ}$; this change having commenced at four o'clock in the morning. Much of the new ice dissolved therefore, more sea appeared open, and we had an excellent view of the land; the atmosphere being as clear as the air was calm.

The shore still displayed the same flat features, forming a crescent of about sixteen miles in extent, and to the north of the point which the ship faced. At that place a small island was discernible, and the shore still seemed skirted by small rocky islands, which appeared to form many harbours and creeks. We were not more than four miles from the beach; but could not by the telescope discover any living creature except two large whales. At noon the observations showed that we were a mile and a half further south than on the day preceding, but we had no sights for the longitude. 
The ship continued beset, and went on drifting with the ice, in all directions, as the wind chanced to vary, while the depth of the water increased to 87 fathoms. The men were employed, in their several departments, about the rigging and the engine, and in fitting a collar and bits for a. new bowsprit. Towards the evening the slacking of the ice was more perceptible, and a lane of clear water to the south-east was discernible by the terrestrial refraction. The Krusenstern, which had continued raised on the ice, dropped into the water, and there was a considerable pool round the ship.

Anonst 22. This day, being almost calm, the ice remained in the same state. The ship was warped round to the north side of the floe, where there was a larger extent of water; and it was in a better situation in case the ice should open. In the morning we were visited by a large whale, and after breakfast by a bear, which was wounded by a shot, but escaped on some of the loose ice, and then plunged into the water. Many seals were shot during the day, but they all sank, so that we obtained none. A second bear, in the evening, was similarly wounded, but escaped in the same manner.

At noon the latitude showed us that we had been drifted threequarters of a mile to the north; as we found ourselves a mile off the shore, by the bearings of the land. Owing to the clearness of the day we had the best view of the coast that we had yet obtained; and as we could more certainly perceive a line of clear water near it, our incapacity to extricate ourselves from the ice was the more provoking. The temperature of the air rose to $40^{\circ}$, and that of the water to $35^{\circ}$ : the land, in the evening, becoming very much ele- 
vated by the refraction, so as to exhibit the open water along the shore with great distinctness.

Early this morning the wind came from the south-east, and August 23. rendered it necessary for us to cast off from the floe which had been our anchorage for so many days; when the ice having slacked, we were able to get half a mile nearer to the land. At nine, however, we were again obliged to make fast to a piece of ice which we could not pass. Being Sunday, divine service was performed. After dinner we got two iniles nearer the land, by sailing and warping; but at six we were again obliged to bring up at a large floe in fifty fathoms water. The temperature of the air varied from $35^{\circ}$ to $37^{\circ}$, and that of the water was about $31^{\circ}$. It was altogether a beautiful day, with a clear sky and a light breeze.

We saw here some sea unicorns and many seals; and, during the evening, found ourselves drifting to the southward, though we had made some northing in the morning when under sail. No clear water was seen on this day except to the north-east; but the ice was apparently lighter, and it had not frozen during the preceding night. 'The ice being too unsteady for the artificial horizon, no observations were procured. The weather continued fine at midnight.

The morning, being calm, gave us some hopes of getting nearer August 24. to the land, especially as the ice seemed sufficiently opened to allow us to force the ship through it. The engine was therefore got ready, and we began to propel with the paddles and icepoles at seven o'clock; so that although the engine acted very ill, we succeeded, by two, in getting hold of a large iceberg which lay 
aground about a mile from the low point which bore south-west when we started. About noon, a breeze had however sprung up from the eastward, and thus checked our attempts to get further south at this time.

We were fortunate, nevertheless, in having secured ourselves to this immovable rock of ice; since, as the evening came on, the whole pack which we had quitted began to drift with great velocity to the northward, showing us what our own fate would have been had we remained with it. The ice to which we were fast was aground in seven fathoms; and after this the water rose above four feet; the tide beginning here to the southward, while that in the offing was running in the contrary direction. The weather being cloudy, no observations were made, but at midnight the air was at $32^{\circ}$ and the water at $30^{\circ}$. Many seals were seen, and the lead brought up limestone. Our position was in the middle of a large bight, and we had closed in the island to the southward.

August 25. We had fully resolved to try the steam, but the wind freshened against us before long, to the exact degree, though no more, that would have rendered it useless, feeble as was all the power it could exert. On no occasion was this want of power more provoking; since if it conld but have forced us two miles an hour, we should have been able to gain the most distant point in view, which was about sixteen miles off. We tried what we could do, but to no purpose; so that we were obliged to console ourselves in being at least quiet, and in a better place than the one that we had left; since it had now drifted many miles to the northward, while we 
could see immense masses of ice passing over the very spot where we had been.

Although the tide both rose and fell with us this day, the current set steadily to the northward; in consequence of which there was no returning ice to annoy us. All that we wanted was a fair wind, as the passage along the land was clear; yet even this want was probably in our favour as matters were situated; since, by carrying the ice away from the quarter to which our views were directed, it would probably give us a still clearer sea in no long time.

Though the wind increased considerably towards evening, the weather became much warmer, and, to our great joy, there came on some rain, since we concluded that it would aid in thawing and breaking up the ice. At noon the observed latitude was $70^{\circ} 54^{\prime}$, being rather more than four miles south of our last observation. One seal was killed, and proved excellent. At noon the air was at $36^{\circ}$ and the water at $32^{\circ}$, with no variations afterward; and the tide continued to rise about four feet and a half.

At six o'clock this morning it became quite calm, and the ice August 26. being sufficiently open to the southward, the water smooth, and no current, the engine was put in action, but performed so badly that we made no more than one mile in the hour, not being able to obtain more than seven revolutions in a minute. We passed the low point near which we were moored, in seven fathoms water, at the distance of two miles from the beach, and then gradually dropped into eighteen, when we opened the entrance of a spacious bay exposed to the south-east. At the bottom of this there appeared to be a stream, and the land that we were approaching 
was more rugged and lofty ; consisting, in that part, of what again seemed to be granite, while, below, it appeared to be limestone, as before, with many loose fragments. Within a mile of the shore the water deepened to fifty fathoms; but even here we found that the large icebergs were aground, touching the rocks in many places.

About four o'clock a fog came on, but we were able to keep the land in sight by sailing within a quarter of a mile of it. At seven Commander Ross was sent to look for a harbour in the bay, and he was fortunate in finding a very good one, which I named Port Logan.

We entered it at eight, the water being shoaler, and the icebergs grounded at such a distance from the shore as to give us an excellent pier harbour within them, with twelve feet at low water, and our stern not above fifty fathoms from the rocks.

This was, however, a safe position, notwithstanding that proximity and the small depth of water, since the icebergs were immovable. We landed at nine to take possession, and walked three miles, up a valley of a much more pleasing character than the general aspect of the country had led us to expect. It was traversed by a river, through the channel of which a small stream was now running, but which bore the marks of being a considerable torrent during the melting of the snows. This river was named the Macdoual. We saw here the recent marks of deer and of the musk ox, and also shot a white hare.

August 27. This day was a continued calm, and though foggy in the morning, sights were obtained for the chronometers. I ascended 
with Commander Ross to the precipice at which the ship was fast, which seemed about 200 feet high, but our view was obstructed by much higher land to the southward and westward. We saw no animals; but the traces of bears, deer, and ptarmigan were visible in many places. This hill was of granite, so as to confirm our conjectures respecting the higher lands at a greater distance, and was intersected by veins of quartz; and, at its foot, with granite fragments, there were also masses of whitish limestone, with shells imbedded in the slaty strata that accompanied it. There was very little vegetation, but the margins of two small lakes on the summit were surrounded by lichens and mosses.

This, and all the adjoining land was entirely clear of snow; and the water of the lakes stood at $38^{\circ}$, while the air was to-day as high as $42^{\circ}$. Obtaining here a meridian altitude of the sun, we found the latitude to be $70^{\circ} 48^{\prime}$, and the longitude $93^{\circ} 18^{\prime}$, giving $92^{\circ} 48^{\prime}$ when corrected by that of Fury point. The dip of the magnetic needle was $89^{\circ} 46^{\prime}$ west. After these needful observations, we took possession of this continuation of our discoveries, according to the usual forms, selecting another elevated spot for this purpose. At that part of this coast the land was undulated into hills and valleys; most of the latter containing lakes abounding in small fish about three inches long, not unlike trout, described among the other articles in natural history, hereafter. We obtained some dozens by means of our net; but it was too large in the meshes to secure as many as we might otherwise have taken.

We hence proceeded to a hill about 300 feet high, five miles 
further to the southward, from the top of which we had a most satisfactory view. The land appeared to extend in a south-westerly direction from the island, and, to the eastward of south, all was water for a space of thirty miles; the ice being such as to give us every prospect of getting through whenever the wind should become fair, since it was vain to reckon on the assistance of the engine any longer. We here fell in with a covey of ptarmigan, and killed a brace; as we also shot the only other bird we saw, a snow bunting. From the furthermost point of the bay in which we lay; and at the distance of six miles, there appeared an inlet, or bay, about two miles deep: the point which was to the southward of it extending considerably to the eastward, while off its northern one there was an island which seemed, on its north side, to have a good harbour about half a mile in circumference, which I named Moltke bay, giving the name of Bjornstjerna to the inlet itself.

The narrow and low island lying to the eastward of this, appeared not more than a quarter of a mile long and twenty yards wide; being scarcely elevated above the water, and seeming to offer a passage between it and the shore. It was named Rosea island. From its southern extremity the land trends to the southsouth-east, presenting a succession of points and harbours which we had occasion to examine more particularly afterwards. Behind the southernmost point of the island mentioned on the $22 \mathrm{~d}$ as bearing south $14^{\circ} \mathrm{E}$, the land appeared to trend more to the westward; and we were now sure that the furthest point we saw was the same that bore south of us when lying at the floe on that day. 
We returned at nine, after an interesting walk, but which had proved very laborious along the shore, in consequence of the fragments of ice and rocks. In the evening it was foggy; and towards midnight there was a breeze from the north-north-west. The tide rose three feet six inches, it being three days before full moon; but it was irregular, and we could not make out its velocity.

At the bottom of the bay, I must now add, we had found about twenty summer habitations of the Esquimanx, situated between two streams there flowing into the sea. They were of such recent erection as to mark no distant time during which they had been occupied. Near them we found a pair of reindeer's horns and some fox-traps, as well as some of the graves of the natives.

Again the engineers were clearing the pipes, which were once more choked with coke dust; and we had more reason to-day than ever to regret the ill performance of this wretched machine, since we might easily have made thirty miles, with one of the most moderate power. At midnight the weather was thick and foggy.

Our hopes of proceeding on this day were disappointed by the August 28 . wind coming to the eastward of north; so that, during the night, the ice was set in upon the land, and, among it, a large and heavy floe which impeded all passage. The thick weather which accompanied this change would indeed have been in itself a complete impediment, since, for want of the compass, all navigation is impossible under such circumstances. At one time the ice appeared to be floating against the wind, which was light, and 
towards the north; but as the breeze increased, it returned and floated to the southward.

The sails were however loosed, and warps laid out, in expectation that the weather might so far clear up as to enable us to discover some channel: but the fog continued so dense the whole day, that at eight we gave up all hopes, and furled the sails. The wind indeed now freshened so much, that we thought ourselves fortunate in not having started as we at first wished. We found it expedient in consequence to carry out some ropes, in order to secure the ship better to the bergs and the rocks.

The wind after this veered a little more to the north; and as it was to be new moon the following day, we began to fear lest the icebergs should float and carry us further up the bay, among the dangerous rocks and shoals which we had there seen. The tide rose three feet, the high water being exactly at noon and the ebb at six : the temperature of the air being $34^{\circ}$, and that of the water $32^{\circ}$. Nevertheless the ice seemed to be dissolving fast around us, though some heavy floes were drifted into the mouth of the bay; yet giving us no uneasiness, as we were well protected by the grounded icebergs.

As we would not venture on shore to-day, for fear of a change in our favour, it was employed in examining and preserving the specimens in natural history that had been collected the day before. A ready method of cleansing the seal-skins was found, by putting them overboard, where they were rendered free of every particle of flesh and blubber by the shrimps, in the course of a very short time. The seal's flesh, as before, turned out good, with very much of the 
flavour of the loons which we had shot in Davis's strait. We had the good fortune to recover a rifle which had fallen overboard last night; the clear water enabling us to see it at the bottom, in the eleven feet sounding where we lay.

It was high water this morning at two; being nearly at the August 29. change of the moon, which took place, at Greenwich time, at 9 A. м. The tide rose exactly six feet; having been but three feet six inches the preceding day, as, on the following, at half-past one, it was but twenty-two inches. This is a sufficient proof of the irregularity of the tides in this strait; preventing all possibility of anticipating their extent and nature. Whatever other circumstances may be among the causes of this uncertainty it seems plain that the northerly winds and currents make them come earlier and rise higher, and that the reverse happens in southerly winds.

The ice in the offing was seen, during the flood, to move up and down, or both ways, even when there was no wind at all. This causes some difficulty in judging of the direction of the tides; but I still think that the flood must come from the northward, because the motion was always greatest towards the south when the wind was in that direction; as it was also gradually later in proceeding to the southward.

At four in the morning the weather was so clear that there seemed a chance of a passage through the pack of ice which had been driven on the coast during the night. We therefore cast loose from the iceberg, and made sail; yet could find no passage through on reaching it, and were compelled to tack. But we had 
run to the leeward so far, that we could not fetch any place of safety, and were therefore obliged to warp back to the place we had left, which we reached at seven o'clock.

Before noon it came to blow hard from the north-east, which set in the ice so thick on the shore, that not an interval of water could be seen. We therefore considered ourselves fortunate in having got back to our station; disappointed as we might be in having made no progress. Raining now once more, while it blew hard, we also once more hoped that the ice would feel the effects, to our speedy profit. Though no clear water could be seen from the ship, we, however, obtained a view of a considerable tract in the offing, by ascending some of the higher ground on the shore.

Seeing now that there was no chance of proceeding till the wind changed, an additional hawser was carried out to a rock for further security, in the evening; and another in the morning, after we had found that the tide had risen so high as to float the icebergs; lest we should be altogether drifted out, or at least be carried further up the bay. At sunset, however, the weather had a more settled appearance : yet this was of short duration. It soon afterwards became cloudy, with the wind from the east; and at midnight we had our first fall of snow. The gales became then very strong from the north-east, and the ice was packed close round the outside of the bay; but the icebergs still defended us from its pressure. The temperature of the air was $34^{\circ}$, and that of the water $32^{\circ}$.

Aแֻบำ 30 .

During the night it blew a strong gale, but the tide rose only five feet six inches; and as the icebergs did not move, the ship lay in perfect security. As it was high water half an hour earlier than 
on the preceding night, we had additional proof of the irregularity of the tides in this strait; caused, unquestionably, by the complicated action of the winds and the drifting ice. In the morning the hills were covered with snow; a sight which was very far from agreeable; though we had no reason to expect aught else. Yet we had not much reason to complain, though we should eventually have been stopped here; since we had already penetrated further, by a hundred and twenty miles, even during this very short summer of ours, than any previous expedition had done in two years. This being Sunday, was made a day of rest.

The gale continued from the north-east the whole day, accompanied by snow and sleet, the temperature of the air being at $34^{\circ}$ and that of the sea at $32^{\circ}$. Both the ebb and the flood had so diminished, that the difference was scarcely two feet : and we could now see that our little harbour was the only secure place on the coast, all the rest being closely beset by ice. But we still expected that the wind would remove these fragments, and that we should be able to make some miles of progress before the winter should fairly set in.

This morning the land was entirely covered by snow, and there August 31. was no more of the usual blue colour to be seen. Once more the tide rose five feet and a half, and the ice was closely packed all round. As the day advanced the snow turned to sleet, and at length to a steady rain; the temperature of the air rising afterwards to $37^{\circ}$. With this, the snow on the hills began to melt and disappear. Groing on shore, a lane of water was found to have made its appearance in the south, and another in the east, while 
the ice began also to slacken both to the northward and southward of our harbour. The rivers were found much swollen, but no animals were seen. This day the water only rose two feet and a half. Sept. 1. At four in the morning, as there appeared a possibility of working the ship into clear water, she was hauled out to an iceberg, and, by the aid of a north-north-west wind, we contrived to steer along the land in a south-east by south course. We passed outside the low island, and then bore up for the outermost point, though in constant doubt of our position, from the thickness of the weather and the frequent changes of course we were obliged to make in working through the ice. But it cleared at seven, so as to show us the land, bearing from south $88^{\circ}$ east to south, and also from south to south-south-west. It was the island which we had seen on the twentieth, but its distance proved to be much greater than we had then imagined. It was named Alicia island. We kept under sail as long as we could, but were at last compelled, by the closing of the ice, to make fast to a large piece of it, which happened to be at hand. This, with the whole pack, proved to be drifting to the southward, and thus brought us nearer to the islands, though we were beating in the opposite direction. Towards evening it became moderate, and the ice seemed to have stopped. The rudder was therefore unshipped, and the Krusenstern placed in a secure situation, in case we should become permanently beset, as now appeared inevitable; while I need not say that we were once more reduced to a state of utter helplessness. The temperature of the air was $36^{\circ}$ in the day, but at night it fell to $34^{\circ}$. The depth of water was 52 fathoms, and the distance from the nearest land three miles; but as we 
approached within two miles in drifting to the southward, it deepened to eighty fathoms. Some seals were seen, and an ivory gull was shot.

By this morning the ship had drifted abreast of the highest part Sept. 2. of that island which had been so long in sight; which now, however, proved to be, not one island, as we had thought, but a rocky chain of islets extending in a south-east and north-west direction. The latitude was $70^{\circ} 36^{\prime}$, and the longitude $92^{\circ} 6^{\prime}$; whence we found that we had made eleven miles to the southward. After noon the current changed, and the whole pack began again to drift to the south-east: clear water was visible about three miles to the north, but in no other direction. The islands from which we were now only two miles distant, presented the most barren and repulsive tract which we had yet seen; displaying an entire surface of dark and rugged rocks, without the least trace of vegetation, or the presence of even a bird to enliven them. The clearness of the day allowed us to see some land which appeared to be about nine leagues off: and it was higher, as it seemed to us, than what we had passed before; while, in the intermediate space, were more of the rocky islands.

The piece of ice to which we were now fast was about two acres in dimensions, and had a pond of fresh water, whence we replenished our stock; after which it was made a washing place for such articles as demanded this operation. Though the temperature of this day was only $40^{\circ}$, the dogs were panting with beat, and seeking such shade as they could find on the rough ice. It however fell to $31^{\circ}$ before eight o'clock, and finally to $29^{\circ}$. The 
depth of water was here ninety-five fathoms. Except a small whale, no living animals were seen about this place. The snow had disappeared from this part of the land, with exception of a small quantity on the mountains in the extreme distance. In the evening it was calm, and we continued fast beset, but drifting to the southward with the whole pack. At midnight we sounded in a hundred and twenty fathoms, with a muddy bottom.

Sept. 3.

The weather was thick this morning, with light and variable winds, chiefly from the northward. The water shoaled to sixtyfive fathoms, and then deepened to eighty. The ice was fast all round us, but appeared more slack towards the islands we had passed. In the afternoon the fog turned to small rain, the thermometer being at $36^{\circ}$; and some clear weather in the evening discovered to us that we had made three miles further south since yesterday. The sight of one bear and one seal was not enough to. enliven this wearisome day.

It appeared to us, at this point of our progress, that the large island whose aspect had so often changed, consisted in reality of three, which formed part of a rocky chain extending along the coast as far as we could see, and which, by stopping the ice, caused the difficulty of the inshore navigation. Thus we again found use for our patience: while, by following this chain in the train of the ice, we trusted that we could always keep behind such heavy masses as would ground in time to prevent us from being wrecked or suffering any material injury. Heavy rain at midnight, with a shift of wind to the eastward, gave us some hopes of a change, though setting us on the shore. 
As the wind had shifted, during the niglit, to the east-south-east, Sept. 4. we found this morning that we had drifted two miles to the northward, approaching towards the shore at the same time. It rained hard till nine, and the wind increased to a gale; so that, by noon, we had drifted four miles further in the same direction, being fixed between two floes, but so as to sustain no injury. Thick weather coming on at three, we saw the land no more, but were convinced by the lead that we were continuing to drive; and after various changes of soundings, found ourselves, by the evening, in one hundred and twenty fathoms, which diminished to seventy-five at midnight. The shooting of a glaucous gull, and of a seal, were the only amusements of a provoking day, under which we were losing all the ground we had just been gaining, if not more.

The gale continuing all night, with rain, the large floe separated Sept. 5. from us very early in the morning; and, as it became clear, we found that we had drifted off the land. Perceiving then that the whole pack had considerably slackened, we attempted, in consequence, to force through it towards the land, in spite of many heavy blows, which fortunately did no mischief. We here found that our latitude was $70^{\circ} 55^{\prime}$, and that we had lost nineteen miles in a northerly direction, together with fourteen miles in longitude, during the three hours which we had been driving with the ice.

At five it cleared, and we saw, in the south-east, but at a greater distance, the never-ending island which, it almost seemed, we were destined not to quit. Forcing the ship through much heavy ice, we at last cleared the whole pack; when, the wind favouring us a little, we made up all the way that we had lost, and having again 
got hold of the land, made fast at ten o'clock; to an iceberg aground in five fathoms, and about five hundred yards from the shore. It rained hard till midnight, but was nearly calm. We saw two whales on this evening, with several seals; and the water was clear between the pack and the shore, while we were surrounded by large icebergs.

Sept. 6. The wind continued in the same quarter, with rainy weather, so that we could form no plan for proceeding. After divine service we went on shore to seek for a more secure harbour, as our present place was a very unsafe one. Entering an inlet with the boat, about a quarter of a mile wide, we sounded in fifteen fathoms; and, following it for a mile, we found it open into a spacious harbour, having twenty fathoms in the middle, and shoaling gradually to the sides. We here too ascertained that what we had taken for an island, the night before, was a peninsula. The harbour was named Elizabeth, in compliment to a sister of the patron of our expedition.

The country consisted of limestone and granite, resembling what we had formerly examined. A herd of reindeer passed at a sufficient distance to make us waste some shot, if not to tantalize us, as we proceeded to ascend the hill to the southward. Hence we had a perfect view of a harbour not exceeded by any in the world; before this, we had not been able to form a just estimate of its extent or nature. The pursuit of some hares which we saw, did not, however, tempt us to prolong our stay, since we could discover that the ice was drifting fast upon us. 


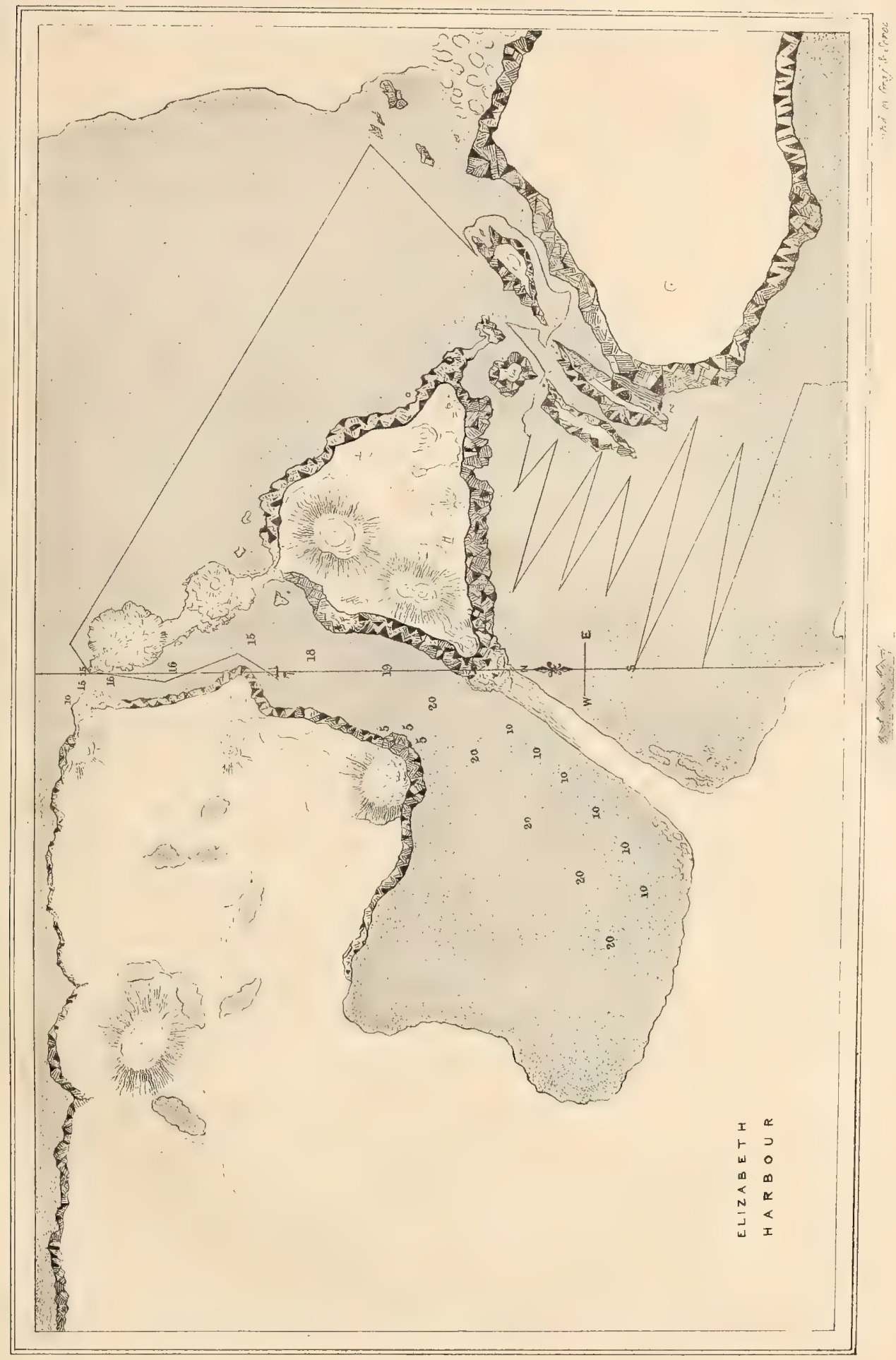





\section{CHAPTER X.}

ATTEMPT TO QUIT ELIZABETH HARBOUR-SLOW PROGRESS ALONG SHORE-CRITICAL POSITION OF THE SHIP AMONG THE ICE, AND ESCAPE Through PERILOUS PASSAgE-Discovery OF EClipse HARBOUR-FURTHER DISCOVERIES-CAPE ST. CATHERINE, AND LAX HARBOUR.

HAVING returned on board by two o'clock, we made sail there1829. fore from the iceberg, and entering into the harbour, moored the ship to a small one in seven fathoms, not far from the beach. A boat was then despatched to see if there was any exit on the southern or eastern side; but the result was, that we had entered by the only opening, as it was also found that it was separated from the strait without, by a narrow range of limestone about three miles long, level and straight. The boundary to the westward was of high land, and that to the north consisted of lower hills interspersed with lakes containing fish: the rocky point and peninsula where we had first taken possession forming its eastern side. The granite here presented many varieties, and was studded with garnets, probably in the veins, which we did not take sufficient care to distinguish at the time. I now indeed suspect, that on this and other occasions, what I have termed granite was gneiss; a mistake 
which is often easily made by those who are not practised mineralogists; but as I could not collect specimens at every place that was visited, and as I could not bring home even all those which were collected, for future examination, this very unimportant error, if such it be, must remain.

In the evening, landing at the north side, and ascending the heights in that quarter, we obtained a still better view of this splendid harbour, in which the whole British navy might safely ride. Except at the edges, it was clear of ice, though a few icebergs seemed, like ourselves, to have taken refuge here; but we saw no marks of any shoals or rocks within it. In many parts there were five fathoms water close to rocks on the shore, where vessels might lie as at a pier, and where they might also heave down and repair damages; and, from marks on the margin, we judged that there were eight feet of rise at spring tides; the present, which was neap, rising but four.

Sept. 7. In the evening it blew hard from the northward, bringing the ice past the place which we had left, and packing up the whole channel to the southward. But we were safe, and quiet; with the security that if this ice should clear away, we could easily get out by aid of the tide, and take advantage of the opening. The temperature of the air was from $34^{\circ}$ to $35^{\circ}$, and that of the water $32^{\circ}$. At midnight there was rain, the wind continuing fresh.

It rained heavily all the morning, and a good deal of small ice drifted into the harbour, proving that there was a considerable quantity moving along the strait with the current. We therefore proceeded in the boat, to examine into the condition of things out- 
side, more particularly, and landed on the northern isthmus. We thius saw, that at the back of the great isthmus, the quantity of ice was much diminished since the preceding day, while there was a bay to the eastward quite clear; but, near the mainland, it was still closely packed. The west side of the southern islands, however, were also clear of ice. In this excursion we saw some reindeer, and shot three white hares. The air felt warm; but, on board, the thermometer was only $36^{\circ}$, the weather being calm, with a thick fog.

Though things remained in the same state till noon, we expected a wind, and therefore left the harbour by means of the ebb and of towing; making fast to an iceberg at the entrance, that we might be ready. But the wind coming now from the south-south-east, we could proceed no further, and I therefore sent a party to examine the state of things along shore, in the whale boat, which was, however, obliged to stop after proceeding two miles. Being then hauled up, the party proceeded by land along the isthmus, and thus saw that the ice was closed up to a rock at its termination, so as to prevent all further passage in this direction. Two rocky islands and a good harbour were also seen in this quarter; as it was further ascertained, that while the shore was covered with heavy ice, the channel of moving ice and water lay between it and the heavy pack which was about three miles off.

The evening being calm, and the ice stationary, Commander Ross went on shore to take angles, and in his way found a dead deer, which we had wounded on our first landing. It was so large that they could only bring on board the head and horns, leaving it for the next day to remove a carcase too valuable to be lost. Men 
were also sent to erect a cairn of stones to mark the entrance of the harbour, otherwise difficult to find, in case we should be obliged to return to it. Landing, myself, afterwards, I obtained a good view, from the north side, of the several places that we had passed, killing also two hares. At eight the wind was light, and southerly, with clear weather in the night, the temperature of the air from $34^{\circ}$ to $36^{\circ}$, and that of the water $32^{\circ}$. Our fresh water was replenished, and many seals were seen.

The geological structure of this part of the coast exactly resembled what we had formerly examined, with perhaps more varieties of granite, or gneiss; the whitish shale of the limestone containing shells as before. The soundings were in clay so tough as to require great force to extract the lead from it. Some sandstone was also observed here; and in many of the small bays there were accumulations of white sand, which, however, might equally have been furnished by the granite. There was no wood: a heath, with stems about an inch thick, being the largest plant growing. Near the sea the land was generally bare; but, inland, there were plains and valleys of considerable extent, covered with vegetation; each of the latter containing a lake, of which the largest seemed about two miles long, as many of them were but large pools. These, as before, were full of fish, which we then had no means of taking. Many hares, far from shy, were concealed among the rocks, and tracks of reindeer were seen near the shore. On the north side the remains of Esquimaux summer habitations were numerous, together with fox-traps and bones of whales; but all of so old a date as to show that it was long since this part of the shore had been inhabited. 
It was quite calm all this day, with an occasional light air from Sept. 9. the southward, sufficient, with the current, to prevent us from making any progress. Notwithstanding this, we hauled still further out, to be in readiness in case of a favourable change. It froze so hard in the previous night, that the harbour was covered with bay ice; insomuch that the whale boat which had been sent for the deer could scarcely make her way through it. Towards evening, however, it was all dissolved, as was that which had been formed in the lakes. Even at three o'clock it was like a summer's day in England; and, though close to the iceberg, the temperature on board was $38^{\circ}$, while on shore it was $41^{\circ}$. This, indeed, had an unfortunate effect on our deer, which, though but three days killed, was only fit for the dogs. We here built a cairn on the highest hill on the north side of the harbour.

A slight breeze coming from the north-west at daylight, we left Sept. 10. the iceberg at half-past three, and stood out among the loose ice under all sail; steering through various lanes and openings which led towards the south-east. But at two o'clock the wind came directly against us; and it was with much difficulty we reached an iceberg which was aground about half a mile eastward of the islands described on the second of September, and about eight miles from our last station. After two hours, however, the ice set in with such rapidity, that we were obliged to cast off, when a more favourable breeze enabled us to reach a small harbour in the passage between the islands and the main, whence we were able to warp into a situation for the night.

Thus we were enabled to land on the islands; and, having 
ascended the highest summit near us, we had a good view of the state of the ice, which was such as to make us resolve to attempt a passage between the rocky islands and the point, so as to get hold of the mainland. The ship was therefore warped, with much toil and hazard, through a narrow and rocky sound leading to the channel, and made fast to an iceberg, and to the rocks, from which she was not more than half her length distant, in three fathoms water. It was not, however, a good place; since the ice set both ways, alternately, with great rapidity, so as to be in constant motion.

Angles were here taken from a cairn which we erected on the highest hill, being about three hundred feet, and sketches made. The furthest projecting land was an island bearing south-east, at a considerable distance from the point of the mainland. The outermost of the islands on which we were seemed about a mile long, and the land formed a great bay, in which we counted nine islands and some clusters of islets; together with two inlets, and some openings that seemed to constitute three good harbours. Here we also concluded that our best chance of proceeding appeared to be by the channel within these islands, and close to the mainland; as the ice was all broken up, though thick and heavy, and was likely to move with the first favourable wind.

The islands on which we now were, turned out to consist of gneiss, I presume, disposed in inclined beds with vertical fissures; and in two little valleys there was some vegetation, though the greater part of the surface was quite bare. The aspect of desolation was indeed extreme; nor did we see the trace of any living creature. The temperature of the air was $34^{\circ}$, and that of the water $31^{\circ}$. 
.Our iceberg floated last night at half-past twelve; but we at sept. 11. last succeeded in mooring it, together with ourselves, to the rocks within a small bight on the side of the stream; while, as it drew more water than the ship, it kept us from grounding; allowing us to lie quiet all night within a few yards of the rocks, and in three fathoms water. After a foggy morning, there appeared, at one, some chance of moving, as there was a fresh breeze from the north-west. The attempt, however, was made in vain; and, after three hours of hard labour, we could neither proceed, nor extricate the ship, so that we were obliged to submit ourselves to the ice, which was now closely packed in the whole channel which it occupied. It was in vain that we attempted to disengage ourselves, even when it got into motion; labouring hard for this purpose till ten o'clock; but a calm occurring at midnight, we became comparatively tranquil and easy.

Nevertheless it was a critical position, beset in the rapid current Sept. 12. of a rocky channel, at the spring tides of the autumnal equinox; and, as the tide rose, the heavy masses of ice which were set afloat increased our danger, its action forcing them on us. We therefore thought ourselves lucky in getting hold of a grounded iceberg; though the points of rocks were appearing all around, and close by our ship. Unfortunately, however, a wind springing up from the westward, brought down an additional quantity of ice, before daylight, with a great increase of pressure; when the whole mass began to move to the eastward with frightful rapidity, carrying along with it our helpless ship, and amidst a collision and noise, from the breaking of the ice against the rocks, which was truly awful. 
The day had scarcely dawned when we found ourselves near to a point separating two channels; and it was for some time doubtful into which we should be hurried, or whether we might not rather be driven on the rocks which surrounded us on all sides, some below the water and some above it. But our good fortune prevailed; and the stream carried us into the northernmost and widest passage; though it was to the north-eastward, and therefore, otherwise, to our loss. And here, to complete our success, such as it was, the ice shortly opened, so as to allow us to extricate the ship, though by extraordinary exertions; on which, making her fast to a grounded iceberg, we found ourselves near the point on the north side of this channel, and felt ourselves thus secure for a time.

During the night, and especially when contesting our way to this spot, the ship had been repeatedly raised, and sometimes heeled over, by the pressure; while the Krusenstern was once thrown out of the water, on the ice. But neither received any injury. We had reason to be surprised: but every new adventure of this kind had the good effect of increasing our confidence, in the case of future and similar emergencies; of which, it was but too certain, there were many yet before us.

At nine, the change of tide, and that a rapid one, setting to the westward, drove us from our place of refuge; and we were carried within three yards of some rocks which were just under water, at the narrowest part of the point. Believing that we might succeed in rounding this place, and thus getting into what seemed to be still water, we laboured hard by warping; there being a small creek immediately beyond it which held out a promise of security. This, 
most unluckily, proved to be a whirlpool: and having been turned round by it many times, for more than an hour, we were obliged to leave it, and trust ourselves once more to the confusion withont. Thus situated, no resource was left but to attach ourselves to a mass of ice which was floating along in the middle of the stream; hoping: thus to escape a repetition of what we had just been enduring.

We were thus at length extricated, but not without undergoing heavy pressure; our iceberg carrying us to the westward, even against a strong wind. The tide, however, diminished in force as we proceeded; and as the smaller pieces of ice now sailing with us did not drift so fast as that to which we were attached, the whole became at length so slack that we were able to make sail before noon, and at last got into clear water.

The danger, however, was not yet over; since we were subject to be carried back by the next tide, unless we could get out of its influence before the change. But the wind was right against us, and we could expect to make little progress with our sails, and such a vessel, by plying to windward; while, to anchor in a tideway like this, was out of the question. Thus we soon found that we were losing ground; but at four o'clock we began to gain considerably, when it fell suddenly calm. A harbour now appearing not far off, in the nearest land, we contrived to warp into it by means of the boats, and found good shelter behind a reef of rocks, lined by icebergs, within a cable's length of the shore; making fast to two of these masses which were aground in four fathoms water.

More than I among us had witnessed similar scenes, and, in some manner or other, we had been extricated: but, with all this, we 
could not but feel astonishment, as well as gratitude, at our having escaped here without material damage. For readers, it is unfortunate that no description can convey an idea of a scene of this nature: and, as to the pencil, it cannot represent motion, or noise. And to those who have not seen a northern ocean in winter-who have not seen it, I should say, in a winter's storm-the term ice, exciting but the recollection of what they only know at rest, in an inland lake or canal, conveys no ideas of what it is the fate of an arctic navigator to witness and to feel. But let them remember that ice is stone; a floating rock in the stream, a promontory or an island when aground, not less solid than if it were a land of granite. Then let them imagine, if they can, these mountains of crystal hurled through a narrow strait by a rapid tide; meeting, as mountains in motion would meet, with the noise of thunder, breaking from each other's precipices huge fragments, or rending each other asunder, till, losing their former equilibrium, they fall over headlong, lifting the sea around in breakers, and whirling it in eddies; while the flatter fields of ice, forced against these masses, or against the rocks, by the wind and the stream, rise out of the sea till they fall back on themselves, adding to the indescribable commotion and noise which attend these occurrences.

It is not a little, too, to know and to feel our utter helplessness in these cases. There is not a moment in which it can be conjectured what will happen in the next : there is not one which may not be the last; and yet that next moment may bring rescue and safety. It is a strange, as it is an anxious position; and, if fearful, often giving no time for fear, so unexpected is every event, and so quick the 
transitions. If the noise, and the motion, and the hurry in every thing around, are distracting, if the attention is troubled to fix on any thing amid such confusion, still must it be alive, that it may seize on the single moment of help or escape which may occur. Yet with all this, and it is the hardest task of all, there is nothing to be acted, no effort to be made: and though the very sight of the movement around inclines the seaman to be himself busy, while we can scarcely repress the instinct that directs us to help ourselves in cases of danger, he must be patient, as if he were unconcerned or careless; waiting as he best can for the fate, be it what it may, which he cannot influence or avoid.

But I must not here forget the debts we owed to our ship on this as on other occasions before and afterwards. Her light draught of water was of the greatest advantage; and still more the admirable manner in which she had been strengthened. It is plain that either of the ships employed on the former expeditions must have been here lost, from their mere draught of water, since they would have struck on the rocks over which we were hurried by the ice; while, however fortified, they would have been crushed like a nutshell, in consequence of their shape.

Our position, after this adventure, was on the mainland, seven miles from the cairn which we had erected on the tenth; being not far from two harbours, one on each side of us; which I named.

The night was clear, and it began to freeze at eleven. At midnight there was a visible eclipse of the moon, but the weather did not permit of any observations. I named the place Eclipse 
harbour; and we found high water, with a rise of seven feet, at a quarter before three, at full moon.

Sept. 13. Early in the morning $I$ ascended the high land near the shore, by which I found that it was possible to proceed a few miles along the coast: and, after building a cairn and taking some angles, $I$ returned on board, and we got under way at nine, with a westerly breeze. We steered to the southward through new ice which offered little resistance; and, as we proceeded, the heavy masses became more slack. Passing a rugged point, with icebergs aground, it received the name of Cape Allington, being the boundary here, of the spacious harbour just mentioned by the name of Eclipse harbour.

We very soon rounded a cluster of islets, which, as equally new, I named Grace; and, passing them, we saw a round island, now also named Louisa. Within these, such channel as there seemed, was full of ice; and therefore, passing to the eastward, we approached, at three o'clock, a smooth rocky island about two miles in circumference. It being calm, we attempted to tow the ship between it and the preceding ones; when the tide changed, and we were glad to secure ourselves for the night to an iceberg that was aground near it, which formed a snug harbour with an islet with which it was in contact.

This island was three miles from Eclipse harbour, and seven from the extremity of the land to the southward. On inspection, we found it a solid mass of granite intersected by veins; and we also observed fragments of limestone and of yellow sandstone. Here we built a cairn, with a pole on which was fastened the ship's name, and the date, engraved on copper. The prospect was such as to 



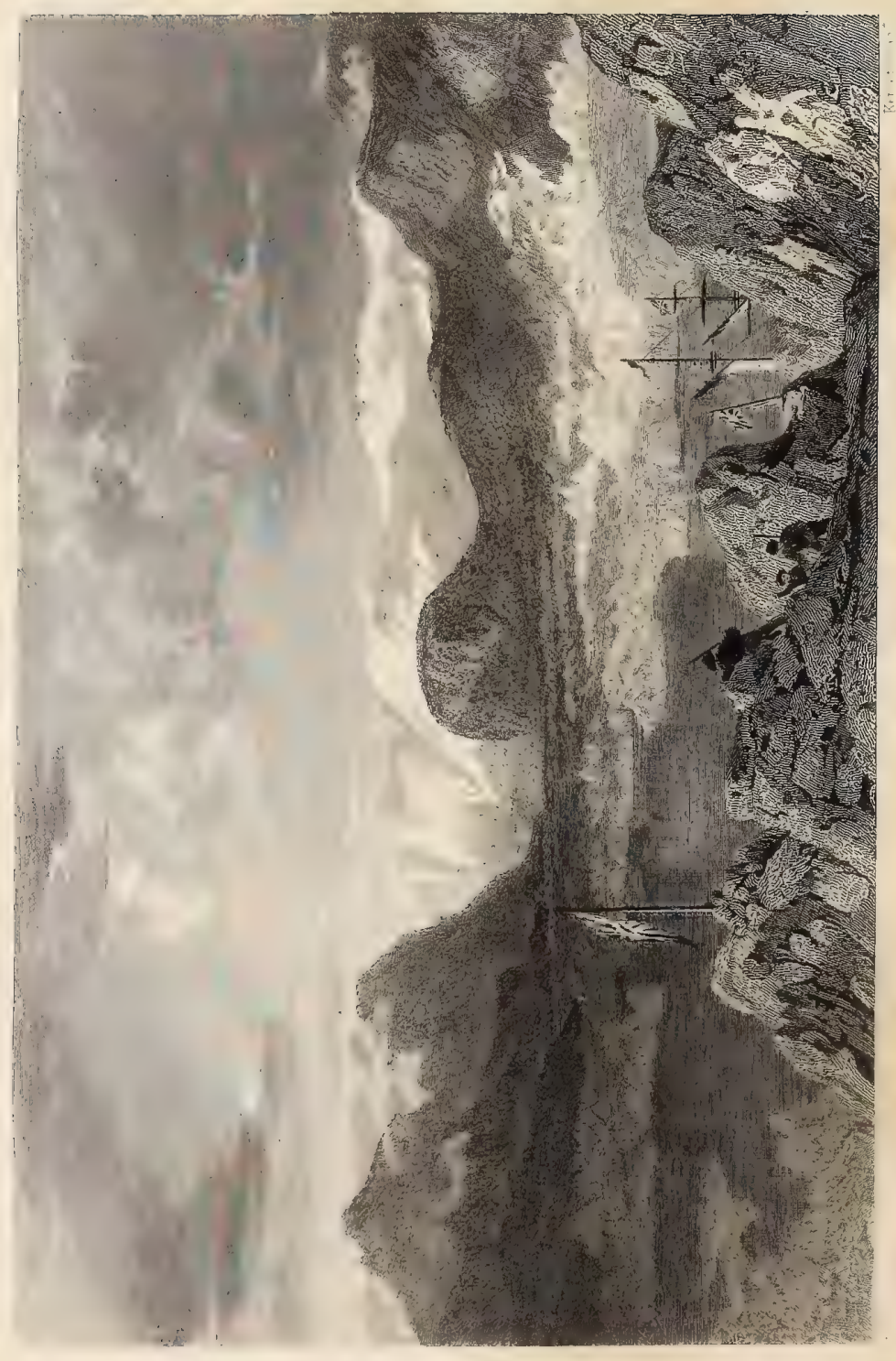


show us that a fair wind might carry us clear of the ice as far as that point which seemed seven miles off: but beyond this we could barely discern that the land did not trend to the eastward. An island was seen, open with the cape; and, near this, a harbour, which was named Lax island, while, to a large inlet, full of ice, south of this, I gave the name of Mary Jones bay.

On the south side there were smaller inlets and creeks; and, to the north, a remarkable mountain, shaped like a tomb, and covered on the south side with a reddish vegetation. It was named Christian's monument. Proceeding along the coast, we found an Esquimaux fox-trap, with some remains of summer habitations, and counted thirty-three islands of different sizes, for the names of which I must here refer to the charts and the tables. The vegetation on this island, which is in the middle of the bay, was very backward compared to that on the mainland.

The new ice had totally dissolved this day; the temperature of the air being $38^{\circ}$, and that of the sea $32^{\circ}$. There was now no snow on the high mountains of the interior to the southward, and all the fresh-water lakes and pools were open. In the evening the wind came from the south-south-east, and thus prevented us from moving: while the water fell so low as to compel us to haul further out.

It was high water soon after one in the morning, and the tide Sept. 14. rose to six feet eight inches, with the flood from the northward. The two icebergs to which we were moored just floated; but we kept them fast to the shore by ropes until the tide had lowered. A thick fog prevented us from moving till two; when, the wind 
being north-north-west, we made all sail and stood for the point through loose ice, which, however, soon closed, so as to oblige us to run for a small bay to the north of the cape.

This proved a very good shelter : and having gone on shore, and ascended the hill on the point, we saw that the ice was still more open than it had been the day before, that the land trended more to the southward, and that the outermost portion was but an island, six or seven miles from the mainland. Many fine harbours were also visible, and the shore was intersected by inlets in every direction. Having taken the usual formal possession of this cape, since even that which is nugatory or absurd must be done where custom dictates, a cairn and a beacon were erected, with the ship's name, and the date, on a plate of copper, as before. This cape was named Verner, and the harbour Joanna. The geology was here nearly what it had all along been : but one of the masses of granite formed a pyramid alike striking from its form and its dimensions, while we also perceived some coarse argillaceous schist.

As the point on the north side of the harbour was the most convenient for observation, we erected a cairn here also, for determining angles and laying down positions; though it was not likely to prove of much use hereafter in verifying the accuracy of the discoverers. Just before dark, the channel between the shore and a small island was cleared of ice by the rapidity of the ebb: but too late to allow us to attempt our way through it. The temperature of the air was from $35^{\circ}$ to $36^{\circ}$, and that of the sea from $31^{\circ}$ to $32^{\circ}$ all this day; and the tide rose two feet less than it had done in the night preceding. No animals, nor any traces of Esquimaux were seen. 


\section{CHAPTER XI.}

A HEAVY GALE: SUCCESSION OF TEMPESTUOUS WEATHER, WITH SNOW-PARTIAL CLEARING OF THE ICE, AND EXTRICATION FROM IT-DISCOVER THE ISLAND OF ANDREW ROSS, CAPE MARGARET, BEST HARBOUR, AND MARTIN ISLANDS-A NEW BAY-END OF SEPTEMBER-GENERAL REMARKS ON THE PAST PROGRESS OF THE SHIP AND THE MODE OF NAVIGATING AMONG ICE.

T The evening; and the wind, rising, increased to a storm during the night. Having also veered round to the northward, it brought around us a great quantity of heavy ice; so that, at daylight, we found ourselves completely locked in, to our no small vexation, which was much augmented by seeing clear water within a quarter of a mile. Every exertion was made to warp out, or to extricate ourselves in some manner: but a whole forenoon of hard labour gained us scarcely more than four times the length of our ship. At length the ice accumulated to such a degree, that we were obliged to abandon the attempt.

In the mean time the storm increased, with squalls of snow, so as to render our situation both critical and uncomfortable; since 
we could not regain the harbour which we had so prematurely left. Thus exposed to the storm, the pressure of the ice was also to be feared, as the icebergs were accumulating on the shores of the cape, which they were too deep to pass. At length the one to which we were moored went afloat, giving us much trouble: while the largest one near us split into six pieces, with a noise like thunder; falling over and throwing up the water all around. One of these fragments gave our ship a violent shock; and another, rising up beneath the Krusenstern, lifted her out of the water on the ice, and then launched her off again. Fortunately, no damage was sustained.

The night tide was further diminished, and we continued, after this last adventure, to be not far from the point of the cape behind which was the clear water: while we were obliged to wait with patience for some favourable change of the wind. The thermometer was at $34^{\circ}$, and the snow was so heavy as to cover the mountains. A party was sent to the cairn, to examine into the state of the ice, and, having returned, they reported it to be quite closed to the southward, with exception of a narrow lane of water along the land, which now appeared to trend more to the southward. Shortly, the temperature fell to $28^{\circ}$, with clearer weather and the barometer rising. The latitude of this cape was found to be $70^{\circ} 22^{\prime}$, and the longitude $92^{\circ} 15^{\prime}$, which, with the correction, is probably $91^{\circ}$.

sept. 16. The wind was somewhat more moderate this day, and the weather milder; but the ice was quite close every where, excepting for a small space on the south side of the cape. We went on shore to survey the channel through which we had intended to pass; 
when we saw that there were two reefs of rocks in the middle of it. It was a lesson to our impatience; as it was one among many incidents occurring in this voyage, calculated to teach us that apparent misfortunes are often benefits. Had we been but ten minutes sooner, we should have made the attempt; and, without a miracle, the consequences must have been fatal. Of this, we could entertain no doubt, when we saw that their depth would then have been six feet, enough to conceal them from us, while, on taking the ground, we should have been overwhelmed by the descending masses of ice. Thus was our disappointment converted into a source of enjoyment, and of self gratulation: with the same knowledge on the day before, we should have thought our icy prison a paradise.

A little before noon, the wind shifted suddenly to the south-east, and blew a gale; while we had in the mean time moored to the largest floe in the passage, that we might be ready in case of any favourable chance. In consequence of this reversal of the wind, the ice began to move in the opposite direction to what we had expected : so that we were glad to regain our position in the bay, though this was not effected without several hours of warping.

Going on shore in the evening, we had the satisfaction of seeing that the ice was fast leaving the land, and that it would probably allow us to try again in the morning, with the probability of making ten or fifteen miles. We here found that the fine harbour to the south of the cape had an entrance from a bay to the southward, and also another from one to the northward, rendering the cape itself an island. The channel was narrow and crooked, and singularly intersected by the projections of hilly points on both sides, with 
inlets branching in every direction. The harbour was clear of ice, and contained three inlets. We here saw three hares.

The observations at noon confirmed yesterday's latitude. The thermometer in the twenty-four hours, varied from $30^{\circ}$ to $34^{\circ}$, the water being at $29^{\circ}$; and there was new ice in the pools among the rocks on shore. Various bearings were taken; and we thought that the land trended less to the east than we had formerly supposed; rendering it a matter of hope, rather than of aught else, that we had now arrived at the south-eastern extremity of this land.

At ten at night the wind suddenly changed to the north-west, and blew with increased violence; when, once more, the ice which had not yet cleared the bay, closed in upon our protecting icebergs, forcing us to carry out additional ropes, both to them and the shore. The Krusenstern was transported to a place of safety in the innermost harbour; and, during the night, it blew extremely hard, with squalls of snow ; the thermometer falling to $21^{\circ}$ in the air, and $23^{\circ}$ in the water. We had therefore, once more, great reason to be thankful that we had not been able to get out of this haven, where the heavy masses of ice around us afforded very tolerable security, since they were aground on all sides, and exerted no pressure against us.

sept. 17. The gale continued with undiminished fury from the northward quarter, accompanied by heavy squalls of snow ; and the sea froze as it washed over our decks and the adjoining icebergs. The outer edge of the ice to windward was but a mile from us; and, on this as well as the islands, the sea broke in a tremendous manner, producing a considerable swell, even where we lay, though sheltered 
by a point of land and this extensive tract of ice. The thermometer in the air fell to $21^{\circ}$, and the water to about $28^{\circ}$; and though the tide rose high, the icebergs did not float. In the evening the ice broke up so much as to bring the open water a quarter of a mile nearer to us; and, in no long time, the wind became more moderate: while some masses of ice were seen floating through the channel of our intended passage, which displayed a good deal of clear water.

The moderating of the wind on the preceding evening was but sept. 18 . a delusive promise. In the night, the gale increased once more; and to a degree of violence exceeding all that we had yet felt, accompanied, as before, by snow. As some of the icebergs began to move; three large masses came across our bows, threatening to break the two cables which we had made fast to the rocks, and obliging us to carry out a third. The ice on the outside of us was soon broken up by the swell, and at daybreak the waves reached within a quarter of a mile of the ship: while the motion of the solid masses around produced such an agitation in her as to compel us to carry out steadying ropes and fenders.

In consequence of the tide now rising to an unusual height, many. icebergs drove near to the shore; but as that fell, things became comparatively quiet: though the rapid destruction of the ice, under all the present violence, gave us great alarm lest we should lose the protection which had hitherto sheltered us so well. At ten in the morning, therefore, we went on shore, in hopes of obtaining a better view of the circumstances in which we were now engaged; the wind having once more moderated. We thus discovered that 
there was nothing to obstruct our passage as soon as we should be released from our present durance, and that although there was much ice in the harbour, it was not such as to prevent our entrance.

We here confirmed our former observations for the latitude : and the barometer rose; as also did the thermometer, from $21^{\circ}$ to $28^{\circ}$. The moulding of ice collected round the sides of the ship drifted off in consequence, during the course of the day, as did the icicles which had been formed on the icebergs. It still, however, blew hard: the sea continued to draw nearer to us, and the agitation was scarcely less; so that the motion of the ship was extremely troublesome. Our situation thus became so hazardous that we were about to seek a new position, close to the rocks : when, suddenly, we saw a fleet of heavy ice islands bearing down on us, which, by five o'clock, took their stations at the outer edge of the now narrow field, and, in a very short time, all was quiet.

Such is the ice, and such the compensation it offers for the too frequent assaults which it makes, and the obstructions which it creates. It is far from being an unmixed evil; and, estimating all our adventures with and among it, I might not be wrong in saying, that it had much oftener been our friend than our enemy. We could not, indeed, command the icebergs to tow us along, to arrange themselves about us so as to give us smooth water in the midst of a raging sea, nor, when we were in want of a harbour, to come to our assistance and surround us with piers of crystal, executing, in a few minutes, works as effectual as the breakwaters of Plymouth or Cherbourg. But they were commanded by Him who commands all things, and they obeyed. 
The gale continued, though with somewhat less violence; nor, Sept. 19. even towards night, was there any announcement of a change. We were safe within the large pack which had accumulated, and could now see additional masses of blue ice attached to its outer edge; the sea breaking high over them, in a tremendous manner. I therefore went on shore, and, having a good place for such a record, caused the ship's name and the date to be painted on the pyramidal rock formerly described: ascertaining the latitude at $70^{\circ} 23^{\prime}$, and the longitude at $91^{\circ}$. No immediate hope of a removal was held out by the state of the ice as we now saw it from the land; but there was very little snow on the ground, after all that appeared to have fallen, and the temperature was from $25^{\circ}$ to $27^{\circ}$. How much of the disappearance of this snow, on this, as on many subsequent occasions, arose from the mere sweeping force of the wind, we could not determine; but we had often, in this region, abundant proof of the great evaporation which it undergoes, even at very low temperatures ; confirming a fact respecting the production of vapour, which has long been known to meteorology. In no other way indeed could we account for the small thickness of snow which generally remained to be converted into water, by the common process of thawing, at the approach of spring; since its hard frozen surface very widely prevented the gales from dispersing it in the form of drift, while we were quite sure that a much larger quantity had accumulated during the winter than that which remained when the thaw commenced. On the utility of this arrangement in diminishing the great flow of water which would otherwise take place at that period, I need make no remarks. 
Sept. 20. It was comparatively moderate during the night, with the same wind, but no snow. At daylight a large pack of ice was seen approaching the bay, when it divided: one portion passing to the eastward of us, while the rest closed in, so as, in a few hours, to block us up more completely than we had ever yet been. After divine service, the crew were allowed such relaxation on shore as they could contrive in such a place: and the view hence still showed some clear water to the southward; attainable, if we could but obtain a westerly wind. The thermometer was at $27^{\circ}$, but there was no new ice in the harbour, although the land pools were frozen over. In the evening, the swell subsided every where, and at midnight it was calm and freezing hard; but the ice did not open, as we hoped it might do on the ebb.

Sept. 21. This ice still appeared stationary, there being a light air from the north ; and, on examination, we found that the huge masses around us were frozen together, giving us the prospect of being condemned to remain here for the rest of the winter. But the breeze becoming westerly at nine o'clock, all hands were set to work, and continued occupied the whole day in separating the masses which had been cemented by the frost, since this afforded us the only chance of getting clear. This being done, we placed the ship's head in the best position for getting out; and, after this, she was soon surrounded by new ice, the thermometer being at $25^{\circ}$.

Sept.22. A strong breeze arose during the night; and, at daylight, we found that, with the exception of two pieces, it had carried away all the ice that we had cut, while the water was clear outside. We again, therefore, set all bands to work in breaking the ice that 
remained, soon detaching many large pieces, which the tide carried away. The work, however, became more heavy as we proceeded; so that the last cuts through a thick floe were not completed till the evening. At this time a large mass to the eastward of us broke away, promising to sail off and assist in clearing us, when, unfortunately, it took the ground and remained fixed; and, still more vexatiously, just opposite to the channel which we were attempting to clear.

Thus we were obliged to make a new attempt at another point; appealing again to that patience, and exerting once more that determination not to be foiled, which, for ever wanted under every situation in life, are never more needed than by him who must work his way through the never ending, ever renewed, obstructions of an icy sea. By the time it was dark, we had completely succeeded, and had once more the satisfaction of finding ourselves in clear water; when we hove out beyond the icebergs, and made fast for the night to that floe which we had cut into the resemblance of a pier. Soon after this it began to blow hard from the southward, and the ice which had passed by was seen returning; producing, once more, a new enigma to be solved, as it threatened us again with a repetition of what we had been so often and so long undergoing. It became necessary therefore to go on shore, that we might the better understand how matters were likely to be with us now; since our position in the ship was not sufficiently commanding to allow of an adequate view. We thus found that the circumstances were even worse than we had anticipated; since we could not even get round to the good harbour which we 
had occupied before, until the weather should moderate. There was also seen some new ice, the thermometer being at $22^{\circ}$, and thence to $26^{\circ}$. By the time, however, that we had returned to the ship, the wind fortunately rose from the very quarter that we desired, being that which was best adapted for carrying away the ice; while, blowing with sufficient force to remove it, we were enabled to go to our repose under some hopes for the following day. Sept. 23. These hopes were quashed by the appearance of the morning. It had snowed hard since midnight, and every thing, land, rocks, ice, our deck, was deeply covered; while our intended passage outwards was blocked up by large pieces of floes and bergs; two more having detached themselves from the land to aid in the obstruction. The wind, indeed, had it been more moderate, would have been sufficiently favourable; and thence were we induced to renew our labours, in spite of the storm and every other discouraging circumstance. So successful also were they, that the passage was cleared by eight o'clock; at which time the gale began to abate, and the fall of snow to diminish; so as to hold out some better prospects than the early morning had promised.

We therefore undertook another survey from the shore, when we found that the north entrance of the harbour was still blocked up, but that there was much clear water to the southward. This induced us to go off in the whale boat, that we might survey the very intricate channel before us; leaving it to those on board to warp the ship out and get her under sail in the mean time. Thus we investigated the pilotage; and, returning at ten o'clock, we succeeded in carrying our vessel through, without any accident, in 
spite of a rapid tide and the numerous sunken rocks in the passage. The whole of this expedition, successful, if of little extent, was terminated in an hour.

It was our intention to have entered the harbour; but, on standing towards its entrance, we thought it probable that we might reach a few miles further, the current being still in our favour, though the wind was against us. We continued, therefore, to work along shore, and having passed the harbour at noon, reached the furthest point that we had seen from our last station. Hence, the land trended nearly due south, being more bold and rocky, and also more elevated than what we had hitherto seen : and here also we discovered an inlet some miles to the south, with high land on each side of it, which, on a nearer approach, proved to be full of ice. Near it there was some low land, which was conjectured to be an island, and, more towards the south-east, a decided one, which was the most distant land we had yet seen.

At four o'clock, being opposite the bay, we were obliged to force through two streams of ice, and, by seven, closed in with the island: when, having a favourable wind and current, we attempted to work up to the mainland. The coming on of night prevented this ; and we were compelled to run round a point on the island, where we secured ourselves to some heavy ice, about fifty yards from the shore, and in four fathoms water. It was far, indeed, from being a safe place, and, in an easterly wind, would have been a hazardous one: but, after much examination, we could find nothing better, and were obliged to be content. The snow continued the whole day, but was not such as to prevent us from seeing to distances of two or 
three miles : the temperature of the air rose from $26^{\circ}$ to $32^{\circ}$, but the barometer fell half an inch. By our reckoning, we had made about fourteen miles : an unexpected progress, which put us all into high spirits, and made us anxious for the return of another day.

sept. 24. Though the weather had been moderate during the night, the flood tide set in with great rapidity, and the iceberg to which we were fast received so many severe blows from the floating masses; that we began to suspect it would itself be carried off at high water, An alarm to this effect was indeed given : but, on examination, we found that it was the vessel which had sheered; on which she was moored to the rocks. The wind, which had been gradually changing during the night, became south-east at daylight; and we could then see from the island, that the ice was fast closing on us : so as to give us timely warning to quit a place where it was impossible to remain long with safety. We therefore made sail ; and, passing: to the eastward of the island, found a channel through which the tide was running with a moderate velocity. We then sent the boats to examine into this apparent harbour, and to select a place where we could make fast : but it was soon discovered that there was only a reef of rocks, so that we were obliged to moor to a large iceberg, within a few yards of the shore, and not far from a shallow entrance opening to the south-east.

As soon as the men had breakfasted, we prepared to remove again, when the boat should have found a better position. Suddenly, however, the ice turned round; and, before we could prevent it, the ship's bow was carried on the rocks with such violence, that it was raised eighteen inches. But as, at this time, the ice 



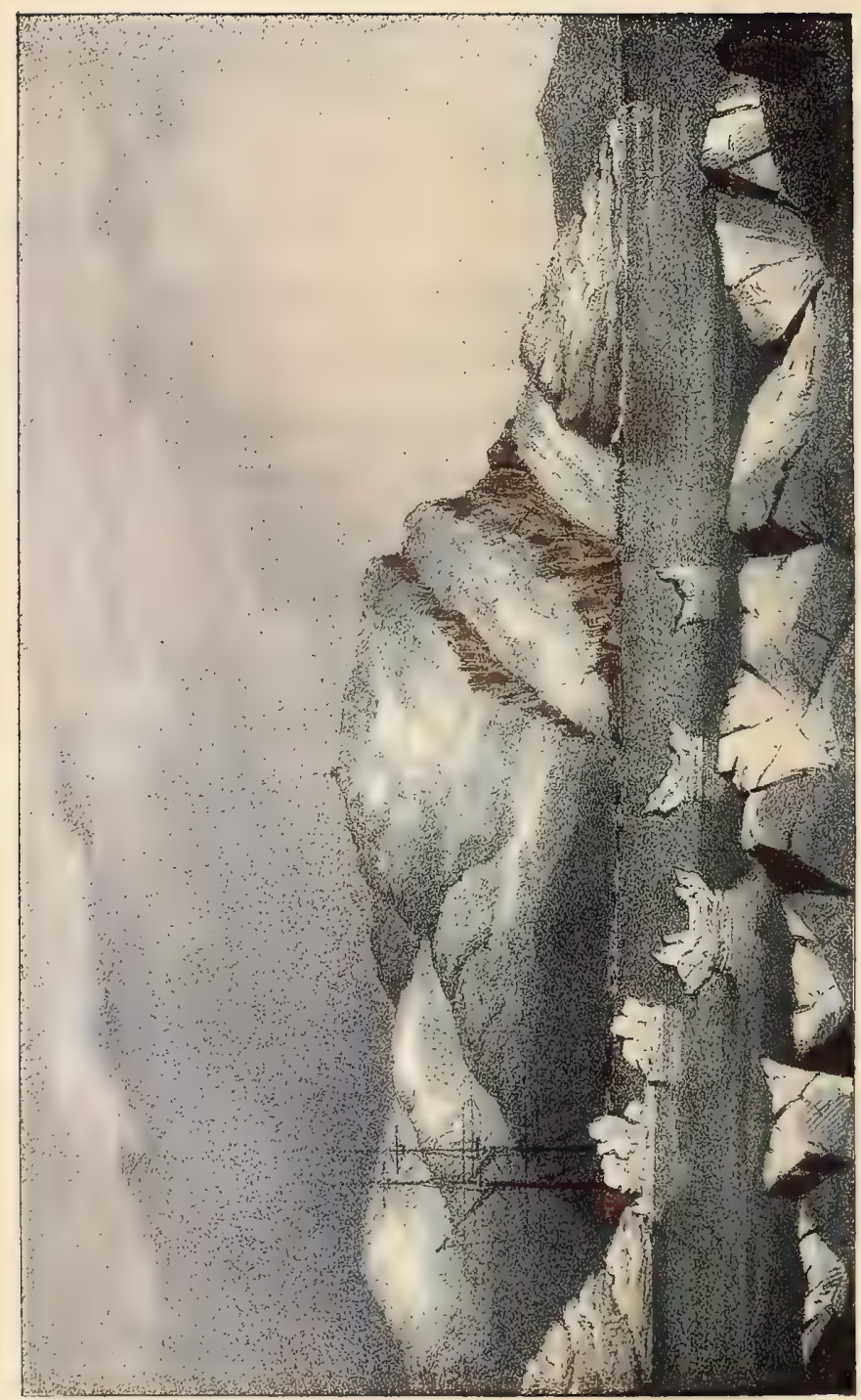

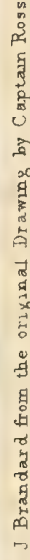

a

尔

$\cdot 1$

-

(1)

:

$\propto$

3

w

z

家

:

a 
grounded again, no further assault was made on her : and by means of hawsers, she was soon got off, without having sustained any damage. The breeze then freshening, the sails were set, enabling us to stand out with the intention of lying to while we waited the report of the boat.

But our success was very small ; since after running half a mile, with great difficulty, through rocks and icebergs, the situation which we attained, and did not gain without much toil and hazard, was found to be little better than that which we had left. It had but ten feet water; and we saw that we should not be able to haul out of the stream before the ship had arrived within her own breadth of some rocks that rose above the water; while her stern lay close to others that were not six feet beneath the surface. We therefore proceeded in the whale boat to seek for a better place, for which the now increasing wind made us more anxious; and thus succeeded in finding an excellent deep-water channel between the mainland and the first range of islands. The entrance, however, seemed extremely hazardous; being scarcely wider than the ship herself, with a tongue of ice, having only seven feet water on it, extending across, from side to side.

There was, however, neither a choice to make nor time to be spared in resolving. We therefore dropped the ship down by hawsers, grazing the rocks with our keel. How to carry her over the tongue was another problem, seeing that her draught exceeded its depth; but, while considering this, the tide swept her on it, and she stuck fast; it having proved, contrary to our reckoning, that it was now ebb. The hawsers were then carried out again, and we 
contrived to heave through; yet not without sawing off some projecting points on the two opposite icebergs, so narrow was the passage.

We did not, however, extricate ourselves from this perilous situation, without passing two other icebergs, one higher than our mast-head, and so close that the vessel had only half her breadth to spare. But, this achievement over, we had no further difficulty in sailing two miles through the channel, when we reached a place of security, and made fast to two large icebergs, out of the stream, and near the entrance of a good harbour. In this position there was a large island on each side, and, before us the mainland.

This mainland was what we had seen the day before, and displayed a high range of mountains close to the coast, extending in a north and south direction; while it seemed to trend in a more favourable manner than formerly, and no land was visible beyond the cape. We proceeded to examine and sound the harbour near us, together with the several entrances to it: but these latter were all blocked up, with the exception of the one to which we were opposite. Thus, after all, the place which we had first chosen proved the most convenient; and we therefore remained satisfied with the result of our day's work, and not thankless for our escapes through so hazardous a navigation. There was a little snow, and no bay ice was seen; the air and water both at $29^{\circ}$, and the wind, in the evening, coming from the north-east. We were here obliged to fill our casks with ice, as there was no fresh water to be procured. The land near us consisted, as usual, of granite.

The wind came to the northward during the night, causing such a rise of the tide that all the icebergs were set in motion. In con- 
sequence, they were shortly all carried off, except one which was kept in its place by our ropes. In the morning it was clear, and we saw, from the mast-head, a good deal of open water to the southward, forming the receptacle of the ice, which was sailing out of this narrow channel. Thus we at first thought that it would clear itself, so that we might perhaps proceed by noon: but the unlucky arrival of a large pack of ice at the northern entrance, not only filled it up once more, but produced a general stoppage which compelled us to remove the ship further within the harbour.

In the afternoon we landed and took formal possession of the island to which we were now moored, giving it the name of Andrew Ross, being that of my son. From the cairn which we built, we obtained a very extensive view, and saw land bearing south of us at a distance of eighteen or twenty miles; yet not so as to ascertain whether it consisted of islands, or was a continuation of the land near us, and the American continent. Much clear water was also seen in the same direction; giving some prospect of a further progress, in case the wind should come to the northward, and enable us to clear the channel by which we were imprisoned. A sketch being taken, the islands were named.

The last night's gale had so blown away the snow, lodging it in the ravines and hollows, that the land seemed comparatively clear, and the island on which we stood was so bare as to show its clean granite, without a mark of vegetation. A slight fogginess in the direction of the newly-seen islands continued to render the view of them indistinct; and, in the evening, the weather was quite moderate, with a temperature of $24^{\circ}$, though without the formation of 
any new ice. The harbour having been at length quite surveyed, was found to have fifteen feet at low water, with an even muddy bottom, to be free of currents, except in the main channel, and secure from every wind. Where the current did run, it was, indeed, very powerful; carrying the ice through it with fearful velocity and tremendous collision. Except a glaucous gull, we here saw no animal.

Sept. 26. Though calm and clear after midnight, and the thermometer not more than $27^{\circ}$, no new ice was formed in the still water, and the tide carried away the greater part of that which had occupied the channel. But, at nine, it began to come in at the northerly opening; which, with a north-easterly breeze and a heavy fall of snow, put an end to all prospect of advancing for this day. Soon after dark, the temperature fell to $25^{\circ}$; and the snow continued to fall; but, under the influence of the tides, the ice began to clear away in both directions. An increase of wind forced us to carry out additional ropes, and the Krusenstern was also moored in a place of security.

Sept. 27. During the night it blew a very hard gale from the northward, and the tide rising high in consequence, all the icebergs were set in motion. Our strongest hawser slipped off the rock to'which it was fastened, and obliged us to let go an anchor, as it was dark : but when daylight came, we transferred the former to another rock, and got the anchor up again. It was then seen that the channel was closed with ice at both ends; and thus it continued the whole day, though having some clear water in the middle, at its widest part. A good deal of heavy ice came to the entrance of this little 


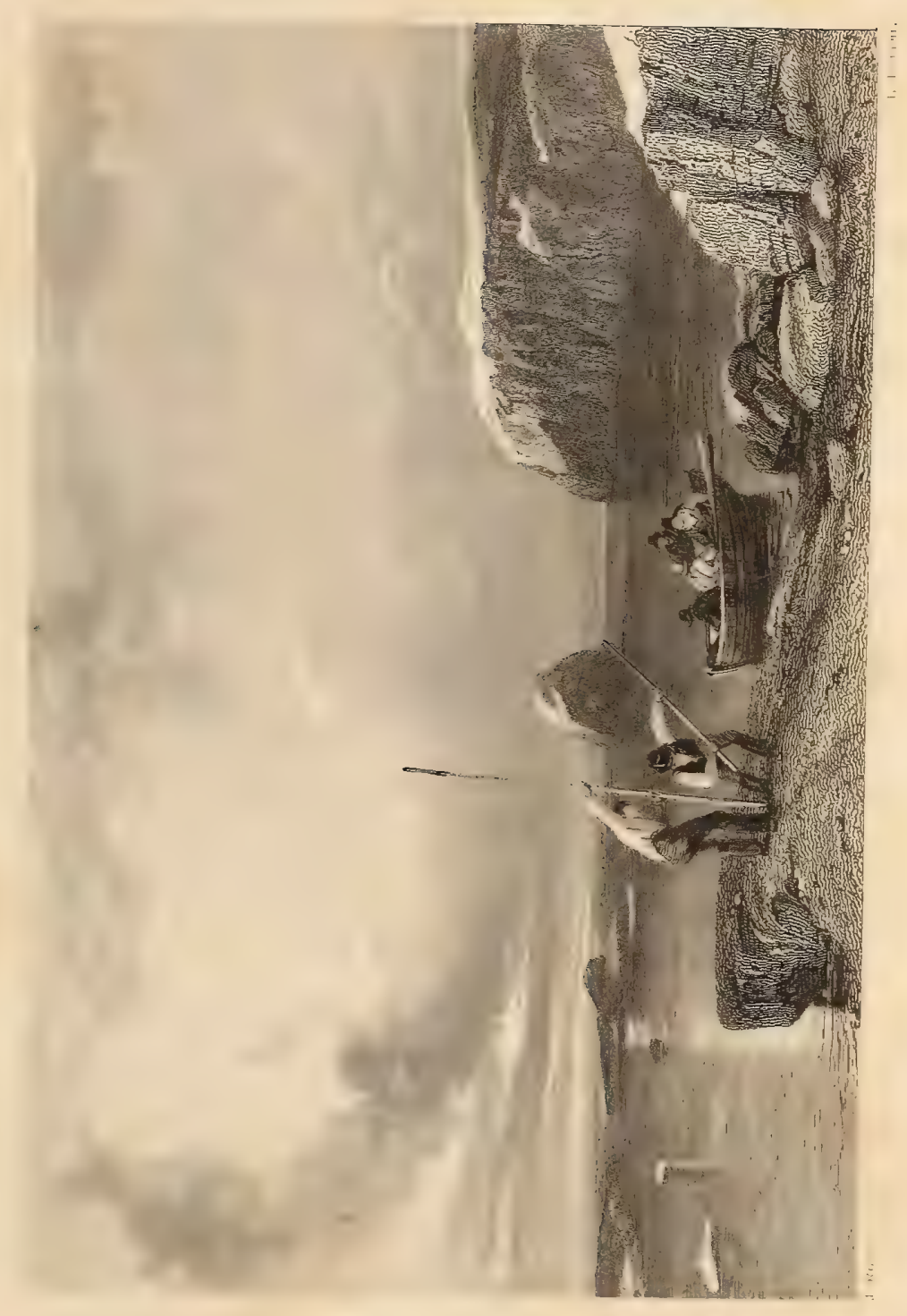



harbour, but did not reach our own clear water, on which no new ice was formed, in consequence, probably, of the gale.

After muster and prayers, part of the crew was sent on shore for exercise, and the remainder in the evening. Being with this last party, we saw that in spite of some open sea, there was no chance of our being released from our present situation without a change of wind. We had time to walk over this island, which is the largest of the group, but found no vegetation, nor any animal; though, on the following morning, we killed a seal and a glaucous gull. The temperature of the air and water equally, was $29^{\circ}$, and it came on to blow hard from the north-west soon after we got on board.

Though the wind veered to the west during the night, it did not sept. 28. release us, as we had hoped. The ice, indeed, had drifted a considerable way off the coast, but our channel was still locked up. Besides this, there was much heavy ice driving up and down, with great velocity, before the tide, which, even could we have got out, it would not have been prudent to encounter. Some of these masses, indeed, entered the channel, sweeping it clear from side to side for a time, as some of them blocked up the entrance of our harbour. A survey by the boat, however, showed at last that we might get out at the southern entrance, if we could release ourselves from the prison that now enclosed us.

Though it was moderate all day, the barometer fell an inch, prognosticating what soon occurred. Accordingly, we were visited by a very heavy gale, in the evening, from the north-north-west, with a snow storm, which obliged us to carry a cable to the rocks, and another to the next iceberg, for the sake of keeping it between 
us and the shore, in case any shift of wind should drive us on the rocks from which we were not many yards off. The thermometer was at one time $22^{\circ}$, and rose to $28^{\circ}$. We examined the island to the south of us to-day, but found nothing on it to attract our attention.

The snow storm continued without intermission all night; but, in the morning, it had so far cleared away the ice as to render the passage navigable. The state of the weather would not, however, permit us to get under way, since no canvas could have stood against the gale. Towards noon, and in the evening, the wind was in squalls, and the snow ceased to fall; when such was the effect on the land, as to blow away the snow by which it had been previously covered. The thermometer was at $23^{\circ}$ in the middle of the storm, and did not sink below $21^{\circ}$ : while, in the evening, the barometer began to rise. By this time the entrance of the harbour was cleared, and all the new ice and frozen snow were dispersed. After the tide had risen, it continued the whole day at nearly the same elevation, marking that effect of the winds which we had more than once before noticed. The latitude was observed at $70^{\circ} 12^{\prime}$, and the longitude, uncorrected, at $92^{\circ} 21^{\prime}$. No one could leave the ship during the whole of this day.

Sent. 30. The storm abated gradually during the night; and at five, being daylight, it seemed sufficiently moderate to warrant an attempt to get out: the channel, to the southward, being nearly clear of ice. Accordingly, the cables and hawsers were cast off, and at six we got under way, with the Krusenstern in tow. Though the tide in the channel was setting north, or against us, the northerly breeze 



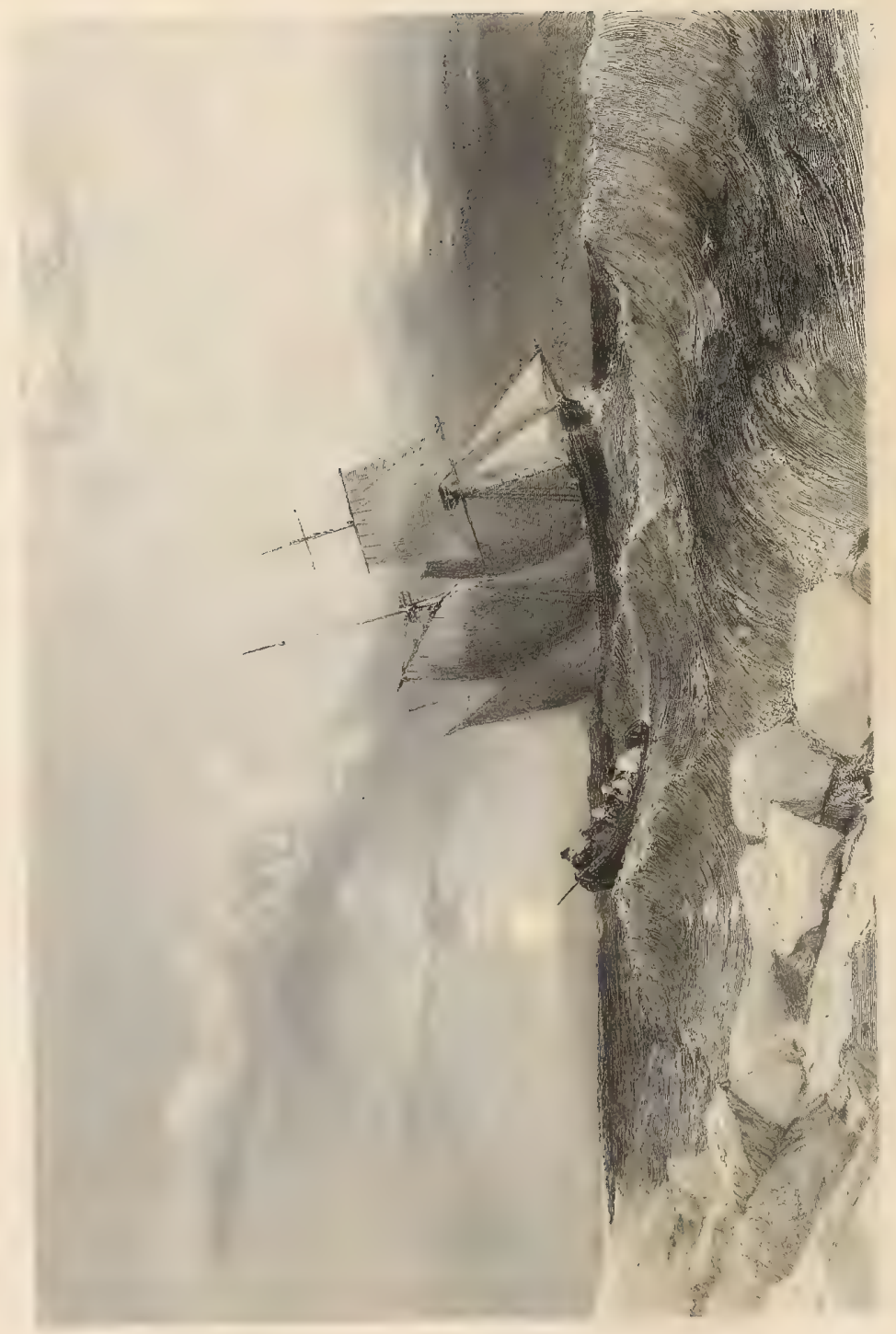


with us was sufficient to make us run through it at the rate of five miles an hour; estimating the current, at the same time, at half that quantity. At seven we passed the southern entrance of the harbour and the south-east opening of the channel; finding the tide stronger as we advanced, and most rapid in the narrowest part, as might have been expected.

It was now necessary to know more of what was likely to follow, since we had arrived at the boundary of our present knowledge; and we were, therefore, in great anxiety to discover the trending of the land; watching the westernmost cape, and every successive point that opened as we advanced. We found that the distant land which we had seen between the round island and the main, was a cluster of large islands, and that the coast was trending to the westward. At eight we had rounded the cape; successively opening out seven points, of which the fifth marked the place of a large inlet or bay, which, on our approach, we found to be full of ice. A bay beyond the second point seemed also to offer a good harbour: while we further noticed a remarkable inlet, with what appeared to be two islands at its entrance. These several places were named; but I need not here give what will be more usefully seen in the chart and tables.

Our distance gradually increased, in running down the coast, from a hundred yards to two miles; and, at noon, the great body of ice was seen extending from the shore about two miles north of the extreme point of the mainland, to the islands southward; thus completely obstructing all further passage, since it consisted of very heavy masses most closely packed. We had run seventeen 
miles; five to the south and twelve to the south-west: and we now, therefore, tacked and beat up to the land in search of a harbour, detaching a boat as we approached, to sound and seek for a safe position: while, in the mean time, we made fast to a neighbouring iceberg, but in a situation that could not be trusted, from the small depth of water.

The boat discovered, to the north-eastward of our place, a spacious bay, but open on three points of the compass; and, to the south-west, an island which offered a place of security, having a rock above water to the south, with a shallow ridge near the northern entrance. This position we therefore took; making fast to two icebergs, and under protection of the islet, so as to be not more than a quarter of a mile distant from the barrier of heavy ice, which we could now better see to consist of hundreds of icebergs wedged together into a solid mass. We had passed, in our course hither, some large pieces which were sailing to join this threatening barrier, and had also been obliged to force our way through some pancake ice, as it is termed, so dense as to give us considerable trouble.

The thermometer was from $23^{\circ}$ to $25^{\circ}$ in the day, but in the evening it became calm, when the temperature suddenly fell to $18^{\circ}$. At sunset, the weather was very clear, and high land was seen beyond the point, at the distance of ten or eleven leagues, bearing south-west, and extending to the eastward of south; but, whether connected with the land near us, or not, we could not discover. The large islands bore from east-by-south to south-south-east, at about nine miles distance, and were surrounded by heavy ice, separated from them, in one place, by a small line of water. 
The aspect of the land had now considerably changed. It was far lower than those parts of the coast which we had already examined, and the general surface was much more even. There was some vegetation on the little island, and we observed recent tracks of the hare and the ermine. Here also were two circles of stones, being the remains of the summer habitations of the Esquimaux, but of a much more recent date than those we had seen before. Though there was snow, the greater part had been blown into the ravines and lee places, which allowed us to see that the rocks consisted of red granite. One track of a bear was afterwards found near the place where we were moored, and many seals also made their appearance. As no observations were taken, we were obliged to estimate the latitude, by our reckoning, at $70^{\circ}$, and the longitude (uncorrected) at $92^{\circ} 40^{\prime}$.

With the termination of September, of which we had now reached the last day, I considered that all hope of making any further progress this season was at an end. And thus I entered that opinion in my journal; adding to it those remarks which I now transcribe without alteration, because they better show the impressions and opinions consequent on our proceedings and situation, than aught that I might have written at a later period, or should write now.

"My full conviction is, that in every voyage of this nature, the safety of the ship ought to be that prime consideration to which every thing else should yield; since, upon its preservation, the chance of success depends in a greater degree than in any other navigation; though, in every case, the same proposition is, to a 
certain extent, true. And, on a calm review of what is just past, $\mathbf{I}$ have reason to blame myself for not having acted up to this principle with sufficient steadiness. A not unnatural anxiety to proceed has often induced me to push forward as soon as there appeared any probability of creeping along shore: yet $\mathbf{I}$ have been comparatively justified in doing, in a small ship, what would have been infinitely more imprudent in a large one; as it is partly for the sake of those who may hereafter renew these attempts in larger vessels that I make this remark.

"But, justified or not, every thing which has occurred has proved that nothing was gained by this ambition and impatience: it was fighting against the unsurmountable obstructions of climate; against winds and currents, and ice and rocks; against nature herself, daily threatening to draw the boundary which we were not to pass. It is now plain, (and let future navigators in these seas profit by the remark,) that had I patiently waited, in numerous instances, until sure of reaching a place of refuge, we should have attained our present position far sooner than we have done, and with far less of toil and anxiety and hazard. But it is nevertheless plain, from the state of the ice, that although we had reached this point much earlier in the season, we could scarcely have succeeded in making any important progress further before the winter. As far as our operations for the following season are concerned, we are probably in as good a position for deciding, here, as we could have been, though more advanced : being also, while three hundred miles further than any preceding expedition, not more than two hundred and eighty miles from the coast laid down by Captain Franklin." 
" On the mode of navigating in these seas, I may here also declare my now acquired conviction, that where there is no harbour, and the ice is setting along the shore, there ought to be no hesitation in taking a position in the pack, especially when a ship is near the land. It is, in reality, the most secure proceeding; and, although the consequence may often be a retrograde movement, that is not to be put into competition with the safety of the ship; while we never experienced any difficulty in extricating ourselves sooner or later. I am earnest in enforcing this doctrine on navigators, because the reverse opinion is rooted; as the consequence of the opposite practice is, to keep a vessel in a constant state of actual, as well as apprehended danger, or anxiety. And this is, in fact, the source of all the dangers and narrow escapes of which we read; while a little care and patience would generally avoid that frequent casualty, the being beset in the ice. A little reflection should indeed show, that it is not within the power of a ship to force herself through such obstructions : and thence do I recur to the conclusion, that it is imprudent, as well as idle, to be perpetually pushing on to reach every tract of open water, unless it can be done without risk; and unless also there be a prospect of retaining the ground that has been gained, or of making a determinate progress.

"It is indeed true, as it may be answered to these remarks, that it is the business of a ship to seek for a harbour, especially after a long run, and on an unknown coast. But it is generally easy to send boats on this duty, with little or no comparative hazard, when there are prospects of refuge on shore: while, instead of thus endangering the ship, it is, as I have already recommended, the 
safest, and indeed the only prudent practice, to take to the ice. This is, if I mistake not, the refuge furnished by Providence; and he who neglects it, still trusting to Providence to escape the dangers which he unnecessarily incurs, must not complain in case of failure; since he has not exerted his utmost care and prudence to render himself entitled to that protection. Let that be kept in mind by him at least who may hereafter attempt a ' north-west passage :' and let him never lose sight of the two words, caution, and patience." 


\section{CHAPTER XII.}

REMARKS ON THE PRESENT CONDITION OF THE SHIP, AND PREPARATIONS TO REDUCE THE ENCUMBRANCE OF THE ENGINEUNRIGGING OF THE SHIP-A SUCCESSFUL BEAR HUNT-ASCERTAIN THAT WE ARE TRULY FROZEN IN FOR THE WINTER-A POWDER MAGAZINE ERECTED ON SHORE-PROVISIONS EXAMINED -THE GUNS AND PARTS OF THE ENGINE HOISTED OUT.

BEFORE proceeding with the journal of the following month, 1829.

I must offer some remarks on the actual condition of our ship, especially as regards the engine. The record of the last weeks has already shown that we had ceased to consider her as aught more than a sailing vessel: and it is also true, that whatever advantage we had latterly derived from our machinery, it was not greater than we might have obtained from our two boats, by towing. But, thus rendering us no service, the engine was not merely useless; it was a serious encumbrance; since it occupied, with its fuel, two-thirds of our tonnage, in weight and measurement. It had been, from the beginning, a very heavy grievance in another way, and in addition to the endless troubles and vexations which $I$ have already recorded; since it demanded and employed the services of four persons, who 
were necessarily landsmen, not sailors: thus cramping, very seriously, the number of our real, or nautical, crew. As the engine, moreover, had been considered the essential moving power in the original arrangement of the vessel, the masting and sailing had been reduced accordingly, since it was presumed that the sails would only be required in stormy weather; so that, in fact, she was almost a jury rigged ship. To add to all these disadvantages, she had, under this imperfect power, the heavy duty of towing a boat of eighteen tons, a dimension equalling one-fourth of her own: the whole comprising a mass of obstruction and encumbrance which we certainly as little expected as we had foreseen when we quitted England.

If with all this, we had not less reason to be thankful for the progress we had made, than really to wonder at our success thus far, these were not things to make us shut our eyes to what it seemed now most needful to do. In future, our ship was to be a sailing - vessel, and nothing more. I therefore determined to lighten her of the most ponderous and least expensive part of this machinery, and to apply, towards strengthening the ship, whatever might seem available for that purpose. With this view, arrangements were made on the last day of September, for taking to pieces the boilers, that we might land them as soon as the ship should be frozen in; an event that could not be distant; while, to this, I had more than the concurrence of every officer, and, probably, that of every man. It is true that we thus consented to reduce ourselves to a degree of power far inferior to that of any preceding vessel engaged in these services; but, in reality, that evil had already occurred against 
our will, and our voluntary act of self condemnation was, after all, little more than a form.

During the last night, the thermometer fell to $17^{\circ}$, threatening us Oct. 1. with having reached our last position for this season; but, towards daylight, the weather became cloudy, and the temperature rose to $21^{\circ}$, with a fall of snow, which continued the whole day. We were thus, however, prevented from ascending the high land near us, and, thence, from making those observations on the state of the coast and the ice, which were indispensable towards any further attempt at proceeding. We could do nothing more therefore than sound and survey our little harbour; and were pleased to find that if we should really be frozen up in this spot, we should find it a safe place, after making some alterations in it, by clearing away the heavy masses, and sawing into the bay ice, which was now six inches thick. The snow ceased at night. A very recent foxtrap was found on the shore: and as the seals were very shy, while numerous, it was a natural conclusion that the Esquimaux had not long quitted this place.

Though the morning was cloudy, it was not an unfavourable Oct.2. day for an inland excursion. We landed on the north side of the harbour, as the ice was not such as to enable us to cross it to the southern one, which was, to us, the important point. After passing a valley containing a frozen lake, I ascended a high hill, and. thence discovered that a creek which had caused us to make a circuit, was an inlet running about six miles within the land, in a north-west direction. Here I also saw the head of the great inlet which we had observed on the thirteenth, surrounded by land 
appearing considerably higher than that to the south-west, which consisted of a succession of uniform low hills. Beyond this land I could see no water. To the south-east, there was a perfect view of the islands that we had passed on the thirtieth of September, together with some land to the eastward and southward, which was probably the American continent; though this point could not then be determined, any more than I could ascertain whether it was a continuation of that on which I was now standing.

At present, it was more important to know what the state of the ice was, and what it was likely to be; but what we saw gave us no hopes of any further progress. We were at a stand. We had indeed long suspected that the event which could not be very distant, was impending, nor could we, in reason, be surprised that it had arrived. Yet we had been busy and active up to the present point, and our perpetual efforts had, as is usual in life, prevented us from thinking of the future, from seeing that the evil which could not for ever be protracted, was drawing nearer every hour, that it was coming every minute, that it was come; thus nourishing that blind hope, which even in the face of inevitable danger or of certain ruin, even on the bed of death itself, is the result of effort and resistance; that hope which ceases only with the exertions by which it was supported, when the helpless ship falls asunder on the rock, and the sun fades before the eyes of the dying man.

It was now that we were compelled to think, for it was now that there was nothing more to be performed; as it was now also that the long and dreary months, the long-coming year I might almost say, of our inevitable detention among this immovable ice rose 
full in our view. The prison door was shut upon us for the first time; while feeling that if we were helpless as hopeless captives, that not even Nature could now relieve or aid us, for many a long and weary month to come, it was impossible to repel the intrusion of those thoughts which, if they follow disappointment, press on us ever more heavily, under that subsidence of feeling which follows on the first check to that exertion by which hope was supported. Should we have done better, been further advanced, have passed through these difficulties, and more, should we have passed all, and found ourselves where we wished, forming a junction with the discoveries to the westward, had the engine not disappointed us, had we been here, as we ought to have been, a month or six weeks sooner? Was it the badness of our vessel, a complication of defects not to have been foreseen, which had prevented us from completing the outline of America, from ascertaining the "northwest passage" in a single season? This was the thought that tormented us; and not unnaturally, when we recollected all that we had endured, all our delays and disappointments. But, like that self-tormenting under which mankind make themselves so often fruitlessly miserable, these thoughts were purposeless, and worse; so that we hastened to discard them as they arose: aware, on reflection, that we could not see into the distant and the future, that we could not speculate on the nature of the land before us, could not be sure what the ice had been before our arrival, and could, therefore, as little know, whether there was a passage westward to be found in this direction, as whether we should have been one foot further advanced, had every thing we desired conformed to our wishes. 
We saw here many tracks of hares, and shot some which were, even at this early period, quite white: this needful change taking place, as should now be well known to naturalists, long before the ground has become permanently covered with snow, and long before the weather has become truly cold; proving that it is, at least, not the effect of temperature, as it is assuredly a prospective arrangement for meeting the cold of winter. The track of a bear was also found; and, in the interior, we could see, even through the snow, that the plains were covered with vegetation; while the protruding rocks consisted of red granite, accompanied by fragments of limestone near the shore; indicating a continuity of the same geological structure that we had traced ever since entering this strait. There were many Esquimaux traps, with a great number of those cairns, or stones, resembling men when at a distance, which these people erect for the purpose of frightening the deer within their reach. In this space, amounting to five miles, which we had traversed, there were two large lakes.

Oct. 3. During our yesterday's excursion the men nearly demolished the iceberg which chiefly obstructed our possible exit, so that it was hove out into the tideway before five o'clock; but as it continued calm, with a temperature of $20^{\circ}$, there was little chance of proceeding, even after this impediment was surmounted; since, in this state of things, the new ice could not fail to set us fast. This morning the temperature promised even worse, being only $13^{\circ}$ : but, during the day, it rose to $21^{\circ}$, the weather being clear and moderate. Landing again, we reached the summit of the highest accessible hill at noon : but the sight of the horizon from it was 
imperfect, and we could decide on nothing, though what we did see was by no means of a promising nature. The ascent of a second hill disclosed nothing but a vast extent of land from the north-east to the south-west, with no space of water but that where we lay, and which resembled the bottom of a great bay. We again saw the tracks of hares, and that of a white bear, together with those of ermines and foxes; picking up, moreover, the horns of: a reindeer.

The state of the ice was however the important consideration; while knowing too well how difficult it is here to judge of the nature and connexions of the land, I was fully aware that we could not form any decisive conclusions from what we had yet seen. The former appeared nearly in the same state; and we had now even more reason to believe that the great pack was so firmly cemented for the winter, that it would separate no more. Of the land I was determined to acquire more knowledge, if that should be possible, by travelling as far as it should prove accessible. Our ship was not absolutely frozen in; but she was placed in the most desirable position that could be found, in case of that event occurring; as we had now so much reason to expect.

As to the nature of the land thus traversed, it differed little from what we had already examined; though more uneven and rugged. The valleys, as before, included lakes; but those which we saw were but a few feet deep, and seemed to contain no fish. Angles were taken from a cairn erected on the highest hill, together with the usual observations. In the mean time, the men on board were employed in taking the engine to pieces, for the purpose of landing 
it, the dogs were exercised in the sledges, and other preparations for wintering were made. The thermometer, in the night, sank to $16^{\circ}$ with a fall of snow, while the air had a peculiarly raw and cold feel.

Oct. 4. The morning temperature was $13^{\circ}$, but it rose to $17^{\circ}$ at noon, and the snow ceased. Being Sunday, divine service was performed, and the men were sent on shore for exercise, when some ptarmigans were seen. The ice had but little increased, and there was still much open water to the north-east, with some to the southward, though the heavy pack which lay in our way remained in the same state. There was more snow on the hills, yet the approach of winter was much more gradual than it had usually been found in these climates.

Oct. 5. The men were employed in unbending some of the small sails and in unreefing the running rigging, while the engineers were busied in continuing the work which they had commenced on Saturday. The temperature rose from $14^{\circ}$ to $17^{\circ}$, but fell again to $14^{\circ}$ in the evening; and there was open water not very far from the ship. The dogs were again exercised, and a fox was seen on the ice, being the first that we had met with. An aurora borealis was observed at one o'clock, and the barometer rose to $30^{\circ} 73^{\prime}$. The weather, at the same time, became so thick as to render it hopeless at present to get any further sight of the land; and as we were at length quite frozen round the prospect of advancing became less and less every hour.

Oct.6. A fresh breeze of wind made the last night colder than any which had preceded; and, in the morning, the temperature was at 
$12^{\circ}$; rising in the course of the day to $14^{\circ}$. We now therefore proceeded to cut the ice, so as to get the ship into what we considered the position of greatest safety for the winter; a work which occupied the whole day. There was still a little open water to the northward: not much snow fell, and, in the evening, the wind shifted to the south, by blowing fresh.

The tedium of this day, the forerunner of many far worse, was enlivened by a successful bear hunt, being the first chance of the kind which had occurred to us. The animal, having approached the ship, was turned towards the island; and in this way our party was enabled to cut it off from the land. Thus imprisoned, we turned our Greenland dogs on it; but they proved to be of no use, showing nothing of the instinctive desire to attack this animal, which is so general in their race. It was then chased to the water; where, plunging into the new-formed ice, it could make little progress, and was, consequently, overtaken by the skiff and killed. Being brought on board, it proved to be a female of a medium size; measuring six feet eight inches between the nose and the tail, and weighing five hundred pounds.

After a fine morning, the snow came on at eight; but the Oct.7. weather was so much milder, that the thermometer rose from $12^{\circ}$ to $21^{\circ}$. The sawing of the ice was finished at noon; and the ship, being hauled in, was placed with her head to the northward, between the island and the main, so as to be quite defended, both from the eastern and western blasts. With land also toward the north, and the rock to the south-east, she was open to only three points of the compass, so that we had reason to be pleased with 
our success, where no great choice could have been commanded at any time. The depth of water was thirty-three feet: and as there had been a current as long as there could have been one, we had a right to conclude that it would return with the summer, and expedite the disruption of the ice, so as to assist us in getting out, whenever that season should arrive. The boats were now therefore landed, the decks cleared of ropes and spars, and the other needful arrangements made for housing the ship during the winter.

Oct. 8. There could, in fact, no longer be the least doubt that we were at our winter's home; if we could indeed have reasonably doubted this some days before. But, as I have already said, it was a time to come, sooner or later; and if we had, within this last week, found reasons enough to feel neither surprisenor disappointment, so, as I had concluded at our first entanglement in this place, were we far from being sure that we had any thing to regret. We could not, indeed, expect to lead an active life now: we did not even know that we should find any thing useful to do: but it was our business to contrive employment, and to make ourselves as easy and as happy as we could, under circumstances which we had ample reason to expect. We were, I believe, all pretty well provided with patience, and there was no reason to want hope; it was for after years to draw somewhat deeply on the former, and to prove, of the latter, that more, perhaps, depends on a fortunate constitution than on aught else.

Our conviction was indeed absolute; for there was now not an atom of clear water to be seen any where; and excepting the occasional dark point of a protruding rock, nothing but one dazzling and monotonous, dull and wearisome extent of snow was visible, 
all round the horizon in the direction of the land. It was indeed a dull prospect. Amid all its brilliancy, this land, the land of ice and snow, has ever been, and ever will be a dull, dreary, heartsinking, monotonous, waste, under the influence of which the very mind is paralyzed, ceasing to care or think, as it ceases to feel what might, did it occur but once, or last but one day, stimulate us by its novelty; for it is but the view of uniformity and silence and death. Even a poetical imagination would be troubled to extract matter of description from that which offers no variety; where nothing moves and nothing changes, but all is for ever the same, cheerless, cold, and still.

Amid all this, it was a satisfaction to find that every one seemed pleased with the progress which had been made. It was indeed far short of what had at first been expected; but on examining what had been done, much more quietly and far more in detail than we had been enabled to do in our first reflections under this obstruction, and on comparing that with our numerous impediments and misadventures, the view now taken was not less reasonable than gratifying. We could not forget the days when we should have thought ourselves fortunate though we had only reached Port Bowen in this season, and though we had failed in attaining to the wreck and the stores of the Fury. But when the chart was at length displayed before us, we saw that we had not merely reached this great point in our voyage, but had passed it by a hundred and sixty-six geographical miles, and were two hundred further than that harbour where we had expected to be laid up, if we had even attained that spot. Nor was it less satisfactory to reflect on the 
numerous dangers which we had escaped, in navigating passages so truly intricate and perilous, under the gales that we had evaded, and through the ice which had been rendered our slave rather than our master. Thus comparing and considering, as we had at length ample time and much reason to do, we came to the tranquillizing conclusion that we were now become a little united and settled family; all equally zealous and equally patient; all ready for new difficulties whenever they should occur, and, while all thankful for our success, all, whose duty it was to obey, giving obedience with a good will, or an alacrity, which might not have been equally conspicuous under positive martial law.

During twenty-four hours the gale was fresh from the east-southeast, with driving snow, which was inconvenient as far as our works were concerned; but the thermometer being at $\mathbf{2 4 ^ { \circ }}$, the cold was not severe. The men were employed in clearing the hold and measuring the remaining fuel, and the engineers were busied on the engine: while the carpenters were at work in making alterations in the cabin, to secure us better from the cold. We had not lately been able to keep it higher than $28^{\circ}$, in consequence of the position of the door; but by these alterations we could now keep it at $45^{\circ}$, and had no desire for a higher temperature. This is sufficient to keep off damp: and in this climate, that is a circumstance more to be avoided than mere cold. We boiled the blubber of our bear and some seals, on shore; but the smell attracted no foxes or bears, so that we believed there were no animals at this place.

Oct. 9. The snow ceased this morning, and the thermometer rose from $19^{\circ}$ to $25^{\circ}$, the sun shining bright during the day. The engine was 
nearly taken to pieces; and, by throwing down the bulk head, the seamen's accommodations were materially extended. Observing some large holes of water to the south-west, we went to examine them, and found them varying from twenty square yards to an acre, in extent, with a strong current boiling up at their western sides, and running towards the east, in which direction their longest dimensions lay. During the whole day this current remained the same; a fact which puzzled us, as we were obliged to postpone the determination of its real nature and cause to the ensuing summer. If there were any among us who had theories of springs here rising in the sea, or rivers running into it, they are not worth the trouble of either detail or examination.

Towards evening the wind came round to the northward, and the thermometer fell to $13^{\circ}$. A seal was shot, but was lost by sinking; and the skeleton of the bear having been sunk in the water that it might be cleaned by the marine animals, wasbrought up with some shrimps and shell fish attached, to increase our small collection of specimens. This was the only perfectly clear night we had seen since our residence in these straits; and, the moon being full, the aspect of every thing was unusually cheerful.

The northerly breeze had blown hard, but subsided towards oct. 10. morning, so as to leave us a bright and clear day; the sea horizon, however, presenting a thick fog. Nothing remained standing on board but the lower masts with their rigging. An excursion on shore led us to a rude stone of a columnar form, erected by the Esquimaux, but for a purpose that did not appear; and we observed the tracks of foxes. A small quantity of clear water was 
still seen to the northward, as well as in the openings already mentioned; but we could conjecture no cause for this current. In the day the temperature was $15^{\circ}$, falling to $10^{\circ}$ at night. The latitude was settled at $69^{\circ} 58^{\prime} 42^{\prime \prime}$ and longitude $92^{\circ} 1^{\prime} 6^{\prime \prime}$.

Oct.11. The sky being overcast, the thermometer rose to $18^{\circ}$, but, even at this temperature, it did not feel cold, as the breeze was moderate. The ship's crew were mustered in good health, excepting $\mathbf{R}$. Wall, who had fallen down into the engine room, yet without any serious injury. After church service, the men were allowed their turns on shore; and, in their walk, they set up a landmark for the ship, about four miles off on the coast. The wind freshened at night, and the thermometer fell to $11^{\circ}$.

Oct. 12,13. There was no material change. The work in the ship was continued, and a place for a powder magazine selected on the island near us, which was consequently named Magazine island. The hold being restowed, the fuel was measured, and found to amount to seven hundred bushels of coal and coke; being, as we computed, sufficient for the ordinary wants of the ship during the same number of days. A complete examination of the provisions also took place: and the result was, to find that there was enough for two years and ten months; on full allowance; a quantity easily made to cover three years consumption. The quantity of oil and tallow was found such as to promise a duration equivalent to that of the provisions; presuming, at least, on the further assistance that we had a right to expect from our captures of bears and seals, on sea and land.

The thermometer, on the twelfth, was $14^{\circ}$, falling to $10^{\circ}$ the 


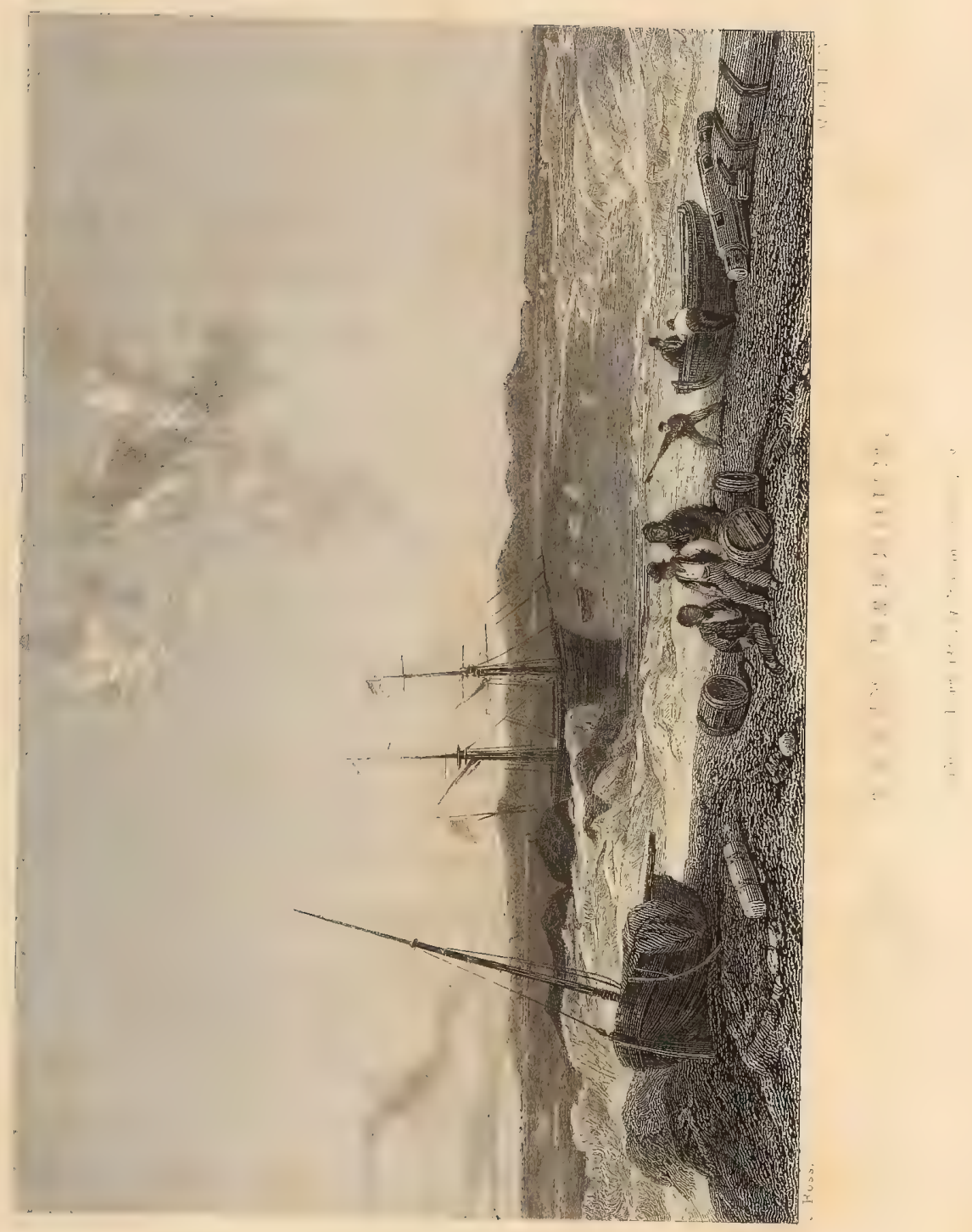



next day; and, again rising to $20^{\circ}$, it remained till late, not falling below $17^{\circ}$ at midnight; the weather becoming more and more cloudy, with an appearance of threatening snow. We thought ourselves fortunate in discovering here what might turn out a source of fresh provisions, in a large whelk, which had not been seen in the former voyages. Some unsuccessful attempts were made on the seals, and a part of the engine was hoisted over on the ice. The snow, on the following day, fulfilled its promise; Oct. 14. coming on very early in the morning, when the thermometer rose to $20^{\circ}$, and then to $22^{\circ}$, falling back to $17^{\circ}$ towards night. The brass guns were put on the ice, with more of the engine, and the lower deck was cleared of some spare stores, by stowing these in the hold. They who valued omens were left to speculate on the prophesying of a raven which flew round the ship. How far they did speculate, and what their prognostics were, I did not take the trouble to inquire; had they been either absurd or important, it is probable that I should have heard enough of them, without inquiring. 


\section{CHAPTER XIII.}

REMARKS ON THE ACTUAL TEMPERATURE AND ON THAT OF SENSATION-PROCEED IN LIGHTENING THE SHIP-THE ENGINE FINALLY LANDED, AND THE KRUSENSTERN SECURED-ROOFING OF THE SHIP COMPLETED-REMARKS OF THE TEMPERATUREABOLITION OF THE USE OF SPIRITS ON BOARD-CONTRIVANCES FOR WARMING AND VENTILATING THE VAPOUR BETWEEN DECKS -DESCRIPTION OF THE SEVERAL ARRANGEMENTS MADE FOR WINTERING, AS RELATING BOTH TO THE SHIP AND THE CREW.

1829. THE snow ceased before daylight, but it blew fresh from the north ; feeling very cold, though the thermometer was $18^{\circ}$; a temperature, which, but a few days before, had not been disagreeable. This difference is, very obviously, as it is vulgarly, explained by the different strength of the wind; while the immediate cause, on this supposition, is too simple to require statement. But there is much more to be taken into consideration; while some of the circumstances are either so little heeded, or so difficult to perceive, that if the reader is sometimes puzzled to explain the apparent contradictions in the reports on the actual heat and on that of sensation, they who feel that of which others read, are often not less puzzled themselves. I may as well state here, once for all, what 
has struck me when thinking on this subject; since the same collision of facts is likely to be of frequent occurrence, and the reader will be thus enabled to explain for himself, many future statements of the same nature, and save me the trouble of recurring to what I believe to be the philosophy of this subject.

Among these considerations, is the hygrometrical state of the air, of which we did not preserve any register; but this is not so simple a case as it appears at first sight. Every one knows that a damp air feels cold and raw; it is a better conductor of heat. Yet the same effect on the sensations is produced by the reverse condition of the atmosphere. A dry air increases the evaporation from the body, and that evaporation is a source of cold. Combining one or other of these conditions with the varying strength of the wind, we already see a certain way into the intricacy of this question; but that is not yet the whole, even as the mere atmosphere is concerned. The damp air does not, necessarily and always, produce a sensation of coldness, and, least of all, does it produce this effect when the weather is calm; since a fog, by checking the radiation of heat from the surface, may be more than an equivalent to the cold which its conducting power might cause; while it also acts in the same direction, in another manner, by checking the evaporation from the body.

But the state of the body itself is scarcely of less moment than all this, in any attempts to explain these apparent contradictions; as it complicates the whole question in a far higher degree. Every one knows that the sense of cold can exist in certain fevers, even under the burning sun of Africa; and the same internal sensation, 
as of a low temperature, is of frequent occurrence from other diseases, and moreover from derangements of health so slight as to be undefinable. It is far more remarkable, that the feeling of extreme cold can be present, under fever, when the temperature of the body is many degrees above the natural standard, and when, to the touch of others, the patient is burning hot; as, in the space of a very few minutes, it may appear the same to himself, though no change of the actual temperature has taken place.

Thus also, if the circumstances differ, does exercise, or the want of it, produce sensations of temperature, when there is nothing external to cause them; and the case is similar under want, or reversely, under abundance, of food. There are things which affect the power that generates animal heat; as the greater or less energy of this power is perhaps the chief cause of all the facts which are often so difficult of explanation under a simple regard to external temperature. That energy, too, is not the mere produce of food or exercise; there are cases, in which no allowance of food and no exertion of the muscular powers, will suffice to preserve a high temperature in the human body. In reality, though it is little remarked, and, as far as I know, is not even observed by the writers on physiology, the power of generating heat varies exceedingly in different individuals, and is as much a portion of the original constitution, as are the muscular or the mental energies. Any onewho pleases may observe this in common life; it was always striking to us, in circumstances where the application of the test was so often extreme; so that, after a little practice, it was easy to anticipate who would suffer from degrees of cold which others would despise. 
In mentioning this, $I$ am also, in justice to the chief sufferers in our crew, bound to observe, that I have myself been noted, by a physiologist of well-known reputation, as possessing in a very high degree, the power of generating heat, whence too, as he infers, that indifference to cold of which I was always conscious; together, consequently, with the very limited comparative suffering that I experienced during that long protracted winter, as I may fairly call it, which occupied four of the winters of England, yet such winters as England never saw and will never conjecture, together with five summers, of which every one would, in that country, be deemed severe beyond the severity of its own Januaries and Februaries. I must leave it to the reader to judge how far this constitution may have influenced my reports on the temperature of sensation, on many occasions; it is certain that I could not judge what others felt; but I could not have described what I did not myself feel.

These remarks are not mere matters of philosophical speculation, nor are they questions of amusement or curiosity alone. They offer useful hints to those who may hereafter engage in similar expeditions; since they deserve some among the first attentions in the selection of a crew. Other circumstances of apparent health and strength being equal, it is he who seems the readiest generator of heat who ought to be the selected individual ; for no one will know, until he has suffered from it, what disappointments and vexations and labours, and restraints to the service, follow from the susceptibility of cold in the individuals who may form the crew of a ship, on a service like this : to say nothing of the accidents, in mor- 
tifications and death, and in scurvy too, I have little doubt, which follow from the same canse. I know not, however, that I can give rules that will not produce disappointment, where the test of facts would be the really desirable guide. But this at least seems certain, that men of the largest appetites and most perfect digestion produce the most heat; as feeble stomachs, whether dyspeptic, as it is termed, or merely unable to receive much food, are subject to suffer the most from cold; never generating heat enough to resist its impressions.

Physicians must determine whether the strong digestive power and the heat-generating one are but parts of one original constitution, or whether the large use of food is not a cause of the production of heat; but what follows is at least practically true, as the reasons seem abundantly plain. He who is well-fed resists cold better than the man who is stinted; while the starvation from cold follows but too soon a starvation in food. This, doubtless, explains in a great measure, the resisting powers of the natives of these frozen climates : their consumption of food, it is familiar, being enormous, and often incredible. But it is also a valuable remark for those who may hereafter be situated like ourselves; since if these views are correct, as $\mathbf{I}$ believe them, both from experience and reasoning to be, it shows that no effort should be spared to ensure an ample supply of the best food.

Our system, whether in the navy or the merchant service, and in whatever parts of the world, be it the icy seas, or the tropical ocean, has been as fixed as it is uniform; and perhaps I ought not to blame those who have made regulations, when they did not know, 
and could not therefore take into consideration the grounds on which their orders ought to have been regulated. If the allowance of the food for seamen, under all possible differences of climate, or labour of service, technically speaking, has been fixed, and uniform, implying circumstances, and involving consequences respecting which I dare not here take room to speak, so, in the case immediately before me, have we been accustomed to fix the allowance of food, to restrict it, I may fairly say, through an experience founded on far other circumstances, or under a system calculated from very different data.

The conclusion therefore in which $I$ wish to rest, willingly as I would have extended these remarks, and perhaps then extending them so as to produce the greater conviction, is this; namely, that in every expedition or voyage to a polar region, at least if a winter residence is contemplated, the quantity of food should be increased, be that as inconvenient as it may. It would be very desirable indeed if the men could acquire the taste for Greenland food; since all experience has shown that the large use of oil and fat meats is the true secret of life in these frozen countries, and that the natives cannot subsist without it; becoming diseased and dying under a more meagre diet. Nor do I know that this is impossible; since it is notorious that where the patients in English hospitals have been treated with fish oil for the cure of rheumatism, they not only soon learn to like it, but prefer that which is strongest and most offensive. I have little doubt, indeed, that many of the unhappy men who have perished from wintering in these climates, and whose histories are well known, might have been saved if they 
had been aware of these facts, and had conformed, as is so generally prudent, to the usages and the experience of the natives.

I know not that I am safe in making another remark respecting the constitutions which peculiarly generate heat, because this is the business of physicians; but they will be ready enough to correct me if I am wrong. A ruddy, elastic, florid, or clear complexioned man, has always seemed to me better secured by nature against cold, than the reverse constitution; and the term for the former is a sanguine temperament, while that which is applied to the other is, a phlegmatic or a melancholic man : but physicians best know how many species there are in this class. At any rate, the pale, and flabby, and sallow, and melancholy-looking men, are not the men for an arctic voyage; they suffer most from cold, whatever individual exceptions there may be; and therefore I suppose that they do not manufacture heat to the same extent as the others. If such men also are slow and melancholy in mind, as I believe to be very common, this is most assuredly an additional reason against employing them; for even when these feelings occur in a better temperament, they diminish the power of resisting cold; as if the exciting passions, as they are termed, a fact which I know not how to doubt, led to the generation of heat, and the depressing ones to the reverse. And this, be the theory true or not, being practically the fact, inasmuch as hope and confidence make men bear that cold under which the timid and desponding suffer, though perhaps it is only that the same constitution leads to both results, producing hope and displaying energy while it also generates heat, another suggestion offers itself respecting the care to be bestowed on 
the crew, and the occupations which should be invented for them, as well as in regard to the original choice; since it thus becomes the interest, not less than the duty, of the commanding officer, to keep up their spirits and hopes, by any means that he can contrive; as, in doing this, he also knows that he is adopting one of the best expedients against the attacks of the scurvy.

I will only add to these remarks, what may, I trust, be of use to future arctic navigators, namely, that although every expedient in the way of clothing should be adopted for resisting the impressions of external temperature, as these are too well known to require detail, nothing will compensate for the want of the heat-generating energy, but external heat; as that is but too often an imperfect expedient. It is of little use to clothe him who will not, in himself, produce heat; it is like the attempt to warm a piece of ice by means of a blanket; but it is too common a mistake to imagine that the expedient which can only preserve heat is capable of producing it.

The weather continued fine, but the thermometer fell to $6^{\circ}$. We continued to lighten the ship and get out the boilers. I ascended the highest accessible hill to the south-west, and obtaining a good view, conceived that the distant land was continuous from the southwest till it closed in with the west end of the island, though I could not be positive respecting objects so far off, nor be sure that there was not some opening. The land was very rugged, and intersected by ravines, with many small islands scattered along the shore. There was still some clear water to the northward and in the inlet; but the horizon being hazy, we could not see further than Hecla and Fury island. The holes in the ice which we had noticed, were now 
frozen up, and all marks of a current had, of course, disappeared. Oct. 17. A strong north wind made the cold very severe on the following day, though the thermometer ranged between $14^{\circ}$ and $8^{\circ}$. A single coal fish was taken; and I doubt if it was before known that this species frequented the seas so far north; if, indeed, it should not. prove a new one.

Oct. 18. It was a beautiful day, with calm weather; the thermometer was between $6^{\circ}$ and $8^{\circ}$; but in the evening it fell till it reached one degree only, at seven o'clock. This was by very much the lowest temperature we had yet experienced. Sunday found all our men well, and him who had met with the accident recovered. More than fifty lunar distances were obtained for the longitude. The aurora was seen in the south-east. Our nets continued to bring up the welcome shell fish, but not in great numbers.

๑ct. 19. The thermometer rose a few degrees as the sun proceeded to the meridian, and, at sunset, fell to $2^{\circ}$. It continued calm till evening, when there was a light air. We again obtained lunar distances to the amount of a hundred and twenty, with meridian altitudes of the sun and of several stars. A chronometer, intended for the transit observations, was set to mean time. In the course of the evening, the frames belonging to the engine were got out: and $I$ believe the men felt that they were fast ridding themselves of a nuisance; of an: enemy, where they had reckoned on a friend.

oct. 20. The fine weather continued, and the temperature fell to two degrees under zero. It was our first minus, and we began to agree that the cold weather was really arrived. But it was very tolerable thus far. In the course of the day it rose to plus $7^{\circ}$; but, at night 
fell again to minus $9^{\circ}$. The last of the engine was hoisted out: may I not say that there was not one of us who did not hail this event with pleasure. We could not even look at its fragments without recollecting what it ought to have been, and what it proved to be; nor without reflections, and those not kind ones, on its maker, when we remembered the endless and ever recurring trials of our patience which it had caused, the never ceasing labour of the men in its reparation, the ever renewed hopes, producing ever new disappointments, and the loss of temper, to most of us, I fear, of which it had been the fertile cause. The enemy, however, was at last at our feet; and while it was incumbent on us to store it up, though it would in reality be difficult to say why, were it not from that habit, or feeling, which rebels against absolute wastefulness, I believe there was not one present who ever again wished to see, even its minutest fragment.

The Krusenstern was secured yesterday, and, at night, an aurora Oct. 21 . made its appearance. A fish, which we believed might be a new species, as we had not seen it before, was taken. The thermometer was low, ranging between plus and minus $4^{\circ}$ : the weather nearly calm. The erection of a roof over the ship was commenced, and a white fox shot. We could get no lunar observations, and were not likely to procure them again for the next four months.

Though the land was much elevated by refraction, this day, it Oct. 22. showed us nothing new : the thermometer did not materially vary. It now became necessary to cut away the ice round the ship, in consequence of her having been so much lightened; that she might settle to her natural line of flotation. This being done, she rose 
nine inches; and we proceeded to build up a bank of snow and ice round her, for shelter from the cold. The galley was also moved, and placed in the centre of the men's berths, that the heat from the fire might be more equally distributed. A tank of plate iron was, further, placed on the upper deck, over the coppers; and, by this contrivance, the steam, which is a constant annoyance at these low temperatures, was secured and condensed. Another raven was seen ; and our fishery of whelks, though never very productive, was continued daily.

Oct. 23. A fresh breeze rendered the cold very sensible to-day; but its effect was, nevertheless, to raise the thermometer from minus $6^{\circ}$ to plus $8^{\circ}$ Oct. 24. in the course of the day. This wind continued on the following day, with drift snow; the thermometer falling to minus $3^{\circ}$, and then rising again as high as plus $15^{\circ}$. This is a sure indication of snow in these climates; and accordingly a heavy fall came on at midnight. Some other useful alterations were this day made in the ship; and, among the rest, a pipe was carried from the upper deck to the fire, by means of which that was easily regulated. These things being done, it was found that a very small quantity of fuel was sufficient to keep the lower deck, where the crew lived, dry and comfortable, and to maintain a medium heat of about $55^{\circ}$, being what I judged the most advantageous one.

The snow continuing in the morning the thermometer rose to $18^{\circ}$, but began to fall at noon, and, in the evening, was at minus $6^{\circ}$. Prayers, and exercise on shore, occupied, as usual, their portions of the present Sunday. We had set a fox-trap yesterday, and to-day it was found robbed by the dogs. 
Though the temperature was not materially different this day, oct. 26 . a smart gale made the cold very severe. We therefore hastened to complete the roofing, which was done by means of the spare sails procured from the Rookwood's and the Fury's stores: and we immediately found the advantage of this additional security against the cold. Other needful arrangements on the part of the carpenters and engineers, found us in-door employment, when it was especially unsafe for inexperienced men to work out of the ship, lest they should be frost-bitten.

After continuing to blow a storm all day, the wind fell at six Oct. 27. o'clock, and the weather cleared : after which the snow ceased, and it became calm. We were thus enabled to make considerable progress for a time in our snow fortification; but in the evening it blew as hard as ever, and the thermometer fell to minus $11^{\circ}$. Thus it continued till six on the following morning, when it settled and cleared. In the course of this day the temperature sunk to minus $13^{\circ}$, being the lowest that had yet occurred. The ship, however, being now completely housed in, we found ourselves in a very comfortable position.

In the course of the preceding night the thermometer rose to Oct. 29. plus $3^{\circ}$, and, during the day, to $4^{\circ}$; a state of things, as I have just remarked, always attending snow, which accordingly fell in considerable quantity. On the following day, the drift was so great oct. 30. that we could not proceed with our embankment. The changes in the temperature were not so remarkable as to need recording here; but I must remark, that on this, as on almost every preceding occasion, the barometer indicated the coming gale. A white fox was taken in the trap, alive. 
Oct. 31. ? The wind blew still harder, and the thermometer fell to minus $16^{\circ}$. At sunset there was a large halo, being but the second that we had seen; it was, however, only a white one. There was afterwards an aurora to the southward. The tops of the mountains were considerably bared of their snow by the gale: but the contrast of their dark rocks with the whiteness around, only served to render the aspect of this winter landscape more desolate. The poor fox was accidentally strangled: only, however, anticipating a fate which we shonld have been obliged to inflict hereafter, though we did not then foresee it.

We had, on this day, completed the first month of our imprisonment in this dreary and miserable country, and were naturally led to compare our present condition with those of preceding voyagers, and to make some general remarks on various matters, the most important of which I may now record, as briefly as may be.

I may first note, that in this climate, unlike to Sweden and Norway, the degree of the temperature bears little or no relation to the latitude. This will be sufficiently evident by the brief comparative table which $I$ here insert, relating to our own mean for this month and those which had been formerly found at Melville island, Winter island, Igloolik, and Port Bowen. It is not however a very accurate comparison; because, in these cases, the temperatures were observed on board the ships, not on the ice; while the allowance of three degrees for that difference is far from sufficient; my own experience showing that it may amount to even $6^{\circ}$. 
These are the facts in question :

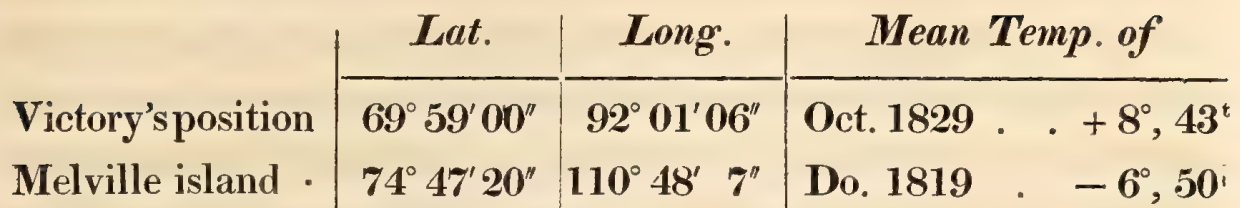
Winter island .
Igloolik . . .
Port Bowen .

$\left|\begin{array}{l}74^{\circ} 47^{\prime} 20^{\prime \prime} \\ 66^{\circ} 11^{\prime} 27^{\prime \prime} \\ 69^{\circ} 20^{\prime} 30^{\prime \prime} \\ 73^{\circ} 13^{\prime} 40^{\prime \prime}\end{array}\right|$

$110^{\circ} 48^{\prime} 7^{\prime \prime}$
$83^{\circ} 11^{\prime} 0^{\prime \prime}$
$81^{\circ} 52^{\prime} 46^{\prime \prime}$
$88^{\circ} 54^{\prime} 48^{\prime \prime}$
Do. 1821 . $+9^{\circ}, 51^{\mathrm{t}}$
Do. $1822 \quad+\quad+9^{\circ}, 79^{t}$
Do. 1824 . $+10^{\circ}, 85^{\mathrm{t}}$

In the next place, comparing our progress with some preceding ones, it was true that we had not reached so far westward as Melville island; but we had wrought our way through as much ice, since the extent of this navigation had been 240 geographical miles, as our progress had also been a very laborious one, and not a little hazardous on more than one occasion.

It was now, further, quite ascertained that the tides came from the northward, and were both later and lower when the wind was from the south. We had seen no whales for the last sixty miles, and had never fallen in with a walrus.

I formerly mentioned the quantity of provisions and fuel that we had remaining, which were computed to last till August, 1832. But there was only one year's allowance of spirits, which was a subject rather of congratulation than otherwise, since there can be no question of their pernicious effects in these frozen climates; one of those being, I have no doubt, to increase the tendency to scurvy. It was necessary, however, that what we had should be reserved for the future parties on land excursions, where it might often prove of considerable, if temporary service; or, as might become necessary, 
for our use in case of shipwreck, and our being condemned to take to the boats; since this article would then be valuable not merely as an article of diet, but as fuel ; or, finally under the chance of our being unable to liberate the ship in the spring, and being thus compelled to continue our investigations by land. Orders were accordingly given to stop the use and allowance of grog; while it was very satisfactory to find that these were received without remonstrance.

Our roofing had been perfected in this month; but it still remained to complete our embankment, and to cover the upper deck with snow. More arrangements than those yet noticed had also been made in the interior of the ship, by constructing a room in the place of the steerage, to receive the men's chests and the apparatus for cooking and baking; while copper flues were carried from them round the whole apartment, in order to convey away the vapour. Over the steam kitchen, oven, and after passage, apertures were made in the upper deck, on which were placed iron tanks with their openings downward. In these the vapour was received, and became immediately condensed: but though we rather expected that we might have drawn it off in the shape of water, and had contrived means accordingly, we found it so generally frozen that these were of no use.

We found this last contrivance to be the best that had yet been adopted; and chiefly as, by keeping the apartment of the crew dry, it saved the necessity of forcing up the temperature, as had been done on former occasions, for the purpose of keeping the vapour afloat till it was condensed on the beams and deck. This, too, involved a great saving of fuel : since we found that a temperature 
between $40^{\circ}$ and $50^{\circ}$ was sufficient to make the place dry, warm, and comfortable, whereas it had, in the ships that preceded us, been necessary to carry it as high as $70^{\circ}$.

The regulations adopted on other matters were the following; and I point them out, that future adventurers in this country may gain, without labour, the experience which had now been purchased by many successive voyages. It will easily be seen how much of all this was directly useful, for some one or other specific purpose, and how far the intention was to find occupation for the minds of the men, and exercise for their bodies.

The men slept in hammocks, which were taken down at six in the morning, and hung up at ten at night, being also aired twice a week. The lower deck, being the dwelling floor, was covered with hot sand every morning, and scrubber with sand till eight, when the men breakfasted. Monday was settled in future as the washing day; and this operation being finished by noon, the linen was dried at the stove. The upper deck having been at length covered with snow two feet and a half in thickness, it was trod down till it became a solid mass of ice, and was then sprinkled with sand, so as to put on the appearance of a rolled gravel walk. Above this, was the roof already mentioned, of which the canvas sides were continued so low as to cover those of the ship. The surrounding bank of snow being completed, reached to the ship's gunwale, so that the union of this with the roof formed a perfect shelter from all wind, and thus excluded, very materially, the impressions of the external cold. In the same manner there was a covering of snow to the cabin deck, while the skylight was fitted with double sashes: but the way from 
the cabin to the deck was not closed, since the frost was not yet so intense as to render that necessary: the inner doors were merely fitted with ropes and pulleys.

With respect to the arrangements below, a communication was made from the steerage to the fore part of the space between decks, by means of a door leading first to an antechamber screened off by canvas, and then to a space, similarly about five feet square. Into this last the men descended immediately from the deck : and thus passing the antechamber into the dwelling apartment, they were not exposed to any sudden change of temperature. In this way, after first ridding themselves of snow, they were compelled to leave all their dresses, which might still contain snow or moisture, in the first division, or chamber ; thence advancing into the canvas apartment, which further served as a guard to prevent the entrance of the cold external air into the steerage, their dwelling place.

During the day, including the space between six in the morning and nine at night, the steam kitchen was found sufficient both for warmth and cooking; and, in the night, the baking oven served the same purpose, while it also heated the sand for the morning's use. As it is a pernicious plan, being a very clumsy and inconvenient one, even in the domestic arrangements of England, to supply, from the doors, the air required for the fires, I caused a large copper pipe to be brought from without to the fireplace. Thus, not only was the external air prevented from making a cold "dranght" through the room, but the pipe itself became sufficiently warmed to assist in keeping dry the air within this principal apartment.

By these means the vapour was enabled more easily to ascend 
and settle in the external condensers, instead of becoming water in the room itself; while, what was not less important, the fires were kept burning with a uniform degree of strength. In proof of the effect of the utility of the condensers, I may now remark that it was our practice to clear them out every Saturday, and that the quantity of ice they contained averaged about a bushel a day: the representative of a quantity of vapour first, and of a corresponding proportion of water afterwards, that would not only have been extremely annoying but truly pernicious.

In continuation of our wintering system, every atom of rigging was taken down, cleaned, marked, and stowed away. In arranging the duties and the victualling of the men, the following plan was adopted; the whole crew being divided into five watches. The three leading mates, the engineer, and the harpooner, had, each, with one seaman, the charge of the deck in their respective turns: their duty being, to keep a look out respecting fire, wild animals, and natives, to register the direction and strength of the wind, with the appearances of the sky and weather, and the temperature, as well as the state of the tides and the occurrence of auroras. The officers, with their servants, the carpenters, the armourers, and the cook, had sufficient other duties in their respective departments.

The breakfast, of which the hour has been already mentioned, consisted of cocoa or tea; and the dinner was at noon. When the weather permitted any thing to be done outside of the ship, the men worked, after that meal, till three or four o'clock : while, when that was impossible, they were obliged to walk for a certain number of hours on deck, beneath the roof. Their tea was at five o'clock; 
and, after this, they attended an evening school, commencing at six, and lasting till nine; which being closed, and the hammocks slung, they retired to bed at ten.

On Sunday, no work was allowed. The men were mustered, and inspected in their best clothes, by ten o'clock, after which there were prayers and a sermon. To occupy the remainder of the day, there was a collection of tracts which had been presented to us by Mrs. Enderby, of Blackheath, proving a judicious as well as a useful gift. But, at six there was a Sunday school: the occupation on this evening being the reading of portions of scripture by the men, while the day was concluded by psalms and by the lessons appointed in the liturgy. Of the good effect of this system of religious duties and of instruction, I could entertain no doubt; for the men seemed truly to feel that they all belonged to one family: evincing mutual kindness, with a regularity and tranquillity of behaviour which are not very general on board of a ship.

The days of baking for the men were on Sundays and Thursdays, and those for the officers every other evening excluding Sundays : all these regulations having regard to the collateral uses we might derive from the heat necessary for those purposes. The allowance of provisions to the men and the officers, issued for fourteen days, is seen in the following table. 
Account of the Daily Proportion of Provisions served to 18 Men for 14 Days.

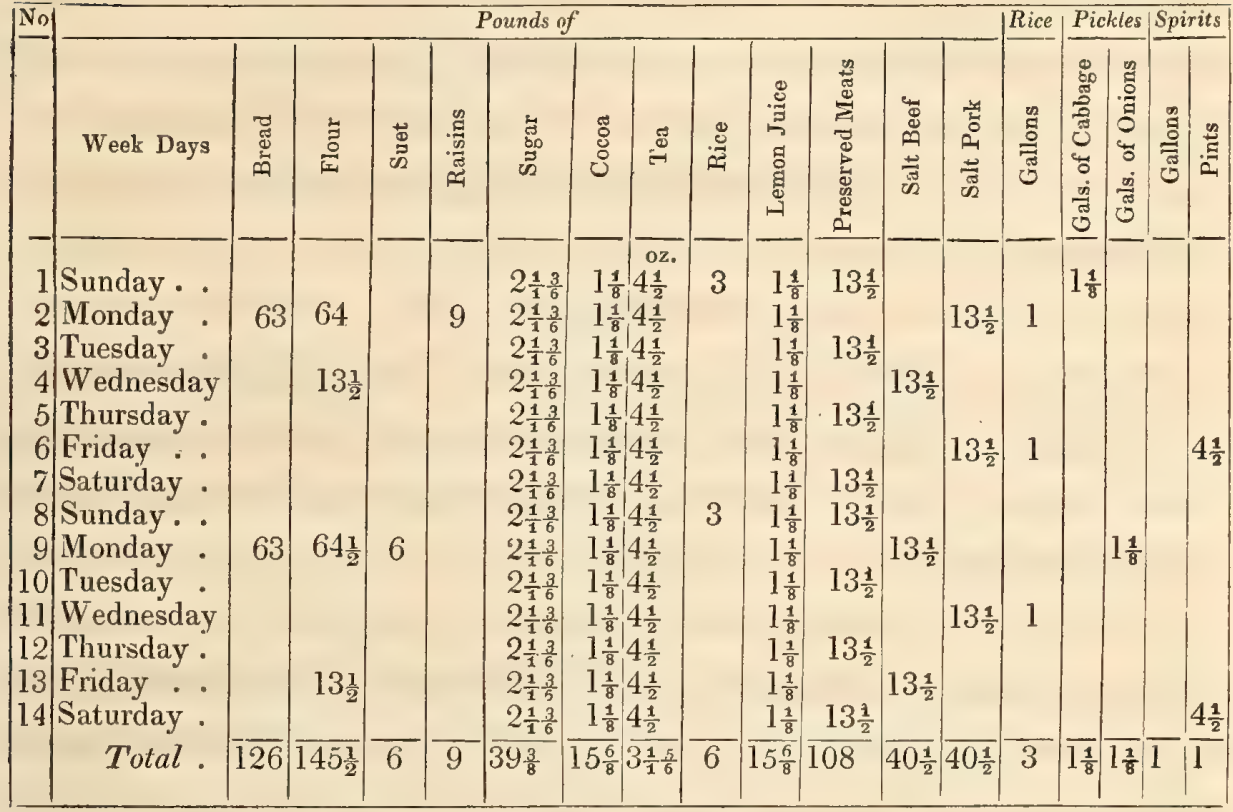

Besides this, vinegar was served as it was required; but, more rarely, preserved soups, as it was thought best to reserve them for the coldest weather, or for particular occasions. There were also lemons and tamarinds for those who might be unwell.

This portion of the ship's duty appertained to Mr. Thom, who had also the charge of the log, as master not less than purser; together with that of the barometer, and its attached thermometer. The chronometers were now under the charge of Commander Ross; who also took a joint duty with myself in the navigation and the different classes of observation: with the further undivided command over the department of natural history. 


\section{CHAPTER XIV.}

THE MONTH COMMENCES STORMY AND COLD-IMPROVEMENT IN ITS PROGRESS-REMARKS ON THE THERMOMETER AND BAROMETEROCCURRENCE OF A SPLENDID AURORA BOREALIS-SUMMARY OF THE MONTH.

1829. THE most severe storm that we had yet experienced came on this day; bursting suddenly from the north, with a heavy fall of snow, and the thermometer under zero. Sunday was spent as usual, except that it was impossible to take exercise on shore. There was an Nov. 2. aurora at night, but not brilliant. The gale then subsided, and was followed by a fine day: when, although the temperature was at minus $14^{\circ}$, the cold was by no means disagreeable. Though the distant horizon was not very clear, we could see that the ice was partially broken up by the storm; some clear water appearing in the south-eastern quarter. In the evening of this day the wind came to the westward, and there was another aurora, of short duration.

Nov. 3. There was no material change of wind or weather this day, the thermometer being at minus $9^{\circ}$. We found traces of foxes during our walk on shore. More was done towards completing our snow fortification; and I believe most readers now know, that the frozen 
snow is cut into masses resembling squared stones, and applied in the same manner, as the cement is formed of water. On the fourth, Nov. 4. there was snow again, during the whole day: the thermometer rose to zero; falling again, in the night, to minus $10^{\circ}$. We had now ceased to take the shellfish for some days.

The morning was fine, and as is then unusual, the temperature Nov. 5. got up to minus $1^{\circ}$. Four willow partridges were killed. On the following day the wind was fresh from the northward, but not so cold as to impede the necessary work. An examination of the condensers proved that they collected, jointly, a bushel of ice in the day, as I noticed in the summary of last month to be the expected quantity : and we could not but be highly pleased at reflecting, that had it not been for the collection and condensation of this bushel, we should have been ourselves the condensers, and been involved in vapour and internal rain, to an equivalent amount, all the twenty-four hours. It is always desirable to be relieved from suffering; but it is infinitely more gratifying, when we know that we have been benefited by the exertion of our own invention and industry. These are among the true rewards of exertion, in all the circumstances of life; and the self congratulation which follows is more than pardonable.

In spite of a brisk wind from the north-east, with much drift Nov. 7 . snow, our officers contrived to kill two ptarmigans; but, notwithstanding such a breeze from this quarter, the thermometer rose to plus $3^{\circ}$. I must confess that these vacillations in the heat were not always intelligible; we knew, generally, what a peculiar wind ought to produce, why an overcast sky should raise the temperature, or a fall of snow make the air comparatively warm, and 
why also we ought to expect the severest cold with a clear sky. But all our causes sometimes failed us; and I can only now conclude, as I did then, that our knowledge of the atmosphere and its conditions is as yet not sufficient to explain even the changes of temperature; failing us, as it does, in every thing else, when we attempt to lay down those general rules, without the certainty of which, there is no sound knowledge.

Nor is this less true of what has been deemed most certain, namely, the changes in the barometer; and if what we had occasion at different times to observe, be at present inexplicable, I can only remind my philosophical readers, that it has often, and amply, been confirmed, by the reports of La Perouse and the experience of navigators beyond number. The mercury has risen when it should have fallen; and it has sunk when there was present every reason that has been assigned for its rise. It has fallen with winds from the east and the north; and also (for this has been a reason given for its rise) with winds from the land; while it has risen under the reverse circumstances, being the received ones for its fall. Thus has a low barometer brought fair weather, and a high one rain; while I have also seen it fall, with an east wind, bringing violent rain, when, on coming round to the west, the mercury rose, even more than half an inch, within a very short time, and with fine and settled weather. In a nautical view, these must indeed be considered as exceptions: I should be very sorry, among others, were not this instrument still of much use on board of ships, especially in those seas and those seasons in which sudden and violent gales arise : but if its prognostics are not absolute, and not therefore such 
as to be an excuse for inattention to other circumstances, or for the omission of constant watchfulness at sea, so must it be recollected, that, in philosophy, such exceptions prove our ignorance of laws which we pretend to know. It is a silly maxim, as it is a false one, popularly rooted as it is, that the exception proves the rule; the slightest exertion of common sense should show, that nothing can be a law in philosophy if it admits but of one exception.

On the preceding evening, the wind blew hard from the north- Nov. 8. west; but the morning of Sunday was beautiful, with a brilliant sky, without a cloud. Divine service was performed, and the exercise on shore was enforced as on former occasions: this being intended as a standing order for every Sunday on which it might be practicable. All were well, except the armourer, whose constitution could not bear the climate. He ought not, indeed, to have been with us; having been destined for our consort, the John, as the armourer of that ship was intended for the Victory. Unluckily, that man was one of those who joined the mutineers; and though $\mathbb{I}$ had intended to send the present ailing and feeble person home by the first whaler that we should meet, not one had fallen in our way.

The fine weather continued, with the thermometer at minus $10^{\circ}$. Nov. 9. A shooting party had no success; seeing merely some hares, and the track of a bear. On the next day the same party was soon driven Nov. 10. in, by the thermometer falling to minus $20^{\circ}$, though the weather continued fine. At night it was $22^{\circ}$ minus; being the lowest yet experienced. In the middle of the next day it came to blow, and, in Nov. 11. the evening, abundance of snow fell; both the force of the gale and the quantity of snow increasing till midnight. Thus we were pre- 
vented from getting some occultations by the moon, in Taurus, on which we had calculated, and for which we had made preparation.

Nov. 12. After blowing with increased fury, the gale became somewhat more moderate towards the evening. It is worthy of remark, that the range of the thermometer, in the last thirty-six hours, was $48^{\circ}$. If the ice was at all broken up by this gale, it was a matter which we had no means of discovering, as there were now but three hours of daylight. But it was likely ; for the wind coming from the northeast to the south-east in the evening, there was an unusual high tide, and the ice near us burst open with a tremendous noise, admitting the water above it. The thermometer at midnight was as high as $26^{\circ}$ plus.

Nov. 13. The temperature did not begin to fall till after noon on this day, and then very gradually. This was a long duration of what may be called a high heat at this season of the year; since it had been above $\mathbf{2 4}^{\circ}$ plus, for about eighteen hours : but the more remarkable fact is, that there was a north-easterly wind all the time ; confirming the observations I have just made respecting the obscure causes by which temperature is regulated. According to general experience in these regions, the cold ought to have been severe. As to the thermometrical observations themselves, there can be no doubt of their accuracy, because they were made on shore, remote from the influence of the ship, while the instruments were the same that had been used on former expeditions. It was almost amusing to find the sportsmen complaining of the heat; and, with the snow that fell, there was some rain.

Nov.14. Though our sport was without any success, the position of the sun to-day, and the clearness of the air, when on the hill we had so often visited, gave me a more extensive view of the distant land than 
I had ever yet obtained; displaying a range of mountains more remote than those which we had yet seen. The colouring was admirable this day, as it had been for a short period in the afternoon before. It was not only that the clouds and the sky in the south presented all those rich summer tints of evening which are occasionally seen in our own country, and those hues contrasted by the deep, dark, calm purple of the northern horizon, but, in addition to the aerial tints and reflections of the snow of the mountains, emulating or exceeding those on the clouds, the hills near the sun were often splendid with prismatic colours as it passed along them in its course. In reality, the noonday sun of these regions is an evening sun ; and it is not surprising, therefore, that its whole diurnal progress exhibits but the appearances of a similar sun in our own latitudes. I had reason to believe, from the colour of the sky, that there was some open sea to the northward: and we could distinctly see one clear space of about a mile in diameter, not a very great way from us, together with some smaller pools, the effects of the late storm.

The weather continued calm, and not cold; since the thermome- Nov. 15. ter did not fall lower than $\mathbf{1}^{\circ}$, and rose as high as $8^{\circ}$. A very little snow fell : but, on shore, the valleys and ravines were already quite filled, as the far larger part of the hills and of the other ground in general was covered; only a solitary black rock appearing here and there, wherever the gale had acted with most violence. Traces of foxes and hares were now seen every day, by the parties on shore; but that was all. The Sunday was spent as usual. The sun had not Nov. 16. been seen yesterday, and neither sun nor moon was visible this day: the weather was nearly as mild. In the night, however, it fell to minus $4^{\circ}$, and continued nearly the same on this day. 
Nov. 17. On Monday, the seventeenth of November, a very singular appearance of the sun occurred, with an effect too incredible and absurd to admit of representation, splendid as it was to the eye. The centre was darkened by a cloud, while the circumference was surrounded by a belt, under which the rays shot out in such a manner as to give it the semblance of a star of the order of the Bath. If there was any one on board who imagined that this appearance was ominous of that, or any other knighthood, to any of us, the secret was kept ; fortunately for the prognosticator, who might have lost his fame by trusting to a fallacious omen; though, by a very singular coincidence, it has been accomplished on the very day that the correction of this sheet, in passing through the press, enables me to add its fulfilment.

Nov. 18. It was still mild; but, from the force of the wind, there was enongh drift, on the hills, to prevent shooting: the thermometer reached plus $\mathbf{q}^{\circ}$ at midnight. Our school was completely organized,

Nov. 19. for instruction in reading, writing, arithmetic, mathematics, and navigation; and the men being divided into classes, the necessary materials and books were distributed. Out of the eighteen, three had not learned to read and write; but the want of arithmetic was very general: the three mates were capable of commencing with astronomy and navigation. No compulsion was here necessary; all were volunteers; and the school hours always terminated by reading two chapters from the bible, together with the evening psalms.

Nov, 20. There had been neither sun, moon, nor stars to be seen these two last days, and the weather still continued gloomy, with little wind and less snow. The thermometer reached $9^{\circ}$, and averaged $5^{\circ}$ during the twenty-four hours. A white hare was shot. The folNor. 21. lowing morning was equally dull and dark, with occasional snow ; 
though the moon made her appearance, once or twice, for a very short time. At midnight the temperature fell to minus $1^{\circ}$. A female fox was taken in the trap to-day, and was brought on board for the purpose of being tamed. A very faint aurora was seen in the south-eastern horizon.

Sunday was calm and clear, with the thermometer as low as Nor. 22. minus $9^{\circ}$. In the course of their walk after service, the men found the tracks of reindeer, but nothing more. On Monday the thermoNov. 23. meter continued falling till it reached minus $16^{\circ}$. Intending to pursue the tracks of yesterday's reindeer, Commander Ross proceeded for a certain distance along shore, and thus found, for the first time, that the south-west point of the nearest land was insulated from the main by a channel leading to the westward, but without being able to ascertain how far it penetrated. The wind shifted to the southward; and the men found work in extricating the engine boilers, which, being on the ice, had been partially buried in a new layer formed by the breaking through of the water a few days before.

An overcast sky caused the thermometer to rise a few degrees, but Nov. 24 . the change was only temporary. There was enough of work for the day, in cutting out the various ironwork of the engine, as well as the whale boat, which was in the same predicament. A cairn on the island, intended as a guide to the ship for those who might lose their way, was completed; and a thermometer, constructed purposely for us, was fixed on it. There was a brilliant aurora to the south-west, extending its red radiance as far as the zenith. The Nov. 25. wind vacillated on the following day, and there was a still more brilliant one in the evening, increåsing in splendour till midnight, 
Nov, 26. and persisting till the following morning. It constituted a bright arch, the extremities of which seemed to rest on two opposed hills, while its colour was that of the full moon, and itself seemed not less luminous; though the dark and somewhat blue sky by which it was backed, was a chief cause, I have no doubt, of the splendour of its effect.

We can conjecture what the appearance of Saturn's ring must be to the inhabitants of that planet; but here the conjecture was perhaps verified; so exactly was the form and light of this arch what we must conceive of that splendid planetary appendage when seen crossing the Saturnian heavens. It varied however, at length, so much as to affect this fancied resemblance; yet with an increase of brilliancy and interest. While the mass, or density, of the luminous matter was such as to obscure the constellation Taurus, it proceeded to send forth rays in groups, forming such angular points as are represented in the stars of jewellery, and illuminating the objects on land by their coruscations. T'wo bright nebulæe, of the same matter, afterwards appeared beneath the arch; sending forth similar rays, and forming a still stronger contrast with the dark sky near the horizon. About one o'clock it began to break up into fragments and nebulæ; the coruscations becoming more frequent and irregular until it suddenly vanished at four.

Nov. 27. It being now the spring tides, the water flowed through the firehole, as it is termed, (being an aperture made for procuring water in case of the occurrence of fire on board,) and covered the ice near the ship in such a manner, that we were obliged to make a fresh embankment round it, to prevent this inconvenience. The thermometer fell, in the evening, to minus $27^{\circ}$, and yet the air did not 
feel very cold. According to our latitude, the sun should have disappeared for the winter, yesterday; but, unluckily, for the last three days, there was a cloudy horizon which prevented us from seeing it. It was not, indeed, certain that we might not see it once or twice more, from the effect of refraction. The twenty-eighth was, however, no clearer than the preceding days, but the thermometer rose to $21^{\circ}$, minus.

It fell again however to $27^{\circ}$, and the cloudy horizon at noon once more prevented a sight of the sun. Every thing proceeded as was Nov. 29. usual on Sundays. Monday was the clearest and the calmest day we had experienced during the month, but it was also very cold, the thermometer falling to minus $37^{\circ}$, and thus far outdoing whatever we had yet felt. Once more, the meridian, or the rising and setting sun as it may be called, was obscured by a cloud, so perfectly, from the ship, that ino sight of it could be obtained above the fog bank which lined the horizon. But one or two glimpses of it were procured from the higher part of the island, whence, at noon, it was just able to clear that low cloud, for an instant or two.

Thus closed the month of November, and, as we calculated, with the last sight of the sun which we were likely to have this winter. It was still pleasing to find that it was a beautiful day, in spite of the actual cold, which was really by no means severe to the feelings. We had reason to believe that the ptarmigans were now quitting this coast, and migrating to the southward, with the intention of following the sun in its course. Comparing now the mean temperature of this month with that which had occurred in preceding expeditions, we found no reason to expect a more severe winter than is usual in 
these climates, notwithstanding the appearance of severity at the commencement, and the very low temperature on the last days.

It was also now discoverable, that the highest temperatures had been with the north-easterly winds, and the lowest with the southerly ones: being the exact reverse of what was to be expected, and of what had occurred in former voyages. The only explanation that we could suggest, whether right or wrong, was, that there was open water to the northward, and that the whole southern quarter was a mass of ice, whether on land or at sea ; in either of which cases, the prospect of future progress in this direction was far from flattering.

The weather was such all this month as to deprive us of the power of making any observations on the occultations of stars by the moon, as well as all others, of whatever nature: and the men were too much occupied with more indispensable duties to admit of our erecting observatories for magnetic and astronomical observations on shore. It was most satisfactory, however, to find, that the effects we had intended by all these arrangements had been attained. The system of comfort and economy which had been planned was as perfect as could be desired; and the satisfaction of the men, with these things; with each other, and with their officers, could not have been greater. Under their system of education, they had improved with surprising rapidity; while it was easy to perceive a decided change for the better in their moral and religious characters; even, as I have reason to believe, to that which is always rendered difficult from long habits, the abolition of swearing. 


\section{CHAPTER XV.}

REPEATED OCCURRENCE OF AURORA BOREALIS-CHRISTMAS DAYSUMMARY OF THE MONTH-REMARKS AT THE TERMINATION OF THE YEAR 1829.

W $\mathbf{E}$ saw the upper limb of the sun to-day, for a short time, from 1829. Dec. 1. the island; the atmosphere being unusually clear. It was elevated about two minutes of a degree. This was the result of refraction; since its astronomical disappearance had occurred six days ago. We were now also but three weeks from the shortest day: so that, with the same circumstances at its next rising, we should not be condemned to more than six weeks of total absence. We obtained the altitudes of several stars. The thermometer stood from $31^{\circ}$ to $37^{\circ}$ minus : the barometer at 30 inches.

A black clond in the southern horizon would have prevented Dec. 2. the sun from being seen, though it had still risen above that line as it did the day before. The magnetic observatory was erected, and the other one commenced. At midnight there was a magnificent

Dec. 3. arch of an aurora, but it was only five degrees high. The colour was a light yellow, and it emitted rays; finally breaking up and disappearing about one o'clock. The day was calm, and the sky Dec. 4. clear, but with a cloudy horizon. The thermometer rose to minus 2 G 2 
$19^{\circ}$, and, on the following day, to $14^{\circ}$; with light clouds above, and deep red ones near the passage of the sun. We now compared the mercurial and the spirit thermometers, as we might soon be called on to depend on the latter alone; and the necessary corrections were recorded for adoption.

Dec. 5. A strong wind rendered this morning very cold. But the wind shifting from the north-east to the south-west, it fell four degrees Dec. 6. lower; confirming the remarks already made on the subject. An ermine came on board, quite starved, and was taken and fed by the crew. Sunday was very stormy and squally, with snow, and the thermometer began to rise when the wind fell. The day was kept as

Dec. 7. usual. A strong breeze blew all Monday, till the evening, when it became moderate and clear; the thermometer falling from minus $12^{\circ}$ to $23^{\circ}$. The moon was clear, for the first time during a considerable period; but as it passed over no stars, it gave us none of the observations that we wished.

Dec. 8. The calm weather was succeeded by a breeze from the north-east, Dec. 9. and the thermometer rose to minus $16^{\circ}$. On the following day there were light winds and hazy weather. The observatory being finished, we obtained some occultations of stars by the moon. The temperature fell to $26^{\circ}$ minus, in the evening, and there was an

Dec. 10. insignificant aurora. On the tenth there was a halo round the moon; sending out rays to a great distance, in the form of a cross. This

Dec. 11. was repeated on the following day; and the thermometer during the three days ranged between minus $16^{\circ}$ and $27^{\circ}$. A transit of Aldebaran was obtained.

Dec. 12. There was little to note this day: the temperature and weather 
having little changed, and the men's employments remaining as usual. The following was spent in the usual manner fixed for Sunday. It is remarkable, that through the last week, the state of the weather allowed the fires to be discontinued for eight hours every night, without lowering the heat between decks beyond the degree which had been fixed on as the best. On the following day, Monday, Dec. 14. the thermometer was generally at minus $13^{\circ}$; and we were again annoyed by the water overflowing the ice. The weather was hazy, and mild to the feelings, both on this day and the following morning; on which there was a large halo round the moon. But the wind rose, so that it became so cold as to prevent the men from working on the ice, while the thermometer sunk also to minus $24^{\circ}$.

The same wind, with an equally low temperature, continued to impede all out of door work; but, on the 17th, the westerly wind Dec. 16. came round to the east, and it was then followed by a great increase of cold, when the thermometer at length fell to $37^{\circ}$ minus. At this point the mercury froze; whether from being alloyed, or from the instrument having been ill graduated, we had no means of ascertaining; though the former was probable, as some other quicksilver which we had on board did not freeze. There was another beautiful aurora this day. The ice round the ship was much rent by the tide, but not so as to allow the water to overflow.

There had been a short calm, which was succeeded by another Dec. 18. easterly breeze; and the thermometer then rose to minus $28^{\circ}$. Clouds obscured the aurora of yesterday, though it was still partially visible; as if occupying the whole space from east to west. On the 19th Dec. 19. the thermometer went on rising till it reached $17^{\circ}$; but it was far 
colder, as there was a smart breeze, until after noon, when it became calm and pleasant. There was no success in shooting: all animals seemed to have nearly deserted this part of the coast. Our carpenter being a musician, I ought already to have said that the men were permitted to dance on the Saturday nights; holidays of this nature having always been found acceptable, and advantageous; while it was also, necessarily, a school holiday.

Dec. 20. The aurora still continued; and, in want of other variety, it aforded us amusement amid this wearisome uniformity. There was much snow drift; and the wind rendered it so cold that we could not expose ourselves in any manner beyond a few minutes; the thermometer being at minus $20^{\circ}$. After the aurora had ceased, it recommenced at night in a more brilliant form, with bright flashes amid its other varieties, disappearing a little after midnight. The clearness of the sky over head was such, that we could see perfectly well in the cabin at midday, even through the double skylight, though it was covered by snow. Outside the ship, the smallest print could be read distinctly. Sunday was occupied in the usual manner.

Dec. 21. The weather continued bright; and though the wind changed from the north-west to the north-east, it became calm. The air felt mild, as is generally the case in those circumstances; the thermometer being at minus $16^{\circ}$. The horizon was so clear that every thing on it was visible; and thus we saw all around, more perfectly than ever, all the land that we had seen at several times before.

Dec. 22. On the next day it was the same, and we obtained, from the hills above, a complete view of the horizon, particularly to the south- 
ward: where the colouring of the sky was most various and splendid; being a fitter subject of painting than of description, if it was indeed within the limits of art. Much of the snow was blown away from the summits of the hills, so as to leave the brown and bare rocks visible.

The morning commenced with an overcast sky and a breeze, but Dec. 23. it soon became calm, and was followed by an aurora of short duration. The same weather continued the next day, and the Dec. 24. clearness of the sky allowed us to see stars of the first magnitude during the brightest part of the twenty-four hours, including, of course, the hour of noon. Venus was also seen in the southern quarter, displaying a bright golden colour. There was again an aurora: another to add to a succession of these appearances more regular and durable than any which had been experienced in the former voyage to this climate.

It was Christmas day. There are few places on the civilized earth Dec. 25. in which that day is not, perhaps, the most noted of the year; to all, it is at least a holiday; and there are many to whom it is somewhat more. The elements themselves seemed to have determined that it should be a noted day to us, for it commenced with a most beautiful and splendid aurora, occupying the whole vault above. At first, and for many hours, it displayed a succession of arches, gradually increasing in altitude as they advanced from the east and proceeded towards the western side of the horizon; while the succession of changes was not less brilliant than any that we had formerly witnessed. The church service allotted for this peculiar day was adopted; but, as is the etiquette of the naval service, the holiday 
was also kept by an unusually liberal dinner, of which, roast beef from our Galloway ox, not yet expended, formed the essential and orthodox portion. I need not say that the rule against grog was rescinded for this day, since, without that, it would not have been the holiday expected by a seaman. The stores of the Fury rendered us, here, even more than the reasonable service we might have claimed; since they included minced pies, and, what would have been more appropriate elsewhere, though abundantly natural here, iced cherry brandy with its fruit; matters, however, of amusement, when we recollected that we were rioting in the luxuries of a hot Londou June, without the heat of a ball in Grosvenor Square to give them value, and really without any especial desire for sweetmeats of so cooling a nature. I believe that it was a happy day for all the crew : and happy days had a moral value with us, little suspected by those whose lives, of uniformity, and of uniform ease, peace, and luxury, one or all, render them as insensible to those hard-won enjoyments, as unobservant of their effects on the minds of men. To display all our flags (as shown in the engraving), was a matter of course; and the brilliancy of Venus was a spectacle which was naturally contemplated as in harmony with the rest of the day.

Dec. 26. Christmas day was followed by a calm and clear morning, with the thermometer ranging from minus $18^{\circ}$ to $22^{\circ}$. A few observations by the transit instrument were taken, and there was another

Dec, 27. aurora. 'This continued till eight on the following morning, and the thermometer sank to minus $32^{\circ}$. Being Sunday, no work was done. There was little change, and nothing new, on the following. day; except that the temperature rose several degrees. On the 


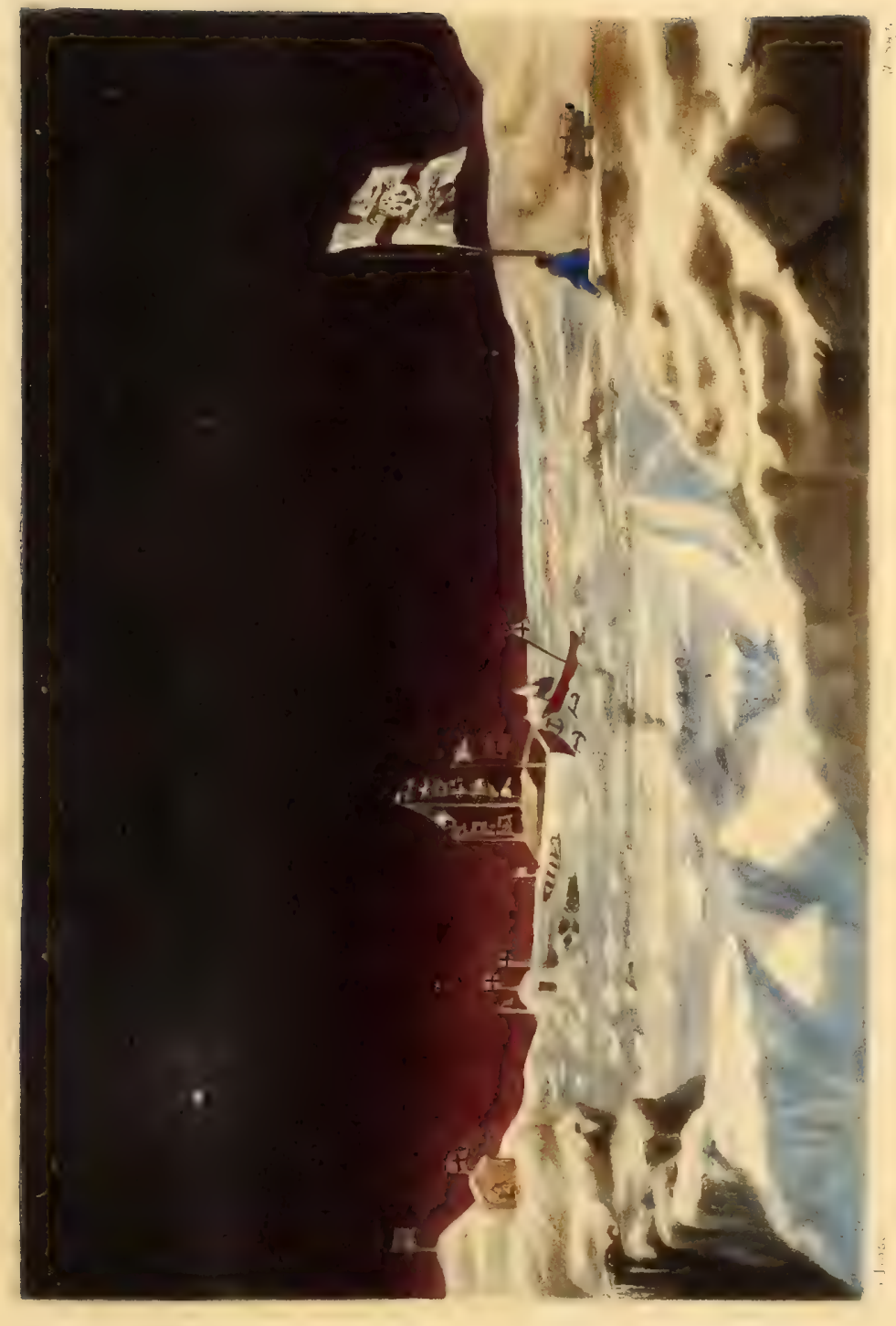



twenty-ninth, it went down as low as $37^{\circ}$ minus, so that the Dec, 29 . suspected mercury froze again; but, being calm weather, the cold was not felt to be very severe.

On this day we saw one hare, having seen two yesterday; so Dec. 30 . that all the animals had not disappeared. There was very good light during the day, from ten till half after three; and, in the course of it, the temperature rose to minus $20^{\circ}$. There was also a faint aurora; and some transits of stars were observed. On the following morning the sky was overcast; but the weather felt mild, Dec. 31 . and the thermometer rose twelve degrees. We found, on shore, the footprints of a wolf, which seemed to be travelling northward, having passed the ship at no great distance. Our chase of it ended in tracking it two miles, when we lost its traces.

Thus ended the month of December, and the year 1829. The temperature had maintained, like the preceding one, where the general results are tabulated, a medium ratio among those appertaining to the former voyages in the same month. Uncertain as temperature here, as elsewhere, must be, when examined under short periods, uncertain as even the monthly means should be, in different years, when we know how the general characters of those years differ, it is a remarkable circumstance, that the means of all the latitudes and longitudes of Melville island, Igloolik, Winter island, and Port Bowen, give nearly the actual situation of the Victory at Felix Harbour, while the temperature there also agrees with the mean temperature of these four positions; indicating thereby a gradual relation of temperature, which is at variance with a popular theory on that subject.

The observatory, I must now remark, was built on a much better 
plan than that of former years. Being larger, as well as more commodious, the breath of the observers was not so ready to condense on the instruments. Our transit instrument was also on a much larger scale, being of thirty-six inches; while its position had been perfectly verified by observations on circumpolar stars. With respect, however, to observations in general, it had not been a fortunate month. During its northern declination, the moon had been always obscured by clouds, and thus disabled us from obtaining the usual lunar distances. We had still to hope that January would be more favourable, as we were in an excellent state of preparation for the observations that we were desirous of making. On the aurora borealis, which we had so often seen, no experiments could be made, from the state of the weather and the force of the winds at those times.

I do not here note the state of the barometer; as I have seldom also mentioned it in the journal. It is a fitter subject for an appendix and a table; where the whole can be seen together, on a simple inspection, and where it can also be compared with the temperatures, the winds, and the weather, at the same time: circumstances to which these observations owe the better part of their value. With these it will be found in approximation in the tables on this subject. I need only here say, that this instrument was regularly registered four times in the twenty-four hours; being, with same others, that which was used in former voyages, and furnished by the liberality of the Admiralty. The magnetic arrangements furnished nothing worthy of record.

In the crew, it was highly satisfactory to find that not the slightest accident had occurred from the frost; as, with equal care, we hoped 
to avoid them in future; though quite aware that all care was sometimes unavailing, since the mere turning of an angle after a progress through an inoffensive temperature, might instantaneously expose us to an unforeseen blast, to some partial or casual current of air, with an effect so sudden as to be unavoidable; while the sufferer himself is the only one who does not know what has happened, and, if alone, may therefore be irremediably frozen. With this general good state of health, it was painful to see that the poor armourer was approaching to his end ; being, however, equally conscious of the inevitable event, and prepared to meet what he had for some time expected. But it was a destiny that he could not long have protracted, though he had remained at home; and we had no reason to think that it had been accelerated by the voyage or the climate.

The trial of another month continued to satisfy us of the goodness of our internal arrangements; nothing had failed, and there was nothing to alter. We were especially pleased with the success of the apparatus for condensing the vapour from within : the principle of which, it is evident, is similar to that of the condenser in Watt's engine, different as the circumstances are. The proof of its efficacy had been ample: but I must now note, in correction of the first statement respecting the quantity of ice collected weekly in the three condensers, that it was subject to considerable variations. I originally stated it at about a bushel in the day, for the whole: that being the result of our first trials, before we had fully regulated the production and the average of the heat between decks. But in the course of these attempts at discovering and maintaining the best temperature, it was found to vacillate; the produce being, in some weeks scarcely four bushels : while we easily ascertained 
that the quantity increased with augmentation of the internal heat, and remarkably so on the days when the washed linen was dried; as a little consideration will show to have been a necessary consequence. In this increase of the heat there was no advantage; and as the temperature first adopted was found unnecessarily high for comfort or use, it was reduced to an average of $45^{\circ}$, while the ice then produced weekly, amounted to a mean of four bushels or less.

It is not all, that the men were thus made comfortable, and the interior, with its various materials kept dry. All necessity for placing stoves in the hold and in remote corners ceased; and while there was thus a great saving of labour and inconvenience, and not improbably of hazard, the consumption of fuel was materially diminished. Every one knows that those points had engaged the attention of all the former navigators in these climates; and it was, therefore, also a source of self-gratulation, that we had been the first to succeed, and that too by means as simple and little expensive as they were rigidly philosophical. That I here point out this expedient, in future, to ships, in general, navigating the northern seas, on whatever pursuit, would be to little purpose, were it not as easy of adoption as it is intelligible, without any further description than the general one already given.

The school had continued to engage the men's affections; and their continued improvement, both in knowledge and in religious and moral feelings, was evident. It would have been valuable, even though it had found no more than an occupation: and, in some manner or other, we contrived to be always occupied. The pursuit of game was indeed an unproductive one, but it was still exercise, and it was variety; while we amused ourselves with hope, in 
defect of hares: often traced, seldom seen, and so seldom shot, that our sporting book was nearly a blank. In some manner or other, however, the last three months, constituting the whole period of our durance up to this point, had passed away without weariness, and had indeed been almost unfelt; while, I may add, that we had been under no necessity of inventing any idle amusements for the purpose of killing time. Those among the men who were ambitious, thought, I believe, that it had passed too quickly; since they foresaw that the duties of the summer days would render it necessary to interrupt the school, before they had made the progress of which they were so desirous.

The retrospect of the past year presented a mixed picture of good and evil: as if, indeed, this is not the history of human life at large. The expedition itself was at one time a thing almost beyond hope; it had been fitted and despatched by the spirited and liberal "London merchant," whose name can never be forgotten. Unexpected, and afterwards unavoidable and incorrigible misarrangements, had vexed, detained, and disappointed us, had filled the despondent with fears and forebodings, and had not left even the more confident without anxiety. Yet the end was far better than we had hoped: it was better than any one could have expected; since we had outstripped in distance our predecessors through the same strait, notwithstanding all the advantages, in time and in all else, which they had possessed over us. We had been in frequent and imminent peril, and had been rescued : yet not by efforts of our own: and thus we hoped for the future protection which we should still more labour to deserve. If, thus far too, we had pursued the "chimera of a north-west passage," as it has been termed, there 
were hopes before us, of following it out to a much further result; of ascertaining, at last, this unknown portion of the American geography, which, I presume, has been long the limit of the hopes of all sensible men on this subject. We were in an advanced position, with a new summer about to give its earliest notices in no long time: and when the period should come to set us free, every new step would be a new discovery.

If our reflections also turned to England, it was not to regret an idle promise that we might possibly return by the new year; but we were disappointed that we had found no means of sending an account of ourselves since our departure from the Danish settlement at Holsteinborg, in July. We had met no whalers: but, considering what our course and the season had been, these ships could easily inform our friends, that not to have met with us was no reason for doubting of our security; while all knew that we were provided with a winter home, with all indeed that our own homes could have furnished, in the wreck and the stores of the Fury.

\section{ABSTRACT OF 'THE METEOROLOGICAL JOURNAL.}

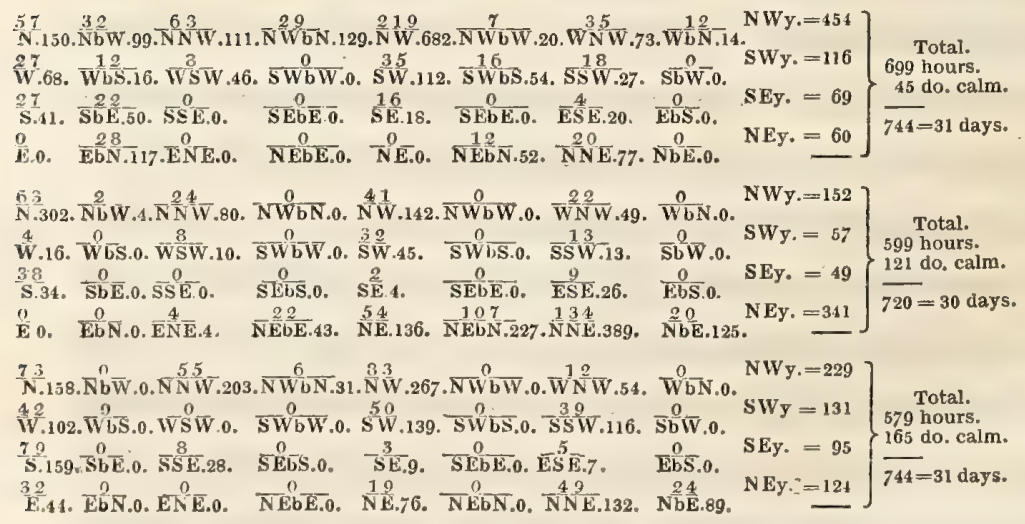

OCTUBER, 1629.

$\begin{gathered}\text { Highest, lowest, \& } \\ \text { mean temperature }\end{gathered}+24-16 \frac{1}{2} 7.94+$ mean temperature
Total force of the Wind . . . 1970 Mean force of the Wind . . $\overline{63.74}$ NOVEMBER, 1829 .

Highest, lowest, \& $\}+26-37-3.58$ mean temperature
Total force of the Wind . . . 1649 Mean force of the Wind . $5 \overline{1.90}$ DECEMBER, 1829. Highest, lowest, \& $\}-8-37--23.08$ Total force of the Wind . . 1614 Mean force of the Wind.$\overline{52.07}$

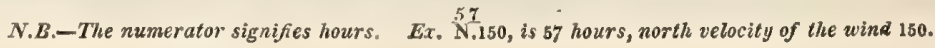




\section{CHAPTER XVI.}

COMMENCEMENT OF THE YEAR 1830-FIRST MEETING WITH THE ESQUIMAUX ON THIS COAST-DESCRIPTION OF THEIR VILLAGE, AND OF THEIR SOCIETY AND MANNERS-THEY ARE ENTERTAINED ON BOARD-COMMUNICATE SOME GEOGRAPHICAL INFORMATION, AND PROMISE MORE.

THE new year commenced with serene and beautiful weather, and it was mild, though the thermometer was at minus $16^{\circ}$, falling afterwards to $22^{\circ}$. The meridian sky displayed the beautiful tints of a summer evening, but of a character different from any thing occurring in more southern climates; the distant hills on the horizon being of a nearly scarlet hue, while a glowing purple sky above, gradually darkened into a shade deeper than an analogous twilight would produce in England. This second holiday of the Christmas season was celebrated by the same indulgences to the men; who contrived for themselves a concert of about the same quality as their ball; each of them, however, being in very just and harmonious proportion to our apartments, our establishment, and our climate; and having therefore the merit of fitness at least. But what matters the mode, if people can make themselves innocently happy? At home, it is probable, half of them would have been in- 
toxicated; that being the exclusive road to happiness in the estimation of our countrymen; but I cannot help thinking with Froissart, that although this is the usage of Britain, it is to enjoy ourselves "bien tristement," while it were well if this was the worst result.

Jan. 2. Last night the thermometer underwent many changes within a few hours, without any apparent cause, and there was a remarkable halo round the moon. On cutting through the ice, it was found to be five feet four inches thick, giving an increase of nearly three feet during the last month, unless, as was possible, some loose pieces had been floated in beneath the field, by the tide, and there attached. The wind increased to-day with gloomy weather, and the cold was severely felt, though the temperature was not lower Jan. 3. than $19^{\circ}$. The next day it was milder, because calmer; the temperature being the same at first, though afterwards rising to $11^{\circ}$. It was Sunday, and was spent as usual.

Jan. 4. There was some snow from the southward, with an overcast sky; and the thermometer rose to minus $7^{\circ}$. The rocks that had been laid bare were once more covered, so that all the landscape was one indiscriminate surface of white; presenting, together with the solid and craggy sea, all equally whitened by the new snow, the dreariest prospect that it is possible to conceive, while unaccompanied by a single circumstance of the picturesque, or any thing capable of exciting the smallest interest. Such it is indeed, almost every where, in this wretched country, and, above all, in winter. The voyager may be a painter, or he may be a poet; but his talents at description will here be of no value to him; unless he has the hardihood to invent what there is not to see. Whatever may be 
the interest attached to the illustrations adopted in this work, it is easy at least to perceive that they owe nothing to the actual landscape; to a nature void of every thing to which the face of a country owes its charms.

We thought there was a visible increase of the meridian twilight Jan. 5. yesterday; but this day was overcast and dark, though calm, and therefore mild; the average temperature being minus $8^{\circ}$, and the greatest heat minus $4^{\circ}$. The thickness of the weather, increasing in the evening, turned out provoking; but did not finally prevent us from getting an occultation of Aldebaran by the moon, together with one of Capella, and some others of importance. It happened that the hares appeared in numbers to-day, and one was shot: a circumstance worth noticing, because, in the former expeditions, they had never been found so late in the season as January. The fabrication of a snow staircase, with a wall, found useful employment as well as amusement for the men, who had learned to pride themselves in the beauty and perfection of their icy architecture and masonry.

The wind shifting to the northward, it became very cold; but the sky was brilliant with red and purple tints in great variety. A remeasurement of the thickness of the ice confirmed our former suspicions; it was found to be but four feet and a half thick; but Jan. 6 . even this is a greater thickness, by half a foot than had been found at the same period of the year in former voyages, while the cause was, probably, the greater shallowness of the water. Another obscure aurora made its appearance in the zenith. On the fol- Jan. 7. lowing day, a brilliant sky at ten in the morning presented an entirely new aspect; the space above the setting moon being of a 
rich golden colour, and that near the sun's place displaying a bright silvery tint; both of them the reverse of what is the usual rule in other climates.

Jan. 8. The wind increased, with a snow-drift; but a fine night allowed us to make many useful observations on transits and other matters. The sky presented the same colouring, and the thermometer was at minus 26. Again, many of the rocks on the hills were cleared of their snow by the wind; and the men were employed to-day as well as yesterday in bringing gravel to the ice, preparatory to the cutting of a canal which we intended for the exit of our ship when the time should arrive.

Jan. 9. Going on shore this morning, one of the seamen informed me that strangers were seen from the observatory. I proceeded accordingly in the direction pointed out, and soon saw four Esquimaux near a small iceberg, not far from the land, and about a mile from the ship. They retreated behind it as soon as they perceived me; but as I approached, the whole party came suddenly out of their shelter, forming in a body of ten in front and three deep, with one man detached, on the land side, who was apparently sitting in a sledge. I therefore sent back my companion for Commander Ross to join me, together with some men, who were directed to keep at a distance behind him. Proceeding then alone, to within a hundred yards, I found that each was armed with a spear and a knife, but saw no bows and arrows.

Knowing that the word of salutation between meeting tribes was Tima tima, I hailed them in their own language, and was answered by a general shout of the same kind; the detached man 



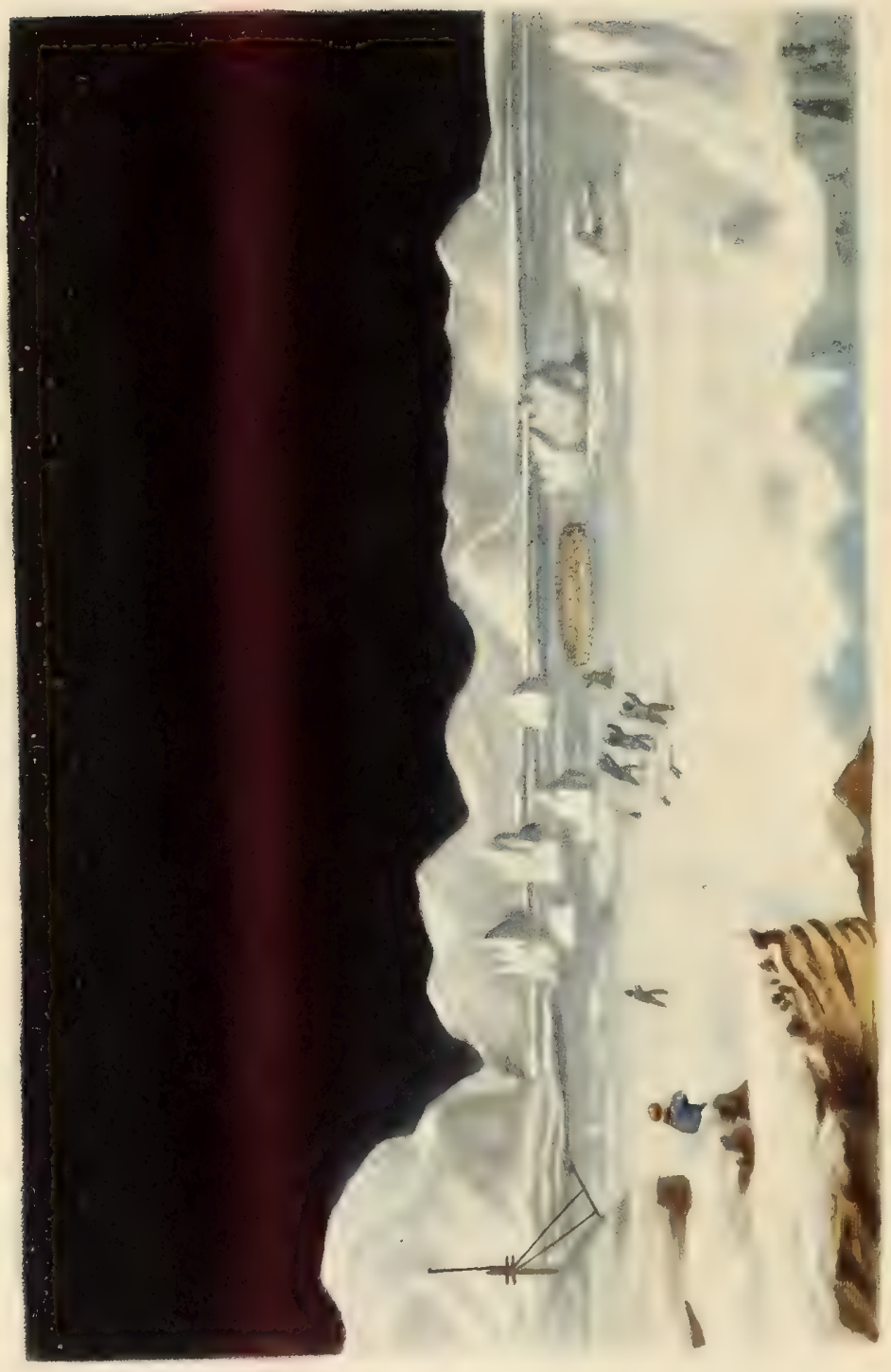


being then called in front of their line. 'The rest of my party now coming up, we advanced to within sixty yards, and then threw our guns away, with the cry of Aja Tima; being the usual method, as we had learned it, of opening a friendly communication. On this, they threw their knives and spears into the air in every direction, returning the shout Aja, and extending their arms to show that they also were without weapons. But as they did not quit their places, we advanced, and embraced in succession all those in the front line, stroking down their dress also, and receiving from them in return this established ceremony of friendship. This seemed to produce great delight, expressed, on all hands, by laughing, and clamour, and strange gestures: while we immediately found ourselves established in their unhesitating confidence.

Commander Ross's experience was here of great use; and, being informed that we were Europeans (Kablunæ), they answered that they were men Innuit. Their numbers amounted to thirty-one; the eldest, called Illicta, being sixty-five years of age, six others between forty and fifty, and twenty of them between forty and twenty; the number being made up by four boys. Two were lame, and, with the old man, were drawn by the others on sledges: one of them having lost a leg, from a bear as we understood, and the other having a broken or diseased thigh. They were all well dressed, in excellent deer-skins chiefly; the upper garments double, and encircling the body, reaching, in front, from the chin to the middle of the thigh, and having a cape behind to draw over the head, while the skirt hung down to the calf of the leg, in a peak not unlike that of a soldier's coat of former days. The sleeves covered 
the fingers; and, of the two skins which composed all this, the inner one had the hair next the body, and the outer one in the reverse direction. They had two pairs of boots on, with the hairy side of both turned inwards, and above them, trousers of deer-skin, reaching very low on the leg; while some of them had shoes outside of their boots, and had seal-skins instead of those of deer, in their trousers.

With this immense superstructure of clothes, they seemed a much larger people than they really were. All of them bore spears, looking not much unlike a walking stick, with a ball of wood or ivory at one end, and a point of horn at the other. On examining. the shafts, however, they were found to be formed of small pieces of wood, or of the bones of animals, joined together very neatly. The knives that we first saw, consisted of bone or reindeer's horn, without point or edge, forming a very inoffensive weapon; but we soon discovered that each of them had, hanging at his back, a much more effective knife pointed with iron, and some also edged with that metal. One of them proved also to be formed of the blade of an English claspknife, having the maker's mark on it, which had been so fixed as to be converted into a dagger.

This was a proof of communication with the tribes that trade with Europeans, if that was not the case with themselves. Commander Ross did not indeed recognise among them any of his former acquaintances, while he was evidently unknown to them; but when he mentioned the names of places in Repulse bay, they immediately understood him and pointed in that direction. $\mathrm{He}$ could also make ont that they had come from the southward, and 
had seen the ship the day before, that their huts were at some distance to the northward, and that they had left them only in the morning.

Having no foresight of these visitors, we had of course no presents at hand for them, and we therefore sent a man back to the ship for thirty-one pieces of iron hoop, that there might be a gift for each individual. But, in the mean time, they consented to accompany us on board, and we soon arrived at our snow wall. At this they expressed no surprise ; it was, indeed, too much like their own work to excite any; nor did they show any of those marks of astonishment, at either the ship itself or the quantity of wood and iron before them, which we had found among the northern savages of Baffin's bay in 1818. It was evident that they were no strangers to even an abundance of these materials.

The present of the iron excited universal delight. In return, they offered us their spears and knives, which, to their equal astonishment and satisfaction, we refused. We could now easily see that their appearance was very superior to our own; being at least as well clothed, and far better fed; with plump cheeks, of as rosy a colour as they could be under so dark a skin. Like the other tribes of Esquimaux, their goodnatured faces were of a regular oval, the eyes dark and approaching each other, the nose small, and the hair black : nor were their skins of so dark a copper tint as those which I had formerly seen in the north. They seemed a cleaner people too; and, what I had not seen before, their hair was cut short, and arranged in no careless manner.

Their dresses were made with peculiar neatness; and some were ornamented with fringes made of sinews, or with strings of small 
bones. The skins of gluttons, ermines, and grey seals, hung at the breast, seemed also to be ornamental appurtenances. Their sledges were singularly rude; the sides consisting of pieces of bone tied round and enclosed by a skin, and the cross bars on the top being made of the fore legs of a deer. One of them was but two feet long, and fourteen inches wide, the others were between three and four feet in length. On the under part of the runner there was a coating of ice attached to the skin, rendering their motion very easy.

Three of the men were, after this, introduced into the cabin, where, at length, they showed abundant signs of wonder. The engravings, representing their countrymen, selected from the several former voyages, gave them great delight, as they instantly recognised them to be portraits of their own race. The lookingglasses, as usual, were, however, the chief source of astonishment, as, especially, was a sight of themselves in our largest mirror. Scarcely less surprise was excited by the lamp and the candlesticks; but they never once showed a desire to possess themselves of any thing; receiving, merely, what was offered, with signs of thankfulness that could not be mistaken. They did not relish our preserved meat; but one who ate a morsel seemed to do it as a matter of obedience, saying it was very good, but admitting, on being cross questioned by Commander Ross, that he had said what was not true; on which, all the rest, on receiving permission, threw away what they had taken. But the same man, on being offered some oil, drank it with much satisfaction, admitting that it was really good. Thus admirably are the tastes of all these tribes adapted to their compulsory food, and their views of happiness to 
the means of it which have been provided; nor, assuredly, had these men, amidst their blubber and their oil, their dirty diet and villainous smells, any reason to envy the refined tables of the south; as, among those, they would not only have experienced disgust, but felt pity for our barbarism and ignorance; while if they had been induced to partake, it could have been only under the impulse of starvation.

In succession, three more were treated in the same manner, while the first set proceeded to amuse the rest with what they had seen. $A$ short race was also run between one of them and an officer of our party; but with so much and such equal politeness on both sides, that there was no victor to be declared. The violin being afterwards produced, they joined our men in dancing; and thus seemed, whether it was the fact or not, to have a much greater relish for music than had generally been found among the other tribes by our predecessors.

It being now necessary to separate, we proposed to accompany them part of the way to their huts, the direction of which they pointed out; making us understand that their wives, children, dogs, and sledges, were all at home, and that they had abundance of provisions. During our walk we met a seal hole on the ice, and they showed us the use of the spear in enlarging it for the reception of a twig of ash or birch, together with their method of throwing that weapon. But we could not make out by such inquiries, what was of chief importance to us, namely, the direction of any open sea. They, indeed, pointed to the north as being the place in question; but not being able to understand from them what lay 
to the southward and westward, we were obliged to defer further questions to another day. Having proceeded about two miles, we now made a mark on the ice as the place of rendezvous on the following day, when they were made to understand that we should visit their huts : a proposal which was received with the highest satisfaction. We parted under the same ceremonies which had attended our meeting.

This was a most satisfactory day; for we had given up all expectations of meeting inhabitants in this place; while we knew that it was to the natives that we must look for such geographical information as would assist us in extricating ourselves from our difficulties and in pursuing our course. It was for philosophers to interest themselves in speculating on a horde so small, and so secluded, occupying so apparently hopeless a country, so barren, so wild, and so repulsive; and yet enjoying the most perfect vigour, the most well-fed health, and all else that here constitutes, not merely wealth, but the opulence of lnxury; since they were as amply furnished with provisions, as with every other thing that could be necessary to their wants. And if the moralist is inclined to speculate on the nature and distribution of happiness in this world, on the admirable adaptation found, here as elsewhere, between the desires and the means of gratification, the pious one will not forget the Hand, which, under the most apparently hopeless circumstances, thus spreads for His creatures, a table in the wilderness.

After divine service, which, for that purpose, we lield unusually early, we proceeded to perform our promise, though the thermometer had fallen to minus $37^{\circ}$. We found the natives at the 



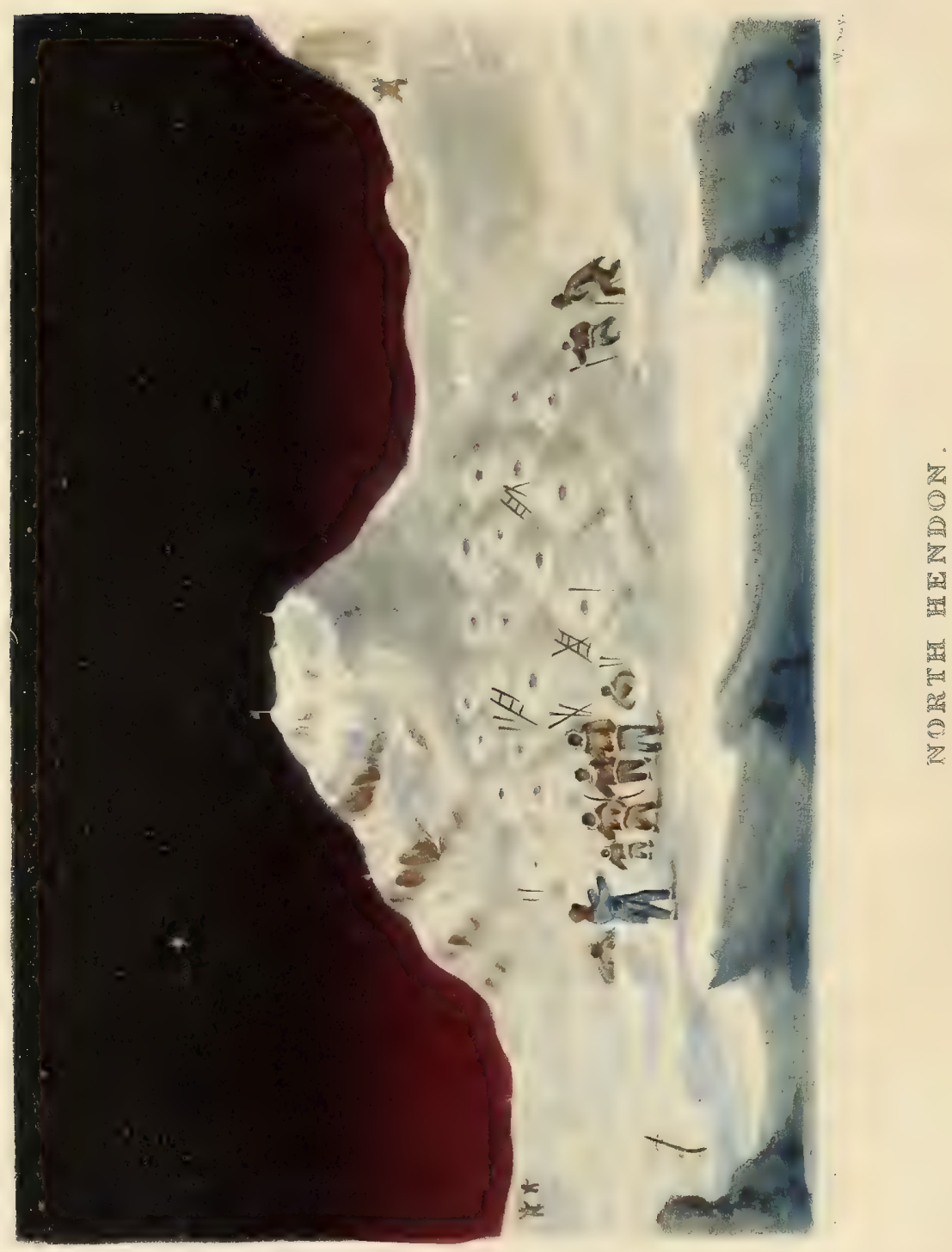


appointed place, and, on approaching, one, who appeared to be a leader or chief, came a hundred yards in advance, holding up his arms to show that he had no weapons. We therefore threw away our guns; on which all the rest, in the rear, threw their warlike instruments into the air, as they had done before, and, with the usual exclamations, waited our approach. The number was now increased by about twenty children, and we went through the usual forms of salutation.

The village soon appeared, consisting of twelve snow huts, erected at the bottom of a little bight on the shore, about two miles and a half from the ship. They had the appearance of inverted basins, and were placed without any order; each of them having a long crooked appendage, in which was the passage, at the entrance of which were the women, with the female children and infants. We were soon invited to visit these, for whom we had prepared presents of glass beads and needles; a distribution of which soon drove away the timidity which they had displayed at our first appearance.

The passage, always long, and generally crooked, led to the principal apartment, which was a circular dome, being ten feet in diameter when intended for one family, and an oval of fifteen by ten where it lodged two. Opposite the doorway there was a bank of snow, occupying nearly a third of the breadth of the area, about two feet and a half high, level at the top, and covered by various skins; forming the general bed or sleeping place for the whole. At the end of this sat the mistress of the house, opposite to the lamp, which, being of moss and oil, as is the universal custom in 
these regions gave a sufficient flame to supply both light and heat; so that the apartment was perfectly comfortable. Over the lamp was the cooking dish of stone, containing the flesh of deer and of seals, with oil; and of such provision there seemed no want. Every thing else, dresses, implements, as well as provisions, lay about in unspeakable confusion, showing that order, at least, was not in the class of their virtues.

It was much more interesting to us to find, that among this disorder there were some fresh salmon; since, when they could find this fish, we were sure that it would also furnish us with supplies which we could not too much multiply. On inquiry, we were informed that they were abundant; and we had, therefore, the prospect of a new amusement, as well as of a valuable market at the mere price of our labour. They now offered us, in return for our presents, any thing which we might choose; and we accordingly selected some spears, and some bows with their arrows; together with an ear ornament of iron ore, being a ball attached to a string, and some specimens for our collection of natural history; the former object being rendered more ornamental by some foxes' teeth that were attached to it, with a fringe of sinews in addition. Some more needles, which we now added to our former gifts, served to gain their unreserved confidence and friendship.

Of these huts, built entirely of snow, I must add, that they were all lighted by a large oval piece of clear ice, fixed about halfway up on the eastern side of the roof; while the variations among the different ones that we inspected were trifling. But we also saw afterwards, what had escaped us before where was so little light to. 
discern any thing, that about the middle of each passage was an antechamber leading into a recess for the dogs. It was obvious, too, that the external aperture could be turned at any time, so as to be always on the lee side, and thus prevent the wind from entering. We found that these huts had been but just erected: they were scarcely a day old; so that the architectural processes of this country did not occupy much time. It was also ascertained that their winter stock of seal and reindeer was buried in the snow, that this store was laid up in the summer, and that they returned to it in the winter. Hitherto, this practice had not been found among the natives of these countries; whether overlooked or not, we could not decide.

The females were certainly not beautiful; but they were, at least, not inferior to their husbands, and were not less well behaved. All above thirteen years of age seemed to be married; and there appeared three or four such in every house, whether belonging to one establishment or not, we were not sure, but appearing to be the young wives in a house where there was one old one. Their stature was short, and they were much inferior in dress and neatness to the men; their hair especially being in a matted and disordered state. Their features were mild, and their cheeks, like those of the men, ruddy; one girl of thirteen was even considered to have a pretty face. All were tattooed to a greater or less extent, chiefly on the brow, and on each side of the mouth and chin; this ornament consisting in lines alone, without any peculiar figures, and thus conforming to the usages of the north-western Esquimaux of America, as they have been described by different voyagers. 
Their dress did not differ materially in form from that of the men; except that the outer garment had a peak before as well as behind, while some were ornamented with fringes of shred skins.

The important inquiries were now, however, to be made; and the answers, containing mixed good and evil news, were of the following nature. They were acquainted with Igloolik, Winter island, and Repulse bay, and had left Ackoolee, a station opposite to the latter, only thirteen days before; having come to this place to be nearer to the open water, which they informed us lay at some distance to the northward. They said that the land to the eastward was an island named Kajaktagavik, and that they had come along the coast to the westward of it, where there were several great rivers; but we could not exactly discover whether there was a passage to the southward of that island or of the south point now in view. This was especially vexatious; as our hope of a further progress lay in this direction, and as we could not doubt that the land to the eastward was the American continent.

They further informed us that there were plenty of musk oxen on the hills to the southward, and that the reindeer all came this way in April: while the skin of a glutton which we bought from them proved the presence of this animal also. Their method of hunting reindeer, as they described it, is precisely that which is adopted in other parts of this country; and as it has often been minutely stated, I need only say that it consists in aping the appearance of the animal, by means of two men, the foremost carrying the head and horns over his own; thus giving them unsuspected access, even within the herd. 
The attempt to make a drawing of this village excited much uneasiness at first: but they were satisfied as soon as the purpose was explained, and were delighted with the identity of the representation when the sketch was finished; each recognising his own house. It being then time to think of returning, many of the people offered to accompany us, and we took leave of the women and children; inviting the lame man to come on the following day, that he might be examined by our surgeon. Eight of the men attended us to the ship, and while six were turned over to the care of the seamen, we invited the two leaders to our own cabin dinner.

Much astonishment was of course excited by the knives, plates, and other furniture of the table; and if their taste was not improved since the day before, while it had probably, then, only been taken by surprise, they at least relished the soup, and, with scarcely any awkwardness, immediately learned the use of the spoon. They were at least good mimics; since, after observing our proceedings for a little while, they equally found out the management of the knife and fork, shortly using these as if they had been long accustomed to them. They seemed now to relish the preserved meat; as they did some salmon, more naturally : but they did not like the salt meat, and equally rejected pudding, rice, and cheese. Having dined, they desired to rise, and we attended them forward to their companions, who had been equally well treated by the sailors; when we found them all dancing together.

As we were returning to the ship with them, before these adventures, a very cold blast of wind came down a valley, when one of 
them observed that the frost had seized one of my cheeks, on which he immediately made a snowball and rubbed it, thus certainly saving me from a disagreeable sore, at least. After this, he continued always near me, frequently reminding me to put my hand to the same part, for fear of a recurrence of the attack. This was goodnatured, and aided, with all else, to give us a favourable impression of these people: while they all shared the same dispositions, in aiding to carry our things, as if they could not do too much to oblige us.

Jan. 11. The morning was clear, but cold, with the thermometer at minus $35^{\circ}$; while, expecting our new friends, we did not go out. At one o'clock the man who had lost his leg, whose name was Tulluahiu, arrived, with another, very intelligent native, called Tiagashu, drawing him on a sledge. On examining the stump, the surgeon found it a sound one, long healed, while, the knee being bent, there was no difficulty in applying a wooden leg. The carpenter was therefore sent for to measure him; while, anticipating the purpose, he expressed the greatest delight. As they seemed now to be unusually communicative, the chart was produced; when it appeared that they were acquainted with every place between Igloolik and Repulse bay, or with their names at least, and with those of some of the inhabitants. When Ackoolee was mentioned and pointed out in the chart, they immediately recognised their own position and that of the ship.

One of them, Tulluahiu, then took the pencil and drew the line by which they came, afterwards making spots on it, and counting their fingers to show that they had slept only nine times on the 
journey. Tiagashu then drew a line of coast round which we could sail in the autumn ; this being in a westerly direction, and including several capes, bays, and rivers ; while, off it, were drawn several islands, in one of which he placed a lake: during which demonstration he further pointed out where salmon and other fish abounded. After this, his draught of the coast took a northerly direction, considerably beyond our present position, and not less to the westward of it; while his estimate of the distance was two days; adding, that here also there were rivers running into the sea.

The first man then resumed the pencil, and drew several large lakes in that part of the country where we were now fixed; further noting places where we should find natives, and drawing a route by which he conld go over land to the salt water in nine days. They, however, told us that one of their party was a much better geographer than themselves, and promised that we should see him. This philosophical discussion being at an end, they informed us that eighteen of their men had gone out to kill seals, but that it was too cold for the women and children: and we then amused them till dinner time with the engravings in the preceding voyages. They seemed to recognise all the names, as if they had, at least, heard of the persons mentioned, though they had not seen them; and, had we known their language better, we should doubtless have found that the science of being acquainted with whatever may discredit one's neighbours is as well understood here as in an English country town; and that it is not even necessary to be very near neighbours to be very intermeddling, and as malicious as possible. I should be very glad to find, that in this conjecture, 
I had done our new friends injustice: about our own at home, it would be far more desirable to be proved in the wrong.

In our cabin, the snuffers proved a great object of attraction; but still more effect was produced by a large reading-glass, through which, when held between them, each saw his friend's face magnified beyond all understanding. Such are the delights of novelty, and thus does the curiosity of pure ignorance ever find new gratifications. But we who, here, know every thing, knowing even what we have not seen or learned, have contrived to get rid of these pleasures; it is even to be feared that the "schoolmaster abroad" will shortly find his place a mere sinecure; so universally does knowledge seize, even on those who do not take the trouble to pursue it. It is almost a proverb, that there is no royal road to science; but a road as brief as royalty could have desired, without being able to command it, has been found by those to whom the privileges of knowledge cease to be odious whenever they can themselves exert those.

Fortunately, thus far, for our new guests, there was no penny science, in this land of little light, to interfere with their admiration; it was absolute, as that of their countrymen had been the day before: though one bad effect at least of their ignorance was displayeed in their abhorrence of plum pudding, with which we had vainly hoped to regale stomachs accustomed to find blubber a sweetmeat, and train oil preferable to maraschino. This, indeed, we had not to give them; but our brandy was as odious as our pudding; and they have yet, therefore, to acquire the taste which has, in ruining the morals, hastened the extermination of their 
American neighbours to the southward. If, however, these tribes must finally disappear, as seems their fate, it is at least better that they should die gradually by the force of rum, than that they should be exterminated in masses by the fire and the sword of Spanish conquest; since there is at least some pleasure, such as it is, in the mean time, while there is also a voluntary, if slow suicide, in exchange for murder and misery. Is it not the fate of the savage and the uncivilized on this earth to give way to the more cunning and the better informed, to knowledge and civilization ? It is the order of the world, and the right one: nor will all the lamentations of a mawkish philanthropy, with its more absurd or censurable efforts, avail one jot against an order of things as wise as it is, assuredly, established. All which it is our duty to provide for, is, that this event be not hastened by oppression and wrong, that it may not be attended by the suffering of individuals.

But amid these depressive reflections, the time came to end our entertainment and send our company home; the carriage, such as it was, being in waiting. We explained that the new leg would be ready in three days, when we hoped for the pleasure of trying it on; and then, presenting them each with one of the empty meat canisters, they took their departure in high glee. It is delightful to be able to overwhelm the needy with gold; not less so, I imagine, when it is done at no cost; and here we had made these poor men as rich and as happy, with what was little better than an old saucepan, as if our canisters had been made of silver, and were to be purchased with gold. Let no man imagine that he knows what a present is worth, till he has found what happiness can be pro- 
duced by a blue bead, a yellow button, a needle, or a piece of an old iron hoop.

A very cold breeze prevented us from escorting them on their journey, as we had intended. We did nothing else on this day, but remove some small stores out of the way, lest they should tempt these hitherto honest people, and thus make us guilty of teaching them a vice to which they appeared strangers : a vice common among all savages, and too much so, even in some of this race, as we are assured by the experience of many navigators. 


\section{CHAPTER XVII.}

RECEIVE MORE GEOGRAPHICAL INFORMATION FROM ONE OF THE NATIVES CALLED IKMALLIK-CONTINUE OUR COMMUNICATIONS WITH THEM-PURE MERCURY FREEZES AT LENGTH, AT MINUS $39^{\circ}$ - THE FIRST SUNRISE OF THE YEAR-DEATH OF THE ARMOURER-END OF THE MONTH AND SUMMARY.

THE promised hydrographer, Ikmallik, came to us this morning, Jan, 12. accompanied by Tiagashu, and they were taken into the cabin; six others who attended them being turned over to the care of the men. The first information which we received was, that they had killed several seals on the day before, at the seal holes; the method being, as many readers perhaps already know, to transfix them by the spear, when the agitation of the signal twig that is placed in the hole of the ice, shows that they have come up to breathe. Thus is the cunning of even the lowest of mankind an overmatch for the wisdom of the wisest animal : though neither our friends of this country nor the animal which they outwit, are to be ranked in the extremes of these classes.

Some paper containing a sketch of the land already known between Repulse bay and Prince Regent's inlet, was now laid before them, with the names of the different places marked. These were at 
once recognised: and Ikmallik then taking the pencil, proceeded to prolong the sketch from Akullee, following very nearly, for a very considerable space, the line already traced by Tulluahiu. After this, he prolonged it still further westward, instead of turning to the north, as the latter had done; then continuing it to the north-west, in a direction more favourable to our views. He did not, however, insert the islands; nor could we discover how many days it was estimated from the end of his chart to Akullee near Repulse bay; but he drew Wager bay and its river very correctly, making also several other rivers. He further gave us to understand that our ship could sail that way till the autumn; and with this information we were obliged, for the present, to be content.

We showed our new friends the engravings of the natives who had been known and drawn in the preceding voyages, being those which had been displayed to our first visitors; repeating their names at the same time. The names were recognised as before : but both of them expressed surprise at the difference of aspect and style between those persons and themselves; while, but for the beards, they were inclined to believe them portraits of women. This leader, Ikmallik, was a strong active man, about five feet ten inches high ; being the paragon of the party, and indeed, among these tribes, a man of unusual power and stature. The same presents sent them all home, happy and thankful.

Jan. 13. A thermometer at minus $35^{\circ}$ made this a really cold day; but the wind was not such as to prevent us from performing the promise we had made, to accompany the natives on a seal-hunting expedition. We met them accordingly, about halfway from their village, un- 


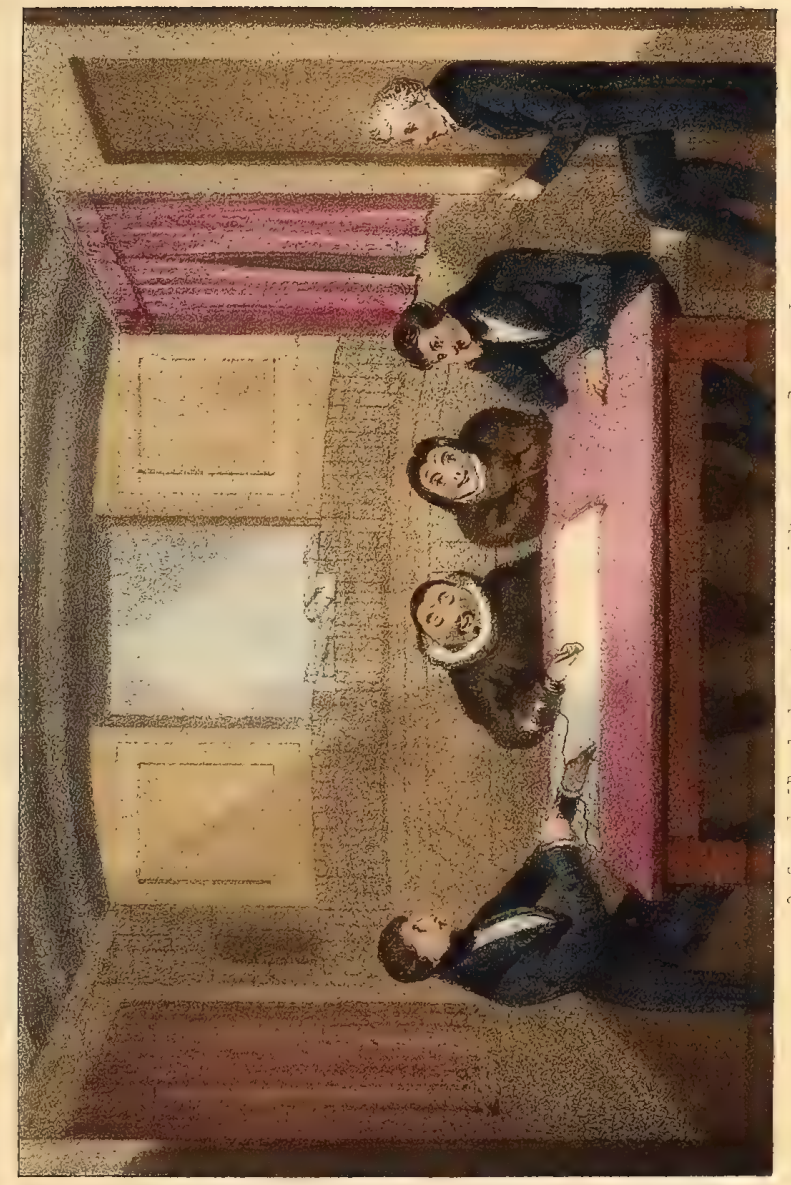





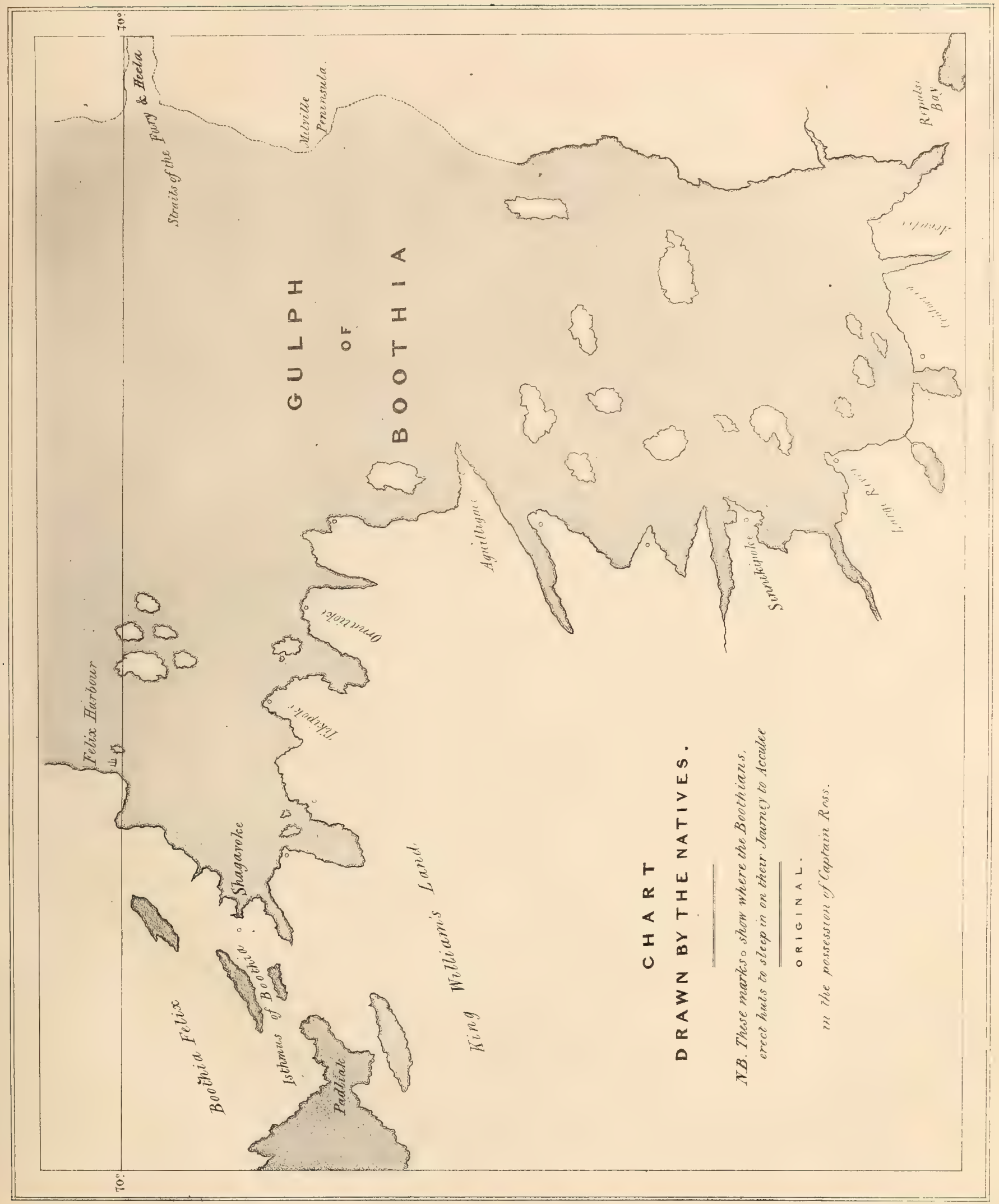



armed; and they turned back quite delighted when told that we meant to proceed to their huts. A sharp breeze then springing up against us, the danger of being frost-bitten became considerable: on which they all undertook to watch us, giving notice whenever it was necessary to apply our hands to any part of our faces that were in danger of suffering, that we might rub them for restoring the circulation.

The women had lost much of their timidity, on this our second visit: and finding that the seal-hunting party was absent, we entered Tulluahiu's hut, where we met a kind reception from his mother, wife, daughter, and two young children, forming his apparent family. A complete female dress had been made ready as a present for me; being of the materials and construction already described, with an appearance of unusual care in adjusting the symmetry of the skins, so that the colours should correspond on each side; while there was a fringe below, and a border of white round the hood and the openings for the arms. I had no doubt that it was a first-rate specimen of mantua-making; and it was my business to estimate it as a London lady would have done the loftiest production of the highest dress-maker in the calendar of fashion. In return, I presented this generous lady with a silk handkerchief; being the article, of all that I had shown her, which attracted her chief admiration. I soon found too, that this personage, woman though she was, did not want a knowledge of geography, and that also, of a different nature from what she might have acquired in an English boarding-school, through the question book and " the use of the globes." Tiriksiu, for that was her name, perfectly comprehended the chart; and being furnished with the means, drew 
one of her own, very much resembling it, but with many more islands: adding also the places where we must sleep in our future progress, and those where food was to be obtained. On these points, at least, it was an emendation of the knowledge we had attained before.

The hunting party now returned, with a large white seal : while the rest of our crew also joined us, having experienced the same kind treatment wherever they had been, and having seen, among the people, large quantities of venison and fish which had evidently been buried in the snow. The politeness of the natives, as it must be esteemed, caused a party to accompany our men on their way, in apparent return for the same civility before shown by us; but, after a time, they asked leave to depart, and we separated with the usual noisy forms. It was settled at the same time, that Tulluahiu should come for his wooden leg the next day, while the rest were to resume their seal hunting. It was exceedingly cold on our way back to the ship, and I did not escape without losing some skin from one cheek. We had seen three ptarmigans in the morning, but it was in vain that we tried to start them again on our return.

Jan. 14. : The thermometer fell from its station of minus $33^{\circ}$ last evening, to $38^{\circ}$; and as the breeze made it very cold, I doubted if our patient would keep his appointment. He came, however, by noon, accompanied by his friend Otookiu, whose wife Kuanga, together with an elderly woman, four men, and two boys, completed the party. The three principals were taken into the cabin, as we could there accommodate no more, and the rest were left in charge of the mate. The wooden leg was then fitted, to ascertain 
whether the length was correct; and as it had, after this, to be finished, the man for whom it had been made was desired to return on the following day. A re-examination of the chart added little to our previous information; but what we conld conclude was, that there was a great bay between Akullee and this place, and that if there was any opening to the westward, it must be a very narrow one.

That they knew what it was to delineate land, was evident, because they drew the lakes near Repulse bay very accurately, together with the places of several inlets and rivers on the coast, both to the southward and westward. They had heard of the sea houses of the other Esquimaux, but had not seen them; and thence, while we concluded that they had never been on the east coast, so we inferred that this tribe does not travel out of the limits of this bay, though we could not yet be sure of the nature of their mode of life and migration.

Desiring to go at one o'clock, the rest of the party were called from below: and we were entertained to find that the mate had prevailed on the elderly dame to have her hair cut, and combed, and arranged; the result making such an advantageous change in her appearance, that all of them desired to undergo the same operations. This was an unusual display of ambition and taste among these tribes; making me regret that I had not provided myself with a stock of combs, as presents; but the string of beads which I gave to each of the women was probably of more value in their eyes, if of far less use.

We tried some mercury, known to be pure, and it froze. This Jan. 15. was the test of a temperature of $39^{\circ}$ minus; and as the thermometer 
by which we were now observing stood at the same mark, we were satisfied with its accuracy, as far as this point at least. It fell afterwards to $40^{\circ}$, being, hitherto, our lowest degree. The meridional horizon was less clear than usual, so that we derived much less advantage from the sun's noonday twilight. The two men of yesterday came alone; it was understood that the rest had gone to hunt for seals. The promised leg, being now complete, was fitted on; and there was little time lost in finding its use and value; as the disabled person soon began to strut about the cabin, in apparent ecstasy; with more reason certainly to be delighted with his present, than all the others united, with what they had received. All the surgery of this case lay indeed with the carpenter; not the worst operator, I believe, in this compound profession; but I doubt if any effort of surgery ever gave more satisfaction than we had thus conferred, in reproducing a man fully serviceable once more to himself and his community.

The gratitude, however, in this case, took a very amusing course; yet, though somewhat ludicrous to us, it was natural in them, who had no reasons to doubt their own medicinal knowledge; while the only medical superiority that we had yet displayed, consisting in a greater command of timber and tools chiefly, was not such as to render them suspicious of their own powers. But whatever the vanity might be, the good will was unquestionable. The poor armourer, they saw, was worn to a skeleton; and as Otookiu was an Angekok, or conjuror, and physician in one, they proposed to apply their charms towards the cure of our fast-wasting patient. It is true enough, that diseases can be conjured out of a man's 
body, or mind, as is more likely; and that were it not for the power of conjuration, physic would want its right hand, even in London, abounding in other successful Angekoks than the several bold quacks, who, each in his own department, heals all the diseases of his own peculiar set of gulls. But our poor man's case was too serious to permit our countenancing such trifling as this; and the proposition was therefore passed by, till it was forgotten amid the other objects of attraction by which the attention of our new friends was so fully occupied.

The leg was inscribed with the name of the ship, and packed up in the sledge, as it was not yet sufficiently familiar for a journey of two miles through ice and snow. That we parted better friends than ever, cannot be doubted. We learned to-day that Tulluahiu had a brother who was engaged with a party further north, whom he intended shortly to join for the purpose of hunting the musk ox ; that there was excellent salmon fishing in spring and summer, and that there was also large fish in the lakes; while he further informed us, that they were to continue for the present in this place, as they had taken many seals the day before. We regretted to have ascertained, that under the same language, their dialect differed much from the vocabularies in the books, and also from the Danish dictionary of the Esquimaux tongue which we possessed. We had therefore an interest in studying it seriously, since it was likely to be our chief future source of information : and, in this pursuit, Commander Ross, very naturally, proved the most apt scholar.

Three natives came on board to-day, reporting that they had Jan. 16 . killed six seals the day before. Tiagashu, the son of the old man 
of the tribe, was amongst the most intelligent that we had conversed with; but neither of them, after inspecting the chart, added any thing new to our previous information. They were amused, as these people had always been, with the sketches which we made of them, and laughed heartily at the portraits of the wooden-legged man and his companion. Those who had not received tin canisters before, as presents, were now treated with one each; and on parting, if we understood them rightly, they informed us that they had lately seen some of the people from Igloolik. The thermometer fell to $42^{\circ}$ minus, in the evening, and there was an inconspicuous aurora.

Jan. 17. After having been at $43^{\circ}$ minus in the morning, the temperature rose a few degrees in the course of the day. During divine service, five of the Esquimaux came to the ship; and after that was over, they were adnitted. That Sunday is unknown to them, I need not say. The features of an elderly man, Holishaktoo, which were preserved by a portrait, differed considerably from the general character, as if he had belonged to a different tribe. They informed us of the capture of five more seals; making up the whole week's hunt to eighteen, which they considered a successful one, though they should even take no more at this time. The presents were repeated, as before, to those who had not received any; and two of the number were pleased to get rid of their beards under the hands of the mate. The rising of a smart wind under this temperature, made us invite them to remain for the night; but though two were willing to stay, the rest had appointed a seal hunt, and they all departed. 
There was to-day a violent storm of drift snow, since the wind Jan. 18. of the morning soon rose to a gale; and it was consequently so thick at noon, that we could not see the sun, on which we had calculated. The thermometer, however, rose to $32^{\circ}$ in the course of the day, and, at nine at night, was but minus $9^{\circ}$. It was a day of absolute imprisonment, of course. The wind was much less Jan. 19. severe on the following day, having been from the north-westward, with the barometer at $28 \frac{1}{2}^{\circ}$ or thereabouts.

It did not, therefore, prevent the visit of our friends, as the preceding one had unquestionably done; three men and two boys arriving early in the forenoon, and remaining with us a few hours; after which they departed, with the usual gratifications. The first fraud attempted on us occurred to-day, but it was a sufficiently pardonable one. A boy begged a canister for his mother, whose husband, as we found, had already received one; but the detection of this scheme only occasioned merriment among them : a result which we experienced on many occasions afterwards. One of the men was distinguished by a row of foxes' teeth in his hair, and seemed especially intelligent. It occurred to me to-day, that we might, by taking a couple of boys into the ship, contrive to teach them English, and also, by aid of the books furnished by the minister at Holsteinborg, enable them to learn the art of reading and writing their own language. Thus, should we succeed, they might be rendered of essential use hereafter; and I therefore concluded on making the proposal at the first opportunity.

The gale abated to-day, and the weather became settled and Jan. 20. clear. Commander Ross and the surgeon paid a visit to the native 
village, and were amused by an exhibition of singing and dancing. The sun appeared for the first time, after an absence of fifty days, being above half its diameter above the visible horizon; so that we might have seen the upper limb before, as we had calculated, had the sky been sufficiently clear. That, however, which gave us pleasure, had no such effect on the Esquimaux, to whom the night of this region is their day; or to which it is, at least, far preferable, since it is of far more value to them in hunting the cunning and cautious seals. For this reason they always returned home when the day broke; complaining of the light as their enemy and as the cause of a compulsory, not a wilful idleness. After this, having informed us that they had marked down 'some ptarmigans, we were induced to proceed on the pursuit of this game, and at length contrived to shoot one. It proved, however, to be a willow partridge; showing that this bird exists in these regions during all seasons of the year.

The unfortunate armourer, James Maslin, died this evening. It had been long ascertained that he was suffering under tubercular consumption, and could not survive; so that our regrets were necessarily limited. That he had been in hospitals in England for the same complaint, had been known to us from a very early period of our voyage, but not under such circumstances as to enable us to send him back. His age was forty-five; and he did not quit this life without having been long prepared for the event.

Jan. 21. The twenty-first was calm and clear. A boy and a girl from the Esquimaux, in company with some men, paid us a visit. The 
latter was so wrapped up in furs that she made the figure of a globe standing on two pins; but black piercing eyes, added to ruddy cheeks and youth, produced a pretty face, where our standard of beauty had ceased to be fixed at a very high degree. I imagine that this is a much more tractable standard than is commonly supposed; and that habit effects, in a far shorter time than has been thought, that change in the feelings on this subject which we vainly suppose can never occur. Such at least has been the experience of all travellers; and the arrangement is unquestionably a wise one, since that which is the only accessible ought also to be the most acceptable. This young person was already betrothed, as is the custom of this country; the affiance being even settled, in many cases, during extreme infancy, or almost from the birth of the female child. We have all read romances in which these early contracts had proved unsuccessful: perhaps they succeed better here, because there is so little variety to distract attention, that one wife is equivalent to any other that might be chosen; but if the system is not practically very different from that of the Turks and Chinese, (presuming the contract to be irrevocable, which we do not know, ) the husband at least sees his future bride, can watch her progress upwards, and does not, to use a very vulgar phrase, "buy a pig in a sack," like the man of China, or him of the race of Othman.

My readers are probably tired of the names of men who can have no peculiar interest for them, and whom, like the writers of Indian history, (if these persons would but recollect it, which, unfortunately, they have never yet done,) we can distinguish by nothing to make one hard word remembered in preference to 
another. Nor can it much interest any one, who was the wife, son, nephew, grandaughter, or betrothed, of whom, when the wedding day was fixed, or what were the politics, gossipings, squabbles, friendships, or parties, in this septentrional city. Much, therefore, which we learned, I may decline to record: I much doubt if it could entertain even the female ancients of an English village : as universal knowledge "progresses," a new interest will attach to a region so robbed of its " natural rights" by nature herself, and a newspaper will, of course, approximate this frozen and furred people to the great fraternity of mankind. It was much more important than all that I might have here told of the yet dormant Morning Post of this ill-used country, to find that the wooden leg had enabled our friend to attend the seal hunt: but as the philosophy of our worthy carpenter, Chimham Thomas, had contrived a more fitting foot to it, for walking on snow, and that the said foot was in progress to completion, he was appointed to come for it on the following day.

They departed not long after noon; and the remainder of the people's time was employed in digging the armourer's grave. 'To the professional in this task, there is, in this, nothing: to us, a small circle, mutually dependent, and separated from all the world, it would have been a painful office, since it was almost that of the parent or brother who digs the grave of his dearest relation, on a desert island, not knowing when his own turn may come to claim the same service from those who remain; but our long conviction of the inevitable event had blunted those feelings and wearied those reflections. The task, however, was executed in silence, at least; 
and it was not for any of us to inquire of the feelings of those who were employed in this painful office.

The sun was really brilliant at noon, and considerably elevated : it was a regaling sight; while it also gave a promise that could not be broken, the promise of increasing in brightness and duration every day. This is indeed a sunrise, though more in promise than performance, to which all the splendour of morning suns in a southern climate is as nothing. It is an ever welcome luminary, undoubtedly, when it first announces day, to all at least whom an artificial life has not corrupted: it is welcome even to them, should chance afford them the means of seeing the morning's rise. But it is a far other morning to those who have been deprived of the sight of the glorious sun for weeks, who have seen little more than a prolonged evening for months. Its rise seems a new life; and though it has here finished its almost momentary career before we can well say it is here, there is the certainty of a better to-morrow, the assurance that summer is to come, and that it is now truly approaching.

The twenty-second of January was the finest day that we had Jan. 22. seen for a long time; and though the temperature was at minus $35^{\circ}$, it was so calm that the cold was little felt. The owner of the new leg came to us, with a large party, including a flock of boys from five to thirteen years of age : and the new foot, being ready, promised so well, that we could scarcely prevent him from returning immediately, that he might try its powers. The magnitude of the benefit seemed indeed to overwhelm both himself and his friends: and we felt, of course, carpenter and all, the full triumph of superior 
civilization; as the people themselves evidently admitted that we were a more cunning race than they, though we could not equally harpoon seals at an ice hole, nor eat walrus flesh stewed in train oil.

Thus much for the useful arts. Navigators have often missed that acknowledgment of superiority which they expected in the estimation of savage nations, by furnishing them with objects of pure luxury; and when, finding their error or not, they have desired to do better, they have forgotten that new wants cannot be formed in a moment, nor old habits broken in half a day, by a bottle of porter and a beef steak, or an uncomfortable pair of breeches: that custom alone, were vanity of no account, causes the savage to estimate his own clothing, or the want of any, at a much higher rate than all which even a Stultz could produce, to value and cling to his own modes of life, and his own food, repulsive as it may be to ourselves, far beyond all that can be offered in exchange. A wiser politician would measure the mind first, and, to that, adapt his attempts at beneficence or improvement. But it is very unreasonable to expect that all men should be wise; and most unreasonable of all, to expect this in improvers and inventors. I will not, therefore, note the errors of well-meaning men, to whose plans I need only allude, on this subject; but I am sure that the simple contrivance of this wooden leg, raised us higher in the estimation of this people, than all the wonders we had shown them, and, undoubtedly, far higher than the superior attainments of all kinds, belonging to us, which they could not appreciate.

It was not politic to exhibit all our wonders at the beginning of our acquaintance; and having therefore reserved something for 


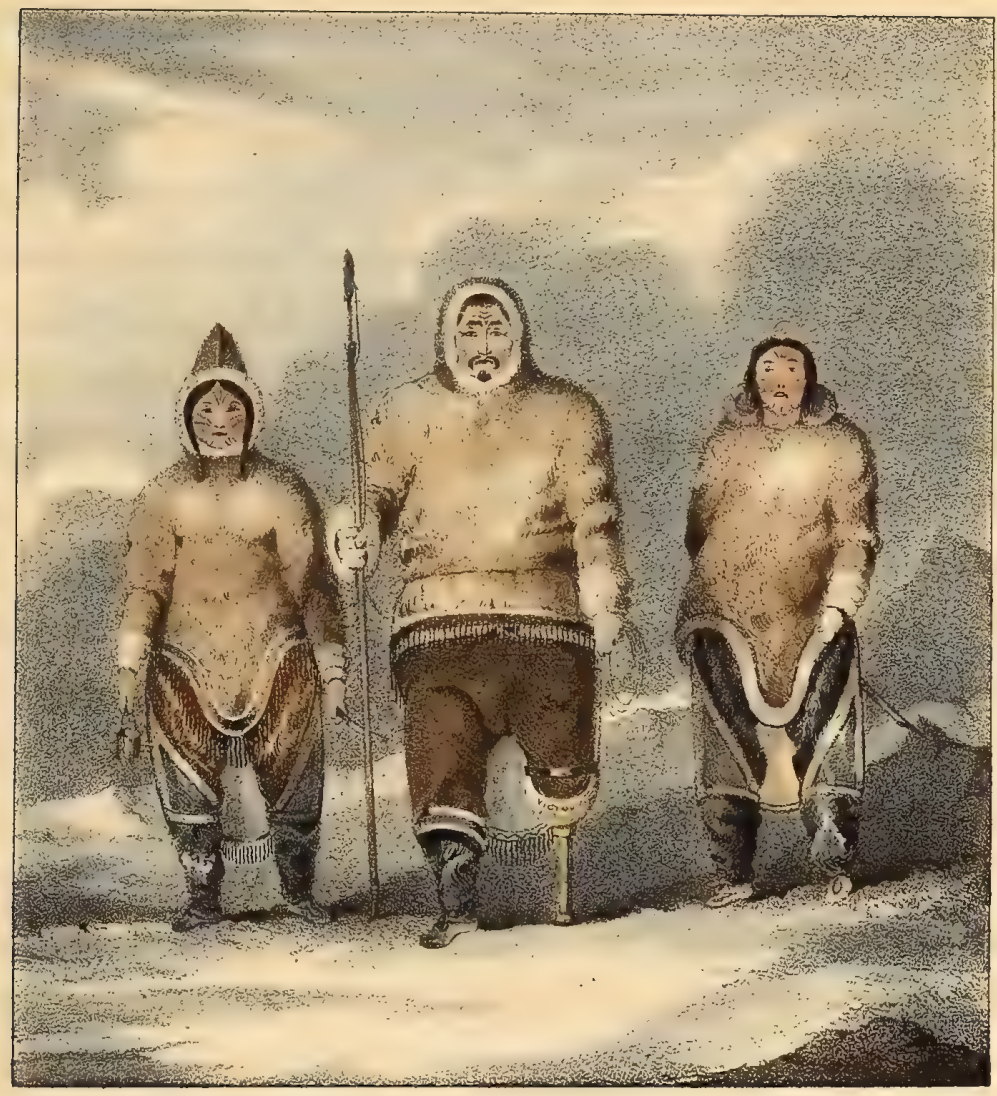

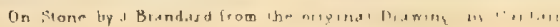

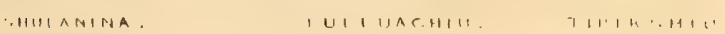



a further display, the apparatus for instantaneous light, which was now produced, excited, in the phraseology of our day of cant phrases, a strong sensation. The interior of a watch seemed more than incomprehensible; and we seemed in great danger of being reputed among the conjurors: our betters in philosophy had acquired the same reputation, but too often a very serious one for them, in ages not far removed, and amid more light, it must be hoped, than irradiated the mental climate of a tribe of Esquimaux.

In the mean time, three willow partridges were brought in by my nephew; we had not chosen that any of the natives should go with him, being as yet unwilling that they should know the effect of our weapons. The game was however examined by them very minutely; and they expressed a great desire to know the nature and operation of the guns; questions which, for the present, we contrived to evade by unintelligible explanations. The comparative measurements of their statures excited much interest among them, and they were exceedingly clamorous at finding that there was one who measured but four feet ten inches, since two of them were five feet eight inches high. Their departure left us, once more, to our usual occupations for our own comfort and future projeets.

We had another visit of men and boys. One of the former was Jan. 23. from Neitchillee, and had Indian rather than Esquimaux features, This place, to the south-west, they estimated at nine days' journey of a sledge: we supposed it might be a hundred and fifty miles. The effects of the magnet were the chief novelty shown this day. The exhibition of snapdragon, as it is called, produced also great 
surprise; especially in the conjuror, who rewarded us with one of his conjuring songs. The use of a pistol was now also at length shown; since it was, sooner or later, necessary for them to know that our arms were superior to their own.

Jan. 24. From minus $35^{\circ}$ yesterday, the temperature rose to $20^{\circ}$. We had settled that the armourer's funeral should take place before the church service; and it was accordingly performed with the usual forms and solemnity; an appropriate sermon being afterwards selected for that of the day. Fortunately, the natives offered us no interruption by their visit; but, after noon, they arrived, to the amount of fourteen, including five children. The man with the wooden leg had walked the whole distance, being two miles and a half, and was therefore quite master of his implement. Among. them was a stranger from another tribe, with his hair in a different fashion; but we could not make out the place of his residerice. The tame fox unfortunately died, from having got access to a specimen of the willow partridge, in the preparation of which arsenic had been used; thus causing us a double loss.

Jan. 25. Another party came on board, and among them a woman with an infant at her back. She was hideously tattooed all over the face; and her portrait, like that of many others, was drawn. Her husband was a stranger, belonging to some southern tribe, and knew the names for copper and brass; whereas, with the present people, the name for iron applied to all. The presents which we made to these also, did not prevent the disappearance of a pair of snuffers; though we could not ascertain who the culprit was.

Jan 26. Fifteen of the Esquimaux arrived to-day, with some clothing to 
sell; and they thought themselves amply rewarded in receiving a knife for each. To put a check on their troublesome familiarity, I admitted only four into the ship; two of our former friends, with their wives. To prevent temptation also, all the portable articles which were outside of the ship, having been placed on the ice for convenience, were brought on board; while some men were appointed to watch, in case of any attempts at pilfering. Even without the case of the snuffers, we had no right to expect absolute honesty among this tribe above all others; and, at any rate, were bound to expose them to no temptations. After their departure we took our walk, and found a raven feeding on a hare which we had probably wounded to death in some of our excursions. The temperature was at $34^{\circ}$ minus.

Another set of visitors brought two more dresses, which we Jan. 27. purchased at the same price, together with a seal-skin, valued at a piece of an iron hoop. We had, of course, the trouble of the usual office of showmen: but to our further inquiries about Neitchillee the only answer we could get was, that there was a large river, with plenty of fish. They had taken more seals during some days past, and were to proceed with this hunting.

The temperature rose, and the sun was felt to have some power Jan. 28. this day. Fourteen Esquimaux came alongside, including five women who had not seen the ship before: and we had again, of course, to go through all the ceremonial of showing wonders and making presents : thus, however, increasing our collection of portraits. A female fox was taken in a trap, in a state of extreme starvation: displaying corresponding voracity when meat was 
produced. It served to replace the former. Another, in the same Jan. 29. condition, was caught on the following day: and the unfortunate solitary raven, approaching the ship, was shot. It had been a companion of our stay all the winter, and deserved to have been spared. In other days, or in minds more deeply tinctured with poetry or superstition, I know not what mental misery might not have followed an act so sacrilegious.

Jan. 30. Proceeding to the Esquimaux village, we met the wooden-legged man coming alone towards the ship, with a present of an arrow, and with the intention of informing us that Otookiu was sick. We found him with a swelled face; and it was settled that he should come to the ship, on the next day, for remedies. We were kindly received by the women, and purchased some small articles. The thermometer this day was at minus $30^{\circ}$, and some transits were obtained.

Jan. 31. This month ended with a very fine day. Half the village arrived while we were engaged in our church service; Otookiu, with the swelled face, being among them. He received his medicines, and then was sent on shore to remain with the rest till we should have concluded. On coming out, we found that most of them had gone away; and we then dismissed some others, from whom we purchased the deer-skins which they had brought. We found, from the three men admitted, that the women had departed, under the supposition that they should be refused entrance into the ship: and as these perpetual crowds were really inconvenient, we took this opportunity of settling that only five or six at one time were to come in future. 
We learned that they had found a bear, torpid in its den, and had killed it with their knives. We offered to buy it of them, and they promised to bring it on the following day. We had a specimen of their cunning, in one who, having a sore on his leg, begged to have a wooden leg made; expecting thus to gain a piece of timber. It was easily explained, that the first condition was, to cut off the sore leg; which of course put an end to this application.

We had now terminated the first month in a new year, and it had passed away like a dream; our occupations and amusements had been greater than usual, and our visitors prevented time from dragging on in a tiresome uniformity. The mean temperature of the month had been minus $25^{\circ}$; corresponding, as those of the former months did, with the means of the other voyages, in the manner I formerly stated these. This too is considered the coldest month in the year, taken as a whole, in these climates; though colder single days often occur in February and March. It had been the most stormy month, however, for some time; and the barometer was orce as low as 28 inches.

The health and appearance of the crew was rather improved than the reverse; and the armourer's originally lost case could not be reckoned among the casualties arising from the climate. If he might have lived longer by remaining in England, the fault was his own; since he had already sailed in these seas, and knew well what he was hazarding, while keeping a secret which we could not discover till it was too late. He deserved praise indeed for his spirit; though, for many reasons, we could have wished he had acted otherwise. 
If our meeting with the Esquimaux had been, in many ways, interesting as well as amusing to us, so was it an acquaintance which could be rendered serviceable. They had already furnished us with some dresses, much more useful to the men than those which we had brought from England, and we had reason to expect more.

It was probable also that they might supply us with fresh meat; thus enabling us to economise our own stores.

The information which they had given us was of even higher importance: while we now also hoped, that by means of their dogs and sledges, we should be able to examine a great deal of the coast, so as to decide on our future motions by sea, long before we should be released.

In our interior establishment, every thing had proceeded with perfect order and comfort, the school promising, ere long, to produce some able navigators. The observations by the transit instrument had been numerous and successful. The preparations for cutting a canal in the ice had been continued as occasion offered. 


\section{CHAPTER XVIII.}

PILFERING ON THE PART OF THE NATIVES-THE FIRST FALL OF SNOW OF THIS YEAR-NATIVE DANCE-SUMMARY OF THE MONTH OF FEBRUARY.

THERE was another arrival of Esquimaux, on the first day of this new month, with wives and children; and we bought from them three skin dresses; but the bear continued to be promised. The man with the swelled face was better, and brought a bow that he had proposed to give us. One of the women had an ornament on her head, consisting of the head of an owl, with some ermine-skins. The temperature was minus $25^{\circ}$, and the day so cloudy that none of the expected occultations in Taurus could be observed, nor any of the moon-culminating stars.

It did not become clear till the moon had passed Taurus and IFeb.2. there was nothing more to be observed; a mortification sufficiently common with astronomers. The Esquimaux brought some more skins, which we bought; but not the bear: we had reason to suspect that this promise was not about to be kept. But we had now something more to discuss with them: and the event was to show that they were not those examples of absolute honesty, which 
we had at first supposed, if much less inclined to stealing than most savages have proved. And whatever excuses navigators have made for these races, from the strength of the temptation when iron has been the subject of theft, they do not, I fear, apply here, where the objects stolen could be of no use, if indeed, I except the snuffers; though, in fact, even these, iron as they might be, were not likely to be of much service, though the hammer might be applied to some purposes.

A large reading-lens had disappeared for some days; and I had reason, on consideration, to suspect the conjuror Otookiu; the candle having gone out, for some time, in the cabin, after I had been exhibiting its effects to him. This was confirmed afterwards, by his unwillingness to admit me into his house at my last visit to the village. I therefore told him that the swelled face had been produced by the magical glass, and that it must be returned. His confession immediately followed, together with a promise to bring it back on the following day: without which, I assured him that his other cheek would swell in the same manner. It was brought back accordingly, together with a hammer which had disappeared; while the snuffers were admitted to be in the possession of one of the women, together with a glass out of my spectacles, which one of the children had found, on its having dropped out. The terror of the conjuror was indeed so great, that he brought back a hook and a harpoon head which I had given him in exchange for a bow ; on which, to preserve this probably useful impression of terror, I agreed to a re-exchange.

Feb. 3. On the preceding day we observed a transit of the moon, and had many observations of stars on this one; the weather being unusually 
clear. The thermometer was first as low as $38^{\circ}$ minus, and it afterwards fell to $40^{\circ}$. The Esquimaux brought nothing but a part of the bear's skin; but we purchased a reindeer-skin from them. The spectacle glass was returned, and the bearer rewarded with a tin canister, as this had not been a true theft. The snuffers also were produced; and it was then explained, that if any thing should hereafter be lost, none of the natives would be suffered to come on board any more. Nor would we admit any of them at this time, that we might give a tangible proof of our resolution, and of our firmness in adhering to it.

The temperature sank to minus $42^{\circ}$, but the day was clear and calm, so that the cold was not severe on shore. Some natives came, and sold us some dresses, together with the ornament made of teeth. Eight seals had been taken by them in the last two days. They brought a small part of the bear, saying that they could get no more. A few returned on the following day, and, among the rest, a woman with a nursling, whom she took out of her bag, and exposed naked to the air, at the breast, with the thermometer at minus $40^{\circ}$.

It rose to $32^{\circ}$ to-day, the weather continuing calm and fine. The Feb. 6 . whole thirty-one Esquimaux came; and as two had not yet seen the ship, they were admitted. The conjuror was in great distress, because he had taken no seals; attributing his ill luck to the magical glass. I promised that the enchantment should cease in two days; and they agreed to bring us a seal on the following day, if they succeeded in taking one. On cutting through the ice, which we had begun to do the day before, it was found to be six feet thick; being an increase of twenty inches within the last month, 
and giving a greater thickness, by a foot and a half, than at the corresponding season at Port Bowen in $\mathbf{1 8 2 5}$.

Feb.7. The cold increased on this Sunday, falling in the afternoon to minus $43^{\circ}$. Of fifteen Esquimaux that came alongside, some were admitted after church, and sold us some excellent skins. On the

Feb. 8. following day they brought us three more, and informed us that their dogs had killed a bear on the ice, which would be at their houses on the next day. We proposed to purchase it, together with a seal. The wind changed very often in the course of this day, and the thermometer rose to minus $30^{\circ}$.

Feb.9. It fell again to $42^{\circ}$, and this weather was very cold to the feelings. Nevertheless we proceeded to the village, in company with our principal friends who had come for us; meeting with the usual kind reception : but as neither bear nor seal had yet arrived, our labour was thus far lost. In returning against the wind, the cold was very severe; yet we visited the cairn which had been erected for one extremity of a trigonometrical base, where also we had made experiments on the velocity of sound at these low temperatures, which I shall have occasion to note hereafter. In the evening, the thermometer sank to minus $45^{\circ}$.

Feb. 10. We estimated on this day, the tenth of February, that it must have sunk to $48^{\circ}$ : but, at this point, our instrument was uncertain. The Esquimaux arrived, with some faces much frost-bitten, selling us the skin of a young bear and some other articles. They informed us that the expected bear had not yet arrived. There was an aurora seen; but not so marked in character as to deserve

Feb. 11. description. On the following day, they brought more things for sale; the wooden-legged man also bringing a thimble and a needle 
which one of the natives had either found or stolen; for which he was rewarded by a sail-needle.

The thermometer rose four degrees, but the cold was nevertheless

Feb. 12. very severe, as indeed could not fail; since a difference of twenty, or even of forty degrees, I may say, at such a temperature as this, produces little difference to the feelings. Some Esquimaux women brought gloves and other things for sale returning at noon, without coming on board. It was calm at night, and the thermometer fell to minus $45^{\circ}$. On the following day, more women, Feb. 13. with some boys, came to sell other articles, and all were bought; a man also bringing his seal spear and harpoon, for which he received his price.

The sun had considerable power to-day, and the thermometer Feb. 14. rose to $33^{\circ}$ minus. After church, some Esquimaux men and women came, bringing some seal blubber for our dogs, and promising a whole seal on the morrow. A gale had come on last night, with heavy squalls, but it moderated this morning. The natives came again with some small articles, but we refused to admit them till they should bring the promised seal. Otookiu brought also a knife, having an English maker's name on the blade; saying that he had obtained it from those of his nation who had seen the ships formerly at Igloolik.

The barometer rose to $30^{\circ} \mathbf{7 9}$, without any apparent reason, as Feb, 16 . the weather was not so fine as it had been for some days past. The temperature vacillated upwards, till it reached $32^{\circ}$ minus. A native came in the morning to say that they had been unsuccessful in catching seals; and three others, in the evening, confirmed the same tale. Some of the officers went to the village, but did not procure one. A male fox was caught in the trap. 
Feb. 17. The sky was overcast, with some drift snow, and the thermometer rose to minus $16^{\circ}$. We bought some articles brought by the natives, but did not suffer them to come on board. But this was not the only purpose of their visit; since there was a general restoration, as we understood, of all other things which they had purloined; among which, a table knife from the mate's mess had alone been missed. With this there was a piece of iron, another of an iron hoop, and a sheave of a block. The cause of this repentance and restoration was, we found, to be attributed to the guns which had been fired for the purpose of the experiments on sound. One of them having attended Commander Ross to the observatory, and having asked what the "guns said," was informed that they were naming the thieves who had taken our property, of whatever nature, from the ship; on which there was a general convocation held at the village, and it was agreed to return every thing. We had to regret that we possessed no such powers of conjuration over the much less: pardonable thieves of our own dear native land: among its other advantages, the "march" of knowledge has deprived the good of this power also, over the evil ones of this world. What the relative gain and loss may be it is not here my business to discuss; but let us recollect, at least, that it is not all gain. At any rate, we here made use of the advantages still in our power, and therefore did not lose the opportunity of confirming them in their good intentions to "steal no more;" informing them consequently that this was the cause of their late ill success in seal hunting. The failure of this chace, with which we had become acquainted, was a piece of knowledge, of which, like many much less pardonable conjurors, we took this justifiable advantage.

Feb. 18. The temperature rose as high as minus $9^{\circ}$, and the average of 
the day was $12^{\circ}$; the wind being from that which was always the warmest quarter; north-easterly. The natives brought the long promised seal at last; but it was so mutilated as to be fit only for the dogs. They desired also some remedies for one of the women, who had been taken ill. The surgeon therefore went to visit her, in the sledge, drawn by six dogs; and having prescribed for a cough and cold, returned at night.

The first fall of snow for this year was to-day, and the temperature rose to minus $7^{\circ}$. Some native women came, with trifling articles for sale, and were much gratified by the sight of a sledge of our own construction: this being machinery much more within their comprehension than what they had generally seen with us, and thus, I doubt not, giving them a more rational idea of our superiority. The snow did not last a second day, and the weather Feb. 20. was cloudy and mild. A female fox was taken in the trap, and we had thus the means of procuring a breed, if we chose. Some Esquimaux arrived; and it was lucky for our denunciations, that those who had restored the stolen prorpety had been successful in the seal hunting. But their families were so much in want, that they could not spare us any of their capture.

This was the finest and the warmest day that had yet occurred Feb. 21 . since November. It was calm, and the thermometer continued rising till it reached zero at midnight. It may surprise an English reader to hear of a warm day at a temperature of $32^{\circ}$ under the freezing point; but the temperature of sensation is more relative than is imagined, and the body soon contrives to find a new and much lower scale of comfortable and endurable heat. The natives arrived, at length, and, with a seal of middling size, for which they received the promised reward of a woman's knife. This is the usual knife 
of the leather-cutters, being a semicircular blade; and it is used by them for the same purposes as a butcher's knife is with us: the reserved duty of cutting up the seals being the privilege, or service, be it whichever it may, of the fair sex. They were put under charge of the watch during divine service; as we were determined that this should never be interrupted while we had the means of performing it. We had now learned to part, without the usual noisy and troublesome ceremonies.

Feb. 22. The temperature, to-day, ranged between minus $11^{\circ}$ and $2^{\circ}$ : in other respects, it was mild. Many hares were seen; but they had been so often chased, that they were now unapproachable. Some

Feb. 23. more skin dresses were bought to-day. On the following, with a cloudy sky, the thermometer rose to one degree plus, and rested at minus $5^{\circ}$. Among other articles bought this day, was the skin of a glutton; and as it had been taken in a trap the day before, we proceeded to construct one, in hopes of a similar prey. A seal was also brought in the evening, and a ptarmigan was killed. This was the first day, for a long time, that we had both breakfasted and dined by daylight.

Feb. 24. It was a fine day, though overcast, with a temperature generally about minus $5^{\circ}$. A fine hare was shot, and the new trap finished and set. More skins were purchased; so that we were in a fair way. to get an ample supply of clothing for a long time. The heat fell Feb. 25. to minus $16^{\circ}$ on the following day. The two fox-traps produced each a female prisoner, one of which was reserved alive. We also bought some sealskin jackets from the natives.

Feb. 26. The weather was much colder, though the fall of the thermometer did not exceed five degrees. The natives brought another skin of a glutton, caught also but the day before, with three more 
sealskin jackets. A knife was the established price of all such articles. Whether there was any holiday among them, or whether it was to be taken as a tribute of gratitude, Ikmallik, the geographer, had brought a party for the purpose of treating us with a dance. There were not less than twenty. The dance was more like an exhibition of bears than aught else; though a Savoyard bear, at least, must be admitted to be the better dancer. The dance was followed by a vocal concert, the women ranging themselves in a semicircle, shutting their eyes, and opening their mouths, while vociferating Amna Aija with all the power of their throats and lungs. I fear that we were not musicians enough to analyze and estimate the peculiarities and merits of this national music. The Esquimaux of Greenland, whom we had heard, had very different conceptions of this art. It remains to be tried by some one else, whether these people also, here and elsewhere along this coast, have the faculty of music, waiting only to be brought forward by education, by hearing what they had never yet heard. We should be as unjust in passing on them an unlimited condemnation, as the early travellers in Southern Africa had proved themselves in the case of the Hottentots; who, under Moravian instruction, have surprised their teachers, and even produced, as their reports say, a rival of Catalani. I must add, that Ikmallik, being the Coryphæus I. presume, continued dancing in the centre of the semicircle.

This day was very fine, but not so warm. The natives brought Feb.27. some trifles for sale, and the officers saw a glutton and a hare during their excursion. On the Sunday it became once more cold, the Feb. 28. thermometer falling to $31^{\circ}$. A fresh breeze made it severely felt during some attempts at observation in the evening. An entire seal, well adapted for a specimen, was brought by one of the 
natives, who confirmed also some of the geographical reports of the former man. They departed so early as not to interfere with our church service.

The ending of this month leaves little to be said in the way of summary. It was a very cold one; and I now believe that the thermometer must have reached to minus $50^{\circ}$. The average of the first fourteen days was certainly not less than $40^{\circ}$, and might have been more; but, in the latter part of the month, the mean did not exceed $28^{\circ}$ : the whole corresponding, once more, to those formerly noted as found in former voyages. The oscillations of the barometer were remarkable, as has been noted in the daily journal, but the mean was $30^{\circ} 11^{\prime}$.

A summary of the success of the natives in hunting during this month, gives two white bears, threè gluttons, a dozen of foxes, and fifty ${ }^{\star}$ seals : and as we had also, ourselves, killed or taken five foxes, with some hares, ptarmigans, and willow partridges, this is a country not so destitute of game, even at this time of the year, as has been generally supposed; while it is thus proved that they do not migrate to the south in winter.

In our internal comforts and the satisfaction of the men, there was no alteration : all had gone on well. Some valuable observations had been added to our astronomical collection, and many experiments on sound made. Of our communications with the natives, I have nothing more to remark; except that we had come to a perfect understanding respecting the price of each article of sale which they brought. Their pilferings, there was reason to hope, were at an end: but it was certain that they considered these acts no vast crime, since the detection generally produced laughter. 


\section{CHAPTER XIX.}

PURCHASE OF DOGS FROM THE NATIVES-COMMANDER ROSS DEPARTS ON AN EXPEDITION TO THE NATIVE HUTS, FOR INFORMATIONPROCESS OF BUILDING SNOW HUTS-SUMMARY OF THE MONTH OF MARCH.

IT was an extremely cold morning, but, to the feelings more than 1830. to the thermometer. Two of the natives arriving, I accompanied them in a walk, where they pointed out a better place for a trap to catch the glutton; it being in a pass which they use in going to the northward. One of them was persuaded to sell one of his best dogs : which was warranted for keeping at bay a bear or a musk ox, for finding seal holes, and for drawing a sledge. With such qualities, it was cheaply purchased for a knife. As nothing else was offered for sale, we concluded that they had parted with all their disposeable articles.

Another dog was bought this day, to complete our team : I could March 2. not venture to buy more at present, lest we should not be able to feed them. They brought us an account of the death of the old man whom we had remarked at our first meeting. We had not seen him since that day; and, on inquiry, when at the village, were informed he was asleep; though he was not in the hut then pointed out, as we ascertained; while there was one shut up. The 
solution of whatever mystery there might be in this matter, was necessarily deferred.

March 3. The natives brought us a fine reindeer-skin, and promised another seal. Hazy weather continuing, prevented all observations. March 4. The following day was colder, because there was more wind; but including both, the temperature ranged between minus $24^{\circ}$ and $38^{\circ}$. A bear-skin was brought; and we understood that two parties were about to be detached, one to the northward, and the other eastward on the ice, for the purpose of catching seals, but that they would soon return to watch for the animals which were then expected to be migrating from the southward.

March 5. There was little change in the weather. Two women came to inform us that the rest had all gone to build some huts further to the eastward, on the ice, near the island that was in sight, and that they were to join them in the evening. The distance, therefore, could not be great. The dead man was said to be not yet buried: and when some of our officers afterwards visited the village, they found nothing altered, except that some of the entrances were demolished, and the ice windows removed.

March 6. The sun had power enough while it lasted, to raise the temperature from $38^{\circ}$ to $18^{\circ}$ minus, but it then fell to $24^{\circ}$. The huts were revisited by the same party, who found the corpse of Illicto, in one of them, in the posture in which he seemed to have died. An incision in the abdomen had been evidently made after death; and as they had not removed him, we supposed that they considered his present place a sufficient tomb; at this season of the year, perhaps the best, or only one. A hole was cut in the ice, and a tide pole inserted; by which we found a rise of four feet 
and a half. An unlucky cloud robbed us of a very promising observation.

No Esquimaux interfered with the present Sunday. The weather March $\%$ was fine, and the temperature not very different. We could now observe the tides, which were very irregular; but the extreme rise was nearly six feet. On the Monday, it was but one foot eight March 8. inches in the morning, but was five feet three in the evening. Two old females came, and informed us that five seals had been taken: and we killed a fox.

It was fine and calm weather, with a full moon. The irregu- March 9. larity in the ebbs and flows, and in the heights of the tides, was extreme. Two of our officers walked to the new town on the ice, which proved to be about seven miles off. They found five families, that had been very successful, having taken a great many seals. The rest had gone about fifteen miles to the northward. Commander Ross went in the sledge, about the same distance, to the south-westward; and though he could see land all round, he could not determine whether or not it was continuous; although the coast seemed entirely skirted with islands. Some natives came in a sledge, and brought us some very acceptable smoked salmon.

The temperature rose to minus $12^{\circ}$ in the course of the day; and March 10. the tides were as irregular as usual. Two sets of the natives arrived from their different new establishments, bringing us a good dog and two seals, which we bought, with some shoes and other articles; treating them, in addition, with a good dinner. Two of them built us a snow hut for our instruments, and consented to remain all night, if we would return with them in the morning. They had killed thirteen seals, and were amply stored with provisions. A 
good supper for them followed the good dinner; but when it was time for rest, although there was a good bed for each, one waked while the other slept. Whether this was suspicion or ceremony, we could not discover. Our school seemed to surprise them even as much as the kaleidoscope.

March 11. The thermometer ranged from $14^{\circ}$ to $32^{\circ}$ minus, being colder than it had been for some days; but the weather was very fine. We found that when it had become very late in the morning, both our visitors had consented to fall asleep: perhaps their suspicions were quieted. Their breakfast, consisting of five or six pounds of seal each, seemed a highly satisfactory one to them: we had judged as incautiously in measuring their appetites as their tastes by our own : but a special larder was admitted to be necessary, if we were to give dinner parties. The nine cooks of Prince Talleyrand would scarcely, with all their art and means, have prepared a dinner for nine Esquimaux, capable of influencing their politics or diplomacy. In return, however, for this luxurious breakfast, they completed the snow hut for our observatory: while the neatness of the workmanship was the least part of the merit, since, excluding perfectly the annoyance of wind or cold air, it was sufficiently transparent to allow us to read off the instruments.

At ten, Commander Ross went away in our sledge, drawn by a team of six good dogs, in company with Ikmallik, the geographer. A party of our own men were sent out to erect more cairns for our trigonometrical operations. Some of the natives arrived to fetch away the other man, Nulungiak, who, on coming upon deck, took up a loaded gun, which went off in his hands; luckily doing no mischief, but giving him such a fright, that he was little likely to touch a gun again for some time, 
The tides and their irregularities need not be recorded, though March 12. the latter continued; since, thus far, they had led to no inferences; not even to those which we had formerly drawn. Whatever mystery there might be, respecting this subject, we had to wait for the solution. The temperature subsided as low as minus $35^{\circ}$, in the night, and did not exceed $18^{\circ}$ in the day. In the morning, two of the dogs, which had escaped from the sledge, returned to the ship, and a third was brought back by a native, its former master, to whose new hut it had found its way. He well deserved the reward he received for his honesty; and we also bought from him, notwithstanding our former resolutions, another, which was distinguished as a bear hunter. In no long time, Commander Ross returned from his expedition, accompanied by some natives bringing a seal. He had found their huts on the ice, about twelve miles to the north-eastward, amounting to ten, and had been very kindly treated; his supper being from a young seal, of which he made a favourable report. Their success had been considerable.

The cold increased, with a breeze, but did not prevent the natives March 13. from bringing a young seal which they had promised, and part of a musk ox. Besides the price of their articles, they were treated with a dinner, and departed well pleased. The week was concluded with the usual work and proceedings of Saturday and Saturday night.

The cold went on increasing, and the thermometer fell to minus March 14. $40^{\circ}$. The mercury can freeze in the bulb of this instrument without breaking it. Whatever expansion it may undergo on crystallization, if indeed that which has been supposed be true, the increase of bulk is not adequate to this effect. It is more likely that if it does 
not contract, like silver and bismuth, and many other metals, it does not at least vary its dimensions considerably. I had fully ascertained that it must have often thus frozen, without having destroyed the bulb, by having broken one of the instruments, at a temperature which had frequently occurred without injury, and having found it in a solid state. Some natives came to-day from the northern party; bringing two seals, with a dog in place of one that we had returned. A dinner, which, after such jonrneys had become a sort of indispensable civility, sent them home very happy.

A disagreeable accident happened on board, to one of the children of this party. Being in the habit of licking their dishes and other utensils, as well as each other's faces, the creature applied his tongue to the iron hoop on a cask, and was not released without leaving the skin behind. We found the meat of the musk ox to be very good beef, and without the musky flavour, which may possibly occur only at a particular season. With seven dogs accustomed to this chace, we had thus a prospect of being able hereafter to supply our crew with a proportion of fresh provisions.

March"15. The weather became so much milder, that the thermometer rose to minus $15^{\circ}$. A large party of natives came on board, and nine of them remained to dinner. A better $\operatorname{dog}$ was brought, in lieu of one that had been returned; and we found that they had taken five March 16. seals. The temperature fell again to minus $38^{\circ}$ on the following day, and we received another visit from a party which brought us a small seal, a sledge made of the bones and skin of the musk ox, and some boots and gloves. We heard also that there was a new party of Esquimaux about two days' journey from us to the southward.

March 17. The men under Commander Ross had been employed for some 
time in measuring a base for the trigonometrical operations; and this work was still going on, in spite of the cold, which to-day was: minus $40^{\circ}$. Some of the natives arrived, with the boy Kawalua, an orphan, and the nephew of the geographer Ikmallik. It was he that I had marked out as the most fitting to be taken on board and: instructed; and he therefore remained, on the return of the others, commencing his attendance at the school on the same evening.

It being a fine day, Commander Ross took a journey in the sledge March 18. about thirty miles to the southward, returning in the evening; and having taken the Esquimaux boy with him, he received much information. By his account, they had reached half the way to Neitchillee, and it was not, therefore, so far off as we had imagined ; while his information respecting places agreed so well with what we had heard before, as to assure us of his accuracy. He also described a place where they were obliged to cross, in their canoes, a stream of salt water that was always flowing to the eastward; and which could never be passed in any other manner. As this was not more than a two days' journey, by his account, we hoped soon to be able to explore it, and ascertain the nature of this strait and current. He saw, in this excursion, the tracks of a glutton and of a reindeer, but no living animal. In the course of the day, our friends brought us a fine seal and its young one. In my own walk, I found the tracks of hares and foxes in much greater number than formerly; and two ravens from the northward flew over the ship.

The natives brought only trifles this day, and we allowed the March 19. boy to go back with them, under a promise of his returning on the following. They brought us then some more gloves and boots, March 20. 
with a fine $\mathrm{dog}$; as we were now making up a second team, trusting that we should be able to feed them hereafter in some manner, at least as well as their original masters. Mr. Thom and the surgeon set out to walk to a rock which was determined by the survey to be ten miles off, but were overtaken by night in returning, and did not arrive till very late, nearly exhausted, after having given us some alarm. Nothing of moment was seen from the point in question, as the weather was hazy. I shot two ptarmigans.

March 21. This was a day of most capricious weather, exhibiting all kinds of changes, but with an increase of temperature to $13^{\circ}$ minus. After church service, some natives came to inquire into the meaning of the guns and the blue lights which we had fired and burnt as signals to the missing officers; having been much terrified by them. The dog was brought, but one of our own disappeared in return, having probably broke loose to follow its own master. We could now easily treat them with boiled seal, and thus could always afford to give them dinner.

March 22. In the day, the thermometer rose as high as minus $5^{\circ}$, sinking to $28^{\circ}$ at night. Two women brought back the absent dog, but were sent home for a swivel which was missing from the harness. A March 23. little snow fell on the following day, and the heat rose to $\mathbf{1}^{\circ}$ plus. The swivel was returned, and a party from the other station brought us a seal, which was bought for an old file, being the article now in demand. We attempted to clear away the snow from our bows, but the water came up and obliged us to desist.

March 24. The temperature rose to plus $16^{\circ}$, and it was thus a mild day: the mean of the twenty-four hours being $1^{\circ}$ plus. Parties from each of the new stations arrived, and a stray dog was brought back. 
A dinner was repaid by the national song and dance. A breeze March 25. from the north, on the following day, lowered the temperature to plus $5^{\circ}$, and made it cold to the feelings. Together with a party, came two men to settle with us about a journey to Neitchillee; when it was arranged that they should sleep on board three or four days before the next full moon, which would be about the fifth of April, and then attend Commander Ross. They were to bring their canoes, as we understood, for the purpose of pursuing the deer in the water.

There was no material change in the weather, and every thing $M_{\text {arch }} 26$. proceeded in the usual manner, except that the men were employed in cutting a dock on the larboard side of the ship, where we were troubled by a leak. The tides ought to have been high to-day, but it was the reverse ; the usual irregularities continuing. A cold breeze on the following, did not prevent our receiving a visit; but March $2 \%$ we had now no dinner to give, and informed them that they must. not expect any more till they brought us some seal.

There was a strong breeze with some snow in the night; and the March 28. weather was so thick that it prevented any visit from the Esquimaux : in consequence of which we had a quiet Sunday, and were well pleased to be alone. A clear day following, enabled us to get March 29. some good observations, particularly two lunar distances with the sun west of the moon; of the inore importance, because all our former ones were under the contrary position. A man and a woman came; but, bringing no seals, were not admitted on board. The thermometer rose to plus $15^{\circ}$ at noon, and the mean was about zero.

The thermometer rose to $18^{\circ}$ plus, being the highest degree it March 30 lad attained for many months. An Esquimaux brought some 
March 31. skins. The following day was equally overcast, and felt warm; the thermometer being at $20^{\circ}$ for three hours, and not falling below $4^{\circ}$ plus. In the evening, four families of the natives, comprising fifteen persons, passed the ship to erect new huts about half a mile to the southward. They had four heavy laden sledges, drawn, each, by two or three dogs, but proceeded very slowly. We went after them to see the process of building the snow house, and were surprised at their dexterity; one man having closed in his roof within forty-five minutes. A tent is scarcely pitched sooner than a house is here built.

The whole process is perhaps worth describing. Having ascertained, by the rod used in examining seal holes, whether the snow is sufficiently deep and solid, they level the intended spot by a wooden shovel, leaving beneath a solid mass of snow not less than three feet thick. Commencing then in the centre of the intended circle, which is ten feet or more in diameter, different wedge-shaped blocks are cut out, about two feet long, and a foot thick at the outer part; then trimming them accurately by the knife, they proceed upwards until the courses, gradually inclining inwards, terminate in a perfect dome. The door being cut out from the inside, before it is quite closed, serves to supply the upper materials. In the mean time the women are employed in stuffing the joints with snow, and the boys in constructing kennels for the dogs. The laying the snow sofa with skins, and the insertion of the ice window, complete the work; the passage only remaining to be added, as it is after the house is finished, together with some smaller huts for stores. Some of the children, in the mean time, were aping their parents in a toy architecture of their own. One, 
whose hand had been bitten by a dog, was taken on board to the surgeon; and we supplied them with water, to save them the trouble of thawing for themselves.

The summary of the month of March, now ended, does not present much variety. The minimum temperature had been minus $40^{\circ}$, the highest plus $20^{\circ}$; the mean being minus $20^{\circ}$, and thus one degree greater than that of the former voyages, as formerly compared. The ice was dissolving, though slowly, on the south side of the ship, and the rocks were bared of snow by the sun.

Our trade with the natives had produced a good stock of clothing and skins; and having got rid of two of our own dogs, which were useless, we had purchased eight new ones, thus having a good team of ten. The information acquired respecting Neitchillee led us to think that a passage westward must exist there; the more detailed account of the natives being, that there is eally a strait to the northward of it, communicating with a sea to the westward, and presenting a strong easterly current. In this channel also they mentioned some islands, called by them Shag-a-voke, signifying strong stream; further saying, that the waves in this place often broke very high. Besides all this, they described another channel to the northward, by which the ship could go better into an open sea where no land was to be seen. 'Though now on terms of entire confidence, the intended pupil had not been persuaded to remain, nor could we obtain any substitute. He had not returned after his first departure on what we had believed a mere holiday or leave of ab rnce. The lane of gravel on the ice, intended, throngh the action of the sun on it, to thaw a channel for us before it would naturally break up, had been finished; and the dogs and sledges were in good training and 
order. All our internal arrangements continued satisfactory, and all were in perfect health. Game had been very scarce; the four foxes constituted our chief captures. The highest tide had been six feet; the mean of the barometer 30 inches.

The triangulation had proceeded: but the observations in this month, respecting occultations by the moon, were not more successful than formerly. It was always cloudy at those times. Some transits and lunar distances were of value. It is lastly worthy of remark, be it explained as it may, if indeed it be a steady fact, which we do not yet know, that all the coldest days occurred near the time of the full moon, and a little after, and that the temperature was highest immediately after the change. 


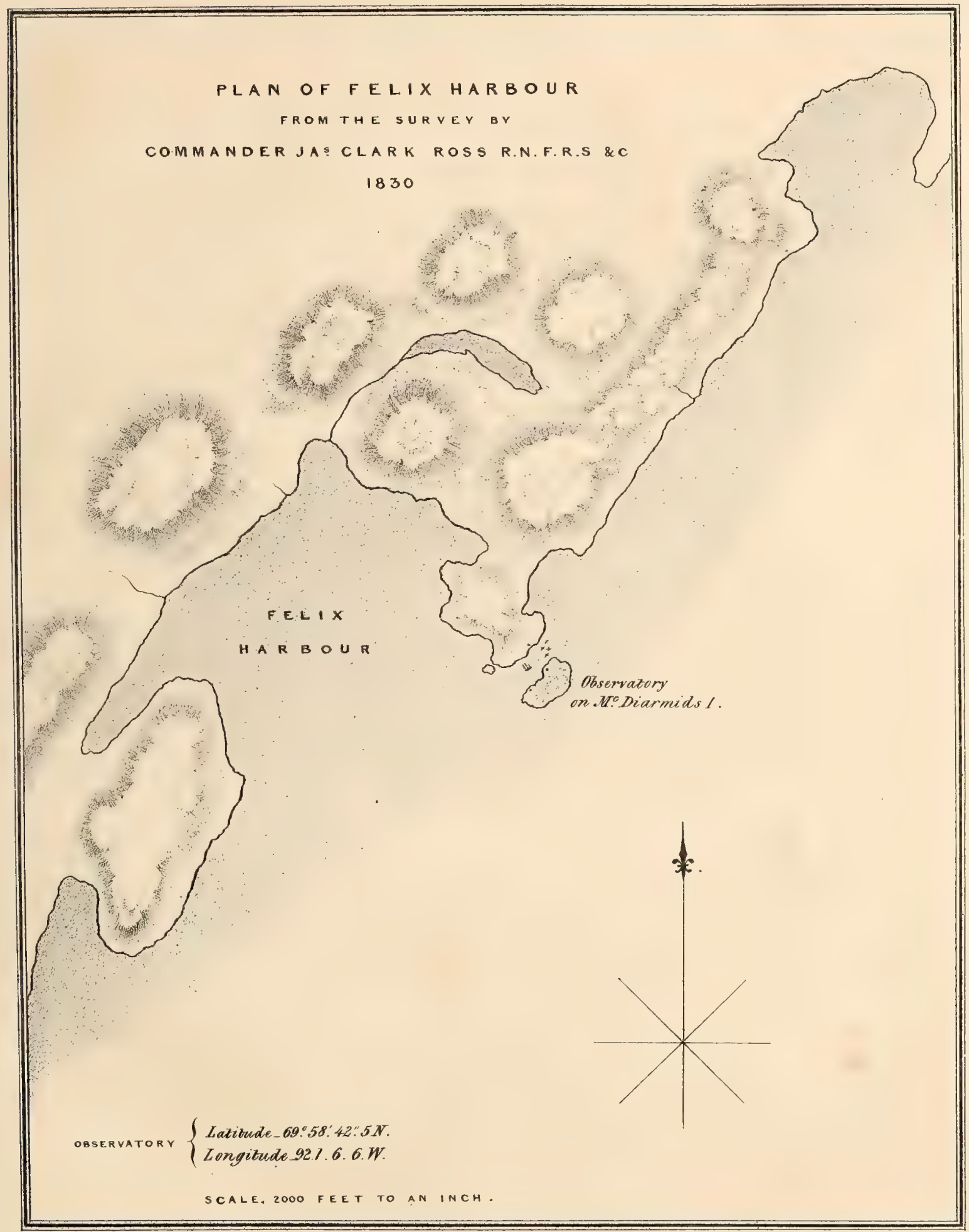





\section{CHAPTER XX.}

PROCEEDINGS TO THE TENTH OF APRIL-JOURNEY AND NARRATIVE OF COMMANDER ROSS.

THERE was snow, with a much lower temperature and a cold

$18: 30$. April 1. breeze. The natives came to us from all their quarters; and Awack, the future guide to Neitchillee, was especially welcome. The nearest party had been unsuccessful in seal hunting. The next day was like the summer to the feelings, and the thermometer rose to plus $22^{\circ}$. The Esquimaux were still unsuccessful, and began to fear they should be short of provisions. Seeing the sextant in use for an observation, they were very desirous to know if it related to seals, and if we saw any. The sun was sufficient to dry the washed clothes, and the melted snow was every where flowing in water down the rocks.

A seal was brought, and exchanged for a file; but there was still a failure of this hunt. In proof of the effect of external heat on our arrangements within, the quantity of ice in the condensers, this week, was but two bushels. It was a few degrees colder than yesterday : but it now became necessary to build a snow wall round the pillar to which the thermometer was attached, to protect it from the reflected heat of the surrounding snow.

Sunday did not prevent the natives coming from all quarters; Aprit 4. 
but we did not allow them to impede us in our usual duties. Among them, Awack and Ooblooria, the two promised guides, came with their sledges, dogs, and provisions; and all the former information was confirmed. Our own preparation for the journey had been completed, and the officers that were to accompany them were ready. The thermometer fell to minus $8^{\circ}$ at night.

April 5. The weather was cloudy, with a moderate breeze, which, being from the north-eastward, was favourable for travelling. Commander Ross, with the chief mate, Blanky, and the two Esquimaux, departed at ten, on two sledges, with ten days' provisions : but the thermometer falling to minus $4^{\circ}$, we were concerned that their departure had not been delayed. Still more unfortunately, snow began to fall at one o'clock, and by evening, there was a gale of wind, which we feared would arrest them entirely. Our consolation was, that our two officers had with them the most experienced and active of the Esquimaux guides, and that they would therefore be housed in good time. The natives from the eastward brought us a fine seal, and we were thus enabled to afford some assistance to Tiagashu's family, which seemed to be in want.

April 6. It continued to blow fresh, with snow, shifting from the northward to the eastward; yet the thermometer became plus $21^{\circ}$ at noon: while, in the evening, it went round to the south. A blue light was hoisted, and a signal rocket thrown up, to indicate the ship's place to the travellers. At night, the wind moderated a little.

April \%. This morning was again stormy, with drift and falling snow; but, towards evening, it became calm and clear. The same signals were then repeated, thongh we hoped the party would have reached 
Neitchillee. Some of our neighbours came to beg food; and as their huts were known to be empty, we supplied them with some seal's flesh. The next day was still snowy, but calm at first, fol- April 8 . lowed by variable winds in the course of the afternoon. Nine Esquimaux came for meat, of which we fortunately had some still remaining; and they were so hungry that they devoured the seal's flesh raw; not, however, forgetting to take some home to their families. The men were now making various preparations on board for the summer : the signals were repeated at night.

The snow was still worse, and the drift obscured every thing; April 9. the wind finally settling in a heavy gale from the south-westward. The rocket was repeated at night, and at the hour agreed on, namely ten o'clock; attention to the ship's place being first secured by a blue light: since, by this method, the longitude of the expedition could be ascertained through the chronometer. The Esquimaux came, but brought nothing. One of our foxes escaped, and probably fell into their hands. The thermometer sank to minus $13^{\circ}$.

The gale decreased, and it became moderate by nine. At five in April 10 . the evening our party returned, after a very laborious journey, and much suffering from the cold, but without any serious accident. They had seen the sea to the westward, and were confident that we were now on the coast of America. The channel of which we had heard as leading to the sea, was still, however, uncertain; there being two inlets a little to the northward of our harbour, with apparently equal claims as yet, while it might also exist in what had been termed Cresswell bay, in latitude $\mathbf{7 2}^{\circ} 30^{\prime}$. But the narrative of Commander Ross must be given in his own words. 


\section{CHAPTER XXI.}

\section{NARRATIVE OF COMMANDER ROSS.}

1830. 'THE morning was far from proving favourable for our journey, as it snowed hard, and there was a fresh northerly wind: my guides, indeed, disliked the look of the weather so much, that they were very desirous of deferring the expedition to another day. I still hoped, however, that it would improve; and as I was anxious to reach the spot which we had been looking to with so much desire and interest, we at length prevailed on them, and set off at six in the morning.

Our party consisted of A wack and Ooblooria, as guides, together with Mr. Blanky, the chief mate, and myself. Our own baggage was lashed on two sledges, drawn by dogs; and being much heavier than that of our companions, we were much troubled to keep up with them, especially as they occasionally rode in their sledges, while we were obliged to run by the side of ours, and very often to drag them through the deep snow-drifts which were perpetually occurring.

Our direction was to the south-westward, and close along the shore, until noon, when the wind increased to a fresh gale, and the driving snow became so thick, that Awack, who was leading the party, lost his way, and getting among some hummocky ice, had 
his sledge broken in two places. This accident had nearly put an end to our journey before it was well commenced, as they had no means of repairing the damage. On that account, and because of the gale, which it was now impossible to face should we have desired to return, the guides began to build a snow hut; a project which we did not at all approve of, could any means of proceeding be discovered. Mr. Blanky, therefore, suggested the possibility of mending their sledge by means of their spears; but as I knew that they would not consent to this surrender of their weapons, I broke them both, without asking any questions, into lengths fit for the purpose. As might have been expected, this was followed by a sudden burst of united surprise and anger; but on assuring them that I would give them two much better spears as soon as we should return to the ship, they became pacified, and set about the work with the ntmost good nature.

Having succeeded in this, we set off once more, in spite of the snow and the gale, but found ourselves even more hampered than we had expected; since, in addition to these extreme annoyances; we had the ill fortune to fall in with a considerable tract of rough and hummocky ice. This occupied us during two hours of severe labour, when we once more contrived to reach the mainland. The guides, however, were now completely at fault, as they could not see twenty yards before them, from the thick drifting of the snow storm; so that we were obliged to give up all further attempts for the present, and to consent to their building a snow hut.

This was completed in half an hour; and certainly never did we feel better pleased with this kind of architecture, which, in so very short a time, produced for us a dwelling, affording a shelter at least, 
as perfect as we could have obtained within the best house of stone. It was, indeed, barely large enough to hold our party of four; but in the wretched plight that we now were, even a worse accommodation than this would have been most acceptable. Our clothes were so penetrated by the fine snow dust, and frozen so hard, that we could not take them off for a long time, and not till the warmth of our bodies had begun to soften them. We also suffered exceedingly from thirst; so that while the Esquimaux were busied with the arrangements of their building, we were employed in melting snow by the aid of a spirit lamp. The quantity which we thus produced in a short time, was sufficient for the whole party : while the delight of our guides was only equalled by their surprise; since, with them, the same operation is the work of three or four hours, performed as it is, in stone vessels, over their open oil lamps.

There was, however, an attendant evil, owing chiefly to the exceeding smallness of our hut. Its walls naturally melted also; and so fast, that our dresses became soon wetted to such a degree, that we were compelled to take them off and get into the fur bags. Here at length we could keep out this enemy, and in those we slept.

I have already said, that we travelled along the mainland during the whole of this day; but as the density of the snow-drift prevented me from seeing objects, at any time, more than a quarter of a mile off, I was unable to form even a tolerably correct idea of the direction in which we had travelled. I believe, nevertheless, that the distance did not exceed twenty miles. This, however, had occupied us during eight or nine hours, notwithstanding the rapidity with which we had performed the first part of our journey; and so many hours of exposure to labour and cold, together with 
the severe exertions that we had undergone among the rough ice, had very completely tired us all.

We had, in return, the advantage of sleeping most soundly; and April 6. might not have awoke very soon, had it not been for a mutiny and rebellion which broke out among the dogs. 'They had rid themselves of their traces and got loose; while, never being over fed, and at that time, doubtless, tolerably hungry, they had attacked the sledge of Awack for the purpose of devouring the frozen fish of which it was constructed, unless, indeed they preferred the hides of the musk ox by which these were bound together. The owner soon ran to the rescue; and as the damage was only commenced, the repairs were neither very difficult nor tedious. We had, indeed, but too much time on our hands for this work; as the inclemency of the weather rendered it impossible to proceed.

This leisure enabled us to have a good deal of conversation with our new friends; who being now at their ease, and free from the apprehensions which they had at first entertained, began to improve very much in our estimation : displaying, in particular, far more acuteness and intelligence than we could have expected to find under countenances so heavy, and physiognomies so dull. What was of most importance, however, to us, was the information which they afforded respecting the nature of the coast, and the ocean to the westward; the latter of which they represented to be of great extent.

For the first time, also, they now spoke of an island, which they called Oo-geoo-lik and where, in the summer, as they informed us, we should see great numbers of Esquimaux; naming particularly, among those, a man who was described as lame, and a 
woman called Kablalla, who was spoken of as a personage of great importance among them; and giving me, in addition, the name of her husband and children, together with those of many more of her kindred.

They described the place termed Oo-geoo-lik as very distant; saying also that it required many days' journey across the salt water, to reach it. This confirmed their previous account of the extent of the sea to the westward; but I could not at this time contrive to make them understand my wishes to go there. I was therefore obliged to content myself with listening to the anecdotes which they related about their people, and to answer, as well as I could, the several questions which they asked me about the Esquimaux whom I had seen at Igloolik, in whose concerns they seemed to take a very lively interest.

Their principal questions, however, related to the manner of hunting among those people, to their amusements, and to their singing; and they were also curious to know whether I had seen the "angekoks," and witnessed their tricks. With all this I had formerly been familiar; having been on many excursions with those people, after the seal and the walrus, and having seen also enough of the operations of the conjurors. I was to say also whether I had heard "Torn-gah," the spirit, and to repeat what he had said; all of which questions I answered as well as I could, so that there was amusement at least, if not employment, for this day of detention. I was also obliged to repeat frequently the names of the "angekoks," with those of their wives and children, as it was their desire to remember those; for which they laboured by frequent repetition. They seemed greatly amused to hear that so 
many of them had two wives; adding also, that they knew a man to the westward who was thus doubly provided, having brought them from Repulse bay. From this I should have concluded that the practice of bigamy was very rare among the present tribe; but we afterwards found abundant reason to recal this conclusion.

We were much more interested, however, in hearing them relate the circumstances which had brought them to this part of the coast, and to our immediate neighbourhood. Two of their people had been

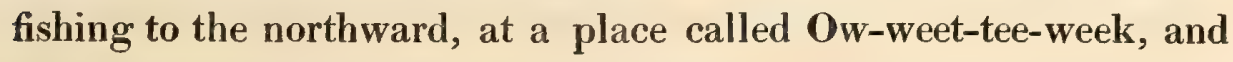
there saw the ship beset by the ice and carried past to the southward; this being, as well as I could conjecture, on the second or third of September. Being much alarmed in consequence, they immediately set off to join the main body of their tribe at Nei-tyel-le, where they remained till the arrival of a woman called Ka-ke-kag-iu. This person had a sister who was one among the party that had been with us at Winter island, in the former voyage to this part of the world; and from her, they received so enticing an account of the reception which the latter had met with from us on that occasion, that they came to the resolution of going to seek us, wherever the Victory might chance to have been brought up. This they accordingly did; and our companions now described to us their sensations at the first sight of our footmarks in the snow, their astonishment at the size of the prints, and the consultation which was held, to determine whether they should proceed or not. The eloquence of Ka-ke-kag-iu, however, overcame all their fears; and they now repeated to us the delight which they had felt when, after drawing up in a line to receive us, they had seen us throw away our arms. 
During all this time their oratory did not interrupt their eating; for this is an occupation never neglected, as long as there is any thing to eat; nor could all our experience among this gluttonous race diminish the perpetually recurring surprise that we felt at the persistence of their appetites, the capacity of their stomachs, and the energy of their digestive powers. To say that they ate thus from hunger, or even from appetite, cannot be true : no human being, governed by the instinct of appetite alone, could feel such wants, in whatever way nature contrives to dispose of the enormous superfluity. No animal, however carnivorous and voracious, acts thus: the very glutton itself, in spite of its reputation, or of the truth of its name, if truth it be, fills itself and is satisfied. Man alone eats from pure wantonness; that he may gratify his taste, not satisfy his hunger; if, indeed, this is not also the frequent effect of the principle of avarice or appropriation. This it is, to be a rational being; but, as in many other cases, and worse ones, it is to use that reason, not to control the evil passions, but to aid them; to make man, whenever he chooses so to be, the most evil animal in creation.

The provisions in question were, however, consumed sooner than they would have desired; for their stock was small, in consequence of the division which they too made of them among their friends, before we came away from the ship. It was therefore fortunate, yet for other and better reasons, that the weather soon began to clear, and thus gave our guides a speedy prospect of replacing their larder. In consequence of this, I obtained some observations for determining our position, and for the angles required for my intended survey. 
The latitude of our present position was $69^{\circ} 44^{\prime} \cdot 20^{\prime \prime}$, and the longitude $0^{\circ} 44^{\prime} 6^{\prime \prime}$ west of the ship. The hut was built on the south shore of an inlet about three miles long, lying on a westsouth-west line. On each side, the land presented high and rugged shores of granite; and a considerable river entered on that which was opposite to us, at about the distance of half a mile. The name which our natives gave to this, was Ang-ma-look-took, and they described it as abounding in fish, in the summer time. The name of the inlet, in the language of the country, is Too-nood-lead, and it is thus distinguished in the chart which $I$ drew up.

On my return from a rising ground to which I had gone for the purpose of obtaining better ideas of our situation and of the coast in general, I found the two guides Awack and Ooblooria busily employed in loading their sledge, and was equally surprised and displeased to find that they were preparing to return to the place that we had left, to obtain a fresh supply of every thing, and especially of provisions, since they had eaten up every thing, damaged their sledge, and broken their spears for the purpose of repairing it: while without these latter, they had no means of procuring provisions.

There was nothing left for me, to prevent them from putting this provoking resolution into practice, but to trick them into abandoning this scheme; since it is not very easy to reason with a man's stomach ; above all, with that of an Esquimaux; and as, in truth, it was not very easy to produce any good reasons against such arguments as these. A question of their own geography would not have weighed with them, when put into competition with a dinner of seal and a drink of oil; and how could I expect that 
our pursuits of this kind, which must really have seemed abundantly purposeless to them, and which, perhaps, may not seem of any vast importance to persons of very different information, were to influence them, when put into the balance against the slightest wishes or caprices of their own ?

To carry my object, I therefore engaged them apart in conversation, while Mr. Blanky selected some of the best pieces of seal's flesh in our possession, part of a considerable provision that we had made for the dogs, and wrapped them up in a piece of canvas. I then informed them that I should proceed to Nei-tyel-le without them, that they would thus lose the promised reward, and that I had moreover plenty of meat in my possession, as they could now see. On this, they consented to go on, and we were therefore soon on our road again towards our original destination.

After crossing a neck of land, about three miles broad, and occupied by two small lakes, which, as we were informed, were well stocked with fish, we again descended upon the salt-water ice, which the guides described as belonging to the head of a maritime inlet to which they gave the name of Tar-rio-nit-yoke. The meaning of this phrase, however, is, "not salt water :" so that it is probably a place into which there runs a river, or rivers, so considerable as to justify this name. Thus it is that its exit, or mouth, is also termed by them Shag-a-voke, which means "it runs fast ;" there being probably some great accumulation from the interior fresh waters and snow during the thaw; so as to cause a rush through a narrow opening, at one part of the year, sufficient to have given rise to this descriptive appellation.

We halted on a small islet in the north-west corner of this bay, 
where we found Tul-lo-ack's canoe covered with stones, having been buried in this manner to preserve the timbers from rotting; while the skin covering had also been taken off, for the same reason. The wood itself, they had procured, as they informed us, very far to the westward, in the neighbourhood of Oo-geoo-lik.

From this place we now continued our course directly inland; ascending the bed of a river, and passing several narrow lakes; travelling through deep snow for the space of four or five miles. Our progress was necessarily, therefore, very slow, until we reached the banks of the furthest one, to which they gave the name of Tyshag-ge-wuck, and which they described as abounding in three kinds of trout. I here shot two grouse which had allowed me to approach them sufficiently near to render my aim certain: to the equal surprise and delight of our guides, who had never before witnessed the effect of fire-arms.

The wind now increased, and blew over the snow so keenly, carrying with it a perfect torrent of drift snow, that we were no longer able to face it; so that we were at last, at seven in the evening, obliged to betake ourselves to the shelter of a snow hut, April 7. which our guides built at the west end of the lake where we were now engaged in our cold and laborious journey.

Our friends had noticed and recollected the inconvenience that we had experienced from the smallness of the hut which they had constructed on the preceding occasion, and the present one was therefore made considerably larger. The Esquimaux, as every one knows, are very short, though thickly made; and thence, calculating for themselves, and forgetting our much greater stature and longer limbs, that which they had made before was so con- 
fined, that we could not stretch ourselves out, without opening the doorway and putting our feet and legs beyond it; which, in such a temperature as that of this country, was by no means agreeable. We were now very thankful, even for the small portion of observation which had discovered this fact, and for the goodnature, or politeness, which had laboured to find the remedy.

April 8. In the morning it was foggy, with much snow. Our guides therefore proposed to leave the baggage behind, that we might travel the more quickly, and thus be enabled to reach Nei-tyel-le, and afterwards return to sleep at the hut. I could not have selected a more unfavourable day for a visit to a place of so much interest; but as I well knew the capricious and changeable characters of these people, I was unwilling to make any objections. In any event, I should thus have seen the place and ascertained the way to it; so as to enable me to reach and examine it at some future day, under more favourable circumstances.

We accordingly set off at nine in the morning; and after passing two small narrow lakes, called Kung-uck from the hilly country by which they were bounded, we arrived by a short and steep descent at the place named Pad-le-ak; a word which means "journey's end." The total absence of any tide-mark made me, at first, doubt whether we had really reached the sea; but the man Awack having cast off his dogs, one of them soon found a seal hole, and thus allowed me to taste the salt water. The occurrence of some hummocky sea ice, shortly after, would alone have set this question at rest; as it completed my satisfaction by ensuring this essential fact respecting our geography and the journey which we had thus made. 
Keeping on our course to the south-west until eleven o'clock, we passed an island which the guides called $\mathbf{O}$-wuk-she-o-wik because the particular cod, termed by them $\mathbf{O}$-wuk is caught near this place during the summer and the autumn; frequenting its shores, as they informed us, in great abundance. From this we turned toward the south, and, after that, to the south-east; when, passing first a small lake where I procured a meridian altitude of the sun, and traversing a low shore of limestone, we arrived at the great lake of Nei-tyel-le at one o'clock.

The east shore of this piece of water presented a ridge of granite hills, and the guides pointed out on the faces of these, several winter huts which they called O-ka-u-eet. The guide Awack had left his canoe here; and he therefore separated from us to go in search of it, while we pursued our course to the southward, soon reaching the banks of a river. I attempted in vain, at this time, to form some estimate of the size of this lake; for the snow-drift was so heavy as entirely to prevent this, since I could never see more than a mile in any direction, during the time that we were near it.

We found the canoe belonging to the other guide, on a small islet in the river; and, at this point, we estimated the stream to be half a mile in breadth; while, as the ice on it was of very considerable thickness, I was inclined to believe that the water was deep. From the information of the guide Ooblooria it runs into the sea in a direction to the south-west of this islet, flowing out of the south-eastern end of the lake which we had passed. The banks were of limestone; and, from some fragments of this rock, with the assistance of Mr. Blanky, I erected a cairn, and we went throngh the usual ceremony of taking possession. At three o'clock we had 
finished all that we could now do in this quarter, and prepared for our return.

In no long time we found the canoe, which Awack had left for us to pick up, while he went forward to melt some snow to be ready on our arrival at the hut. At six we reached the sea once more, and the river of Pad-le-ak at seven; at which time the weather had become settled and clear. I therefore ascended an elevated ground, with Ooblooria, and thus obtained a very perfect view of this extensive inlet.

He here informed me, that to the quarter he pointed, extending from north-west to south-west, there was a continuous open sea, or a sea free of all ice, during the summer, and that at a short distance beyond a high and bold cape, which terminated the north-east shore of the inlet, no land could be seen to the westward. But, from the south-west to the south-east, there was a tract of land connecting the ground on which we stood with Ac-cool-le and the shores of Repulse bay, while there was no way into this sea from the south: so that if our ship desired to reach Nei-tyel-le from her present position, she must go round a long way to the northward.

From this evidence which appeared to be as accurate as he was clear and consistent in giving it, I concluded that we were now looking on the great western ocean, of which these people had so frequently spoken to us, that the land on which we stood was part of the great continent of America, and that if there was any passage to the westward in this quarter, it must be sought to the northward of our present position. To the cape in question $I$ gave the name of Isabella, being that of my sister, on whose birthday it was. discovered. 
The guide Ooblooria now pointing to the south-west, said that the way to Oo-geoo-lik lay in this direction; on which I endeavoured to persuade him to accompany me there in the coming spring. In this, however, I could not succeed by any offers or promises that I could make; his objections seeming to arise from the great distance, and from the difficulty of procuring food; the last being a reason far too solid to be removed by aught but the complete demonstration of a sufficient and well-secured supply. In the course of this discussion, he informed me that some of the tribe which inhabits that place had brought their people drift wood from it, but that none of them had ever been there; so that their communication was very limited, and their knowledge, of course, but imperfect.

We reached our hut at nine in the evening, and found that Awack had, as we had expected, arrived before us. He had displayed his newly acquired learning, or his ingenuity, in a rather unexpected manner; having succeeded in procuring a light by means of the oxymuriatic matches which he had seen us use for that purpose; and he had thus provided us with an ample supply of water; a refreshment of which we were much in need, and the want or scarcity of which is always exceedingly tantalizing in a country of snow and ice; seeing that we are living among water, walking on water, and eternally annoyed by water, in one at least, of its forms, and always forgetting that the snow and ice of this frozen land is a far other thing than that of our own winters, and not to be converted into drink without great labour and expense of heat.

Being now on our way home, we for the first time afforded our- 
selves a warm mess of grouse soup, while we also boiled some seal's flesh for our companions. Ooblooria was completely tired, from his great exertions during the day. His partner was suffering from snow blindness; and thus it fell on him to lead the way, as it was unknown to ourselves. Thus labouring through snow which was often very deep, with the drift in his face, and at a very quick rate, at the head of the sledge, he had gone at least forty miles, so that his fatigue was no cause of surprise. All slept soundly, and April 9 by ten o'clock the following morning, we resumed our journey homeward.

At noon I observed for the latitude, near the east end of the great lake of 'Ty-shug-ge-wuck and found it to be $69^{\circ} 38^{\prime} 53^{\prime \prime}$. Here Awack left us, but rejoined us again within four hours, at Tar-rio-nit-yoke; bringing with hin the paunch of a deer, which they esteem a great delicacy, together with some fish that he had concealed in the summer. We arrived at our hut on the inlet of Too-nood-lead at four in the afternoon, and just in time to escape a most violent gale of wind from the northward, accompanied by a very heavy drift, which continued without intermission during the whole night, and made us doubly thankful for the shelter which our little nest afforded us. It was suffeicutly cold too; for the thermometer fell to minus $16^{\circ}$. April 10. Towards nine on the following morning the gale began to abate; and as we were anxious to reach the ship, we set out at noon, when the wind gradually subsided, and the remainder of the journey proved very agreeable, as the weather at length became as fine as possible. The guide Ooblooria was, however, in a very lamentable condition, suffering from snow blindness, and his knees being ulcerated from the friction of his frozen trousers. 
The Esquimaux sledge was occupied by the three canoes which formed the principal object of their journey, so that there was no room in it for this unlucky man, who could scarcely see his way, in consequence of the streaming of tears from his inflamed eyes. I therefore desired him to seat himself in ours : and was much pleased at the difficulty which I had in prevailing on him; as his politeness or goodnature did not choose that we should walk for his accommodation. This, however, proved of no inconvenience, either to Mr. Blanky or myself, who were fresh, and had not laboured more than was necessary to keep us warm. Knowing now also the ground, we took on ourselves the office of guides, walking at the head of the sledges alternately, to point out the best way through the rough ice and hummocks. It was, finally, the only good day and the only agreeable journey which we had experienced since quitting the ship; while it also permitted me to make all the observations necessary for the future survey of this line of coast; and thus we at length reached the Victory at six in the evening. 


\section{CHAPTER XXII.}

PROCEEDINGS IN THE SHIP, AND WITH THE NATIVES.

April 11. THE wind became settled, and the sky serene, though there was still a little snow. The travellers were recovered; and the guides having received the promised files, departed very happy; being, however, to return the next day for a new spear each, in place of those that were broken, with wood to repair one of the canoes, which was much damaged. The average dimensions of these was about twenty feet in length, by a foot and half in breadth. Some specimens of the salmon and lake trout were procured; but we afterwards got much better ones from the sides of the sledges that we had purchased from them, which were formed of these fishes, frozen together into a mass. The service of the day, Sunday, was not omitted.

April 12. There was a fresh breeze from the north-eastward, but it was not cold. It was necessary to build a new place for the thermometer, the other being inundated with water. A party came from the huts to thank us, bringing a valuable seal-skin as a present, with another of a pair of gloves for the mate, in lieu of a borrowed pair which the dogs had eaten. They received their wood of course, and gave us the native names of the fish used in constructing their 
sledges, which he had bought, informing us that they were caught in the lake of Neitchillee. The descriptions of these, amounting to four, must be sought in the report on the Natural History of this country.

The temperature rose so much, as nearly to reach the freezing April 13. point, and the sky was overcast. It was still remarkable, that during the changes of the wind on this day, the highest degree of the thermometer was when it blew from the north, and that it sank very quickly when the wind changed to the south. We were not yet prepared with a solution for this fact. It is more easy to say than to prove, that there was open sea to the north, and that the south wind blew over a great extent of frozen land. There was ice enough, and land enough also, in the former direction, to render this explanation more acceptable in the closet, to those whom words will satisfy, than to us who knew the country. It was our business at least to wait for a better, whether that should arrive or not. A native came to beg a new stick for his spear, in lieu of his own, which was broken: but we thought it expedient to refuse him. To give lightly, was to deprive ourselves of the power of rewarding; even had it not been absolutely necessary to keep up the price of our commodities, lest they should fall to no value, and deprive us of the future means of purchasing what was indispensable.

A visit from our friends to-day was satisfactory, inasmuch as we found that they had all recommenced taking seals. The weather, both on this and the followiug day, was mild and tranquil: and we received visits from both settlements, which were now united into one, so as to comprise uine families in eight huts. The vessel had heeled so much, from the failure of the ice on one side, that it was 
necessary to remove the weight of snow from that part of the deck. It was now also time to clear away the snow-bank round the ship, April 16. being no longer wanted. This found us work for the following day also. The temperature during these three days vacillated on each side of zero; the greatest rise being plus $2^{\circ}$. On the last, another visit informed us that some of the party had removed to an inlet northward of their first position.

April 17. Commander Ross and the mate departed on the sledge. The natives brought us a skin and a seal, and I was again teased by one, while making observations, to show him where the seals might be found. To get rid of him, I pointed to a place, at hazard; and, in the event, acquired the reputation of a conjuror, inasmuch as they afterwards caught three. Prognostication was, however, a trade far too dangerous to our reputation, to be indulged in; and I hoped that the opportunities would not often be forced on us in this manner. One of the seals was very gratefully brought to me, as an acknowledgment; but the bearer was nevertheless rewarded with a file. The first snow buntings of the season were seen this day. Commander Ross returned in the evening from the newly erected northern huts, about six miles off: and having explored the reported inlet, determined that there was no passage in that direction. Thus was one of our projects exterminated; but there were two still remaining.

April 18. This Sunday was a calm one; but the temperature did not rise beyond $11^{\circ}$ plus. After church, one of the men brought back the iron door of the fox-trap which his brother had stolen after he had built it. There seemed more temptation to steal, than desire to retain; for they never had any reluctance in returning what had 
been stolen. Their opinion seemed to be, that although it was wrong to steal, no harm was done if the owner did not miss the property: an argument not uncommon, I am sorry to say, among their betters in our own country, but not the more defensible because it has an apologist in Shakspeare. Making no concealment from their friends, these did not fail to inform: while, not denying when accused, they seemed to consider the whole matter, the reproach of thief, and all else, as a "good joke." Yet they sometimes brought peace offerings; as they did on this day, in a small seal. I also recovered the trough of the artificial horizon, which had been missed for two days, together with a dog which had been detained: the culprit, who was going to Neitchillee, being apparently very penitent, and desirous of making friends with us before his departure. All of them were about to remove; and it is probable that we were more sorry than they, at a parting, after which, as we then thought, we were not likely to meet again.

It blew fresh, with thick drift snow, but it did not prevent many April 19. of the natives from coming to us, to take a second farewell. Each received some present; and at ten, they drove off to the southward, leaving their former habitations empty. They were evidently sorry at parting, though expecting to see us at Neitchillee; and their final adieu was a universal shout of thanks and goodluck, in their own, now tolerably intelligible, tongue.

There was a cold breeze till evening, when it became calm. April 20. A seal was brought to us from the northern village; and Ikmallik's son proposed to be a guide to Shag-a-voke, the station near Neitchillee, where we were desirous of examining a strong current of the tide. He was accordingly kept on board till the morning, when the 
expedition was to take place: the promised reward being a file. They told us that they had seen the first gull of the season, on the day before, which was good news; but we could not persuade them to remain all night, because they had promised to return. The engineers were employed in cutting up the boilers, to obtain a new sheathing for the outside, where the iron had been originally bad, and whence arose some of our leakiness. The thermometer did not rise beyond zero.

April 21. Commander Ross, and Blanky the mate, departed with their guide and seven days' provision; the weather cold, but clear, and the wind favourable. One of the former delinquents brought a seal-skin, and his brother a spear; but they were bought, not accepted. On their complaining that they had taken no seals, they were informed that it was on account of the iron which they had stolen; an accusation which induced the former to confess respecting some, of which we did not know.

April 22. On the twenty-second, it was colder than it had been for a month; the thermometer falling to minus $9^{\circ}$. The natives brought a large seal and four skins, which were bought; while they informed us, at the same time, that they were soon to leave their present station for a more southern one. At eight, our own officers returned from their journey, leaving the guide, who was quite exhausted, with his friends, who had encamped six miles further, to the south of our station.

In spite of the cold and drift, they had succeeded in ascertaining that there was a crooked channel, not more than two hundred feet wide, at the new settlement of Shag-a-voke; that it was a mile in length, and lay at the bottom of an inlet, while also leading inland, 
to the westward, into a spacious basin, five miles in diameter. It was the same which they had crossed in their former journey, before they came to the reported inlet into the western sea, where they had ascertained the existence of a narrow isthmus. The capes which bound the entrance of this inlet were visible from the ship, as was the continent to the south-east, which seemed to trend towards Akullee in Repulse bay. But I must give the narrative of Commander Ross in his own words. 


\section{CHAPTER XXIII.}

COMMANDER ROSS'S SECOND JOURNEY AND NARRATIVE.

1830. W $\mathbf{E}$ had already ascertained that it was the western ocean which we had formerly seen across the narrow isthmus of that tract of land which we afterwards named Boothia; and coupling this knowledge with the account which the Esquimaux had given us of the place which they called Shag-a-voke, and where they described a strong current running from the westward, through a narrow strait, we conceived the not unnatural hope that we might there find some passage into the western sea. The natives, indeed, gave us no encouragement; assuring us that the land was here continuous from north to south within the whole range of their knowledge, and affirming positively that there was no passage where we fancied that one might possibly exist. But we did not think ourselves at all justified in taking this on their showing: they might not be correct; and, at any rate, we were sure that we should leave a source of repentance for ourselves, and probably a ground for reproach from our countrymen, should we be satisfied with any thing short of ocular demonstration; above all, when we had come so far for such an object, and had the means of absolutely satisfying ourselves, in our power.

But as Awack and Ooblooria continued to suffer from their 
exertions during the last journey, and were unable to accompany April 21. us, Noak-wush-yuk, a lad of sixteen or seventeen, offered to act as my guide, and we accordingly began our journey on the twenty-first of April, at an early hour in the morning.

The day commenced, unluckily, with haze and snow; and there was too much wind to allow us to travel with comfort or expedition; especially as that brought with it the usual snow-drift, which is the almost invariable attendant of a winter gale in these regions. We nevertheless held on toward the south-west, along the land, until we reached the inlet leading to Shag-a-voke : getting sight of its entrance, and landing on one of the three islets which lie off the cape, which they term Ac-cood-le-ruk-tuk, at four in the afternoon. Here the guide endeavoured to persuade me that this was the place called Shag-a-voke; but it differed so much from the description which I had received from Ooblooria that, on my pointing up the inlet, he immediately said Shug-loo-ooanga, "I have told a story," and begged to be allowed to build a hut: saying that he was so much fatigued that he could go no further.

By this time the wind had subsided, and the weather, which had before been so disagreeable, was succeeded by a beautiful evening. Unwilling, therefore, to lose the advantage afforded by weather as rare as it was fine, the boy was put on the sledge, and we proceeded along the north-west shore of Ac-cood-le-ruk-tuk, in a west-south-westerly direction: during which little journey I had an opportunity of ascertaining its general appearance.

The entrance of this inlet is formed by Cape Tad-le-achua on the south-east, and the low point of Ac-cood-le-ruk-tuk on the northwest; these two points being about five miles asunder. Both the 
shores are composed of red granite; and there are some islets lying off each of these points, in such a manner as to occupy a large portion of the entrance. In proceeding upwards into it, the shores gradually approximate; and, at the distance of about four miles from the entrance, where they take a remarkably tortuous course, the breadth of the inlet was only a hundred and twenty feet; that place forming its narrowest portion. Narrow too as this channel is, it is still further contracted by some rocks within it, which rise above the water, on which, at this time, much heavy ice was grounded. From all these particulars, I doubted whether even a boat could be carried into the upper part of this arm of the sea; as it certainly would not afford a passage to any ship.

But being now desirous to make a more accurate examination than I could do while we were in motion, I selected a spot for a hut; and declaring my intention to halt, set Noak-wush-yuk to work to build us the usual snow house: departing alone on this pursuit. That I might proceed the more lightly, I left my gun behind, which I had soon occasion to regret; as, within an hour's time, I perceived two animals trotting behind me. It being dusk, I mistook them for wolves, and though these were not the most agreeable companions for an unarmed man, I was infinitely more mortified at the want of my gun, on finding them to be two fine deer, which passed within ten yards of me. They were the first which had been seen this season.

I here saw, that above the narrow strait just mentioned, the inlet expanded again to a breadth varying from one quarter to three quarters of a mile; and after about three hours of quick walking, I arrived at its further extremity, and landed on the small islet. 
where we had found Tulloack's canoe buried. I had thus completed the examination of the only inlet to the south through which we could have hoped to find a passage to the western sea.

This inlet, Shag-a-voke, derives its name from the rapidity with which, in the summer time, the stream rushes out through the contracted and narrow channel which it must pass in its way to the sea; and I formerly remarked, that the name is expressive of this fact: since the literal interpretation of that is-" it runs fast."Respecting the cause of this current there can be no difficulty; since the mass of water by which it is produced is evidently derived from the melting of the snow on the upper lands; the whole of which finds its way in numerous torrents, as we had afterwards occasion to see, through the valleys which tend down to the head and the sides of this inlet. Hence the great rush of water in the early part, at least, of the summer : that being also the time in which this place is chiefly frequented by the natives, as it is the season of the fishery, when the salmon are labouring to work their way upwards from the sea.

It was midnight when I returned to the hut, which had been erected for some time; after a much longer journey than I had intended, but which I could not prevail on myself to shorten when I found myself led on gradually from point to point, lest I should leave this investigation incomplete. I must confess that I was extremely fatigued; as I had travelled fifty miles during this day, and had reason, on this account, to blame the stupidity of the guide in not having built a larger hut. We had great difficulty in forcing ourselves into it, by all our ingennity and perseverance; and when there, it wonld not hold the three which formed our party, in any 
but a posture between sitting and lying; but it was, for that reason, the warmer, and we contrived to get some of the sleep which fatigue brings, in return for its grievances.

April 22. It was not, however, that sleep which the restless envy, and which all would gladly prolong. We were much more gald to rise than we had been to lie down; if such a term can be applied to a posture as like to that in the parish stocks as aught else, or the word bed to a "form" which even a hare could not have occupied, and which would have required all the flexibility of a fox or a rabbit. Luckily it was a very fine morning; and after having shook ourselves, like the bears, I proceeded to finish my observations, which being completed, we set out for the ship.

As we proceeded down the inlet, the dogs got a sight of three deer which were passing over to the opposite shore; and before we could stop them, or were well aware of the matter, they set off in full chase, with the sledge at their heels. At every bound which this carriage made over the rough ice, some part of our baggage flew out, to the great amusement of our guide, who shouted with joy at the "fun." The whole was soon out of sight; and we had nothing to do but to follow, and to pick up our instruments and other matters, as fast and as well as we could ; till, after three hours' hard walking, we overtook the machine, hard wedged between two pieces of ice, and the dogs so fatigued that they were scarcely able to move. No harm was however done, but that of prolonging our journey, as the course of the deer was very different from ours; so that it was eight o'clock before we reached the ship, sufficiently tired. We were obliged, however, to leave our guide some miles in the rear, since he was incapable of keeping up with us, and was in fact 
completely exhausted. But he had found a party of his friends to receive him, and was therefore very well taken care of.

In the morning he came to the ship; yet not with the same confidence as usual, and with a somewhat different reputation from that which he had carried out with him. The fact of his having attempted to deceive us by a falsehood, had been made known to his countrymen, and he was now called "Shug-loo," the liar. He himself was evidently ashamed; though whether of his conduct or his nickname, we could only at first conjecture: but it was probable that his conscience was the cause, since he did not apply to ne for the file which I had promised him as the reward of his services; and, still more did this appear to be the reason, because when I afterwards asked him why he had forgotten it, his answer was that he was not entitled to it, because he had not told the truth. He, after that, related the whole affair to the people of his own party who had come to the ship with him ; without any feeling. of offence, and with perfect apparent simplicity.

What sort of disapprobation is here attached to falsehood, it was not very easy to discover; since it was more often a matter of jest with those people, than of actual censure. If that which is termed a "white lie" is only a matter of joke in this country, our friends here did not differ much from ourselves on the subject of veracity; but there seemed reason to believe that the merit or demerit of a real one, intended to deceive, depended on its success or failure; that, as in the case of theft, whether in Sparta or among its fellow savages of the South sea, the unsuccessful rogue was the only one deserving blame or ridicule; as the very fact that our friend was laughed at rather than blamed, confirms this notion. There have 
been two hypotheses, and two errors, among travellers who have visited the rude and savage tribes of the world. The one sees virtue every where, and even finds it disguised under the garb of vice: the other is the direct reverse. I cannot help sometimes suspecting that we ourselves had been somewhat too much inclined to look at our Esquimaux friends through a sunny coloured glass: but at any rate, that is the most comfortable view which preserves ourselves in the best humour.

The farce, however, ended at last by a promise from the "liar" to commit this sin no more: on which the file was given to him: and he trotted off to join his friends, with a light heart, and, doubtless, with a conscience no longer aching. 


\section{CHAPTER XXIV.}

DEPARTURE OF COMMANDER ROSS ON A THIRD EXPEDITION THREATENING OF A RUPTURE WITH THE NATIVES-COMMANDER ROSS'S RETURN.

I $\mathrm{T}$ had now, therefore, been completely ascertained that there was 1830. no passage into the western sea to the south of the 70th degree; and it therefore became unnecessary to lay plans for proceeding in this direction with the ship. The more minute examination to the northward, was therefore the object to which our attention was next to be directed. Thus also did we find reason to be thankful that we had made no further progress ; little as we foresaw, at one time, that we should have come to such a determination as this. Had that been the case, we should have been entangled still deeper in a bay encumbered with peculiarly heavy ice, and, after all, been obliged to retrace our steps to the northward; while under infinitely greater difficulties in extricating ourselves, and perhaps not to have rescued our ship from the ice during the whole summer. It was not an unimportant part of the report of this journey, to find that reindeer had been seen only twelve miles to the south of our place, with innumerable tracks of the same animal, attended by the traces of their enemies, the wolves.

Being St. George's day, the usual ceremony of a royal salute and April 23. 
the display of flags was adopted. There was no one, indeed, to witness this customary loyalty ; but it was right to maintain the etiquette of the service. The better part of the day, after this, was occupied in cutting out the rudder, which had received some damage from the ice; but there was still a holiday left for the crew. Some of the natives arrived; and the guide boy passed on his way home.

April 24. The morning began fine, but ended with snow from the northward. Making an excursion to the top of the neighbouring hill, two of the natives joined me, and pointed out the position of Shag-a-voke, when I also ascertained those of many more places that were named, and learned the native names of some of those which we had seen, as well as of our own place and the immediate neighbourhood. We afterwards purchased what they had, and sent them home fortified with a dinner. The ice in the tanks was this day reduced to a bushel and a half for the week; so much less was the evaporation within, under the recent temperature.

April 25. It was cold in the wind, though the thermometer was at $2^{\circ}$ plus; and there were some showers of snow, with an overcast sky. We received a visit from the people in the northern village, who were about to remove to Neitchillee. Nothing else interfered with our usual duties and repose on Sunday.

A rril 26. On Monday, the natives arrived from their three stations. There were some skins to sell, and there was also a present of boots for Commander Ross, from the mother of his guide, as a testimony of gratitude. It was settled after this, that they should furnish another guide next day, to an expedition intended to the northward for the purpose of examining the reported passage in that direction 
but as it afterwards was discovered that some of them were to go there on their own pursuits, the arrangements were made accordingly .

Commander Ross and one of the mates departed to explore the April 27. inlet to the northward. At the village all was confusion, in consequence of the death of a child that had been killed by a stone falling on it. The father and five brothers came out, in an apparently frantic state, with their knives in their hands; and as it was doubtful what this meant, our own party prepared their guns, on which the father was forced back into the hut, and peace was restored. It was then settled that the man and boy, who had been previously engaged, should accompany the party in the morning, being confident that they should see musk oxen. On board we had abundant work, in caulking the ship as far as the men could contrive to reach : and this, with other preparations for our future journey, occupied the following day also, which presented no parti- April 28. cular interest.

The two last days had been gradually becoming colder, and the April 29. thermometer to-day was at minus $2^{\circ}$. The caulking and pitching were finished, and the men commenced to fit the skins on the canoe frame which they had prepared. The thermometer at night sank to minus $9^{\circ}$; and a snow storm came on in the morning, with the April 30. wind from the northward. It was impossible to work outside of the ship, and we received no visits.

In summing up this last month, I may remark that the first half was much warmer than was to have been expected at this season: but the end was so cold, that the average for the whole was zero. The most important of the events in it were the two journeys : and the sum of the information procured by them appeared to be the following: 
We were sure that we were on the continent of America. The western sea had been seen; but we found also, that if there was any passage to it, that must be within a degree to the northward of our position, at the bottom of Prince Regent's inlet, and in Cresswell bay, where, after sailing up six miles, no land could be seen in any direction. As the limits to our necessary researches were, thus, much contracted, our obvious business was to examine minutely the several inlets to the northward; while, should we find no passage, we should return to Prince Regent's inlet, and examine the only remaining opening on the south side of Leopold's islands. This had been done, as far as it could by land, in the first journey; but the result, thus far, was not satisfactory. It was for a future day to know the success of the expedition on which Commander Ross had just proceeded.

Much needful work had been done in the ship, and the men were in good health : they had even escaped the usual inflammation of the eyes from snow; excepting the mate, who had suffered from it in his first journey. The ice had been found seven feet and a half thick; and we did not expect that it would increase any more. Many good observations had been made, and the experiments on sound continued : but the results of these were so irregular that we knew not yet what conclusions to draw.

May 1. This was not the May-day of the poets, but it was mild, at least, till the evening, when there was a strong north-easterly breeze. There were no visits from natives: and though many hares were seen, none were killed. We expected the return of our party to-day, in vain. 'The midnight temperature was minus $4^{\circ}$, and the barometer fell half an inch. 
There was still no signs of our party, nor did the natives visit May 2. us. After church, the mate and a party went five miles in the direction in which they were expected; but returned without any tidings. The thermometer rose, for some hours, to plus $18^{\circ}$ : no observations could be taken, excepting a transit of the moon; such was the state of the sky.

Our party being still absent, we began to be anxious : and $\mathbf{M r}$. May 3. Thom, with the surgeon and two men, were consequently sent to the northern huts, to see if the natives were still there, and, if not, to deposit a supply of provisions, with a signal to give notice of its place: it was possible they might want it, and they would thus be enabled to continue out, and proceed in their investigations without returning to the ship. In the mean time, however, some natives arrived from another village, and informed us that our party would arrive the next day, with a musk ox which they had killed. They sold some skins and received their dinners; being nine in number. Shortly afterwards, Mr. Thom returned; and having found the huts empty, executed his commission. It was certain that they were gone to Neitchillee; but those who had been with us were to remain some time longer.

Our party returned in the afternoon to our great satisfaction. May 4. They had killed two musk bulls, and had brought part of them within three miles of the ship. It was much more important to know that they had found a channel leading to the western sea: but, as on the former occasion, Commander Ross's narrative must be given in his own words. We lost no time in sending for part of the beef: the animals had been unusually large ones. Many reindeer had been seen; and some ptarmigans shot on the wing, to the great surprise of the native guide. 


\section{CHAPTER XXV.}

NARRATIVE OF COMMANDER ROSS.

18:30. As the season was now rapidly advancing, I became very desirous, if it was possible, to visit that place to the northward which the natives called Aw-wuk-too-te-ak, as a preparation for the journey which we had projected to the Western Ocean. The Esquimaux had now also broken up into different parties; and we were therefore afraid that they would all quit our neighbourhood before we had ascertained the position of that place. It was, to us, a very important one, if their information was correct: since they said that, beyond that point, the coast turned and extended to the northwest, and that this was the only route by which we could get round to the sea of Nei-tyel-le. Correct as this information might be, for aught that we could suppose to the contrary, having no grounds to form any conclusion, we thought it a remarkable circumstance, as it was one which diminished our confidence in the reporters, that although many of these people had been at Aw-wuk-too-te-ak, and some of them three or four days' journey beyond it, none had ever gone to Nei-tyel-le by the route which they indicated to us. All their information was derived from report; and when they spoke of a communication between the eastern and western seas, existing at a certain point, we began to suspect that this was at so great a distance as probably to imply the passage at Barrow straits. 
But under any doubts, whether Aw-wuk-too-te-ak was situated at no greater distance than we were told, or wherever it might prove to be, it was most needful that we should see it. The country was quite unknown to us; every thing around was equally obscure or doubtful; however generally accurate the geographical descriptions of these people had proved, they could never be thoroughly trusted; the land might be intersected at any part by narrow straits, or we might be on an island: while, under any view, it was our business to search this country as we would seek for the mouth of a river; since for this purpose we had come, and since we could never foresee where the long sought honour might not be lying in wait to reward our exertions.

A large party of the Esquimaux had come to the ship while these reflections were passing through our minds; and taking advantage of this incident, one of them was engaged to conduct me to the place in question, and the arrangements made for our departure on the following morning. I was to be accompanied by the mate Abernethy; and the surgeon was to attend me to the huts, where the guide was to meet us, that he might bring word back to Captain Ross of the nature of our final arrangements for the journey itself, and of the probable time of our absence; so that, if needful, he might take measures for supplying us with provisions.

We departed accordingly, early in the morning of the 2\%th of April 27. April, and approaching the huts, were exceedingly disappointed at not hearing the cheerful shouts with which we had been usually greeted. That was succeeded by a very disagreeable surprise, on finding that the women and children had been all sent out of the 
way, since we knew this to be a signal of war; a fact of which we were speedily convinced by seeing that all the men were armed with their knives. The fierce and sullen looks of these people also boded mischief: but what the cause of all this could be, it was quite impossible to conjecture.

We could see them better than they could distinguish us, as the sun was in their faces; it was the noise of our dogs which gave them notice of our arrival and proximity; and as soon as this was heard, one of them rushed out of a hut, brandishing the large knife used in attacking bears, while the tears were streaming down his aged and furrowed face, which was turning wildly round in search of the objects of his animosity. In an instant he lifted his arm to throw his weapon at myself and the surgeon, who were then within a few yards of him, having advanced in order to ascertain the cause of all this commotion. But the sun, dazzling him, caused him to suspend his arm for an instant; when one of his sons laid hold of his uplifted hand, and gave us a moment's time for reflection.

The result of that was, of course, an immediate preparation for defence; though we could have done little against such odds as our unexpected enemies displayed. We therefore retired to the sledge, where I had left my gun; and not daring again to quit it, as Mr. Abernethy had no arms, waited for the result, while losing ourselves in vain conjectures respecting the cause of offence, seeing that we had parted good friends on the preceding day.

The ferocious old man Pow-weet-yah was still held fast, and, now, by both his sons, who had pinioned his arms behind him; though he strove hard to disengage himself; while the rest of the party seemed to be standing in readiness to second any attempt 
which he might make on us. That there was some difference of opinion among them, however, and that all were not equally hostile, was plain from the conduct of these young men; so that we could still hope for some parley before matters came to extremity. They now began to talk among themselves, and then separated in such a manner as to be ready to surround us, which having 'nearly effected, and we not choosing to be so cut off from the ship, I warned those who were closing in on the rear, to desist. This produced a short pause, and a still shorter conference; but they immediately again began to close in, brandishing their knives in defiance, according to their usual custom, and had nearly gained their object, when finding that further forbearance would be hazardous, I placed the gun to my shoulder, and was about to fire, when I fortunately saw that the threat alone was sufficient to give them a check. With little loss of time, those who had advanced nearest broke off; in evident alarm, and retreated towards their huts; thus leaving us an open passage in the rear.

But as I could not induce any of them to approach, or to answer my questions, we continued for nearly half an hour in this state of suspense and perplexity, when we were relieved by the courage or confidence of one of the women, who came out of a hut just as I was again raising my gun, and called to me not to fire, advancing up to our party immediately, without showing the least mark of fear.

From her, we soon learned the cause of all this hubbub, which, absurd as it was, might have had a fatal termination, as we should probablyhave been the chief sufferers. One of Pow-weet-yah's adopted sons, a fine boy of seven or eight years of age, whom we knew, had been killed on the preceding night, by the falling of a stone on his 
head. This they had ascribed to our agency, through the supernatural powers which we were believed to possess; while the father, not very unnaturally under this conviction, had meditated revenge in the manner which we had experienced.

I had much difficulty in persuading the good woman that we were totally ignorant of this catastrophe, and that we were very sorry for the misfortune; she however repeated all that I had said to two of the men who had not taken any share in the business of the attack, and who now approached us unarmed, in token of peace. Their object was to persuade us to go back to the ship, and to return in three days, when they offered to be our guides to the desired place. But many reasons opposed this scheme; of which the chief was, that as this was the first misunderstanding that had occurred between us, it was essential to come to an understanding, and to renew our friendships, without any delay, lest the opportunity should not again occur; as they might go away in the mean time, whether from fear of our returning in greater numbers, or for any other reason, and thus, not only cause a lasting estrangement as to themselves, but a general hostility or desertion on the part of all the natives within their connexions or reach; thus rendering the whole land our enemies. I therefore objected to this proposal, and declared that I would not go back till we were all once more good friends: when perceiving that the hostile party was gradually approaching our group, though, probably, but to hear the conversation that was passing, I drew a line on the snow, and declared that none of them should cross it without putting away their knives, which they still continued to grasp in their right hands, with their arms folded across the breast. After some 
conversation among themselves their grim visages began to relax, the knives were put up; and, becoming at last apparently convinced that we had no concern in the death of this boy, they seemed now very anxious to remove the unfavourable impression which their conduct, as they must needs conclude, had made on us.

But they still urged us to return to the ship, because, as they said, it was impossible for them to make use of their dogs till three days had passed away after the death of any one belonging to a family. Though in all probability this was really a funereal usage, or a settled period of mourning, I was unwilling to yield this point, could I possibly carry it; as the loss of even three days at this season was an important consideration.

I therefore produced a large file, offering it to any one of the party who would go with me, and assuring them at the same time, that if they all refused I should go alone, and they would thus lose the reward. On this, a consultation of some minutes took place, in which I heard the word "Erk-she" (angry) frequently used, accompanied by my name: which being ended, the man called Poo-yet-tah seemed to yield to his wife's entreaties, and offered to accompany me, provided I would allow Il-lik-tah, a fine lad of sixteen or seventeen, to be associated with him.

This, I of course agreed to, as two companions would be more useful than one; and they accordingly went off to the huts to prepare for the journey. 'That the peace was now considered as perfectly re-established, there could no longer be any doubt; since they crowded round us, soon resuming their usual friendly and confidential behaviour, and putting on that cheerfulness of countenance which was their habitual expression. 
If I have dwelt on this adventure at some length, it is because this was the only occasion on which they ever showed any hostile feelings towards us, during all the years which we passed in their neighbourhood. I must not, however, take to myself all the merit of having brought our little party out of this adventure in safety: the coolness and self-possession of my two companions were mainly conducive to a termination of that, in which the least act of temerity or incaution might have cost the whole of us our lives.

It was at ten o'clock that we commenced our journey towards the north-west corner of the bay, and we were followed by the acclamations of our friends as long as we were within hearing. Mr. M'Diarmid went back, as was agreed, to inform Captain Ross of what had happened, and to say that we expected to be absent four or five days, as far as I could judge from the calculation of the guide; so that our party consisted now but of four, including the two Esquimaux.

The baggage and provisions were placed on two sledges, each drawn by six dogs; and, by their aid, we travelled very quickly over the smooth ice of the bay. After having thus made ten or twelve miles, the guide Poo-yet-tah stopped his sledge, and said that he was going to a seal hole that he knew of, at some distance on our left hand. As I could not help suspecting that he might leave us and return to the huts, I proposed to accompany him ; to which he consented without any hesitation.

After we had walked some time, he, being in advance, turned round, and, striking me on the breast, said that I was "good;" when remarking also for the first time, that I had left my gun behind, he placed his spear in my hand, saying that I should be 
armed as well as he, and drew from his dress, where it had been concealed, his long knife, for his own arm. On arriving at the seal hole, he lay down, and, putting his nose to the slight coating of snow by which it was covered, said that the animal had deserted it for some days. As there was thus nothing to be gained, we returned to the sledges and continued our journey; each, by turns, undertaking to lead on foot, and then, in rotation, taking his seat in the vehicle.

At two in the afternoon we entered an inlet which the guide called An-ne-reak-to, running in a north-north-west direction, and being about a mile wide at the entrance. The eastern cape of the opening was named by him Ne-ak-kog-e-nek; an appellation derived from a rock projecting through the shingle, which bore a fancied resemblance to a human head. The western point, termed Neck-ler-rid-yeoo, forms the termination of Ac-cood-le-ruk-tuk; a name which they seem to apply to all pieces of land, or peninsulas, which are nearly surrounded by water, be that fresh or salt.

We continued, hence, to journey along the western shore of this inlet, till we entered the mouth of a river, about a mile and a half from its entrance, turning off to the west-north-west, and leaving to our right the termination of An-ne-reak-to. This part of the river is called Ac-cood-le-it-pang-ut, and though covered with freshwater ice, bore evident marks of a rise and fall of the tide on its shores. At three o'clock we arrived at a point where the stream was contracted, so as to produce a rapid, or fall, of about twenty yards in length; but hence our journey became exceedingly laborious, as the whole valley was so filled with loose snow that we could no longer pursue the windings of the river as we had hitherto done. Thus far, the 
right bank of the stream consisted of loose blocks of limestone, through which masses of gneiss could be seen projecting in different places, while the left side ascended from the water in a gentle slope, so as to attain an elevation of a hundred feet at the distance of a mile.

At six we came to a small lake, which is the source of this river, surrounded by high, rugged, or precipitous shores, the ravines of which were filled with closely-packed drift snow, by which the summits of the hills in the distance were also covered. From this place we then turned more to the northward, crossing a high ridge for the purpose of reaching another lake, and undergoing great labour during an ascent of an hour and a half, from the steepness of the ground and the depth of the snow. It was not till ten at night that we arrived at our halting place, and finished this day's journey; men, and dogs too, all equally tired with a laborious struggle against a high wind and driving snow, during a space of thirty miles which we computed that we had travelled.

The two Esquimaux soon erected an excellent snow hut, and, after our supper of frozen meat, we betook ourselves to rest; being all so fatigued that we could not converse, even on the events of the morning, on which I should otherwise have entered, for the purpose of understanding better the nature of their funereal usages, as well as that I might convince myself of the entire removal of all their fancies respecting our supernatural and mischievous agency.

April 28. The night was extremely tempestuous; and in the morning, it blew very hard from the north, with a heavy driving snow, so that we could not quit our hut till nine. From this cause we made very little way till towards noon, when the wind moderated a good deal, 
after which the day became beautiful. The latitude by a meridional observation, was $70^{\circ} 25^{\prime} 19^{\prime}$, and at this time, being noon, we passed a great number of Esquimaux marks placed on an islet in a large lake. This, as our guides informed us, was a fishing station much frequented in the summer and autumn; the lake abounding with salmon during these seasons, which was the time during which they ascended from the sea, through a river which finds its exit from the north-eastern corner of this piece of water. The station itself was called Nap-pur-re-uk-ta-lig. This place is entirely surrounded by granite hills, and the islets consist of the same rock. The lake itself is of a very irregular shape, and of considerable extent from the north-east to the south-west.

Leaving this spot, we crossed this piece of water in a northwesterly direction, but found the travelling very laborious, from the great depth of the snow, which was also loose, and occupied the course of the river and lake: being unfortunately the direction most convenient for us. This, like all similar places in this country, they called It-tib-lin-ne-ak. Though the road was as bad as could well be, throughout the whole of this hollow, or watercourse, there was one place which far outdid all the rest. This was a frozen rapid in the river, where, in addition to the irregularity and roughness of the ice, which also projected in slippery masses through the loose snow, the declivity was so considerable that the sledges ran down it with fearful rapidity, getting before the dogs, which they dragged along, and endangering the vehicles themselves, with all which they carried.

We found a safer, though a more rugged path for ourselves, and halted at five o'clock to make the necessary observations for the 
longitude. It was not very wonderful that the sight of the instruments revived in the mind of the guide the belief in our powers of conjuration. And as the idea of eating is ever predominant in the mind of an Esquimaux, while hunting and fishing are almost the only occupation of their lives, his inquiries took this very natural turn. Should we find any musk oxen by means of this inexplicable brasswork, or see them among the hills, while looking so intensely through these tubes and glasses? In fact, we were in the parts frequented by those animals; and it was a very natural conclusion that we had come thus far, and taken all this trouble, for that most important of all purposes, a dinner or a feast. Poo-yet-tah had yet to learn that civilized Europeans must gain their dinners by operations much more circuitous than killing and eating them: and would have been puzzled to understand a system which had brought so many men in a large ship, all the way from England to his shores, that they might command the means of present and future dinners by measuring angles and looking at the moon.

I was by no means desirous, however, of passing for a conjuror. We had found ourselves in a sufficiently awkward predicament already, in consequence of this, to us, unenviable reputation; and I therefore declared my total ignorance of all musk oxen and their ways. At this he seemed greatly disappointed, and then proposed that we should build a hut in this place, to watch for them; but on my expressing my desire to go still further this day, he quickly again put on his good-tempered face, and we proceeded accordingly.

In less than half an hour his sharp eyes observed the tracks of several of these animals on the face of the steep hill, at the foot of 
which our road lay. On examining them, he found that the animals had passed many days before : but making a further search, he soon found the traces of two which he asserted to have been at this spot on this very evening. We therefore went back to the sledges; and after selecting a spot to build a hut, and leaving the work to be executed by the boy, he took his bow and arrows and set off; leaving two of his dogs in couples, and desiring me to follow with my gun and favourite dog Tup-to-ach-ua.

On regaining the tracks, he immediately let slip the dogs, and I followed his example with mine. They went off at full speed, and were very soon out of sight; as the nature of the surface did not allow us a very distant view of the ground. His politeness, however, induced him to think me too much fatigued to accompany him in search of the dogs and the game; and he therefore slackened his pace, refusing to leave me behind, though I urged him to do so lest we should lose our expected prey, and assuring me that the dogs would take good care of their own business.

We went on, therefore, laboriously enough, for two hours, over a very rugged country and through deep snow; when finding that the footsteps of the dogs no longer followed that of the oxen, he concluded that they had got up with the animals, and were probably holding one or both of them at bay. We soon found this to be the fact, on turning the angle of a hill; when the sight of a fine ox at bay before the three dogs, cured our fatigue in an instant, and we went off ourselves at full speed to the rescue.

Poo-yet-tah, however, kept the lead, and was in the act of discharging his second arrow when I came up. We saw that it had struck on a rib, since it fell ont without even diverting the attention 
of the animal from the dogs, which continued barking and dodging round it, seizing it by the heels whenever they had an opportunity, or when it turned to escape, and then retreating as it faced them. In the mean time, it was trembling with rage, and labouring to reach its active assailants, but unable to touch them, experienced as they were in this service.

It was easy to see that my companion's weapons were of little value in this warfare, or that the victory would not at least have been gained under many hours; as he continued to shoot without apparent effect, finding his opportunities for an aim with much difficulty, and losing much time, afterwards, in recovering his arrows. I was pleased, therefore, independently of the value of the expected game, to find an opportunity of showing him the superiority of our arms, and I therefore fired at the animal with two balls, at the distance of abont fifteen yards. They took effect, and it fell: but rising again, made a sudden dart at us, standing close together as we were. We avoided the attack, by dodging behind a large stone which was luckily near us; on which, rushing with all its force, it struck its head so violently, that it fell to the ground with such a crash that the hard ground around us fairly echoed to the sound. My guide, on this, attempted to stab it with his knife; but failing in this, he sought shelter behind the dogs, which now again came forward to the attack. At this time it was bleeding so profusely, that the long hair on its sides was matted with blood; yet its rage and strength seemed undiminished, as it continued to advance and butt with the same ferocity as before.

In the mean time I had reloaded my gun behind the stone, and was advancing for another shot, when the creature rushed towards 


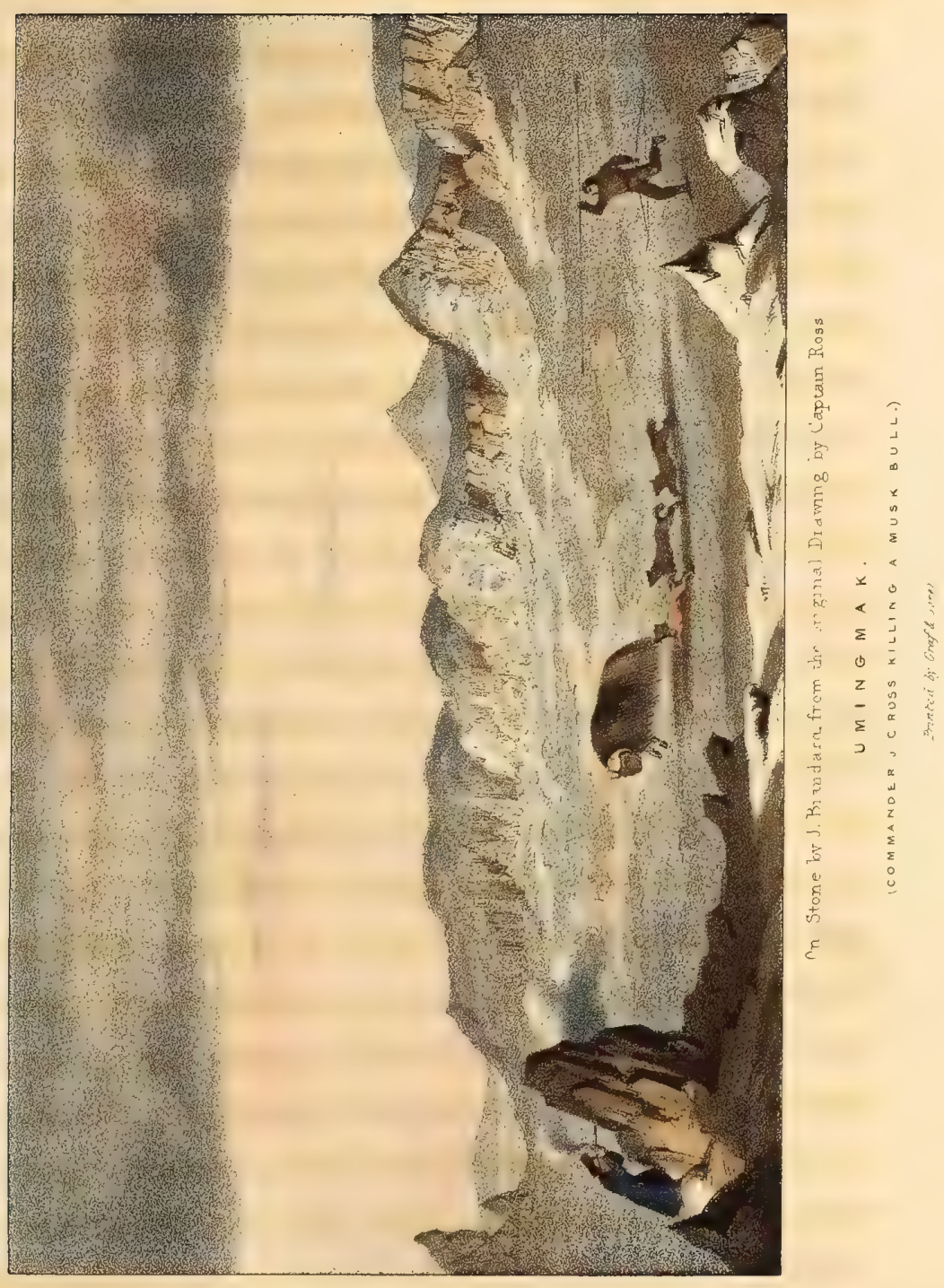



me as before, to the great alarm of Poo-yet-tah, who called to me to return to the same shelter. But I had time for a cool aim; and it immediately fell, on the discharge of both barrels, but not till it was within five yards of me. The sight of his fallen enemy made my companion scream and dance with joy, and on his coming up, it was dead; one ball having passed through the heart, and the other having shattered to pieces the shoulder joint. He was lost in astonishment at the effect of the fire-arms; first carefully examining the holes which the balls had made, and pointing out to me that some of them had passed quite through the animal. But it was the state of the broken shoulder which most surprised him; nor would it be easy to forget his look of horror and amazement, when he looked up in my face and exclaimed "Now-ek-poke!" (it is broken.)

We had now been eighteen hours without any refreshment, and I naturally, therefore, expected that my friend would have lost no time in extracting a dinner out of the ox. I had however done him injustice: his prudence was more powerful than his stomach. He was content with mixing some of the warm blood with snow, thus dissolving as much as he required to quench his thirst, and then immediately proceeded to skin the animal; knowing very well, what I might have recollected, that the operation would shortly become impossible, in consequence of the severity of the cold, which would soon freeze the whole into an impracticable mass. For the same reason, he divided the carcase into four parts; afterwards disposing of the paunch and intestines in the same manner, their contents being previously separated. I did not before know, that they did not eat these as well as the 
analogous matters of the reindeer; and could only conjecture, that at this season of the year, the plants on which the musk ox feeds were disagreeable to their taste. In the reindeer, the matters found in their stomachs are considered a great delicacy; and however our own might revolt at a vegetable dish cooked in this manner, this forms a very useful and salutary ingredient among their gross animal diet, since it is scarcely possible for them to collect any eatable vegetables by their own exertions.

As we were unable to carry off our prize, we were obliged to build a snow hut over it, after which, setting up marks to enable us to find it again, we set out on our return to the place where we had left our companions. In the way, we discovered another ox about a quarter of a mile off, under the face of a precipice, but were far too fatigued to think of pursuing it. The guide, however, assured me that this was of no consequence, since it would remain there for some time, and we might easily go after it in the morning.

April 29. We reached the hut that had been built, at five in the morning of the twenty-ninth, hungry and fatigued enough to find a very serious enjoyment in a hot supper and rest. We had brought away some of the beef, and found it exceedingly good, not having, at this season of the year, the least flavour of musk. In August, at Melville island, on a former occasion, this taste was very offensive: and it is only consonant to other experience in many animals, to suppose that this effect takes place in the rutting season. My observations here, made the latitude $70^{\circ} 35^{\prime} 49^{\prime \prime}$, and the longitude $0^{\circ} 38^{\prime} 33^{\prime \prime}$ west of the ship.

We had not been asleep more than four or five hours, when we were awoke by the shouts of Poo-yet-tah and the barking of the 
dogs in full cry. On inquiring of the boy, he informed me that our guide and huntsman had crept out of the hut silently, about an hour before, and was gone in pursuit of the ox which we had seen on the preceding day. In a short time he returned, and told us that he had found the animal grazing on the top of the hill, that he had advanced upon it by the only accessible road, keeping himself in the middle of his dogs, and that he had done this with so much rapidity, that the creature finding no other mode of escape, had thrown itself over the precipice.

On going to the spot, we accordingly found the carcase in the place which he had mentioned, exceedingly mangled by the fall, which had exceeded thirty feet, while the place which it had struck was an irregular block of granite. As far as use was concerned, it was however no worse than if it had been uninjured; and the same operations were therefore repeated: the whole day being afterwards occupied in this work, and in bringing the meat to our hut.

This, however, left me leisure for my observations; and the morning proving fine, I was successful in making them. Among other things, I thus ascertained that our present place was about forty miles from the ship, in a direction north $19^{\circ}$ west. In the afternoon there arose a strong breeze with drifting snow : so that we were glad to have recourse to the shelter of our hut, and thus also made our dinner at a much earlier hour than usual : getting into our fur bags shortly after, that we might ensure a good night's rest.

It blew so hard a gale from the north during the whole day, April 30. that we were unable to leave the hut; which gave us an opportunity of some conversation with our guides and companions, and 
which I made use of in endeavouring to extract from them a fuller history of the event which had led to our dissensions, and of their feelings and proceedings in consequence.

Poo-yet-tah himself was equally anxious to explain : so that it was scarcely necessary for me to name the subject. Having commenced, he proceeded in his tale with so much rapidity and vehemence, that it at first seemed to me as if he had re-excited his anger on this subject, and that we were now likely to renew a quarrel which had been suspended, not settled. I soon found, however, that all this energy was the result of his anxiety to convince me that his friends were not in reality to blame, that they had acted under what they believed a conviction of our treachery, or wicked interference, and that we ought now to be perfectly reconciled, since we had exculpated ourselves to their satisfaction. The peacemaker was even the more praiseworthy, that I mistook the energy of his eloquence on the amiable side, for a renewal of hostilities and a declaration of war.

In spite, too, of their numbers on that occasion, and of their evident intention to attack, they were impressed with a strong feeling of our superiority ; an impression which we were, all, naturally, most desirous of cultivating; since it was not less a ground of respect, as it must ever be among rude nations, than a tower of defence to us under the numerical difference between ourselves and this collected nation. C'nder this conviction, he thanked me frequently for not killing his father, or breaking his shoulder as I had done that of the musk ox; while he still seemed to fear, that when I returned to the ship I should do him some harm. I endeavoured, of course, to convince him that nothing of this kind could ever 
happen, that we were all attached to his people, and desired nothing so much as to continue friends; and with these assurances he seemed satisfied.

If the remainder of our conversation was not highly interesting, it will at least serve to convey some ideas respecting the usages of these people. I was at first surprised to hear my guide Poo-yet-tah call Pow-weet-yah, his father ; since, to my eye, there were not many years of difference in age. On asking the reason, I was informed that he was only the step-father, and that he was even the second in this relation which Poo-yet-tah had possessed; while both of them were such during the lifetime of his own father, who had taken another wife and left his own to the first of these two. It was, however, an amicable separation. The man had desired to inigrate to the westward, and the wife, on the contrary, preferred staying among her own relations; they therefore separated, a short time after his birth, and the woman then married a man called Arg-loo-gah by whom she had four more sons. This husband was drowned; leaving his widow a large fortune in the shape of these five sons, who are here considered a valuable estate, since the maintenance of the parents in old age devolves on them. Thus she easily procured another husband, Pow-weet-yah, the brother of her first one; but by this marriage there were no children. To replace this want, they adopted two grandsons as such; and the boy who had been killed was the eldest of those. The original husband, Ka-na-yoke's true father, had also procured a son by adoption, among the tribe at Oo-geoo-lik, to which he had gone, and he was now living in a small island, called $\mathbf{O}$-wut-ta, three days' journey to the westward of Nei-tyel-le. 
The terms husband and wife are words of usage: the ideas are simple, and excite no doubts; the language is smooth, and belongs to good breeding and good morals: and the term marriage is one which equally excites neither reflection nor commentary. It has been the custom, too, however it began, to praise the temper, conduct, and morals of these tribes; but some readers may perhaps question the conjugal system and usages of this people, should they take the trouble to think on the subject; as they may also perhaps suggest that concubinage, and not of a remarkably strict nature, is a more fitting term than marriage, for the species of contract under which the parties in question are united.

They might even be the more inclined to think so, had they heard the further anecdotes which Poo-yet-tah related to me on this subject; of which it must, however, suffice to notice one, as a sort of general result. Among the Esquimaux of Igloolik whom we had formerly visited, it was not uncommon for a man to have two wives; a practice that excites no surprise, wide spread as polygamy is, and has been from all time. But my friend here informed me that he and his half brother had but one wife between them, as, if I rightly also understood, this was held a justifiable system, and, if not very common, merely such because of a general numerical equality between the sexes. Of this custom we had found no instance at Igloolik: and I know not that it is related by travellers of any but certain tribes in India. Others must consider for themselves, of the propriety or delicacy of such a connexion as that of two brothers with a single wife, since I do not set up for the moral commentator on a people, respecting whom every one is now nearly as well informed as myself; so much has been written 
respecting them by us, the recent northern navigators, and by many more, foreigners as well as English.

As it was my intention to make an excursion in the direction of Oo-geoo-lik after returning from my present journey, I procured from my informant a list of the names of all those whom I was likely to meet, and was charged at the same time with several messages to them. These I wrote down, as the best letters of introduction that I could have received : and, if aught could now have been wanting, the entire confidence between us was thus perfectly established.

Thus this dreary day was shortened; and a truly dreary one it was. The wind without, howled round our walls of snow, and the drift which it brought sounded against them with a hissing noise, which I was glad to forget in the talk that rendered it for a time inaudible. If our house was but four feet high, so that it kept us constantly in a sitting posture, it was nevertheless warm, and, by contrast, comfortable; a far better one has not often been so acceptable, and has rarely indeed afforded such a sense of thankful security and enjoyment.

The talk of our friends did not, however, prevent them from using their jaws in a very different manner. During the whole day they were employed in removing the meat from the upper half of the ox; cutting it off in long narrow slips, which, in the usual manner, they crammed into their mouths as far as they could push it in; then cutting the morsel from the end of their noses by the means of their sharp knives, they bolted the mouthfuls as a hungry dog would have done. Thus passing the slice from one to the other, alternately, they contrived at length to swallow all the meat 
from the neck, backbone, and ribs, of one side of the ox : suspending their motions, however, every now and then, to complain that they could eat no more, and lying back on their beds, but still retaining their knives in one hand, with the unfinished morsel in the other, and again beginning with as much energy as before, as soon as they felt it possible to get down another lump.

Disgusting brutes! the very hyæna would have filled its belly and gone to sleep: nothing but absolute incapacity to push their food beyond the top of the throat, could check the gormandizing of these specimens of reason and humanity.

By the time that they seemed really incapable of devouring any more, our own soup was ready, and I therefore offered them to partake. Out of politeness, Poo-yet-tah took two or three spoonfuls, and then confessed that he could swallow no more. Placing my hand on his stomach, I was perfectly astonished at the distention which it had undergone, and which, without such an examination, I could not have believed it possible for any human creature to bear; as, had I not known their habits, I should have expected that nothing but death could be the consequence.

May 1. This enormous stuffing caused our guides to pass but a restless night : if they had possessed a term for the nightmare, we should probably have heard of it in the morning. In the mean time the gale moderated; so that, when we rose at five o'clock on the next day, the weather was such as to allow of our proceeding; though still hazy and somewhat threatening, as the breeze was from the northward, and was accompanied by some drift.

Our sledge was soon loaded, but the guides had not so soon recovered from the effects of their dinner, so that it was past seven 
o'clock before we could get them to move. But when ready, Poo-yet-tah said, on my expressing my unwillingness to lose another day; that as we should be obliged to travel over high hills, where the sledges could not go, we must leave all our baggage at the hut, and that we might then proceed to Aw-wuk-too-teak and return to sleep.

We accordingly set out at half-past seven, taking with us our arms and three of the dogs, in case of our falling in with any more of the musk oxen, and leaving Mr. Abernethy and the boy in charge of the baggage. 'Travelling over a very rugged country covered with deep snow, during two hours, we at length descended on the lake which they call Aw-wuk-too-teak and which will be found in the chart.

This piece of water extends, according to its longest dimensions, from north-east by east to south-west by west, and, in this direction, appeared about four miles in length. In shape, it is very irregular, as it is bounded by five distinct hills, separated from each other by an equal number of ravines, which, during the thaw, are watercourses, supplying the lake. Where it empties itself, the issuing stream is broad, and appeared to be shallow; but its source seemed to be a rapid one, and its termination was in the sea to the northward.

The names of these hills as given by the guide are as follow, distinguishing them by their true bearings, from the centre of the lake: namely, that to the west is called Pood-le-ra-nuk, to the north-west II-Jow-nuk, to the north-east Ac-cood-le-ruk-tuk, to the west-south-west Tak-ke-noo-ra-lig, and to the south Il-low-na-lig. Poo-yet-tah further informed me that the lake contained three 
different kinds of fish, which remain in it throughout the winter, that it was of great depth, and that in the smaller lake to the

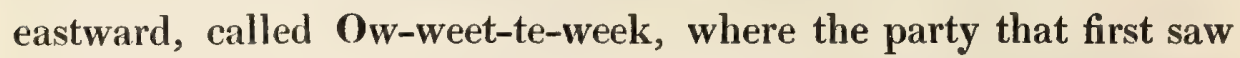
our ship in the September of 1829, had been encamped, there was also abundance of fish of a large size.

Leaving the water side, we now ascended the high hill on the north-east side, called Ac-cood-le-ruk-tuk; and, on reaching its summit, which we had surmounted soon after ten o'clock, I could see the high rugged ice extending from the north-north-west to the north-east by east. The hazy state of the weather, however, limited our view to a distance of four or five miles, so that it was impossible to ascertain the depth of an inlet, of which the entrance seemed to be formed by the separation of the spot on which we stood, from a remarkable cape that we had named the Old Man of Hoy, when on our way to the southward during the preceding autumn, and which $I$ had no difficulty in recognising.

This was the place where I had expected, if any where, to find the way open to the western sea, since it was that which the natives had spoken of to us on several occasions; or thus, at least, we imagined, as it was not very easy to come to a right understanding on this subject. The man called Ib-lu-shee had indeed assured us that the opening at this place was nothing but the mouth of a large bay, and that we must travel many days to the northward before we could find a passage to the westward; an assertion which made me suppose, as I have already observed, that he could mean nothing but Barrow's strait. But as we had not examined the present inlet, since it was filled with fixed ice when we had passed in the preceding year, I thought it indispensable to take the 
present opportunity of doing this, that we might at least remove the natural uncertainty which we felt respecting it.

When, however, I came to examine the nature of the ice which now lay between us and the inlet in question, as well as the great distance that it would be necessary to travel for that purpose; I found it impossible to undertake such a work at present. Pooyet-tah indeed became very anxious that we should return, as he saw that the north wind, with its driving snow, was rapidly increasing; but, as the haze seemed to be partially clearing away, I proposed to him to descend to the beach, as I might hope thus to get a better view.

This, however, he absolutely refused: but as.I felt confident that I could find my way without him, I went off, and left him to follow his own inclinations. In about an hour and a half I reached the beach in question, which was formed of loose fragments of limestone, and found the tide out: while, as far as I could see, the ice consisted entirely of hummocky masses which had been closely packed against the shore at the commencement of the winter.

I had not gained much by my attempt to investigate this piece of ground; for the falling.snow, and the thick haze by which it was accompanied, obscured every thing in such a manner that I could never see beyond two miles, if I even -saw so far. The weather also became more unpromising, instead of improving; so that I resolved to give up all further pursuit of this object, and turned my face to return to the hut where I had left my companions.

On this, I immediately heard the voice of Poo-yet-tah, hallooing from behind a stone, close to me, and was not a little surprised to see him, when I expected that he had been safely 
lodged in the hut by this time. I found that he had followed me slily, to watch my proceedings; being desirous to know what could be the object of so long a journey from the ship as that which I had thus undertaken, and probably also conceiving that I had here some object of profit in view, in the finding of game or fish, in which he was desirous of partaking. I had great trouble in trying to persuade him that I had no other pursuit than that of seeing this place among others, yet did not finally succeed in convincing him: since, however possessing that knowledge of geography which is so general among these people, their pursuits and acquisitions of this nature are all directed to the immediate and important end of procuring food.

On further conversation, he told me that he should be at Owweet-te-week in the summer, together with his brothers, for the purpose of hunting or fishing, and that they would bring us salmon and venison. Wishing to know the situation of this place, that I might be able to recognize it again from the ship, he agreed, and we set forth together.

After two hours' travelling toward the south-east, we crossed

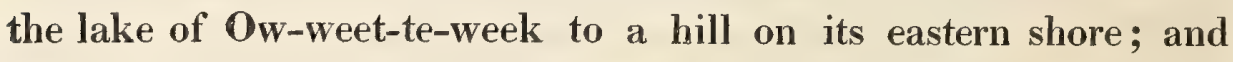
on ascending it, he showed me the spot where his tent had been erected in the preceding summer when we passed by, and where he was to be in the impending one. He also pointed out to me some stores of food which his companions had abandoned on leaving this place; and, opening one of his own, produced some pieces of ironstone which he had wrapped up in a piece of swan's skin; reminding me of what I had forgotten, that he had promised me some on our arrival at Ow-weet-te-week. He said that one of 
his brothers had found it, in the preceding summer, on the shores of an islet called Toot-ky-yak, which was a day's journey to the north-west, and that it had been taken from beneath the water, by the washing of which it was probably rendered more obvious to their inexperienced eyes. This substance constitutes their only article of commerce, and they exchange what they have obtained, every three or four years, with the natives of Oo-geoo-lik ; getting drift wood in return, and, in a similar way, purchasing the potstone of which their kettles are made, from the inhabitants of Repulse bay.

Poo-yet-tah now became anxious to return to the hut; but as we passed the foot of the hill whence I obtained the first view of the sea, I prevailed on him to accompany me to the top. The weather indeed had become even more unfavourable than before, but I could not bear to abandon a spot which seemed to contain the only chance of a passage by which our ship might reach that western sea which I had now seen. My labour was however lost. The snow began to fall thicker, nothing could be seen, and we were glad to descend again in all haste, and make our way back to the hut.

In our progress thither, we put up a pack of six grouse, and I had the good fortune to bring down one with each barrel. These were the first objects that Poo-yet-tah had seen shot on the wing, and his surprise was even greater than it had been at the killing of the musk ox. Shortly after, they rose again at half a mile's distance, when he urged me to fire once more, as he afterwards, wished me to follow them to the spot where they had alighted after this flight. But I did not choose to risk my reputation, or rather that of the 
gun, which it was important to preserve: while we had also now more game than we could use, or transport to the ship.

We therefore pursued our journey, and arrived at the hut at seven in the evening; being just in time to save ourselves from the commencement of one of the most stormy nights we had ever experienced. The wind blew during the whole of it, in the most violent gusts that can be imagined; descending from the hills around with such squalls of driving snow, that they threatened as much to demolish our little structure as to overwhelm and bury us in a hill of their own making. This indeed they nearly did before the gale moderated: such was the accumulation of snow that was blown up into deep ridges around and above our hut, which was, however, too strong and solid to give way to the force of the wind. We were afterwards surprised to find how very confined this storm was, since there was nothing more than a moderate breeze at the ship, though only forty miles distant.

May 2. Having been well recruited by a night's rest, I had hopes of inducing Poo-yet-tah to make another excursion to the sea; but we had first to encounter the task of digging ourselves out of the snow. This occupied four hours, since it had attained a depth of six feet above us: and when we were at last freed, we found it still blowing hard, and the air filled with haze, and with snow drift from the surrounding hills. The appearance of the weather was certainly most unfavourable to this or any other travelling; and the guides were very desirous to remain at peace in the hut. To this I should have agreed, if I could have prevailed on them to have gone once more with me to Aw-wuk-too-teak ; but this was absolutely refuser, so that I was compelled to abandon this project for the present. 
I now reflected on the uncertainty of the weather at this season of the year, and being also aware that our absence from the ship had been prolonged beyond the time which had been anticipated, I became fearful lest considerable anxiety should be felt by Captain Ross on our account, and the more so from the circumstances of doubtful friendship with the natives under which we had departed. It was possible, also, that some inconvenience might occur in consequence of our absence; more especially, should that induce Captain Ross to send out an expedition in search of us.

Coupling these reflections, therefore, with the fact that it would require several days to examine the desired inlet in a satisfactory manner, and that these probable inconveniences would be materially increased in consequence, $I$ at length resolved to return to the ship, and to take some better opportunity of completing an examination too important to be slurred over as it must have been under such circumstances as the existing ones. Knowing its exact position I could also now revisit it without difficulty, and, should that be necessary, without a guide; so that although I had not attained the object in view, I had saved future time by having thus pioneered the way.

We therefore began our journey at eight in the morning; the sledges being heavily laden, and the travelling, in consequence, both difficult and laborious. Often, indeed, where the ground was especially bad, we were obliged to throw off a part of our load, and then, after advancing with the remainder, return to bring it up; then proceeding as best we could, though of course with no great speed.

About noon we saw that Poo-yet-tah was separating from 
our own party, and was leading his sledge on to the left shore of the lake. We therefore followed; and, on coming up to him, found his inducement to have been the tracks of some musk oxen which he had seen, and was now tracing. He expressed a strong desire to kill some more, and wished that I would halt here for that purpose; a very natural wish on his part, and one that I would gladly have complied with, not only on his account, but for the sake of ourselves and our crew on board, had there been any use in making such an acquisition. But we had already more meat than we should probably be able to carry to the ship, and the state of the ground was as yet such that we could not contrive to bury it so as to protect it from the wolves and gluttons. It was therefore to kill the poor animal for no end, or rather perhaps to regret that we were in possession of a valuable supply of fresh beef for our people, which we should be compelled to abandon to the beasts of prey whose tracks were every where visible.

I therefore refused to stop here, and tried to persuade them to go on; but in vain. Turning a deaf ear to my representations, Poo-yet-tah immediately began to build a hut, saying that we must sleep in it this night. He evidently believed that we were unable to proceed without his guidance, and that we could not, by ourselves, find the hut in which we had slept on the night of the twenty-seventh, which was the place that we had proposed to reach when we had set out in the morning. I was, indeed, somewhat doubtful of that matter myself; but rather than submit to the loss of another day, I determined to make the attempt, especially as the weather began to improve, and promised to become more favourable every hour. 
It was, nevertheless, to the considerable surprise of our two guides when we departed without them; and as we occasionally turned, to see whether they might not change their minds, we saw them abandon their work several times, for the apparent purpose of watching the route which we were taking, and the progress that we made. The former was a subject of some hesitation, and the latter far from rapid; since the recent gales had completely obliterated our former tracts, and the fall of snow had so altered the features of the country in some parts, while others had been bared and rendered black by the storm, that I continued in great uncertainty about the road, till we arrived at the place called Nap-purre-uk-ta-lig. Here I immediately recognised the peculiar form of the lake, and thus found that we had not materially deviated from our intended direction.

If our progress was small in proportion to the time and exertion we had spent in reaching this place, so were we exceedingly fatigued, and suffering extremely from thirst. I was therefore obliged to unload the sledge in the middle of the lake, for the purpose of getting at the spirit lamp, that we might melt some snow for drinking; which having done, we were soon refreshed, and fit to continue our journey.

It must appear strange to readers ignorant of these countries, to hear that the people suffer more from thirst, when travelling, than from all the other inconveniences united. By us, at home, where the snow can never be very cold, where it can therefore be easily melted by the ordinary heat of the body, and where it can even be eaten as a substitute for water, the very different temperature of the same substance in that country is easily overlooked, as many persons. 
are even ignorant of this fact. No great inconvenience can occur as to this matter, where its heat is rarely much below the freezing point, and scarcely ever falls as low as twenty degrees. It is a very different thing, when perhaps the highest temperature of the snow during the winter months, is at zero, and when it often falls to minus fifty or more, or to eighty degrees below the point at which we should attempt to thaw or to eat it in England. Were it not so bad a conductor as it is, we could, in this country, no more take it into the mouth, or hold it in the hands, than if it was so much redhot iron: but, from that cause, this consequence at least does not follow. The effect nevertheless which it does produce, is that of increasing, instead of removing, the thirst which it is endeavoured to quench: so that the natives prefer enduring the utmost extremity of this feeling, rather than attempt to remove it by the eating of snow. I am not sufficiently acquainted with medical philosophy to explain this, nor am I aware that it has been explained; and it is, perhaps, as unfounded, as it is, in me, presuming, to suggest that the extreme cold of the material thus swallowed, when the body is heated and exhausted by fatigue, may bring on some inflammatory state of the stomach, so as to cause the suffering in question.

Resuming our journey across the lake, we found the travelling much improved by the late gales; and, soon after midnight, we arrived at the hut, truly exhausted by fatigue. In this condition, it was an exceeding mortification to find that a wolf had torn off the door with which we had secured its entrance, and that it was filled with snow. We were therefore compelled to commence digging into it, tired as we were; when, after an hour's hard labour, we contrived to make it habitable for the night, and got into our bags at two in the morning. 
When we awoke, and began to bethink ourselves of departing, May 3. the weather was very unsettled and blowing in squals from the north; while fresh falling snow added to the obscurity and annoyance caused by that which was drifting before the wind from the faces of the hills. The dogs too were so tired, by the labours of the preceding day, that nothing but my great anxiety to rejoin the ship and relieve the probable fears of Captain Ross and our other shipmates, would have induced me to proceed.

We found the travelling extremely bad : but the worst part of it, by far, was a space of about a mile, crossing the high ridge which separated the next lake from that which we had left. This alone cost us from nine in the morning until two; nor did we accomplish it without making three separate trips with the sledge, so as to bring forward all our matters to the same point.

On the lake, however, the ice was as smooth as glass, for the winds had swept it clean; so that we crossed it very quickly, and at a run all the way, having the additional advantage of a breeze in our rear, which very much diminished our exertions. The river had been laid equally bare; and, though comparatively rough, it was still slippery, so that we got over it easily, with the exception of a few falls in the snow holes which are generally found in ice of this nature.

In the evening, by seven o'clock, we had arrived at that expanded portion which I had formerly named after the Rev. Edward Stanley; and at nine reached the western point of the inlet called An-ne-re-ak-to. The whole length of the Stanley river, from the lake to the sea, I thus found not to exceed ten miles, while its greatest breadth appeared to be about a quarter 
of a mile. We had been informed that it abounded with fine salmon in the summer; and we could now see the evidences of this, in the remains of huts scattered about its banks, being the places where the natives are accustomed to secure and conceal their winter stocks of fish.

We were now approaching the huts where our threatening adventure had occurred at our first setting out; and being doubtful of their feelings, or uncertain of what might have occurred during our absence, I was desirous of passing them unobserved, if I could effect this; the more so, as we were now alone, and the absence of our guides might have been a source of new suspicions, or the cause of a renewal of hostility. But as soon as we had reached the level ice of the bay, we saw Ib-lu-she coming toward us, though evidently approaching with much caution, as if not quite sure of his reception. If this proved the existence of very different feelings from that of hostility, the fact that he was unarmed sufficed to remove all doubts, and I therefore greeted him in our usual kind manner, to his infinite delight. Explaining then to him the proceedings and objects of the guides that we had left behind, the chief of whom was his brother, for whom he had at first expressed considerable anxiety, he became quite satisfied, and went off to communicate the news to his party at the huts.

In no long time we gained sight of our ship, after having now travelled eighteen hours, without rest or refreshment. Unluckily, at this moment, one of the runners of the sledge sank into a deep crack, and stuck so fast that we were unable to extricate the machine by all the force that we could apply. We were therefore 
obliged to throw off the load, which we did with much difficulty, as we were both seized with a giddiness that threatened fainting; to have undergone which at this temperature, and with no aid at hand, would probably have been fatal to us. This, however, being effected, and our stores left behind, to be brought on the next day by our comrades of the ship, we got into the sledge, and arrived on board the Victory at four in the morning of the fourth of May, exceedingly fatigued, but otherwise in good health. 


\section{CHAPTER XXVI.}

REPETITION OF HEAVY SNOW-ANOTHER EXPEDITION BY COMMANDER ROSS-ANOTHER EXPEDITION UNDER MY OWN CHARGESUMMARY OF THE MONTH OF APRIL.

1830. I T was colder on this day than on the preceding, and there was a fresh breeze. We were visited by a large party of natives from the northward, bringing some good skins for sale. There came afterwards from the westward, the two who had been Commander Ross's guides on the last journey; but they had not been able to bring in the other musk ox, and had not seen any more. On the

May 6. following day, another party came from the southward, bringing some seal, and some skins; and, afterwards, an old man whom we had not seen before, but who was father to two of the boys whom we knew. His wife, it seemed, had left her last husband, of three, to live with him; and, as far as we could make out, this was law, or usage equivalent to law. Tikatagiu also arriving, on his way southward, I engaged him to remain, that he might accompany me in a tour on the following day.

May 7. A heavy fall of snow rendered this journey impracticable: it would at least have been useless. The guide himself was much more pleased to remain on board than to travel in such weather. May 8. It was equally useless to proceed the next day, as every thing was buried in snow; but the guide went away by himself to fetch his 
canoe. In the evening we received a visit from the stranger old man, his wife, and two children. The wife was a young one; but we found that he had another, while the two young men had but one between them; the whole party living together. There was also an old woman with two husbands, uniting to form this strange polygamous family; and we were assured that matters went on with perfect harmony. Of course, it required more intimacy than we had yet attained with these tribes, to understand thoroughly their system of matrimonial arrangements; but what we thus already knew, sufficed to render it probable that the history which Cæsar has given of our British ancestors on this subject, is not so untrue as it has been sometimes thought.

A northerly wind, as usual, brought the thermometer from zero May 9. up to $18^{\circ}$. Sunday service being performed, the man who had gone for his canoe returned with the frame on his back, having brought it from Shag-a-voke. He was promised a new hoop for it, if he would bring us a seal; and, preferring to travel at night, set off at ten o'clock. A fox was taken in one of the traps.

The weather continued cold; but when the snow ceased, it was May 10. clear. A party went to the great lake to measure the ice, which they found to be eight feet thick, and the water seventeen fathoms deep. They saw no fish, but baited and set some lines. The temperature continued again far lower than was to be expected at May 11. this season; giving us some disagreeable anticipations. Some natives brought a skin. The traces of reindeer and hares were seen, and eight snow buntings killed. At the end of our base line, soundings were obtained in $\mathbf{9 0}$ fathoms.

All the power of the sun, with a clear sky, could not raise the May 12. 
temperature beyond $11^{\circ}$. No fish were found at the lines, but a ptarmigan was shot. Two of our chief friends among the natives arriving, arrangements were made for a new journey. Some more May 13. came from the south, on the following day, but brought nothing; they went on to the northern huts; and, finding that this party was gone on an expedition, returned to sleep on board. The thermometer ranged between $1^{\circ}$ and $15^{\circ}$.

May 14. Nearly the whole of the northern party came to us, and brought the head and skin of the second musk ox; but as it had lost the hind legs, it was spoiled as a specimen. They also brought the remaining quarter, or rather haunch, which weighed forty-three pounds, together with some skins, and a specimen of a greenstone May 15. chisel. Our only success in sporting was a single grouse. We had stipulated for a seal, for our dogs, but they did not arrive on the next day: having probably been unsuccessful. Every thing was arranged to-day for the contemplated journey on Monday. The fitting of the ship went on; but the condensing tanks were now removed, as being no longer necessary.

May 16. Church being held as usual, a large party came from the northward, and another from the southern village; but they brought no seal, nor aught else. The last set informed us that they were to break up the next day, and to divide into two parties; one for hunting the musk oxen, and the other for fishing in the lake. Each promised to bring us supplies before they took leave. The thermometer was about $10^{\circ}$.

May 1\%. The men and the leading mate went on with the sledge and the boat, for the purpose of transporting them a stage of ten miles, when the men who were not intended to proceed were to return. 
This they did in the evening; on which, Commander Ross and the surgeon proceeded in the small sledge, to join the mate and the advanced party. No supplies arrived from the natives, nor did we see any of them. On the following day it became so much warmer May 18. that the thermometer rose to $30^{\circ}$, and small pools of water appeared on the rocks, under the influence of the sun. The eyes of the men who had constituted the party of the last expedition had been inflamed by their journey, and they were taken care of accordingly.

The surgeon returned, with the mate, from the detached party, May 19. which he had left about twenty miles off, under the care of two Esquimaux; bringing back their sledge and dogs. The mate's eyes were so much affected, that he could not proceed. They had purchased food for the dogs, from the Esquimaux; and their stock of provisions was increased by the return of our two officers. We were pleased to find, on the following day, that the weather May 20. continued to favour their expedition. The different patients were better, and we proceeded to lay gravel round the ship and over the Krusenstern.

The sun could not raise the thermometer beyond $19^{\circ}$; and on May 21. going to the hole which had been made in the lake, it was found covered with ice six inches thick; the ice of the lake itself being seven feet and a half. The baits were untouched; and our other search after game was unsuccessful. On the following day we May 22. ascertained that the ice near us had not increased in thickness, though there were four inches formed in the hole. The track of a musk ox was seen on the ice not far from us. A summer tent was made, and some sails repaired.

This Sunday was the anniversary of our departure from Eng- May 23. 
land. The musk ox furnished us with fresh boiled and roast meat for the whole crew. It had no more taste of musk than before; and, having been longer kept, was more tender. During their walk after church, the men tracked a white bear, as well as some hares and grouse. In the evening, Ikmallik, the geographer, with his wife and family, and two other men, arrived, with the intention of attending Commander Ross on his expedition, and were much disappointed to find that he had been so long gone. It appeared that he had miscalculated the day, counting ten instead of five. We therefore engaged them to follow or meet him with provisions, within a week; at which they were much pleased. We also borrowed a $\operatorname{dog}$ from them, as our own were all absent, in case we should meet the bear that had been marked. They had been unsuccessful in seal hunting, but had discovered some holes, and hoped shortly to bring us an animal for the dogs. Each of the men received a fish-hook as a present; and the wife a pincushion. One of the men gave proof of his parental affection, by giving his stockings to his boy, who had stepped into a pool of water, and going barefooted home.

Nay 24. The canvas roof was to-day taken off as far as the mainmast, the sledge prepared, and other work done to the ship. The wind was May 25. north; but, at midnight, the thermometer was at plus $12^{\circ}$. Both days were clear and fine: the work went on; a ptarmigan was killed, and the tracks of deer and wolves seen. We had a right to conclude that the former were migrating to the north, with their enemies hanging on their rear. It was the highest tide we had yet witnessed; rising to nearly eight feet.

May 26. The first fog we had seen this year came on this morning, and 
was followed by a fine day, the thermometer reaching $25^{\circ}$. The snow was reported to be melting fast; and a hole being cut in the ice, in a place which had been originally late in freezing, in consequence of a current, it was found to be little more than five feet thick. The temperature continued rising on the following day, yet May 27. slowly; and the mean, being the highest we had seen this year, was 20 . At the hole just mentioned, I found a current running a mile an hour to the eastward, with ten fathoms water, which was less salt than that near the ship. The footmarks of deer continued to tantalize us: it was difficult to guess how they contrived to pass in this manner, so long, without being seen.

The weather became so much warmer as to average $25^{\circ}$, rising to near the freezing point. I ascertained, from a measured base, that the height of the highest hill near us was 400 feet: that of the island close to us was forty. I obtained five sets of lunar distances, and made some trials with the dipping needle. A brace of ptarmigans was killed. The thermometer rose next day to $34^{\circ}$, and I obtained more lunar distances : preparing also for my intended journey on Monday.

After divine service, we waited in vain for our promised guides, May 30. whose appointment had been fixed for this day. I knew that it would take a longer time to convey the provisions to the appointed place without their assistance, and therefore determined to go by ourselves, in advance. 'The sledge was therefore loaded with five days' provisions for Commander Ross's party, and eight for my own, with the addition of a summer tent; and I departed at seven, with the surgeon, two mates, and one of the fire teasers. An addi- 
tional party was taken to draw our sledge ten miles, when they returned; leaving us at one in the morning.

That I may not interrupt the narrative of this journey, I shall here give the summary of the present month.

The anxiety which naturally attended Commander Ross's absence during the expedition which he had undertaken, terminated in congratulations on account of his safety and success. His guide had conducted him to the narrow channel leading between the two seas, and he had determined its latitude to be such as to give fortyfive miles to the north of our position; being in one of those inlets which could not be explored, on account of the ice, situated a little to the northward of Elizabeth harbour. Hence it was probable that Cape Manson would be found to form the north-east point of America, supposing the sea to be continuous to Cape Turnagain.

The exploring of the coast to the northward of Pad-le-ak bay, together with that to the westward of it, had further been the work of the same officer, as had Neitchillee. In his journal, will be found what I need not here repeat, respecting the commencement of this expedition, and the little obstructions which it experienced at the outset. And if I need not notice these and some other matters relating to the outfit, so is it unnecessary to give any summary of our transactions with the natives, during this month, since they included nothing important in addition to the details already given.

The temperature of May was considerably below that mean of the former expeditions with which I have so often compared our own monthly ones, being only plus $15^{\circ}$; while that at Port Bowen was $17^{\circ} 65^{\prime}$, and the mean of the four different places $16^{\circ}$. This augured but ill for our speedy release: but we were willing to 
think, that having taken better care of our thermometer, it had only shown a lower temperature because the others had been managed with less attention to a true result.

We had been constructing lee boards for our ship, with the intention of making her more weatherly; and our labours in refitting the rigging were in a state of great forwardness. Many observations, of various kinds, had been made.

As yet there was no appearance of scurvy; but two or three of the men showed just enough of threatening to make us fear that they would not be long exempt, unless we obtained a more ample supply of fresh provisions during the coming summer. The snow blindness was not more common among us than with the natives: and, in other respects, the health of the men was good. We had not succeeded in procuring much game: while, in reality, we were too steadily occupied to allow much time for this pursuit.

But I must not forget, that, in this month, we completed our twelvemonth's absence from England, It had been an eventful year, but far from an unsuccessful one. We had done much by sea; and it must not be forgotten, that even a year of sea in these climates is little better than a month of action, as it cannot well be more, in the value or extent of its results. They who live in our own England, cannot understand how a year, or years, are expended with a progress so small as that which has attended all these northern exploring voyages : if they would translate the word year into month, it would enable them to form juster conceptions of these voyages, and of the actual time expended on the results which have been obtained.

But we had also done somewhat by land; with the prospect of 3 с 2 
doing much more, should the sea fail us: and, while there was one view, at least, holding out hopes in which we could scarcely be disappointed, as there was another, which, on the average of chances, might have been equally gratified, if far less promising in the anticipation, we had reason to be content with our present situation and prospects. The year, too, had been passed busily, and with as little discomfort as was well possible: there had been dangers, but neither frequent nor extreme; and, with constant occupations, not well likely to fail us, we had not the day to kill, nor the loss of time to regret. To find that our crew continued in really good health, notwithstanding the trifling evils just mentioned, and that no one had suffered during so long a navigation and so bitter a season, was not the least source of satisfaction: the case of the unfortunate armourer not being a genuine drawback on this state of things, if the loss of the stoker's arm in Scotland ought perhaps to be enumerated among our contingencies. 


\section{CHAPTER XXVII.}

EXPEDITION COMMENCED-NARRATIVE OF OUR JOURNEY-RETURN TO THE SHIP-OBSERVATIONS MADE TO OBTAIN THE DIFFERENCE OF THE ELEVATION OF THE EASTERN AND WESTERN SEAS-THE DIP OF THE NEEDLE, AND INTENSITY OF MAGNETIC FORCE.

THE weather was foggy during the journey of this day, so that I obtained no good views of any part of the land, except a rock resembling the Bass island off the Firth of Forth. We saw four gulls and an owl ; and proceeded along a rocky coast to the south-westward, skirted with large islands, very much resembling some of the shores of Sweden, between Gottenburg and Strömstad. We passed within them all, in a clear channel, wide enough for large ships, and clear of icebergs. At seven in the morning we arrived at the huts, seventeen miles from our vessel: all taking an equal share, officers and men, in the heavy work of drawing the sledge, which, for the last four miles, was considerable, as the snow was mid-leg deep. The men were much fatigued; and the mate, Blanky, could go no further. But having lighted a fire and made some coffee, they were enabled to proceed to the next place, containing the huts, at twenty-two miles from our ship.

Accordingly, at eight, we set forward; and, the fog having cleared away, I obtained some views of the land. We arrived 
before eleven, where we found seven of the natives, who supplied us with water, but had no meat remaining. As we calculated on getting their dogs for a few miles further at least, to assist our labours, we pitched our tent to make our meal, being breakfast and dinner conjoined. We soon, however, discovered that they were going immediately in the same direction as ourselves, and were thus to be so heavily laden that they could give us no assistance; since it would take themselves two days to get to the first place at which they could expect food. They departed accordingly, at one o'clock. I procured some observations at noon, determining the latitude, among other things, at $69^{\circ} 59^{\prime}$, and the longitude at $92^{\circ} 1^{\prime}$.

At five, an old woman whose avarice had procured her the nickname of Old Greedy, passed us to the southward, with three dogs drawing a seal-skin full of blubber, which she was to deposit in advance; but we could not prevail on her to lend us one of her team. Our present position was considerably picturesque, being surrounded by rugged mountains and islands, in every direction except to the north-eastward. The conical hills to the north-west were partially covered with snow; and at the foot of the nearest, was a detached rock not unlike a milestone, on which we found inscribed, by our preceding party, "twenty miles from Victory." All the rocks appeared to be of granite; but we also found fragments of limestone : every thing seemed to be what we had found it since first making this coast. The men being fatigued, they were sent to rest till eight o'clock.

June 1. We had started at ten o'clock on the preceding night, but we went first to a hut, a mile off, to seek for an axe that had been buried by the 
surgeon and the mate, on the former expedition. We searched in vain, as the natives had probably taken it away, and we were thus scarcely under way till midnight. Landing at the bottom of this channel, we proceeded south-westward, and, at the distance of half a mile, reached a lake about forty feet above the level of the sea; following the bed of the river to it, as that was still frozen over. It was only three-quarters of a mile wide, and about two hundred yards in breadth; being surrounded by precipitous cliffs. Following upwards from it, we came to another of similar dimensions, a hundred feet higher, which discharges itself into the one below. Thence proceeding in the same direction till we had attained thirty feet more of elevation, we descended about ninety feet to the sea of the gulf of Shag-a-voke, and about seven miles from its entrance.

By means of a seal-hole, we found the water to be salt, and crossed this part of the bay near an island where the natives deposit their canoes and winter stores. The land here changed its character, though the rocks were the same; the whole surface being covered with fragments of granite and limestone, and thus presenting a most dreary and barren appearance. Reaching the land, we still pursued a south-westerly direction, up the channel of a river, and about a mile onwards, at an elevation of about fifty feet; and at length arrived at a small lake, part of which was covered, above the ice, by water. Here we met the old woman returning with her dogs, having deposited her load. On being questioned about the axe, she confessed that she was of the party that had stolen it, and that it was in possession of two of the men at the eastern huts.

Having passed this lake, we then held our way over another of 
the same size and aspect, bounded by lower land, which was, however, equally covered by huge blocks of stone, some of them in very fantastic shapes. This was about twenty feet higher than the former; and, following the windings of the hills for a mile, we came to the north-eastern end of the great lake, which seemed eleven or twelve miles in length. We soon found the huts of the Esquimaux who had left us on the preceding day for the purpose of coming here to fish : they were still built of snow, as before, but were now covered with skins. The people denied all knowledge of the axe, and said it was in possession of the old woman. Proceeding on the lake, after this, we found a ridge of icebergs on it, differing much in aspect from those of the sea: but here we were obliged to stop for rest and refreshment; some of the party being much fatigued.

We set forward again at half-past five, and, soon after eight, arrived at an island in the middle of the lake. The men, however, were so much tired, from the sinking of the sledge into the soft snow, that we were obliged to stop; lighting our fire and cooking our dinner, without pitching our tent. The time required in melting snow for drink, detained us so long, that we did not move again till ten o'clock; the weather being clear, with a gentle breeze. We saw some reindeer, as we. had done at our first resting-place on the day before, but had no opportunity of firing at them, from the distance at which they passed us. By midnight, we had reached the end of the lake, not without much labour, as the way was very bad.

We now travelled south-eastward for a mile, and gained what we julged the highest elevation on our track, which I conjectured to 
be three hundred feet above the level of the sea. Thence we soon came to a narrow lake tending in the same direction, which brought us in sight of the western sea at Padliak, arriving at it after a descent of a mile. Here we found one of the Esquimaux packing up to proceed to the summer huts about two miles off. I halted to take angles and make observations, while I also measured the height of the lake above the level of the sea : thus, too, allowing the men that rest, of which they were much in need. The land about this bay was very rugged, and generally bare of snow; while numerous stones were set up in, several places, as if to represent men; often presenting very grotesque resemblances.

Thus far we had followed the marks of Commander Ross's sledge. Of this we were sure, knowing that, as the natives had none of their own, having eaten those which were made of fish, and having used the bones of the others to make rafters for their tents. These sledge marks, however, now turned off to the north-westward, towards the cape forming the northern boundary of this bay: but it was our business to steer eastward for the island where we had agreed to deposit the provisions, and which was visible, about three miles off. In our way, we met two of our Esquimaux friends, going in the opposite direction, with three dogs drawing a skin; and, being much tired, I offered them a knife if they would assist us with their animals and show as where to catch fish.

This being agreed to, we proceeded to arrange matters, when I found that, among other things, the skin bag contained a fine haunch of venison, which we purchased for a file, without difficulty. Hungry men soon revive, even at the prospect of a good dinner; and, in half an hour, we were at the appointed island. It was a very 
small islet, about two hundred feet long, and of half that breadth ; being a mile from the shore where the native houses were built. We found it to consist of granite, covered with fragments of limestone, and with large blocks of both kinds of rock; but were better pleased at its offering a very convenient place for our tent, which was pitched without delay. The employment of cooking our venison furnished us with those pleasures of anticipation which they alone feel, who have no fears of any sinister chances between "the cup and the lip;" while it was satisfactory to find that the seller, with his file, seemed fully as happy as we who were regaling on the dinner which it had furnished.

We were informed that Commander Ross had gone toward the north; and they drew, on the ice, the shape of the land to the northward of the cape, called by them, Kingaruick; which I copied, noting all their names of places. This cape had been previously named Isabella, by Commander Ross. The man, Tiagashu, an old friend, soon came, and gave us permission to fish in the hole that he had made, in the ice, about two hundred yards from us. A nother of them went off in the night, and made another hole, which I bought from him for two hooks : and here we afterwards caught two dozen of small fish, supposed to be cod, in three fathoms water; the native name being Irriktu. This was named Spence Bay, in compliment to my relation of that name.

June 2. We allowed our people to sleep till six in the morning. Except myself, every one was suffering from sore eyes, and they were therefore kept within the tent; while my work was to fish, cook, draw, and make observations. Our dinner being of fish soup, was an acceptable novelty, since we had not seen such fare for many 
months. The weather was warm enough to melt snow, on the rocks, for drinking, without the labour of artificial thawing. I here made some observations on the dip of the magnetic needle. This bay is ten miles wide at this part, and is full of small islets. At three in the morning a party arrived and pitched their tents a little to the south of us; promising to bring us fish, in which, however, they disappointed us, having been unsuccessful. In the evening I repeated the observations on the dip of the magnetic needle and the intensity of its force.

The third of June was a very fine day, and we were employed in June 3. fishing. We caught a dozen of fish; which were carelessly deposited in reach of one of the dogs, by which they were, very naturally, devoured. Two of the men were unable to see at all, from the effect of the snow. The chief mate was better. The tide, in a hole furnished with a measuring line, rose only fourteen inches; and we remarked that we caught no fish except during the bright sunshine. It is to be suspected, that in these frozen seas and lakes, they are in a torpid state during the extreme cold : and that they are roused, like the dormouse, on the occasional occurrence of heat.

The men being blind for the present, from the effects of inflammation, and the native not having brought the promised dogs, I was compelled to remain. I caused a hole to be made in the ice, and found it seven feet and a quarter thick; being very nearly what it was at the ship when we came away: but there being only six feet water in depth, we had a proof of the great irregularity of the bottom. There was nothing left for me to do during this detention, except to make observations and catch fish; but the occurrence of gloomy weather was equally hostile to both. 
June 4. I went with the surgeon to the tents, and found that the natives had been unsuccessful in their seal hunting, or fishing, which last is perhaps the more appropriate term. One of them entreated me, with tears, to tell him where he should find one: how were they to suppose that men so superior to themselves in a hundred things, did not know whatever concerned them most ? I pointed to a place at hazard, that I might give them hope, at least, to occupy their time and stay their hunger: but it was not a very profound jest, to say that they would certainly take some if they would wait till the animals came.

We now learned that the breach of engagement, by another native, respecting a dog, arose from the circumstance of the animal having been bitten by a glutton: and the lameness of the creature proved this to be true. Finding, however, that they had two other dogs, it was agreed that we should have them harnessed to my sledge, with a guide, to proceed to Neitchillee. This too would be advantageous to the ailing men, who would thus have a longer rest, and might be well enough to return to the ship by the time I had finished my short expedition. The surgeon was well enough to go with me, but I thought it right to leave him, to take care of the rest.

We set out accordingly, at seven o'clock, accompanied by another native, who was to deposit some blubber at Neitchillee. Proceeding to the southward, we passed the mouth of a river named Keteoara, and also two stations called Owhyahriu and Oaheushrek. Six miles further, we came to a fine clear spring of water, called Amitioke, rising through sand, and much warmer than the thawed snow, of course; while we found that it had considerably over- 
flowed the surrounding land during the winter: a sufficient proof of its high temperature, which, unluckily, I had no means of ascertaining. Looking from the river in which we now were, the west bank of which was low and flat, we could see the mountain of Neitchillee, and in the reverse direction, other high land, whence a ridge seemed to join the former, taking, after this, a south-west direction.

Proceeding now down the Amitioke, which was still frozen, and a hundred yards wide, we arrived at its entrance into the great lake of Neitchillee; beyond which, at the distance of half a mile, is the exit of the river that leaves this lake; the course of which we could trace in a south-east direction, as far as the eye could discern any thing. On the west side there was a plain; but on the eastern one the land was high, with the two insulated mountains of Neitchillee and Tulluktok.

The name Neitchillee is equally given to the land, the river, the lake, and the village, or settlements, of the natives. There were here houses for both seasons : the usual snow huts, namely, amounting to twenty-one, and the summer houses, some of which had circles of stones nearly three feet high, forming a group of thirty. The largest of these was an oval of fourteen feet by twelve. The surface was here covered by the bones of the animals which the inhabitants had eaten.

I took the Esquimaux who had conducted us hither, to ascend the mountain with me; and, in our way, found a wolf that had been pursuing a large herd of reindeer. It took to flight on seeing us; to the joy of the guide, who was afraid it might have carried off one of his young dogs. The colours, which had been carried up 
for that purpose, were placed on the top, with the consent of the natives, and thence $I$ had a most extensive view. The termination of the extensive piece of water beneath us, towards the south-west, was invisible; but it was bounded by flat land on each side, on which I could count hundreds of reindeer. To the northward, the river Amitioke was seen for a long space towards its source, when it was lost among the distant mountains. The land in that direction was higher than that on which we stood; and a stream, running from it through a ravine, formed a cascade, which, presenting nothing but its complicated pendants of icicles instead of falling water, produced a very singular effect. The name of the Viscountess Melville was given to this remarkable scene.

After descending, I measured the breadth of the river opposite to the huts, and found it to be two hundred feet, with a depth of thirty. I was informed that there were many rapids and water-falls between the lake and the eastern sea, and that a canoe could not ascend. The guide said that there was also a river at the other end, which, he believed, was not navigable, and which ran into the western sea; but that it was very far off. The alternate effect of the sunshine and the cold on the face and hands, blistered the skin while I was here employed in sketching the land. Having finally taken a meridian observation, I quitted Neitchillee at one o'clock.

We saw many cranes and plovers; but having unfortunately lost my stock of percussion caps after shooting a snipe, I could fire no more; to the great surprise of the natives, to whom I could only excuse myself by pretending snow blindness; not wishing them to suppose that our fire-arms could ever be disabled or useless. This loss proved still more vexatious on the passage of a doe and her 


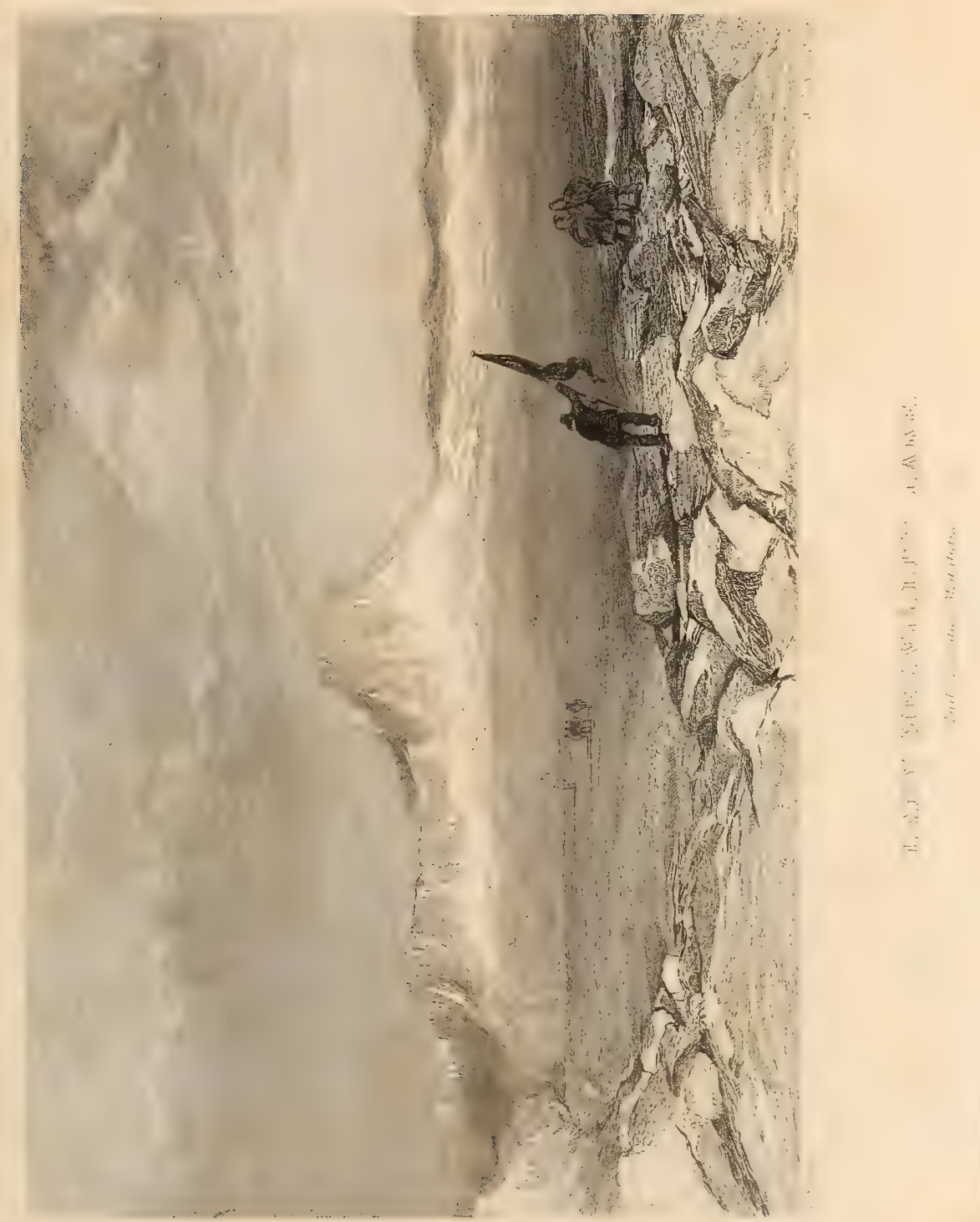



fawn, which came within twenty yards of the sledge; at the sight of which temptation, greater perhaps to them than even to a deerstalker of my own country, they encouraged me to fire, with loud vociferations. This, unfortunately, was impossible; and the dogs, breaking the restraint in which they were held, set off in chace, with the sledge at their heels, but were soon stopped by its becoming entangled among the stones.

Having arrived at our tent at five o'clock, the guide was paid; on which he departed, after being informed that we would call on them in our way homewards. It was satisfactory to find that the people were nearly recovered, and that we had still provisions until Sunday. Another note for Commander Ross was now deposited under a cairn which we erected : informing the natives that it was a mark for the ship, which would hereafter be useful to them as well as to ourselves, and receiving their promise not to pull it down.

At nine o'clock we struck our tent in a thick fog; and, departing at eleven, called at the huts according to promise. We found two pairs of the inmates, each a man and his wife, in their respective beds, with a trough of boiled fish and oil between them, on which they were feeding, much like swine, their faces and hands being bedaubed with this odorous compound. Another native then arrived with a seal : and as it was he whom I had directed where to find those animals, he seemed to think that I should claim a share, but was soon relieved of this fear by my refusal, which produced vociferous thanks.

To turn this gratitude to some account, I desired him to deliver a note to Commander Ross, which I accordingly wrote; informing him, for the third time, of the place of the provisions left for him, 
and of other matters; promising also to the Esquimaux, that the delivery of this letter would be rewarded by a fish-hook. We then parted, on the most friendly terms, after I had presented each of the women with a sixpence to hang round their necks; one of them giving us a complimentary convoy along shore, for about two miles.

We had here found the native who had been ill of a sore throat some months before; and the phial of medicine he had received was hanging from his neck, surrounded by other ornaments. It did not seem to have been opened, and had probably been kept as a charm. In return for it, seeing that the surgeon was suffering from toothach and a swelled face, he proceeded instantly to his own mode of cure, by tapping the cheek three times, and blowing as often in the patient's face. That the doctor shortly recovered, is certain; and if it was by means of the charm, it is not the first time that toothach has been cured in the same manner.

June 5. The men being now quite recovered, we continued our journey with spirit, in fine and clear weather. At seven, we reached the north-east end of the great lake called Teijgriak, and pitched our tent; the sun being very powerful at eight o'clock in the morning. Our breakfast was called supper, because we had inverted the usual order of things by going to bed at nine. The snow had been deep as we came, but it was now just enough frozen at the surface to prevent our light sledge from breaking through it.

This great lake, which is ten miles long, appears to be only a mile wide in some places, because it includes a chain of islands; but, in other parts, it seems three or four miles in breadth, and may indeed be more. The icebergs on it had probably been collected into the ridge which crossed from side to side, by the storms in the 
early part of the winter. The flattish lands round it were still much covered by snow.

We departed once more, at seven in the afternoon, having made what was termed our breakfast: the weather being fine and clear. Having crossed two lakes, we arrived at the gulf of Shag-a-voke, which is the upper end of an arm of the eastern sea, extending inward about eight miles. Thus the isthmus is reduced to seventeen or eighteen miles in breadth; while twelve of these are fresh water: so that there are in reality but five miles of land between the eastern and the western seas.

As the gulf, inlets, and strait of Shag-a-voke had not yet been regularly examined, I now changed our course to the south-eastward; and, after travelling two miles through a very deep snow, we came to the strait which separates the gulf, or upper part, from the sound. Here, on each side, there are precipices of nearly three hundred feet high, the general breadth of it being three-quarters of a mile; while a flat boggy tract, under the northern cliff, reduces the breadth of the water, in that part, to less than two hundred feet.

We could not make this Sunday a day of rest; and I continued June 6 . my examination of this inlet. About the middle, it was half a mile wide, and bounded by high mountains. Our progress was rendered very tedious and laborious by the depth of the snow; so that we did not arrive at the second strait, which separates the middle of the inlet from the lower part, or bay, till three o'clock. A point of land here projecting from the north side, seems to block out the sea; looking like an island, but connected with the shore by an isthmus, and leaving the breadth of the water, in this place, about 
a hundred feet. There were many rocks in the middle of it: and the ice being now partially broken up, the tide was running up at the rate of four miles an hour; while we calculated, from the old high water-mark, that it would still flow for two hours. This would be five o'clock, and it was the day of full moon.

Below this peninsula, the channel of this strait bends to the southward, and a part of it runs into a gulf formed by a second peninsula, resembling the first, but projecting at various points, so as to produce a very intricate passage. At this division of the water, there is a reef of large stones, resembling a mill-dam, being placed diagonally, and probably a work of the natives for the purpose of directing the water to the southern shore, where the principal channel lies; while, on the opposite side, that forms a spacious bay backed by high land. The isthmus was covered with circles of stones, being the remains of native houses; and we saw a singular square mound, smooth, and covered with vegetation, resembling the two faces of a bastion, which proved, on examination, to be an alluvium deposited at the meeting of two streams. How often such deposits have been mistaken for Roman and other encampments, in our own country, is well known.

The great inlet near this place measured about two thousand feet at the narrowest part; and, from this position, we saw the entrance of the bay, three miles off, being the onter part of Shag-a-voke. The north side of this opening descended gradually to a low point projecting eastward; the southern one continuing four miles more in the same direction, and then trending to the south-east. This side appeared clear of rocks and islets; but off the other, there was a rock, very remarkable, which, with two other islands, were named. 
after my friend, T. Tilson, Esq., and his daughters, as seen in the plate; while, further north, there were three islets, taking an easterly direction, which seem nearly joined to the main at low water.

We arrived at the southernmost of these islands at seven in the morning; and at this time the action of the sun on the snow had rendered travelling very difficult: the proper time, in reality, being the night; whence our inversion of day and night for the purposes of rest and sleep. The tent was here therefore pitched, and the men allowed to rest and eat, while I made some necessary observations for the latitude, but was obliged to refer those for the longitude to a future comparison with the ship's place, as my chronometer had met with an accident. A hare and a brace of ptarmigans were killed, and I saw many gulls and small birds.

At five in the afternoon, the men being rested, we proceeded with our package, and departed at seven. The labour in this part of the journey was very severe, as we were obliged to draw the sledge over hummocky ice for eight miles; sinking up to our knees at every step, and often being obliged to lift it over the obstructions. This piece occupied us six hours. The weather was fortunately very clear, and the snow had wasted away very much from the land.

At half-past one we had reached Cape Keppel, where we hoisted our colours, and halted for refreshment: after which, resuming our journey, we found the ice smoother, and got on very well, making a drawing of that rock which resembles the Bass, and giving it the name of Adolphus Dalrymple, on account of its similarity to the crest of that family. Two miles further off, we saw a flag flying, and thus knew that a party from the ship had been sent in search of 
us. Arriving at it, we found a note from Mr. Thom, who, fearing that we might want provisions, had caused some to be deposited in a place indicated, where we accordingly found them. We did not happen, however, to be in want; having husbanded our own, by means of fish and venison. We saw, about the precipices today, many gulls and owls, with numerous seals in the pools which now lined the shore.

At seven, we arrived at the ship, after an absence of nearly nine days, and found every thing right, and all in good health. If it is but justice to the men to say that they exerted themselves to the utmost, they deserve even more praise for a very different display of obedience and self-devotedness. As I was the only one who drank no spirits, and was also the only person who had not inflamed eyes, I represented that the use of grog was the cause, and therefore proposed that they should abandon this indulgence: showing further, that although I was very much the oldest of the party, I bore fatigue better than any of them. There was no hesitation in acquiescing; and the merit was the greater, since, independently of the surrender of a seaman's fixed habits, they had always considered this the chief part of their support. Thus we brought back all of this stock which had not been consumed the first day.

It is difficult to persuade men, even though they should not be habitual drinkers of spirits, that the use of these liquors is debilitating instead of the reverse. The immediate stimulus gives a temporary courage, and its effect is mistaken for an infusion of new strength. But the slightest attention will show how exactly the result is the reverse. It is sufficient to give men, under hard and steady labour, a draught of the usual grog, or a dram, to 
perceive, that, often in a few minutes, they become languid, and, as they generally term it, faint; losing their strength, in reality, while they attribute that to the continuance of the fatiguing exertions. He who will make the corresponding experiments on two equal boats' crews, rowing in a heavy sea, will soon be convinced that the water drinkers will far outdo the others: while no better testimony to this is required than the experience of the men who work in the iron foundries. That is the hardest work which falls to a man to do: and so well do the labourers in this department know that they cannot perform it, if they drink even beer, that their sole beverage during all the hours of this hot and heavy labour, is water. If London draymen and coalheavers are of a different opinion, every one knows the result; as the self-indulgence which leads to this luxurious and profligate practice is not less known.

It is not that $I$ am declaring myself an advocate for temperance societies, whatever may be their advantages, nor that I am desirous of copying a practice lately introduced into some ships, under whatever motives: but were it in my power, as commanding a vessel, I would exclude the use of grog, on the mere grounds of its debilitating effects, and independently of any ulterior injury which it may do : reserving it for those cases alone in which its use may be deemed medicinal, or, for any special reasons, useful.

Such is the account of this journey: but as it contains no register of the proceedings at the ship for so many days, I must resume that once more from the first of June, the records having been made, in my absence, by Mr. Thom. 


\section{CHAPTER XXVIII.}

\section{PROCEEDINGS IN THE SHIP FROM THE FIRST OF JUNE-COMMANDER ROSS'S RETURN.}

1830.

June I.

THE men were at work at the leeboards. The thermometer at $27^{\circ}$, with a fog.

June 2. On the following day the caulking proceeded, and the dead eyes were preparing for the mainmast. Three grouse were shot, and June 3. the thermometer rose to $29^{\circ}$. On the third there was little change in the heat; the work in the ship still going on.

June 4. On the fourth much of the snow was dissolved round the ship; the sun now having great power. A party of natives came to it, including the wooden-legged man, who, having broken bis new leg, was drawn by dogs, on a seal-skin, their fish sledges having been eaten. He was repaired by the carpenter, and departed. The thermometer was $27^{\circ}$ at midnight. The usual work about the ship June 5. occupied the following day as well as the present, and the temperature did not materially change.

Juиe 6. Being Sunday, the church service was read, as it had been during my presence on board. A party of seven men, with the carpenter, was afterwards sent to the southward, with directions for depositing a supply of provisions at the flagstaff, where we found it; and also in the hopes of meeting me, should they be able to extend their 
walk far enough. They returned, after travelling seven miles to no purpose as far as that was concerned.

This was the day on which we rejoined the ship, after an absence of eight days and a half, and I may here resume my own journal. I found the thermometer to-day at $32^{\circ}$, and the work on the ship June 8 . going on. The snow was rapidly and steadily melting during the day, and the appearance of the land was, in consequence, greatly changed. The rigging of the main and fore masts was fast advancing; and the heat rose as high as $55^{\circ}$, falling to $31^{\circ}$ in the night of June 9 . the following day, which found the foretopmast got up, and the bowsprit better secured, by new work.

In addition to the progress of our other work, we cut a hole in June 10. the ice above the Krusenstern, but could not get a sight of her, such was the depth under which she was for the present buried. A hare and four grouse having been killed, were found to have acquired their summer plumage and coating. The ice became June 11 . more and more covered with water, daily; though the thermometer had rather sunk for the last three days.

The canvas roof was entirely removed this day, and a summer June 12. awning spread. It was cloudy; and the first rain of this season fell in the evening. The torrents were seen running down the hills, and numbers of ducks and brent geese made their appearance for the first time. The several kinds of animals, I need scarcely now say, form a calendar of the year in this country, as the flowering of plants does in our own; where the emigrations of birds, if I except the swallow, nightingale, and cuckoo, are little noticed in comparison.

On Sunday, a heavy fall of snow came on, early in the morning; June 13. 
and, lasting till night, the ground was once more covered. At eight p. m., Commander Ross and his party returned, all in good health. They had travelled along the coast that led westward, a hundred miles west of Neitchillee; establishing the continuity of the continent as far as the $99^{\circ}$ of longitude, and in latitude $70^{\circ}$; being about a hundred and fifty miles to the westward of our present position. They had also travelled along the coast about twenty miles to the westward, north of the inlet which enters on the westward of the isthmus. In returning, they found that my deposit of provisions for them had been partly eaten and partly destroyed by the natives; but they still found as much as they required, visiting the south-west river of Neitchillee before returning homeward. The country which they traversed was barren, and formed of limestone; they saw no deer nor any other animal except the willow partridge. But they found that the ice in the small lakes at Padliak had given way, and that the same was the case in the bay of Shag-a-voke. I must however now, as I have done before, refer to Commander Ross's own narrative. 



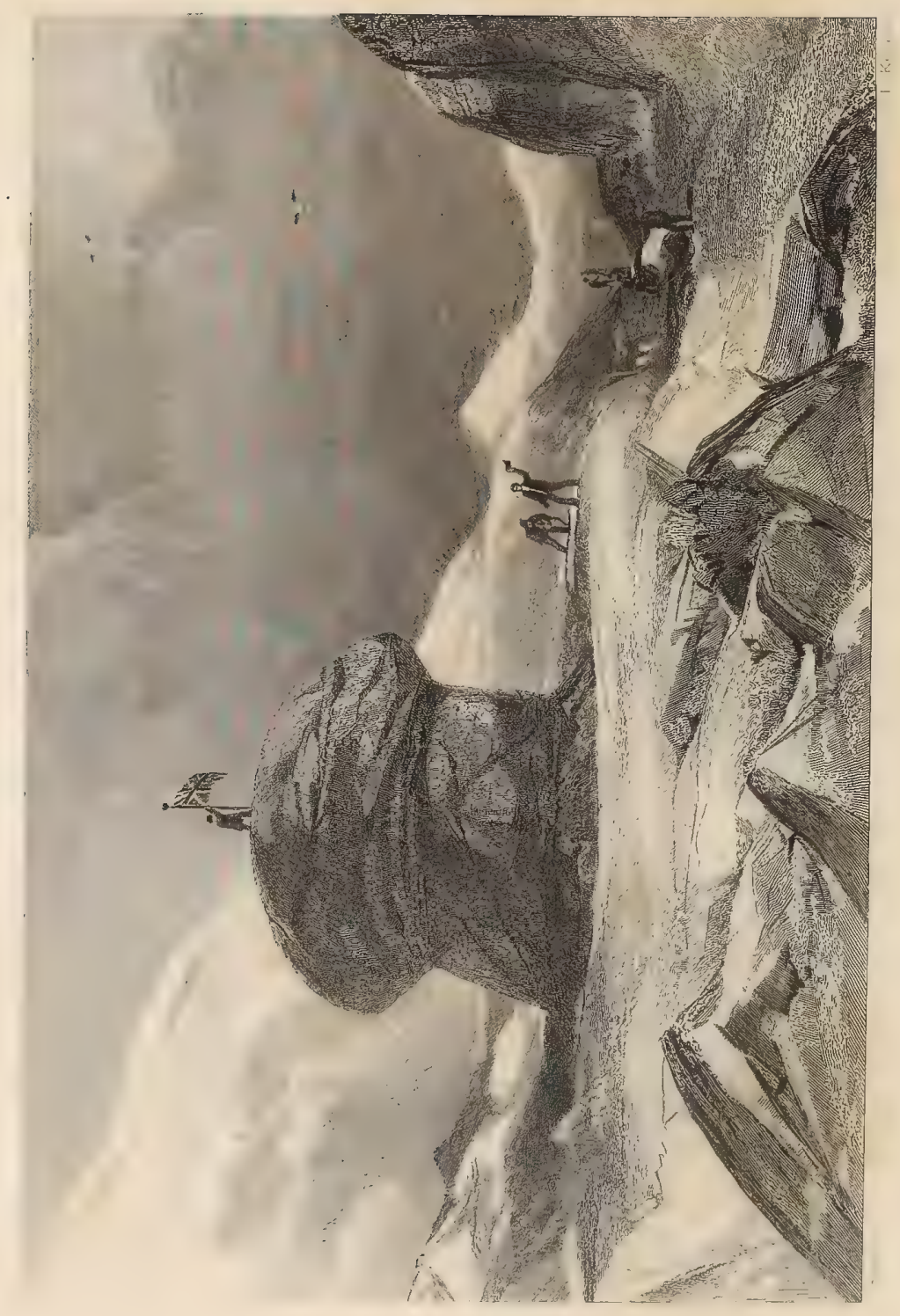




\section{CHAPTER XXIX.}

\section{COMMANDER ROSS'S NARRATIVE.}

$\mathrm{O}_{\mathbf{N}}$ the present expedition I was accompanied by Mr. Mac- 1830. diarmid as far as Graham's Valley : the object of his attendance being that I might point out to him a spot to which provisions might be carried to await us on our return. Following the track of our party, we found them encamped four or five miles to the north of Too-nood-leed; and on inquiry we found that one of them had been so affected by cramps, soon after setting out, that the rest were obliged to carry him in the boat as far as they were able to do this; the additional load thus produced, together with the loss of one hand out of their small number, having prevented them from making any further progress. Some of the men were also suffering from inflammation of the eyes; by which the mate Blanky, in particular, was especially affected.

The sun's rays now became so powerful at noon, that, added to May 18. this evil, already commenced, but too soon, I resolved to resume the plan of travelling by night: we therefore commenced the present day's journey at three in the afternoon; but the snow was so soft that we were three hours in reaching Too-nood-leed, whence Blanky's increased inflammation prevented us from proceeding for two or three hours. We at length found it necessary to leave him behind 
under the care of the surgeon, however inconvenient such a loss was to our small party: as it was also easy to procure a sledge from the Esquimaux to carry him back to the ship. Thus also we unfortunately were unable to carry on the surgeon to the intended spot; since it was necessary that he should return with a man whose future services we could not afford to hazard; and hence, unable now to calculate on the depot of provisions which we had intended to make at Pad-le-ak, I was obliged to limit materially the period which I had intended for my absence on this expedition.

Leaving them comfortably placed in the hut which we had formerly occupied, together with a quantity of provisions in case of detention, we proceeded on our journey. Our force was thus reduced to four men, including Abernethy; and though assisted by eight dogs in a second sledge, our load was quite as great as we could manage, since it consisted of three week's provisions, besides instruments and clothes, and a skin boat.

Ascending the hill from the bay of Too-nood-leed, and on the first lake, we noticed the tracks of a deer, with those of two wolves in pursuit, accompanied by fragments of hair and skin which the latter had torn from its sides; finding, not long after, the animal itself, partly devoured by its enemies. Our approach had probably frightened them away, and our dogs thus came in for a share of the prize.

A fall of snow, with a fog, at midnight, rendered it very difficult for us to find our way across the great Middle Lake, and we were therefore obliged to guide ourselves chiefly by the direction of the May 19. wind until three in the morning, when we encamped for rest. But a serene afternoon followed; and, recommencing our exertions at 
six in the evening, we arrived in sight of the sea at eleven o'clock. Here, a view from the hill on our right enabled me to determine our future route; and hence I could discern the low land of the opposite shore, stretching across the bay from Nei-tyel-le to within fifteen or twenty degrees of Cape Isabella. To this cape I then determined to proceed, because I could there obtain a more commanding view of the inlet, on account of its greater elevation.

The party which I had thus quitted for a short time, had announced their arrival on the shores of the western sea by three cheers : it was to me, as well as to them, and still more indeed to the leader than to his followers, a moment of interest well deserving the usual " hail" of a seaman; for it was the ocean that we had pursued, the object of our hopes and exertions; the free space which, as we once had hoped, was to have carried us round the American continent, which ought to have given us the triumph for which we and all our predecessors had laboured so long and so hard. It would have done all this, had not nature forbidden; it might have done all this had our chain of lakes been an inlet, had this valley formed a free communication between the eastern and western seas; but we had at least ascertained the impossibility; the desired sea was at our feet, we were soon to be travelling along its surface; and, in our final disappointment, we had at least the consolation of having removed all doubts and quenched all anxiety, of feeling that where God had said No, it was for man to submit, and to be thankful for what had been granted. It was a solemn moment, never to be forgotten; and never was the cheering of a seaman so impressive, breaking as it did on the stillness of the night, amid this dreary waste of ice and snow, where there was not an 
object to remind us of life, and not a sound seemed ever to have been heard.

At midnight we proceeded over the level of the sea ice, and, passing some hummocks, arrived at the desired cape, at six in the Nay 20. morning. Our encampment here was of a novel nature; being formed by excavating, in a ridge of snow, a burrow, large enough to contain the party, which was then roofed by the skin boat; securing afterwards its sides to the surface, by means of the snow that had been removed. An opening being made on the lee side, it was stopped up by a block of snow for a door, and, by means of the blanket bags, we contrived to make our beds both warm and soft. A spirit lamp served to melt sufficient snow for drink; while thus, for many subsequent nights, we enjoyed a sounder sleep than we had often done under circumstances far more comfortable and promising.

Cape Isabella rises abruptly, and often precipitously, to about five hundred feet above the level of the sea, and is formed of grey granite, presenting patches of vegetation, which, for this climate, seemed to have been unusually luxuriant in the past summer. The tracks of grouse, hares, and foxes, were the only indications of animal life that were seen.

From the accounts of the Esquimaux, I had expected to see a narrow entrance to this inlet, beyond the cape, to which they had given the name of Ik-ke-rush-yuk; as they had also described it to be formed by a low point to the westward, and some islands. But, instead of this, the land on which I stood, still preserved its westerly trending, while the opposite shore diverged; and I thence concluded that the reported inlet was on the side opposed to my 
present place, where several small islands skirted the northern part of it to the south-west. Under these circumstances, I considered that my best plan was to continue along this coast as far as the entrance of the inlet; the boundary of which would be determined by the hummocky ice of the ocean. The needful observations for this cape were then made; but, in returning to the party, I had the misfortune to break my only compass by a fall; an accident which prevented me from making any further observations on the variation of the needle, and thus causes a blank which I must regret, pervading the remainder of this journey.

Our labour hitherto had exceeded our strength; and it was therefore regulated thenceforward, that we should rise at four in the afternoon; and, after our meal, with the necessary stowage and arrangements, proceed on our daily, or rather nightly, journey between six and seven: limiting the length of it to ten hours. The labour of encamping, the evening (being truly a morning) meal, repairs of clothes, and other matters, then occupied three or four hours, so that the seven or eight remaining were left for sleep.

Under this new arrangement we set out at six in the evening; pursuing our route close along shore, under the projecting point of limestone which skirts Cape Isabella, and extends along this shore for some miles, where it is broken into capes and inlets by means of long ridges of that rock. The direction, here, of the coast, for about ten miles, is west-north-west, after which it becomes more northerly: and it became necessary to examine the whole of the bays and inlets thus formed, because I understood from the natives that the entrance of the expected inlet was narrow. They, however, proved shallow; and being light in comparison with the 
loaded party, I was enabled to search the whole accurately, while the rest skirted the coast between the several points.

May 21. After a fatiguing day's journey of twenty miles, we halted soon after four in the morning; and, in this as in the preceding, we passed several canoes covered with stones, and some cachées of provisions belonging to the Esquimaux, which, of course, we took care not to disturb. The occasional discovery of seaweed, shrimps, and shellfish, also served to confirm us in the belief that we were really on the shores of the ocean, and not of any freshwater lake, supposing that there could have been, here, one of such magnitude as to occupy the great flat space of ice before us. This, indeed, had been at one time imagined by some of the party, in consequence of the want of a tide-mark on the shore, and of there being no hummocky ice in the offing.

For the last four or five miles of this journey, the coast was formed of granite, containing large crystals of felspar, with garnets; the hills, at a short distance from the sea attaining the height of six or seven hundred feet.

Our present encampment was on the shore of a small inlet; and, on examining it, I found a good harbour, but of no great extent, at its end, well protected by two small islands. Meeting the party at the further point of this sinuosity, a snow hut was found; and this we believed to have been occupied by the natives, who had arrived at the ship shortly before our departure. Here, from a lofty point, I gained a very extensive view of a considerable inlet to the westward of the cape, which seemed to promise the desired opening to the polar ocean, as I judged from the very different characters of the two shores. That on which I stood was formed of granite, 
high and rugged, deeply intersected by ravines, and skirted by numerous rocky islets; while the opposite one was very low, and consisted of limestone.

In order to save time, I proceeded immediately, in company with Abernethy, to examine this inlet; taking, to aid us, the sledge, with five dogs, so as to assist us alternately, and thus diminish that fatigue by which we should have been inconveniently retarded. We thus passed many islets along the eastern shore, presenting abundant traces of Esquimaux; and, after an hour's travelling toward the north-west, arrived at the entrance of an arm of the sea, or perhaps of the mouth of a river, about half a mile in breadth. Here the hills on each side were of granite, rising, in some places, perpendicularly, to the height of three hundred feet. The glassy surface of the ice, here at least, indicated its freshwater origin; and this, with other puzzling circumstances, rendered a minute examination necessary.

We therefore continued our journey; and after travelling five or six miles to the north-north-east, reached the termination of the inlet, and there found the estuary of a river; the banks being contracted at the exit to a few hundred feet, so as to produce a rapid; while, a little higher up, it was a quarter of a mile in breadth. The number of canoes that we found buried on the western bank, proved it to be a principal fishing station of the Esquimaux; as we might equally have judged from the numerous landmarks and eachées.

The weather being very fine, I ascended a hill about a thousand feet high, whence I obtained an extensive view of a chain of lakes, leading to the north-east through a limestone country, while the 
grànite hills took a north-north-westerly direction. In descending; the party came in sight near the bottom of this inlet; and being directed onwards to the further point, I completed the survey of this bay, and rejoined them at their encampment. The river thus discovered was named after Nicholas Garry, Esq.

Nay 22. A fresh breeze made our burrow colder than was agreeable, though the thermometer was still above zero. The drift and haze which accompanied, prevented us also from starting till eight in: the evening, when we continued our journey along the coast, which: soon began to trend to the northward of west; and, shortly after, the cheering sight of the sea, covered with hummocks of ice, convinced me that we had at length arrived at the strait called Ik-kerush-yuk by the Esquimaux. Continuing to follow the coast, wefound it turn quickly round to the north-west; while the heavywashed sea ice on our left removed all doubt of the course now to be pursued.

I therefore resolved to reach the opposite coast, should this attempt prove to be practicable; and finding a favourable tract of smooth ice, we left that on which we were, before midnight. In proceeding, we came to a ridge of hummocky ice thirty feet high, running across our path, which we had great difficulty in surmounting; it being necessary to carry the luggage over it, and to cut a passage for the sledge with axes. This occupied more than an hour; when, observing some islets to the south-west that had previously been concealed by this ridge, we steered for them, and after passing several lower ones, nearly on a level with the flat ice, were obliged by a supervening haze, to encamp on the east side of an extensive island, at five on the morning of the twenty-third; 
having travelled about sixteen miles. This, being the anniversary May 23. of our departure from England, was distinguished by a dinner of frozen roast beef, and, what was now rare with us, a glass of grog.

The group of islets to the north-west was named Beverly, and the land on which we encamped Matty Island, in compliment to the fair donors of the beautiful silk colours which we then displayed, in honour of the day, and on the usual formalities of taking possession of this hitherto undiscovered spot.

Towards noon, the clearing away of the haze allowed me to obtain a good view, disclosing the north end of this island, about two miles off, with a great extent of ocean, terminating in heavy packed ice. Here, also, seeing that the land to the south-west was low, and apparently broken into islands, I resolved to keep along the north shore of Matty island, where the hummocky ice assured me that we were on the boundary of the great northern ocean.

We therefore pursued our journey at the usual time, but found the way extremely laborious among this rough ice ; while our toils were much increased by a thick fog, which froze on our clothes so as to render us nearly incapable of moving under their weight and stiffness. It was even with great difficulty, so much were the men exhausted, that we conld form our encampment at six in the morning, when we halted. The place we chose was under the west point of Matty island, formed, like the Beverly islets, of small ridges of limestone, rising to a considerable height, which have a west-south-westerly direction. We had coasted along it about twelve miles; but all else that we had seen consisted in a few tracks of partridges, together with some footsteps of bears, hares, and foxes, which appeared quite recent. 
May 24. We were in a miserable plight, from the fatigues of this day, and passed a comfortless night. To resume our hard and frozen dresses, was also a most difficult and painful operation; but the evening proved fine, and a little courage and exertion soon put us in motion once more. From the place which we, thus, shortly attained, the opposed shore of the island which we had left, appeared divided into numerous islets; while the ridge of hummocky ice which we had crossed on the day before, was elevated above the heavy pack that filled the inlet, and stretched out in an unbroken line as far as the eye could reach, in a direction toward the north-north-west.

After three hours of hard labour, we succeeded in crossing from Matty island to a low point of the mainland to which I gave Mr. Abernethy, our mate's name; conferring that of Cape Sabine on a cape to the northwest which we shortly afterwards rounded. We thence found the coast trending directly to the westward; and here May 25. finding level ice as well as fine weather, we made a rapid progress along the shore; halting at six on the morning of the twenty-fifth of May, after a smart day's journey of twenty miles, and encamping, or burrowing, on a point which I named Cape Young, after the member for Tynemouth.

A reef extending from this point north-westward, for two miles and a half, so as to meet the north point of Tennent island, protects an excellent harbour, could such a harbour ever be of any use: and its entrance, which is two miles wide, is divided in the middle by an islet that would effectually cover it from the invasion of heavy ice. As the island was named after Mr. Emerson Tennent, so has this, by the title of Port Emerson.

Setting out at eight o'clock, we passed along the reef and by the southern end of Tennent island, gaining the opposite shore of the 
harbour at eleven o'clock. Here the land trended to the westnorth-west till we came to the last point of an extensive inlet, or bay, to which was given the name of Bannerman, in compliment to the member for Aberdeen. To cross this was a very laborious task, and occupied us three hours; the ice being extremely rugged and hummocky, and also covered with loose snow, which lay very deep among the crevices. After this, the land trended more to the northward; when, following it during three more hours not less laborious, we at length rested at five in the morning, in one of our May 26. usual burrows; a house, which with a little pardon for the want of precision in the term, might be called subterranean.

I here began to doubt what our actual position might be, when I now considered all the indentations of the coast that we had seem or passed. The question with me was, whether we were in reality skirting a continent, or whether all this irregular land might not be a chain of islands. Those unacquainted with frozen climates like the present, must recollect that when all is ice, and all one dazzling mass of white, when the surface of the sea itself is tossed up and fixed into rocks, while the land is on the contrary, very often flat, if not level; when, in short, there is neither water nor land to be seen, or when both are equally undiscriminated, as well by shape as by colour, it is not always so easy a problem as it might seem on a superficial view, to determine a fact which appears, in words to be extremely simple.

At any rate, I could not satisfy myself, in our present position : and thence one disagreeable consequence, which, trifling as it may seem to a reader when compared to an essential geographical fact, was of no small moment to us, and indeed to the progress and 
success of the expedition itself. Had we been sure that we were on the continent, we might have left in concealment a large portion of our provisions, and this would have enabled us to proceed with much more ease and rapidity. But in case that it proved but a chain of islands, these would have been left behind, to our unspeakable inconvenience, or rather perhaps to our destruction, in case I should do what was really essential, in returning by the continental shore; while, if not daring to attempt this for such a reason, a principal object of our journey would have been abandoned. I was therefore at length determined to take the safest resolution; and thus consent to be still encumbered with the heavy load that so much augmented our labours, and so disadvantageously contracted our time.

And, indeed, diminished as the weight was by the consumption which our provisions had already undergone, that load was not only still a heavy one, but was relatively to our strength, even more troublesome than it had hitherto been. The dogs had become worse than useless, from the continued labour which they had exerted, and which we could not diminish by giving them an occasional rest for a day or two, since we could not afford to hazard the loss of that fine weather, of which the term was fast approaching. Lest readers may have forgotten it, I ought perhaps to say that the height of summer in these climates renders travelling as impracticable as does the depth of winter. It is not that the heat is more intolerable than the cold, though it is sufficiently tormenting and hurtful, but that the frozen surface becomes at first so loose and wet as to be nearly impassable; while, as the ground is laid bare on shore, and the water opens at sea, it becomes utterly impossible 
to travel either by land or water, or rather, as I might safely say, by that which is both or neither. Latterly, indeed, we had but two of these animals in a serviceable state, and one of the poor creatures died at our present encampment.

I here contrived to shoot two partridges, which not only gave us what was now rare, a warm meal, but enabled us to save our provisions; a most important matter, as we were now situated. No one will be surprised to hear how often during all these years we had formed the idle wish that men could live without food; a wish, idle and nonsensical as we felt it, that was ever intruding, since the necessity of eating was the ever-recurring obstacle to all our endeavours.

Three low islands, situated about ten miles to the northward of our present position, were named Beaufort islands, after the wellknown hydrographer to the Admiralty. A dense haze prevented us from moving till nine o'clock on this evening, when, continuing: our journey, we arrived at the eastern point of an extensive bay, and held along down its eastern shore, in a south-westerly direction, for two hours. From different places, I obtained a complete view of it, and afterwards rejoined the party on the opposite side. The western side being steep, we had great difficulty in dragging our sledges up the bank; but, having surmounted it, proceeded across the country in a north-west direction, till we were compelled, by a thick fog, to halt on the margin of an extensive lake, at six in the evening. We had gained but eight miles, owing to May 27. the time expended in examining the bay just mentioned, to which I gave the appellation of Parry, in gratitude to an officer whose name is here a sufficient distinction. 
The projecting point in the centre of this bay was named Stanley, from him who is sufficiently known by his travels in Iceland; and we here found several stone huts which appeared to have been occupied by the natives not long before.

The weather being fine, we could hence distinguish the coast still trending to the north-west; and thence, as for other reasons, I was desirous to continue our journey for another day or two, in hopes that the sea line would shortly take the direction of point Turnagain, which, could we have attained it, would have been an object of first-rate importance; since we might thus have also completed this line of coast, and, here at least, have left nothing remaining for future investigators. Will it be believed that I was not anxious to complete the survey of the north coast of America, that with so important an object almost within my very reach, I was not desirous to attain this great triumph?

But my men were not less so; and it would be doing them great injustice, did I not here record their spirit and ambition. For such an attempt, it was necessary to make a still further reduction in the allowance of provisions; and whatever they who are well fed and at ease may think, such sacrifices are not small to him who is already under fed and hard worked, who must exert himself every hour beyond his strength, who feels that food would enable him to go through his task, and who, independently of this reasoning, is actually suffering under the instinctive and irrepressible cravings of animal nature. Yet on mentioning my wishes to the mate Abernethy, he informed me that the men had intended, themselves, to make the same proposal to me, and were only waiting for the proper opportunity of transmitting their wishes through him. 
It may be believed that I rejoiced in this generous feeling on their parts; and the necessary reduction was therefore immediately announced.

Under this alteration, which enabled us to advance for two days longer, we set out at eight in the evening, and, after passing over some small lakes, reached the sea at eleven. We then continued our course along the coast, in a north-westerly direction till midnight, much annoyed by thick fogs for a time, but finally reaching a point, at two o'clock on the twenty-eighth of May, which formed May 28. one side of an extensive bay. This was named after Dr. Richardson; and as it was a convenient spot for a depôt, since by it we should be obliged to return, we resolved here to disburden ourselves of part of our encumbrances.

We therefore left behind every thing which we could spare, and taking four days' provision in the sledges, set out at three in the morning, crossing Richardson's bay, and encamping at six. Departing again at six in the evening, we found the land to trend May 29. toward the north-west till midnight, when we reached a point that was then named Cape Felix, after the founder of our expedition; at the back of which was an accumulation of hummocky ice. This point is the south-west cape of the gulf of Boothia, named after the same singularly generous and spirited individual, whose fame and deeds will go down to posterity among the first of those whose characters and conduct have conferred honour on the very name of a British merchant.

Here we found the land trend to the south-west, while the vast extent of ocean then before our eyes, assured us that we had at length reached the northern point of that portion of the continent 
which I had already ascertained with so much satisfaction to be trending towards Cape Turnagain. The pack of ice which had, in the autumn of the last year, been pressed against that shore, consisted of the heaviest masses that $I$ had ever seen in such a situation. With this, the lighter floes had been thrown up, on some parts of the coast, in a most extraordinary and incredible manner; turning up large quantities of the shingle before them, and, in some places, having travelled as much as half a mile beyond the limits of the highest tide-mark.

Continuing hence to the south-westward, till about two in the morning, we arrived at the north point of a bay, across which we passed, over much hummocky ice, gaining its southern point after two hours of hard labour. Hence the coast continued to trend about south-west by south, till we halted about six o'clock, after a journey of twenty miles, though with much fatigue to the whole party. The latitude here was $69^{\circ} 46^{\prime} 19^{\prime \prime}$, and the longitude $98^{\circ} 32^{\prime} 49^{\prime \prime}$.

The reflection that we had now rounded the northernmost point of this part of the continent, and that we had found the coast trending in the desired direction, could not fail to give us the greatest satisfaction. The great extent of sea also which was now seen from Cape Felix, free from all appearance of land served to raise our expectations as to the further success of the ensuing season, when we might hope, now that we knew what was before us, to succeed entirely in completing the survey of the north shore of America, since we could now make our arrangements accurately to meet what was still to be done and endured.

Additionally desirous, therefore, to be quite sure of the facts as 
far as they could here be ascertained, and that I was not deceived by some large indentation of the coast, I devoted the day to a still more accurate examination of the circumstances. How extremely unwilling I was to return at all, from this point, with the main object of the expedition almost, it may be said, within our reach, may well be imagined; but others must be in the same situation before they can conceive the intensity of this regret and the severity of this disappointment. Our distance from Cape Turnagain was now not greater than the space which we had already travelled; as many more spare days at our command would have enabled us to do all that was remaining, to return triumphant to the Victory, and to carry to England a truly worthy fruit of our long and hard labours.

But these days were not in our power; for it was not days of time, but of the very means of existence that were wanting to us. We had brought twenty-one days' provision from the ship; and much more than the half was already consumed, notwithstanding the reductions which had been made, without which we should have even stopped far short of our present point; to reach which had occupied thirteen days, when we had provided ourselves for no more than eleven outwards. There was nothing therefore left to us but to submit; and thus, however mortified at the necessity of such a resolution, I was compelled to settle finally for our return to the ship, after we had advanced one other day. By the shortest route back, our distance from her was computed at two hundred miles; and, even on a very scanty allowance, we could not reckon on provisions for more than ten days.

As some of the party were now suffering in their feet, I took this 
opportunity of giving them a day's rest, and left our station, with Abernethy, at eight in the evening. Being light, we now travelled quickly along the land, to the south-westward, till midnight, when, from a stranded mass of ice about forty feet high, we saw a point of land bearing south-west about fifteen miles distant, and could also trace its continuity with that in which we stood; the line forming an extensive bay; occupied by very heavy packed ice. A little examination, however, led us to doubt whether the remote point might not be an island, as there was an intermediate one about eight miles off. But to make an actual examination was now impossible; since our time was nearly expended, and the ruggedness of the ice between these points would have demanded a very tedious and laborious journey.

We now therefore unfurled our flag for the usual ceremony, and took possession of what we saw as far as the distant point, while that on which we stood was named Victory point; being the "ne plus ultra" of our labour, as it afterwards proved, while it will remain a standing record of the exertions of that ship's crew. The point to the south-west was also named Cape Franklin : and if that be a name which has now been conferred on more places than one, these honours, not in fact very solid when so widely shared, are beyond all thought less than the merits of that officer deserve.

On Victory point we erected a cairn of stones six feet high, and we enclosed in it a canister containing a brief account of the proceedings of the expedition since its departure from England. Such has been the custom, and to that it was our business to conform; though I must say, that we did not entertain the most remote hope that our little history would ever meet an European's eye, 
even had it escaped the accident of falling into the hands of the Esquimaux. Yet we should have gone about our work with something like hope, if not confidence, had we then known that we were reputed as lost men, if even still alive, and that our ancient and tried friend Back was about to seek for us, and to restore us once more to society and home. And if it is not impossible that the course of his present investigations from Cape Turnagain eastward may lead him to this very spot, that he may find the record and proof of our own "turnagain," we have known what it is for the wanderer in these solitudes to alight upon such traces of friends and of home, and can almost envy him the imagined happiness; while we shall rejoice to hear that he has done that in which we failed, and perhaps not less than if we had ourselves succeeded in completing this long pursued and perilous work.

It was at one in the morning of the thirtieth of May that we May 30 . turned our backs on this last and furthest point of our journey, arriving at our former encampment at six. We had here found a single piece of drift wood, the only one that we had seen since we left the ship; but were far better pleased to have augmented our slender store of provisions by a hare and two grouse. Every thing thus united to render this a marked day: and, such animals are we, in spite of ourselves, that the rare occurrence of a hot supper and a glass of grog made us for a moment forget all our disappointments, and rather caused us to feel pleasure that we were now returning home, than regret that, in so doing, we were renouncing the very object of our long anxiety and hard pursuit.

The longitude of the point on which we were encamped, and which I named Point Culgruff, was determined by a pocket chro- 
nometer, in preference to that which might have been deduced from our sets of lunar distances, because we found, on our return to the ship, that its rate of going had been remarkably steady. The hard trials which this watch underwent, united to its wonderful regularity, form a compliment to the makers, Parkinson and Frodsham, which it would be superfluous to state in other terms.

The longitude of this point, thus ascertained, is $98^{\circ} 32^{\prime} 49^{\prime \prime}$ west, and the latitude $69^{\circ} 46^{\circ} 19^{\prime \prime}$. The time of high water was three o'clock, and the rise and fall but seventeen inches. Victory point lies in latitude $69^{\circ} 37^{\prime} 49^{z}$, and longitude $98^{\circ} 40^{\prime} 49^{\prime \prime}$ : while of Point Franklin, as near as those could be determined from an estimated distance, the latitude is $96^{\circ} 31^{\prime} 13^{\prime \prime}$, and the longitude $99^{\circ} 17^{\prime} 58^{\prime \prime}$.

At seven in the evening we commenced our journey homeward, steering across the country direct for the point of our depot. We were thus enabled to cut off a considerable distance; and as we thus also contrived to cross several lakes where the travelling was easy, May 31. we reached our store at six in the morning of the thirty-first, very much fatigued however by the exertions which we could not, nevertheless, have slackened or delayed, as we had nothing in the shape of provisions left.

The unlucky dogs had been unable to continue their work for some days past: they were consequently unharnessed, and one of them died in the course of the day, while another was missing when we rose at six in the evening to continue our journey. Proceeding, we traced the coast line between this station and Port Parry, June 1. and at length reached the encampment of the twenty-sixth of last month, at four in the morning of the first of June. I here com- 
pleted the examination of the bay, which I had then left unfinished; and, after this, we arrived at Point Young about six in the morning of the second. A brace of grouse and a fox were here shot; and we found many circles of stones, marking the former summer residences of the Esquimaux.

Setting out again in the evening, we arrived at Cape Sabine June 3. at three on the following morning; and here we obtained water to drink, without the trouble of melting the snow. A small pool was open, and it was the first indication of a thaw which we had seen. At six we reached Cape Abernethy; and being desirous, if possible, to survey the whole coast line of the continent towards Nei-tyel-le, we proceeded in a south-south-easterly direction along the west shore of the strait which separates Matty island from the mainland; encamping at half past six. The latitude here was $69^{\circ} 30^{\prime} 42^{\prime \prime}$, and the longitude $96^{\circ} 8^{\prime} 26^{\prime \prime}$ west.

A strong westerly breeze prevented our departure till nine o'clock, June 4. from which time we continued the examination of the coast to the southward till five; having made a journey of but nine miles during this night. The snow was deep, and the party now much weakened, so that we found it impossible to travel faster. For some time past, indeed, we had found the usual march of ten hours too much for the strength of the men, reduced as their allowance of provisions now was; but this part of the arrangement could not be altered, though we could not succed in surmounting more than ten or twelve miles in the day. We were still eighty miles from the ship, and the remaining provisions amounted only to five days' consumption ; while we were by no means sure that we might not meet with many impediments in our way back to Nei-tyel-le. 
This also served to alter my plans, or at least to throw a doubt over their accomplishment; since I saw that unless the coast should assume an easterly direction the next day, I must abandon the intention of completing this whole line of shore, as I had hoped.

Soon after recommencing our journey in the evening, we arrived at the entrance of a considerable inlet, but the haziness of the weather prevented me from gaining a distinct view of its termination. I therefore crossed to the southern point, and thus obtained such a sight of it from a high hill, as to trace the continuity of the land round a small bay to the south, and afterwards joined the party at the eastern extreme point at three in the afternoon, giving to it the name of Captain W. H. Smyth, of the Royal Navy. This journey proved so difficult, from the quantity of hummocky ice to be passed, and the depth of the snow in the intervals, that we suffered great fatigue, and two of the dogs were left behind.

June 5. As the coast still trended to the south-south-east, I determined now to steer direct for Nei-tyel-le, as our provisions would no longer permit any further examination of the shore in this quarter. We therefore left Point Smyth at four, and directed our course to the southernmost of a group of islets, nearly east of us, where we arrived at seven in the morning. This islet, of which the latitude is $69^{\circ} 59^{\prime} 32^{\prime \prime}$, and the longitude $95^{\circ} 45^{\prime} 50^{\prime \prime}$, is high, and afforded an extensive view of the neighbouring islands, with much more of the continental shore than I had seen from Point Smyth; but a thin haze which covered the land prevented me from tracing it very distinctly to the south-eastward. The snow was now separated into patches in different places; and we found three snow huts, which had been occupied in the preceding winter by the 
family of Kan-ny-yoke, whose route towards the ship by the Stanley river could be traced for a certain distance, by the marks of the sledges. The number of the traces of the Esquimaux found about here, showed also that this was one of their steady places of resort; while, further finding the landmarks in great numbers, as they had been described to us, I had no hesitation in giving to this islet the native name of $\mathrm{O}$-wut-ta, since by this it had been indicated to us.

Though the evening was foggy, the sun's place could be occasionally seen through the haze, and enabled us to proceed at nine. We travelled over very level ice, though sometimes passing hummocks that appeared to have been formed in the preceding year. At four in the morning of the sixth, we obtained a sight of the June 6. high land of Cape Isabella : it was like that of an old friend; and as it gave us a no distant prospect of the termination of our present toils, it excited our party to exert themselves with a spirit which had for some time been flagging.

Halting for the day, at six, in latitude $69^{\circ} 15^{\prime} 46^{\prime \prime}$, and in longitude $95^{\circ} 13^{\prime} 6^{\prime \prime}$, we had some difficulty in finding snow deep enough to form our burrow; while the hardness of the ice beneath, on which we were thus compelled to lie, was sufficiently uncomfortable, contrasted with the soft bed which the snow had formerly afforded.

We set out again on a very fine evening, meeting now, at every fresh step, with well-known land, and thence gaining, hourly, fresh spirit to work our way onwards to our home: a temporary and not a very comfortable one, it is true, but, where every thing is comparative, a home to our hopes and feelings, such as even 
England would be whenever it should be our fate to leave this land of cold and misery, and to find that every degree of latitude was bringing us to rest and peace, as far as there are in this world peace or rest.

Our path was also good; and, under all these advantages, we proceeded with unusual speed : since there was here no appearance of a thaw, nor the least yielding in the crust of snow which covered the ice of this inlet. We were soon made aware of the presence of Esquimaux in our neighbourhood, by tracing the marks of a man dragging a seal; and this also was an acceptable circumstance, since it promised us a supply of provisions. Here, also, we saw gulls, together with some seals, basking in the sun with their young. A laborious journey of fourteen miles at length brought June 7 . us to our encampment for the day, in latitude $69^{\circ} 20^{\prime} 37^{\prime \prime}$, and longitude $94^{\circ} 31^{\prime} 55^{\prime \prime}$, near a low point formerly seen from Cape Isabella. Several small islets at this place were named Catherine, and the point itself Margaret.

A reef stretches out from the northernmost end of Point Margaret nearly a mile to the south-west, and the heavy masses of ice that were grounded on it, indicated the force by which they had been brought into that position. From the same point the shore of the continent was seen trending away to the south-west, and could be distinctly traced to the distance of seven or eight miles. The extreme point in sight was named Point Scott. The islets, as well as the mainland, were here formed of limestone, like the rest of the coast to the westward. We here saw innumerable tracks of reindeer, directed hence to the high land of the opposite coast, and had the good fortune to kill a fox and a brace of grouse. 
It blew hard at eight, when we set out; and, steering direct for Nei-tyel-le, we passed within two miles of Cape Isabella. On one of the islets we found a small pool of water, butwe afterwards understood that the thaw had commenced at the ship some days earlier. After a fatiguing journey, we again encamped on the ice at seven in the morning of the eighth of June, about seven miles from Nei-tyel-le.

At noon it blew a strong gale; and, for the first time since leaving the ship, I was unable to obtain any observations for latitude. It was an occurrence that reminded us how highly we had been favoured on this journey, by a long tract of good weather.

Early in the evening I set off alone in search of the Esquimaux, whose footsteps were every where visible; directing the party to follow at the usual hour. After tracing these marks for two hours, I reached the islet where I had requested Captain Ross to send a supply of provisions, but could discover no mark of the visit of our own people. I soon, however, heard the shouts of the Esquimaux: and a young man shortly after joined me, with a welcome expressive of the highest satisfaction. A set of dogs was immediately harnessed by them and sent off to assist our party in coming up.

Atayaraktak now led me to a cairn of stones where I found a note from Captain Ross, informing me that he had there waited for my return till the fourth, and had deposited some provisions for our use at a short distance from the cairn. The dogs of the natives had however discovered the prize, and Mil-luk-ta had that morning carried it home. I immediately therefore went to his tent, when his mother brought out all that was left, acknowledging that they had made use of the rest. All 
that we thus saved consisted in eight pounds of meat and some bread; but most of this was unfit for use, though even the little that remained was very acceptable. They had emptied the canister of rum and lemon-juice, which they called very dirty water : and then pointed out a stream where we could supply ourselves with what was clean.

They now presented us with some fish that seemed to be a small species of cod, promising to catch more for us; and I therefore determined to halt the party at this spot, for rest and refreshment. We encamped near them, in consequence; but having now no snow, were obliged to build a stone shelter, in which they gave us their assistance. Of the eight dogs that we had brought from the ship, there were now but two remaining; and these were so exhausted, that another day's work would probably have killed them also. Yet this was a selection from the very best of those which the Esquimaux possessed: while the whole of them had become unserviceable after eight days travelling, so that they were cast off from the sledges and suffered to do as they pleased. It was plain that we had overworked them; and we now found that, had it indeed been possible, we ought to have followed the system of the natives, who never drive these animals for more than four days at a time, seldom so much, and then give them one or two for rest. We had travelled, on the contrary, twenty-three consecutive days: a rare occurrence in that climate, and for which we were indebted to the very uncommon serenity of the weather.

Our encampment was completed by four in the afternoon, and we at last enjoyed one good dinner out of the fish which had been given to us. The natives, in the mean time, collected round us to 
ask questions respecting our journey and our objects: matters much more easy to ask of than to answer; but they were above all desirous to know whether we had been at Oo-geoo-lik. The strangers were formally introduced to us by some of our old friends: and we were afterwards entertained by a history of their own adventures during our absence, in which we could not help imagining that they were indulging some wit at our expense, from the bursts of laughter which followed these anecdotes. Still, every thing was in good humour; nor could we be otherwise than gratified by the union of this mirth with their kindness towards us. The length of our beards, which had not been shaved since we left the Victory, was, among other things, a source of great amusement; while one of them, a stranger, whose beard was of unusual size among this tribe, claimed consanguinity with us on that ground.

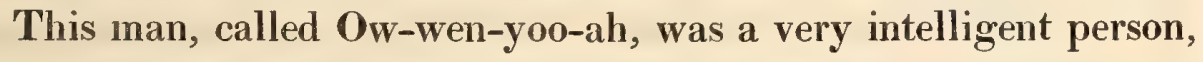
and a great traveller. He told me that he had passed the winter with Kan-ny-yoke, and immediately recognised a piece of deer's horn which $I$ had found at the huts in $\mathbf{O}$-wut-ta island. He also informed me that Oo-geoo-lik was many days' journey beyond that place; there being first an inlet to be entered, after which there were three days' journey on lakes, across some low land; having passed which, they again arrived at salt water, and were obliged to travel many days along the sea-coast. His wife and son were now packing up their tent; and on our retiring to rest, they all departed, informing us that we should find them at Tar-rio-nit-yoke. The day having been very fine, I obtained observations at this place, the name of which is E-nook-sha-lig.

In the morning, two of the women brought us some seal blubber 
for our fire; and another, who had fished for us while we slept, presented us with about thirty of the same fishes, being all that she had taken. As I was desirous to know whether these presents were tokens of gratitude for our former favours, or were brought in the hopes of a reward, I desired the men not to make any return for them. Notwithstanding this, the women who had brought the fuel, which seemed their most valued article, informed us whose turn it would be to bring the next supply; and thus in rotation, every three hours, we received from some of them a fresh stock, which proved much more than we required. The fish were also furnished abundantly, in a similar manner, but not with the same regularity : even our two dogs were not neglected, being regularly fed twice a day, while they took care to keep off their own, lest they should interfere with those which were most in want. For all this we offered nothing in return, nor did they seem once to expect it ; so that whatever avarice or keenness in dealing we might have suspected them of on other occasions, we had here ample proof of their hospitality, if not of aught so refined as gratitude; on the want of which virtue, however, our limited acquaintance with them could never have enabled us to pronounce.

Anxious to ascertain where the river which I had discovered on the eighth of April discharged its waters into the sea, I prevailed on the native called Atayaraktak to take me to the entrance of the inlet. He informed me that he had been there some days before, for the purpose of making a fishing hole in the ice; that he would willingly conduct me thus far, but that if I chose to proceed further, he must remain behind to fish : a reason which seemed abundantly solid, since I could not but perceive that our consumption had materially reduced their store. 
Leaving the party, therefore, to work at such repairs of various articles as were now wanted, I set out with this man, and after travelling about five miles to the south-south-westward, we arrived at the entrance of an inlet somewhat less than a quarter of a mile in breadth, but enlarging considerably in its progress. This strait he called Ik-ke-rush-yuk, a name derived from the rapidity with which the water rushes out in the summer; the stream being fresh and good for drinking, as he said, though at this point, where I tasted it, I found it very salt. I obtained no sounding here in six fathoms, which was the length of my companion's line.

While he remained to fish, I proceeded along the left shore of June 9. the inlet, about four or five miles; and ascending an elevated ground, gained a commanding view of the inlet, though I could not be quite sure of the continuity of the opposed and remote shore. My conclusion, however, from the report of the Esquimaux, was, that the west branch of the river in question must fall into the sea somewhere to the southward of Point Scott.

The shore on which I stood had gradually changed its trending from south to south-east by east; and at two or three miles beyond, the inlet appeared to be not more than half a mile broad, whence it turned more to the north-east: and here I could see the spot I had visited on my first journey to this place. But as I could pursue the present examination no further, I returned to my fishing friend, whose patience was nearly exhausted. He had caught about thirty fish, and was ready to go back to his party. We reached E-nook-sha-lig at six in the morning; much exhausted, in consequence of the laborious walking through the soft snow. 
Mr. Abernethy here informed me that during our absence the natives had given them a feast; each family having cooked a kettleful of fish. They were consequently first invited to one of the tents, where the contents of the kettle having been despatched, the next family treated them in the same manner, and so on, in rotation, till they had run this sort of eating gauntlet through the whole of the five tents. It is not surprising if they thus ate much more than they ought to have done. It was a feature of somewhat refined politeness in their entertainers, and more to be expected from an ancient Spaniard than an Esquimaux, that during the whole time of this prolonged meal these really kind hosts continued thanking them for the honour thus conferred: reminding them also that they had themselves been fed in a similar manner at the ship, in the preceding winter, and thus proving those grateful feelings which we might formerly have doubted; while of this we could now be quite sure, since, having hitherto made no presents in return, we made none on the present occasion, nor during the whole of our stay with them : being desirons to put off till the very last what we intended to give, that we might remove all doubts on this subject.

Being now much recruited by a day's rest and all this good living, we set out at ten in the night of the tenth of June: having first, since we could now entertain no doubt of their real gratitude, distributed among these natives every thing which we could spare. This, however, was fully returned to us in an ample supply of fish; which, in addition to the blubber that had been served in superfluous abundance, fully provided us for all the remainder of our journey. Some of them also accompanied us as far as Pad-le-ak, to assist us in dragging our sledge, and to point out to us where 
their tents would be pitched in the summer. On finally separating, they continued to cheer and thank us as long as we were within hearing, and when they could no longer see us, owing to the irregularities of the ground.

They had desired us to follow the tracks of a party which had preceded; and this instruction proved of essential service, in spite of my endeavours to find a shorter road for myself by neglecting their advice. I had imagined that they were going to fish at some place which would take us off the most direct road, and therefore quitted the indicated track, attempting to gain the route by which we had formerly travelled. In this, however, I was completely baffled, by the great depth of the snow and water on that line, wherever I attempted to diverge into it; so that I was at length glad to abandon, and I believe fortunate in surrendering, my own opinion, and consenting to follow my yet unseen guides. A dense fog, indeed, soon served to convince me of the wisdom of this choice; since, without that track which served us as a compass, we should have been compelled to halt in the middle of one of the lakes, without being exactly certain where we were, or what was to be done next.

We arrived at Tar-rio-nit-yoke in latitude $69^{\circ} 41^{\prime} 6^{\prime \prime}$, and longi- June 11 . tude $92^{\circ} 54^{\prime} 21^{\prime \prime}$, at eight in the morning of the eleventh, and encamped on the south side of the stream which carries the waters of this chain of lakes to the sea. The party of Ow-wen-yoo-ah was here seen on the opposite shore; and as soon as they perceived our arrival, one of them waded across the stream, which was between four and five feet deep, to bring us some fuel. This man

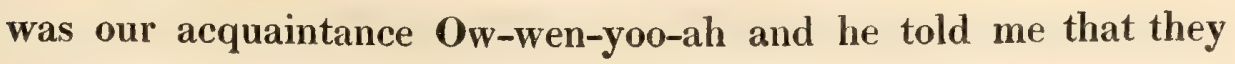


intended to remain there fishing, for some time. He expressed himself much disappointed at the absence of a large party which he had expected to find here; informing us also that he had gone, the day preceding, in pursuit of some reindeer with their fawns, which had been seen in the neighbourhood of Shag-a-voke, but without success.

When we rose in the evening, to pursue our journey, the whole of Ow-wen-yoo-ah's family came over to us. His present wife and children belonged to another man who was his particular friend, and an angekok, to whom he had, in the preceding autumn, lent his own two wives; a loan which is here considered a peculiar mark of friendship, and, it must be admitted, not very unreasonably. He had expected the restoration of this pair of spouses at this time and place; but the borrower Shoong-ug-u-wuk had taken them with him on the expedition after deer, and this breach of agreement seemed to be the chief cause of our friend's vexation and disappointment.

If we once supposed that this practice, for which these people may plead the authority of ancient Rome, was limited to the natives of Repulse bay, we had subsequent occasion to believe that it was universal among this tribe; the inhabitants of Boothia, as we must now term this country. Others may analyze the morality of this fashion; but one thing at least appeared certain, namely, that the women had no voice in the matter, and were therefore considered merely as property or furniture, conformably to the high authority already quoted, and to the practice of some other nations in states of civilization rather more resembling, it must be owned, that of Boothia than of the Mistress of the world. 
At this place the thaw was proceeding with such extraordinary rapidity, that the stream which we had crossed in the morning with the greatest ease, was now impassable. The torrent of water thus discharged from the lakes had also covered the ice which was to be traversed, to the depth of several feet. Not a dry spot remained any where; for there being no tide powerful enough to break up the frozen barrier towards the sea, this disengaged water could find no passage to it, except through a few seal holes which were quite incompetent to drain it off.

Had we not already known that such must be the case at this season of the year, we should have had ample proof of the necessity of condensing the expedition from which we were now returning, within the very limits to which it had been fixed. It is true that our confined stock of provisions formed the actual restraint on our further advance, and that our return was, as I have already shown, compulsory, from this cause. Yet in thus restricting that allowance, and, with it, the time of our absence, we had not acted imprudently, as the facts now proved; whether or not we are to be allowed the credit of having shown prudence and foresight in our calculation. And however impossible it was then, and even now is, to suppress the constantly returning regret that we did not reach Cape Turnagain, I cannot see how we could have completed that survey and returned in safety, or perhaps returned at all, even though we had been amply provided for a longer journey. At any rate, it was plain that the arrangements for such an expedition must be very different from what ours had been; and that if it was to be undertaken in the following season, a new calculation must be made, and very different expedients 
adopted, together with much more force, to ensure any chance of success.

Under the present obstructions we were recommended by $\mathrm{Ow}$ wen-yoo-ah to go round by Shag-a-voke, since he considered that the water was too deep for us to cross. This however would have materially increased our distance from the ship; and, as I also knew that the ice was very bad at the entrance of the inlet which we should thus be obliged to traverse, I determined to attempt the wading of the bay at this place, since the distance was not much more than two miles. I therefore caused all the holes in the skin boat to be repaired; and having stowed the luggage in it, we proceeded on this amphibious portion of our journey at ten o'clock. The water did not finally prove more than knee deep, and was barely sufficient to float our boat: but we found no difficulty in reaching the opposite shore by midnight. We should not indeed have been displeased had this watery tract extended much further; since we found it a very laborious task to get over the high craggy ridge of land that intervened between it and Too-nood-leed bay, which was now bare of snow.

In this bay, to compensate for that difficulty, the travelling was among the easiest that we had found. The water, which had here also overflowed the surface, had dissolved the snow, and afterwards escaped through the fissures beneath, which had been produced by the rise and fall of the tide. We found therefore a smooth plain of polished ice; and on this we proceeded with great expedition, not without wishing that more or all of the territory which we had passed, both outwards and on our return, had been of the same character. 
The river Ang-ma-look-took now appeared much more extensive than I had formerly supposed it to be; and, from the number of landmarks near it, together with similarly numerous cachés on its banks, I concluded that it was a fishing station of considerable importance to the natives.

At eight in the evening of the twelfth we halted, in latitude June 12. $69^{\circ} 48^{\prime} 10^{\prime}$, and longitude $92^{\circ} 23^{\prime} 9^{\prime}$, on a small rocky islet, much fatigued, and chiefly by the labour of wading. Here we found in flower, the Saxifraga oppositifolia; being the first that we had seen for this spring; though we afterwards found that it had appeared much earlier in the vicinity of the ship.

It was near midnight before we again got into motion; at first finding the way extremely rough, from the intermixture of hummocks of ice and deep pools half frozen, but proceeding with much more ease after reaching the mainland, while feeling additional energy and strength as we diminished our distance from the ship. It was at seven in the morning when we came in sight of her; June 13. when I issued the last remaining dram to the party, and, hoisting our flag, we arrived on board at eight, all in good health, though much reduced in appearance. 


\section{CHAPTER XXX.}

CONTINUATION OF THE JOURNAL-SUMMARY OF THE MONTH.

J830. A STRONG westerly breeze made the weather cold, and the thermometer fell to $33^{\circ}$, with showers of snow. It did not prevent

June 15. our work from going on, neither on this nor the following day, when it fell in much greater abundance. It only remained on the

June 16 ice, however; on the land it soon melted. On the next it was much the same; and we began therefore to expect a later summer than we had at first anticipated, since no visible alteration had taken place in the ice for some days. The thermometer during these latter days was rather under the freezing point at night, and the highest heat of the day, being on the fifteenth, was $50^{\circ}$.

June 17 .

On the seventeenth the weather looked better and more settled, but it was not warm. Two natives came, bringing a couple of seals : a very welcome supply, with the large pack of dogs that we had to feed. They had been successful at the Comptroller's islands. After rewarding them in the usual manner, I presented Ikmallik with a sovereign to wear round his neck, as being the picture of our great chief; desiring that he would preserve it, and show it to any European he might hereafter see. It was not likely to be spent, whatever else might happen; but if it was too valuable a gift intrinsically, for one who was as ignorant of its uses as inca- 
pable of applying them to a purpose, he would have been greatly astonished could he have exchanged it for its English value in timber and iron, in fish-hooks, axes, knives, and needles. Nor must I forget that the two guides took leave of us, with much gratitude for the presents they received and the kindness which they had experienced; hoping soon to see us again. We learned from Ikmallik, that all the rest had gone to the southward, except his own family and another, which were to remain some time in Comptroller's islands. He gave us the native names of the birds which had been shot; these being minics of the cries of the several animals; and they all departed under a promise to see us again.

The weather was fine, but it froze both in the morning and the June 18 . evening. The work went on, and the boats were cleared of snow. Some men now complained of rheumatism, and were relieved by the steam bath. The Saturday began cold; and, in the course of June 19. the day, it rained heavily. Fortunately, the caulking of the deck had been finished, so that it did not interfere with the comfort of the men below.

The weather seemed to have taken a sudden turn on Sunday; June 20. the rain having ceased in the night, and the air being mild and serene, while the thermometer rose, in the middle of the day, to $62^{\circ}$, being at $60^{\circ}$ for more than seven hours. Much of the snow was consequently disappearing, and the torrents again running down the hills. After church, the men having been sent to their walk on shore, brought back a fine specimen of the great northern diver, and reported that they had seen many hares and much wild fowl. Some insects were also collected, and much of the ice was broken up round the ship. 
June 21. Monday was misty, with small rain; the thaw continuing, though it was less warm. A diver was again shot, together with a king and a queen duck. Preparations were made for a travelling party to trace the line of coast to the south-eastward, and the men were June 22. employed within the ship. On the next day, the weather was foggy till the evening, under a north-east wind; when it became clear. The larboard leeboard was fixed, and the preparations for the travelling party completed, should the weather permit of moving on the following day.

June 23. It proved fine. The sledge and the skin boat were got ready, and the provisions stowed away in them after breakfast. The chief mate, with ten men, went off to draw it ten miles in advance, returning at eight in the evening. At nine, Commander Ross and four men left the ship, with the dogs : with the intention of proceeding as soon as they had reached the deposited sledge. The returned party had killed some ducks, and seen reindeer. These animals had been gradually passing in increased numbers; since we had latterly seen many, though, for so long a time, we had found nothing but their tracks.

The morning of the twenty-fourth was fine, but there were rain and snow about noon, continuing till midnight: it was not, certainly, a midsummer day in effect, whatever it might be in the calendar; and even if the usages of St. John's day had penetrated to these lands, there was as little temptation to light bonfires as there was an utter dearth of materials for constructing them. In consequence, however, of the thaw, a considerable quantity of water flowed from the decks into the hold, being produced from the snow which still remained on the sides of the ship; and this we were 
obliged to drive out by the forcing pump, as the others were not yet clear of ice. The surgeon, who had escorted the party, returned early in the morning with a brent goose; and the first June 2.5 . swan of the season was seen. At this time flights of ducks began to pass, in considerable numbers.

The snow still fell, occasionally, though it was mild; and the day ended in a fine evening. The men were employed in cutting the ice on the larboard side of the ship, to allow her to right herself; in consequence of which, she rose fourteen inches. The thermometer at night was $34^{\circ}$. On the Saturday, at noon, it was $62^{\circ}$; such were June 26 . the extremes of day and night in this climate, and at midsummer ; as, to confirm this, it fell again to the freezing point at night. It is the alternate reign of the sun and of the accumulated ice. Whatever the former effects, cannot last, and it ceases as soon as the great source of heat becomes depressed in its career. I took an opportunity of setting the net where a stream entered the nearest lake, but caught no fish; we did not even see any. An egg of a goose was found; proving that they breed here; and many of these birds were seen, while one was killed. The ship was, at length, nearly upright.

Nothing worthy of note occurred on Sunday. The men, how- June 27. ever, were not forbidden to shoot, in their usual walk after the service of this day; and their sport brought us five ducks and a diver.

It was snowy, and became so far cold, that the night temperature sank to the freezing point: in the course of the day we finished our June 28. preparations for the projected journey of the following. In the June 29. morning, the snow threatened interruption: but, clearing at noon, 
a party of seven men went off in advance, with the sledge, a boat; and our provisions and packages: the supply being for six days, and the place of their halt the north-west inlet. At seven, I followed, with the surgeon and three men, and found one of the party returning with a report that the sledge had been broken. He had been sent back for a new one, attended by three men and a dog: they had not succeeded in reaching further than six miles, being a mile short of the northern huts, which formed the appointed spot. But this did not prevent our proceeding : our principal object being to catch fish, for which we had provided ourselves with the necessary materials.

June 30. To complete the journal of this month, I need only say that it snowed on the last day, with the same low temperature at night, and a fresh breeze: and I may therefore give the usual summary, that I may not interrupt the account of our journey.

It is scarcely needful to say, that it had been a very unfavourable month to our prospects of proceeding at an early period in the ship. At Port Bowen, two hundred miles further north, there had been rain as early as the seventh of the month; while it had not appeared here till the nineteenth, and was followed, moreover, by frost and snow, so as to throw back every thing to the same condition as in the earlier days of June. In many places, indeed, the ice had become much thinner; but it was still very thick and compact.

The weather had however been favourable for the exploring parties. Commander Ross had not been at all interrupted in his travelling, and his reports were favourable: while, among other things, the limits of our future endeavours were much narrowed by the result of this expedition. 
Our intercourse with the natives had much decreased, in consequence of their removal; but, whenever it occurred, we were on terms of greater confidence than ever. They had been unsuccessful in hunting, and had therefore been unable to bring us any supplies; but whenever they were in want, and we could furnish them with food, we did so; receiving in return every mark of gratitude and thankfulness. In reality, with exception of the adventure consequent on the boy's death, in which their mistake was afterwards fully rectified and atoned for, and excepting also some sufficiently pardonable and not very serious pilfering, we found every reason to be pleased with the character and conduct of this tribe, not only to us, but towards each other. I have given several instances of their kindness, in their dragging the helpless on sledges, and the care of their children; and if they seemed an affectionate and goodtempered people, so did they appear to live together in perfect harmony, and to be free of selfishness, even on the subject of that great article, food, which constitutes the whole, it may almost be said, of a savage's enjoyments. I had no reason to suppose that I had prematurely formed this favourable opinion, though it is so much at variance with what has been reported of other tribes of the same people. It remained for time to determine what the exact truth was.

The alterations and fittings in the ship had made so much progress, that it was plain we should be ready long before it could serve any purpose. Though the health of the crew was generally good, three or four continued to show such a proneness to scurvy, that we were obliged to regulate their diet and treatment accordingly. They had been much harassed and fatigued during this period, but bore their toils cheerfully. 
The observations and surveys had been going on, including many on the dip and variation of the needle. The highest temperature of the month had been $62^{\circ}$ plus, and the lowest $26^{\circ}$ : the mean was $36^{\circ}, 76^{\circ}$ : I need not repeat the comparisons with those of the other expeditions in the same month.

Our sport was but indifferent: yet some good specimens of animals were procured. The perpetual hunting of the natives seemed to prevent the deer, together with the animals of prey which followed on their traces, from resting for any time in this neighbourhood; while the same cause, doubtless, drove the musk oxen, and possibly also the hares, from this vicinity, to places where they could find greater security in the solitude of these deserts. 


\section{CHAPTER XXXI.}

IN EXPEDITION TO FISH FOR THE SUPPLY OF FISH FOR THE CREW, UNDERTAKEN BY MYSELF AND PARTY-NARRATIVE AND RETURN.

Having proceeded towards the place where the sledge had 1830. been appointed, we came suddenly on two large white bears, before we had reached the end of the lake; but as our guns were loaded with small shot only, we were compelled to avoid them. It is not a safe animal to provoke unarmed. We met, after this, the men returning with the broken sledge, and afterwards arrived at the boat where the ammunition and fishing tackle had been deposited. We then proceeded over the ice, which was very full of cracks and holes.

Early in the morning, we reached the point forming the entrance June 30. of the inlet, which we believed to be the estuary of the river in which we had proposed to fish; but were obliged to pitch the tent, as it began to snow heavily, with a strong northerly gale. Being in a sheltered spot, we were, however, enabled to cook our dinners and go to rest. We had killed two ducks and a plover, and seen some reindeer. The land at this place was rugged, clear of snow, and divested of all vegetation. We found the ice, in many places, dangerously thin, independently of many large holes and wide cracks 
After dinner, at five in the evening, we proceeded up the inlet, which turned to the north-east; travelling over the ice for five miles, till it divided into two branches; one leading to the northwest, and the other north-north-east. We followed the latter a mile, and arrived at its termination. Here we ascended a high mountain, where we saw that the north-west branch took a northeasterly direction, as if it was about to join the great inlet to the northward, from which its visible end could not be more than a mile distant.

We saw no river of any importance, though we had expected one: there was only a small lake; but we found on its margin some remains of snow huts. On its banks, the game, such as it was, proved somewhat abundant for a country so barren in this respect as it generally had been found, and our sporting produced us some ducks and gulls, all equally acceptable to those whose variety of food was for the most part very disagreeably confined. The hill bounding the other inlet was, like those we had ascended, rugged and bare, and there was a narrow channel of water along its shore, extending all the way up, excepting where two points projected. Many showers of rain fell during this walk, and the weather at length became so thick and misty, that all further view of the interior land was unattainable.

July 1. We returned about two in the morning, for the purpose of resting till six, during which time it blew a gale from the northward. After this, I set off, with the surgeon and one man, to examine the coast to the west, in search of a river; and passing along the shore, came to an island in the sonth of the inlet, and, afterwards, to two points, the bays near which received nothing larger than a 
small rivulet. We then passed two more points on the right, and three islets on the left; finally arriving at the arm of the sea and that mouth of a river which were formerly examined by Commander Ross. Finding it still frozen, we proceeded to the north shore ascending the rising ground as we went on; and at length, at the distance of three miles, meeting two small lakes.

Thence I ascended a mile, leaving my companions, lest I should fatigue them; and, crossing a lake, proceeded to the summit of the highest mountain. Hence $I$ saw the termination of the northern branch of the inlet which I had observed yesterday, and beyond it a neck of land dividing it from the one further to the northward, which was also distinctly seen, about seven miles distant. I returned after two hours, and, joining my companions, we arrived at our tent.

While resting near it, a man was perceived crossing the bay, on which we fired a shot, to attract his attention. He seemed at first alarmed, but at last stood still to look at us, when the surgeon went to meet him, throwing away his gun, as the signal of friendship. On this he also threw away his bow and arrows and spear, when, approaching with the usual salutation, he was discovered to be our friend Awack. I then persuaded him to accompany us to our tent; giving him the gun to carry, in hopes of thus better establishing confidence among us. We had walked thirteen hours, and were glad to find a dinner, in which we made our friend partake. He informed us that his uncle Ikmallik's party were at a river that entered the bay about ten miles off; and thither we determined to go, to his great satisfaction.

Our tent and baggage were immediately packed on the sledge with the little boat and the net, and we set off with fresh spirit, 
passing several islands and points, till we came to one of those alluvial mounds which I formerly described; on rounding which, we saw the river, and the huts of the natives about a mile away on the north bank. At our guide's desire, we announced our approach by firing a gun, which produced a general acclamation. Leaving the sledge behind, I was soon at the village, and was received with open arms by our old friend Ikmallik.

He informed us that the season for fishing in the river was ended, and that they were about to set off for the lakes; but that they would stay another day, if we would remain with them. Our sledge then arriving, we erected our tent, and they began to replace theirs, which had been taken down; the number of families being four. They were highly delighted when I displayed the flag above Ikmallik's tent instead of our own. We were then presented with fish, including two fine salmon, which we proceeded to dress in our cooking apparatus : a process that excited great attention, from the quickness with which it boiled one of these fishes and fried the other.

They had proposed to dine with us, and of course we could not refuse; though perplexed to know how to cook for so large a party, with our limited kitchen. The whole twelve were, however, invited into the tent; and, with our own party of five, it was more than sufficiently filled. We were soon relieved from all anxiety about cookery, finding that they preferred their fish raw. Our two dinners, therefore, made a parallel progress : in time, however, not in quantity: since, while we found that one salmon, and half of another, was more than enough for all of us English, these voracious animals had devoured two each. At this rate of feeding, it is 
not wonderful that their whole time is occupied in procuring food: each man had eaten fourteen pounds of this raw salmon, and it was probably but a luncheon after all, or a superfluous meal for the sake of our society. Nor is it wonderful that they so often suffer from famine : under a more economical division of their food, with a little consideration for to-morrow, the same district might maintain double the number, and with scarcely the hazard of want. The glutton bear, scandalized as it may be by its name, might even be deemed a creature of moderate appetite in the comparison : with their human reason in addition, these people, could they always command the means, would doubtless outrival a glutton and a boa constrictor together.

Whether Captain Cochrane's extravagant accounts be true or not, the voracity of the northern savages, on both continents, is sufficiently known. But it is a question that has not been examined as it ought; and my medical knowledge is far too small to allow me to say much on a subject on which I cannot find that either preceding travellers or physicians have written any thing of importance. These northern stomachs have been supposed especially powerful; but the Boshman of southern Africa has a digestion of the same energy, and can equally bear the alternatives of gross excess and want. It may be true also, to a certain extent at least, that the severity of these climates demands more abundant food than one more temperate, and that, in particular, oily food is useful, as I had occasion formerly to remark. But the inhabitants of the alpine regions of southern Europe demand no such extravagance of food, nor are even the people of Lapland and the northern extremity of Norway conspicuous for such eating; as is not less true of the 
Icelanders. In Norway, indeed, the peasant is very much limited to milk, and to bread of the very worst quality : yet, in neither of these cases, do we find the people less strong, or less capable of labour, while equal, at least, to the Esquimaux tribes in longevity and in general health.

If this extraordinary consumption of food, and that of the most nutritious kind, is therefore not necessary, under this comparison with people most nearly corresponding in climate, the contrast is far more remarkable when we compare them with some of the people in the hotter parts of the earth. The Arab, on one small allowance of barley meal in the day, is more enduring of fatigue than an Esquimaux, who perhaps eats twenty pounds of flesh and oil ; while he is also stronger and more active. Other comparisons are easily made by any one acquainted with the geographical history of man. It is for physicians to explain these accommodating powers of the human stomach and constitution; but they should also account for the disposal of that which cannot fail to be superfluous: we were all as well fed on a pound of salmon a day as these people on twenty.

Be that explained as it may, this vast power of digestion must be the result of practice and habit; while, unfortunately, the habit being once established, the consequence of a more restricted diet is suffering and weakness, or starvation. That is fully proved by the appetites of the Canadian boatmen. The Esquimaux is an animal of prey, with no other enjoyment than eating; and, guided by no principle and no reason, he devours as long as he can, and all that he can procure, like the vulture and the tiger. The half savage Canadian equally eats all that he can obtain, under the same 
impulses; yet he gains nothing in strength or power of endurance by it; except that when the habit has once become established, he cannot endure privation at the first trial, nor without such perseverance in moderation as may once more reduce the condition of his stomach and constitution to a more natural state. Yet, with six pounds of solid meat in the day, or eight pounds of fish, which form his regulated allowance, he is not worth more, in point of exertion, than the Englishman, after a little practice in that labour, who is amply fed with one pound of the former, and a proportional quantity of the other.

To return from these remarks, we were not a little amused with the fashionable usages of the table here. The head and backbone being taken off from two fish, they were handed to Ikmallik and Tullahiu, the seniors, who slit the body longitudinally into two equal parts, dividing each of those afterwards into two more. They were then rolled up into cylinders of two inches in diameter, when putting one end into the mouth as far as possible, it was cut off by the knife so close as to endanger the end of the nose; the party then handing the remainder to his neighbour. In this way they proceeded till the whole stock of fish was consumed. One of them, afterwards eating the scraps on one of our plates, where there chanced to be some lemon-juice, made wry faces, to the great amusement and laughter of the rest. Man seems a laughing animal, as he has been termed, even where he approaches as nearly as he can to his inferiors of four legs.

We proceeded, after this, to try our drag net, though they assured us that we should take no fish; promising, nevertheless, that if we caught none, we should partake of their store. Their 
prophecy was correct; for, in three casts, we took but half a dozen small fish called Kanayoke, while the last brought only a large stone. This produced great laughter; but if it did not give them a good opinion of our dexterity in this art, so it had the advantage of preventing them from coveting our net. But the fame we might have lost in fishing, was compensated by our shooting, on the wing, a gull and a wild goose; and, by presenting them with these and some other birds that we had shot, our favour went on increasing. After twenty-five hours of wakefulness and labour, it was, however, necessary that these natives at least should sleep, and I therefore sent them all to their beds, appointing a meeting when the sun should be in the south. July 2. I accordingly went with Ikmallik to one of the pits where they keep their fish, frozen; and seeing that it probably contained not less than forty salmon, offered him a large knife for the whole, which was readily accepted. He had always been the most contented of these dealers, while the others looked up to him for example; so that the other two men offered me their stores at the same price. Had I known the contents of the whole, I could not have ventured to offer such a price; as I found two hundred and twenty fish, averaging five pounds each, and therefore producing a ton weight of salmon; of which the purchase money was thus no more than seven shillings and sixpence.

We had thus more than we could well carry; but as this fresh meat was most needful for the health of the crew, especially for those who were threatened with scurvy, we adopted several contrivances for transporting at least as many as we could. The sealskin beds were made into two bags, and, with one more lent by 
Ikmallik, we succeeded in packing up two hundred and ten of these fishes, keeping the rest for present use. The offer of two pieces of wood to make a spear and a paddle, produced us, further, the loan of four dogs, with the assistance of three natives, to aid us on our journey home, and to bring back the animals, together with their reward.

Having all dined together, as before, we were ready to depart, when they said that they would show us their method of killing seals; pointing to a large one half a mile off, on the ice. Eight of them consequently set out along the shore nearest to it, and then approached the animal slowly until it raised its head, when those in front stopped, and shouted as loud as they could; on which three others ran up with incredible swiftness, but as the leader raised his spear to strike, the creature suddenly plunged into a crack on the ice, and disappeared. We did not retaliate their laughter at our want of success in the fishery, as we were really disappointed.

They afterwards showed us the manner in which they take the salmon. The weapon is a spear, with two very divergent barbs of bone or ivory; and, by this, they are struck in the water. They described this method as being without difficulty; as the fish swam up in the channels between the ice and the land, in such dense crowds, that they could not throw their instrument without striking some. This was the migration to the rivers for spawning, without doubt; and it was the end of this migration that had caused them to abandon a place, which, if we had then understood these matters better, we should have resorted to at an earlier period. That report also confirms a discredited American 
tale, in which the fish are described to be so abundant, at some seasons, in certain rivers, that they are trampled to death by the hoofs of horses in fording; while, if confirmation were necessary, the reports of La Perouse on the same subject, are beyond questioning.

We at length set off, dragging the three bags of fish after the sledge, as it could not bear the weight. The ice being hummocky, and full of cracks and holes, gave us much trouble: so that it required four hours of hard work to reach the first of the islands, about four miles off. I here determined on burying two of the bags ; carrying on only one, in the boat on the sledge. At midnight we arrived at the second island, four miles further: and here it was necessary for us to eat and rest, having thirteen miles more to the ship.

The route continued very bad the next day, being through pools of water, often knee deep, and with holes quite through the ice, besides very wide cracks. Falling into one of these, the sledge also overset near me, the bag of fish falling at the same time in such a manner, that had I not been first, it would have gone down through the crack and been lost. The only event, fortunately, was a sound ducking. Not long after, it began to blow hard, and to snow, while we had still seven miles before us; but our perseverance at length brought us within sight of home, at three miles distance; when, after much difficulty, in consequence of the separation of the ice, obliging us to unload and carry things piecemeal over the loose fragments, we got near enough to hoist our colours, and were answered by those of Commander Ross, who had not arrived many minutes before us, from a similar fishing expedition. We found all well on board. 
There is little to add to the narrative of this short expedition. The river which we had visited is called by the natives Tatchik, and is only fifteen miles from the ship, though our circuitous course had made it twenty to us. It is about five hundred feet wide, and from six to ten deep; the bottom full of large blocks of granite, and the current running strong at first, but diminishing before we had left it. There was a rapid also about two miles up the stream, preventing its navigation: while the natives informed me that it ran out of a large lake which was supplied by others at a greater distance.

To our communications with the natives I must also add, that they endeavoured to entertain us in their best manner; acting over again the drama of our first meeting, together with that which was to take place when we met hereafter at Neitchillee. Our attempts to repeat their words was also a source of great amusement to them. If the meeting had been fortunate for us, in procuring such a supply of fish, which we should have missed had we been a day later, I now also found that this had been stored up with the intention of selling it to us the next year. I might indeed have procured a hundred and thirty more, but they were not so fine, nor could we contrive to take them away. I ought also to mention that we bought from them three wolf whelps as specimens.

The proceedings on board during our absence had been marked July 1 . by little variety. Some of the men had been lamed in their expeditions, and required management in their allotted work. The thermometer at midnight was $37^{\circ}$. On the second it did not vary, and the men were recovering. The third was the day of the return of July 3. Commander Ross's party and my own, being foggy in the morning, with snow and rain. In the evening I detached a party to bring home the fish that had been left behind. 


\section{CHAPTER XXXII.}

JOURNAL OF THE MONTH OF JULY-SUMMARY OF THE MONTHTRANSACTIONS DURING AUGUST, AND ITS SUMMARY.

3830 .

July 4.

July 5. the salmon returned: and part of Monday was occupied in cleaning them and packing them in the tanks, with ice. The snow had nearly left the land; and, this night, the nocturnal temperature rose to $48^{\circ}$. There was little to note on the two subsequent days: July 6 . the necessary work for fitting out the ship was going on. The July 7 . temperature fell, however, so much on the seventh, that it froze hard. The men were now ordered to receive three pounds of the fiesh fish every other day.

July 8. It was less cold, yet at midnight the thermometer was but $37^{\circ}$.

July 9. On the following day, it rained hard for twelve hours, and the effect on the remaining snow was considerable. A native arrived with an offer of more fish, which we agreed to purchase when brought, and we undertook to send for it while he pitched his tent July 10. near us, with his family. In taking a walk to-day, I found the ice not more than a foot thick in many places, and so brittle, that our weight broke through it. Our projected canal had melted away to two feet, in depth of ice, at the surface. Some ducks and other birds were killed. 
In the course of this Sunday our party returned with the fish for July 11. which they had been sent. It was foggy in the morning, and some rain came on at night, lasting till the following day. Thus it con- July 12. tinued on the thirteenth; so that the snow on the land was almost July 13. entirely dissolved, and the ice covered by water. The several works went on in the mean time; and our sportsmen shot, among other things, some small birds that we did not know.

It did not clear up till the evening of this day, when it became July 14. fine, continuing so on the following day. At this time a piece of ice came up to the surface from beneath the ship, so forcibly as to lift her up on one side and cause her to heel, to the temporary alarm of those who were below. On shore, the mosquitoes had just commenced their most unwelcome summer visit, and were in swarms. The thermometer was $42^{\circ}$ at midnight.

This day was fine, with a strong northerly breeze ; and our sportsJuly 16 . men were very successful in shooting several birds. It still blew hard on the following, with some heavy rain. The outer part of July 17 . the canal was now open. Sunday's muster, after service, found the July 18. men much improved, in consequence of the change of diet. The ice round the ship was now broken in pieces, and the snow had entirely left the hills; but no clear water was seen at sea.

Calm and clear weather brought the mosquitoes even on board the ship, where they were very troublesome. On this and the following day the thermometer was as high as $42^{\circ}$ at midnight. July 20 . On the twenty-first, the ice was so broken up about the ship that July 21. we could have hauled her out to the end of the canal. The several chief sails had now been bent; and most of the painting, caulking, and other repairs and alterations, were nearly finished. 
July 22. The weather was really hot, as well as calm, the thermometer rising to $70^{\circ}$. The swarms of mosquitoes were as great and as troublesome as in the West Indies. There seemed to be different July 23. species; and a large kind was the most venomous. 'The same calm July 24. and warm weather continued on the following two days, bringing us to the end of the week; but with as little variety of occurrence as during the preceding. We had work, indeed, to employ us, but it was nevertheless dull. We were prisoners now, equally, by land and water; for the former was unfit for travelling, in its present condition, and as to clear water at sea, there was, as yet, none. Even our sporting was impracticable, except at midnight; such was the annoyance from the mosquitoes.

July 25. A south wind drove some of the ice to the northward, but, still, we saw no clear sea from the top of the highest hill: the whole visible surface was a compact mass of ice. Being Sunday, no work

July 26. was done. But on Monday, the Krusenstern was cleared out, and launched off the ice to the beach, that she might be repaired and caulked; and as the ice was now in motion around us, it became necessary to moor to the rocks, on each side. This was a day of hard rain, for the most part.

July 27. The rain continued, with a fresh breeze and a lower temperature, Iuly 28. by which we got rid of the mosquitoes for a time. The Krusenstern's and other work went on, on this and the following day, part of which was expended in reshipping such parts of the engine as might be convertible to the general uses of the ship. Among these was the main shaft: the cylinders were to be cut up for the purpose of examining their materials. But as the boilers and their frames could be of no use, and were not worth the transport, in any 
state, they were left on shore; with the satisfactory reflection, at least, that they would prove a valuable iron mine for our friends the Esquimaux.

Some trout had been observed in the lake yesterday; but being late in going with the boat and the net, we had only one haul, and took but four. This day we set out again, and had the luck to take above a hundred, averaging a pound each. It was the best sport that we had had for some time, while it also furnished two days' full allowance to the crew. On the next, there were only seven taken. July 30 . Some rain fell in the evening, and also on the following morning. This day, more than a hundred trout were taken by the net and the rod; amounting to upwards of seventy pounds. The various works had been going on as usual; and Saturday night brought them to a close for the week, bringing with it also, the end of the month of July.

Although it had been a warmer and a better one than June, it had not compensated for the lateness of the season in the two preceding ones. The first of August was arrived, and we had not yet seen any clear sea, nor had any of the ice on it appeared to move. Still it was probable that the first southerly gale would break it up, could that last but for forty-eight hours : so that we might still feed on hope.

The month had been uniform, and therefore comparatively dull to us; but we had not at least been wearied for want of occupation. The ship had been completely refitted; and the new painting, while useful, had also improved her appearance. She was so little leaky now, as not to make more than five or six inches of water in the twenty-four hours. Lee boards had been applied to her, and 
we trusted that these would improve her sailing : of the disposal of the several parts of the rejected engine, I have just spoken.

The health of the men had so far improved, on their amended diet, that even the suspicious ones were now quite well. This great supply of fish was a matter of congratulation, and somewhat balanced our other disappointments. They who, in reading this journal, may read of meat and eating, must add something to the common ideas usually associated in their minds with this subject. At home, a good or a bad dinner is but a matter of content or the reverse; and the first salmon of the season no more than a luxury. The bad dinner of yesterday will also be compensated by a better one to-morrow; and he who cannot get salmon will easily find an equivalent. But, to us, good diet or bad, salt provisions or fresh, sufficed to turn the scale between activity and weakness, health and sickness, and, as well might happen, as used to happen but too often in former days, between life and death. And the first salmon of the summer were a medicine which all the drugs in the ship could not replace: while, though they had done no more than diminish the wearisomeness which men feel from being confined to the eternal sameness of a ship's provisions, they would have had a value to us, greater than all the salmon of the Thames to those who can provide themselves with such dainties.

Our communications with the natives had continued to confirm our good opinion of them: while, if we had attained to more knowledge of their peculiarities, and had witnessed many things repugnant to our habits and feelings, I must reserve these for future remarks.

Having frequently spoken of the Krusenstern, I have now to 
observe, that when the ice had overflowed it had sunk her, carrying her with it to the bottom. On the thaw she was at last relieved and brought on shore; but she had sustained more damage from the pressure than we had suspected. Many of her timbers were broken; but these and all other defects had been at last repaired, and she was now in a better condition for towing than she had originally been. The other boats had also been put in order.

The collection of natural history had been increased, and the sporting had on the whole been successful. In addition to our living foxes, we had tamed a hare so as to stay in the cabin with us.

Not many observations had been made this month, as all travelling by land was impracticable. It was time, too, for taking down and embarking our observatory; while we had now but eight weeks before us of that short summer which, under our purposes, was in reality the only one; after which we should again be compelled to settle ourselves for another winter of ten months.

Respecting the temperature, it remains to add, that the highest was $70^{\circ}$ plus, and the lowest $32^{\circ}$ plus, the mean for July having been $44^{\circ} 57^{\mathrm{t}}$ plus.

After church, we found that a strong northerly breeze had at Angust 1. length put the ice in motion to the eastward; and it now assumed the appearance of hummocks interspersed with pools of water. The party on shore afterwards reported that it had broken up in the north bay.

The thermometer was at $39^{\circ}$ at midnight. On the next, nothing August 2. seemed wanting but a south wind to disperse the broken ice: the effect of the northerly ones was to pack it together, loose as it was. About seventy trout were taken in the net: and, on the following 
August 3. day, the fishery was nearly as successful. The weather continued very fine.

August 4. It was still fine weather, but the fishery failed; excepting that we took the largest trout that we had yet seen; weighing three August 5. pounds and a half. The evening of the fifth produced a smart shower of rain: but things settled back to the same state on the August 6. following day, when a still larger trout, weighing nearly five pounds, was taken, with about twenty others of the ordinary size. The Krusenstern was launched and brought alongside.

August 7 . At five in the afternoon, a breeze sprang up and blew fresh from the south-westward for ten hours. This, setting the ice in motion, carried away one of our hawsers, and the ship was forced against the rocks near her; but was soon got off again, and secured, without any damage. This was a sort of return of our labours of the preceding autumn, but of a very different nature, as we now hoped; since it was the probable commencement of our liberation, as the other was of our imprisonment. This moving ice, however, soon stopped near the shore: further out, it continued in motion to the northward till two in the afternoon, when the tide carried it back, having now, at this spring, a rise of five feet and a half.

tugust 8. It was a foggy and rainy day, with variable winds. The men, in their walk after church, reported that there was much clear water in the large bay, but that there was a ridge between Fury and Angust 9. Hecla islands, and the point. The weather differed little on the Angust 10. following day, and on the tenth the rain was much heavier. It served to prevent all fishing, nor had our success been very great on the preceding ones. The wind was to the north-westward, and became very strong, so as to pack the ice as close as possible. Many seals were seen, and some water taken on board. 
The weather improved: some fish were taken; and a southerly August 11. wind caused the ice to move. By the next day, under the same August 12. breeze, much more cleared away, so that an extent of two miles of clear water was seen to the northward. A good deal was, however, afterwards brought back by the wind shifting to the north: nor indeed would the tide have admitted of making an attempt to get ont. For many days now, the midnight temperature had been about $38^{\circ}$.

The observatory was taken on board: the day being calm, and August $1 \%$ no change in the ice. Nor was there any on the fourteenth. The August 14. fishermen were now supplying us with enough for our daily consumption. It was a memorable day, inasmuch as it was the anniversary of our first visit to Fury Beach. The thermometer fell to $34^{\circ}$ at night. There was reason, indeed, why the night should become colder, as the sun was now situated; but there was less subsidence by much, than when it had been far higher, because the ground was then all covered with snow, and was now clear; thus retaining some of the heat which it had acquired during the day.

The morning of Sunday had a favourable aspect, as a westerly August 15. breeze had moved the ice from the coast; but it soon changed to the north-east, and all became as it had been before. The first star that we had yet seen for the summer, Capella, was visible at midnight. The midnight temperature fell to $6^{\circ}$.

After a tranquil morning of westerly airs, the wind, towards August 16. evening, became a strong breeze from the south-west; but as the tide was very low, and the ice aground, there was no motion with us, though there was some in the offing. The following day was August 17. 
calm and mild, and there was no change in the ice. The midnight temperature rose again to $34^{\circ}$. Nor was there any thing worth August 18. noticing on the eighteenth. Our success in fishing, on all these days, was very small; and we had to regret the loss of one of our tame foxes, after having been one of the family for six months. The vacancy of the sea, it is well known, makes even the flight of a gull or the rising of a porpoise an important event. Whether the vacuum of wide-spread ice and snow, when the ship is itself a prisoner, instead of being only a prison, be not much worse, they must decide who have experienced both : but we shall probably be excused for considering the death of this unlucky fox as among the important occurrences of our present life.

August 19. A fine day, with a northerly breeze, was but a continuation of this now sleepy uniformity: our ship could do nothing; and we, little. The capture of some fish, and the occurrence of rain at August 20. night, scarcely varied the sameness of the following day. The August 21. twenty-first closed another week: and thus did the third week of August find us where we had been since May in prospect, since September in place. The rise of the tide, during these past days, had vacillated about the standard of six feet; having once been at more than seven, and being now five. The ice was still close, to the northward, under a fresh breeze.

August 22. It was the same on Sunday; though the afternoon was warmer than it had been for a considerable time. There was an open lane of water seen from the shore, lying along the land to the westward Angust 23. of the furthest visible point north. On Monday there was no change: but in the night the wind increased to a fresh gale from Angust 24 . the northern quarter, and, at daylight next day, the ice was seen in 
rapid motion to the southward, and packing into the bottom of the bay. The inner part of the harbour was thus cleared, as the coast was, for about two miles to the southward; but afterwards, a pack of the ice streamed in, and filled all except the place where we lay, that being defended by the grounding of some heavy masses outside.

The wind continuing to blow fresh from the north-eastward, August 25. the ice continued to accumulate so on us, that a very small space was left clear. It was more moderate in the morning, with rain; August 26. but there was otherwise no change. Both the subsequent days August 27. were equally free of any events worth noticing, beyond some August 28. indifferent success in fishing and shooting, including the taking of a seal. Another week was gone; and the night thermometer had little changed, varying between $36^{\circ}$ and $38^{\circ}$.

Sunday promised something new; the wind becoming a gale August 29. from the north-westward. Thus the ice began to move with considerable rapidity, and the harbour was once more cleared. We tried to console ourselves by recollecting, that on the same day last year, the ground was covered with snow, and the temperature ten degrees lower.

The ice continued moving to the southward till four o'clock, August 30. when it stopped, and remained stationary the whole day. On the following, there was no change in the weather till evening, when it August 31. rained from the westward, with a fresh breeze. We made ready for hauling the ship out into a pool to the northward of us, that we might be more in the way of extricating ourselves when the ice should fairly open. And with this was summed up the month of August. 
The end of that month also left us eleven months fixed to one spot. Whatever value voyages of discovery may have in these countries, they are certainly purchased at a high price in time, though there were nothing else. We might have circumnavigated the globe in the same period: and I imagine no one was very sanguine about future north-west passages, even should we contrive to make one ourselves.

That this was a month of daily and hourly anxiety, of hopes and fears, promise, and non-performance, I need not say; while no record of feelings could give a picture of them. There were but four weeks of this never assured summer to come; and, really, the hope of its speedy arrival was by no means great. On many past days we had more than hoped, we had almost expected, that the next day, or the following, or some other not far distant, would release us; and they who reflected most, were perhaps the least easy under this constantly recurring disappointment. It was my business, at any rate, to keep up the hopes of the men, and, where that might be difficult, to find them occupations to prevent them from thinking too much of the future. In this, the permission to shoot and fish gave much aid; while the variety of diet this procured them was also advantageous. Of their health, indeed, there was no reason to complain.

The commencing temperature of this month was promising; but the northerly winds of the latter portion were extremely adverse, since it was the effect of these to pack the ice upon us as fast as it broke up. One conclusion seemed obvious, namely, that the winter in that quarter had been particularly severe; though we had once thought otherwise, when observing how often the temperature rose 
when the wind blew from this point of the compass. This was an unfavourable view of things: but there was no remedy. I need only add, that the highest and lowest degrees at which the thermometer stood were $58^{\circ}$ and $33^{\circ}$ plus, and that the mean of the month was $40^{\circ} 87^{\mathrm{t}}$ plus.

Every thing about the ship, boats and all, had been entirely refitted and made ready for sea; and she had never been so trim, neat, clean, and comfortable. We had obtained abundant room by the dismissal of the engine; and that was no small gain, to compensate a loss, if that machinery can be esteemed a loss, whence we had derived so little advantage and undergone so much inconvenience and vexation. It was probable that the Esquimaux would profit for a long time to come, by the cachés of Messrs. Braithwaite and Erickson.

Having concluded, for the present, a long train of observations, it was very satisfactory to find how well the chronometers had performed. No. 571 of Parkinson and Frodsham had continued its rate of plus 1.1 seconds per day without variation.

The season had been very favourable to vegetation, and the collection of plants contained, as was believed, many new ones. After so long a time of confinement to a narrow and unvarying society, it was highly pleasing to find that the general harmony was unaltered. 


\section{CHAPTER XXXIII.}

WARPING OUT, UNLOADING, AND FINAL ESCAPE FROM OUR HARBOUR -INEFFECTUAL MOVEMENTS AMONG THE ICE-BECOME FIXED IN THE ATTEMPT TO FIND A NEW HARBOUR FOR THE WINTERSUMMARY OF SEPTEMBER.

1830.

Sept. 1. THIS month set in with great severity; the thermometer was at the freezing point, sinking finally to $29^{\circ}$, and there was a violent storm of snow, which covered the hills for the first time this season : while it was also the severest gale we had experienced during the whole summer. It varied between the west and the north; and though it continued to pack the loose ice, this could not move far, being soon stopped by the fixed mass at the bottom of the bay. Our own passage to the main was filled by two large icebergs.

Sept. 2. The same gale blew, and was very heavy about two o'clock, when there was an eclipse of the moon, invisible to us. The ice was driving to the southward with great rapidity, and packing itself in immense masses. In the evening the wind diminished, and the snow which had fallen on the hills disappeared.

Sept. 3. It did not blow so strong, and the ice was at a stand; but it froze Sept. 4. hard at midnight, with the thermometer at $29^{\circ}$. The weather being fine next day, and expecting a high tide at two in the morning, we attempted to cross the bar between the island and the main; but before we could warp out it fell so much, that we remained aground 
in only fourteen inches of water. By this accident, however, we profited so as to examine the ship's bottom, and thus also repaired several small damages which she had received from the ice. Having also shored her up, we proceeded to lighten her by discharging four tons of water, and putting ten tons of other articles in the boats, that we might, if possible, float her off at the next tide; laying out hawsers to warp her off when this should take place. There were showers of snow in the day, and the night was equally cold. We had the misfortune of losing our best dog, which died.

We were obliged to work to-day. At two o'clock in the morning Sept. 5 . we attempted to heave the ship over the bar, but in vain. The wind had shifted to the southward, and the tide did not rise so high as before. It became necessary, therefore, to unload the vessel, as the tides were now diminishing, while we could not run the risk of being neaped in this manner. A bridge was, in consequence, laid to the rocks, which were but eight yards from us, and we carried over it all our remaining stores and provisions, together with that iron-work of the engine which remained on board. In the evening, the wind came to the eastward with some snow, giving us a better tide the next day. Three treenail holes were hopes of here discovered in the ship's bottom, in the search after a leak which had plagued us, and they were accordingly secured.

A shift of the wind up towards the north produced such a tide as Sept. 6 . enabled us to heave off the bar very early in the morning. Yet the ice had so grounded, that we could not advance far enough to avoid grounding ourselves when the tide should fall, and did not thence dare to bring on board much of what had been landed. During the day every thing was covered with snow, which partially 
dissolved under an evening haze; and at night it was clear and frosty.

Sept. 7. It blew a gale from the northward during the night, but the ice did not move. Towards morning we contrived to heave out, so as to get a foot more of water, which enabled us to proceed with the reloading of the ship; and, after this, by aid of the ice at our bows, we gained another foot, thus advancing about ten feet in distance. This was a depth sufficient to allow us to reload entirely; but that caused us work enough for two days. The thermometer was $5^{\circ}$ higher, and there was some snow.

Sept. 8. The changes in the wind and weather were trifling, and we proceeded with the reloading of our discharged stores; also cutting some ice at our bows, that we might have no obstruction to our Sept. 9. next attempt. The following day was without change or interest, except that more ice was cut, and the ship hove a few feet ahead. Sept. 10. Every thing, however, was got on board and stowed. The next day did not advance us even a foot. The lakes on shore had not yet frozen, though there was ice on the pools.

Sept. 11. The wind came to the southward, but was not sufficient to move the heavy ice. The pool between the island and the main was covered with thin bay ice, having a very prognosticating evil aspect; and the temperature fell with the setting sun to $21^{\circ}$. We still went on cutting the ice, and the ship was hove a little further ahead. The cold weather seemed really coming on, as the thermometer by midnight was $18^{\circ}$; and the shooting of ducks was now rather a vexation than otherwise, since we could see that they were returning to the southward.

Sept. 12. The changes of temperature to-day were very unexpected: the thermometer ranging from $16^{\circ}$ to $41^{\circ}$ between four in the morning 
and noon. The men who went on shore after church, found the water, nevertheless, completely covered with bay ice.

There was some damp snow on Monday, and, though the wind Sept. 13. was southerly, it was light, and had no effect on the ice at sea. In the night tide, the ship was hove about ten feet ahead, and that which we had to cut through was not frozen to the union of the separate fragments. The next day was fine; but this was not sept. 14. favourable weather for us who were in want of a gale, and that gale, too, to be of our own choosing. The midday heat was the same. The sight of a hare that had been shot was by no means gratifying, for it had now acquired its winter dress.

The wind having freshened in the night from the sonthward, the Sept. 15. jce began to move north, about the time of high water, and, after daylight, it was very loose, and full of lanes and pools. The night tide allowed us to heave some space ahead, and the day one brought us into five fathoms water, though not two ships' length from our position of yesterday. What remained on shore, of ironwork, anchors, and other things, were now, therefore, got on board; but that furnished us occupation for the whole day. We were consequently ready to start by evening; but the breeze died away, with the ice still drifting up and down before the tide, in the calm.

That wind was of little service to-day, being light and unsteady, Sept. 16. between the south and west; but as the ice near us was becoming slack, the ship was hove out two cables' length, to take advantage of any opening that might occur. Some lanes of water appeared in the evening, along the shore to the northward. The thermometer was $40^{\circ}$ in the day, and $29^{\circ}$ at midnight. It fell to $25^{\prime}$ before the sept. 17. following morning, and there was an aurora borealis. At daylight 
we could see that the ice had drifted off the land, but there was still a complete ridge between the ship and a lane of water which led to a point three miles to the northward. About two in the afternoon, however, it seemed to be breaking up; when we immediately cast off, warped through the bay ice around us, and, in half an hour, our ship was, at length, once more in clear water, and under sail.

Under sail-we scarcely knew how we felt, or whether we quite believed it. He must be a seaman, to feel that the vessel which bounds beneath him, which listens to and obeys the smallest movement of his hand, which seems to move but under his will, is a thing of life, a mind conforming to his wishes; not an inert body, the sport of winds and waves. But what seaman could feel this as we did, when this creature, which used to carry us buoyantly over the ocean, had been during an entire year immovable as the ice and the rocks around it, helpless, disobedient, dead. It seemed to have revived again to a new life; it once more obeyed us, did whatever we desired; and in addition to all, we too were free. It was the first burst of enjoyment on the recovery of our liberty; but we were not long in finding, as other pursuers of other liberty have found, that it was a freedom which was to bring us no happiness.

Thus freed at last, we advanced about three miles; but then finding a ridge of ice, we were obliged to make fast near the point which was at that distance to the north of us; and, in a sufficiently commodious harbour between two icebergs, we passed the night. We shot some grouse on shore, to pass the time, and saw many seals. The thermometer at midnight was $30^{\circ}$.

Sept. 18. In the mean time, the wind came round, unfortunately, to the 
southward, and, by morning, our passage was blocked up; so that we were compelled to remain. In the offing, it was sweeping up and down before the tide; and, in the evening, as the wind became northerly, it went away rapidly once more to the southward. There was much snow to-day, and the land was entirely covered. Four hares that were shot did not much comfort us under this detention, however they might vary our dinners.

A gale had come on suddenly last night, and, continuing till Sept. 19. high water, this forenoon, as it served to raise that tide considerably, our bergs floated, but did not change their position so much as to destroy our harbour: while the arrival of a large floe protected us from a pressure that was now threatening to be considerable. Every space was indeed filled by the ice: but as the wind ceased, it did not fix, being kept in alternate motion by the tides. In the evening it was a little more slack; and there was nothing in this day to make us neglect the duties of Sunday. The thermometer was at $25^{\circ}$ at midnight.

The ice opened so slightly under a westerly breeze, that it rendered us no service; and, as we were frozen round by new ice, we were obliged to cut around the ship. Our detention was more perfectly assured the next day, by a south-easterly one in the morning, Sept. 21. bringing the ice in upon us. After many changes, it at last settled in the north-north-west, and blew a heavy gale. The ice being thus set in rapid motion, came in contact with the bergs which protected us, and forced them and us together, onwards, till our stern was within twenty yards of the rocks. The Krusenstern was at the same time forced out of the water. It was fortunate that the icehergs which covered us were not carried away, else we should 
have gone with them into the moving pack, or been driven on the rocks; each of them but hazardous positions, if not worse. The temperature fell to $48^{\circ}$, and there was snow with this gale.

Sept. 22. It continued on the next morning, yet the ice in the bay seemed partially cleared. But, after this, coming to blow even harder, we were worse blocked up than before, though there was still a lane of water in the bay. It was however the only clear water visible: all else was a solid surface of ice. At night the wind was much Sept. 23. more moderate. On the following day there was no change. We were completely frozen in; and were obliged to cut round the ship, that she might right herself, having been heeled over by the ice.

Sept. 24. There was a heavy fall of snow all day, and it continued on the Sept. 25. twenty-fifth. The week was expended; and we were idle and immovable. The thermometer, from having been at $24^{\circ}$ for the past days, reached to $30^{\circ}$.

Sept.26. There was nothing to interfere with the services and repose of Sunday; and no change. The temperature, however, seemed graSept. 27. dually falling; it had been but $7^{\circ}$ in the night, and was no more than $14^{\circ}$ all Monday. A lane of water was seen near the islands that Sept. 28. were next to us. It became wider on the following day; so that, had we not been imprisoned, we might have made some progress to the northward.

Sept. 29. The thermometer fell to $5^{\circ}$, and the clear water of yesterday was covered with bay ice. The surrounding hummocks were also cemented together in such a manner, that nothing but a storm could separate them. Our hopes of a liberation were therefore fast passing away; and our work was now to cut through the ice, so as to attain a harbour that was likely to prove our home for the better 
part of another year. It was found to be a foot thick; and as there were also many heavy pieces in the way, our progress was necessarily very slow, and the labour hard. There was not wind enough to prevent the formation of bay ice.

Under the continuance of the same low temperature, the whole Sept. 30. sea was now covered with ice. There was no longer, therefore, occasion either to hope or fear: and there was an end to all anxiety at least. The agitation under which we had so long laboured had subsided into the repose of absolute certainty. Our winter prison was before us; and all that we had now to do, was to reach it, set up our amphibious house, and, with one foot on sea and one on shore, "take patience to ourselves."

Though we had done much, we still, however, found it very hard work to cut through the remainder of this ice, which, though but newly formed, was already sixteen inches thick, independently of the broken pieces from the former winter that were mixed with it. Thence, what we had cut off was to be lifted to the surface, as it could not be sunk under the field; and, in consequence, we only made eighteen feet way in this and the preceding day; a slow navigation, though, fortunately, our harbour was not very far off. It seemed almost a fated period for us; as it was the very anniversary of the day which had fixed us not three miles from the spot which we were now seeking to occupy; while we were perhaps again captives-and who could conjecture ?-for another year. It was the end of September; but the summary of September, 1830, is one of the least agreeable that I have yet to record.

It was now winter, without dispute. Theoretically, it ought to have been such; and that it was practically so, we had long been sure, whatever efforts might have been made to flatter the men, or 
ourselves, that it was otherwise. It had been a busy and a laborious month; but it was busy idleness, as far as any result had followed, and all the labour had produced no return. It was, in every sense, a wasted month, and it had been an amply provoking one: there was not one in all the preceding year in which we had not done something useful, or at least made preparations for it; thus finding occupation that satisfied us; while there was not one which had not held out, what was even better, hopes, and those most lively when the chance of release was most distant. We had now to hope again, for nearly another year; to count months, weeks, even days, yet with less confidence than we had done during the last winter.

He who can hope a second time as he did the first, is of a more fortunate constitution than some of our people seemed to be. The despondent could not conceal their feelings; though, of the greater number, I am bound to say that their contentedness, or rather resignation, exceeded what I had anticipated. It was my business to show them the brighter side of this picture, by recapitulating our success in discovery, the excellent condition of our ship, the comfortable home which we had now learned to make of it, our ample stock of provisions, our good health and peace, and the better harbour which we should now secure, as it was one also whence it would prove much more easy to extricate ourselves hereafter. But the bright side of life is not easily seen through the dark one; and I had, therefore, to trust to time and habit, and to hope that between our own resources and the communications of the natives, supplied, as we expected to be by them, with fresh provisions, and, before long, with the power of renewing our expeditions by land, time would pass on, and the present evils become lighter. 
In reviewing the weather and the temperature during this month, it is seen that it was more severe than that of the preceding September; and thus, being an earlier winter, it also promised to be a worse one. The highest and the lowest in the present were $43^{\circ}$ and $5^{\circ}$ plus, and the mean $27^{\circ}, 42^{t}$ plus: in the former, the two first had been $50^{\circ}$ and $8^{\prime}$ plus, and the last $32^{\circ}$ plus. In the September of 1829, there were several gales from the west and south, which cleared the coast in such a manner that it could often be navigated; but in the present one, there had not been a single breeze from those quarters, capable of making any impression on the ice. On the contrary, there had been several gales from the northward; so that as fast as that which was in the southern part of this sea dissolved, the space was filled by the arrival of heavier masses from the north. It was as if the northern ocean were sending all its stores into this quarter; and we knew that it was now the unquestionable parent of an inexhaustible supply; while, as if the blockade was not already sufficiently complete, every little shift of wind from the north to the eastward, filled up the little bays which might have afforded us a retreat. Bad, too, as this was in itself, it was rendered much more effectually so by the state of the tides, which did not allow these masses to float again, when once aground; so that they could not be removed, even though we had cut them, while, when once taking the shore, they became as much a part of it during the ensuing season, as the rocks themselves.

I need not, in this summary, go back to any general record of the ship's proceedings or our own; they offer less interest than usual, and we had not been in a situation to make any observations of moment. Our sporting calendar presents little more than some fruitless firing at seals, and the ineffectual pursuit of a white bear. 


\section{CHAPTER XXXIV.}

LABOUR IN CUTTING THROUGH THE ICE-BECOME FIXED FOR THE WINTER-SUMMARY OF THE MONTH.

1830.

Oct. 1.

OCTOBER commenced with clear weather, and, in the course of the day, a strong breeze from the westward broke up so much of the bay ice to the north-east as to display a little clear water. It made no impression, however, on the rough ice which was attached to the land; and one of the bergs near us having split under our quarter, we received a violent concussion. The labour of cutting our way was renewed, and with rather better success. The thermoOct. 2. meter was $12^{\circ}$ at night. On Saturday there was little change, except that our labour was harder; and in this position we ended another week.

Oct. 3. We were obliged to persevere in the same tedious toil ; and the whole gain was but sixteen feet, which, however, released us from the pressure of the icebergs. This had been very inconvenient, if not more; since they rose above her gunwale, and also lifted her up in such a manner as to suspend her three or four feet higher Oct. 4. than the water which she drew. The Monday morning came with a gale, which broke off some pieces of ice, but rendered us no service. Our labours only gained us an additional advance of other 
sixteen feet. The thermometer adhered to $20^{\circ}$, and there was drift snow at times.

It became more moderate, and more favourable to our operations; Oct. 5 . in consequence of which we advanced eighteen feet. There was snow in the day, and a gale from the north in the evening, the night thermometer falling to $13^{\circ}$. At daylight on the sixth, the weather was fine, and the breezes had broken up the new bay ice to the northward, so as again to show some clear water. The ship was cut in as far as twenty feet more; being thus much nearer to our intended position for the winter. Being calm and clear at night, the temperature fell to $10^{\circ}$.

We advanced fifty feet this day, but had only six feet water at Oct. 7 . the ebb: though we were now at length clear of the heavy ice. Towards the following morning, the thermometer fell to $5^{\circ}$; and, at Oct. 8. daylight, there was not an atom of water to be seen in any direction. All was ice; and it is remarkable that this day was the anniversary of the same event in the preceding year. We however gained fifty feet more; and, on the following day, forty; but being now but in Oct. 9 . three feet water, we were obliged to shore the vessel up. The thermometer had been always low, and, on this night, was only $2^{\circ}$; but the weather was calm and clear.

It was now apparent that we should soon be obliged to adopt Oct. 10. the negative scale of the thermometer as well as the positive. It stood at zero this morning; and it had not reached that point last year, till the 19 th of the same month. We were thus obliged, again, to labour on Sunday ; since another forty-eight hours of such frost would render it extremely difficult to cut the ship in; as the ice around her was, even now, three and four feet thick. Nor had we made more 
than the half of our needfinl voyage; while it was absolutely necessary for her safety, that she should be removed to a place where she could float, which was not less than a hundred yards off. We gained but thirty feet by all our exertions.

Oct. 11. The weather did not change, and we advanced forty-five feet. oct. 12. On the next morning a fog covered the rigging with ice, and we Oct. 13. gained as much more. The thirteenth was a beautiful clear and calm day; and I found, when on shore, that the sun melted the snow upon the rocks, though the noon temperature was as low as $8^{\circ}$, falling to $\mathbf{1}^{\circ}$ at midnight. Other forty-five feet were gained by cutting.

Oct. 14. In the course of this forenoon there was a gale from the west, with snow, raising the thermometer to $12^{\circ}$, and at last to $22^{\circ}$, at midnight. More of the canal was cut, but the wind prevented us from heaving the ship into it. This gale increased in force till the morning of Oct, 15. the fifteenth, when it fell calm; and we could see that the new ice in the offing had been once more broken up, so as to show some clear water. The ship was advanced fifty feet this day, and fortyOct. 16. five on the following; but she did not yet float at low water. The weather was variable, and the thermometer did not materially alter.

Oct. 17. A week, a second week, had done little for us, and we were obliged to make Sunday once more a day of work, thus advancing forty feet. A gale, which had arisen the night before, continued Oct. 18. till noon. We gained twenty more on the Monday, and saw that Oct. 19. the clear water to the northward had enlarged. The following day our progress was thirty; while the ice was so heavy, that we were obliged to heave the pieces up by the capstan. From the shore I could see that the ice was forming again in the water, which the gale had cleared during the preceding days. 
The temperature fell from $12^{\circ}$ to $4^{\circ}$. We gained thirty feet in Oct. 20. advance, but found the ice rapidly increasing in thickness. On the Oct. 21. twenty-first our progress was forty feet, and we had entirely lost sight of the clear water. A strong gale, with snow, impeded this Oct.22. work on the following morning; but, in the evening, we gained fourteen feet, which enabled us very nearly to float at low water. Oct. 23. On the next day we gained as many more. During these four days the weather had varied much, and the temperature changed with it; but.it was generally higher than it had lately been, and was this night at $21^{\circ}$.

It was necessary again to occupy Sunday, as before; and the Oct. 24. work was harder than usual, since the ice was about sixteen feet thick. It was too heavy, therefore, to lift, even when it was cut, nor could we sink it : so that we were obliged to cut a space for the fragments in the thinner surrounding field, that we might lodge them on it, and thus make room to pass by. What was done, was not, however, finished in time to enable us to heave the ship any further in advance.

This was a fine clear day, but the thermometer fell just below Oct. 25 . zero. Our apparently endless work was resumed; and on the following day the heavy piece in our way was removed, and the Oct. 26. place for its reception was cut, so as to allow us to advance forty feet. On the next we gained fifty, and were at length afloat at low Oct. 27. water. We had seen a good many hares, foxes, and birds, for some days past, during our walks on the shore, but had shot little or nothing.

The weather seemed to have seriously changed this day; the Oct. 28. temperature, from zero, in the morning, went down to minus $10^{\circ}$ at 
Oct. 29. night. The snow on shore was knee deep, and made walking very laborious. We gained but thirteen feet; the ice being very thick, and freezing again as fast as it wascut. On the next we advanced fourteen more, so as to have eleven feetat low water. There was some at night, and the temperature rose to $6^{\circ}$ plus.

Oct. 30. We now cut six feet further; it was not much, and there were two hundred yards remaining before we could obtain deeper water or a better position, being work for a hundred more days, at the same rate. But the ice was daily becoming so much thicker, that we conld not hope to make any impression on it during that time, at all proportional to what we had already affected; and as our place was at least not very unsafe, hemmed in as we were all round by ice, we concluded on putting an end to our labours

Oct. 31. and remaining as we were. We could, therefore, at length make Sunday a day of prayer and rest, nor was that less acceptable than necessary.

The summary of October can be little but the abstract of our labours, since the whole month had been employed in making a worse than tortoise progress, the entire amount of which, after all our toils, was but eight hundred and fifty feet. We had not even, with all this, reached the place that we had intended; we were, however, not very far from it, and were compelled to be as content as we could. I believe that some of us could not help calculating the number of centuries it would require to make a single north-west passage, at this rate; as others speculated on the premiums that might be demanded at Lloyd's on such a voyage; could, indeed, one man have been found to "write it."

If our place was not very unsafe, it was by no means a de- 
sirable one. Yet, comparatively, it was a great gain : since, had we remained in the shallow water, suspended on icebergs, the ship would have been almost uninhabitable, from her motions and change of positoin, and might also have been destroyed. If the gradually-increasing thickness of the ice, added to the necessity of heaving up what could not be sunk in the usual manner, and to the often severe weather, rendered this an unusually laborious month to the people, the toil seemed to call forth the zeal and display the perseverance of every man. No one's health was affected; and on the whole, there had been a not unexpected advantage in this perpetual occupation, since it had diverted their attention from their obvious subject of grievance, and trained them to a new detention, for another winter.

As we were now to commence a fresh residence, for little less than another year, at the best, having already undergone one of thirteen months, it became proper to take an account of our provisions, and to regulate the expenditure and the nature of the diet for the period on which we were entering. These details can have little interest for general readers; but as it is in such things that navigators seek for information, they cannot be omitted: while, for the convenience of the latter, and not to occupy the time of the former, I shall here state them in the briefest manner, as the original report was drawn up. 
Account of Provisions on board of the Victory on the first of October, 1830, together with the Arrangements then made for the Men's Diet.

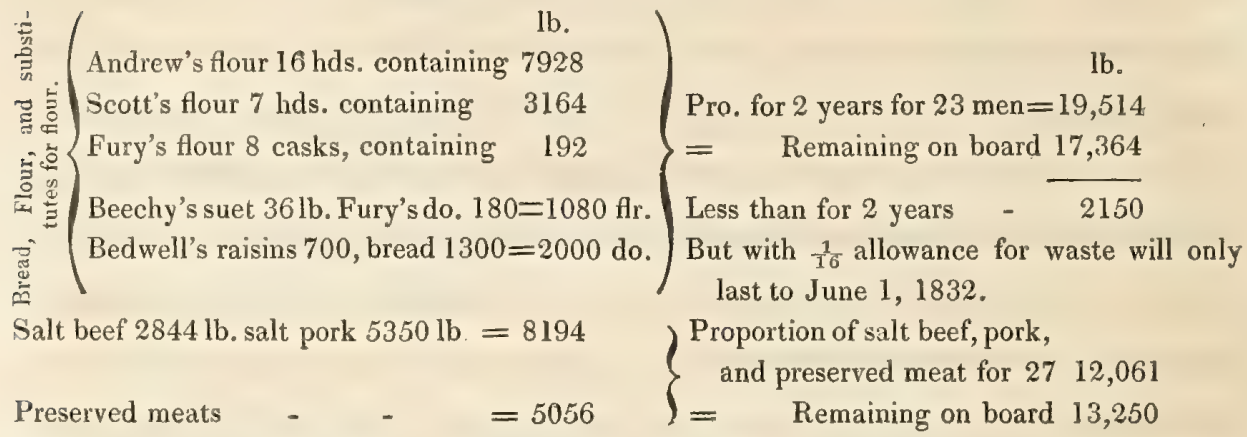

This surplus consists entirely in salt pork; there being, with allowance for bad canisters only $2 \frac{1}{2}$ of pork$$
-
$$$$
\left.\begin{array}{r}
\text { lb. } \\
2233 \\
30
\end{array}\right\}=\text { Remaining on board }
$$

1189 surplus

Sugar 2 hds. and 1 box Bedwell $1184 \mathrm{lb}$.

Fury $2 \frac{3}{4}$ B. $1049 \mathrm{lb}$

Molasses 1 cask - _ _ $\quad-30$ = Remaining on board lb.

2828

2738

Quantity of sugar, short of 2 years, from October 1, 1830.

90 less

Cocoa 6 cases, termed Bedwell, 595; Fury $2 \frac{3}{4}$ barrels, $614=1209 \mathrm{lb}$. Proportion for 2 years $1371 \mathrm{lb}$. Diff, $162 \mathrm{lb}$. less than 2 years' proportion.

But the 162 short for 2 years made good by tea 1 chest, $82 \mathrm{lb}: \frac{1}{6}$ ditto, $14 \mathrm{lb}$, which will complete tea and cocoa for two years.

Peas, split, $7 \frac{1}{2}$ casks, 18 bush. 6 gall. ; round do. 1 bag, 3 bush. 6 gall. $=22$ bush. 4 gall. Proportion for two years, 32 bush. 4 gall. = short of two years, 10 bush.

Spirits, rum, 120 gall.; Rice, $250 \mathrm{lb}$. ; Lemon-juice for one year at the present allowance.

Pickles 4 small casks; sliced lemon 2 cases; Mustard 2 boxes; Barley 2 casks, and 5 jars.

This is exclusive of preserved soups, of which we have 100 gall., which, together with a cask of wine, are reserved for the sick. Finding, therefore, that we should have provisions at the allowance just sufficient to support nature in this climate, until the period in 1832 , when we must have either reached the Fury's store ground where there are still some provisions left, or must abandon the ship to save our lives, we determined to make the following arrangement, as suggested by Mr. Thom; which, by giving the men a soup day and a meat day alternately, during six months, to commence from the first of November, 1830, appeared to vary the diet better than any other scheme which we could have adopted.

1. Monday $-\frac{3}{4}$ pound salt beef and $\frac{3}{4}$ pound of flour.

2. Tuesday $-\frac{1}{2}$ pound preserved meat, and $\frac{1}{4}$ pound ditto with barley in soup.

3. Wednesday -1 pound of pork, with pease soup.

4. Thursday - $\frac{1}{2}$ pound of preserved meat with $\frac{1}{4}$ pound of preserved meat with barley sonp.

5. Friday - pound of salt beef, and 3 pound of flour. 
6. Saturday $-\frac{1}{2}$ pound of preserved meat with $\frac{1}{2}$ pound of ditto made into barley broth.

7. Sunday -1 pound of pork with pease soup.

8. Monday - - pound of preserved meats with vegetable soup. Thus the men would have soup on six days out of every eight-and on the other two, beef and pudding-while a constant succession of diet would be obtained. Thus we trusted that their health and strength would be kept up, so as to enable them to go through the fatigue of travelling in the spring.

The place of the ship, I must now remark, was in a bay extending to the south, after entering the inlet to the eastward, which was termed Sheriff's bay, while the point to the east was called Watch point.

Though the clear water in the offing did not reach so far south as in the preceding year, it was longer open; and notwithstanding the occasional severity of the cold, the mean temperature was higher by five degrees than in the corresponding month of 1829; the highest having been 24, and the lowest 12. It closed also at plus $24^{\circ}$, being $40^{\circ}$ higher than on the final day of last October.

On the whole, having but the surgeon to spare for the chace, the produce in hares had been respectable; but this tract having been the residence of the Esquimaux in the preceding year, the animals in general had been frightened away or exterminated. The place where we were now fixed was very near to the huts which they had then inhabited. 


\section{CHAPTER XXXV.}

TRANSACTIONS IN NOVEMBER-SUMMARY OF THAT MONTH-PROCEEDINGS IN DECEMBER, WITH A SUMMARY.

1830. THIS month began at least favourably; the temperature aver-
Nov. aging $21^{\circ}$ plus, with winds varying both in direction and intensity. To commence our winter preparations, the sails were unbent, and Nov. 2. the topmasts unrigged and taken down. On the following day it blew a hard gale, which afterwards moderated, and the thermometer fell to minus $4^{\circ}$. The raftering for the ship's roof was Nov. 3. commenced, and it was continued on the following day. On the Nov, 4. next it blew, with snow, so hard, that the men were confined to work below. It was from the north; but the winds changed much, and the thermometer also varied between zero and plus $24^{\circ}$.

Nov. 5. This day the roof was covered with sails: the valleys and ravines on the shore were filled with snow. The condensing tanks were Nov. 6. replaced in their old position. On Saturday our covering was completed, the deck cleared, and many matters put to rights. There was snow on both days, and the temperature did not fall Nov. 7. below $22^{\circ}$ plus. Sunday was a day of rest: and the regularity of our church service was re-established.

Nov. 8. It snowed so hard in the forenoon, that the men could not work Nov. 9. outside: but there was plenty of work in the hold. On the ninth 
they were employed in breaking up the snow round the ship, and on the following, in banking it up, as they had done last year. Nov. 10. The weather on those two days varied much, and the range of the thermometer was from plus $10^{\circ}$ to minus $16^{\circ}$; but, on the eleventh, Nov. 11 . there came on a very severe snow-storm, which lasted sixteen hours; the temperature varying between minus $2^{\circ}$ and minus $16^{\circ}$.

No work could have been done outside yesterday, but it being Nov. 12 . fair and moderate to-day, the embankment went on. It was not less fine on the next, but the thermometer fell to minus $20^{\circ}$, being Nov, 13 . the lowest we had yet experienced. On the same day in last November, it was plus $26^{\circ}$; making the great difference of 46 degrees.

It was a clear and calm Sunday, but cold enough, as the Nov. 14. thermometer fell to minus $29^{\circ}$. A bright aurora borealis was the only noticeable event. They had been rare or absent for a long time. A fire-hole was cut in the ice on Monday, and the em- Nov. 15. bankment went on. An overcast sky on the next day caused the Nov. 16. thermometer to rise five or six degrees, but there was otherwise no change, either in the weather or our proceedings.

Things were only varied this day by a little snow, and by our Nov. 17. men being employed in preparations for the observatory, which they were occupied in constructing during the following day and Nov. 18. the next, when it became cold enough to depress the thermometer Nov. 19. to minus $30^{\circ}$. On the twentieth the labour of observation re- Nov. 20. commenced, and some transits were noted. If the journal of a Nov. 21. week is thus meagre, there is nothing new to be remarked respecting Sunday.

The chief variety of this day was the taking of a black fox in the Nov. 22. 
trap; being the first that we had seen this season. It was young and starved; and immediately devoured what was offered; we gave it the place which had been rendered vacant by the death of Nov. 23. a former white one. A pillar for the thermometer was erected on Nov. 24. the following day. The ordinary works went on as usual; the weather gradually becoming colder, though clear; and thus several transits were obtained.

Nov. 25. The thermometer was at $39^{\circ}$ minus, and the mercury froze for the first time. It has been thought that mercury expanded on cooling, like many other metals, and would therefore break the bulb of a thermometer. This does not happen; and therefore it contracts instead of expanding, like lead, tin, and many more. The sun did not rise above the southern hills to-day; and was therefore not seen from the ship, though visible from the higher grounds on shore; it was the first warning of a very long night to come.

Nov. 26. The two last days of this week were without interest or variety. Nov. 27. The weather was alternately gloomy and clear, now and then threatening snow, and the thermometer rose to minus $16^{\circ}$. On

Nov. 28. Sunday it was $\mathbf{1 1}$, and the history of the rest of that day is as usual. On the preceding, the work of embarking, and other matters, had been going on.

Nov. 29. The morning being mild and fine, I walked to the place where the ship had wintered during the last season. I found that our old harbour was much more hampered with heavy ice than it had then been: as was the case equally, with the bay. I certainly thought our present one preferable, independently of the fact of its being so much further to the north, which was our intended direc- 
tion. It, indeed, seems trifling to talk of two or three miles as a great space gained; but when it is recollected that we were a month navigating scarcely three hundred yards, and that the lucky chance of being present when and where the ice opens, be that but for an hour or two, may turn the balance between a free escape and a winter's imprisonment in this " thick-ribbed ice," even two miles were a subject of congratulation.

I now thought it advisable to set up some direction posts for the natives, as it was probable they would come here before long to seek for the ship. These marks simply pointed to her present place, and that was sufficient. We might even have concluded that they would seek for us till they found us, since their interest in the matter was greater than ours, as far as opinions went, at least; though ours was not small, when we expected to obtain fresh provisions, of some kind, from them. I saw neither animal, nor trace of one, in this walk.

Yesterday and this day the men lodged the powder in a maga- Nov. 30. zine, which they had constructed on shore. It was a fine day, and we went to the mountains to look for the sun, but a fog-bank obscured the meridian horizon. A flag-staff was erected on the hill, to aid the natives in finding the ship. The temperature was from $11^{\circ}$ to $18^{\circ}$ minus. It was the end of another month, but its summary is not such as to present any variety or interest.

In point of temperature, it had promised favourably as far as the tenth; but, after that, the weather became very severe, though recovering a little towards the end. The mean was $4 \frac{3}{4}$ less than in the last corresponding month. The mercury froze also on the twenty-fifth; and, though some bad mercury had frozen with us 
on the seventeenth of December, when the temperature was but $37^{\circ}$ minus, it was not till the fourteenth of January that it reached $39^{\circ}$, so as to freeze that which was pure. The period of the real freezing of mercury, between the two seasons, differed therefore by nearly two months.

Having reserved the meteorological tables to an appendix, I have not hitherto introduced any such record into the journal of our transactions; but as many readers will never consult those, I here add a specimen of the present comparison, which will at least show the manner of this registry.

Abstract of the Register of the Thermometer, taken hourly by the Officer of the Watch, and compared with 1829, on the Ice.

\begin{tabular}{|c|c|c|c|}
\hline $1830\left\{\begin{array}{l}\text { To Noon }-10^{\circ} .5694 \\
\text { ToMidnight }-10^{\circ} .9716\end{array}\right\}-10^{\circ} .774305$ & $\begin{array}{l}\text { Mean of Max. } \\
6^{\circ} .400\end{array}$ & $\begin{array}{c}\text { Mean of Min. } \\
15^{\circ} .333\end{array}$ & $\begin{array}{c}\text { Mean of Max. \& Min. } \\
10^{\circ} .866\end{array}$ \\
\hline $1829\left\{\begin{array}{l}\text { To Noon }-5^{\circ} .9736 \\
\text { To Midnight }-6^{\circ} .1277\end{array}\right\}-6^{\circ} .050690$ & $1^{\circ} .383$ & $11^{\circ} .133$ & $6^{\circ} .2583$ \\
\hline $\begin{array}{l}\text { Diff. of Temp. } \\
\text { 1829-30. }\}-4^{\circ} .723,615 \quad 4^{\circ} .723,615 \\
\text { Being lower in } 1830 \text { than } 1829 \text {, by } 4 \text { degree }\end{array}$ & $\begin{array}{l}5^{\circ} .016 \\
\text { and } 7, \& \mathrm{c} .\end{array}$ & $4^{\circ} .200$ & $4^{\circ} .6083$ \\
\hline$\left\{\begin{array}{l}\text { Barometer. } \\
\text { at } 9 \text { А.м. } 30.00753 \\
\text { at.м. } 30.03663\end{array}\right\} \quad 1830$ mean 30.02283 at & $\begin{array}{l}\text { Temperature of the } \\
9 \text { A.M. } 39.08 \\
5 \text { P.M. } 41.80\end{array}$ & $\{1830$ & $\begin{array}{l}\text { Chronometer Room. } \\
\text { mean } 40.425\end{array}$ \\
\hline
\end{tabular}

We had no occasion to alter our opinion of our harbour, as to good or evil. Our vessel was out of the stream of the drift ice, whenever it should move, and that was a most important consideration.

The whole month had been occupied in housing the ship, building the embankments, and levelling the hummocks of ice near us; and having now had more practice, we had done our 
work better than in the preceding year. The lower deck had been rendered lighter and more comfortable, by a coat of white paint.

The observatory had been erected on a rock as near to the ship as possible, and its construction had been much improved, by snow walls, and a snow passage with double doors. The transit instrument had given a few observations. Our sporting had proved as little successful as possible, being limited to the entrapped fox.

The regularity of the school had been grievously interrupted by our labours; but the most backward were kept to their lessons : and I had reason to believe that the perfect health of the men was not a little owing to the incessant exercise which kept both the mind and body fully occupied.

It was a mild commencement of December to the feelings; but Dec. 1. the thermometer ranged between minus $12^{\circ}$ and $22^{\circ}$. The ice on the lake was two feet and a half thick. We pursued in vain two willow partridges; but the time for sporting was now very much contracted, even had there been game, since it became dark at two o'clock. But this was the smallest evil arising from these short days, which so utterly impede travelling in the depth of winter; though the state of things is little better in summer, when the melting of the snow and the state of the ice render it equally impracticable for the far greater part of that season. The whole of life is here curtailed: sea and land, summer and winter, it is difficult to say which is worst; and I believe a sound philosopher would come to the conclusion that it is the Esquimaux alone who here know the true secret of happiness and the rational art of living; while, as he is not likely to grant this great and long sought discovery to their reasoning powers, he will be obliged to admit that 
nature is not always the stepmother which she has been termed. And if to eat and to sleep, to sleep and to eat again, be a mode of happiness which has been disputed in other lands, however it be practically followed, no one will contest its value here, or will doubt that it is truly the ro roxon, the sum and consummation of human happiness. The Esquimaux eats but to sleep, and sleeps but to eat again as soon as he can: what better can he do? The adaptation is perfect, his happiness is absolute. Had we been better educated, we should have done the same; but we were here out of our element, as much in the philosophy of life as in the geography of it.

Dec.2. The weather was not disagreeable, though, in the day, the thermometer was but minus $12^{\circ}$, rising in the evening to $2^{\circ}$. It was arranged that two watches of the men should walk on shore in the forenoon, for exercise, and two in the afternoon. I need not say that this has been held one of the preventatives of scurvy. We took a white fox in the trap. It blew hard in the night, and there was a Dec. 3. gale on the following morning; but it soon abated, though there was snow till the evening. The tide was observed to be as irregular as it had formerly been in our other harbour.

Dec. 4. The gale was over, but the snow continued to fall till night. It was then fine, and the thermometer about zero. This last snow was about a foot deep, and we were obliged to clear it away alongside. A foot of snow is not a great depth of water, at least till it is frozen into a mass. Nor is it an easy matter to measure the depth to which a fall of snow is equivalent; such is the drifting, and, still more, the difficulty of securing any thing like an average within the compass of any gauge that has yet been devised. Had it been otherwise, we should have been as pleased as we were desirous, after a whole year's residence, to know the actual fall of water in 
this country and climate. As far as I have read, no such estimates have been attempted respecting these northern regions and lands of snow.

But if, under a vague estimate from mere recollections or observations of weather, we had considered this a country in which much water fell in the course of the year, we might not be very wrong. The past registry, which is but the usual noting of weather, gives many days of snow or rain. Future observers, if future observers should ever have such opportunities, must try to determine what the fact is; but whatever that may prove, the rain that falls here is of little use, since it has no duty to perform for vegetation; and if the snow protects any thing, it is a soil without plants to derive benefit, or rocks which are alike indifferent to rain or drought, heat, or cold.

Our tanks had now once more come into full use, since the cleaning them on Saturday night produced three bushels and a half of ice. That was a proof that we were warm enough between decks; and the comfort was disputed by no one. I formerly described the nature of this contrivance, when I suggested also the principle on which it acted; comparing it to the condenser of the usual steam engine. But I ought then to have said what I may do now, namely, that by this very simple expedient, all necessity for the operose means formerly adopted for preserving the comfort of the men between decks has been superseded. It is well remembered that none of the expensive contrivances in cork linings, or whatever else, prevented that condensation of steam from the human and other evaporation within the ship, which caused a perpetual dripping of water, and rendered the situation of the people 
most uncomfortable, particularly in their sleeping places. I do not wish to pass any censure on those who suggested those contrivances, and am the less entitled to do this, when my own ship in the voyage of 1818 was not free from the evil in question, and when the present scheme had not occurred to me. But having now been fully tried, and with the most perfect success, I may safely recommend it among those fittings which should be applied to every ship undertaking a voyage in these northern regions.

Dec.5. The week was ended in the usual manner; and the day of rest and religion was kept in the way from which we made it a rule never to deviate when it could be avoided.

Dec.6. The sixth produced no change worth recording: too many of these records, indeed, are but registries of labour, of which the identity is tiresome, of weather which has not very often much interest, and of temperature which would have as little, were it not interesting to know the state and trace the changes of such a climate as this, which does not seem exceeded in badness by any other yet recorded, whatever rivals it may have. Man is a strange animal when he can live in so many different countries, in climates so opposed, and on food so diverse. He would be a still stranger one, if, having ever known another country (I need not say a better, when there cannot be a worse), he had made a voluntary choice of the America of Prince Regent's inlet. But he has contrived to wander hither, whencever he might have come; if he ever knew bananas, he has learned to prefer fish oil, has made bones a substitute for bamboos, and blubber for pineapples; learning also that a seal-skin is a more fitting dress than a cotton wrapper, and that snow may be substituted for wood and stone: while, not 
forgetting to bring with him fire, and what is better, as much cunning as he can convert to use, he has made himself at home, and is so at home, that he would envy no man of any country, nor any country of any man, even though he knew what they were, and what they possessed. Is not the animal as vain of himself and his superiority as any other man under any other life? If he is not much vainer, then it is not true that the vanity of all rude and ignorant people is commensurate with their ignorance and rudeness. But the arrangement is admirable; and philosophers are right:-in the generals, however; not so right in the application. Man, in the mass, is equally happy in all conditions of life, all regions of the earth, and all states of cultivation. It is a very different thing to maintain that, individually, all are equally happy, or that, to all, there are equivalent compensations of happiness and suffering.

If there was little novelty to-day, there was at least the first Dec. 7. glorious evening that we had seen; the joint morning, noon, and evening of a sun which never rose and never set: which, promising both, performed neither, and of which the highest noon was but a twilight, creeping, not along the horizon, but over the short space which told us that it would see us no more for a long time. Yet it was a glorious golden meridian of twilight and sunset; while the crimson clouds were brilliant with tints rarely seen in the more favoured climate of our own country.

The erection of an observatory for the magnet had occupied Dec. 8. our people yesterday, and found them work this day. There was nothing worthy of peculiar note on the two following. The weaDec. 9. ther was, on the whole, agreeable, though varying; but it ought Dec. 10. to be called fine. The lower ranges of the thermometer varied 
Dec. 11. between $10^{\circ}$ and $32^{\circ}$ minus, and this was the termination of another week of durance. They who were fond of idle puns, thought the term Sheriff's harbour not misapplied.

Dec. 12. - The men who went on shore for exercise, after church, saw the Dec. 13. tracks of a glutton. Monday, like Sunday, was calm and clear, Dec. 14. and there was an aurora of no great note. On Tuesday there was little change in the now unavoidable sameness of our occupations and our amusements. On this and many other days we tracked animals and did not see them; carried guns and did not fire; watched for the invisible sun that we might at least know it was still in existence; and were not sorry when (I cannot say the day was done, where all was night), but when we might at least end another of our own days by going to bed.

Dec.15. A strong breeze, with snow, formed a sort of variety just now ; but it imprisoned the men, and that was an evil. No one is much the better for thinking : those who had nothing very cheering to think of, were always the worse. They who commanded had however no great right to believe themselves of a more hopeful and buoyant character, than those whose business it was to obey; whatever the fact might have been as to either party. They had an object in view which the others could scarcely keep in sight: and ambition, or vanity, or whatever else, looked forward to a gratification which, under any success, could be little to those who had only to follow as they were directed: participating the labour, yet, if not the fame, so also, be it remarked, free of all anxiety, and subject to no responsibility.

Dec. 16. There was little to note this day but a slender aurora. The weather and the temperature scarcely differed so much from what they had generally been for some time, as to require notice for any 
other object than that of a register. The present work of the men Dec.17. was to cover the boats with snow, for the purpose of protecting them from the weather. A strong gale interrupted this, but did not last beyond the day. Yet it began again on the following, though soon Dec. 18. moderating, and giving us the remainder of Saturday for our several works, now not requiring notice. On shore, the effect was to harden the snow so that it could generally bear our weight, and to bare the rocks in such a manner as to alter the appearance of the land. Sunday was passed as it ought to be: as we had always Dec. 19. passed it whenever it was in our power.

If this day was without mark, it was one in which we compared Dec. 20. the tides that we had observed. Nothing but a tide-table, which I need not give, would make their singular irregularity sufficiently conspicuous. I noticed the same facts last year, and they were even more remarkable in the present. Every thing was out of rule: whatever the moon might effect, the counteracting causes, in winds, currents, ice, and perhaps more, set all calculations at defiance. It was a high or a low tide whenever it chose to be; and that was nearly all we knew of the matter.

In the calendar, this was the shortest day; that was tolerably Dec. 21. indifferent to us, who had no day at all; but as the sun attained its greatest elongations at midnight, this and the following were, to Dec. 22. us, of equal lengths. The temperature was as low as $27^{\circ}$ minus, and rose to $21^{\circ}$ on the succeeding, which was stormy. To confirm what I have just said of the tides, that of to-day rose, in the forenoon, but one inch.

The gale blew hard till night, but ceased so as to leave us a fine Dec.23. morning. It was even calm and pleasant; and the gale, by still Dec.24. 
further baring the rocks and filling the ravines with snow which had afterwards hardened, rendered our walking more easy than ever, and almost agreeable. There was nothing, however, on shore, to amuse us: for us, as for the men, the land afforded exercise, and that was all. It is likely that they at least thought this a task and a labour rather than a pleasure; but it was necessary, and more for them than us. The night temperature was minus $18^{\circ}$.

Dec. 25. A violent storm of snow interfered with the parade of Christmas Dec. 26. day, but all else was done according to custom. Sunday, immediately Dec.27. following, gave a second day of repose ; and on Monday the usual Dec. 28. works were resumed. The weather improved, and during these three days the average cold at night was minus $20^{\circ}$, rising to $9^{n}$ Dec.29. with snow, and then falling again to $17^{\circ}$ on the two subsequent ones. There was little to mark these days but the capture of a fox.

Dec. 30. The ice on the lake was measured, and found to exceed three feet in thickness; and, the mercury froze once more. The frost in the tanks amounted to four bushels; being what we had found the largest quantity last winter, after we had put our arrangements in good order, and fixed on a reasonable temperature at which to regulate the dwelling place of the men between decks. The month and the year ended together with very cold weather. It was the highest tide that we had yet seen, being nearly eight feet and a half.

In summing up a month which presents neither variety nor interest, I may first make a few remarks respecting the transactions of the year. It is the period which contains the chief of our discoveries; and although these do not occupy a large geographical space, they are of great importance, since they have so narrowed 
the limits of investigation as to render it possible to finish what remains to be done, in a single season, and with much less of hazard and expense than would otherwise have been necessary.

There is now some reason to believe that we might have extricated our ship in the present winter, had we proceeded in a different manner; had we begun sooner, and attempted to creep along the shore. In this matter, however, I thought it prudent to yield to the superior experience of Commander Ross in this kind of navigation; and the more especially because he, in particular, was acquainted with this great inlet. He considered such a proceeding not less perilous than laborious, and entertained no doubt that the ice in the channel would clear away in time sufficient to enable us to make as great a progress, or a greater one, by the same date, and without needless risk. That his anticipations were wrong, the event has shown; whether we might really have succeeded by adopting the other plan, will never be known.

The ship appeared to have suffered some damage by being so long and so often aground, since she was again leaky. But our winter accommodations were perfect, and the men seemed as healthy as possible; having apparently profited by our new system of diet. If the regular exercise contributed to this, that was conducive to another good end; since the men would thus be well trained for travelling by the time the season should arrive.

Though the weather had been often very cold, the temperature was very changeable; nor was the mean so low as that in the last December, by four degrees. That mean is minus 20.24; the highest temperature was plus 6 , and the lowest, being on the last day of the month, was $47^{\circ}$ minus. 


\section{ABSTRACT OF THE METEOROLOGICAL JOURNAL.}

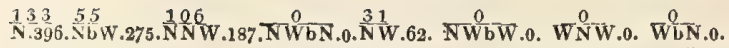

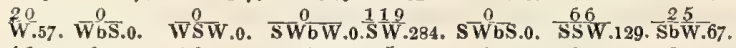

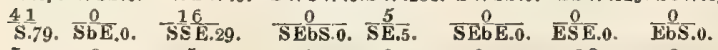

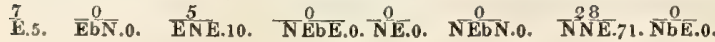

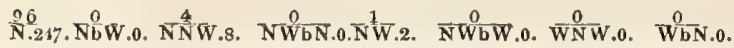

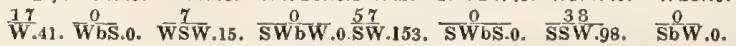

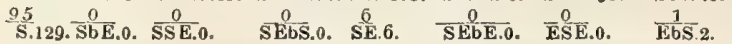

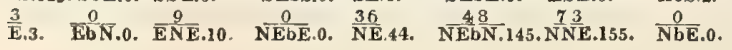

$\left.\begin{array}{l}\text { NWy. }=325 \\ \text { SWy. }=230 \\ \text { SEy. }=62 \\ \text { NEy. }=40\end{array}\right\} \begin{gathered}\text { Total. } \\ 657 \text { hours. } \\ 87 \text { do. calm. } \\ 744=31 \text { days. }\end{gathered}$

$\mathrm{NWy}=101]$ $\mathrm{SWy} \cdot=119$ SEy. $=102$ NEy. $\Rightarrow 169$ $\underline{-169}$
Total. 491 hours. 12 do. wind vble 169 do. calm. $\overline{672}=28$ days.

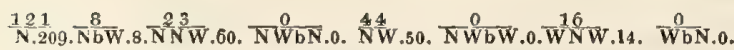

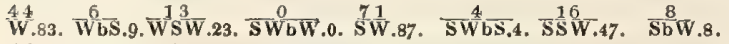

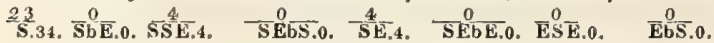

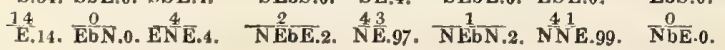

JANUARY, 1830.

Highest, lowest, \& $\}-5-45-27.25$ Total force of the Wind . . 1656 Mean force of the Wind . $\overline{53.42}$

FEBRUARY, 1830.

Highest, lowest, \& $\}+14-47-29.9$ Total force of the Wind . . 1058

Mean force of the Wind . . 37.8

MARCH, 1830.

Highest, lowest, \& $\}+20-12-20.93$ mean temperature $\}+20-12-20.93$

Total force of the Wind . . $\frac{862}{\text { Mean force of the Wind }}$

APRIL, 1830.

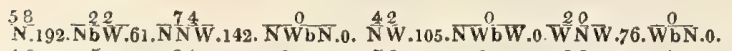

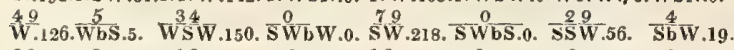
S.0 13.23. EbN.0. ENE.0. NEbE.0. NE.188. NEbN.0, $\frac{1}{\mathrm{~N}} \frac{1}{\mathrm{~N}} \mathrm{E} .308 . \mathrm{N}_{\mathrm{N}}^{0} \mathrm{E} .0$

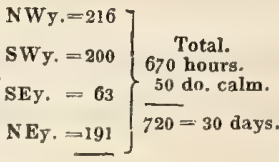

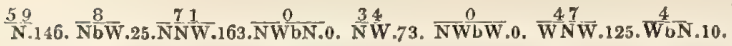

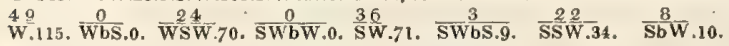

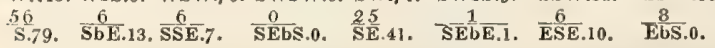

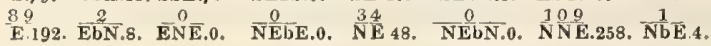

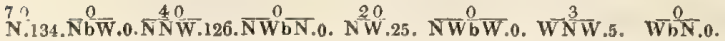

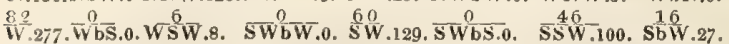

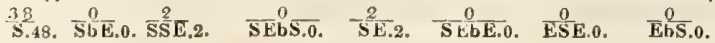

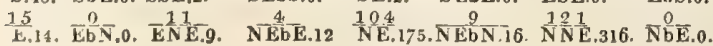

NWy, $\rightarrow 223$ swy. $\Rightarrow 142$ SEy. $\Rightarrow 100$ NEy. $=235$ Total. 00 hours. $\overline{744}=31$ days
MAY, 1830.

Highest, lowest, \& $\}+37-1+15.27$ Total force of the Wind . . 1512

Mean force of the Wind . $\overline{48.78}$

JUNE, 1830.

SWy, $=210 \quad$ Total. SEY. $\left\{\begin{array}{r}649 \text { hours. } \\ 71 \text { do. calm. }\end{array}\right.$ $\overrightarrow{720}=30$ days. $\left.\begin{array}{c}\text { Highest, lowest, \& } \\ \text { mean temperature }\end{array}\right\}+62+26+36.76$ Total force of the Wind : . 1425 Mean force of the Wind $\quad, 4 \overline{47.6}$ 


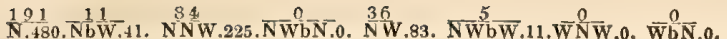
W.

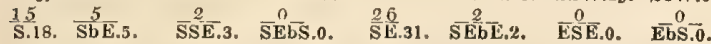

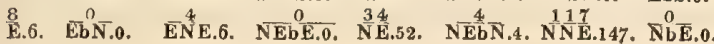

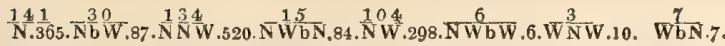

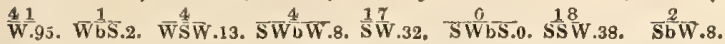

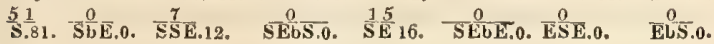

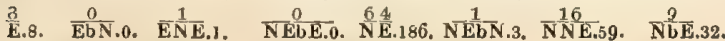

$\left.\begin{array}{l}\text { NWy. }=440 \\ \text { SWy. }=87 \\ \text { SEy. }=73 \\ \text { NEy. }=99\end{array}\right\} \begin{aligned} & \text { Total. } \\ & 699 \text { hours. } \\ & 16 \text { do. wind vble } \\ & 29 \text { do. calm. }\end{aligned}$

$\left.\begin{array}{l}\text { NWy. }=327 \\ \text { SWy. }=93 \\ \text { SEy. }=50 \\ \text { NEy, }=167\end{array}\right\} \begin{gathered}\text { Total. } \\ 637 \text { bours. } \\ 5 \text { do. wind vble } \\ 102 \text { do. calm. } \\ 744=31 \text { dass. }\end{gathered}$

\author{
JULY, 1830. \\ Highest, lowest, \& $+70+32+44.57$ \\ Mean force of the Wind . . 42.03
}

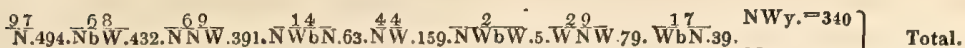

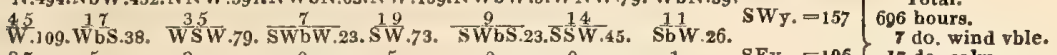

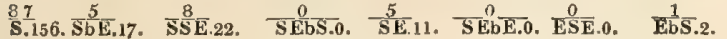

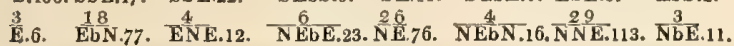
SEy. $=106\} 17$ do, calm.

SEPTEMBER, 1830 .

Highest, lowest, and $\}+43+5+27.42$ Total force of the Wind . . 2633 Total force of the Wind.$\frac{2633}{87.76}$

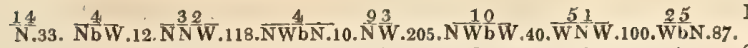

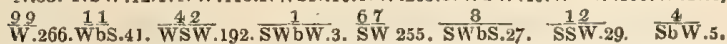

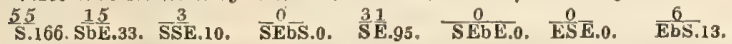

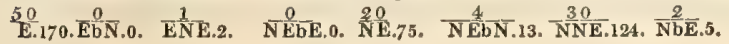

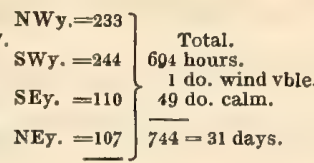

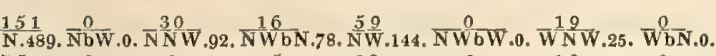

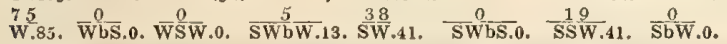

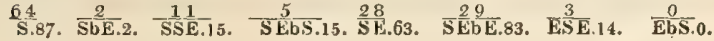

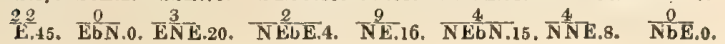

Highest, lowest, \& $\}+58+33+40.87$ Total force of the Wind . . 1996 Mean force of the Wind . . 64.4 $\begin{gathered}\text { Highest, lowest, \& } \\ \text { mean temperature }\end{gathered}+24-12+10.95$ Total force of the Wind . . 2135 Mean force of the Wind . . 68.8

NOVEMBER, 1830 .

Highest, lowest, \& $\}+24-41-11.45$ mean temperature Wind . . 1409
Total force of the Wind Mean force of the Wind . $\frac{46.96}{4}$

DECEMBER, 1830.

Highest, lowest, \& $\}+6-17-20.24$ Total force of the Wind . . 1311 Mean force of the Wind . $\overline{58.42}$ 


\section{CHAPTER XXXVI.}

TRANSACTIONS ON BOARD THE SHIP IN JANUARY, 1831-SUMMARY OF THAT MONTH. FEBRUARY : WITH ITS SUMMARY. MARCH : ITS SUMMARY.

1831. THOUGH the temperature remained at minus $47^{\circ}$, it was calm, and the cold was not severe to the feelings. The colours were hoisted, and the ship dressed out; new year's day being otherwise kept in the usual manner. There was so clear a sky that no stars could be seen during four hours; such was the power of the meridian Jan. 2. twilight. On Sunday, the thermometer fell to minus $52^{\circ}$, but even then, the men who walked on shore after divine service did not complain.

Jan. 3, On the third, fourth, and fifth, it ranged between $46^{\circ}$ and $50^{\circ}$, $4, \& 5$. the weather continuing clear. An overcast sky raised it to $34^{\circ}$ on Jan. 6. the sixth, but it fell again, when that cleared away, to $43^{\circ}$, on the Jan. 7. seventh. The employments of the men were uniform; and the only variety was the capture of a fox, on each of the two last days.

Jan. 8. Saturday ended a dull week, without any change in the weather or the temperature.

Jan. 9. Another fox was found in the trap on Sunday, which, otherwise, passed as usual. The only remarkable circumstance was the vacillation of the thermometer, without any cause that could be 
conjectured, as the weather was uniformly calm and clear. At six in the evening, it rose from minus $45^{\circ}$ to $36^{\circ}$, where it remained an hour, falling again to $45^{\circ}$, so that the frozen mercury thawed, and then froze again. 'There was a faint aurora, both in the morning and the evening.

A gloomy sky raised it next day to $23^{\circ}$ for a short time. The ice on the lake, being examined, was found to be three feet and a half thick. On the thirteenth, the sky presented a beautiful display of colours, as it had formerly done at the same season; and the land was much elevated by refraction. On the fourteenth, there was a gale with snow, raising the thermometer to $10^{\circ}$; and on the following, it reached minus $4^{\circ}$, making a considerable range within this month. The sun was not yet visible.

There was a littlesnow on Sunday, and the temperature reached minus $2^{\circ}$. There was no material change on Monday; but, on Tuesday, it blew a gale with much drift snow. On Wednesday, Jan. 18. the sun was seen for the first time; being one day sooner than we Jan. 19. had seen it last year. It was a welcome sight, even now ; though it was long yet before we should derive much advantage from it, in respect to heat at least.

The two first of the following days were without remark; the Saturday was distinguished by a large and beautiful halo round Jan. 20, $21, \& 22$ the moon, with four paraselenæ, occurring at eight in the evening, when her altitude was 32 degrees. The latter occupied a horizontal position; and there was also a bright arch all round the heavens, parallel to the horizon, and of the same altitude as the moon. The radius of the halo was 25 degrees; and where these two crossed, the prismatic colours were displayed, while there was occasionally an additional halo of five degrees, equally coloured. The whole 
appearance lasted an hour; when the weather became hazy, with snow.

Jan. 23, There was a fresh breeze, with more snow, on Sunday. Monday was clear, with the thermometer at minus $11^{\circ}$; and, rising to $7^{\circ}$ on Jan. 26. the next, that also proved a very mild day. On the twenty-sixth, the sun reached the ship for the first time, and shone bright. The land was very clear, and much elevated by refraction. Commander Ross was employed in measuring a base.

Jan. 27. A remarkable halo occurred to-day, about the sun, being, of course, somewhat more than a semicircle : the lower ends being red passing to yellow, and becoming white in the upper part of the Jan. 28. sky. There was little change of weather or occupation; but some willow partridges were shot, and many ravens, hares, and grouse Jan. 29. were seen, while on Saturday, a fox was taken.

Jan. 30. The temperature of Sunday was $19^{\circ}$ minus. After church, the men walked six miles to the islands where the natives had been resident last year, but found nothing except the deserted huts and traps. Jan. 31. The last day of the month was marked by a strong gale with drift snow: the thermometer rising with the wind, as high as minus $2^{\circ}$.

In spite of occasionally severe days, the mean of this month was not so low as that of last January. It was about minus $23^{\circ}$, whereas the former was $26^{\circ}$. The highest elevation was 2.5 plus, and the lowest $56^{\circ}$ minus; making a total range, with a necessary correction for the thermometer when at its lowest point, of $60^{\circ}$ in the course of twelve days.

During the lower temperatures it was calm, and beautifully clear; but we could make no observations with the instruments on those days, since it was as impossible to tonch the metal as if it had been red hot. After the 25th, we procured some good ones. 
There were many gales, as the journal has shown; and, on all those days, the barometer fell and the temperature rose. But it was an invariable remark, that, when the gale was from the northward, the former fell less, and the thermometer rose more, than when it was from any other quarter; as this was also most striking when the wind was from the southward. The auroræ were very inconspicuous; but the haloes were of a very striking character.

The total of our sport in this month producad seven foxes and four birds. The lake was at last frozen through where we tried it, and the ice nearly four feet thick: the increase having been ten inches since December.

Thongh the sun was first seen on the nineteenth, some following days of thick weather prevented us from obtaining a second sight of it till it was three degrees high. Daybreak was now at eight o'clock; and thus we had abundant time for work and exercise. We had been disappointed in not receiving the expected visit from the natives, but attributed their absence to the badness of the weather.

The month began with a strong northerly gale, and the thermoFeb. 1. meter rose till six in the evening, when it reached plus $6^{\circ}$; being the highest temperature ever observed in these regions so early in the year. It rose to plus $11^{\circ}$ on the following day, which was calm and mild at the beginning, but ended in another equally strong gale from the same quarter. Thus it continued on the third, till Feb. 2. near noon; the thermometer falling to zero, but rising a little in the evening, to recover the same degree at midnight.

It was an overcast day with snow: the wind came round to the Feb.4. south; and, in confirmation of my former remarks, the temperature 
fell to minus $15^{\circ}$. The men had employment in building an observatory for noting refractions, and in repairing the others; one of which had been shaken from the foundation, in consequence of its connexion with the ice near us that had broken during one of the Feb. 5. past gales. Saturday ended with the thermometer at minus $\mathbf{2 4}^{\circ}$. Feb. 6. On Sunday it went down to $32^{\circ}$. Many willow partridges were seen by the men during their walk after divine service.

Feb. $7 \& 8$. The cold weather continued through the two following days, in which there was nothing remarkable but a slight aurora. Nor was Feb. 9. there much change on the next; the only notable occurrence was the taking of an unfortunate fox, which had lost its tongue through the frost, in biting at the iron bars of the trap. On the Feb. 10. tenth, the temperature reached $42^{\circ}$ minus, and it was very cold. Another fox was taken. I attempted, a second time, to make observations on the diumal variation, but the needle would not traverse.

Fel. 11. There being a stiff breeze, with a thermometer at $39^{\circ}$ minus, the men found it impossible to walk on shore; and it was the same on

Feb. 12. Saturday. The tanks having produced five bushels of ice this week, Feb. 13. confirmed the remarks already made. Sunday passed as usual, and Feb. 14. the weather was unchanged. In the evening of Monday, the temperature was down at $45^{\circ}$, and another fox was taken: as was a Feb. 15. second on the following day. In compensation, one of our own Feb. 16. escaped on the next, carrying off with it the chain. The thermometer went down one degree more.

The sea ice was cut through, and found to measure about four feet and a half. 'Two more foxes were taken, of which one had lost its tongue in the same manner as a former. The escaped one was 
forgetful enough to enter one of the traps, and was retaken on Saturday. During these days, the temperature vacillated a little Feb. 19. about the low standard it had held for some time; it was $45^{\circ}$ when midnight closed the week.

Foxes seemed now abundant, Sunday morning having found Feb. 20. another in the trap. A very few grouse and hares had been seen latterly. On Monday, there was again a fox taken. The weather Feb. 21. was much the same as in the preceding week; but, with a cloudy sky, it rose to $31^{\circ}$ minus on Tuesday, when again the trap produced a fox. Had our former neighbours been at their old post, not much of this game would have fallen to our share.

A fall of snow raised the thermometer to 22 degrees; and this weather continued till the following day, when it became clear, as was the next, on which two grouse and a hare were killed. After some variable winds, and many changes from cloudy to clear weather, with correspondent variations of temperature, Saturday night Feb. 26. closed at minus $40^{\circ}$.

On this day, the sun had just power enough to raise the temperaFeb. 27. ture from minus $43^{\circ}$ to $38^{\circ}$; and, after that, it subsided to $42^{\circ}$. Some hares were seen during the Sunday's walk : and more on the Monday; but nothing was shot. It was little more than a schoolboy's experiment, to fire a ball of frozen mercury through an inch plank : but this had, possibly, not been done before. The month closed with the thermometer at $43^{\circ}$ minus.

The summary of this month is more barren than usual. It had been a very cold one, particularly towards the end. The mean proved to have been minus $34^{\circ}$. Yet there was an unusually high temperature in the early part, since it once reached plus $9^{\circ}$; affect- 
ing materially the total mean, but not that of the latter half, which averaged $42^{\circ}$. The lowest fall was about $49^{\circ}$.

The observations experienced much obstruction from the cold, as I have remarked above; but a few were registered. The men retained their health, and, as I believe, their contentedness.

Not having yet seen the Esquimaux, we now gave up the hope of their joining us till May, though not well able to account for their absence.

Our sport, if it be sport to snare foxes, had been unusually successful. Nor must we be accused of wantonness in this; since we had a family of dogs to maintain. It was the stud that we were bound to keep in as good condition as we could afford, for services which were now not far distant.

March 1. The weather continued the same. There was a bright aurora, which agitated the magnetic needle in the manner that has been often observed. Such light as I could collect from it by means of a large reading lens, had no effect on the differential thermometer.

March 2, The three following days scarcely presented any change; but on $3,84$.

March 5. Saturday it was squally for a time, and the thermometer fell to $40^{\circ}$, having begun this month with its lowest at $38^{\circ}$. A fox was taken, and a hare killed.

March 6. Sunday was somewhat warmer; the temperature rising in the day to $28^{\circ}$, for two hours. It was $40^{\circ}$ on Monday night, and a March 7. March $8 \& 9$. hare was killed on that day. The two following days were little noticeable for any thing but a general continuance of the same weather and temperature: except that, on the last of those, there was a bright aurora.

March 10. A fox, coming to the ship, narrowly escaped being taken by the 
dogs. We froze oil of almonds in a shot-mould, at minus $40^{\circ}$, and fired it against a target; which it split, rebounding unbroken. A similar ball of ice had no effect. The two last days of this week March 11. were as uniform in character as the preceding : the Saturday's mid- March 12. night temperature being $35^{\circ}$.

Sunday was unaltered in weather. Monday produced another March 13 fox; and the men commenced moving gravel for making a canal on the ice. It was already seen that the sun could melt snow on some of the rocks. In the afternoon of Tuesday, a change took March 15. place in the weather, and it blew hard, with drift snow: which continued till noon on the following day. On the seventeenth it March 16 was alternately clear and gloomy, but the thermometer held fast about $36^{\circ}$. It was exceedingly cold to the feelings on Friday, at March 18. the same temperature; and, on Saturday, that fell to $44^{\circ}$. The March 19. tanks produced five and a half bushels of ice this week; being the greatest evaporation from between decks that we had experienced since this apparatus was satisfactorily arranged.

The continuance and degree of the cold at this period of the March 20. present month began seriously to attract our attention; and even to the reader, the registry which has now been repeated to weariness will not be uninteresting. The thermometer sank on this day, Sunday, to minus $52^{\circ}$; and the average of the twenty-four hours was but 49. At four on the Monday morning, the sun crossed the equator March 21. at this exceedingly low temperature; an occurrence which had no parallel in the preceding voyages.

There was no change in this respect on the two following days; March 22 though the barometer rose and fell several times. There was a \& 23. difference of a few degrees, for the better, on the next, when the March 24. 
March 25. mean rose to $30^{\circ}$, and the heat in the day to $25^{\circ}$ minus. Friday and March 26. Saturday presented no material changes; and the thermometer on this last night was at $35^{\circ}$.

March 27, Sunday and the following two days were almost equally without $28, \& 29$. note. There was variable weather, gloomy and clear alternately, with occasional showers of snow, and, latterly, a fresh breeze. The lowest temperature of the three days lay from $35^{\circ}$ to $28^{\circ}$, gradually rising.

Narch 30. On the thirtieth, a decided and a very pleasing change took place. The thermometer reached $11^{\circ}$ minus, and the day was so mild to our sensations that the men were congratulating each other on the "fine warm day," even when it had sunk to $20^{\circ}$. There could be no doubt that it did really feel warm; such is the effect of contrast in this case. At forty degrees above this, it would have been a wintry cold seldom known in England, and we all knew what we should have felt there, even with this enormous difMarch 31. ference. It was still warmer on the following, since it rose to $8^{\circ}$ in the day, and did not fall below $17^{\circ}$ in the night. Another month was ended.

The great coldness of this month must already have been remarked. It had much exceeded that of the former corresponding ones in the voyages of the preceding navigators. The mean was $35^{\circ}$ minus, being not less than seventeen degrees lower than the similar means during those, and it was eleven degrees lower than the lowest of them. The highest was $8^{\circ}$ minus, and the lowest $52^{\circ}$.

Much snow having fallen, nearly the entire surface of the land was a mass of ice and snow. On one occasion only, the latter melted for a short time beneath the influence of the sun, on some 
rocks that were exposed to its rays; yet not many became thus exposed, and the effect was of no long duration. In the March of the preceding year, however, during several days, the water was running down in streams.

It was an adverse prospect as our future plans were concerned; and had, at times, some effect in casting a damp on the men, which their tiresome sameness of occupation had no tendency to remedy. Yet they were in perfect health. There had been none on the sick list, and there was no appearance of scurvy.

Altogether, many observations had been made and recorded; the place for which is the appendix, not this journal. In addition to many foxes, twelve white hares had been shot, with some ptarmigans; but of our tamed animals, only two remained alive.

Our disappointment in not seeing the Esquimaux continued daily increasing, as their expected arrival was the longer delayed. They furnished us with occupation and amusement, more required by the men than ourselves. We were also in want of seal's flesh for our dogs, which would have been starved had it not been for our success in taking foxes; for ourselves, too, fresh venison and fish would have been more than acceptable; nor were we so well stocked with skin dresses as not to wish for more. We still looked forward to their visits with hope. 


\section{CHAPTER XXXVII.}

APRIL-AN EXPEDITION UNDERTAKEN-ACCOUNT OF THIS JOURNEY -SUMMARY OF THE MONTH.

1831. April 1.

THE weather improved very slowly; but, on the second, the April 2. night temperature was zero, and the highest in the day, plus $3^{\circ}$. April 3. The dipping needle was found to be out of order. On Sunday there April 4. was a breeze, which became a gale on the following day. The variations in the temperature were unimportant.

April 5. This was the day on which our travelling had commenced last year. The condition of things was now very different, besides which, we could not well manage without the aid of the natives April 6. and the assistance of their dogs. The thermometer fell to minus $17^{\circ}$ on the night of the sixth, thus giving us a temperature $34^{\circ}$ lower than on the corresponding day in the last year.

April 7. A succession of heavy squalls with drift snow blew to-day, but April 8. ceased before the following, which was fine yet cold, with the night April 9. thermometer at $20^{\circ}$. Nor was it at all warmer on the Saturday. Where the sun acted on the snow it was glazed, but there was no How of water, and no apparent clearing. It was colder by two April 10. degrees on Sunday, which passed as usual.

April 11. On Monday it approached zero, at noon, being a great improveinent. We were employed in preparations for a projected journey. 
This favourable change did not, however, last, since it fell to $23^{\circ}$ on the following day. Last year, at the same time, there were many April 12. pools near the ship and along the shore; at present, all was solid ice. On the two next, the temperature gradually improved, and reached near to zero at noon. It came to plus $4^{\circ}$ on Friday; and April 13 $\& 14$. settled, on Saturday, with $2^{\circ}$ as its maximum. Preparations for April 15. travelling continued.

The first snow bunting of the season was seen this morning. On April 17. Monday the preparations for our journey were complete, and we April 18. waited only for weather. A change seemed promised the next day, April 19. as the thermometer rose to plus $8^{\circ}$, and the weather felt warm in spite of a breeze. A walking party was sent away two miles with the sledge, that they might be ready to start very early in the morning, if the weather permitted.

This being the case, the party set off early, and by noon the con- April 20. voying portion returned, leaving Commander Ross and five men to pursue their journey. Another sledge and cooking apparatus were in preparation on board. On the twenty-first the temperature April 21. increased so much as to reach $31^{\circ}$ plus, and we were agreeably surprised by a visit from three of the natives, Neytaknag, Poweytak, and Noyenak.

They came over the western hills with their dogs, and stopped about a quarter of a mile off, holding up their hands to show they were unarmed, and calling out the usual all hail, "Manig tomig :" on which we proceeded to join them. It was the party which had wintered at Awatutyak, consisting of three families; and they were now at their station near the entrance of the inlet leading to that place. They had been met by Commander Ross, from whom 
I received a note, informing me that he had purchased two stores of salmon for two knives. This was welcomenews, and we arranged to fetch this acceptable supply the next morning.

We welcomed them to dinner and to sleep, and received from them the following information. All their friends were well at Neitchillee, except Tiagashu, who had died in the winter. This party had killed many deer and taken much fish, and had been expecting us both at Awatutyak and Neitchillee. One of the men was soon to go to this last place, and would convey the news of our present abode. We regretted the death of our friend Tiagashu, who had been one of the first to inform us of the geography. He was also a peculiarly good character ; and, having a large family, had been at one time so much in want, that we felt it proper to maintain them all for a time. Being poor, from the same cause, he had little to sell, and therefore obtained little from us in barter; but, at the end, he was presented with a file and a knife, thus equalizing him with the others; a bounty well applied, as this family had always been especially kind to us, and had formerly shown their gratitude for very trifling attentions, by bringing us a present of a seal, out of two which they had taken. Whatever he might be as an Esquimaux, he at least died an amiable and an exemplary man. We could not learn the cause of his death; and had to regret that we had not been at hand, since it might have been within the power of our medicines.

April 22. With the track of the former sledge to direct us, I left the ship at four in the morning, with the surgeon, three seamen, and our Esquimanx guests. We reached their station, called Niokhunagriu, at eleven, being the place where we had pitched our tent 
on the 28th of last June. We found there were two packages of fish, weighing, jointly, but 180 pounds; we nevertheless paid the stipulated price. They began immediately to erect us a house, which they finished in forty-five minutes. We were not long in cooking a warm meal, which was very acceptable after a walk of sixteen miles through very rough ice. Though rough, it was, however, good beyond the place where Commander Ross had left his convoy; which it was gratifying to know. The men having forgotten their blankets, we were supplied with skins by our goodnatured friends.

At noon, two of them set off at a great pace, with their sledge and six dogs, to fetch a third depot of fish, which we understood to be at a lake far away. They were to have another knife for it; and it was well worth our while to wait for such a supply. We examined their hut in the mean time, which was large enough for three families, being eighteen feet in diameter; but it was so much decayed as to show that it had been occupied from a very early. period in the winter. We were very kindly received by the women, and found an old one, sick, or thought to be so, to whom the surgeon administered some medicine. It was the woman of many husbands; and she repayed her physic by the stone which is used in striking fire, which was, in reality, a valuable present to make, on her part. They offered us water, which is a scarce article at this season, as it requires much oil to melt any quantity of snow; together with salmon, which we took, that we might not offend them ; returning some trifling presents.

Inquiries about families and new-born children were repaid by questions respecting our own people; one of the children had been 
named Aglugga, in compliment apparently to Commander Ross, whose Esquimanx patronymic it was. The presence of fifty sealskins proved that their hunting had been successful; and, besides the flesh visible in the hut, there were depots in the snow. 'They had further killed two musk oxen and two bears, hoping that we might come to purchase the former; in defect of which, they had been eaten. Of the bear-skins they had made dresses; but they had nothing of this nature to sell at present.

The rising of a breeze in the evening made our hut so cold that we were obliged to construct a crooked passage for it; and, after all, it was but at $25^{\circ}$ minus, at night, while our messengers had not returned with the fish. We were obliged to amuse ourselves with playing at the Esquimaux game of bear and dogs, with the children, to the very great delight of all the party.

At midnight the two young men returned with the fish, which were very fine, and weighed, altogether, a hundred and fifty pounds. The promised knife gave great satisfaction. Their own appearance, and that of their dogs, showed that they had travelled a long way, as they had also been absent fourteen hours, which we computed to be equivalent to thirty-six miles. We sent them to bed; April 23. and, at four, our men rose to prepare a meal before our departure, and to get ready the sledge.

Returning from the pursuit of some grouse, I found that our fish had been plundered by the dogs, and that, including what had been consumed by ourselves and the Esquimaux, we had now but two hundred and fifty pounds. This, however, together with our own stores, was more than our men, not very strong, were able to transport; so that I bargained with one of the two natives to aid us with 
three dogs, for which service, and a spear which he had made, he was to receive a file.

We set out accordingly, after presenting the women with a needle each. It was a fine day, though the breeze was strong; fortunately, however, being with us, it was not inconvenient. After four miles, we arrived at a high cape called Neokouak, and then crossed the inlet by a nearer and better way than we had taken in coming, thus also saving a mile. Halting about half way on our journey, for some rest and refreshment, we were obliged to dispense with water, for want of time to thaw the snow. We were glad to find that the whole bottom of this extensive inlet, which contains the salmon fisheries, was covered with good ice, so that, from this place at least, the journey would be easy as far as the first great river. By three o'clock we had arrived at the ship, with our cargo safe. It was a valuable one, because it contained fourteen days' provisions: which, being fresh, allowed us also to economize the lemon-juice, which was the scarcest article in our stores.

It being the King's birthday, the flags were all displayed; an exhibition which seemed much to delight our native friends; while the men had extra allowance, and so forth, according to custom. One of the natives, being invited into the cabin, informed us of some of the affairs of his coterie. The widow of the dead man had immediately obtained a new husband; because she had five children. The because would not be a very good reason in England, it is certain; the ready made family of another is not often a source of much comfort; and that it is not a valuable property needs not be said. But here, the five children were a commodity of price, a great fortune, a source of profit instead of loss, 
and of happiness instead of vexation and torment. Even at eight they begin to be serviceable: in a few years they are able to maintain more than themselves; and when the parents are old, be they step-children, or entirely and absolutely adopted, as is also here the usage, it is on them that the helpless aged depend for that support which is a matter of course. There are no poor-rates in this country.

Whenever this shall happen, during the progress of knowledge and legislation, the children will cease to maintain even themselves, there will be an end to adoption, the widow of five children will advertise in vain for a husband, they will all go to the workhouse, and they who can catch seals will labour to maintain the idle, till the day shall arrive when all will starve together. It is a Utopian state of things when she of five children is the best of wives, and can take her choice of the young men: it is more than Utopian, when population is not poverty, but wealth : when men really will labour, and when the labour of a man will do, what it always can, or might, support, not only himself, but those who must depend on him till they can, and will, labour for themselves. Let the wise of wiser lands travel hither and take lessons of wisdom from the savages in seal-skins, who drink oil, and eat their fish raw.

Of another portion of their political economy I must not speak with approbation: yet there is some philosoplical fitness in it too, when coupled with that which has preceded. We must not pull a system of legislation to pieces, and then say that this or the other law is a bad one. Let the whole be contemplated in a mass, and looked at in all its bearings, before we presume to decide what is right: that is generally right which is most fitting. It is the cus- 
tom to interchange wives. If the Romans did the same, under very other civilization, I fear that their reasons are indefensible, though I need not here inquire what those were. In this country, the views of the citizens may be physiologically philosophical, for aught that $\mathbb{I}$ know to the contrary, though it remained to discover whether they proved sound in practice. The people thus considered that they should have more children : it is a good thing to have good reasons for doing what may not be very right.

Our absence had occupied the two last days of the week, and April 24. brought back Sunday. It was clear and very cold; the thermometer being at plus $3^{\circ}$ in the day, but falling to minus $\mathbf{1 2}^{\prime \prime}$ at night. It was a more acceptable day of rest than usual : but having removed the snow from the deck, we were less comfortable below. Our Esquimaux guide returned; promising to send back his friend with a seal, and some blubber which we had lost.

He came with the seal accordingly, and had found the blubber April 25. also; remaining all night. A breeze made it very cold, though the thermometer was plus $6^{\circ}$ in the day, and not more than minus $10^{\circ}$ at night. It is probable that we were already beginning to find, in our persons, a new scale of agreeable temperature, though the extreme cold had not very long ceased. Physicians ought to explain these matters. Is it that the body generates more heat in cold weather, and the more as it is colder? If it did not, how could we be as warm at minus $50^{\circ}$ as at plus $10^{\circ}$ or $20^{\circ}$; putting out of the question all casualties from winds or an exposure to them. But, be this explained as it may, why does the body change its standard, its opinions I may say, in such a manner? That which was not disagreeable a month since, was now intolerable: conld a 
cold of minus $52^{\circ}$ occur in July, with a day temperature of $70^{\circ}$ plus, it is not easy to conceive what the feelings would be.

April 26. After a night temperature of minus $16^{\circ}$, the day reached to plus $10^{\circ}$; and the sun, even at this very low point of the positive scale, had a powerful effect on the snow, which was melting during four hours. At night the thermometer was at zero. There was a strong April 2\%. gale with snow drift on the following day, and at midnight it was A pril 28, at plus $6^{\circ}$. On the subsequent night it was again minus $16^{\circ}$; the April 29 gale and snow having continued all the day. The two last days \& 30 . of this month exhibited many changes of weather and of temperature, and it ended on midnight of the thirtieth, calm and clear, at minus $9^{\circ}$.

The summary of April is soon told. The temperature took at last a more favourable turn than had been expected, and the mean proved minus 6.44 the highest and the lowest being plus 30 and minus 25. The several scientific observations had been continued. On the last day of the month, the thickness of the ice was six feet, while it was about seven last year: the reason apparently being, that the surface had been more deeply covered by snow in this season than the preceding, and thus better protected from the cold air.

The health of the men was still good, and the supply of fresh provisions which I had procured was likely to maintain them in an efficient state. We had at length found out the long wished for natives, and at last also had been able to commence our travelling by land. 


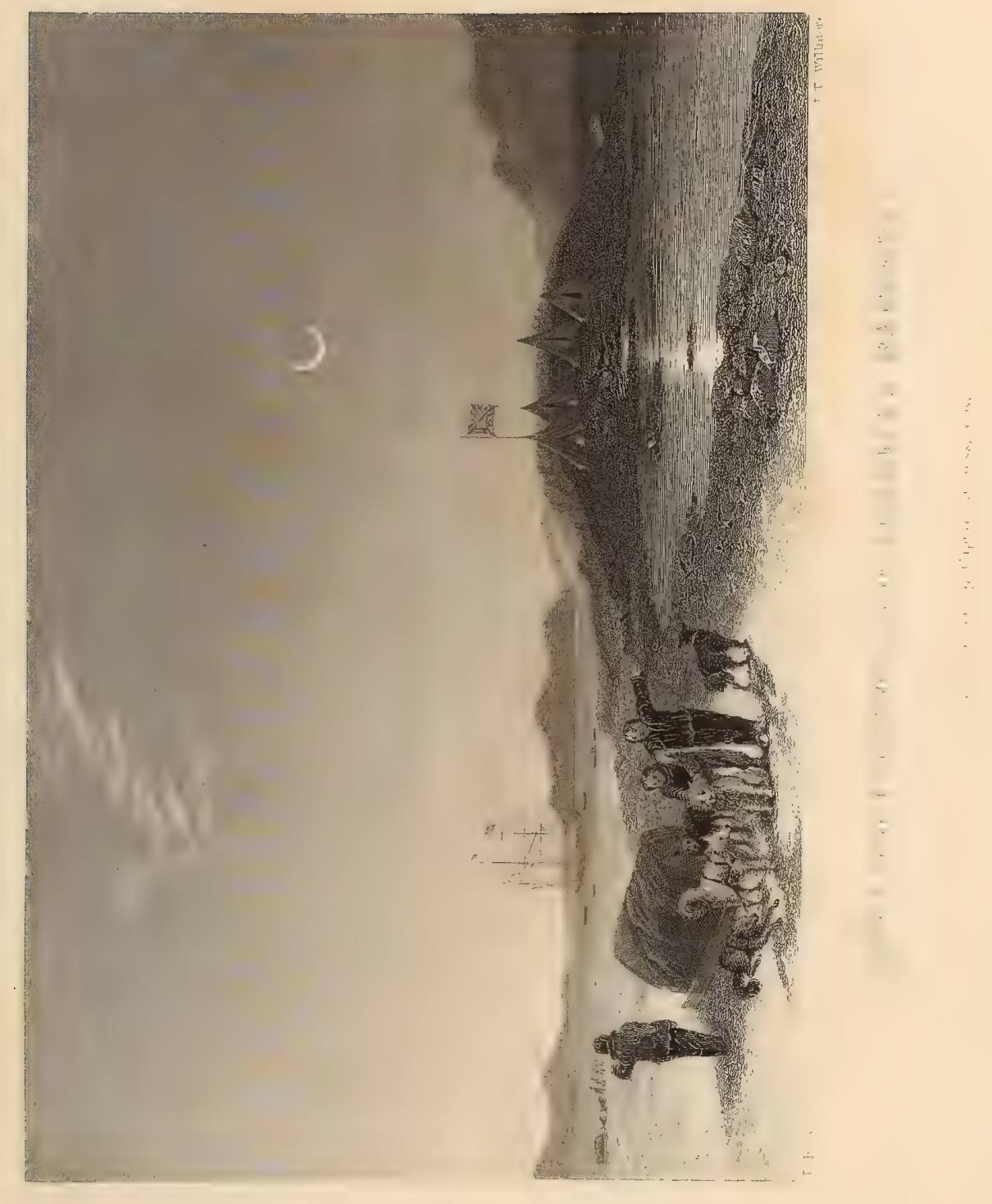





\section{CHAPTER XXXVIII.}

MAY-COMMANDER ROSS'S JOURNEY.

THE temperature ranged to-day between $2^{\circ}$ and $12^{\circ}$ plus, as if May 1. a decidedly favourable change had taken place. After church service, Commander Ross returned, having left his party about twenty miles off to the northward. He came for assistance to be sent to them : the mate Taylor had been frost-bitten in one foot, so that he could not walk, while it had become necessary for the other four men to draw him, although they were themselves much fatigued. All hands were therefore sent to meet them; and while the mate was likely to be disabled for the remainder of the summer, the others seemed much in want of a week's rest.

Commander Ross reported, that from his party having been affected by snow blindness, he did not reach the sea at Awatutyak till the sixth day, Monday, when he proceeded to look for the passage, examining minutely every creek, and traversing the whole line of coast on foot. Thus he determined, without hesitation, that there was no passage here to the western sea. It was plain therefore, that the sea which the natives supposed to lead to Neitchillee, was only the eastern sea, or part of the gulf at this place, between Port Logan and Elizabeth harbour: whence it was plain that there could be no passage nearer than the latitude of $71^{\circ} 55^{\prime}$, where 
there is another great inlet. This, unfortunately, was too far away to be examined by land from our present position; and thence had we much reason to regret that we could not make a further progress in the last autumn. All that we could now do, was to examine the line of coast to the westward of the peninsula; and it was determined that this should form our next expedition.

The further report of Commander Ross was, that he had found the ice very rough, and travelling difficult, that they had journeyed 150 miles, and that it was very cold, since the thermometer was as low as $18^{\circ}$ minus, while they had encountered two severe snow storms. He further remarked that the pressure on the sea ice had been very great, many large pieces having been forced up the rocks to the height of forty feet. They saw no animal but one raven.

But his narrative must be given in his own words. 


\section{CHAPTER XXXIX.}

NARRATIVE OF COMMANDER ROSS.

$I_{T}$ was a matter to be regretted that we could now no longer 1831. obtain the aid of the Esquimaux, who had formerly been of such essential service to us, by means of their sledges and dogs, and by the great ease and expedition with which they raised our temporary encampments. We had nevertheless gained some experience; and the middle of April made us anxious to visit Aw-wuk-too-teak once more, as my former sight of it was very imperfect, and an accurate knowledge of this spot was essential to our future operations.

We left the ship, therefore, at three in the morning of the 20 th of April ; forming a party of five, with a temporary convoy from the surgeon and some other men, who quitted us at 8 o'clock. In a short time I perceived recent traces of the Esquimaux; and as it was important to obtain their guidance to Aw-wuk-too-teak if possible, I followed the footsteps, while my party proceeded along the land. I thus reached Neak-kog-nak, where I saw through my spyglass a snow hut, whence there came out three men, who advanced quickly with their knives, which however they threw away as soon as they saw me lay down my gun, then giving me the usual welcome. One of them was the old man Pow-weet-yah, the death of whose boy had caused the contest between us in the 
previous season, and whom we had not seen since that time; the other two were his sons. By their own account they had waited for us last summer, as they had promised, with abundance of salmon and reindeer; and were much surprised at being told that the ice prevented us from making way to the northward, since they assured us that there had been much clear water at $\mathbf{O w}$-weet-te-week.

We learned that they had been here eight days on their way to a place on the western sea, called Neak-kog-ná-geoo, and that they intended to travel across the country, by a chain of lakes leading to the sea, to the northward of Nei-tyel-le.

The observations made during the two preceding winters, had led me to suspect that the magnetic pole lay in that direction, and at no great distance from our ship; and I was therefore very desirous to examine the spot to which they were bound. I prevailed on them, in consequence; to let me accompany them whenever they should set out for this place, which would not be till we had finished our present journey, and had returned to the ship; but I could not prevail on them to attend me to Aw-wuk-too-teak, though they were willing to wait my time, in the vicinity.

They informed me that they had caught many salmon in the Stanley river during the preceding autumn, which they had deposited in the usual way, and were willing to sell to us, on my giving them a note to Captain Ross, which was to serve as a bill in payment.

April 21. The fog was so thick at four in the morning that we could see but a few yards, yet we departed at six, as they were averse to go to the Victory till we had departed. Our first attempts were much impeded by this dense fog, but at nine it became clear, and we 
continued our journey up the inlet of An-ne-re-ak-to, and thence along the valley of the Stanley, encamping at last on the north bank of the lake at its head.

Our departure on this morning was again delayed, by fog and April 22. snow, till nine, when we crossed the high ridge which separates the two lakes at this place, yet with much toil, from the depth of the new snow. At three in the afternoon, the sun shone out, and with such effect on the white ground, that some of the men were very shortly seized with infiammation in the eyes, so that we were compelled to halt at six and encamp for the night. Our position was on the north-west bank of the lake; and though all the usual means of checking this inflammation were adopted, three of the party were so blinded by its effects, that we were obliged to rest during the whole of the day. The latitude here was $70^{\circ} 29^{\prime} 10^{\prime \prime}$, and the longitude $0^{\circ} 33^{\prime}$ west of the ship.

The sun on this morning was so bright, that though our com- April 23. panions were cured, I did not think it prudent to go on during the day. We therefore deferred our departure till seven in the evening, intending to travel by night, to avoid the future chance of the same inconvenience.

At two in the morning we reached the spot where our hut had April 24. been built in the preceding year. In spite of a fresh breeze from the north accompanied by some drift snow, the weather was very fine, and, although with much labour, we at last succeeded in surmounting with our sledge the hills that lay between us and the lake Aw-wuk-too-teak. We had finished this journey by six in the morning, and encamped on the north shore of the lake, about a quarter of a mile from the exit of the river which flows from it to the sea. 
I here ascended the hill of Ac-cood-le-ruk-tuk, and the morning being clear, obtained a very wide view, including the entrance of the inlet which had so long been the object of our pursuit. It appeared to be about five miles distant, but did not seem very extensive. Some observations which I procured, gave the latitude at $70^{\circ} 38^{\prime} 32^{\prime \prime}$, and the longitude at $0.40^{\prime}$ west of the ship. Above our encampment rose the hill Il-low-na-lig, and here was a snow hut in ruins that had formed the solitary winter residence of Nowyen-noo-ah and his wife.

April 25. At eight in the evening, we proceeded down the course of the river to its estuary, under considerable suffering from the lameness of some of the men, consequent on the freezing of their boots, and from the blindness of another. The termination of this inlet being visible from an eminence which I now ascended, and at no great distance, I caused the men to encamp, and proceeded with Abernethy to examine it. It was not that I here expected to find that opening which the Esquimaux had described to us as leading to the western sea at Nei-tyel-le, because that one, by their account, was so wide, that in some places, one of the shores could not be seen from the opposite side, though the land on both was high. Yet we had not examined the present one when we passed down the coast in 1829, and as it was the only one that had been neglected, I thought it necessary to make a minute investigation of it, that we might not be detained for this purpose when we should proceed northward in the ship during the ensuing summer.

April 26. This survey was finished in a satisfactory manner by seven in the morning of the $26 \mathrm{th}$; so as to unite this part of the coast with that which we had explored from the ship. The latitude of 
our encampment was $70^{\circ} 42^{\prime} 2^{\prime \prime}$, and the longitude $0^{\circ} 40^{\prime} 1^{\prime \prime}$ west of the ship.

In the course of this walk I found the monuments which we had erected in August, 1829, but the Esquimaux had intermeddled with them, and taken away the coins that we had deposited. Here, as in so many other places on this shore, the rocks consisted of red granite and limestone, the western side displaying the former, and the eastern one the latter. The view seaward exhibited a level of smooth ice to the verge of the horizon, where, however, there were sharp points indicating a formation belonging to the preceding year.

Having thus accomplished the main object of our journey, I determined to return to the ship by the sea-coast, so as to survey this shore more accurately than we had previously been able to do. We therefore set out at half-past five in the afternoon, and in spite of a dense fog, contrived to keep on along the shore. On the twenty- April 27. seventh, at one in the morning, we reached the entrance of Port Elizabeth, and found our progress much facilitated by the smooth state of the ice, though the snow was often knee deep. A strong breeze, with much drift, compelled us however to halt at length, at four o'clock, on the southern bank of the isthmus, when there came on the most violent gale, attended by drifting snow, that we had ever witnessed, lasting till the noon of the twenty-eighth.

It then moderated, and the weather became fine in the afternoon; April 28. releasing us from that narrow confinement in our snow burrow, which we always felt to be more painful than even a hard day's work. We contrived to proceed on our journey at eight, but the evening was very cold; while, by midnight, the wind which had been behind us, shifted so as to blow directly in our faces. We would 
willingly, therefore, have halted, but our provisions had been so much reduced beyond our calculation, in consequence of the detentions we had undergone, that we were obliged to proceed, and thus continued our journey till six in the morning of the twentyninth.

April 29. One of the party was now found to have been frost-bitten in the foot, in a very severe manner; but by applying the usual remedies the injury was checked, though with considerable consequent suffering from inflammation. This caused our detention till the April 30. thirtieth at noon, when we contrived to place the man on a sledge and proceed towards the ship. At first the travelling was easy; but, on rounding a point of land exposed to the north, the ice was found very rugged and apparently impassable, being heaped up in a confusion of piled blocks, often reaching to the height of 30 feet. From the top of one of these ridges, however, we could see the level ice at the distance of a few miles, which encouraged us to attempt the crossing of this obstruction. It proved to be five or six miles in breadth; yet, by dint of exertions and fatigue, such as we had never yet made and experienced, we succeeded in crossing it, though not without much suffering to our disabled companion, from the concussions which the sledge underwent. This portion alone of our journey occupied us twelve hours.

May 1. Three of the party had been thus completely exhausted, so that we were compelled to halt at two in the morning of the first of May, about three miles to the southward of Andrew Ross island. But as our provisions were now nearly expended, and as it was necessary that the disabled man should get medical assistance as soon as possible, while in addition, the seamen could not proceed. 
for some hours, I set out alone for the ship, that I might send some relief to the party as soon as possible.

The distance was only twenty miles, but the road being bad, I did not arrive on board till eleven in the morning. All who were able for the journey were then despatched to their shipmates, and soon after midnight the whole were safe on board. Taylor, who had been the frost-bitten man, had suffered much from his conveyance; but the care of our surgeon soon relieved him from the most painful effects of his injury. Of the rest, Richard Wall was ill for some days, in consequence of fatigue, but experienced no ultimate bad effects. 


\section{CHAPTER XL.}

JOURNAL OF MAY-A JOURNEY IN COMPANY WITH THE NATIVES.

1831. TWO of the natives had arrived yesterday with the promised supply of a seal, which weighed 173 pounds, bringing also five large fishes called by them erkalook-ait-loo; when, informing us that they had another store of fish for sale, they were sent to fetch it. The weather was cold to-day, with the thermometer about zero.

May 3. On Tuesday the natives returned with a seal, but only with a small supply of fish, as they had not been able to find their hoard: there were but sixty-five pounds.

May 4. The temperature rose to plus $20^{\circ}$, and the mean was $4^{\circ}$. The two men left us, with a promise to bring us more salmon, and a seal, in three days. They were to fish here in the autumn, and at Neitchillee in the winter. Our new cooking apparatus proved effective: its advantage being, that it would require no fuel but May 5 \& 6. tallow or oil. The ice near us, being cut through, was five feet and May 7. a half thick : the temperature at night, zero. On Saturday a party was sent to bring back some stores that had been left behind to make room for the lame mate; and thus ended the week.

May 8. After church we received a visit from some native families. One of the men undertook to guide us to Neitchillee, by the lakes, in

May 9. eight days; his reward to be a pole. Another, who had remained 
on board, went home on the following, promising to return in four days. Neither on these two days nor the succeeding, was May 10. there much change; though the mean temperature was gradually increasing.

There was a strong gale, with drift snow, this day, which settled May 11. into a stiff breeze on the following. The native returned, but had May 12. nothing to sell except some clothing. The preparations for travel- May 13. ling were in progress; and, among other things, provisions for twelve men during three weeks were made ready. The weather May 14. promised better, as the thermometer now rose to the freezing point at noon, being $12^{\circ}$ at night.

Many tracks of reindeer were seen by the men in their Sunday May 15 . walk: these animals were apparently returning for the summer. Monday morning was employed in preparing every thing for our journey; and, at eight in the evening, the first sledge, with the pontoon and three weeks' provisions, and the second with the same quantity of provisions alone, each calculated for six men, set out to explore the second chain of lakes and the west coast of the peninsula, as far to the northward as it was possible to reach. These parties were to be guided through the lakes by two of the natives. Calculating that we should reach the west coast in seven days, our design was, that the second division under Commander Ross should continue their investigations, while the first returned for a supply of provisions, then contriving to come back to the former by the shortest route. It was our further purpose to obtain from the natives some more geographical information, and also, supplies of provisions and clothing.

We made nine miles before mid-day; the weather being fine, but May 16. cold. On the next, we arrived at the native huts at Neotaknag; May 17. 
preceding the sledges about an hour, and pitching our tent. Our promised guides were to be ready in the evening; and informed us that many reindeer had passed lately, followed by a wolf. We had formerly found among them, a piece of a large spar, some iron hoops, and some stores, and had suspected that they had been either stolen from us, or sold by some of the men; but our disagreeable suspicions were now removed, and the mystery solved. They were articles that we had formerly thrown overboard to make room, and they had been found by those people. I ascended a hill about 800 feet high, to examine the country; and, by evening, our guides were ready, punctual to their promises.

Our march had a very nomadic and new appearance, as the line of it also was somewhat picturesque. The mother of the two men led the way in advance, with a staff in her hand; my sledge following, with the dogs, holding one of their children and some of their goods, and guided by a wife with a child at her back. Another native sledge followed in the same manner; next to which was Commander Ross's, and lastly the other Esquimaux sledge: the rear being brought up by a native drawing two skins of oil, and, at a distance, ourselves with one of the little boys. Many halts were made, as our burdens were heavy, the snow deep, and the ice rough.

May 18. We had with difficulty persuaded our guides to persist, when we at last pitched our tent, and the natives erected their snow huts. It then came on to blow hard, with snow, till noon. We had now passed across the bottom of the spacious bay and the mouth of the great river, named after Lord Lindsay, being the place where we had obtained the salmon last year; and being thus about three miles from the main, andclose within a range of rocky islands lying 



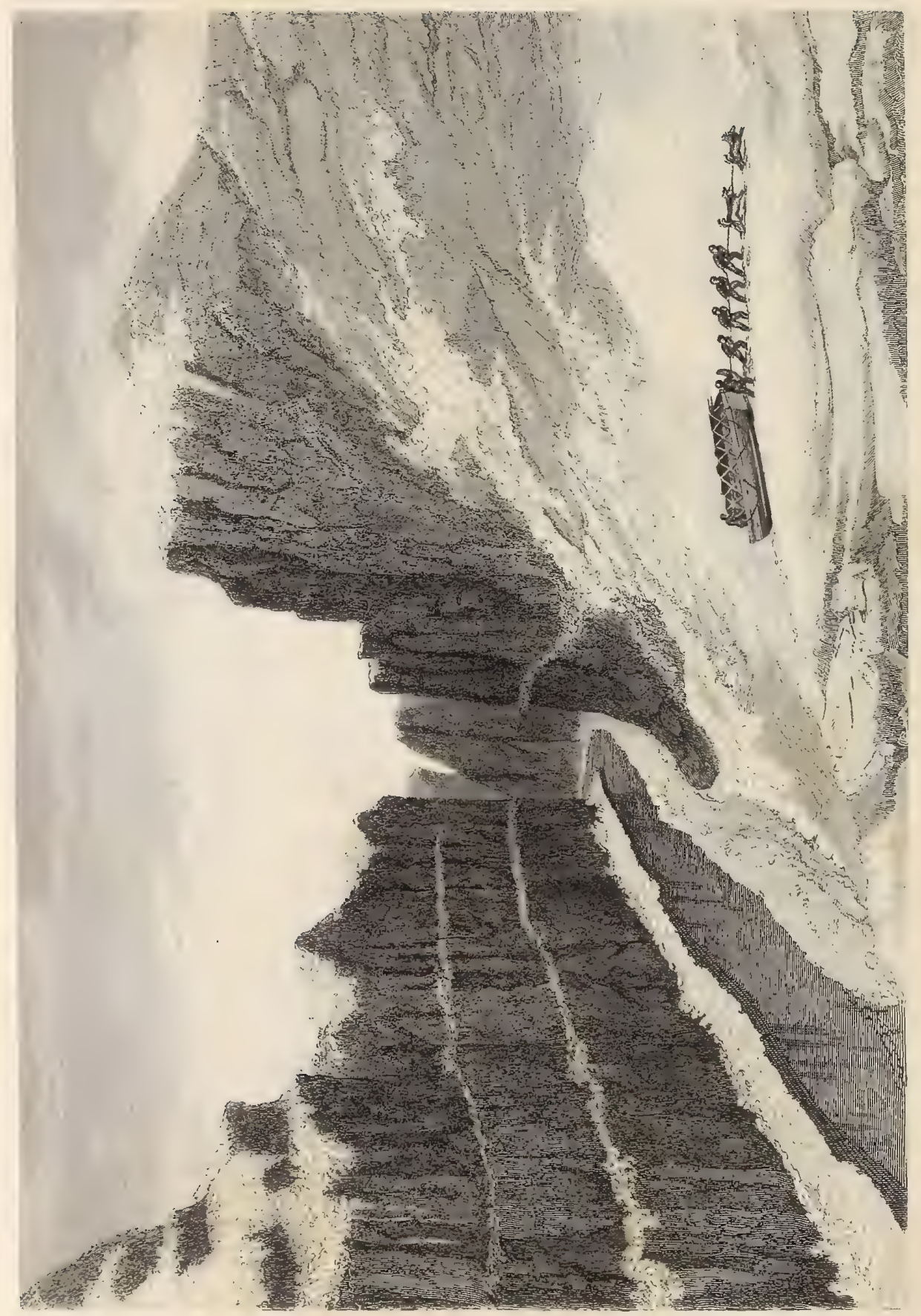


in a north and south direction. On each hand the land was high. and the mountain Kakoloktok before us. Our course had hitherto been as nearly as possible to the southward, and the distance which we had travelled was fourteen miles.

In the evening, all was again ready, and Commander Ross departed for the mountain just named, to take angles, while the march was renewed. As we advanced, the inlet became narrower, and many more islets appeared, indicating shallow water. We soon reached a small river, on each side of which was a rocky hill, five or six hundred feet high, as there was also a channel to the east of the island, leading along the main, by which the distance to the ship could be materially shortened in returning. The snow and ice rendered the travelling difficult, and we proceeded very slowly. At nine we passed the mouth of another small river, called Sokinnohunuting, and arrived at length at that of the river Saumarez.

This was on the nineteenth, and here we joined Commander May 19. Ross. We were surprised at finding this river open, but were more so to learn that it had been in this state all the winter, while it was now running in a considerable stream. On further inquiry, we found that there were many springs in the lake above, which was a mile off. We now hauled the sledges over a ridge, and obtained a. view of it, lying; as it seemed, in a south-west direction. At one place, the river was confined by precipices eighty feet high, through which it forced its way in a space so narrow that we might almost fancy we could jump across it. The temperature of this water was $34^{\circ}$, and it supplied us all with drink, which was still very difficult to procure any where else. 
The ice on the lake was not so deeply covered with snow as that on the sea, but it bore no marks of dissolution. We proceeded along the west side of it, where a high precipice of the mountain descended, and pitched our tent at the distance of three miles from the river, close to the huts of the guides who had preceded us. In spite of all our caution and care, one of the men suffered from a frozen toe, and was of little use during the remainder of the journey; he had concealed the injury so long that we could do little good: the similar accident of another man was easily remedied, as he had given timely notice of the injury.

The natives were here employed in making holes to deposit their heavy stores, of provisions and other matters; and by this we were much lightened. They also made some sledges of the fresh-water ice; the shape being that of a shallow elliptical basin. Two of these, fastened together, contained a considerable quantity of their goods, and could carry one of the women on the top of all : while, though very heavy, they travelled with considerable rapidity.

It was not till nine, however, that they were ready to march, when we continued along the west side of the lake, the old woman still leading the way: finding the sides high and rocky, its breadth varying from one to two miles, and its direction more westerly. At eleven we reached a strait about a hundred yards wide, precipitous on the south side, and having, on the other, a low point covered with circles of stones. These had been the summer tents of the present party, and here was deposited a store for them on their return. We were informed that it was an excellent station for catching the lake trout, but that the sea fish could not ascend so far, in consequence of the strength of the current in the narrow strait of the river just described. 
While our men took their refreshment and rest, the natives made a hole in the ice for the purpose of fishing. We were surprised to find it only five inches thick, being within ten yards of the shore, and in only six feet depth of water, where of course it ought to have been thicker than in the middle of the lake, at which part, however, although we could there find no bottom, it was two feet in thickness. The temperature of the water was however but just above $32^{\circ}$. It was attempted to explain this appearance, by supposing the setting of a current here from west to east until a very late period of the season; but as there was no apparent descent, this solution was not very satisfactory. If no fish were taken, we at least saw the method of catching them. A ball of ivory or bone, with four small pieces attached to it, is fastened to the end of a string attached to a stick, and the fisherman holds this in his left hand, a few feet below the ice, keeping these balls in constant motion, to attract the fish, which is then speared by the barbed machine formerly described.

After an hour's rest we proceeded along the lake, which was now May 20. found to contain many inlets or bays, and several islands, till we arrived at another strait, which was also a fishing station, and, some time after, at a third, near an island, where there were the remains of many huts for the same purpose. Here we pitched our tent, and the native who accompanied us built his house. There were tracks of reindeer, and we saw a wolf. At eight in the evening we resumed our journey, and came to some low land, of a different character, consisting of flat limestone; the preced ng rocks having been of granite. The snow was very deep, and the thermometer at night fell below zero.

Here some of the natives in our company became unwilling to 
travel at night, and they consequently halted, and set about building a hut, promising to overtake us the next day, while one of them, with his wife, consented to go on with us. After eight miles we thus came to an island where we found the remains of an Esquimaux tent, and here one of the natives remained.

We proceeded on the twenty-first, through a very desolate tract, guided by some stones which the natives had set up for that purpose, passing several small islands, and finally reaching the end of this great lake at six o'clock, after a journey, on it, of three days. We encamped, and saw many reindeer, with two wolves; but they were all too cautious to allow us to approach them. It blew hard from the north-eastward, with snow, and was very cold, though the thermometer was not below $20^{\circ}$. This great lake was named after the justly celebrated Admiral Von Krusenstern.

May 22. The gale did not allow us to move; nor would the Esquimaux May 23. have consented. The thermometer sank to $3^{\circ}$. The next morning the wind abated, but still these people would not go till their companions had joined them, which they could not have done during the bad weather of the preceding day. Nothing was to be seen but a vast expanse of snow, covering a flat country, so low near the water, that we could not discover where the boundary was. We learned from one of the men, that there was a third chain of lakes to the westward, emptying themselves into the eastern sea by the great river.

At four, the two men who had remained behind came up, and built a hut; informing us that there was another lake to the eastward, having the same name as the one which we were next to reach, viz. Tishagriahiu, which I named after my friend Captain Jekyll, R.N. While they were preparing to set out, we had time 
to examine a new sledge which they had brought up, and which we found no less beautiful than extraordinary. It was of the shape of an ordinary one, but made entirely of ice, runners and all, and, while very neatly made, having a most delicate appearance. Being transparent, it seemed indeed to be a sledge of crystal, while it was strong enough to bear the weight of all the stores which the owner had heaped on it. Being all ready, we departed at eleven o'clock.

We now passed over several necks of land, and across some small May 24. lakes, guided by marks which were so obscured by the snow, that our guides were often obliged to stop and consult together. At twelve we crossed a river, and entered a small lake; and, at four, passed a ridge of land; arriving after this, at a valley filled with snow, and containing a lake, out of which issued a river, along the course of which we went till we had reached the expanse of water which it served to drain. We found it to be about two miles long, and that it was joined, at no great distance, to another, by means of a river which united some more in this series, so as to constitute a general declivity and drainage. These two were named after Professor Hanstein. At length we finished this day's journey, after having travelled fifteen miles, pitching our tents at last, about ten o'clock. The land over which we had thus travelled was, once more, of granite: the river which we had passed in this journey was three hundred yards wide. The latitude of our position was $69^{\circ} 45^{\prime} 20^{\prime \prime}$, and the longitude $95^{\circ}$.

It was soon necessary, however, to move again ; two of the natives whom we had left behind now joining us. Here, as at every place where we had stopped, they deposited a store, to await them on their return; but it was with much difficulty that one of them 
could be persuaded to proceed, which I believe he would not have done, had he not feared to lose the promised reward. We saw some wolves, together with a raven and an owl: a wolf had been fired at, before this, without success. The temperature at midnight was $14^{\circ}$ plus.

May 2.5. We began our journey at this time, with a cloudy sky and a fresh westerly breeze. Crossing a small lake, we arrived at a ridge separating those which we had passed after leaving the great lake Krusenstern, entering first on a very narrow lake, and then into the channel of a river that led into a larger one two miles off. Halting here for an hour, we proceeded, at five, and crossing another ridge for four miles, arrived at the great lake just mentioned. This lay east and west, and seemed ten miles long; but the snow did not allow its breadth to be ascertained. The land was part of Boothia Felix, and there were several low islands at the east end. It was said to abound in fish; the salmon entering it from the western sea, through a great river. Hence, after walking twelve hours, and having travelled over a distance of eighteen miles, we pitched our tents at its northern side. It snowed heavily all this day, and the thermometer was at $30^{\circ}$ at noon.

Nay 26. We started at one in the morning, and keeping a westerly direction, reached the end of the lake in two hours; when, passing a ridge of land again, we came to a river called after the Crown Princess of Sweden, and having crossed it, arrived at the channel of the great river. After a needful halt, we came to its mouth, which was at the bottom of an inlet three miles long. It was that which had been formerly surveyed by Commander Ross. The land was here rugged and precipitous, and, as was here rare, it 
was somewhat romantic: the place where we first stopped was called Padliak; and the entrance of the inlet had been ascertained to be thirty-five miles from it, west by north. At this place we saw a herd of twelve reindeer.

Here we also found three families of our acquaintance, in two May 27. huts; but were vexed to learn that Kablala had departed some time ago, that Ikmallik's party was beyond Neitchillee, and that we had no chance of seeing either. We were glad to find, however, that they had been very successful in killing deer last winter; and we bought a deer-skin and a pair of trousers, with a skin of oil for fuel, as our own was nearly expended. At ten at night we again started: the plan being, that Commander Ross should explore the coast to the westward, and myself that to the eastward, returning by Padliak. As the former had fifteen days, provisions, I settled that they would be able to travel outwards during at least six of those. But as I then took leave of them, so must I now defer any account of their proceedings till the time arrives for giving their own report of their journey and its results. After parting, we proceeded onward ourselves; first passing an inlet formerly examined, after that a valley with a river, and then, lastly, Cape Isabella, where we arrived at midnight, through very thick and foggy weather.

We pitched about the middle of Padliak bay; but the sun being May 28. obscured, could not well make out our course. Nevertheless we started at eight, though the men complained much of their eyes; guessing our route as well as we could, amid the darkness and confusion which was produced by the density of the fog. At midnight we arrived at an opening resembling that which leads 
from Padliak to the great lake; where, finding no natives, I determined to proceed, as soon as we had made the necessary halt, since our provisions were now becoming short. But having some time on my hands, in consequence, I here repeated the observations which I had formerly made for the purpose of determining the height of this lake above the level of the sea.

May 29. Our tent was on an elevation whence I could obtain a good view as soon as the weather should become clear, but there was a gale with snow, lasting all the day. In the evening it moderated, and enabled me to see Cape Isabella on the western sea, and the high land of Shag-a-voke to the east; but I could not make out whether we had come by the eastern or the western lake. Nevertheless we continued our journey, and found a tolerable road to the lake which was nearest to us; but the new and deep snow had so altered the appearance of the land, that I scarcely recognised any of the objects with which I had formerly been so well acquainted. We however contrived to make our way to this lake, whichever it was; gladly finding on it a surface far more practicable for travelling than the rough ice of the land which we had hitherto laboured through, under no small fatigue. Having thus far succeeded in getting upon a more agreeable road, if road it might be called, we proceeded along its south-eastern side, seeing a great many snow buntings in the course of this walk, and well pleased to meet with these harbingers of the spring-time of this wintry land. I spring indeed, of which the migrations of those and the other animals which instinct drives to these regions, is the only sign, since all else is deep winter. Why they come, is better known to themselves than to me, since we could never at this early season discover where 
they found their food; but it is best known to Him who directs their flights, and who, as He cannot deceive them, has assuredly provided for them those stores which He has ordered them to seek, that the table which He thus has furnished for them in the wilderness shall not be wasted for want of guests.

The weather was calm and fine till four; and at eight we vay 30. pitched our tent on the land, having travelled fourteen miles: after which it became so thick, that we could not proceed. We however started again at eight; and, after some difficulty, found the valley which led to Shag-a-voke. We had seen some reindeer, and two hares; but could get no observation of the sun. I was more fortunate afterwards in shooting two of the latter, and a grouse. I here repeated, once more, the observations which I had so recently made for the second time on the altitude of the land at this place, being very desirous to know what the elevation of this tract was above the level of the sea. It was a question of more interest than may at first appear, since this was the valley, if valley I may term it, which formed the most brief and perfect land communication between the eastern and westem seas, which, in other circumstances and in a very different climate, might, under the aid of art, have formed that "north-west passage," of which, if I mistake not, we now know as much as is soon likely to be known, and far more than will ever be of any use. The result was to determine that it was thirteen feet above the level of the western sea. Had this region been thirty degrees further to the southward, a canal company might have effected that "passage" which nature has now thought fit to refuse.

We crossed the gulf of Shag-a-voke at one in the morning, and May 31. 
left the boat for Commander Ross's party. George Baxter, one of the men, was ill; but being much lightened by leaving this load, we contrived to proceed, and pitched our tent on the sea, about twenty-six miles from the ship, at seven o'clock. It soon came to blow hard, with snow, and as we could not get our bed skins dried, were not very coinfortable, though well sheltered from the storm.

This was nearly the place where we had encamped last year; and we could now trace the difference between the former and the present state of things; while what we saw was by no means flattering to our future progress. At that time, the land was nearly bare, and now it was deeply clothed with snow, while the thermometer was also ten degrees lower. It had then been covered with pools, and there was now not a drop of water to be procured; while, even on the rocks, where it should have abounded, all was ice. The only hope which we had to balance against this sinister aspect, was, that the storms might break up the sea ice in the bay, and thus bring on our liberation sooner than now seemed very likely.

After noon it moderated, and the snow ceased, while it was succeeded by frost. It was therefore resolved to make an effort to reach the ship, as the wind was behind us; for which end I proceeded in advance, that $I$ might send my party assistance from the men who had remained on board. With all my efforts, however, I did not succeed in arriving at our home until ten. I had been tempted to pursue a deer, an object well worth a chace to us, and as the road was now very bad, from the state of the ice, $\mathbf{I}$ also experienced many severe falls, adding to this delay. It blew a gale when I arrived, and was very thick. The men whom I had left made their appearance at two, having left the sledge on the way. 
They were all ill, or utterly fatigued: I was the only one of the party who was quite well. Thus ended a journey which had lasted from the seventeenth of the month of May till its termination.

During this walk, I had a further opportunity of comparing the uncommon severity of the present season with the state of the preceding. I had found no clear water along the shore, while it had been abundant last year at the same period : not a single bird was to be seen on the precipices, while, in the former spring, they had occupied their breeding places and were abundant; a mark, I need scarcely say, of a winter, in severity and duration, which does not only relate to the climate in which we now were, but to that from which these animals migrate; thus indicating the prevalence of a bad and protracted cold season over all the regions of northern America.

The journal kept on board during my absence is merely that of the weather, and does not require to be detailed. For both, for the absent and those at home, the circumstances were nearly the same; and the several sick men were better.

The summary of May does not present much. Its weather had been a great contrast to that of the same month in the last year. The sun had scarcely made any impression on the snow, and no water had yet been seen. The maximum temperature had been plus $36^{\circ}$, the lowest minus $16^{\circ}$, and the mean plus $16^{\circ}$. Commander Ross's first journey had determined that there was no passage into the western sea at Awatutyak and therefore none to the southward of $7 \%^{\circ}$. This journey had been a very unfortunate one for the mate Taylor, who was expected to lose part of his right foot; and the rest were so much fatigued that they were scarcely 
recovered in fourteen days. The report of health for this month is therefore an unpleasant one; but there was no threatening of scurvy, and to this, the supplies of fish, procured from the natives, had essentially contributed.

My own journey had enabled me to extend the geography of this part of the country, in spite of the obstacles produced by the weather, which had also prolonged the intended eight days to eleven. Game, it may be remarked, was still rare; and this was a more interesting matter as related to the season, than as concemed our amusement or our supplies. The southern animals were indeed migrating to the northward, but in no great numbers; and they were the calendar of the spring, as I have already remarked, if indeed we had not warning enough, in the surrounding waste of snow, that it was not yet arrived. 


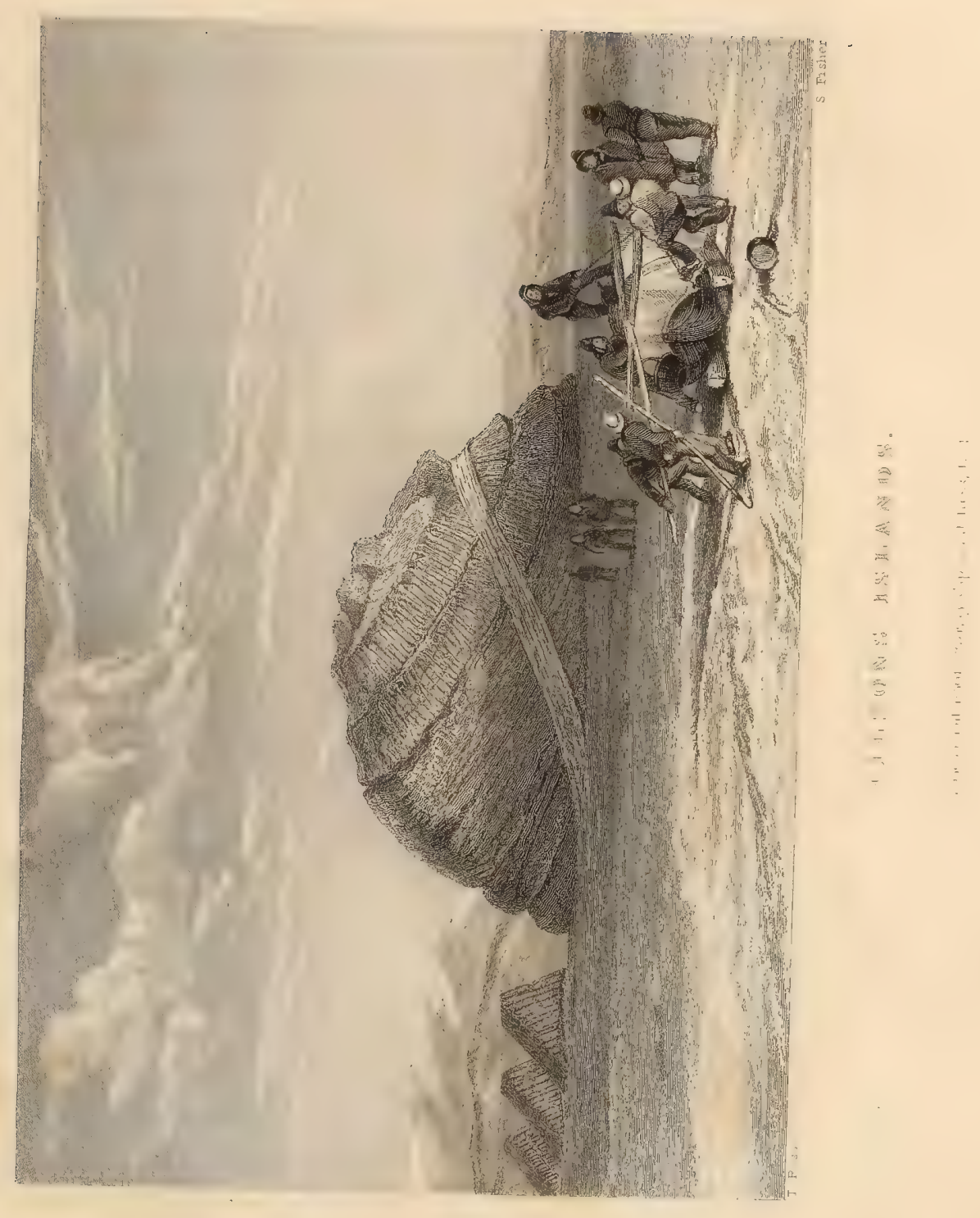





\section{CHAPTER XLI.}

TRANSACTIONS IN JUNE-RETURN OF COMMANDER ROSS FROM HIS EXPEDITION.

'I'HE weather was cold on this day and the following, and on the latter it was stormy. The sledge was brought in from the place June 2. where it had been left. The lowest point to which the thermometer sank was $19^{\circ}$. We should not have occasion, it was now hoped, to register its negative scale, for some time to come.

It was a bad commencement of this month, to find that it had become necessary to amputate part of the foot of the mate Taylor, which was mortified. This was accordingly performed by the surgeon, with credit to both parties; that of suffering well, to the patient. The other frost-bitten men seemed likely to escape for a trifling sore or two.

On this I must be allowed to make a remark : it is not intended for the purpose of praising my own management, but that future travellers in northern climates, not less than navigators like ourselves, may see what a very little care and attention can effect. It is very certain, that no travellers, under any circumstances, nor any navigators, among all those who have wintered in northern climates, have ever encountered the winters of a country more severe in its temperature and its storms, nor in the duration of such low tempe- 
ratures, and the frequency of such storms. Thus was it also our lot to pass, not one winter or one year, far less one or a few months, as most of those who have experienced the cold of these climates have done, but a long succession of years, of which I may safely say, that nearly the whole is one long winter; while, with little exception, as the records of our long detention in the ice shows, those years were, even in this ever wintry climate, seasons of uncommon severity.

Nor were we sparing of our toils out of doors, as my journal has every where proved. Our men, like ourselves, travelled as much as was requisite, and laboured in the open air, without restriction or fear, on every object and for every purpose that our duties demanded, even as if we had been in England. No service was ever shunned or countermanded, from fears of the weather, except under those very peculiar circumstances which I have always pointed out whenever they occurred. How truly this is the fact, may easily be gathered from the whole of this narrative, since it is that simple statement from which all may draw the conclusions to which it is nevertheless incumbent on me to point their attention, while it is not my desire to do more.

What then was the temperature, or rather what were the temperatures, during these protracted seasons of almost one long and nearly unparalleled winter of four years? The reader of this narrative has seen them recorded on almost every day. He has seen that the freezing point was nearly a summer heat to us, that a cold of zero was the " temperate," I may almost call it, of our seasons, and that if we were cold, it was because the thermometer stood from thirty even to fifty, sixty, eighty degrees, under the freezing point. 
Had we storms of wind and snow, did our men encounter them in their several journeys, face the gale and the drift, and fall asleep in a house of ice, even when exhausted by fatigue, and weakened too by want of sufficient food? All this has been seen. It has been seen that we were often far underfed, and I have shown, what all know, how this conduces to the injurious effects of cold on the body. Yet under all these exposures, all these labours, all these privations, and all repeated and enduring through the long space of four years, one man alone was frost-bitten, one man suffered the loss of a foot, while that loss was the consequence of his own inattention, and nothing else. It must not then be said that men cannot be protected from these accidents, even under the worst of circumstances. I boast of no secrets, the commonest precautions sufficed, and those precautions are in every one's power. Let the crew which I brought back to their homes say whether those cares sufficed or not.

The third and fourth were unaltered, and we were not very busy. June $3 \& 4$. The Sunday was marked by nothing but divine service: but we June 5 . had prepared, on the previous day, for an expedition on Monday, June 6 . and every thing was therefore kept in readiness.

In the evening, the surgeon and a party went forward with the sledge, seven miles in advance; but it blew a gale on the fol- June $\%$ lowing day, with heavy snow, so that we could not set out. We attempted it next night: but a strong breeze with snow coming in our faces, we did not reach the sledge till six in the morning. The sun then burst out suddenly at nine; which so blinded us that we were obliged to pitch our tent three miles only, forward, near the rock which we had compared to Ailsa.

At eight in the evening we resumed our march to the south-west- 
ward; and passing inside the islands, reached a precipice twenty miles from the ship, formerly noticed for the gulls which frequented it, where we saw the first that had arrived this season. A mile further we found two native tents, and were invited in by some of our old acquaintances; though they were taken by surprise, and all in bed, with little discrimination of wives, husbands, and children. Two of the young men informed us that they were on their way to the ship with fish; promising further that they would supply us during the summer. They had heard of Commander Ross, but had not seen him, and had observed our pontoon without meddling with it. They were directed to the ship, and we parted.

June 9. A thick fog came on, but we had our own former tracks and those of the natives to guide us. At eight we reached Shag-a-voke and pitched on the shore, as the sun's light was once more too strong to bear. I left the intended stock of provisions for Commander Ross, with a note, and erected a cairn and a flagstaff with the necessary directions. As the fog again prevented me from examining into any thing, we turned our steps homeward.

June 10. The tracks of the natives which we followed, showed that they had no sledges, but were dragging their things on skins; and, at five, we pitched at our former place, where, at last, we found water to drink : after which I left them, that I might send aid from the ship, in consequence of which $I$ arrived three hours before them. I found that the two natives had been there, but had not brought the fish: they were to come the next day. Of the reports of the ship during our absence I need only remark, that the ice-hole had been cut through, and found to contain seventeen inches in thickness of new ice. 
The party with the sledge arrived, and long after, those who June 11 . had been sent to meet and assist them; having missed the place. The welcome natives came at eight, bringing ninety-seven pounds of fish, consisting chiefly of small cod and coalfish, with a little salmon, besides a bear-skin and some clothing. The women came afterwards, and were admitted on deck, as Saturday was an inconvenient day to receive them below. More fish were promised on the following day.

At five in the morning of Sunday, there arose a furious snow- June 12. storm from the westward, which lasted for sixteen hours. Notwithstanding this, after divine service, the promised party came with their fish and clothing, and some other articles. After this, I took them into the cabin, and read to them some portions of scripture from the Esquimaux bible which I had received at Holsteinborg. This, which I scarcely expected, they seemed to comprehend; listening with great attention, and correcting my pronunciation, while making me repeat such words as seemed obscure, till they understood the meaning. I then read the creed and the Lord's prayer from Egede's book, which seemed equally intelligible, as far at least as the words were concerned. To confirm my belief of this, I read to them from Egede's vocabulary also, and was then satisfied that they understood his words better than the more recent ones which have been printed. They were not suffered to depart without a meal of fish; promising to return. It was in vain to be anxious to know what they thought of what they had heard, or whether they comprehended its purpose; since we were not far enough advanced in their language for such an attempt as this. 
This I had much occasion to regret. I neither speak as a fanatic, nor did I ever entertain romantic notions of the perfectibility of savage nations; still less being given to suppose that any human power can ingraft a reasonable and efficient religion on men who have never exerted their reason: who are deficient in every thing on which a rational faith, as well as a sound practice, can be founded, and who, I may safely say it, have in them little of man but what is found in those who approach most nearly to the pure animal nature. Yet even there, God has not left himself without a witness, strange as the demonstrations of this may often be. More than this, however, is what I should have desired to see, but that I had not the means of discovering. Did they comprehend any thing of all that I attempted to explain ? explaining the simplest things in the simplest manner that I could devise. I could not conjecture. Should I have gained more had I better understood their language? I have much reason to doubt. That they have a moral law of some extent "written in the heart," I could not doubt, (and I have said so elsewhere, as numerous traits of their conduct show; but beyond this, I could satisfy myself of nothing, nor did these efforts, and many more, enable me to conjecture aught worth recording, respecting their opinions on the essential points from which I might have presumed on a religion. I was obliged at present to abandon the attempt, and I was inclined to despair.

At five in the morning, Commander Ross returned with his party, and all in good health; the natives took leave, on their return to Neitchillee to fish for us. I shall not make any abstract of the narrative of this expedition, but give it in the words of that officer himself. 


\section{CHAPTER XLII.}

COMMANDER ROSS'S NARRATIVE-HIS JOURNEY FOR ASCERTAINING THE PLACE OF THE NORTH MAGNETIC POLE-OBSERVATIONS FOR THE PURPOSE OF ASSIGNING ITS PLACE, AND DEDUCTIONS FROM THOSE.

HAVING given to the Royal Society a paper on the subject of the North Magnetic Pole, which they have done me the honour to print, I need not here repeat the preliminary or other general remarks which it contains, but confine this narrative, as I have done my former ones, to the facts and reflections which occurred during our voyage and our travelling: thus conforming to the journal character of the volume in which $I$ have borne the share assigned to me. If there are scientific readers who desire to see what I have written on this subject since my return, they will find it in the Philosophical Transactions for 1834.

It must be known to many more readers than those, that the subject here in question had engaged the attention of our predecessors, Parry and Franklin, during their several voyages and travels in these regions for those purposes of geographical discovery which are now so familiar to every one. If all general praise of these conspicuous men is now superfluous, I must here however remark, that the numerous and accurate observations on the subject of magnetism, made by them and the officers under their command, 
have proved of great value towards the advancement of magnetic science in general, if more particularly to the assignment of the laws by which that of the globe, as it regards the needle, is regulated.

The geographical restrictions, however, to which these discoveries had been subjected, were such as to prevent them from extending their observations over so large a space as was to be desired. They had at different times made nearer approximations to the expected place of the North magnetic pole than had ever before been effected, but the spot where it ought to exist had been a sealed place to them: more than once tantalizing with hopes which, it was destined, were not then to be fulfilled. Observations were still wanting at other and nearer points to this desired and almost mysterious spot; that its place might be at least assigned with still more security and precision than it had been from those already made, that, if possible, the observer might even assure himself that he had reached it, had placed his needle where no deviation from the perpendicular was assignable, and had so set his foot that it now lay between him and the centre of the earth.

'These hopes were at length held out to us; we had long been drawing near to this point of so many desires and so many anxieties, we had conjectured and calculated, once nore, its place, from many observations and from nearer approaches than had ever yet been made, and with our now acquired knowledge of the land on which we stood, together with the power of travelling held out to us, it at last seemed certain that this problem was reserved for us, that we should triumph over all difficulties, and plant the standard of England on the North magnetic pole, on the keystone of all these labours and observations.

Under the determinations of the navigators who had preceded us, 
the place of this important spot had been calculated, and with a degree of precision, as it afterwards proved, far greater than could have been expected. At the time of our departure from England, it was presumed to be situated in $70^{\circ}$ of north latitude, and in $98^{\circ} 30^{\prime}$ of west longitude. Thus it appeared, that in the course of my land journey to the westward in the preceding year (1830), I had been within ten miles of this assigned place, when near Cape Felix : but, as I was not then provided with the necessary instruments, I could do nothing towards verifying the fact, and had the mortification of being obliged to return, when thus, as I believed, on the point of accomplishing this long wished-for object.

We had now, however, been compelled to pass another winter in our ship, not far from the place which we had occupied in the former year, and I thus hoped that I should be able to investigate this spot more effectually in the coming spring. With this view I carried on a series of magnetic observations during the winter, and thus at length succeeded in assigning a place for this magnetic pole which I believed to be much more accurate than the one which had previously been supposed. The dip of the needle at the place of observation exceeded $89^{\circ}$; and it was thus a much nearer approximation in distance than had yet been attained.

These observations were continued till within a few hours of our May 27. departure from the ship, on a journey which was undertaken for this sole purpose, and we set out on our expedition on the 27th of May, accompanied by Captain Ross and a party under his direction, as far as the shores of the western ocean, when they separated from us for the purpose of returning to the ship by the way of Neitchillee. 
Unfortunately, however, the weather became so very unfavourable that I could no longer continue these magnetic observations: and this vexatious state of things attended us during nearly the whole of our journey across the country. We were, nevertheless, obliged to persist, as it was impossible to wait for better weather when our time was always so much contracted by the state of our supplies. At three in the afternoon of the same day, therefore, we crossed to the opposite shore of the inlet into which the Stanley river flows, and travelled along the land towards the west until eight in the May 28. morning of the twenty-eighth, when we were compelled to halt, in consequence of the ophthalmia, which, from the usual cause, had severely affected four of our party. We had gained but ten miles, and our encampment was made in latitude $69^{\circ} 34^{\prime} 45^{\prime \prime}$, and longitude $94^{\circ} \mathbf{5 4 ^ { \prime }} \mathbf{2 3 ^ { \prime \prime }}$ west.

The weather now became fine for a time, and I was thus enabled to obtain some very satisfactory observations: by which I found that the magnetic dip had increased to $89^{\circ} 41^{\prime}$ north, and that the north end of the horizontal needle pointed to north $57^{\circ}$ west. By means of these observations, therefore, I was enabled to determine both the direction in which we must proceed, and the distance that lay between us and the great object in view, as far at least as this latter could be made out through our instruments and the calculations founded on what they had indicated. I need not say how thankful I was for this fortunate, if temporary, clearing of the weather, since it thus placed us in the right track, and served to encourage even the weary and the ailing, by showing them that the end of their toils was not far off.

But for their sakes, that I might both give them rest and inspire 
them with greater courage, I determined to remain here during the rest of the day, and to repeat the observations; while by this I should also obtain for myself the greater assurance that we were in the right course, especially as I could not henceforward expect any assistance for this purpose from the horizontal needle.

It was not till the evening of this day, therefore, that we resumed our journey. The coast from this place took a western direction, and we proceeded along a low shore of limestone, ending a walk, rendered unusually laborious by the inefficiency of two of the men, in latitude $69^{\circ} 40^{\prime} 27^{\prime \prime}$, and longitude $95^{\circ} 22^{\prime} 35^{\prime \prime}$ west. Of the geological structure of this part of the country, I now find that I have little to say but what has so often been described before; and may therefore suppress the particulars which I noted at the time, since the result was to find the land, wherever I saw it, formed of the same primary rocks that we had so often examined, skirted or covered by the usual bed of stratified limestone.

The evening proved very cold when we renewed our journey at nine in the evening, and the thermometer fell to zero soon after midnight, while a keen north-west wind blew in our faces. We nevertheless persisted in coasting the land; examining all the inlets and harbours which occurred, and thus materially expending our time and increasing our labour.

Having at length completed a direct distance of about twelve miles, we halted, at eight in the morning of the thirtieth of May, May 30. in latitude $69^{\circ} 46^{\prime} 25^{\prime \prime}$, and longitude $95^{\circ} 49^{\prime} 11^{\prime \prime}$ west. At halfafter nine in the evening we again set out; but a thick haze, accompanied by occasional showers of snow, compelled me to lead the party along all the windings and indentations of the coast, that 
I might perform the remainder of that survey which, under such weather, I could execute in no other manner.

Soon after midnight, however, it cleared; and, ascending a high point of land, I obtained a fine view of the inlet, which was now covered, as far as the eye could discern, with an unbroken surface of level ice, replacing the hummocky and irregular masses that had been packed into it when I passed along the opposite shore in the June of the preceding year. This was a proof that, in the latter part, at least, of that summer, this inlet had been free from ice, and might then have been easily navigated had we been on the spot at that time. How much we all regretted this, I need scarcely say. Instead of a laborious walk, with the hazard, at the same time, of want or starvation, we should have been comparatively at our ease in all respects; while I might then, not only have pursued my investigations in security and comfort, so as to have assigned the absolute and exact place of the magnetic pole, but should probably have been enabled to trace the American shore much further towards Cape Turnagain than it was my fortune to do. We encamped at eight in the morning of the thirtyMay 31. first, having completed thirteen miles.

We were now within fourteen miles of the calculated position of the magnetic pole; and my anxiety, therefore, did not permit me to do or endure any thing which might delay my arrival at the long wished-for spot. I resolved, in consequence, to leave behind the greater part of our baggage and provisions, and to take onwards nothing more than was strictly necessary, lest bad weather or other accidents should be added to delay, or lest unforeseen circumstances, still more untoward, should deprive me entirely of 
the high gratification which I could not but look to in accomplishing this most desired object.

We commenced, therefore, a rapid march, comparatively disencumbered as we now were; and, persevering with all our might, we reached the calculated place at eight in the morning of the first of June 1. June. I believe I must leave it to others to imagine the elation of mind with which we found ourselves now at length arrived at this great object of our ambition : it almost seemed as if we had accomplished every thing that we had come so far to see and to do ; as if our voyage and all its labours were at an end, and that nothing now remained for us but to return home and be happy for the rest of our days. They were after-thoughts which told us that we had much yet to endure and much to perform, and they were thoughts which did not then intrude; could they have done so, we should have cast them aside, under our present excitement : we were happy, and desired to remain so as long as we could.

The land at this place is very low near the coast, but it rises into ridges of fifty or sixty feet high about a mile inland. We could have wished that a place so important had possessed more of mark or note. It was scarcely censurable to regret that there was not a mountain to indicate a spot to which so much of interest must ever be attached; and I could even have pardoned any one among us who had been so romantic or absurd as to expect that the magnetic pole was an object as conspicuous and mysterious as the fabled mountain of Sinbad, that it even was a mountain of iron, or a magnet as large as Mont Blanc. But Nature had here erected no monument to denote the spot which she had chosen as the centre of one of her great and dark powers; and where we could do little 
ourselves towards this end, it was our business to submit, and to be content in noting by mathematical numbers and signs, as with things of far more importance in the terrestrial system, what we could but ill distinguish in any other manner.

We were, however, fortunate in here finding some huts of Esquimaux, that had not long been abandoned. Unconscious of the value which not only we, but all the civilized world, attached to this place, it would have been a vain attempt on our part to account to them for our delight, had they been present. It was better for us that they were not; since we thus took possession of their works, and were thence enabled to establish our observations with the greater ease; encamping at six in the evening on a point of land about half a mile to the westward of those abandoned snow houses.

The necessary observations were immediately commenced, and they were continued throughout this and the greater part of the following day. Of these, the details for the purposes of science have been since communicated to the Royal Society ; as a paper containing all that philosophers require on the subject has now also been printed in their Transactions. I need not therefore repeat them here, even had it not been the plan of the whole of this volume to refer every scientific matter which had occurred to Captain Ross and myself, to a separate work, under the name of an appendix.

But it will gratify general curiosity to state the most conspicuous results in a simple and popular manner. The place of the observatory was as near to the magnetic pole as the limited means which I possessed enabled me to determine. The amount of the dip, as indicated by my dipping needle, was $89^{\circ} 59^{\prime}$, being thus within one minute of the vertical; while the proximity at least of this 
pole, if not its actual existence where we stood, was further confirmed by the action, or rather by the total inaction of the several horizontal needles then in my possession. These were suspended in the most delicate manner possible, but there was not one which showed the slightest effort to move from the position in which it was placed: a fact, which even the most moderately informed of readers must now know to be one which proves that the centre of attraction lies at a very small horizontal distance, if at any.

As soon as I had satisfied my own mind on this subject, I made known to the party this gratifying result of all our joint labours; and it was then, that amidst mutual congratulations, we fixed the British flag on the spot, and took possession of the North Magnetic Pole and its adjoining territory, in the name of Great Britain and King William the Fourth. We had abundance of materials for building, in the fragments of limestone that covered the beach; and we therefore erected a cairn of some magnitude, under which we buried a canister, containing a record of the interesting fact: only regretting that we had not the means of constructing a pyramid of more importance, and of strength sufficient to withstand the assaults of time and of the Esquimaux. Had it been a pyramid as large as that of Cheops, I am not quite sure that it would have done more than satisfy our ambition, under the feelings of that exciting day. The latitude of this spot is $70^{\circ} 5^{\prime} 17^{\prime \prime}$, and its longitude $96^{\circ} 46^{\prime} 45^{\prime \prime}$ west.

This subject is much too interesting, even to general readers, to permit the omission of a few other remarks relating to the scientific part of this question, desirous as I have been of passing over or curtailing these. During our absence, Professor Barlow had laid 
down all the curves of equal variation to within a few degrees of the point of their concurrence; leaving that point, of course, to be determined by observation, should such observation ever fall within the power of navigators. It was most gratifying to find, on our return, that the place which I had thus examined was precisely that one where these curves should have coincided in a centre, had they been protracted on his magnetic chart; and if I do not here state these particulars in a more full and scientific manner, it is because of the limits which I have drawn for myself, and because I can refer to his paper, which was read to the Royal Society six months before our arrival in England.

One further remark I must yet be permitted to make: since in relating what has been done, it would leave an important question imperfect did I not also note what remains to be effected.

It has been seen, that as far as our instruments can be trusted, we had placed ourselves within one minute of the magnetic pole, but had not fixed on the precise spot; presuming that this precise point could be determined by such instruments as it is now within the power of mechanics to construct. The scientific reader has been long aware of this : if popular conversation gives to this voyage the credit of having placed its flag on the very point, on the summit of that mysterious pole which it perhaps views as a visible and tangible reality, it can now correct itself as it may please; but in such a case, while a little laxity is of no moment, the very nonsense of the belief gives an interest to the subject which the sober truth could not have done.

To determine that point, with greater, or with absolute precision (if indeed such precision be attainable), it would be necessary 
to have the co-operation of different observers, at different distances, and in different directions, from the calculated place; while, to obtain all the interesting results which these must be expected to furnish, such labours should also be carried on for a considerable time. What these several expectations are, I need not here say, since the subject is, in this view, somewhat too abstruse for popular readers; though I may barely allude to the diurnal and annual motions of the needle, and to the variations in the place of the pole itself, with the consequent deductions that might be made as to the future in this respect : all of them being of the highest importance in the theory of magnetism.

Having thus therefore stated, however briefly, what yet remains for future observation, having pointed out what, I may fearlessly say, is still wanting, and which, as such, claims the attention of those who have the power of promoting a work of this nature, I can only express my wishes, if I dare not indulge in hopes, that the same nation which has already carried its discoveries so far, that our own Britain which has already established its supremacy in scientific and geographical researches, will not now abandon them, and leave to others to reap the crop of which it has in this case sown the seeds. That the place for the needful observations is now far more accessible than it was once supposed, has been proved by our own voyage and its results; so that the main difficulty is at least levelled, and the readiest, excuse that could have been offered is no longer of any weight.

The chief object of our present expedition having thus been accomplished in a manner even more satisfactory than we could have expected, and in a shorter time also than we had much right 
to anticipate, I became desirous to extend our knowledge of the country as much further to the northward as the state of our time, and of our finances, if I may give this name to our provisions, would permit. Unluckily, the latter would not allow me to devote more than one day to this object. I could only wish that we had been better stored $w$ th the means of travelling: but, as on all former occasions of a similar nature, it was idle to regret what no contrivance on our part could have remedied. Oh that men could live without food! was a wish that had never failed to obtrude itself on every occasion of this nature.

I therefore left the party in their little snow camp, under the care of Blanky, and proceeded with Abernethy, at eleven in this our day-like night, along that shore which here stretches to the northward. After some very quick walking, we arrived, by three June 2. in the morning, at a point of more than ordinary elevation. We dared not venture further, for the reasons just assigned: but hence we saw the line of the coast stretching out due north to the distance of ten or twelve miles; while $I$ then also concluded that it preserved, in all probability, the same direction as far as Cape Walker in latitude $74^{\circ} \mathbf{1 5}^{\prime}$. Here we erected a cairn of stones, to mark the utmost limits of our investigations in this quarter, and, returning homewards, rejoined our companions at eight in the morning.

In our absence, a hole had been cut through the ice for the purpose of examining its thickness, which was found to be six feet and eight inches. The time of high water had been observed to be a quarter of an hour after noon, and the rise and fall of the tide somewhat less than three feet.

We had not been an hour in our hut before the wind shifted to 
the southward, bringing on thick weather, with snow; on which the thermometer rose to the freezing point. The cold, therefore, no longer annoyed us; but the consequence was as vexatious, or even more tormenting, since the snow of our huts melted under this temperature and that of our bodies, so as to wet us in a very disagreeable manner. It soon also blew a hard gale; but as that became more moderate about eleven o'clock, we commenced our return to the ship.

For this haste in setting out, we had the best of reasons; being without any thing to eat, as we had departed supperless, until we could reach the place where we had left our baggage and provisions; hoping all the while, and not without ample cause, that no bear, or no equally hungry and more gormandizing native, had discovered that store on which we depended for many suppers and many breakfasts. We reached it, and found all intact, on the morning of the third, at seven o'clock.

The gale had now renewed itself; and it at length blew a storm, with so much drifting snow that it was impossible to think of proceeding for the present. About one in the morning of the fourth, it however moderated so far as to permit us to move; and as we had examined all the shore on this route, in our progress forward, we now met with no cause to interfere with such rapidity as we could exert. Thus we reached the place of our former encampment at ten in the morning of the fifth.

There was now less than ever to delay us, as we had seen all June 5 . that this line of coast could offer, and had done every thing that was to be effected. Our walk was, therefore, as much without note as without interruption, during two days; nor was I sorry that I had not to record occurrences and remarks which had long ceased 
to interest myself, as they must often have appeared tiresome to the readers, equally of my journal, and of that of Captain Ross, indispensable as their relation has been.

June 6. But I must nevertheless note, that on the sixth, in the morning, we encamped on the spot where we had formerly been detained by the blindness of some of our party, already noticed, and that I here repeated the magnetic observations which $I$ had made in the same place during our progress forward, confirming by them that accuracy of which it was so important to be assured. Here also I had an opportunity of examining my chronometer; and was gratified to find that it had preserved a steady rate, since it was the watch by which I had determined the longitudes on the coast which we had now quitted.

At nine in the evening we crossed over to the south-east point of the inlet; but the ice being very rugged, and some of the party June 7. lame, we did not reach it till seven in the morning of the seventh. At two on this morning the thermometer was at only four degrees above zero: that being a severity of temperature which we had never before experienced at the same period of the year.

On the evening of this day, at seven, we set forward once more towards the now well-known Neitchillee, having chosen this road for returning to the ship. During this route, and early on the June 8. following morning, we arrived at a place where we found a large party of the natives assembled; the situation in question being about three miles westward of Cape Isabella. They were busily occupied in fishing; and their prey consisted of the two species of cod, described in the Appendix of Natural History, by the names Gadus Mochica, and Callarias. These they took through some holes which they had made in the ice for that purpose; and 
we discovered from them, that this fishery was a very productive one. Our application for a supply was readily granted, and it proved a very welcome one to all of us, limited, both in quantity and quality, as we had now been for some days.

From this, after resting about two hours, we proceeded onwards to Cape Isabella, and encamped at eight in the morning. But a dense fog now came on, with the effect of rendering our route very uncertain, as it also made the travelling difficult. This we endured as we could, entertaining better hopes for the following morning; when, at six, we again set out, being as soon as was June 9. practicable, and encamped near Padliak; having found it utterly impossible to travel any further at this time, in consequence of the increased density of the fog.

But towards noon it cleared away; and this horrible mist, bad enough in a known country, but incredibly worse amid such obstructions as the surface here for ever presents, and where there is no guide but a compass, was succeeded by bright and brilliant weather. The sun shone forth, in consequence, with such power, that we obtained abundance of water from the streams which ran from the rocks and lodged in the pools formed among them : a far more acceptable supply than it is easy for readers to conceive, as it may, perhaps, surprise them to be told that it was the first natural water that we had obtained during this year, though it now wanted but a few days of Midsummer. Is there aught that can convey a deeper impression of the state and nature of this most atrocious climate? If there be, I know not weil what it is.

If I here also obtained some magnetic observations, as I had before done at Cape Isabella during this returning journey, they are matter for the appendix, not for this place. There at least 
they can be consulted by the scientific reader, among much more, whether in meteorology or in the other branches of natural history, which it has been judged most convenient to place in such a supplement: but as far as the present observations are concerned, the paper in the Transactions of the Royal Society to which I have already alluded, will give complete information to all those who may be interested in this subject. I have, however, attached to the end of this narrative, the means of the observations in question, that they who are inclined may see at least the general results. It is for this simple journal to say, that we proceeded along the valley of Padliak at ten o'clock, and reached the great middle lake, so often described, about midnight. Then coasting along its southern June 10. shore till nine in the morning of the tenth, we halted on the northern point of a small inlet, putting up some grouse, and seeing a number of deer under the pursuit of a wolf.

At ten in the evening, according to our usual plan, which advantageously turned day into night, we directed our course to the north-east corner of this lake, in order to ascertain whether there was any river which communicated between it and its neighbour, so as to discharge this collection of waters into the sea. Thus it proved, and we thence ascertained that to be a fact which had formerly been only a matter of conjecture.

June 11. At three in the morning of the eleventh, we arrived, in this our homeward progress, at another place, now familiar from its having been a spot of rest during more than one of our former journeys; but it presented at this time a very different appearance from what it had done on the corresponding day in the preceding year. At the same place, during that journey, we had been obliged to wade knee-deep in water for nearly two miles, in crossing to the head of 
the inlet of Shag-a-voke. At present all was solid ice, there was not a drop of water any where to be seen, nor was there the slightest mark to indicate the commencement of a thaw. Can it be believed that there were but ten days to Midsummer, that all was still hard winter, and that winter in the middle, I may almost say, of summer: a season such as the January of our own native land seldom sees.

It was no small satisfaction for hard-worked men and hungry stomachs, to find on the opposite shore of this inlet, some provisions which had been deposited for us by Captain Ross; and, taking possession of them, we crossed the two next lakes and encamped, at six in the evening, near the head of the bay into which their water finds its exit.

Here we were detained by a heavy storm from the south-west until noon on the twelfth of June, when it began to moderate, and tempted us to proceed on our now last day of labour; the ship being at length within our reach. But our attempt proved vain. The gale was soon renewed with increased violence, and the snow drifted so densely as to entirely blind us to our way, so that we were compelled, in spite of all our efforts and wishes, to halt and encamp at nine on the following morning. It was an unusual disappointment. If we had on many former occasions been as wearied, as hungry, and as anxious to reach our companions and our home, we had now more interesting news to relate than had ever occurred to us before; but we were to exert our patience, at least this once more, and exerted it was.

But this trial of our tempers was not destined to be very durable. The gale at length moderated so far, that we could contrive to see and find our way; and having but ten miles remaining, we bestirred our- 
selves in proportion, even till midnight; when, after as much hard labour as we could well manage, and might not have endured if not under such a stimulus, we neared our home; still labouring with all our power till we found ourselves at length, and once more, June 13. on board the Victory, at five in the morning of the thirteenth of June. We had been absent twenty-eight days. If we were fatigued and extenuated, who could be surprised? but excepting petty grievances, we were all in good health.

Observations on the Dip of the Magnetic Needle.

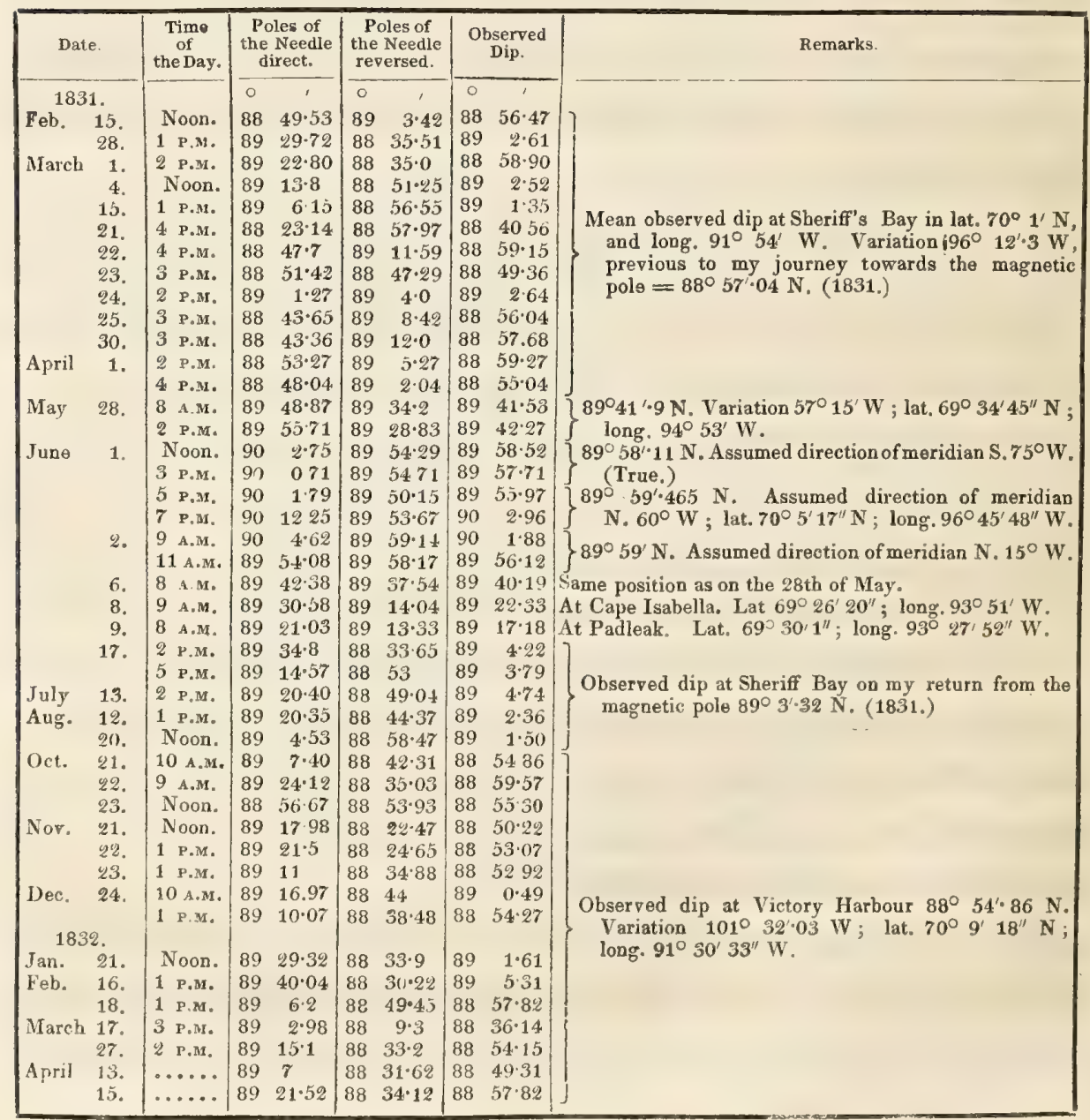




\section{CHAPTER XLIII.}

REMARKS ON THE ASSIGNMENT OF THE MAgNeTiC POLE.

I HAVE not hitherto thought it necessary to add any of my own 1831. remarks to the several journals of Commander Ross: if I do that on the present occasion, it is because I have reserved all my own magnetic observations for the Appendix, so that no opportunity of noticing the important question of the Magnetic Pole has occurred in my own journal.

It might thus have even appeared to the readers of our joint narratives, as if I had taken no personal interest in this investigation : it might possibly be supposed, that in deputing to my active and intelligent nephew, the entire charge of the zoology and botany of this region, I had equally referred to his guidance and labours, every matter of science, and contented myself with the management alone of the ship and its crew.

A popular feeling, alluded to in his journal, which supposes some profound mysteries to belong to the magnetic pole, and some singular miracle, or peculiar good fortune, or marvellous depth of science concerned in its discovery, as if we had unexpectedly found a mountain of adamant or some other wonder never witnessed, has thus also tended to make this product of our voyage a subject of 
discussions which are entirely misplaced, and can only be corrected by a clearer and simpler view of the subject.

That the voyage of the Victory has assigned the place of this particular magnetic pole within at least a very small distance, has been seen; or should I be surprised if it shall hereafter prove, that my energetic and philosophical officer had placed his foot on the very spot, notwithstanding his own doubts; since every man of science, acquainted with the practical difficulties of this subject, whether arising from the imperfection of instruments, or aught else, must know how doubtful or uncertain a truly exact determination of this nature must be, and how easily he may have been right, even when doubting of this himself.

As his narrative has already observed, the supposed place had been long since indicated by many experiments on the dip and the variation of the needle, and, most of all, through those performed by the personal attention or under the direction of Sir Edward Parry. Thus was it known to us, that while we had advanced further into this country than the ill fortune of this officer had permitted him to do, so were we nearer to this presumed point, indicated as it had been by these observations, and others, and by the calculations founded on them. I know not that we should even have felt greater confidence on this subject had we left England with the knowledge of Professor Barlow's calculations, gratifying as it was, after our return, to find how exactly his determination from a sound theory had coincided with our own observations near to and at the very place itself.

While, therefore, this object was among those which we had proposed to ourselves in leaving England, and was but second in our 
affections to the discovery of a passage which should enable us to trace the course of the northern shores of America, even to Behring's strait, hoping too that we should effect this object and return home by Cape Horn, so was it ever kept in view from the first moment of our making the shores of this region, and during the whole of our detention. For this purpose it was, that we, at different times, and in different places, erected those magnetic observatories which I have occasionally noticed in my own journal ; though conformably to its plan, I have nowhere given those observations, nor even alluded to their purpose; as judging them fitter for an Appendix, while reserving any other and general remarks which I might have to make, to the present place.

On the several occasions also of our excursions inland, this was an object ever in view, for whatever other and additional purposes these journeys might have been undertaken; and if in the narratives of those expeditions no notice of this subject has been observed in reading my journal, it is because of the same systematic exclusion of scientific observations, and because no result admitting or requiring a popular record had been obtained, until this last journey by Commander Ross, just narrated, when the successful event which has been seen, had at length furnished the means of such an account of this termination of our labours as has just been given.

It would not now be here worth my while to detail this our progress in the approximation to the magnetic pole, even could it be made intelligible or amusing to popular readers, which is impossible: but scientific men will find them in my Appendix, and can thus trace the last steps to that discovery, or rather determination, which was at length crowned with success. 
If this last journey of thirty miles, as it appears by the narrative; was performed without my presence, which was required in another direction and for other purposes, and this keystone of all our previous labours laid by the party, consisting chiefly of the mates Blanky and Abernethy, under the immediate orders of my successful nephew, heaven forbid that I should attempt to rob them of such honours as they are entitled to on this ground, or to claim the credit of having planted the British flag on this long desired spot with my own hand. Let this last closing act of my labours on this subject, as of theirs, confer such honour on this party as they may claim or deserve: I can say, like others, though in a quotation rather hackneyed, "Palmam qui meruit ferat," and if I myself consent to award that palm to him who commanded this successful party, as is the usage, it must not be forgotten that in this I surrender those personal claims which are never abandoned by the commander of that flag-ship which so often gains the victory through the energy, intelligence, and bravery of the men and officers whom he directs and orders, or by the captain-general who carries a town through the comrage and activity of the sergeant who leads the "forlorn hope."

But if I have done this, I should not be justified in thus surrendering the rights of the brave, and patient, and enduring crew of the Victory, nor perhaps those of him, the noble-minded and generous, who sent the Victory and her crew to the Polar regions. It must be hereafter remembered in history, and will be so recorded, that it was the ship Victory, under the command of Captain John Ross, which assigned the north-west Magnetic Pole, in the year 1831, and that this vessel was fitted out by him whom 
I can now call Sir Felix Booth; a name to be honoured, had it even remained without such a distinction, as long as British generosity and spirit shall be recorded as a characteristic of the merchants of Britain.

In this way and no other, let the discovery of the Magnetic Pole be now viewed; that in doing justice to any, it may be withheld from none. Surely every man of this hard-used ship, from the highest to the lowest, deserves to share in the praise which the public may award for whatever it was our good fortune to effect. It is but a small reward, after all, for what every one endured; and sweet as it may be, it requires much forgetfulness of our past sufferings not to feel that it was dearly purchased, while it would be hard indeed were this tribute withheld from such enterprise, such patient endurance, such toils and sufferings so long continued, and such a spirit of hope and energy, amid circumstances capable of sinking almost any heart into the depths of despair. 


\section{CHAPTER XLIV.}

TRANSACTIONS DURING THE REMAINDER OF JUNE-THE JOURNAL AND THE SUMMARY OF JULY.

1831. SNOW fell to-day, and the ground was so covered, that no land could be seen, nor was there an atom of running water or a single pool visible. The temperature, however, rose to $40^{\circ}$ for the first time. Some grouse were killed yesterday and this day, and also June 15 on the following one. On the sixteenth it snowed; yet the sun \& 16. shone afterwards, and there was at length a pool of water near the June 17. ship. That water froze again an inch thick, and did not open till noon, when some impression was made in the snow, increasing on June 18. the following day, and thus terminating our week.

Jine 19 Sunday saw the usual duties performed. On Monday the day 820 was warm, and the night temperature was freezing. Flocks of ducks and geese were seen flying to the north; and some grouse were killed.

June 21. The sun had now very nearly reached its greatest elongation. It was the summer solstice, and not a drop of rain had yet fallen, nor had the thermometer once made its round of twenty-four hours without reaching the freezing point. But in the course of this day, the first rain fell, lasting two hours: though the ice formed in the night had been an inch thick. 
There was a fresh gale from the northward in the morning; but June 22. on this and the following day, it froze equally hard at night along- June 23. side of the ship. On the twenty-fourth it was still colder; since June 24. the thermometer was at $30^{\circ}$ in the morning, and did not reach the freezing point till nine. On the following it was at the freezing June 25. point all the twenty-four hours, thus bringing round Saturday again. A good many birds, consisting of geese, ducks, grouse, and plovers, had been killed within these past days.

Sunday offered no change; on Monday there was rain in the June 26. evening, and we could now at last supply ourselves with water from the shore. Yet the pools froze again on the twenty-ninth, June 29. the thermometer falling to $31^{\circ}$; and, on the thirtieth, the mean of June 30. the twenty-four hours was but $35^{\circ}$. In the mean time, the rigging of the ship had been going on, and was now nearly completed. It was somewhat dispiriting to find that we should be ready so long before the weather, and that we had arrived at the end of June, had passed the solstice, and were still to see nightly frosts, with little compensation in the day. A winter solstice in England is very rarely indeed what the summer one was in this most miserable region and most abominable climate.

Such, nevertheless, is the climate in which man contrives to live and, as we had no right to dispute, happily. He cannot drink water at Midsummer, it is true, till he has boiled his snow ; and had he not wit enough to produce fire, he would have nothing to drink for nine months of the year. He smells at no flowers, for there are none to smell at; but he prefers the odour of train oil. He has no carrots or "small herbs," for his soup or his seasoning; but his soup and his seasoning are, alike, oil, and he can find a sallad, when his luck 
is particularly great, in the stomach of a reindeer; and that sallad too, cooked in a heat of which the advantages have never been disputed. If he never saw that utterly inconceivable thing called a tree, what matters it, when he can construct coaches of fish, and splinter bars of bones? and if he can make his lodging, not merely " on the cold ground," but on the cold snow, his fare at least is not "hard," and why, if he thinks so, is he not as well lodged as the princes of the earth, the marble of whose palaces does not approach in purity to the materials of his architecture, while his own marble house is erected in an hour, and can be renewed, like that of Aladdin, at every hour of the day, in any place that he wills? Man must be a noble animal, that is certain, be he even under the figure and bearing of a Boothian Esquimaux: is there another beast on earth that could do all this, endure all this, contrive all this, conform to all this, to all this and more, and still be happy: happy if he is in Naples, happy too in Boothia Felix?

But that climate which suited those who know not another or a better, had a very different effect on our feelings, independently of the actual sufferings and privations of which it was the cause: Where all the happiness was based upon the abundance of eating, and where there was nothing to prevent that steady supply of the materials of this happiness, which these specimens of man partook with the animal tribes to whom it constitutes the almost sole enjoyment and purpose of life, all that the severity or badness of the climate could effect was nothing; nor, caring little for a hard winter or a long one, had they any reasons to anticipate a season, bad or guod, to hope or to fear. 'The present state of things was very different to us ; whose misery it was to fear, or to hope, (equal 
miseries in the result $I$ imagine) respecting a summer that might not arrive till winter was once more at its heels, and once more about to resume a command that was likely to endure for the better part of another year.

The summary of the month is not consolatory. If we had considered the last June as colder than any which had been recorded in former voyages, the present had turned out much worse, having been both more cold and more stormy. For the first two weeks, the mean temperature was $7^{\circ}$; and during the last, between $2^{\circ}$ and $3^{\circ}$ : giving a mean, for the whole month, less by $5^{\circ}$ than that of the preceding June. Moreover, the first rain fell on the twenty-first, and was little more than a shower; whereas, in the former year, that had occurred on the tenth. I have already noticed that the summer solstice had passed without our having had one whole day above the freezing point.

There was much stormy weather; but it is also a remarkable fact, that while, in the former year, the temperature always rose on those occasions, it never altered in the present one; making an essential difference between the two seasons, the cause of which was not apparent. The general result, in the state of the snow and the ice, has already been seen; and the prospect was therefore sufficiently discouraging. At the best, and should no worse come, this season was three weeks later than any former one on record in this climate. The possible future was still before us: it might prove better than was expected; but I am not quite sure that many of us hoped much.

Except the mate Taylor, all the men were now well, and his wound was healing. The supply of fish by the natives had been 
abundant and beneficial. The late period at which the waterfowl arrived was remarkable; but our sport in general had been more successful than formerly.

Commander Ross had explored much more of the coast; and it was remarked by both of us, that the temperature on the western side of the peninsula and on the western lakes, was from $10^{\circ}$ to $15^{\circ}$ lower than that at the ship, which was on the east side; while the comparisons were made with such care that we could not have been deceived. 


\section{CHAPTER XLIV.}

PROCEEDINGS IN JULY, AUGUST, AND SEPTEMBER, WITH THE SUMMARIES OF THOSE RESPECTIVE MONTHS.

THE morning was cold and stormy, and it continued to blow July 1 \& 2 . hard in squalls during the following day, the temperature falling to $31^{\circ}$ and the air feeling extremely cold. There was snow at nine, and it moderated. Commander Ross went out shooting with a party, and met a collection of five native families, all strangers to us except one, who had been once on board during the former summer. They pitched their tents for the night, and five of the men came to the ship with our officers, making as much clamour on their arrival as our original friends had done. They had heard of us at Neitchillee, and came for the purpose of bartering some clothing for our valuable articles.

It was proper, of course, to go through all the usual exhibitions of wonders, and the effects were such as might have been expected. They had heard of the more northern men, whose portraits we possessed, but had never seen a ship, as their stations were further west than Akullee. Each received a piece of iron hoop as a present, and they engaged to bring their articles of barter the next day, together with their wives and families.

The frost was so severe in the night, that it froze an inch and a July 3. 
half thick near the ship. There were several showers of snow in the forenoon, and in the evening it blew a fresh gale. Soon after church the natives arrived, forming a large collection of men, wives, and children. They were good looking, as Esquimaux, and their behaviour was orderly ; but they had brought only a pair of sealskin trousers for sale. All were entertained in some part of the ship or other, and none of the women were dismissed without some present, including among these, the valuable tin canisters. The husbands seemed particularly pleased by this attention to their wives.

It really seems as if these people possessed some of those feelings of gallantry, or chivalry as it has been termed, which have been supposed peculiar to the refined among men and nations. How rare this is among the "savages" of the world, every one knows; how directly the reverse the feelings and the conduct are, in most of the islands of the southern ocean, and above all, in Australia, has been long familiar. If we are correctly informed, many others of the Esquimaux tribes in Northern America conduct themselves towards their females in no better manner than the Australians; while among the red Indians of the same portions of this continent, if the treatment of wives varies among different tribes, the balance far inclines to that mixture of severity and neglect which is assuredly the general rule for man in his uncultivated state.

Whence is this difference, equally characteristic of the present tribes and of the Greenlanders? We could not be mistaken as to the facts, if sometimes conscious that our temper was to look at every thing in the most favourable light; and if, to European eyes, what we hear occasionally related of the occupations and duties of 
the women seems to point to a different conclusion, it must be remembered that these belong to a system of the "division of labour." In such a condition, the women cannot be idle; there is no leisure for that idolatry of the sex which would keep them as objects, either of admiration or amusement : all must work, or most would starve: while it is also true, that the duties of women are here claimed as rights, even as it is the right of the women, not their service, to carry the men out of the water on many parts of the French and Dutch coasts, where also any infringement of these on the part of the men, would be resisted by every weapon which the sex so well knows how to use.

It has been said that this gallantry belongs most conspicuously, if not exclusively, to nations under kingly or despotic governments, even as it did to that singular species of despotism which constituted the feudal system. We can refer to the Greek republics in proof of this theory, in the reverse manner; and who is there now, that is not equally ready to quote the United States of America, where the feelings of democracy, in necessarily rendering all men tyrants, has produced that neglect, at least, of the sex, which is as near an approach to oppression as could be practised in a country so far partaking of Europe as it does. In the blessed country, however, now under review, this theory does not apply, for there is not even an aristocracy, as there is, in reality, no government; so that I must leave it to others to solve this problem: while this history of the palmy state of the fair portion of creation in Boothia Felix, may also tend to show that no hypothesis yet advanced is competent to the solution of that great question, namely, the treatment of women by the other sex, its causes and its modes. 
July 4. The men came to-day, according to promise, bringing some clothing and trifles for sale; but they went away soon, with a promise July 5. to return with some seals and some fish. There was snow, both on this day and the next, and the thermometer still fell to the freezing point at night. In the morning the strangers appeared, informing us that they were going to fish in the lake and at the river where we procured the fish last year: on which Commander Ross engaged to accompany them.

July 6. Fog and snow continued; but when our officers had arrived at the native huts, they had been all taken down, and the party was gone in the direction of Neitchillee. We were unable to account for this change of plan. A litter of foxes was discovered by one of the mates, who had killed the male; and a party going out on July 7. this day, shot the old female, and brought away six living cubs. In Boothia Felix there is not at least starvation enough to prevent foxes from having sufficient families. About twenty ducks, and some other birds, were shot on these different days. There was nothing July $8 \& 9$, to note on Friday and Saturday; which last ended with the night thermometer at $33^{\circ}$.

July 10. There was a fresh northerly breeze on Sunday, and it was very July 11. cold. On the following day, it was more squally, and the maximum July 12. of the thermometer was but $37^{\circ}$. On the twelfth, there was the highest tide that we had ever seen; since it rose to more than eighteen feet, being the third day after the moon's change. Our sport was very successful; and we found among other birds, the July 13 Lapland finch with its nest of eggs. The thermometer rose to $40^{\circ}$, \& 14. but fell again on the next day, which was very cold, with sleet and rain and an easterly wind, so that the evening ended at $33^{\circ}$. I 



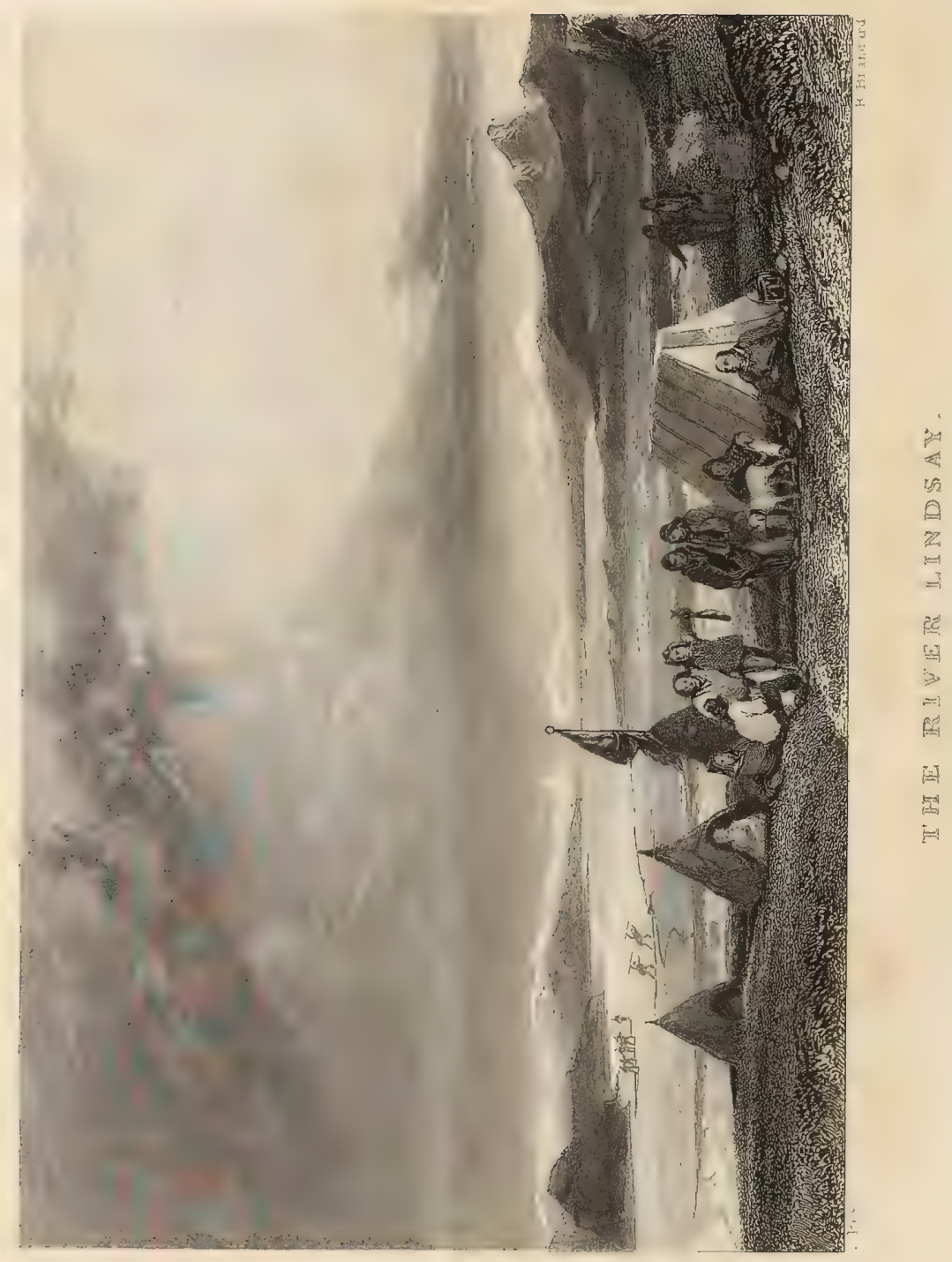


contrived to take several fish, on these days, by means of the spear which the natives use for this purpose.

This morning displayed a mixture and succession of rain, snow, July 15. mist, and clouds; any where else, it would have been a bad fifteenth of November instead of a fifteenth of $\mathbf{J u l y}$, and it nearly froze at night. Two of the natives came with thirty pounds of salmon, informing us that they had many more ; on which it was settled that Commander Ross should go with a party to fetch them; a journey that would occupy four days. On the sixteenth, the thermometer July 16. reached $44^{\circ}$, being the finest day we had yet seen during this year; and Commander Ross, with the surgeon and eight men, accompanied by the natives, departed. Why did we not believe it a fine and warm July day? It could have been but $84^{\circ}$ in England, and when our Christmas heat was but eighty degrees under that of our own country, why should we not have thought a difference of no more than forty a precious boon?

It continued still fine in the day-time, but the thermometer sank to $34^{\circ}$ at night, and it froze on Monday morning, though the heat July 18. of the day was again $44^{\circ}$. It could scarcely indeed be otherwise, surrounded as we were by snow and ice, on which all that a nocturnal sun could do was without effect. It did not materially change on July 19. the nineteenth; and, in the absence of the rest of my companions, my time was passed in taking angles and observations, and in shooting, while the men on board were busy in caulking. Our boats were sunk in the water, to prevent them from splitting.

The mate and five of the men arrived with a sledge load of fish, July 20. and we found abundant employment in sorting and disposing of them. A large proportion belonged to a store of the former year, 
and was not, therefore, in very good condition; thirty-seven, taken in the present one, weighed 129 pounds. After rest and refreshment, the men set out again at nine in the evening, with three days' more provisions, the pontoon, a net, and three dogs, to join Commander Ross, who remained fishing, with the natives, at the place where he had appointed them.

July 21. The weather was the same; there was a warm day with a cold night. I shot a hare in its summer coat; and the ptarmigans had been observed changing their plumage some time before. I now found that there was a much greater variety of small birds here than we had supposed last year: many that $I$ saw this day were unknown to me: but I met with the nest of a sandpiper, with the July 22. young, as I did again on the following day. On that one there was some rain: a rare event as yet, in this extremely backward season. The surgeon arrived before the evening, to report that sixteen hundred fish were taken, and to demand assistance for the purpose of bringing home four hundred which were on the road. These arrived consequently, at midnight; and the whole of the July 23. next day was fully occupied in cleaning and packing them in several ways; among which, some were preserved in vinegar. The weight of those four hundred, after all these operations, exceeded a thousand pounds : it was a great addition to our stock.

July 24. Having no Sunday congregation to-day, from the absence of nearly all the people, there was no service. I found a nest of snow buntings ready to $\mathrm{fly}$, which I brought on board, hoping to rear them up July 25. tame. Five of the men from the second party arrived on Monday, much exhausted. They had lost their way, and had left the sledge five miles off, having, very improperly, no officer with them. Mr. 
Thom and the remaining men returned with them after they had rested, and at six, they brought back five hundred fish, cleaned, and weighing 1500 pounds. The curing and packing of these found employment for every one.

The party again set off for more fish, after the sledge had been repaired; and on the next day, they returned with two hundred, July 26. which was all they could carry; bringing also a note from Commander Ross, by which I learned that they had taken 3378 fish at one haul. The ice was, however, decaying so rapidly, that he found they could not all be conveyed to the ship in a sound state, even had the roads permitted. There was abundant work for us now, and no prospect of want; those that could be spared were sent back on the same errand, to the halfway island where these fish were deposited.

Commander Ross arrived, reporting that both his parties were July 28 . on their way, with five hundred fish: and that there were as many more to bring from the island. They had taken, in all, five thousand and sixty-seven, but were obliged to leave three thousand of them to the natives; the breaking up of the ice compelling them to quit their position. At five, the first party returned, having left the sledge two miles off. One of them was ill, and the rest could bring it no further. The second party came in at eight, with three hundred fish, and with the man, Buck, who had been seized with epilepsy, on the sledge. In the evening, both sledges returned to the island to bring back the tent, the net, and the remainder of the fish.

The thermometer at night was but $36^{\circ}$; but the following day July 29 . was the warmest we had seen, as the mid-day heat was $50^{\circ}$, and July 30 . 
the mean $41^{\circ}$. At eight in the morning, one of the sledges came back with the nets and tents, and three hundred and fifty fish. Finding that two of the men belonging to the other sledge were exhausted, two others were sent to replace them, and all returned at ten. The thermometer on Saturday night was $41^{\circ}$ : it had never yet been so high at that hour.

July 31. The day of rest was especially acceptable. The ice at length dissolved so much, that we could not get on shore from the ship without the aid of a boat; though this bay was far from being so clear as it was at the same date in the last year, while the ice in the offing was not nearly so advanced in decay. The month ended at last, with fine weather: there was not a cloud to be seen when the sun set at midnight.

A comparison of the mean temperature of this July with the preceding one, shows that it had been nearly $70^{\circ}$ colder : that having been $37^{\circ}$ instead of $44^{\circ}$. The highest heat had been $70^{\circ}$ in the last: in the present, it was but $50^{\circ}$ : but the lowest only differed by one degree; being $32^{\circ}$ in the former, and $31^{\circ}$ in this period.

There had been much work for the men, in fitting the ship for sea; and a good deal of extra labour in travelling and in the curing of fish. Many had, in consequence, been ailing as well as fatigued, but were recovering; as was the man whose foot had been amputated. He with the epilepsy was the chief patient; but as he had not experienced a fit ever since we had taken him on board, we hoped that it might not soon return.

The men having become more practised sportsmen, our success in this way had gone on increasing; and as every thing was thrown into the public stock and divided among the messes, the game thus obtained a useful variety in their diet. 
If our success in fishing made up for the disappointment which we experienced from the natives, so was it of great use to them. We had discovered that the salmon arrived, on the breaking up of the ice, in even greater crowds than we had at first understood; since, by entering the water outside the line of their course, the natives could drive them into the small pools on the shore, or even on the dry land itself. It is plain, that whatever the seals may devour, the fish cannot here have many enemies: while this, indeed, seems generally true of all the northern shores where salmon abound.

By accompanying us in our fishery, the natives had now, for the first time, seen the use of a net, and what is not always the case with those whose conceit is ever commensurate with their ignorance, they were fully aware of its value. Seeing this, we took the trouble to teach them the art of making one, though not quite sure whether the materials to which they are limited would enable them to fabricate any that could be of much use. If this should, however, prove the fact, then had we taught them a valuable art, in making them a present of knowledge which, to them, was of the first importance; in this too, improving their condition in a greater degree than by all the useful tools and materials which we had sold or given to them.

One consolation we assuredly had derived from our communicacation with them, of a more durable and agreeable remembrance than all the advantages that we had gained from them in the way of trade. We had sold them no rum, we had introduced no diseases anong them, nor had we, in any thing, done aught to corrupt their morals or injure their healths, to render them less virtuous or less 
happy than we had found them. Nor had they learned any thing from us, to make them discontented with their present and almost inevitable condition. On the contrary, while we soon hoped to leave them as happy as we had found them, we had reason to believe that they would hereafter so far profit by our example, and by the displays of knowledge and ingenuity which they had seen with us, as well as by the various useful things we had distributed among them, as to augment their own ingenuity and resources, and thus improve their condition of life as far as that was capable of improvement.

That we could not instruct or improve them in religion or morals, we might regret; but we could not blame ourselves for not undertaking a task which was rendered impracticable by the limited nature of our communication, and the obstructions consequent on our deficiency in their language: we at least made the only attempt in our power, by endeavouring to instruct one of their youths; but how this failed, I have formerly shown. Where navigators in general have committed so much evil among the rude tribes which they have visited, even this negative conduct was a matter of self-congratulation: while we can now, at home, and when we shall see these people no more, reflect with pleasure on what we avoided to do, and even on what we did; indulging too at times in the dream, that should they ever again be visited by an European people, our memory may be handed down to a remote posterity, with, possibly, as mysterious a fame as that which gilds the name of Manco Capac.

The chief observations made in this month relate to the terrestrial refraction : those of the usual nature were continued when that 
was practicable. The collections in natural history had been augmented.

We were still fast frozen up, though our canal was likely to be soon open; but the bay was even yet full of ice, and that in the offing "hard and fast:" in the preceding year at the same time, it was all in motion, and the bay presented a wide extent of clear water.

I think it proper to state here the mode in which our new supplies of fish were managed and disposed of.

Account of the Supply of Salmon obtained at the River, and received in July, 1831.

Seven casks of salmon pickled in hot vinegar, in No. 1378

One cask pickled and dried _ _ _ . 144

Slightly salted on the rocks - $\quad$ - $\quad$ - 177

Fresh split and dried on the rocks _ _ _ 131

In jars pickled with vinegar $\quad \ldots \quad \ldots \quad \ldots \quad \ldots$

Used for the ship _ _ - _ _ - 80

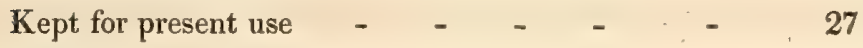

Specimens - - $\quad$ - $\quad$ - $\quad$ - $~ 27$

Received in bags afterwards - $\quad$ - $\quad 302$

2836

Three hundred were afterwards brought to the ship, but only thirty-six were fit for use: the rest were given to the dogs. 


\section{CHAPTER XLVI.}

JOURNAL OF AUGUST-THE VICTORY MOVED OUT OF HER HARBOUR -ATTEMPTS TO PROCEED ALONG THE SHORE-THE SHIP FORCED BY THE ICE INTO ANOTHER HARBOUR-SUMMARY OF THE MONTH -JOURNAL OF SEPTEMBER, AND ITS SUMMARY.

1831. $I_{T}$ was fine weather: a party went for the remainder of the fish and returned to dinner. The ship had long been heeling to starboard very inconveniently; but she was now cut round, and came August 2. upright. The refraction was very extraordinary on the following August 3. day; and the third was true summer weather. On this day the ice gave way near the ship, so that she advanced half her length. It $\Lambda$ ugnst 4. rained heavily on the next, and she was moored by a hawser to a large iceberg outside of us.

August 5. It was cold again. The gunpowder was brought on board, and August 6 . the whale boat repaired. On the sixth, a party on shore observed the ice in motion to the north-eastward, for the first time. There was one large pool; and the separation appeared to extend from Angust 7. the islands to the back of the southern hill. On Sunday, it had August 8. enlarged considerably, and was still increasing on Monday, when the ice was also visibly in motion, though it did not open much.

August 9. On the next day, the large iceberg ahead of us split and upset; obliging us to lay out a hawser in another place. 
The wind was still from the north, but there was no further August 10 . change in the ice: the weather proved foggy and rainy. The fol- Angust 11. lowing day was little different; but we hove out a little further, and got the Krusenstern alongside. On the twelfth there was no August 12. change; but a party of the natives arrived, including four of our original friends and six strangers. They were at a fishing station two days off, and promised to return in two more, with some skins for sale. The strangers received the usual present of iron hoop; and were treated with a supper.

The party returned, wives, children, and all, to the amount of August 13. twenty-three, and were regaled by us with a dinner of fish and fat. We purchased some clothing, and accompanied them to their tents; glad of even their society, under our present dearth of variety or amusement.

Is there any thing that can convey in a stronger manner our utter destitution of all that can interest men, whether in occupation or amusement, than to confess that we found a relief from the selfconverse of our own minds and the society of each other, from the eternal wearisome iteration of thermometrical registers and winds, and tides, and ice, and boats, and rigging, and eating, in the converse of these greasy gormandizing specimens of humanity, whose language we could scarcely comprehend, yet whose ideas were, I believe, more than sufficiently comprehended without any language at all. Let no one suppose that we had not felt all this, during months, first, and during years, afterwards, if I have not told it, if $\mathrm{I}$ have passed it all by, as if we had never felt it. There were evils of cold, and evils of hunger, and evils of toil ; and though we did not die nor lose our limbs, as men have done in those lands; 
we had to share with the rest of the world, those evils of petty sickness which are sufficiently grievous while they exist, though they make but a small figure in the history of life, and would make a much smaller one in that of such an expedition as ours. Had we not also undergone abundance of anxiety and care; of the sufferings of disappointed hope; of more than all this, and of not less than all, those longings after our far-distant friends and our native land, from which who that has voyaged far from that home and those friends has ever been exempt? And who more than we, to whom it could not but often have occurred, that we might never again see those friends and that home? Yet was there a pain even beyond all this; and that grievance seldom ceased. We were weary for want of occupation, for want of variety, for want of the means of mental exertion, for want of thought, and (why should I not say it ?) for want of society. To-day was as yesterday, and as was to-day, so would be to-morrow: while if there was no variety, as no hope of better, is it wonderful that even the visits of barbarians were welcome, or can any thing more strongly show the nature of our pleasures, than the confession that these were delightful; even as the society of London might be amid the business of London?

In the night which succeeded to this day, the thermometer fell to $36^{\circ}$, and it was therefore far from warm : of course, the ice remained unaltered, as may be easily conjectured. It is difficult to convey to my readers the impression produced by this sleepy and stationary condition of a sea thus impracticably frozen. When the winter has once in reality set in, our minds become made up on the subject; like the dormouse (though we may not sleep, which would be the most desirable condition by much), we wrap ourselves up in 
a sort of furry contentment, since better cannot be, and wait for the times to come: it was a far other thing, to be ever awake, waiting to rise and become active, yet ever to find that all nature was still asleep, and that we had nothing more to do than to wish, and groan, and-hope as we best might.

In this visit to the tents, we found that the wooden leg was once more ailing, in some manner of which I did not particularly inquire, since the carpenter-doctor was at hand to examine into the grievance, and was ready to repair it as he best knew how. If, in this matter, he had always displayed abundance of good nature, I believe this to be a praise which was amply deserved by our crew in general, in all our communications with these people. I do not say that any of our men were not really kind in their dispositions ; but certain it is, that good nature is not less contagious than the several evil passions, and that as one peevish or irascible person renders irascible or peevish, a nature otherwise kind and gentle, or finds him to be of morose conduct whom another person or another society esteems as among the agreeable and the mild, so do gentleness and smoothness of disposition and conduct, on the other hand, produce the same character even where it may not actually exist; or, at the least, ensure the display of good nature, where an opposite temper may be the more natural one, and when morose or peevish conduct would have called that into its worst activity. Let the married, at least, profit by a remark to which the gentle tempers of our Esquimaux have given rise. They were not only kind, but as Falstaft says of wit, they were the cause of kindness in those around them, including ourselves; and perhaps, among ourselves, in one or two, who, with a different people, would have displayed a far other character than they did. 
August 14. The natives were not permitted to come on board till after church, when the boat was sent for them. The wooden leg had been bound with copper, and was better than ever. We bartered and made presents as usual. They were to divide their party the next day, for the purpose of going to Shagavoke and to Neitchillee, and promised to bring us venison in the winter. A seal was shot to-day : it was a sport in which we had hitherto found no success.

August 15. The weather was very bad, with an easterly gale and rain, which prevented the natives from moving. In consequence, ten of them came on board, chiefly to apologize for their dogs, which had broken loose and stolen some of our fish. The poor animals had been punished accordingly, and somewhat too severely. This always appeared to us the greatest defect in the general domestic conduct of this people; and it has been equally a subject for the remarks and censures of other voyagers and travellers among these races. They derive great services from their dogs, yet never appear to love them. The animals are hardly used, and worse fed: they would be treated far worse, in every way, were it not for their indispensable utility. It might be an excuse, that the canine race is not here of an amiable character; yet I suspect that this character is only the result of their treatment, and that were they domesticated and treated with the kindness which they experience among ourselves, they would be as attached to their masters and companions as our own are. Yet perhaps I ought not to blame them. Fngland does not treat its horses in a much better manner; and the comparison too between a pack of British fox-hounds and a team of Esquimaux dogs, would not leave much to boast of on the part of our own countrymen. The men were treated to the seal for their dinners; and, in the evening, they left their post, after 
having previously renewed their promise of supplying us with venison in the winter. The ice was in motion, and the pool which had opened was filled up again.

After a continuance of the rain, there was a heavy fall of snow, August 16. and the ground was all covered again, as it had been in the winter, until a renewal of the rain dissolved it once more. The following day presented a mixture of fog, snow, and rain, but it became calm August 17. in the evening; only, however, that the same weather might return in the morning. It was mild on the next; but no alteration took August 18 place in the ice during these three days. On the twentieth, August 20. a southerly breeze made the ice move in the offing, but, coming round to the westward, the motion of this great body of floating masses ceased once more; notwithstanding which, a considerable pool appeared on each side of the point.

There was some shifting of the ice on Sunday, so that it was August 21. loose about the ship; but it came in at last and filled up the bay as before. The next day there was rain which ended in sleet, as the August 22. thermometer was never above $33^{\circ}$. It seemed as if the new winter was already commencing. It was cold and foggy on Tuesday, but August 23. mild on the following day, and every thing remained as it had August 24. been. The shooting of another seal was the only variety.

The weather was much the same, but the ice near us was in Angust 25. motion. The whale boat was thus jammed between the ship's side and a large piece of these never-ending rocks, which, float away as they might, only departed to be succeeded by as bad, or worse, since the storehouse which supplied them was inexhaustible. "Till the rocks melt with the sun" is held that impossible event, in one of the songs of my native land, to which some swain com- 
pares the durability of his affection for his beloved; and I believe we began at last to think that it would never melt those rocks, which, even at this late period of the year, continued to beset us in every shape which their beautiful, yet hateful crystal could assume. Oh! for a fire to melt these refractory masses, was our hourly wish, even though it had burnt up all the surrounding region.

The injury which had thus been sustained by the boat was such that she could no longer be repaired so as to carry six oars. We therefore determined to construct a smaller one out of her, and she was accordingly taken on board. Another seal was shot. The thermometer was $38^{\circ}$ at midnight.

August 26. It fell to $34^{\circ}$ the next night; and the wind being from the south in the evening, the ice began to move, so as to show some clear August 27. water. The tide was high on the next day, and floated off so much of it as to open a line of water, a mile in length, to the northward. Ducks of different kinds, with other birds, were shot within these past days; and we had now a living menagerie on board, consisting of four foxes, three hares, and twelve northern mice.

August 28. The wind blew strong from the westward on the twenty-seventh, and the ice began to drift out of the bay, to the eastward. But it was evening before a passage was practicable. The ship was then warped a quarter of a mile to the south-west, into a convenient place for taking advantage of the first opening. As soon as this was done, we got under sail, but, unfortunately carrying away the mizen boom, could not weather a piece of ice. She was thus brought about by it, and equally failed in weathering a large iceberg on the other tack, which was grounded; by which means she took the 



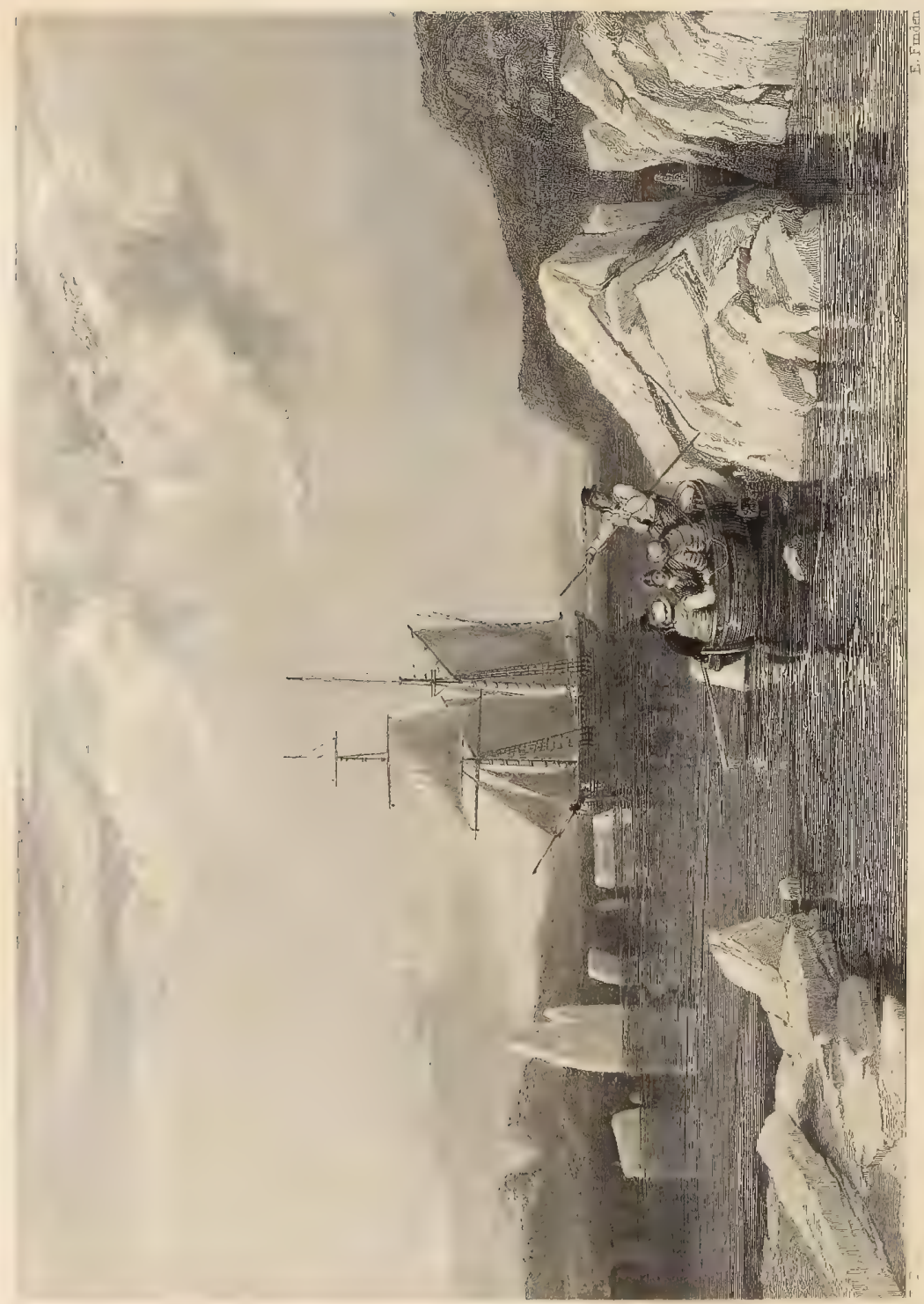


ground herself. We soon, however, hove her off by hawsers to the shore; and though her bottom did not prove to be damaged, the lower rudder iron was broken, so that there was an end to our progress for this day.

Early in the morning the rudder was repaired, and the wind August 29. remained steady and strong at west, with occasional snow. It was the very wind that we wanted; and, after much doubt and anxiety, we felt that we were at last liberated: liberated, however, not yet free. We cast off, therefore, soon after four, and, with a reefed topsail, stood for the islands through what appeared to be loose ice. Unluckily, when about two-thirds over, the wind came to the north-west, and we were unable to fetch within a mile to the eastward of them; after which, shifting to the north, with a snow squall, it brought the ice down along the north shore. We were therefore obliged to ply to windward, in which we derived much assistance from our new leeboards. At nine it backed again to the north-west, and we were soon close in shore, after having run four miles.

We had passed two bays, and two remarkable rocks, when, at one, a heavy shower of snow coming on, we were obliged to haul our wind, and stand in for a little bay; where a baffling breeze nearly laid us on the rocks, and the weather shortly began to threaten for a storm. A boat was therefore sent out with warps, to a rock on shore; but slipping off while we were hauling on them, we were obliged to let go the anchor in twenty-three fathoms. After this, however, we weighed and warped to the weather shore, during which we were able to examine the bay, which we found to be secure from all points of the compass except 
four, and completely out of the stream of ice when that was moving under the tides and currents.

We therefore warped to the head of this new harbour, where a small river entered, and immediately made fast to the shore with two hawsers. No sooner, however, had we done this, than a violent gale came on from the north, with a heavy fall of snow, which compelled us to carry out more hawsers. We here saw the ice passing to the south-west with considerable rapidity, and had occasion to be very thankful that we were so secure. Under this feeling, the hard labour which every one had undergone was soon forgotten.

August 30. It was very cold in the morning, and the thermometer was but $24^{\circ}$. The wind shifted from north to south, and back again, carrying out some new ice which had formed. From the shore, the passage was seen to be clear, at eleven, as far as Andrew Ross island, but the wind was right against us. We found the latitude of this harbour to be $70^{\circ} 18^{\prime} 11^{\prime \prime}$; and, on examining the land further, $I$ found that the inlet to the north of the passage approached within a mile of us, while the intermediate space was occupied by a chain of three lakes nearly filling a sort of valley in it. This cape was therefore a kind of peninsula. From one of the hills, nothing was visible to the northward but one vast sheet of ice, pressed up into hummocks, extending round to the western bay, and completely blocking up our late harbour. It seemed therefore as if we had just got out of it in time, whether it should be our fate to get any further or not.

August 31. The wind fell, and we went on shore to examine the state of things in the strait; when we found every thing blocked up with 
ice : it was impassable. We shot two hares, and found them already in their winter dress. Round the ship, the bay ice was troublesome, but no heavy pieces came in. The wind then came to the southwest, and we hanled further out, in case of a favourable change. The month of August was ended, and we had sailed four miles.

It had been as unpromising a month as it had been an anxious one. The mean temperature was lower than in the preceding August; the snow remained longer on the ground, and fewer of the animals which, in these countries, migrate to the north had appeared. The ice was not so much decayed as it had been last year at the same period, and there had been much less motion among it.

If the last days were the only good ones for our purpose, they had brought us four miles, to the place I had named Mundy harbour, in 1829. And here we were prisoners : yet the prospect was. not absolutely bad, since we could have got out of it last year, as late as the fourth of October, and such might be the case again at an earlier period.

It was an unpleasing circumstance to know, that although we had no men absolutely sick, and there had been no scurvy, the health of our crew in general was not what it had been; as they had also proved that they were incapable of bearing fatigue, and especially the travelling among ice.

That it had been a dull month, on the whole, to us, I need scarcely say. I fear that this meagre journal bears but too evident marks of it, and on more occasions than the present. But what can the journalist do, more than the navigator? If this was a durance of few events, and those of little variety, even these had no longer aught to mark a difference among them, nothing to attract attention or excite thought. The sameness of every thing 
weighed on the spirits, and the mind itself flagged under the want of excitement; while even such as there was, proved but a wearisome iteration of what had often occurred before. On no occasion, even when all was new, had there been much to interest; far less was there, now that we had so long been imprisoned to almost one spot: and, with as little to see as to reflect on, there were not materials from which any thought, keeping clear of the equal hazards of ralsity or romance, could have constructed an interesting uarrative. On the land there was nothing of picturesque to admit of description: the hills displayed no character, the rocks were rarely possessed of any, and the lakes and rivers were without beauty. Vegetation there was hardly any, and trees there were none; while, had there even existed a beauty of scenery, every thing was suffocated and deformed by the ndless, wearisome, heart-sinking, uniform, cold load of ice and snow. On the sea, there was no variety; for here, equally, all was ice during the far greater part of the year, and it was thus indifferent what was water and what land. Rarely did the sky show aught to replace this dearth of beauty and variety below; all the means of picturesque display were wintry, and when we turned to the moral picture, what was it but the rare sight of men whose miserable peculiarities were too limited to interest us long, and whose ideas were exhausted at almost the first meeting. Who, confined to such materials as these, shall hope to produce a book of interest and amusement ? It is worse than the condemnation to "make bricks without straw."

Sept. 1. To-day the ice set in, and carried away one of our warping Jines, obliging us to let go the bower anchor; after which the ship was secured within twenty yards of the shore, with a piece of ice grounded between us and the rocks, and with another at hand to 
which we might moor if necessary. There were rain and snow on sept. 2. the second, and the passage was navigable; but we could not attempt it till the morning's tide. The wind then came to blow sept. 3. from the north; and, in the evening, the ice in the strait had made it impassable. At night there was a gale with snow.

Nothing could be done on Sunday, the ice driving up and down sept. 4. in a compact mass; so that it was in every sense a day of rest. The Sept. 5. gale continued on the fifth till noon, and was succeeded by a fall of snow, so that we could not see the state of the ice in the strait. The land was quite covered on the following morning, and the wind and ebb together brought the ice into the bay with such rapidity, that the ship could not be warped back in time, and we were obliged to take to one of the grounded masses for fear of being carried on the rocks. Here we had to sustain much heavy pressure, and were lifted up two feet, with a heel to starboard; being thus obliged to remain during four hours in this awkward position. The ice afterwards receding, we were enabled to warp up to the shore under cover of a quay formed by a large piece of an iceberg. There were showers of snow in the evening, and the ice was all close set outside.

This day was moderate, but all attempts to get a view from the Sept. 7 high land proved in vain, in consequence of a storm of snow. On sept. 8. the next, there being a northerly wind, the ice in the offing was observed to drive rapidly to the southward. It was the same on sept. 9. the following, with variations of the wind and weather; and the larger lakes were almost entirely frozen over, whereas the small ones had escaped. The harbour was covered with ice in the evening, and the thermometer fell to $22^{\circ}$.

It was even more completely sheeted with bay ice on Saturday; sept. 10. 
and, in the offing, all was motionless. Nature did not permit Sept. 11. Sunday to be other than a day of rest, even had we been inclined Scpt. 12, to transgress its laws. On Monday it blew hard from the northward, and the ice was worse packed than ever, if that could be. After four hours of variable wind, it settled in the north on Sept. 13. the next day, and in the evening, blew a gale, with clear weather: the temperature, for the first time this month, being under $20^{\circ}$. The ice remained unaltered.

sept. 14. The new ice was thick enongh to skate on; but it was an amusement that we would gladly have dispensed with.

Hyde Park is doubtless a great regale to those who can exhibit their attitudes to the fair crowds who flock to see that which the sex is reputed to admire: and it is a regale, in a better sense, when the power of flying along the surface of the glassy ice, as the fishes glide through the water, and the birds float in the air, with a velocity that requires no exertion, is of an occurrence so rare, and is confined to so short a season. In another way, is this almost supernatural mode of motion delightful not less than useful, when the milk-maids of Holland can thus sail with their commodities to a market, the rivals, not of steam-boats and mail-coaches, but of the birds and the fishes. Yet more than delightful is it, to see the ice holidays of Sweden and Russia, when all the world is in motion, as well by land as by water, yet where land and water are but one element; when all the chivalry of each sex, all thoughtless of any thing beyond the present moment, is absorbed in the minutes that pass, as if the whole world had no other occupation than to fly from all care and thought, to leave every thing behind them, even as the lightning flashes through the regions of space, heedless of all that exists beneath its burning career. 
But what had we to do with all this? To us, the sight of ice was a plague, a vexation, a torment, an evil, a matter of despair. Could we have skated the country over, it would not have been an amusement; for there was no object to gain, no society to contend with in the race of fame, no one to admire us, no rivalry, no encouragement, no object. We had exercise enough without this addition; and worst of all, the ice which bound us and our ship in fetters of worse than iron, which surrounded us, obstructed us, imprisoned us, annoyed us in every possible manner, and thus haunted and vexed us for ten months of the year, had long become so odious to our sight, that I doubt if all the occupation which the skating on it could have afforded us, would not rather have been a grievance than an enjoyment. We hated its sight, because we hated its effects; and every thing that belonged to it, every idea associated with it was hateful.

Is there any one who loves the sight of ice and snow ? I imagine, now, that I always doubted this: I am quite sure of it at present. The thought of ice may possibly suggest agreeable sensations in a hot July day; the sight of a Swiss glacier, in the same weather, is "refreshing" I doubt not. This also is picturesque, I admit, as are the frozen summits of the Alps, particularly under the rosy tints of a rising or a setting sun. These, and more, are beauties; and they are not the less beautiful that they are, to some, rarities, while they are also characteristic, and are portions of a general landscape, to which they give a new and peculiar interest, as they add to its varieties. In the present days, it is not also a little in praise of ice, that the traveller can say, I have visited Switzerland, I have scrambled across a glacier, I have seen the sun rise on Mont 
Blanc while the earth below was still in shade, I have ascended it, I, even I, the fearless and enterprising, have ascended the father of mountains, yea, even when the guides hung back in fear. Even thus is ice beautiful, regaling, acceptable.

Thus, too, is snow the delight of schoolboys: have we not all hailed the falling feathers, because we should now make snowballs and pelt each other, and erect a statue of heaven knows who, a colossus of snow, to melt away, like the palace of the great female autocrat, before the sun. Is it not, too, the emblem of virgin purity and innocence, and might not much more be said in praise and admiration of snow? It is an evil, however, to balance against all this, that it deforms all landscape, destroys all "keeping," by confounding distances, and with that, proportions, and with that, too, more and worse than all else, the harmony of colouring; giving us a motley patchwork of black and white, in place of those sweet gradations and combinations of colour which nature produces, in her summer mood, even amid the most deformed and harsh of landscapes.

These are the objections to a snow landscape, which even the experience of a day may furnish : how much more, when, for more than half the year, all the element above head is snow, when the gale is a gale of snow, the fog a fog of snow, when the sun shines but to glitter on the snow which is, yet does not fall, when the breath of the mouth is snow, when snow settles on the hair, the dress, the eyelashes, where snow falls around us and fills our chambers, our beds, our dishes, should we open a door, should the external air get access to our "penetralia;" where the "crystal stream" in which we must quench our thirst is a kettle of snow with a lamp of oil, where our sofas are of snow, and our houses of snow : when 
snow was our decks, snow our awnings, snow our observatories, snow our larders, snow our salt; and, when all the other uses of snow should be at last of no more avail, our coffins and our graves were to be graves and coffins of snow.

Is this not more than enough of snow than suffices for admiration? is it not worse, that during ten of the months in a year, the ground is snow, and ice, and "slush;" that during the whole year its tormenting, chilling, odious presence is ever before the eye? Who more than I has admired the glaciers of the extreme north; who more has loved to contemplate the icebergs sailing from the Pole before the tide and the gale, floating along the ocean, through calm and through storm, like castles and towers and mountains, gorgeous in colouring, and magnificent, if often capricious, in form; and have I too not sought amid the crashing and the splitting and the thundering roarings of a sea of moving mountains, for the sublime, and felt that nature could do no more? In all this there has been beauty, horror, danger, every thing that could excite; they would have excited a poet even to the verge of madness. But to see, to have seen, ice and snow, to have felt snow and ice for ever, and nothing for ever but snow and ice, during all the months of a year, to have seen and felt but uninterrupted and unceasing ice and snow during all the months of four years, this it is that has made the sight of those most chilling and wearisome objects an evil which is still one in recollection, as if the remembrance would never cease.

There was now no open water to be seen from the hill. The Sept. 15. general temperature was $32^{\circ}$, but it did not freeze in the sun; a petty consolation indeed. The record of the sixteenth was Sept. 16. not better, and Saturday left us as it had found us. It is little Sept. 17. 
to notice, but much where there was nothing else to remark, that a great many grouse had been killed in the last week. In such a life as ours, even the capture of an arctic mouse was an event: and if it is the custom, now, for navigators to tell every thing, to write without materials, what could we do but follow the fashion, and conform to the established usages?

Sunday exempts me from any record. Monday does not furnish one, if it be not that we were employed in sawing the bay ice about the ship, in case the outer masses should set it in motion and annoy us. This it did in spite of our precautions; since the heavy Sept. 20. ice from the outside pressed upon it during the following day, yet without doing us any harm.

Sept. 21. It blew fresh, with the wind to the northward; in consequence of which the ice drifted, but still remained stationary at the harSept. 22. bour's mouth, so that we gained nothing. On the next morning, the old ice quitted the bay, but the new remained; the sea outside was covered with heavy masses of the same interminable materials, and the land with snow. We were in a worse condition than ever.

Sept. 23. On this day we were able to carry the ship to an edge of the Sept. 24. outer ice, doing this under the chance that the following day might favour our escape. This, it did not choose to do. There was the usual hope, if wishes can be called by this name, and that was all.

Sept. 25. On Sunday the pressure of the outer ice gave us some additional tronble, but there was no good to balance it. For the present, we were " hard and fast:" I do not well know who expected any thing better to follow. If any one was silly enough to do this, he was disappointed.

Sept. 26. The only addition that a storm and drift snow could inake, was 
that of preventing us from wasting our time in hopes or speculations : there was nothing to be seen, and nothing was now left for conjecture. We had at least the certainty, on the following day Sept. 27. of clear weather, that the ice was as closely packed as it could possibly be: it is some gain in this life not to be troubled with hoping. A gale of wind on the twenty-eighth could not have sept. 28. mended the state of things: but whatever was the fact, the snowdrift was such that we could see nothing. In the last days, the thermometer, at night, had ranged between $16^{\circ}$ and $30^{\circ}$. The two following ones were as nothing; and the end of the month found Sept. 29 $8 \times 30$. us exactly in the same condition, with our prospects of freedom becoming less every day.

I may indeed say that they had ceased. It was impossible to expect any further progress under such a mass and weight of winter as that which surrounded us: even in a much better one, it was not to have been expected. The worst part of the prospect, however, was the distant one; it seemed likely that the ship would never be extricated, and that we should be compelled to abandon her, with all that was on board.

But I believe this dream was like many others which men form, under the usual condition of life. We fear evil events, or rather, I believe, imagine that we fear them, and then argue or talk ourselves into the belief that they must really happen, while our soberer judgment, under the solitude of our own thoughts (unless these should be those of the naturally despairing or the hypochondriacal), is that the probabilities are in our favour, that the evil which we imagined ourselves to fear, will never occur, that something, we neither know nor consider what, will extricate us from 
the evil, as we have been extricated before. Thus did we fear and hope, anticipate in despair, and then anticipate a far other prospect; relief, escape, triumph, the return to our own home in England, and a return to boast of what we had attempted, what we had suffered, what we had feared, what we had achieved.

The uniformity of our journal gives to the whole record of this month, a tranquil appearance; as if nothing was out of the common orler, and as if we had been all, like the ship, at peace. It was a very different thing, however, as our minds were concerned; but what is a journal of hourly hopes and fears, of fears indeed more than hopes, to those who cannot feel them; of regrets under which we could not, on examination, blame ourselves, and of that anxiety which has no repose?

Do men write, on such occasions, what they think and what they feel ? I should desire other proof of this than any which I have yet seen. The every-day work, and, above all, when that everyday work is to exert ourselves for the preservation of life, were there even not the heavier, the ever down-weighing duty of preserving the lives of others, leaves little time for any reflections but those which the circumstances demand. I am much mistaken if the time of action is that also of reflection, of other thoughts at least than are imperious for the ends in view. We act, because we must, and, for the most part, I hope, rightly : a time comes, when we can think of what we did, and when, I suspect, we only imagine what we then thought: but it matters little: historians imagine what other men thought two thousand years since, and surely we have as much right to believe that what we think now was what we ourselves thought a year before. 
On the men, the effect was tangible, because it was simple. When we first moved from our late harbour, every man looked forward to his three years' wages, his return to England, and his meeting with friends and family; the depression of their spirits was now proportionate. They were not less in haste perhaps to relate their adventures, most of them having kept journals; but, at present, it was better not to dwell on these matters, by any premature discussions: the time of resolving what was to be done, and of labouring to effect it, was to come ere long.

Compared to the preceding Septembers in point of temperature the present stands thus to that of 1829 and to that of 1830 , namely, having a mean of 6 degrees less than the first, and of 4 degrees less than the last: and in the three, the extremes stand thus :

1829 highest $40^{\circ}$ plus, lowest $17^{\circ}$ plus.

1830 do. 43 plus, do. 5 plus.

1831 do. 36 plus, do. 6 plus.

The comparison of the weather is more remarkable. In 1829, there were storms, which broke up the ice, and finally drove it to the southward, so as to allow us to navigate this very sea at the same date. It was equally stormy in 1830 , with the same effects: so that we could have sailed from the position in which we now were, as late as the fifth of October. But the present month had been generally a tranquil one; there having been but one gale, and that late; while, as the chief winds had been from the eastward, the blockade of the land and the sea" proved complete. There was not an atom of water to be seen, and the ground was every where deep with snow.

Our situation presented the usual mixture of good and evil. It 
was out of the track of animals, there were no rivers, and we did not know of any fish in the small lakes near us. If we could not therefore look for any supplies from those sources, neither could we from the natives, as the interval between them and us was filled with impassable ice. If our aspect was a southern one, yet there were high hills to the southward, which much shortened the already too short visits of the sun. The harbour was safe; much too safe indeed; since, for all motion, not less than for hazard of injury, we might as well have been walled in with masonry on dry land.

The first of the future objects was to economize in provisions, still more in fuel; and, of course, to take all possible care of the health of the men. Their spirits were to be kept up as might best be; and the topics of consolation could be found, whatever they might seem to the several different characters which our crew included. We were really on our return, and had made some progress ; while there was no reason why that should not be complete in the following year. There was still before us the Fury's remaining store; and there were boats, to carry us into Davis's strait, should we be obliged to abandon the ship; where we should either meet a whaler, or reach the Danish settlements in Greenland. If more was said than I here repeat, the usual result followed: the hopeful did not hope more, and the despondent continued to despair. 


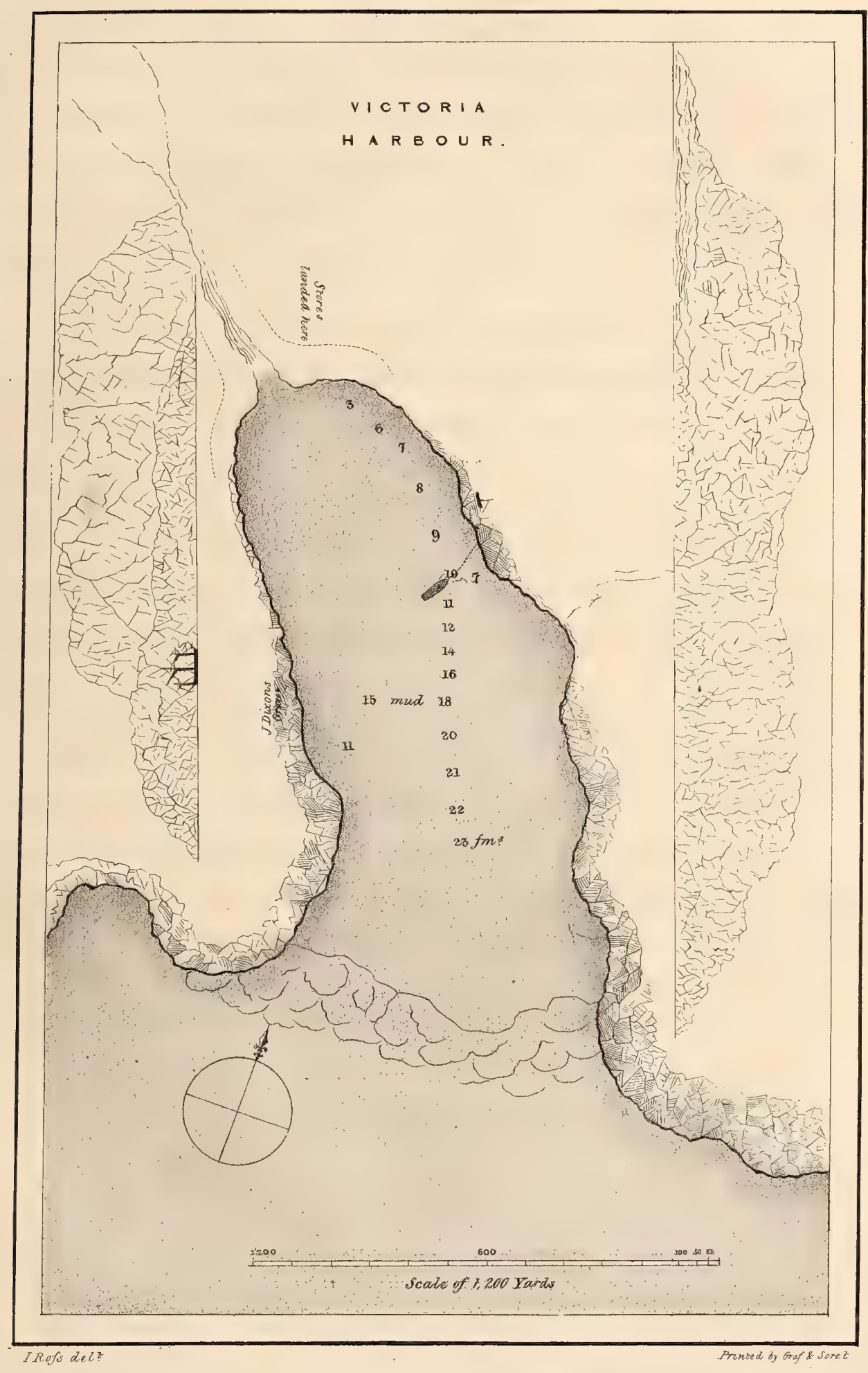





\section{CHAPTER XLVII.}

JOURNAL OF OCTOBER-THE JOURNALS OF NOVEMBER AND DECEMBER, AND THE END OF THE YEAR.

1831.

Oct 1. Oct. $2 \& 3$. Oct. 4. Oct. 5. Oct. 6,7 , $\& 8$. $16^{\circ}$ and $19^{\circ}$; the weather being variable, with a northerly breeze on Saturday, which caused a lane and a pool of water in the offing; but this was all that occurred to mark the first week of October.

Sunday was only noticeable by the thermometer falling to $8^{\circ}$, and by the disappearance of the little open water of the preceding day. On Monday we began to unbend the sails and dismantle the ship. Oct. 10. It would have been keeping up the farce of hope much too idly to have delayed this longer. An observatory on shore was therefore Oct. 11. 
commenced : we were at home for the remainder of another year; such home as it was.

Oct. 12. The weather was little noticeable on the following days. The Oct. 13. unrigging and stowing on shore went on, and a chain was passed Oct. 14. twice round the vessel " a midships." It was our intention to sink the vessel, or rather, as she must sink in no long time, in consequence of her leaks, to provide the means of raising her again, should any vessel hereafter return to the place where she was thus deposited, in safety equally from winds, waves, ice, and Esquimaux. Of the wisdom of this provision for the future, for a future as unlikely to occur as that of a season of spring and roses in Boothia Felix, I have not much to say; but it is probably our nursery education, as it may be something else, which induces us to do all that we can in prevention of waste, or, like our grandmothers, to preserve old rags, or what not, because their turn of service will come round at some indefinite future, should we live on to that problematical period; which does not, I believe, very often arrive.

Having effected this operation, the anchors were carried on shore, and the boats turned bottom upwards on the ice. Part of the housing was also set up, and the week ended with the thermometer Oct. 15 at $10^{\circ}$. A lane of clear water was again seen to the northward, $\& 16$. but this had now become a matter of indifference. Clear water or ice, all was now the same: it was very certain that we had now settled ourselves for the winter. In other days and other navigations such a sight was even more than hope: it was now long since it had been but the water of Tantalus: yet even less than that, since the certainty of disappointment had so far paralyzed all hope, that we had not even the pains of anxiety to torment us. 
All was now indifferent: we were locked up by irruptable chains, and had ceased equally to hope or to fear.

There was variable weather on the seventeenth, but it was fine Oct. 17. for the season, though attended by occasional falls of snow. The temperature went on gradually subsiding till it reached zero on Thursday night, and was once at minus $2^{\circ}$; being the first fall as yet to this part of the scale. At this time there was a strong northerly wind, with snow. The usual work of the ship and its winter arrangements served to occupy these days, and it was fortunate that there was work to do; what else on earth could have preserved us from despair?

The maximum of this day was minus $2^{\circ}$; and it was a very low Oct. 21 . temperature for this month, compared to that of the former years. On the following the lowest was minus $14^{\circ}$. The temperature was but little higher during this day, and on Monday it fell to minus $23^{\circ}$; making the whole fall $50^{\circ}$ within three days. A few hares and Oct. 18 $\& 19$.

Oct, 20 . grouse had been seen, and some were shot, while the track of a glutton had been also observed. Part of our own occupation was to continue the survey of the present spot, so as to complete our chart, and to take the altitudes of the hills; while, if our work is not accurate as well as minute, it was not at least for want of time.

There was a storm on the twenty-fifth, and it blew so violently Oct. 25. as to tear into rags the canvas of our housing, which had now gone through a long service. We could not even attempt to save it, from the great danger of exposing the men to the cold. From the north, Oct. 26. the wind changed to the south on the following day; and when we could look out, we found that it had cleared the hills of snow. It continued variable during the remainder of the week, with a tem-

Oct. 22.

Oct. 23 \& 24 . 
perature about zero; and the reconstruction of a housing found full employment for the people.

Oct. 30. The weather on Sunday was fine, but the thermometer fell to $7^{\circ}$ minus. Two reindeer had been seen on the lakes, somewhat unex-

Oct. 31. pectedly; and, on Monday, it was remarkable that the temperature ranged between $11^{\circ}$ minus, and $17^{\circ}$ plus.

The summary of this October cannot be much, in detail, and is of as little moment in point of interest. Some preparations for sinking the ship in spring, had been made, as I have already noticed, under our project of travelling by land and by boats to the place of the Fury's stores. Every thing, except the provisions and stores indispensable for our use, had been landed; and the two boats had been placed in such a position as to admit of the construction of sledges under them.

The temperature had ranged from $22^{\circ}$ plus to $23^{\circ}$ minus; the mean had been $8^{\circ}$ plus, and the extremes $29^{\circ}$ plus and $23^{\circ}$ minus. The thickness of the sea ice was found to be nineteen inches on the last day of the month; and, of that on the lake, twenty-two.

On the health of the crew there is nothing new to observe.

Nov. 1 to 5 . The first five days of November exhibited no remarkable changes, and there was work enough for the men, in banking up the ship with snow, in building observatories, and in other arrangements similar to those formerly recorded. The highest range of the Nov. 6. thermometer was plus $20^{\circ}$, and the lowest minus $2^{\circ}$. On Sunday it fell to $16^{\circ}$ minus in the evening, and to $17^{\circ}$ at midnight. The weather, consequently, was cold. We had not yet been sufficiently. trained to the new winter.

Of this training to temperatures which men undergo, I have 
spoken before; and every season of our long experience in this country served to convince me still more of the truth of our conclusions on this subject. It is not my business to explain the fact or assign the reasons; why do not the physiologists, who know every thing, tell us the cause, give us at least a wordy theory, if they can do more? I have seen the same under all temperatures, in the West Indies and the East; in Sweden, and here in the extreme north of America, under the equinoctial line, and beyond the arctic circle. Yet I know not how to believe that those who remigrate from India, west or east, to England, endure the first winter better than the second, that they have been so thoroughly heated, as they imagine, by a few years' residence in the tropical regions, as to require a year's cooling to make them sensible of a lower temperature. But words perform greater wonders than this : it has been once so said, they have heard it, and they believe, as men believe in ghosts and much more, because their nurses have so taught them.

The week that followed proceeded in a very uniform and uninteresting manner. The weather was, on the whole, mild, compared with Sunday, and though variable, was, for the most part, fine. Yet the thermometer reached minus $19^{\circ}$ on Monday. After this, it went on rising till the tenth, when it came up to plus $17^{\circ}$ at midnight, ending on Saturday night at $7^{\circ}$, after having fallen to minus $2^{\circ}$ at mid-day. The usual labour, observations, exercise, and shooting, went on, and we were in need of them all.

There is not a novelty to mark the days onwards from Sunday till the following Saturday. The character of the weather changed many times in every day, but it was never very bad. On the whole, it was becoming colder, and the lowest midnight thermometer was 
$20^{\circ}$ minus : on the Thursday it was as high as plus $17^{\circ}$. The deck was covered with snow in the usual manner, for our protection during the remainder of the winter, which was now fully arrived.

Nov. 20 to 26 .

If there was any difference between this week and the preceding, it was that it felt colder, on account of frequent northerly breezes, though the thermometer did not once fall so low; having never been beyond $18^{\circ}$, while not often lower than $7^{\circ}$ or $8^{\circ}$ minus. The first threatening of scurvy in one of the men was observed at this time: and on this subject I am bound to offer a few remarks.

Every reader of voyages well knows what defeats of naval expeditions have been often the result of this terrific disease, how often the crews of ships have not merely been rendered ineffective, but have been destroyed by it; facts for which it would suffice to refer to Lord Anson's voyage. It is known too, that it has raged with peculiar severity in the crews of vessels navigating these northern climates, and not only in men at sea, but among those who had wintered on shore; as is amply testified by the destruction of the Dutch crew so often narrated.

For this latter fact, the nature of the food and the country will account to medical men, so that I need not dwell on the particulars. It is true that the greater precautions, of various kinds, which have been adopted in both the naval and mercantile service since the time of Cook, have most materially diminished this evil; yet we were placed in circumstances that every modern precaution and all our attentions could not have been expected to resist, and to resist for so long a period.

Notwithstanding all this, the event that $I$ have just recorded was the first real appearance of this dreadful scourge; as the subsequent 
record of this voyage, even to the moment of quitting this country after four years of detention, and during the whole of what I may almost call one long winter, unparalleled, too, for its severity, shows that it never very seriously assailed our people, and, almost without exception, was the cause of serious injury to none.

That this was the consequence of care, cannot be doubted: how far the effect is due to the commander of the expedition, it does not become me to say; but care there was, and on the part of more than myself, or the good results in question could never have been. It must be seen, in the first place, that we were entirely cut off from one of the best known and most effective means of prevention and remedy; since the country produced no vegetable food, nor could our men learn the use of fish oil, which I believe to be one of the antiscorbutics provided by nature for the inhabitants of these frozen climates. It is not less true that a large proportion of our provisions consisted in the usual salt meat, of pork at least; but if we had an occasional resource in the fish which we found in the country, and in the preserved meat, the vinegar, the sugar, and the lemon-juice of our stores, I doubt if these, which have so often proved of small efficacy, would have maintained our men in health during so long a period, and in such a climate.

There was more wanted; and that we obtained by those attentions which I must now point out, for the benefit of future navigators in the same country. The southern whalers assert, that as a want of water is one of the most efficient causes of scurvy, so they find a remedy in supplying this to their crews, without stint. In this matter we imitated their practice, though obliged for the most 
part to obtain our own water through artificial heat. With the same view, we never suffered our people to remain in their wet clothes, as our contrivance in warming their habitation between decks, and in carrying off the steam generated in it, maintained this place in a state of perpetual comfort and dryness.

Rarely, in addition, were they ever so long exposed to cold as to suffer materially from it; knowing well, as we did, how this source of debility tends to the production of the disease in question. Being further, too, aware of the value of exercise for the same purpose, it was my object to find them constant employment, or when this was impossible, from the attention paid to the Sundays, and from the nature of the weather, they were commanded to walk, for a certain number of hours on the shore, or if this was impracticable, on our well-roofed and sheltered deck.

Further than all this, and I may name it as the last precaution, their minds were never suffered to brood over evils or to sink into despair, as far as it was in our power to prevent this: while I may say, that on the whole, our efforts were highly successful. Yet if I still add, the restriction at first in the use of spirits, and at length the final abandonment of this false and pernicions stimulus, I have little doubt that I thus cut off one of the causes, which, if it may not absolutely generate scurvy, materially assists others in the production of that disease.

Such is what I have thonght it useful to state on this subject: if they were not the true causes of our exemption, they are all that now occur to me; but though $\mathbb{I}$ should have made any mistake in this matter, I can still appeal to the result. We were almost entirely free from this disease for a very long period; we suffered 
but little, even at the worst; and I brought back to England a crew which, as it had little cause of complaint when in this horrible climate, has now no reason to repent of any of the rigours which it braved, or the sufferings which it endured.

The thermometer being now $20^{\circ}$ minus with a fresh breeze, the men were unable to walk after divine service. On Monday it Nov. 27 to 30 . fell to $30^{\circ}$, and on Tuesday to $40^{\circ}$ in the middle of the day. The lowest of the four days was $42^{\circ}$ minus. We had passed the freezing point of mercury once more ; but the weather being calm, the men were not prevented from walking outside of the ship. The thickness of the sea ice at the end of this month was two feet nine inches.

With the exception of a few days it had been a mild month, the sky being very generally cloudy and overcast: a fact which, as is now well known to every one conversant with the theory of heat, is sufficient to account for this state of things. We had, indeed, abundant experience to make us dread a bright and clear sky; and, while we knew well (apart from all the knowledge that we might possess respecting the radiation of heat) how to value an overcast and cloudy one, even to long for the "ccelum nubibus foedum " of our own dear England, so did we often cease to regret the fogs that covered us (when, at least, they did not obstruct our travelling), by knowing, as well as feeling, that with the few wellknown exceptions which I need not here relate, they served to keep us warm.

The mean temperature for this month turned out to be $9^{\circ}$ higher than that of last November, and $5^{\circ}$ higher than that of the same month in 1829 ; but it ended with a severity far exceeding either of them. 
We had improved the method of covering the deck, by placing a layer of gravel and sand beneath that of snow, which prevented the heat below from melting it. Other improvements, suggested by experience, had been made in the internal accommodations.

Our allowance of bread had been necessarily reduced, but so was that of salt meat: notwithstanding which last alteration, and the use of spruce beer, six men were slightly afflicted with scurvy: which, however, was checked by means of lemon-juice. Their despondency seemed to have ceased.

Very few celestial observations had been obtained, in consequence of the state of the sky; but the magnetical ones and others had proceeded. The sport on shore had been far better than we had anticipated, including hares, grouse, and willow partridges.

Dec. 1. The first day of this month was very cold, with a temperature of Dec. 2. $41^{\circ}$ minus : and the following did not differ.

Dec. 3. At six on the morning of the third it blew a heavy gale from the north; threatening once more to destroy our roof, which was Dec. 4. secured with some difficulty. On Sunday it was still worse, with a heavy drift; and the result was, as soon as we could see any thing, to find that all the hills had been laid bare, and the valleys filled Dec. 5. with snow. It did not moderate till the evening of the following day, with a temperature of minus $6^{\circ}$.

Dec. 6. It became calm and fine, on the sixth, and I ascended a hill, estimated at a thousand feet high. Thence I was surprised to see the sun's upper limb, passing in azimuth : it had disappeared astronomically, on the 25th of November, nor had we seen it since the Dec. 7 23d, through any refraction. Under the same extraordinary refracto 10 . tive power in the atmosphere, the islands were also raised far higher 
than I had ever seen them. 'There was nothing interesting hence onwards till Saturday. The wind was from all quarters alternately, and the lowest mark of the thermometer, being on the last of the week, was $22^{\circ}$ minus.

Sunday came in with a strong northerly gale, which, with a temperature of $24^{\circ}$ minus, made it very cold. On Monday at noon it moderated, so that the next day was calm and clear ; but another gale sprung up on the fourteenth, blowing hard during the two following days, but ending in a calm and clear Saturday. The temperature varied during the week between $2^{\circ}$ and $31^{\circ}$ minus.

It being calm and clear on Sunday, the temperature fell to $35^{\circ}$. It continued fine till the twentieth at night, when it blew a storm, and the thermometer rose to $8^{\circ}$; while that gale, with severe drift snow, increased till mid-day on the twenty-first, subsiding to a calm in the evening. Thus it continued till the twenty-fourth, the thermometer having ranged between $24^{\circ}$ and $36^{\circ}$.

Christmas-day was made a holiday in all senses. In the cabin Dec. 25. dinner, the only fact worth remarking was, a round of beef which had been in the Fury's stores for eight years, and which, with some veal and some vegetables, was as good as the day on which it was cooked.

I know not whether the preservation of this meat, thus secured, be interminable or not; but what we brought home is now, in 1835, as good as when it went out from the hands of the maker, or whatever be his designation, the Gastronome for eternity in short, in 1823. If it can be kept so long without the slightest alteration, withont even the diminution of flavour in such things as hare soup and purée of carrots, why may it not endure for 
ever, supposing that the vessels were themselves perdurable? Often have I imagined what we should have felt had Mr. Appert's contrivance (of which, however, neither he nor his successors are the real discoverers), been known to Rome, could we have dug out of Herculaneum or Pompeii one of the suppers of Lucullus or the dishes of Nasidienus; the "fat paps of a sow," a boar with the one half roasted and the other boiled, or a muræna fattened on Syrian slaves; or, as might have happened, a box of sauces prepared, not by Mr. Burgess, but by the very hands of Apicius himself. How much more would antiquaries, and they even more than Kitchener or Ude, have triumphed at finding a dish from the court of Amenophis or Cephrenes, in the tombs of the Pharaohs ; have regaled over potted dainties of four thousand years' standing and have joyed in writing books on the cookery of the Shepherd kings, or of him who was drowned in the Red Sea. Is it possible that this may yet be, some thousand years hence, that the ever-during frost of Boothia Felix may preserve the equally ever-during canisters of the Fury, and thus deliver down to a remote posterity the dinners cooked in London during the reign of George the Fourth? Happy indeed will such a day be for the antiquaries of Boothia Felix, and happy the Boothia to which such discoveries shall be reserved.

There was nothing to note in the next three days, but the loss of two of our dogs : a serious one now, since they could not be replaced, and were to form part of our future dependence. The remainder of this month was equally uniform and dull, and it ended with the thermometer at $27^{\circ}$ : in the four first it had not been more than $37^{\circ}$. On cutting the ice on the last day, its thickness proved to be four feet in the sea, and six inches more in the lake. 
This month of December commenced with the mercury frozen; but a change took place on the third, just after the new moon; and we experienced, for three weeks, such a succession of storms as we had never before witnessed. These had the effect of raising the temperature, yet less than usual; while, though little snow fell, the drift was very great, since that which had fallen was like fine flour.

The men were much reduced in strength, but the scurvy had been kept in check. One man alone, Dixon, being afflicted with a complication of disorders, was not expected to live very long.

The comparative view of the December of this and the two preceding years, may be thus abstracted:

1829 Highest, lowest, and mean temperature $-8-37-23.08$

1830 Ditto

$-+6-47-20.24$

1831 Ditto

- $\quad-\quad-$

$-2-42-23.96$ 


\section{ABSTRACT OF THE METEOROLOGICAL JOURNAL.}

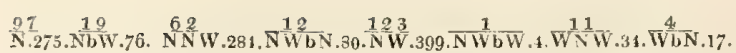

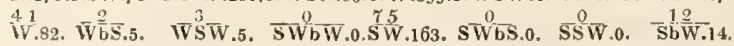

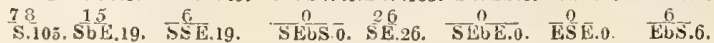

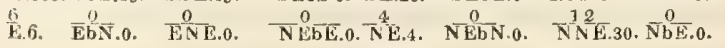

$\left.\begin{array}{l}W y_{1}=329 \\ W y_{.}=133\end{array}\right] \begin{array}{r}\text { Total. } \\ 615 \text { hours }\end{array}$

SWy. $=133 \quad \begin{array}{r}615 \text { hours. } \\ 2 \text { do. wind vble. }\end{array}$

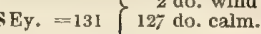

$\mathrm{NEy} .=22 \int \overline{744}=31$ days.

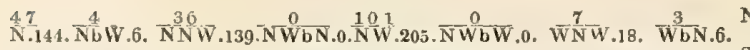

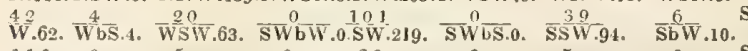

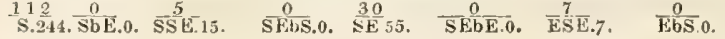

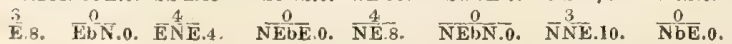

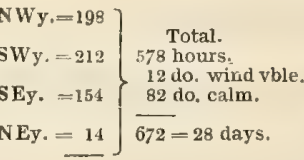

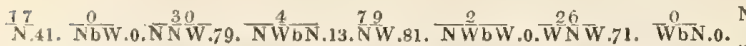

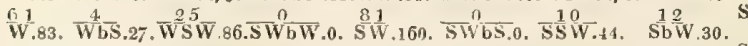

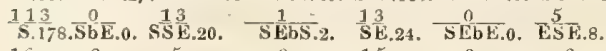

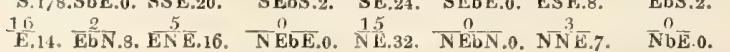

WW $=158] \quad$ Total.

\begin{tabular}{l|c} 
Total. \\
Wy $=193$ & 539 hours.
\end{tabular}

32 do. wind vble.

SEy. $=147\} 173$ do. calm.

$\overrightarrow{744}=31$ days.

10.5

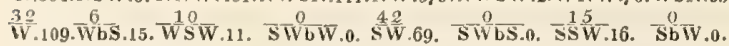

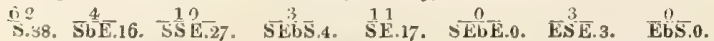

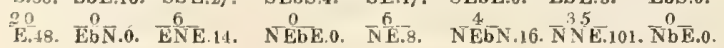

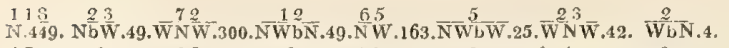

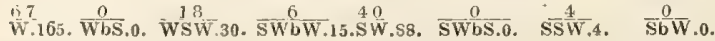

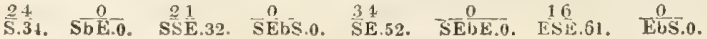

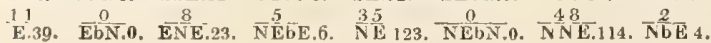

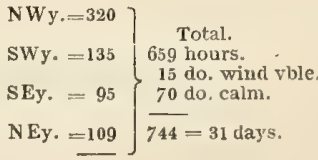

$\left.\mathrm{NWy}_{\mathrm{.}}=390\right] \quad$ Total.

SWy. $=105 \quad 659$ hours.

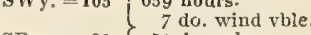

SEy. $=93\} \begin{array}{r}74 \mathrm{do} \text {. wind } \\ 54 \text {. calm. }\end{array}$

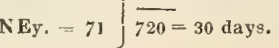

JANUARY, 183 .

Highest, lowest, \& $\}+2 \frac{1}{2}-59 \frac{1}{2}-25.43$ Total force of the Wind . . . 1657

Mean force of the Wind . . $\overline{53.45}$

FEBRUARY, 1831.

$\left.\begin{array}{c}\text { Highest, iowest, \& } \\ \text { mean temperature }\end{array}\right\}+9 \frac{1}{2}-49-32.16$ mean temperature Wind . . $\frac{1333}{47.62}$
Mean force of the Wind. .45

MARCH, 1831.

Highest, lowest, \& $\}-81-51-34.74$ Total force of the Wind .

Iean force of the Wind . . 34.42

APRIL, 1831.

Highest, lowest, and $\}+30-25-6.44$ mean temperature
Total force of the Wind. .169 .5 Mean force of the Wind..$\overline{56.5}$

MAY, 1831.

$\left.\begin{array}{c}\text { Highest, lowest, \& } \\ \text { mean temperature }\end{array}\right\}+36-16+16.02$ Total force of the Wind . $18 ; 6$ Mean force of the Wind . . $\overline{60.52}$

JUNE, 1831.

Highest, lowest, \& $+52+14+31.56$ Total force of the Wind . 1715 Total force of the Wind $\cdot 1715$

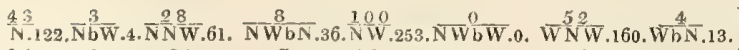

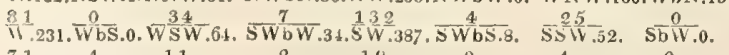

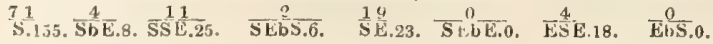

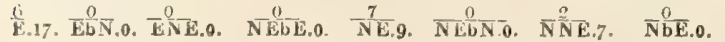

$\mathrm{NWy}=238 \quad$ Total.

swy. $=283 \quad 617$ hours.

SEy. $=111\} \begin{array}{r}8 \mathrm{do} \text {. wind } \\ 65 \mathrm{do} \text {. calm. }\end{array}$

NEy. $=15 \overline{720}=30$ days. 


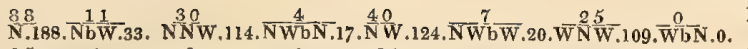

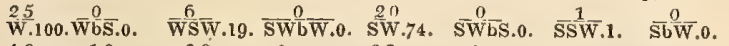

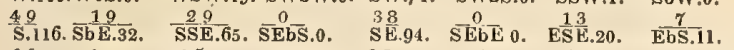
$\frac{66}{6.102 . E b N .2 .}-\frac{15}{E N E .34 . ~ N E b E .0 . ~ N E .189 . ~ N E b N .19, ~ N N E .192 . ~ N b E .121 . ~}$

$\mathrm{NWy}=205$ $\mathrm{SWy}_{,}=61$ Total. SEy. $=155\} 46$ do. calm. NEy. $=255 \overline{744}=31$ days.

$\frac{84}{N \cdot 271} \cdot \frac{1}{\mathrm{NbW}} \cdot 4 \cdot \frac{48}{\mathrm{NNW}} \cdot 127 \cdot \frac{17}{\mathrm{NW} W} \cdot 46 \cdot \frac{50}{\mathrm{NW}} \cdot 127 \cdot \frac{5}{\mathrm{NWWW}} \cdot \frac{37}{\mathrm{WNW}} \cdot 141 . \frac{19}{W b N} \cdot 95$.

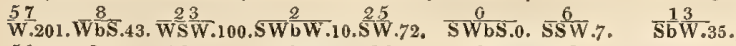

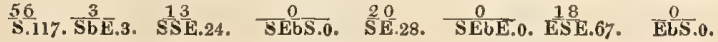

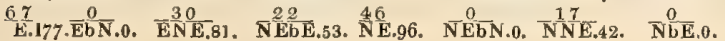

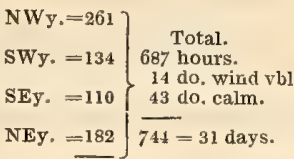

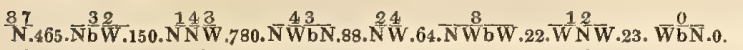

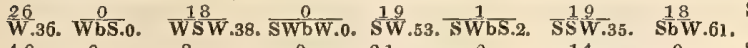

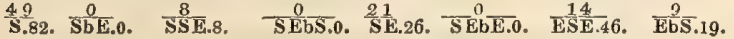

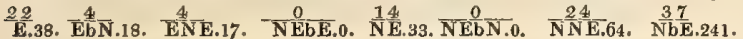

JULY, 1831 .

Highest, lowest, \& $\}+50+32+37.9$ Total force of the Wind , , 1775 Total force of the wind

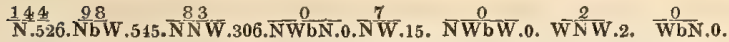

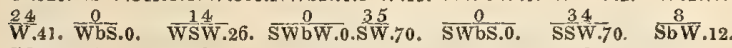

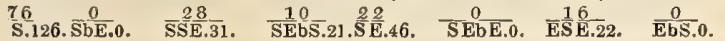

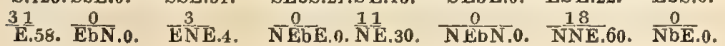

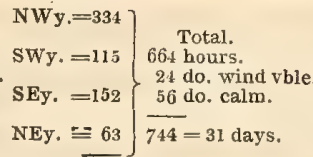

AUGUST, 1831

$\left.\begin{array}{c}\text { Highest, lowest, } \& \\ \text { mean temperature }\end{array}\right\}+54+24+36.51$ Total force of the Wind . . 2001 Mean force of the Wind . . 64.55

\section{SEPTEMBER, 1831}

$\begin{gathered}\text { Highest, lowest, and } \\ \text { mean temperature }\end{gathered}+36+6+23.4$ mean temperature
Total force of the Wind . Mear force of the Wind . . 81.27

OCTOBER, 1631.

Highest, Jowest, \& $3+29-23+8.32$ Total force of the Wind . 204 Mean force of the Wind.,$\overline{65.94}$

NOVEMBER, 1831 .

$\begin{gathered}\text { Highest, lowest, \& } \\ \text { mean temperature }\end{gathered}+20-42-1.23$ Total force of the Wind . 1449 Mean force of the Wind . . . 48.3

DECEMBER, 1831.

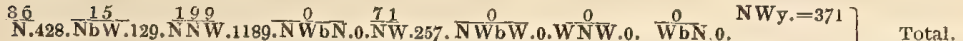

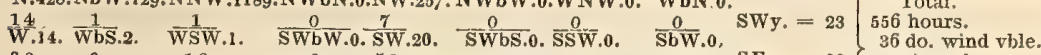

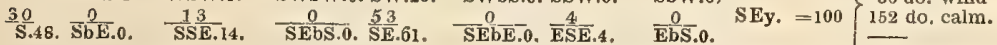

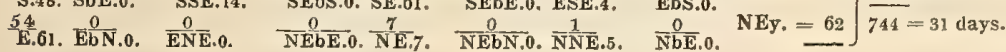

Highest, lowest, \& $\}-2-12-23.96$ Total force of the Wind . . 2977

Mean force of the Wind . $\overline{73.45}$ 


\section{CHAPTER XLVIII.}

THE JOURNALS OF JANUARY, FEBRUARY, AND MARCH.

1832. SUNDAY being past, we prepared our mining tools for the purpose of making a place of concealment for our stores. A very brilliant meteor, as large as the moon, was seen, finally splitting into sparks, and illuminating the whole valley. The thermometer fell to $36^{\circ}$ on Tuesday, and to $40^{\circ}$ on the following day; rising again but to reach the same point on the next, when there was a brilliant aurora of a golden colour, passing through the north star. I repeated the experiment formerly made with the differential thermometer, to as little purpose.

Jan. 6 to 8. The thermometer came down to $45^{\circ}$, but, being calm, it was not very cold: it is certain also that we had now resumed our winter standard of sensation on this subject. The aurora was again seen on Saturday; and Sunday passed as usual. The invalid Dixon was considered as rapidly becoming worse.

Till the thirteenth, the weather was variable, but tranquil, and often calm. The temperature rose from $45^{\circ}$ as far as $12^{\circ}$. On the tenth, the long-ailing James Dixon died. A heavy fall of snow, with a storm from the north-westward, brought another week to a close. The same men who had been employed, whenever it 
was possible on the tunnel, had also prepared the grave for our patient.

It was necessary to postpone the funeral on account of the weather: but a sermon appropriate to the subject was selected for Jan. 15 this Sunday. On the following morning the interment took place with the usual solemnities. The two next days were mild, and the work of the tunnel went on. On the three last of the week, the weather was variable, and the thermometer from $26^{\circ}$ to $29^{\circ}$.

It began however to blow fresh on Saturday night, and continued with great severity all this day and the following. On Tuesday it fell a little at noon, but was as violent as ever in the evening. In spite of the drift, the sun was seen on this day, but the storm continued on the twenty-fifth, and did not subside till the noon of the following day, when it was clear and calm. The last two days of the week were moderate, and the thermometer ended on Saturday night at $33^{\circ}$.

On the Sunday and Monday the wind was north, and it was very cold, with a thermometer at $30^{\circ}$. It varied little on the following; Jan. 29 to 31 . and the month ended on the thirty-first, with a temperature of $26^{\circ}$. Little or nothing could be done out of the ship on most of the past days, and our exercise was equally restricted to the deck.

During three out of the weeks of this month there was windy or stormy weather, which made the cold severe, though the mean temperature was only two degrees lower than it had been in the preceding January. That mean is $27^{\circ}$ minus, and the highest and lowest are minus $8^{\circ}$ and minus $47^{\circ}$. We tried to find some consolation in anticipating that Baffin's bay would be cleared of ice by these north winds. 
The weather interfered so much with our observations, that they amount to nothing; besides which we had not a nautical almanac for the present year. Of the aurora which is noted above, I may remark that it affected the magnetic needle to an unusual degree.

Our medical report now begins to be very different from what it had hitherto been. All were much enfeebled; and there was a good deal of ailment without any marked diseases. An old wound in my own side had broken out, with bleeding; and I knew too well that this was one of the indications of scurvy. That all were in a very anxious state, needs not be said: and he on whom all the responsibility fell was not least the victim of anxiety. But men must be thus situated before they can appreciate the feelings of any of us.

Feb. 1 to 4. The month began with a furious storm, which continued for two days, and subsided on the third; the thermometer rising from $24^{\circ}$ to $18^{\circ}$. The ice was cut through, and its thickness found to be five feet and upwards. The lake, at the same depth, was frozen to the bottom. We were sufficiently prisoners by the hopeless state of the ship: but it seemed destined that she should be really our prison, as the stormy and cold weather rendered it seldom possible to show ourselves beyond the roof or deck. It is not wonderful if we were dull.

Feb. 5 to 11. A strong breeze, from the endless northward, on Sunday, became a gale, lasting during the two next days and not breaking till Wednesday; when, at night, it at length fell calm, and the thermometer sank to $35^{\circ}$. Hence on till Saturday, it was sufficiently fine to allow the men to work at the tunnel, and the sportsmen to take their walks, though without any success.

Feb. 12

But a gale sprung up once more in the night, and blew all to 18 . 
Sunday, so as again to keep us prisoners. It abated on Monday, and the people could continue to work till Thursday evening. A stiff breeze on Friday once more put a stop to all work for the rest of the week ; and, on Saturday night, after seven days of variable weather, the temperature was $41^{\circ}$.

Sunday was stormy and cold, and Monday was much worse. In the morning, a glutton came on board and began to devour the dogs' meat. It was an inhospitable reception to kill the poor starving wretch, but it was the first specimen of this creature which we had been able to obtain. Are the life and happiness of an animal to be compared with our own pleasure in seeing its skin stuffed with straw and exhibited in a glass case? After the twenty-first the men were able to work outside till the end of Friday; but Saturday was once more stormy, and we were all imprisoned. The lowest temperatures during the week had varied from $34^{\circ}$ to $39^{\circ}$.

The three first days following were uncertain, but not bad; and on the two working days some out of door work was done. On Feb. 26 to 29 . Saturday the ice was measured, and found rather more than six feet thick. It had increased sixteen inches in this month, which ended with the thermometer at $38^{\circ}$.

This last month was severe. If the thermometer did not range so much as during the same one in preceding years, the temperature was more uniformly low, while the frequent storms rendered it also bitterly felt. The mean was $34^{\circ}$ minus, and the extremes minus $12^{\circ}$ and minus $44 \frac{1}{2}^{\circ}$.

The thickness of the ice round the ship was such as to prevent all hopes of her liberation, even though we should continue with 
her, which was impossible, from the state of our provisions and that of the health of the crew. The seaman, Buck, who had unexpectedly suffered the recurrence of his epilepsy with an unusual degree of violence, had become blind.

The carpenter had nearly finished the sledges for the boats, and was about to make some more for carrying the provisions. It is a brief summary for this month : and others must try to imagine what we felt, and what they can never see.

March 1 to 10 .

March 11 to 17 .
March 18 Sunday was an indifferent day, but did not prevent the usual

March 18 Sunday was an indifferent day, but did not prevent the usual
to 24 .

The first day of March was mild, though with no great change of temperature. Thus it continued till Saturday, when the ice on the lake was found to be seven feet thick; and the thermometer at 42. The fourth, fifth, and sixth, were little different, and the men could work outside on the two last, though the thermometer fell to $48^{\circ}$. Some work was done also on the next two days; but, on the ninth, there was a fresh breeze, subsiding again on Saturday, when we ended not a very bad week of variable weather. A hare and some ptarmigans were shot.

The men, walking after church, saw the first tracts of reindeer which had been observed this season, together with that of a glutton. Monday was very fine, though the thermometer at night was $38^{\circ}$. Hence to the sixteenth we were all imprisoned by strong north-westerly winds, and it was not fine again till the Saturday evening, with the thermometer at $20^{\circ}$ during the night. walk after church, when the tracts of a white bear were seen, amongst other animals. The rough weather and our confinement returned on Monday, and lasted till Saturday, which became a fine day before it was finished. Nothing, of course, could be done out- 
side. The thermometer during all this time ranged between $31^{\circ}$ and $37^{\circ}$, ending at $35^{\circ}$; and the taking of a fox was the only event of a most tiresome week.

It blew a gale on Sunday, and did not moderate till Monday March 25 afternoon. The whale boat, which could now be of no use, was to 29. broken up. The weather was becoming gradually milder, and, on the twenty-eighth, the thermometer was $4^{\circ}$ minus, with a little snow. The men were not prevented from securing the stores on shore during these days. On the twenty-ninth it again blew so strong as to put a stop to this work; and they were therefore employed on board in preparing stores and necessaries for the ensuing journey.

It was a more moderate day, though the thermometer at night was at $16^{\circ}$. There was abundant employment now, in preparing skin bags for bedding, in working, at the sledges, and in other matters intended for travelling. The sea ice was cut on Saturday, by erecting a tent over the spot, since a strong breeze rendered it impossible to work otherwise, and it was found to be seven feet thick; having gone on increasing in this month, and having gained nine inches on the former. The temperature on the last night of March was $20^{\circ}$.

In this month, the average temperature of the first half was lower than it had yet been in the same on the former years, since it was $42^{\circ}$ under zero. It became gradually milder towards the end, so that the mean of the whole was nearly the same, being minus $31^{\circ}$, as the lowest and highest were minus $4 \frac{1}{2}^{\circ}$ and minus $48 \frac{1}{2}^{\circ}$.

But, like February, it was a very cold month to the feelings, in consequence of the frequent winds; while it is certainly also true, 
that our comparative weakness, and the alteration in our diet, made us feel it more severely.

This had impeded the concealment of our stores, and retarded the work on the sledges; but we had been busy on board in arranging and concentrating our several travelling necessaries: a work of some consideration, since, besides provisions, arms, ammunition, and tools, we had fuel to carry, had it even been but to thaw snow for drinking, besides instruments and all else that belonged to our personal accommodations.

In our crew, we had now one blind man; and the mate, Taylor, was still so lame that he could walk but a very little way: besides which there were three other men, in very indifferent health; while no one was as strong as in the preceding year. On my part, the prudent conduct, as it concerned this state of things, now seemed to be, to restore the whole to full allowance; and this was accordingly done.

The magnetic observations had proceeded; but are likely to be of little value, from the situation of the needle, near high hills and among rocks. What Saussure had originally shown, the observations of Dr. M'Culloch have extended far more widely, by demonstrating the influence of granite as well as many other rocks, not less than the basaltic ones, on the magnetic needle, so as to produce "deviations" such as those which occur from the presence of iron in a ship. On instruments, and with experiments, so delicate as ours, this influence was likely to be destructive of all true results.

There having been little snow, in comparison, and much wind, the hills were tolerably bare. That we had not seen any natives, could not be a matter of surprise. Our success in game had been almost nothing. 


\section{ABSTRACT OF THE METEOROLOGICAL JOURNAL.}

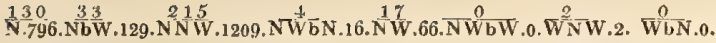

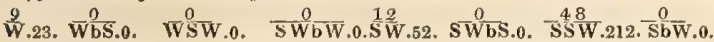

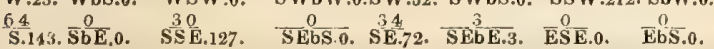
S.143. SbE.0. SSE.127. SEbS.0. SE.72. SEbE.3. ESE.0. E. E.0.

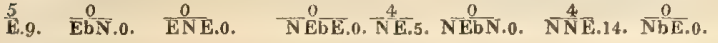

$\left.\begin{array}{l}\text { NWy. }=401 \\ \text { SWy. }=69 \\ \text { SEy. }=131 \\ \text { NEy. }=13\end{array}\right\} \begin{gathered}\text { Total. } \\ 614 \text { hours. } \\ 30 \text { do. wind vble. } \\ 100 \text { do. calm. } \\ 744=31 \text { days. }\end{gathered}$
N

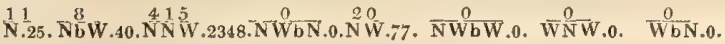

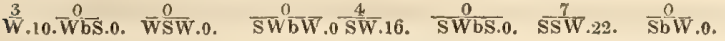

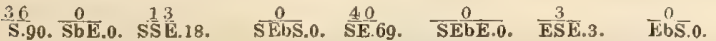

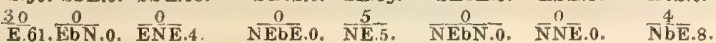
$\mathrm{SWy}=19 \quad \begin{array}{r}\text { Total. } \\ 604 \text { hours }\end{array}$ 13 do. wind vble. SEy. $=92\} 79$ do, calm $\mathrm { NEy } . = 3 9 \longdiv { 6 9 6 } = 2 9$ days.
FEBRUARY, 1832.

Highest, lowest, \& $\}-12-14 \frac{1}{2}-33.69$ Total force of the Wind . . 2817 Mean force of the Wind . . 96.93

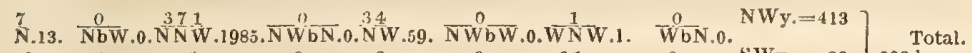
W.13.

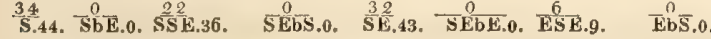

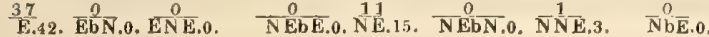

\section{SWy $=32588$ hours.} SEy. $=94\left\{\begin{array}{r}23 \text { do. wind } \\ 133 \text { do. calm }\end{array}\right.$ NEy. $=49 \quad \overline{744}=31$ days.
JANUARY, 1832 .

$\left.\begin{array}{c}\text { Highest, lowest, \& } \\ \text { mean temperature }\end{array}\right\}-8-47-27.52$ Total force of the Wind . . . 2937

Mean force of the Wind . . $\overline{94.74}$ 


\section{CHAPTER XLIX.}

APRIL - COMMENCE THE OPERATION OF CARRYING FORWARD BOATS, SLEDGES, AND PROVISIONS, WITH THE VIEW OF ABANDONING THE SHIP-MAY-CONTINUATION OF THE SAME WORK -THE SHIP IS ABANDONED.

18:32. I T blew so hard that the men were imprisoned after divine service. On Monday it was more moderate, and the people were employed in cutting round the Krusenstern, preparatory to hauling her up. The third, fourth, and fifth, became gradually milder; though the thermometer did not rise above minus $14^{\circ}$, and sank to $30^{\circ}$ at night; but on Friday it was again very cold. On Saturday the thermometer rose on a sudden to plus $7^{\circ}$; not having passed zero before, for 136 days. I do not believe there is another record of such a continuous low temperature: and it was a state of things, most certainly, to confirm us in our resolution of leaving the ship to her helpless fate, and attempting to save ourselves in the best manner that we could.

The thermometer fell once more to $20^{\circ}$ on Sunday night, and to 14 . then to $\mathbf{2 4}^{\circ}$ towards the Monday morning; after which it suddenly rose to plus $2^{\circ}$, with a considerable fall of the barometer, ending in thick weather and snow. That became a gale on the following day, and did not moderate till the evening of the eleventh, after 
which it became calm. It was mild the next day, at plus $11^{\circ}$, and, on the thirteenth, there was a heavy fall of snow, ending the week, on Saturday, with another mild day. One boat was completely fitted on the double sledge.

The fifteenth and two following days were mild, so that, after Sunday, our work went on. On the eighteenth, the cold weather brought us to a stand out of doors; but, on the next day, the boats were drawn on the sledges as far as the second lake, where they were found to answer as well as we had expected. We were ready to start on the following, but were prevented by the snow falling thick, with a temperature of $28^{\circ}$ minus, even at noon, and were therefore obliged to end the week as we were, with the thermometer at minus $18^{\circ}$, when on the same day in last year it was plus $30^{\circ}$.

We could have done nothing on this day, even had it not been April 22. Sunday, as the thermometer was at minus $30^{\circ}$ in the morning, and never rose beyond $3^{\circ}$ minus. I must explain that our present object was to proceed to a certain distance with a stock of provisions and the boats, and there to deposit them for the purpose of advancing more easily afterwards. The abandonment of the vessel had long ceased to be a matter of hesitation; and the object now was to proceed to Fury beach, not only for supplies, but to get possession of the boats there; failing which, our own would be put into a position on which we could fall back.

Though the temperature was equally low, it was clear and calm. April 23. We therefore set out at nine, reaching the nearest boat, which had already been carried to the northern sea, about four miles from the ship; after which we drew her to the other boat and store of provisions, which was two miles further. The weights were then 
divided equally, and we proceeded with great labour and difficulty, through rough ice, so that we were at length obliged to carry on but one at a time, returning for the other alternately; in consequence of which we did not gain more than a mile, after five hours' work. It then began to blow so hard, with drift snow, that we were obliged to halt and build snow huts. These we covered with canvas, and by means of the deer-skin beds, and our cooking apparatus, the whole party of fourteen was well accommodated, though the temperature of our house at night was but minus $15^{\circ}$, while it was as low as $30^{\circ}$ outside.

Degrees of a thermometer make little impression on readers; and, above all, the minus side of the scale is powerless to those who have not lived in lands like that in question. The number thirty may catch the eye, without making the readers feel that it is sixty degrees under the freezing point. Our sleeping room, on this occasion, was forty-seven degrees under that point. How did we continue to sleep, how can men sleep in such a temperature? This is what I have tried to explain on former occasions, yet with very bad success, I fear, since, in this case, there is no exercise to generate heat, or counteract the effects of cold. Once more I must leave it to the all-informed physiologists.

April 24. We proceeded soon after noon, with the second boat, through the same kind of ice, and, after four hours, reached the sea-shore, where we found a terrace of ice formed by the spring tides, so as to produce a level way within the hummocks on each side. Here the travelling was comparatively easy, and, by six, we were about seven miles from North point, where we left the boat and returned to our quarters of the preceding night. 
We began our march early, this day, with the second boat, and April 25. with the provision sledge, alternately, in spite of a very annoying wind, with snow-drift; reaching the advanced boat of yesterday, and then carrying the whole a little way further, till eight, when we were obliged to house ourselves as on the first day of this journey. Our meat was so hard frozen that we were obliged to cut it with a saw, and could only afford to thaw it by putting it into our warm cocoa: we could not spare fuel for both purposes. A strong gale with a snow drift nearly covered our hut in a short time, and we had the greater mortification of finding ourselves obstructed by a ridge of rocks jutting into the sea, on which the ice had accumulated to the height of fifty feet.

Men have smiled at the narratives of eating in "old Homer," and critics have defended him. "Dormitavit" it may be, on many things, but on this subject at least, he never slept; yet the "good man" need not have been very anxious about the dinners and suppers of his heroes, since they were never in want of a cow or a goat, to carve with their swords, and broil on their embers as they best might. If some of us have been wearied of these suppers, and much more wearied when we were least hungry, there are not many, full or fasting, who have not been interested in the dinners or breakfasts in Gil Blas or Don Quixote, possibly too in the eatings of Scott, who, like his predecessors, knew full well how deeply this prime object of human nature interests all who belong to humanity, as to the whole animal race.

Matters of this kind were to us, however, far from being things of amusement or romance; they were of much too serious moment for a poetical or a jesting narrative; we might have had suppers to 
cook, or breakfasts to eat; but there was little inclination for a wantonness of record on things of bitter necessity, or to tell tales of a hungry stomach and short commons for the entertainment of readers. The scanty allowances of yesterday or to-day, the equal prospect of as scanty an allowance to-morrow, formed no matter for aught but serious thoughts, and even anxious care; it was not a question alone whether we should attain our object and execute our plans, but whether we should live or die. It is said that there is no jesting with a hungry stomach : there was assuredly none in our case, on this occasion, and on many previous and subsequent ones. We should not merely have failed in our endeavours, but we might have died, and left as a witness, those bones which would never have been recognised as the relics of philosophers who had come so far, to do-what has been done. Heaven only knows what would have been our fate, had the animals of this country, with four legs or two, plundered our deposits on the various occasions where we had trusted to their stupidity or their more than doubtful honour, or had the failure of our strength or our means of conveyance left us to the miserable and casual resource of a stray fox or a few gulls.

April 26. We were imprisoned all the following day by the storm; but it April 27. gave an advantageous rest to the men. On the twenty-seventh, early, we attempted to make way over the sea ice, where the road was so difficult that we did not gain more than three hundred yards in two hours. Reaching however, at last, the terrace of ice which skirted the shore, the way became comparatively easy, though it compelled us to go round every point of land, and every bay; rendering the gain in direct distance very small. 'Thus, however, 
we at length advanced two miles; when the terrace ended against a precipitous cape, which, for the space of three or four miles, was impassable over such ice as that which occupied the sea.

Nothing therefore was left but to drag our sledges on shore, and attempt to find some favourable place for carrying them over land. With great labour, and being capable of taking only one at a time, we thus at last passed three hills, on which there was frozen snow enough to assist us, and reached the creek we had in view, within an island near the cape where we were detained on the September of 1829. Here, once more, we built snow huts and took our rest.

We could not proceed on the following day, in consequence of April 28. another gale; and as this became worse on Sunday, we decided on April 29. securing the boats and returning to the ship, as the wind was behind us, and could thus be encountered with little hazard. We reached the huts that we had first built, in the evening: and, on the following April 30. day, having concealed a store of provisions there, as we had done at the former place, succeeded in returning to the ship about noon. The total result of this journey was, that we had walked a hundred and ten miles, and had advanced, in real distance, but eighteen; while it would be necessary to go over this space three times more, before every thing could be even thus far advanced in a journey which was destined ultimately to be three hundred miles, though the direct one was only a hundred and eighty.

I deem it unnecessary to give any abstract of the month of April, as the past details are ample.

The first of May was mild, with the thermometer between $2^{\circ}$ and May 1 . $20^{\circ}$ plus.

We were employed in preparing provisions for the advance; and 
the salt meat and other stores which we could not carry were got out in readiness to be deposited in the Krusenstern on shore, as a last resource in case of our return. This, and other work occuMay 2. pied the following day: when, although the thermometer was plus $20^{\circ}$ in the day, it fell to zero at night.

May 3. Two sledges were taken to the sea ice, four miles off, the men May 4. returning at seven o'clock. On the fourth we commenced our second journey: the party consisting of myself and Commander Ross, with ten men, being the whole of our effective crew, dragging one heavy-loaded sledge. After finding that which had been deposited yesterday, we had good ice for five miles, and thus carried on the two sledges, until one was broken in attempting to pass some hummocks in our way; arriving at the first of our stations in the night, with one of them only.

May 5. All was found safe from the expected intrusions of the glutton : and after eight hours' rest, the men went back with the broken sledge for repair, and to bring on the two others which were yet to come up. The day was spent in this alternating labour, and after twelve hours, we had brought one sledge, by midnight, to a distance of eighteen miles from the ship,

May 6. The second was brought up on the following day, and the broken one repaired; when, the loads being equalized, we set out for the next station, which we did not reach till eight at night, in consequence of a fall of snow which rendered the way much worse than before. Then unloading the sledges, we returned to our last night's quarters, after a journey of fourteen miles. The thermometer was at zero.

May 7. We set out with the remaining provisions and bedding, and 
reached the second station of eighteen miles, at three in the afternoon; having succeeded at last in bringing hither two boats and five weeks' provisions, besides a present supply for ten days more. Our labour was much too serious and anxious to allow of any jesting; yet we could not help feeling that our travelling resembled that of the person in the algebraic equation, whose business it is to convey eggs to a point by one at a time. Here, repairing the sledges that had suffered, we advanced another step of seven miles with two of them, and of five more with a single one; having thus made a day's journey of sixteen miles, and sleeping again at our hut.

A severe fall of snow imprisoned us all the day; but if it gave us May 8 rest, it alarmed us for the state of our road. The night thermometer rose to plus $18^{\circ}$. The following was much worse, with an May 9 easterly gale; yet the thoughtless sailors slept and enjoyed themselves as if there was nothing else for them to do, leaving the anxiety and the sleeplessness to him who held all the responsibility. On the tenth, however, there being no cessation of the gale and the May 10. drift, they appeared to become wearied of this rest, in a hut so small that it was impossible to change the position which had first been adopted. At midnight, however, the gale fell, but the thermometer was at zero.

Much of land-jesting there has been, in the prose of the Joe Millers and the songs of the Dibdin race, on the peculiarities of sailors, and on a character which these "land-lubbers" have themselves contrived, as unlike to that of a "British sailor," or any other sailor, as it is to that of a Chickasaw, or a Chinese. The animal has a character of its own, that is certain; but it is as far 
from that which the public, thus trusting to jests and ballads, believes, as it is to any possible form under which human nature so situated can display itself. How far it is worse, I ought not to say; in what respects it is better or different, it is not here within my limits to detail, but this at least is universal : let any thing be, provisions or water in doubt, a gale or a hurricane, the ship's course lost, the sails or the rigging ruined and irreplaceable, or even the vessel on a lee shore in a storm, it is " the captain's business." The men obey their orders, it is true, and what they will attempt and execute, no landsman will believe; but the watch at an end, they sleep as sound as if nothing was amiss : it is " the captain's business." Our own men had, in our present voyage, seen, perhaps, enough to have acquired some thoughts of their own : and possibly too, they sometimes considered of matters for which " the captain" ought not to have been exclusively responsible; yet the radical feeling for ever broke out, and whatever there was of unusual and new to be projected and done, their tranquillity remained unaltered : it might have been wrong or right, but it was " the captain's business," not theirs-a happy responsibility on his part, it cannot be denied; yet is it not one under which he deserves the praise which he does not always attain ?

May 11. We were obliged to dig the sledges and boats out of the snow before we could proceed. Our road was much encumbered with wreaths of snow, from the gale, but we reached one of our positions in about six hours, at an island near the main, and returned to our quarters by the evening. The thermometer in the day nearly subsided to the freezing point, and was plus $18^{\circ}$ at night.

May 12. At eight we set out with the other boat, containing the extra 
week's provisions ; and, in spite of a fresh breeze, with drift snow, succeeded in getting her to the same island, returning once more to sleep. On the thirteenth we picked up the sledge which had been left four days ago, and carried it on to the same point. The next day was employed in carrying forward two sledges, with the tents, May 14. bedding, and provisions, in spite of a gale which, rising when we were about halfway, gave us much trouble; as did the deficiency of two of the men, who had become snow blind. We arrived late, and built huts for the night.

The journey. was on this day deferred till the evening, on account May 15. of the men's eyes; and it became thus necessary that we should hereafter turn day into night. We passed across a narrow neck of land, and continued our route to Eclipse harbour; but were at last entirely stopped at the point, on its southern side, by the formidable nature of the ice. Here, however, we found that this bay was divided from the sea to the northward by only a narrow neck of land, and that, beyond this, the ice was not bad.

On the sixteenth we passed over liclipse harbour, through much May 16. snow, and crossed the neck just mentioned, which was only five hundred yards wide, and not above fifty feet in elevation. We thus descended to the sea on the other side, which proved to be a spacious harbour, containing one island; bounded to the north by a point so high, that the sea could not be seen over it. The boat was then hauled to the mainland; and we returned, after an advance of eight miles.

On this day two sledges were taken on to the same point, and riay $1 \%$. the remainder of the provisions were transported on the following: May 18. each load thus costing us a sixteen mile walk. On the nineteenth May 19. 
we set out with the remainder of our equipage, and arrived at the next advanced post at eleven. The snow was so deep and the road May 20. so bad on the following day, that we could barely draw the two light sledges ; but, in spite of this, we arrived at length at four in the morning, at the station, which was twelve miles from the ship; after which, we took the empty sledges and reached the termination of the bay, on our return to her, about four miles from her place.

May 21. Arriving on board, about noon, we found another month's provisions ready, which was nearly all that remained; but we ascertained that it would require a week to repair the sledges and put the men in a condition to draw them. We had time, therefore, to review what we had lately done; and the result was that we had travelled three hundred and twenty-nine miles to gain about thirty in a direct line; carrying the two boats with full allowance of provisions for five weeks; and expending, in this labour, a month. It was, however, the worst part of the road.

May 22 The two days after our arrival were so bad, from a northerly $\& 23$. gale and drift snow, that we were well pleased to be on board; but, May 24. as it moderated on the next, a party went off with the sledge, containing a month's provision at half allowance, to be deposited at May 25. the twelve mile station. We were busied in making a new sledge, to replace one which was found irreparable; and, on the twentyMay 26. sixth, the party returned, having succeeded in their errand. They had found the snow melting fast, and the aspect of the land was, in consequence, entirely changed.

May 27. Divine service was performed on this Sunday, and the men were allowed to rest. The thermometer was now $22^{\circ}$ plus at midnight, and had risen to $40^{\circ}$ in the day. 
We were employed in preparing for our final departure. The May 28. chronometers and astronomical instruments which could be spared and could not be taken, were concealed in the place that we had made, together with some gunpowder; the masts, sails, and rigging, were placed with the Krusenstern, and the men carried two sledges loaded with provisions and stores, as far as the third lake, leaving one on board to take the remaining articles.

We had now secured every thing on shore which could be of use May 29. to us in case of our return, or which, if we did not, would prove of use to the natives. The colours were therefore hoisted and nailed to the mast, we drank a parting glass to our poor ship, and having seen every man out, in the evening, I took my own adieu of the Victory, which had deserved a better fate. It was the first vessel that I had ever been obliged to abandon, after having served in thirty-six, during a period of forty-two years. It was like the last parting with an old friend; and I did not pass the point where she ceased to be visible without stopping to take a sketch of this melancholy desert, rendered more melancholy by the solitary, abandoned, helpless home of our past years, fixed in immovable ice, till time should perform on her his usual work.

As we proceeded, we found the snow harder, and our road imMay 30 . proved; yet the heavy loads made our progress slow, and we did not arrive at the twelve mile huts till noon. At one on the follow- May 31. ing morning, we proceeded, but could not long carry forward more than two sledges at once, up the hills; so that we did not gain the next post, only eight miles off, under ten hours. We ended the month of May at this halting place, with the thermometer at night about the freezing point. 
I may now explain the plan of the journey we had thus undertaken. This was, to carry both the boats on to Elizabeth harbour, with provisions for six weeks at full allowance, there to deposit the boats and half the provisions, and to proceed with the sledges and the other half till we reached the latitude of $\boldsymbol{7 1 ^ { \circ }}$, whence we should send a light party of five to ascertain the state of things at Fury beach.

This month had brought us to $70^{\circ} 21^{\prime}$ latitude, leaving us sixteen miles more to Elizabeth harbour; and though our crew were in a very indifferent condition for work, all, even the blind man and the lame, were obliged to exert themselves in some manner, under which, with a revival of hope, they contrived to keep up their spirits.

The state of the ice at this period, and it was now a late one, was incredibly bad. The sea was every where one solid mass of the heaviest pieces, as far as the eye could reach, in every direction; and even the cracks which we had lately noticed in the marginal terraces, were again filled up to the same state of solidity with all else. All was rock: it seemed as if there was never to be water again : but whenever this might happen, it was now but too plain that the result could not be to liberate the ship which we had left, within the present year. It was at least satisfactory to find that there was no rashness in our proceedings, and that nothing but what we were doing could have been done. 


\section{CHAPTER L.}

JUNE-OUR JOURNEY WITH THE SLEDGES AND BOATS-ARRIVAL AT FURY BEACH-TRANSACTIONS AND DETENTIONS DURING JULY.

A $\mathrm{T}$ eight in the evening, we set off with three sledges, and found 1832. the snow hard; but there was no water any where, so that we were still obliged to thaw it for drinking. At seven in the mornJune 2 . ing, we arrived at the third station, eight iniles further in advance; and, as usual, the remainder of the day was allotted to rest.

We reached the next huts this day with the remainder of our provisions. The men seemed then much fatigued, and the mate Blanky, being deputed by them, intimated their desire to abandon the boats and spare provisions at this place, and proceed direct for Fury point. I had already suspected something of this nature; but as we should thus leave our resources in a place to which it was impossible to return, I not only expressed my refusal, but ordered the party to proceed, in a manner not easily misunderstood, and by an argument too peremptory to be disputed, after reprimanding the ambassador for the extreme impropriety of his conduct. It was the first symptom approaching to mutiny which had yet occurred.

I am not now willing to say more respecting things which I then thought it best not to notice further than was necessary for 
the safety of the whole party, and had declined mentioning on our return to England. I have ever been more desirous to praise than to blame; and having amply praised what was right in the conduct of my officers and crew, must not now remember, more than I can help, what there was to censure, with somewhat more of severity, as of ill consequence to them, than would be agreeable to my own feelings. It must suffice that these difficulties were surmounted, and that I brought that party safe home : if I have not experienced the gratitude that I deserved, for this and more, I am too well experienced in mankind to be surprised, or to entertain enmity against those who only acted according to their evil natures.

June 4. On the ridge of Eclipse harbour, this day, we found that there had been some pools of water, which were again frozen three inches thick, and we arrived at our huts at six. We here used the suminer tents; and though the temperature was at freezing, they were June 5. not uncomfortable. Having then brought on the remainder of our things, since every stage required two journeys, we proceeded in the evening with the sledge and one boat, and at midnight crossed the ridge which bounds Elizabeth harbour on the south.

June 6. On the following day we reached the extreme entrance, depositing our loads and returning to the tents for the remainder. We had shot two hares in these two days, which aided somewhat our June 7 . short allowance. We crossed the ridge as far as the first boats on the next day, returning to the tents at eight, much fatigued from the snow in our road. In this walk we saw the tracks of reindeer, and found the hares still in their white winter clothing.

We were imprisoned by a storm on the eighth; and, on the following day, every thing was brought forward to the depot in 
Elizabeth harbour. Here we ascended the hill, so as to examine the state of the ice; the extremely bad aspect of which made us conclude that it would be impossible to carry the boats any further. As they were now also within reach, in case we should be compelled to return, I determined to proceed with the people, and three weeks' provisions, for twenty or thirty miles; leaving the rest here as a reserve, and sending an advanced party to Fury beach, to ascertain the state of things at that place.

At half-past one in the morning we accordingly set out, with June 10. three sledges, very heavy laden; since, besides the three weeks' provisions at full allowance, there were arms, ammunition, tools, instruments, clothing, and more. Some valuable articles, which we could not take, were left under one of the boats, which was turned up for this purpose, that they might be safe in case of our return. We halted at the south of the point which forms the bay already often described, and then proceeding, after much toil, from the badness of the ice, passed it at midnight.

The state of the way obliged us to make for the north point, June 11 . where we pitched and had eight hours' rest. On the twelfth, we June 12. reached another point, and again encamped. Here the preparations were made for the advance of Commander Ross, with Abernethy and Park, who departed at ten, for Fury point, taking with them a sledge, fifteen days' provisions, a tent, and such other things as were indispensable. Their directions were to leave a note at every place where they slept, which we calculated on reaching in double the time, with our loads, so as so be advanced about seventy miles when they should have reached to their journey's end, now a hundred and fifty miles away. This was to allow them fifteen in 
the day, and ourselves seven, which was as much as we could execute after losing three of our best men.

june 13. That party was soon out of sight; but we made a very slow progress; being compelled to perform circuits where they had been able to cross. After nine hours, we halted on a point, but even yet could find no water at noon. At this place we left a depot of provisions, and proceeded, afterwards, at four in the morning, while June 14. obliged shortly to halt, on account of the illness of the surgeon. It blew hard, with snow, and our quarters were very uncomfortable.

June 15. We were detained during all the fifteenth by the same causes; June 16. but started once more on the next day, at seven in the evening, in spite of some falling snow; passing over ice so deep with snow, and so full of cracks, that many of us experienced severe falls. We found the note, and the cairn erected by the advanced party, about midnight, and completed a journey of nine miles.

June 17. In our march to-day, we passed many small bays and points of land, and saw the blue mountains to the westward, about ten miles distant; finishing a journey of eleven miles by four in the morning. Here we made another deposit of provisions, and proceeded at June 18. eight in the evening. We found water, for the first time, on the following morning, and halted at the second cairn which the advanced party had erected; finding a note to say that they had been checked by lameness and by inflamed eyes. Our journey this night had not exceeded eight miles.

June 19. We had recommenced at eight last evening, and proceeded; finding, and seeing, all the land as completely covered with snow as if it had been winter. The thermometer had also sunk to $24^{\circ}$; so that every pool was frozen, and we were again obliged to thaw for 
water. At nine in the evening we began again, in spite of a snow which continued all night, and arrived at two in the morning at June 20. the third cairn, pitching, finally, at five, on a point where there were some marks of former native encampments. Here we were obliged to dispense with water; as there was none, and we could not afford fuel to melt ice.

At two in the morning of this next advance, we came to another June 21. cairn that had been left by our predecessors; but it had fallen down, and no note was to be found. We could however trace their intended route, by some stones which they had placed; but that being too rough for us to follow, we took another course, and, after twelve hours of labour, halted at eight.

While the men slept, I proceeded to examine the land, as we June 22. had not before been able to survey this part of the country; and, after this, we proceeded in the evening, as usual, till we arrived at the south Grimble islands, where I found Commander Ross's cairn, being the end of his fourth day's journey. By his observations we were twelve miles, and, by mine, eight, from the place where we had first taken possession on the tenth of August, 1829. As there were eight miles yet to make, before we could cross the inlet, we preferred sleeping on the ice where we were, and after six in the June 23. morning, leaving the men to their rest, I proceeded to examine this inlet.

After the usual measurements and observations, I ascertained its figure and extent, finding that its bottom gave entrance to a large river, and, consequently, that there was no opening, or passage to the western sea at this place, as might otherwise have remained a point in doubt. It was also evidently a shallow piece of water. 
Having proceeded at nine, we passed two considerable rivers at the northern part of this inlet, and, after that, several islands; arriving at a point where we again found a cairn, with a note. We pitched on the south-east side, where I completed the survey of this bay.

June 24. At three on this morning we reached the fifth cairn of our advanced party; and as the note reported all well, I calculated that they would, at this date, have been two days at Fury point, and that they would consequently meet us on their return, in two days more. I therefore left a note at the cairn, informing us that we had passed it, and should keep close to the land; as it was possible they might take a different road and miss us.

We accordingly continued our journey along shore, and passed a point, soon after which we met and joined Commander Ross's party. The information he brought from Fury point was, that the sea had risen high and carried off three of the boats, with many other things, to the northward, and that one of them was seriously damaged. All else was in the same condition as we had left it; and the bread and other provisions were in abundance and in good order. We all pitched for the day, and found, that with what they had brought, and some which they had deposited, there was enough to last us all on full allowance till we should reach that place.

June 26. After starting at eight last night, we proceeded in spite of a very cold fall of snow, till five, when we halted just after having passed the sixth of the advanced cairns. At two in the morning of the June 27. twenty-seventh, we reached Cape Garry, and picked up the provisions which had been left; encamping in a strong breeze, accompanied by snow, which ended in a storm, lasting the whole day, with the thermometer at $32^{\circ}$. 
On this day we reached the land near the bottom of the bay, June 28. which seemed the outlet of a great river; and though unable to make a perfect survey, I not only found the water shallow, but could see the land so well all round, as to assure me that there was no passage westward in this direction. On the next we passed through much water, often above our knees : it was a novelty, yet not an agreeable one; but we traced it to the efflux of several small rivers at this part of the coast.

We resumed our journey as usual, being now obliged to carry June 30 . the lame man, in addition to the rest of our load, and passed several low points and islands of limestone. The sun had a great effect on the snow, and the aspect of the land was hourly changing; but, in the offing, the ice seemed as firm and continuous as ever. At noon the thermometer was at $47^{\circ}$, and at midnight at $32^{\circ}$. We had shot several ducks in the last few days, and they were somewhat better than a luxury to us, especially before our allowance had been increased. Finally, we ended the month within hail of Fury beach.

The water was now, at last, running down the large cracks in July 1. the ice, and every thing was hourly changing in appearance. 'Three ravines that we passed were also pouring down their respective torrents; and at the foot of one of them we pitched our tents; here also finding a cask of flour which had been washed hither. The last part of our journey was unusually laborious, from the wedged masses of ice, so packed as to denote the great violence which they had undergone; but we at length passed them all, and encamped on Fury beach at ten o'clock.

We were once more at home, for a time at least, such home as it July 2. 
was, and however long or short was the time that we were destined to occupy it. There was the feeling of home at least, and that was something : it had been once the home of all of us, since it had been our storehouse; and it had twice been that of Commander Ross. The men I doubt not, felt this most, after all their fears, and the pleasure was little diminished to them, by any anticipations of what might yet be to come.

The first measure which I adopted, was to send them all to rest for the night, that we might once more bring back the regularity of our days: and after this we proceeded to take a survey of the stores. Being scattered in every direction, it was, however, difficult to prevent the half-starved men from getting access to them; in consequence of which, and in spite of all orders and advice, many suffered smartly for their imprudence. Excepting the damage done by the high rise of the sea, formerly mentioned, the only important one we discovered was the loss of candles, by the foxes, which had opened some of the boxes and devoured the contents.

As soon as the men were rested, they were appointed to their several tasks. The first thing to be done was to construct a house, which was planned at thirty-one by sixteen feet, and seven feet in height, to be covered with canvas; and, by evening, the frame was erected, while we ended this noted day with a luxurious supper from the stores which had been left when we first supplied ourselves from this deposit.

July 3. There was a fog yesterday, with the thermometer at freezing, though, before this, it was at $50^{\circ}$, and, on this morning, there blew a strong gale from the eastward; which somewhat impeded our work, as that was aided by the illness of the men who had over- 
eaten themselves; but the rest were employed in bringing the dispersed boats to a proper place for being repaired.

The first shower of rain for the season fell this day, being three July 4. weeks later than had ever yet been recorded. The house was finished, and received the nickname of Somerset house; this tract of land having been previously called North Somerset. It snowed on the fifth; and this ended in a clear northerly gale, so cold, that July 5 . the rain which had fallen, froze ; the highest degree of the thermometer being but $30^{\circ}$, as the lowest was $27^{\circ}$. As it snowed again all the night, the land was as completely covered on the following July 6 . morning as ever it had been during the winter.

The carpenters were set to work on the boats; the plan for which was, that each of them should be strengthened by means of two bulk heads and two strong beams. I had intended to rig the whole with shoulder of mutton sails, as the safest and best; but Commander Ross preferring a spritsail, was allowed to manage one of them in his own way. The house, which we now proceeded to occupy, was divided into two rooms, one for the men, and another, containing four small cabins, for the officers: at present, the cook's department was a tent. The purser proceeded to take the regular account of provisions.

The snow dissolved at night; but the ice in the offing was as July 7 . heavy as ever, and at night it snowed again, being two degrees under freezing. On Sunday the usual regularity of divine service July 8 . recommenced, after many unavoidable interruptions.

Nothing of note occurred on many following days, unless it be that the temperature rose once to $50^{\circ}$, but was at the freezing point July 9 to 15 . at night, on most days. It blew hard on the twelfth, but mode- 
rated on the following day: nor is there any thing to record during the whole of this week, on to Sunday, except that the work on the boats was in progress.

The weather was variable during the three first days of the following week, and there was a little rain on Thursday. The snow was slowly disappearing, but the night temperature never rose beyond the freezing point. On one of these days I was able to ascend the highest hill, about a thousand feet high, whence I could perceive that the whole sea was a solid mass of ice, withont motion, as far as the eye could reach. Some deep ravines, carrying no water but that from the melting of the snow, were, for this country, rather picturesque.

Of the remainder of this month I need not give a detailed journal.

The weather proceeded in the same manner, calm, windy, clear, hazy, and rainy, in rotation; with a temperature at night gradually rising to $40^{\circ}$. Our work was uniform, consisting in the preparation of the boats and provisions: the occasional shooting of some dovekies and other sea birds formed but a small variety in this monotonous life. A slight disruption of the ice on the twentyninth, must not, however, pass without remark; and it went on increasing on the following ones.

In putting in order the Fury's three boats, one of which had been exceedingly damaged, I had at first to regret that we had been obliged to leave our own behind, as they would probably have been ready sooner than the others, which might possibly detain us after the water was open. But as it turned out, all was ready together, and we were in a state of preparation for our voyage. 


\section{The general temperature of this July shows a mean of plus} $35^{\circ}$ with the two extremes of plus $50^{\circ}$ and plus $22^{\circ}$. There had been rain but six times, and the first at a very late period; but there had been a good deal of snow. Vegetation was therefore very backward. The men having been now on full allowance, had improved in health.

The following is an explanation of the Meteorological Tables formed at the end of the years 1830 and 1831 .

The direction of the wind is expressed fractionally, thus $\mathbb{N N W}^{4}$ : that is, 4 hours at NNW; the numerator expressing the number of hours, and the denominator the direction. When the figure 0 occurs, it signifies that the wind was not in the direction expressed by the denominator, during the month. The sum placed to the right of the denominator, gives the total force of the wind in the same direction; this will be given in full in the tables of the Appendix, denoted by figures in the following manner:

0. Calm.

1. Light air, or just sufficient to give steerage way.

2. Light breeze

3. Gentle breeze

4. Moderate breeze or that in which a man-of-war, with all sale set, and clean full, would go in smooth water.

$\left\{\begin{array}{l}1 \text { to } 2 \text { knots. } \\ 3 \text { to } 4 \text { knots. } \\ 5 \text { to } 6 \text { knots. }\end{array}\right.$

5. Fresh breeze

6. Strong breeze

7. Moderate gale

8. Fresh gale

9. Strong gale
Royals.

Single-reefed topsails and top gallant-sails.

or that which a well-conditioned man-of-war would carry in chase full and by.
Doub!e-reefed topsails.

Triple-reefed topsails.

Close-reefed topsails and courses.

10. A whole gale, or that which scarcely could bare the close-reefed main-topsail and foresail.

11. A storm, or that which would reduce her to storm staysails.

12. A hurricane, or that which no canvas could withstand. 


\section{CHAPTER LI.}

AUGUST-DEPARTURE FROM FURY BEACH IN THE BOATS-DETENTION, AND DIFFICULTIES ON THE COAST-SUMMARY OF AUGUSTTRANSACTIONS IN SEPTEMBER-BAFFLED IN OUR ATTEMPTS TO PROCEED-RETURN TOWARDS FURY BEACH-SUMMARY OF SEPTEMBER.

1832. August 1.

ON the last day of the preceding month, the ice had unexpectedly broken up, so far as to leave some navigable clear water, and as the boats were also ready, we prepared to depart, with the hope of being able to quit this strait and reach Baffin's bay before the departure of the whaling vessels. The boats were stored with provisions till the first of October, besides the bedding and other needful things; and each carried seven men, with an officer. Commander Ross and I exchanged copies of our charts and narratives, in case of separation; and a bottle was buried in the house, containing a short account of our proceedings.

We left the beach at four in the afternoon, but found the channels in the ice very crooked, and much impeded by floating pieces, so that it was with difficulty we could use our oars. Our progress was therefore slow; and having passed two rivers, off which there was much heavy ice, we were stopped at nine o'clock under the very precipice where the Fury was wrecked. It being low water, 


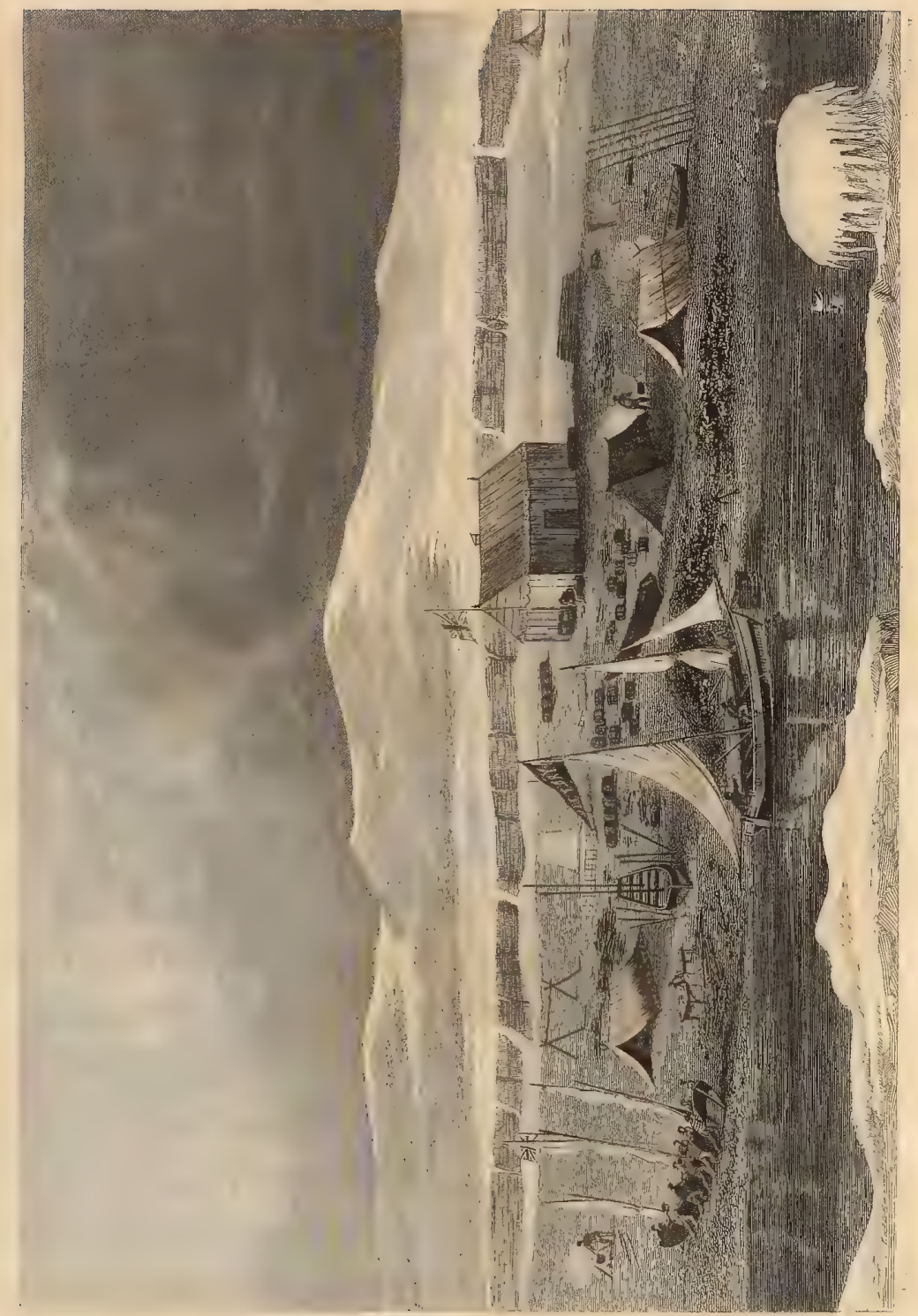



and the northward motion of the ice ceasing at eleven, it was evident that it would soon return on us; so that the boats were unloaded as quickly as possible, and hauled up on the beach.

It was not a minute too soon; since the ice immediately came down, and two floes near us were broken to pieces, with a violent crash, so as to form a ridge of hummocks close to the shore. The distance which we had thus made was eight miles; and it was a singular coincidence that we experienced this narrow escape, not only where the Fury was wrecked, but on the same day that she was lost, eight years before.

We hoped that the flood would have caused the ice to open and August 2. shift in the night; but it became so much worse that we were obliged to haul still higher, and to cut a dock for the boats in a large hummock : a position and a delay which gave the carpenters the opportunity of finishing some work that had been left incomplete. Some rain in the course of the day loosened stones from the precipices, one of which struck a boat's mast; and we found, from the fragments below, that the vicinity of this precipice, which was four hundred and seventy feet high, was a place of danger.

This seems but a cool remark to make, where such a cliff, rising to such an altitude, impended over our heads, and when we knew, what all know, the effects of a thaw in throwing down those rocks which the previous ice has split. In reality, it was a position of the utmost danger: we might all have been overwhelmed, without notice, in half a minute, as the state of the beach below testified, or the brains of any individual among us might have been "knocked out" before he could have suspected any such accident. But I believe that we were fully tried by hazards, and had become somewhat 
careless; though a little reflection soon taught us that we need not add this unnecessary one to all that we had passed through and all that was still before us.

August 3. It was a most intolerable day of rain and sleet, with the thermometer at the freezing point during the night; nor did it clear till August 4. the following evening, while we were constantly annoyed by the August 5. falling of stones from the cliff. The wind continued from the north-east, but the ice was one more fixed, especially to the northward, and the temperature a degree lower.

^ugust 6. It being at length fine, I walked to the northward, and saw a probability of our reaching a safer beach two or three miles off, where a stream entered the sea; since there was considerable fear lest some of us should be killed, in our present position, by the incessant falling of the stones under the effects of the thaw, which was general in the day. We reached it at noon, with considerable difficulty ; and some water shortly afterwards opening, we passed more precipices, and succeeded in getting a few miles further along the shore. We then found the water to the northward to be a solid mass of ice, and were obliged to haul up the boats, once more, on a beach where we were almost as much annoyed by falling stones as we had been in our last position.

August 7 . The thermometer was at $30^{\circ}$ in the night, and did not rise beyond $40^{\circ}$ in the day: during which the outer ice moved a little, under a strong east wind, but without any useful results to us. Foxes, gulls, and dovekies were numerous; but we dared not fire, on account of the falling rocks, nor could we afford fuel for cooking, August 8. even had we succeeded. On the eighth, the ice threatened us, even on shore, such was its pressure: at any rate it secured our imprisonment. 
The ice in the channel streamed off to the north, and at length $\Lambda$ ugust 9 . opened just so much on the coast, as to allow us to embark at two o'clock. But we could not proceed more than two hours, and were then obliged to haul over rugged ice to the first beach we could find, since all was solid beyond us to the northward; while we had barely room for our tents under the precipice. The thermometer was never more than $34^{\circ}$ in the day, and fell to $31^{\circ}$ at night: it was absolute winter still.

It being fine weather on this day, we were able, by lightening the August 10 . boats, to track them along the shore to a better beach half a mile off, where we took our position at the foot of a cascade, bringing forwards what we had left. We attempted to move again the next August 11 . day; but were soon stopped by the ice, and glad to return to the place where we had a good position for the tents and an excellent harbour for the boats. On the twelfth we were imprisoned by snow August 12. and wind, and by the absolute closure of the ice.

As there was no change to-day, Mr. Thom was sent with a boat August 13 . to Fury beach, for three weeks' provisions ; there being open water in that direction, though there was none to the north of us. It blew hard from the north on the next day; but though the effect of the Augusi 14. wind was to produce a pool of water near us, it did not open the passage. The squalls were so strong as to endanger our tents, and to disperse the cascade in mist. The night temperature was still $31^{\circ}$ or $32^{\circ}$, and that of the day was $40^{\circ}$.

A note arrived from Mr. Thom, to say that he had reached Fury August 15. beach in three hours, had hauled the boat up about two miles off on his way back, and expected to return to us by the next tide. I accordingly sent two men to assist; but the boat could not be got 
off, and they came back to us, therefore, with some of the proviAugust 16. sions. On proceeding to examine into the state of things, next day, I found that the boat could not be brought along shore loaded, in consequence of the state of the ice; and, on this and the August 17. following, therefore, the stores which she contained were brought to our present position, and the boat was dragged up to remain till August 18. we were all once more reunited. The weather was still colder, being $30^{\circ}$ at night, while some fresh snow that fell remained till noon.

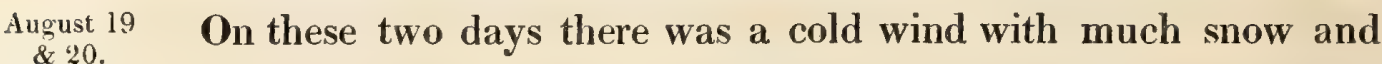
Angust 21. thick weather, but it became clear on the twenty-first; the thermometer sinking to $29^{\circ}$, and the boat's harbour being covered with August 22. new ice on this and the following day. That ice was two inches August 23. thick on the twenty-third; but in the evening the weather became calm, and it did not freeze on that night. A whale was heard, but August 24. not seen. There was no change on the following day, and the ice was every where unbroken.

Augnst 25. A cold northerly wind sprung up, and the tide rose eight feet, but without any effect on the ice. There was snow again in the August 26. evening, at $29^{\circ}$ of temperature. On the following day it fell to $25^{\circ}$, and the breeze was much stronger: it was left to us to guess whether this cold belonged to the old winter or was the commencement of a new one. The ice thus drifted to the southward, and the pressure was so great on our shore, as to force many heavy masses on the boat, higher than it had yet reached under any previous wind and tide.

August $2 \%$ The rise of this tide was nine feet; and as it was still blowing hard from the north, the ice passed quickly to the southward; when, veering to the north-west, it all began to leave the shore, 
and in two hours, the whole coast was cleared as far as we could see. At midnight it blew a gale, with heavy gusts from the precipices, so that our boats could scarcely lie where they were; and, very provokingly, the cascade was so frozen, that there was now no water to be obtained without thawing: the thermometer being at $26^{\circ}$ at night.

It moderated at noon, and we embarked, proceeding under sail August 28. along shore, and exposed to very heavy squalls from the precipices, which rendered extreme care necessary: when, passing Batty bay, we reached Elwin bay at midnight. We then stood for a beach about a mile further north, and, as it was now blowing a whole gale, pitched our tents, amid a storm of snow, which, in the night, covered all the land.

It moderated, however, towards morning, and we put to sea by August 29. four o'clock, standing for the edge of the packed ice, in the direction of Cape York. We then ran along it, in hopes of finding some passage; but it continued to lead us out of our course, till it joined to Leopard's island, so as to embay us : and as the wind was again increasing, it was with great difficulty we weathered it, so as to attain the land about a mile north of Cape Seppings, yet without being able to get to the beach, which was every where blocked up by heavy ice. There was snow, and the range of the thermometer in the twenty-four hours was from $30^{\circ}$ to $36^{\circ}$.

We were obliged to sleep in our boats, in no comfortable posi- August 30. tion; and as our place was not tenable, we re-embarked at six in the morning, with a southerly wind. We soon met with the ice pack, and ran along it up Barrow's strait; but to no purpose, as there was no exit any where. We therefore stood in to the shore, 
and found a good position for pitching the tents and hauling up the boats; while it was near a mountain that promised us a view of the distant ice; the pack being so high above the boats' gunwales that we could not see over it.

Angis 31. It snowed all the morning, and we removed the boats to the ground ice for the sake of launching them more easily. We found here many remains of Esquimaux huts, and some fox-traps; and as we saw many seals, the reason for the natives fixing in this place was apparent. The hill itself was a peninsula, joined to the main by a long bank, or rather a neck of land, about two miles broad, and on each side was a bay; while, as in neither of these the ice had yet broken up, we had a sufficient proof of the severity of the season. All the sea to the north was hence seen to be completely full of solid ice, though it drifted occasionally, near the land, under the influence of the tides.

August had been a month of peculiar anxiety; and a succession of hopes and disappointments severely tried the patience of all. On quitting Fury beach, appearances were so favourable, that every advance to bay, or point, or cape, along the coast, flattered us with the prospect of soon reaching the northern edge of the ice, and then of surmounting the greatest difficulty in the way, by making a passage across Prince Regent's inlet. By the time, however, that we had reached $73^{\circ}$ of latitude, we were unfortunately detained so long by the state of the ice, that it became doubtful if we should succeed during the present season.

Here was one of the main trials of our patience; and a look-out house, built in the cliffs by the men, became the chief thing which afforded them any amusement, while that consisted in watching 
for the changes in the ice, which, after all, did not arrive. This detention reconciled those who had first opposed this proceeding, as unnecessary, to our past labour in bringing on provisions to this place; since we were thus enabled to keep up a better allowance to the people. That consisted of half a pound of meat, with a pound of bread and a pint of cocoa, divided into breakfast and supper, which were regulated, in point of time, just as our travelling permitted. All game was considered as an extra and luxurious allowance; but what we obtained was very little, since it amounted but to three foxes and as many hares, with a couple of ducks. All the waterfowl had disappeared about the end of the month.

The boats sailed nearly alike; but being made of mahogany, proved so heavy, that it gave us great trouble to haul them up on the beach ; so that the whole party was required to draw up one, while even this often required the assistance of tackle. This work also proved an occasional source of great danger, as well as inconvenience, since the ice sometimes drifted down on the shore so rapidly, that these boats ran the imminent risk, on those occasions, of being crushed before we could get them into a place of safety.

The coast which we had thus passed consisted entirely of limestone, often presenting precipices of five hundred feet in height for a space of five or six miles. Every valley bore marks of a stream or of its bed: but these seemed never to convey water, except during the melting of the snow. Scarcely any vegetation was to be seen.

of the temperature I may finally say, that the extremes 
were $40^{\circ}$ plus and $20^{\circ}$ plus, and that the mean was $31^{\circ}$ plus, which, relatively to our former Augusts in this country, gives the following comparison :

1830 Highest, lowest, and mean temperature $+58+33+40.87$

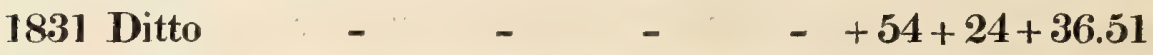

1832 Ditto $\quad-\quad \quad-\quad \quad-\quad \quad-\quad+40+20+31.23$ 


\section{CHAPTER LII.}

ATTEMPT TO PROCEED IN THE BOATS-OBSTRUCTIONS BY THE ICE -PROPOSAL TO RETURN TO FURY BEACH-RENEW OUR ATTEMPT -PUT ASHORE NEAR BATTY BAY-LAND THE STORES-SUMMARY OF AUGUST-ABANDONMENT OF THE MINERAL SPECIMENS.

WE were kept prisoners by a gale of wind, and all our variety was the sight of four black whales and many white ones. There 1832. was no change on Sunday. On Monday I ascended the mountain, which is in reality the north-east point of America, whence I obSept. 1. tained a sight of Cape Warrender and Hope's monument on one side, and, on the other, of Cape York, with three headlands beyond it, including the whole of that part of the sound which is called Barrow's strait. This was an unbroken field of ice: there was not even a pool of water to be seen; every thing was precisely such as it had been on the thirty-first of August in 1818. It was a bad prospect; since it seemed to prophesy that we should yet be compelled to return to Fury beach.

There was no material change on the fourth of September, Sept. 1 except that it became gradually colder, the themometer falling to to 8. $15^{\circ}$ on the sixth. There was occasional snow, with cold winds. The same weather continued till the end of the week, when the 
maximum heat was $16^{\circ}$, and the lowest $12^{\circ}$. No change took place in the fixed ice.

Sept. 9 The three first of these days were, like the preceding, without material change, and without events. A view from the hill on Thursday showed the whole of Lancaster sound, Barrow's strait, and Prince Regent's inlet, covered with solid ice, excepting a very narrow line close to the isthmus near Leopold's islands. The remainder of this week was equally dull and uniform.

Sept. 16. The thermometer was subsiding gradually, never rising to the freezing point in the day, and going down to $21^{\circ}$ at night. It was so cold in the tents, that we were obliged to build snow walls round them : and the drift, together with the snow, rendered the weather Sept. 17. sufficiently intolerable. Some ice moved off the land, under a north-westerly wind, on the seventeenth, but it closed again on the Sept. 18. following day. Two foxes were killed, with some ptarmigans; and we thus had game enough for the different messes. In the beginning of our sojourn in this country, we had thought the fox bad eating; but it was now preferred to any other meat.

Sept. 19. It was still colder, the thermometer falling to $18^{\circ}$, and not rising Sept. 20. above $25^{\circ}$; but as the ice appeared to be loosening on the twentieth, we embarked our things, leaving an account of our proceedings in a tin case beneath a cairn. Putting off at noon, we reached the pack edge of the ice at the junction of Barrow's strait and Prince Regent's inlet, after forcing our way through much of that which had been newly formed. It was found to be a continuous solid mass, giving no hopes of breaking up during the present season, advanced as that now was. The land was equally blocked up by heavy ice; so that we were obliged to return whence we had come; though 
not effecting this without much difficulty, and not landing a minute too soon, as the ice immediately came down on the shore with great force. If any one still hoped to get through this great obstacle, I was willing to wait here for a further trial, though it seemed utterly useless.

We accordingly remained three days, in moderate weather, Sept. 21 the thermometer reaching $9^{\circ}$. On the twenty-fourth, every one to 24. agreed that all hope was at an end, and that it only remained for us to return to Fury beach. On the next day the wind was more Sept. 25. favourable, and the in-shore ice in motion; a little water being also seen off Cape Seppings. We therefore prepared to embark; and I buried, in the same place, a fresh account of our proceedings and intentions, with a sketch of our discoveries.

At noon, we sailed with a fresh breeze for our return "home;" and, arriving at the Cape, found a clear, but very narrow passage, between the main ice and that on shore, just allowing the boats to pass singly: after which, standing on through water which sheathed them two inches thick with ice, we arrived at our former position, near Elwin bay, by six o'clock. We could not, however, approach the shore, and were at last obliged to sleep in the boats, in a creek not far from it, during a very raw, disagreeable night of snow.

Attempting to cross Elwin bay the next morning, we were much sept. 26. beset and stopped by the floes, and were finally obliged, at midday, to haul into a cove in the ice, when we pitched our tent on it. By six on the following morning, the thermometer had fallen to sept. 27. zero, though it rose to $20^{\circ}$ in the day; and we remained prisoners : gaining somewhat towards a dinner, in a fox and two gulls. The ice became more loose on the next day, and we departed, making Sept. 28. 
a very slow progress through heavy bay ice; when a gale coming. on at ten in the morning, increased so fast that we could carry no sail by mid-day, and were obliged to put ashore on the land ice.

We were, unfortunately, under the most terrific precipice that we had yet seen, two miles from the north cape of Batty bay: having but six feet of beach beneath cliffs which rose five hundred Sept. 29. feet above us. A speedy removal was therefore absolutely necessary; but an easterly wind bringing the bay ice on us, we were detained the next day : our only consolation, in the mean time, being the shooting of three foxes, with some ducks and gulls. We were now reduced to half allowance of provisions, having long been on two-thirds.

Sept. 30. A motion in the ice allowed us to pass the north cape of this bay; but we soon found that the southern one was completely blocked by heavy and solid masses; while, after much labour, we could do no more than reach a floe extending a mile from the shore on the southern side of this indentation. The beach being here found promising, the boats were hauled up on the ice, and we proceeded to land the stores.

Anxious as the preceding months had been, owing to the impending prospect of our deliverance from that miserable country in which we had been so long imprisoned, and to the difficulties which had beset our attempts to extricate ourselves, the present one had passed in even greater anxiety, and had been a period of more frequent and more provoking disappointment. Yet we found some occupation for our minds, serving at least to divert our attention from the painful part of our prospects and the vexatious difficulties that were ever recurring, in the discussions among us, 
which, however frequent they had recently been, had now, very naturally, become more persistent and more energetic.

These also were occasionally sources of amusement, deficient as we were in all others; since we could extract this, even from the acrimony which these disputes often engendered; while we were all too intent on one great object to disagree long about the collateral circumstances under which it was to be attained. Nor was it a small advantage that these debates served to keep up our spirits : the sanguine, in the heat of their arguments, magnifying our prospects of success, as happens in all disputes, and the timid and desponding thus gaining some courage, and admitting some brighter gleams of hope, from the very speculations and anticipations which they were opposing.

Each of our three tents thus formed a kind of separate deliberative party, or a little society; in two of which, the opinions of the leader was that of his men also, while the collision of views lay thus between these different bodies. Among them, Commander Ross, who had always been the most sanguine, was still the leader of the hopeful, at least nearly up to this time, whatever doubts might have arisen in his mind during the after days of this attempt. The contrary opinion prevailed in the party of Mr. Thom, whose estimable qualities in all other points were not accompanied by that spirit of confidence which belongs in general to a period of life which my excellent friend had passed. My own tent alone was one of divided opinions; and it afforded, therefore, the greater opportunities for these discussions; while I presume I need not now say what was the extent of my own confidence, after the arrangements and exertions which I have been describing. 
But it was my wish (I believed it my best policy) to conceal my opinions, and to interfere with none of their debates; and thus, not only to see what their several tempers were on this subject, but, as might happen, to profit by that knowledge.

These views and feelings, however, underwent some changes during the time that we were making this often doubtful and always difficult progress. Within the last days of the month, Commander Ross seemed to have more than hesitated respecting our escape; and, on the twentieth, I must needs say, with whatever regret, I began myself to question whether we should succeed in passing the barrier of ice this season; in which case, there could be no resource for us but another winter, another year, I should say, on Fury beach; if, indeed, it should be the fortune of any one to survive after another such year as the three last,

If it was the fruitless attempt to cross the strait on the twentieth which had brought my mind to this state of feeling, the effect was not to be indulged; nor did my opinions tend in any degree to alter iny resolution as to our conduct, or rather as to my own, respecting the men under my charge. While there was the remotest chance for us, it was my duty to persevere, as far and as long at least as I should be justified by the state of our provisions: since, if we should be obliged to leave our boats at the furthest point where we could succeed in placing them, we should be obliged to travel back, eighty miles, over a road so rugged that it would necessarily occupy a very long time, and, with that, induce a great consumption of our stores; which we could not afford to have increased beyond what we had actually taken, from the great labour of transport and our very limited means of carriage. 
Having, as I already noticed, left the chest of minerals near a notable cairn, as being too heavy for us to carry further, I must here point out its latitude as $73^{\circ} 51^{\prime}$; that having been deduced from two meridian latitudes of the sun. The mountain, therefore, which I formerly mentioned as being situated at this place, lies between the latitudes of $73^{\circ} 53^{\prime}$ and $74^{\circ}$ north; and as its longitude is $90^{\circ}$ west, it occupies the place at which I had marked Croker's mountain, in 1818. I can therefore have no doubt that the land on which I now stood was the same that I had seen in my first voyage, and which I had been able to observe very distinctly from the vicinity of the mountain to which $I$ then gave the name of Hope's monument.

Since that period, it has been considered as belonging to what have been termed Leopold's islands; thus receiving a new name which I cannot admit. I must therefore restore to it that one which $I$ originally conferred, and in assuming a right granted to all discoverers, reclaim, of course, the right also of discovery over a land of which I then took possession. Since this spot is also a portion of the mainland, and not that island which has been asserted, in the more recent voyage to which I have thus referred, it is equally my duty to point out that the discovery of the northeast cape of the American continent thus belongs to myself, and to the original voyage which I made to these northern seas. Finally, in thus restoring the original designation of this spot, I must equally assert my right to establish every thing else connected with it, as it stands in my own charts, and therefore to replace the names which I then conferred on several objects in its vicinity.

In thus speaking on this subject, I must not be accused of 
egotism, or of an ambition for insignificant fame. It is the cause of every navigator, of every discoverer, at least, which I am pleading. It is but a small reward which ever falls to their share, in recompense for all their hardships and hazards; and if they are thus to be robbed of the only name and fame they can ever hope to obtain, the effect will be to check their ardour, in addition to the injustice thus committed. The injury inflicted on Columbus by the ignorance, neglect, and torpidity, of the world, is an example to be shunned, not followed: and though the greatest of modern discoveries cannot bear the most remote parallel to his, it must not be forgotten that the fame of every man, however small, is equally his right, and that it is, to himself, not less precious than the repute of greater deeds is to him who holds a loftier position in the world's eye.

The circumstances under which we were now placed, served also to prove another point bearing essentially on my voyage of 1818 , and on the discussions to which it afterwards gave rise. The fact, indeed, was but too surely proved for our safety or hopes: it would have been far better for us at present, had that been false which I had asserted to have been then true; had Barrow's strait been incapable of freezing, had it never been, and was never to be, frozen over; as had been most confidently asserted of late.

It was now frozen, or at least had hitherto been so, during the preceding winter and the present summer, even up to this time, into a solid sea, from Admiralty inlet to Croker's inlet; and this is precisely what I found it to be in 1818. I have equally little doubt, from the state of things with us during all the years of our present detention, that this had been its condition during the whole 
period; while there are even proofs of this, in the endeavours of the whalers to penetrate into Lancaster strait, and in the failures which they experienced.

If the assertion which I have thus controverted is therefore untrue, so are there collateral facts to prove that the condition of this strait in 1818 must have been what $I$ then represented it to be. It had been a calm season, being the most unfavourable weather for navigating these seas, since it is only through the force of the winds that the ice can be opened and dispersed, as navigators are indebted to the northerly gales of summer for whatever progress they can make. In that summer there was but one gale while we were on this part of the coast, lasting two days; and as this was from the south, not the north, its effect was to bring up the ice instead of dispersing it, so as to ensure the result in question, if not to have produced it. Thence it was, that when we arrived off Lancaster sound on the thirty-first of August, the pack of ice was still to the northward of it; while that on the south side was, beyond all doubt, in the same state that we now found it, forming a solid unbroken mass, stretching from side to side of the strait, which neither ship nor boat could penetrate.

During the last days of our detention in this place, when, in addition to what we believed the impossibility of succeeding in our attempt to leave this country, it had further become doubtful whether the state of the ice would allow us to return to Fury beach, or even to surmount a small part of the way to this only hope that remained for us, our situation had become truly serious, not simply critical. We had fixed on the twenty-fifth of September for our departure, should the sledges be then ready, and, from 
that date we had but ten days' provisions left, at half allowance, while we had not fuel enough remaining to melt the snow which would be required for our consumption of water. Thus did our arrival at Batty bay turn ont to be a most providential circumstance, as there were, from this point, but thirty-two miles of direct distance remaining; a line which all the intricacies and obstructions of the route could not well increase to more than forty.

At this time it was, that we began to experience the greatest sufferings we had yet endured from the cold. We had been unable to carry with us our usual quantity of clothes and of canvas, so that we were most in want of protection from the weather when we were least able to bear up against its severity. There was not now the employment that would have aided us to resist it, by keeping us in action; and perhaps, still worse, the diminution of our hopes during the latter days of this month tended to diminish that energy of the system by which, assuredly, the animal heat is maintained. The effect of the exciting, and, reversely, of the depressing passions, on the heat-generating power, cannot fail to be known to every one's experience, not to medical men alone, although they may not express their knowledge in the same terms, and perhaps may not even have noticed the facts till pointed out; and while it ought to be made a primary consideration with every officer having charge of men in these frozen climates, to maintain the spirits and hopes of his men, so may I add it to those rules and precautions which I formerly laid down on this subject. Be all this as it may, we were really very cold, and very miserable; and from what I have formerly said of my own constitution, I have reason to believe, that whatever my own sufferings might have been, every one of 
the party was much more miserably cold than myself. The prospect before us, in the case of being obliged to return, was even worse; unless indeed the excess of our labours in the expected journey, with the conviction that there was an object, and a home, such as that was, in view, should enable us to accomplish this undertaking.

During the latter part of this month our success in procuring foxes and ptarmigans had been considerable; and while our whole party was not so large as to prevent this supply from being of real use, so did it form a valuable addition, both in quantity and quality, to our much too scanty stock of provisions. There was great reason to dread the effect of a narrowed diet on the men : not merely on their health or strength, but on their very lives. All of us had already suffered from this at various times; but the chances of irremediable evil were increasing every day.

A review of the weather showed this to have been the coldest September which we had recorded: a fact which I attributed to the permanence and proximity of the great bodies of ice and snow which surrounded us, and especially to the total want of that open sea which has always such an influence on the temperature. This month had been noted for the tranquillity of the winds, and thence was there no cause adequate to the disruption of the ice. The whole land also, ever since the middle of August, had been entirely covered with snow, so that, but for the appearance of the sun, every thing bore the aspect of deep winter.

Having formerly noticed the necessity which compelled us to leave at North-east Cape the largest collection of minerals which we had made, I may now add, that I afterwards pointed out the 
spot to Captain Humphreys, of the Isabella, with the hope that he might have reached that place in the succeeding summer, and thus put me once more into possession of the materials whence I might have drawn up an account of the geological structure of this country. While this sheet was preparing for the press, that collection arrived; but it is a subject that $I$ am compelled to refer to the Appendix, among the other matters appertaining to science and natural history. 


\section{CHAPTER LIII.}

CONTINUATION OF OUR TRAVELLING SOUTHWARD IN OCTOBER-RETURN TO FURY BEACH-ESTABLISH OURSELVES AT SOMERSET HOUSE FOR THE WINTER-SUMMARY OF THIS MONTH-JOURNAL AND SUMMARY OF NOVEMBER AND DECEMBER.

THERE was a very heavy fall of snow on this day, and the thermometer rose from zero to $10^{\circ}$. A strong north-west breeze made no impression on the ice, which now covered the whole sea, giving it the same appearance as in the depth of winter. It was the work of the whole day to dig a way through it for the boats, and to haul them up on the beach above high water-mark.

The carpenter began to make sledges out of the empty bread Oct. 2. casks ; and his chips became very welcome fuel, serving to cook a couple of foxes in aid of our short commons, which, during the whole of this expedition, had been distributed into two meals, breakfast and supper. That work was not finished till the fourth, Oct. $3 \& 4$. amid very heavy snow; when they were loaded with our tents and whatever else might be wanted at Fury beach. There could be no further hope of getting back there in the boats : and thence I had originally determined to leave them here for the next year's 
use; and to proceed with sledges in the best manner that we could.

We found this attempt almost insuperably difficult; and the whole progress that we could make was but four miles. The way was rendered nearly impassable by the deep and loose snow which had been falling: and, to increase our troubles, the lame man, Taylor, could neither walk with his crutches, nor ride on the sledges, which were perpetually upsetting upon the rough ice. In some manner or other, however, we gained a bad resting place at seven; when it was already dark, with the thermometer at zero.

Oct. 5. We passed a miserably cold night, but fortunately escaped frostbites. In the morning, one of our three sledges being broken, we were compelled to leave here some stores; taking nothing but the provisions, tents, and beds, on the other two, and thus having stronger parties to draw them than on the preceding day. We thus gained seven miles on this day's journey, in spite of a strong cold wind and constant snow, and were enabled to carry the mate Taylor, by returning for him with an empty sledge. Burdened and obstructed as we already were, this was a great additional grievance: but they who were inclined to murmur, had at least the satisfaction of reflecting that their case was better than his.

Oct. 6. It was a difficulty of another kind which we had to encounter on the next day; as the heavy ice was pressed up to the precipices along the shore, and we were often obliged to quit a tolerable track, to get round them in the best manner that we could. But the labour kept us warm; and, by noon, arriving at the cascade, within eighteen miles of Fury beach, the men acquired fresh 
courage; when, having made eleven miles, we pitched within eight of our winter home, killing several foxes in the way.

Sunday morning found us a few hours more of similar work; Oct. 7. and this being over, we reached our house, Somerset house, at three o'clock; our labours at an end, and ourselves once more at home. But we had left the tents at the last stage, to accommodate the men that remained behind, who were to return as soon as possible, for the clothing and other matters which could not be brought forward at this time.

We found our house occupied by a fox, which soon made its escape. Every thing was as we left it: and as we were not less hungry than cold, having finished our last morsel at breakfast, the men were treated with a good meal, which, however, the imprudent did not partake of without suffering. Two of the men were found to have frost-bites, and I had been deeply cut in the leg.

The following day furnished employment for the men, in re- Oct. 8 \& 9 . pairing the sledges and their shoes, for another journey. On the tenth, a heavy gale rendered all out of door work impracticable, and Oct. 10. even our house was in great danger. But it had such an effect on the ice outside, as to set it in motion to such a degree, that every atom of bay ice near us was demolished by the floes, and a large space of water opened to the north-east.

This storm continued on the eleventh; and as our house was not Oct.11. yet prepared for a winter so severe and premature, we suffered considerably from the cold, being unable to raise our sleeping places beyond $18^{\circ}$. The tide rose very high: and many large pieces of ice which we had left here when we went away, were floated off. 
Oct. 12. On the following morning the storm was at its highest; the thermometer fell to $8^{\circ}$, and the tide carried off the remainder of the land ice to the southward, with great velocity, while much water was seen to the northward. That was now useless: a month before it might have aided us; but, at this time, it was what a single hour might obliterate till the next autumn.

Oct. 13. There was no cessation to this most uncommon storm: after promising to lull about noon, it blew harder than ever; and the canvas roof being too weak to bear it, the snow gained admission to our beds, and every thing was frozen. We had great difficulty in keeping ourselves warm by crowding round the stove: but had the good fortune to take three foxes in the trap: a matter now beginning to be a subject of great congratulation.

Oct. 14. We had the same luck on the next day, but there was no difOct. 15. ference in the weather on this and the following one, nor, on the Oct. 16. sixteenth, till noon, when it moderated, and the men were able to work outside in covering the roof with some of the Fury's running Oct. 17. rigging. On the next day, it was good enough to permit the men to set off with the sledges to the place, twenty-five miles off, where some of our stores had been deposited.

Uct. 18 to 20 . Uct. 21 .

Oct. 22.

The thermometer sank to minus $2^{\circ}$, but there was nothing else to mark these three days. On the twenty-first, Commander Ross's party returned, bringing every thing except the tents, which had been left at the last stage. Among the rest was our other stove, which was immediately prepared for use.

The ice that had opened, now closed the bay, as was foreseen, and the thermometer fell to minus $10^{\circ}$. The additional stove, however, now kept our house even warmer than we wished, since 
we could raise it to $51^{\circ}$. A snow wall, four feet thick, was built round it; and further spars and ropes were applied to support the roof, for the purpose of covering it with snow. A continuance of storms on the three following days rendered all work impracticable. On the last days of this week it was milder, and we were able to continue our operations.

Divine service was renewed on this day, after a longer cessation than was agreeable to our feelings, and after a much longer one than was right: but for this there was no help; it were well if those who neglect this duty at home could find excuses as availing. After this, the men had their last dinner on full allowance, as it now became necessary to retrench. We found a roasted fox to be a very good dish. Thus at least we then thought: I imagine that hungry men do not much attend to flavour, or, as the moralists have told us, that hunger flavours all meats. I have had reason to doubt, since my return to the beef and mutton of England, and to the dinners of "Grocers' Hall," whether I might not have overrated the flavour of fox; and I suspect too, that even Barney Laughy, though educated on porridge and potatoes, has made the same discovery.

It blew hard on the twenty-ninth of this month, and increased to a heavy gale on the three following days, so that the month of October ended as severely as was well possible. We however now found the advantage of the snow wall, and had no reason to complain within doors, though the thermometer went down to minus 18. Much clear water was opened in the offing once more, during this last storm.

The month of October in this year surpassed all others for cold 
and stormy weather; there being only six days moderate. Our journey from Batty bay, which was accomplished in four days, was exceedingly laborious, and from the nature of the weather, very trying to all the men; but had we been obliged to walk all the way from our furthest position, the journey would have been fatal to some, if not to all of us, since we should have been overtaken by the storm of the ninth. We therefore felt very thankful that we had been so mercifully permitted to reach even this cold and dreary spot in safety.

Having constructed our house previously was also a very providential circumstance; for, defective as it was, it could not have been nearly so well done at this season; and indeed before it could have been done at all, we must have suffered severely; but what we had most reason to be thankful for is the store of provisions still left, now sufficient to last and maintain us for another season; and when we reflect on the various circumstances which have as it were exerted themselves to prolong our lives, we cannot but offer up our humble acknowledgments to the Great Disposer of events.

First, I may enumerate the loss of the Fury, by which accident the stores and provisions were left : next, the mutiny of the John's crew, for if that ship had come with us, we intended to have cleared Fury beach: thirdly, the engine boilers, without which, we might have got so far that we could not have returned: fourthly, the Fury's boats, after having been carried off in the storms of the winter; having been cast on shore near the same place, without any material damage : and lastly, the construction of a habitation in summer, to which we were now mercifully permitted to return.

Mr. Thom now inspected and took an account of the remains of 
provisions; namely, of the flour, sugar, soups, peas, vegetables, pickles, and lemon-juice, which were in abundance; though we regretted to find, that of the present preserved meats, there was not more than would suffice for our voyage in the boats during the next season, together with half a pound additional on Sundays, and the same on Thursdays.

With respect to the present rations, the men were allowed, alternately, pea-soup, with one made of carrots and turnips, out of the stores of the Fury. Instead of bread, which we could not now furnish to a sufficient extent, they were provided with dumplings of flour and water, and they had no reason to be dissatisfied with this compulsory substitute. They were, indeed, sufficiently fed, since it was observed that they had become in much better condition since our return to this place. Our present allowance in meat, indeed, was a pound in the day: while it was settled that the short rations should begin on the first of November.

The storms of this month, by breaking up the ice in Prince Regent's inlet, and driving it down Baffin's bay, must have been of great service; but the low temperature was against us. Taylor, Laughy, and J. Wood, were on the sick list. We began to keep regular watch, and register the thermometer every two hours.

It still blew a gale from the northward, which did not intermit till the Saturday night; and though the sky was clear, the snow-drift Nov. I to 3 . was so thick that we could see nothing, and no one could venture out. A good deal of open water was seen after this storm, and the thermometer fell to $18^{\circ}$ minus. On Sunday it was comparatively Nov. 4. moderate, and, at night, became at length calm.

The snow wall was finshed; and the ice, under a west wind, Nov. 5 4 s 2 
closed in on the shore. By throwing water on the walls, and pointing the joints with wet snow, it became quite impervious to Nov. 7 cold. On the seventh, the thermometer sank to $35^{\circ}$ minus; and a to 10 .

strong breeze sprung up, ending in a gale with drift snow at night, which continuing on the next day, lasted all the following; the ice driving to the southward, and opening much clear water to the north.

Nov 11 Sunday was calm and cold. On Monday it blew hard, with $\& 12$. drift snow ; still moving the ice and opening more water. Nor did Nov. 13. it change on the next day, while the thermometer fell to $37^{\circ}$ minus. Nov. 14. 'The sun was in the horizon on the fourteenth, and was seen for the Nov. 15. last time on the fifteenth. There was no change in the weather, except an unexpected rise of the thermometer to minus $10^{\circ}$.

Nov. 16. The gale became worse than ever, and there was now clear water Nov. 17. as far as we could see to the north-eastward, which, on the next day, was entirely frozen over and covered with snow. On these days of confinement there had been abundant work within, in fitting up the bed places, and in constructing and supplying a ventilator. The good effect of this contrivancewas immediately felt, in its carrying off the vapour: and, to render the construction of the whole house the more intelligible, a plan and a section are subjoined in the plates Nov. 18. which accompany this journal for that purpose. On Sunday the Nov. 19. weather had moderated, but it was hazy on Monday, becoming Nov. 20. calm on the next day. Thus it continued till a wind rose from the eastward, but not so as to render the work of the men, out of doors, Nov. 21. in constructing a snow passage, impracticable. We saw a second Nov. 22. wolf on this day, which was fired at, but not killed, since it was afterwards seen, wounded, but still able to escape. The men were 
imprisoned till Saturday night, and the thermometer was then at Nov. 23 $13^{\circ}$ minus.

Sunday did not admit of walking after divine service. During Nov. 25 all the remainder of this month, the ice continued in motion, under a west wind, and moderate weather. The men finished their work, and the thermometer at the end of November was minus $32^{\circ}$.

The first part of the abstract of this month, which I shall give, relates to the temperature. The extremes were $8^{\circ}$ and $37^{\circ}$ minus, and the mean is $201^{1}$ minus, being $15^{1} 2^{\circ}$ less than that at Port Bowen in the corresponding month of 1824.

This month had been still more remarkable than the preceding, for the constant succession of storms by which it had been distinguished, and for being the only November on record in which the thermometer never rose above zero. The maximum was $4^{\circ}$ minus, and the mean temperature not less than $191^{\circ}$ below that of the November in the last year; while it was $8^{\circ}$ lower than that of the year before, and $15_{\frac{1}{2}}^{\circ}$ lower than in the November of 1824, at Port Bowen. It was, however, higher than at Melville island, in 1819; though it must be remarked that this is in $21_{2}^{\circ}$ of latitude, further north.

The open water had been seen to a great extent during the gales of this month. It was with much difficulty that we succeeded in finishing our habitation; a plan and description of which is given, as I have just said, in an explanatory plate.

During this very severe month, the men, not having clothing to withstand the cold, could seldom work in the open air; but we at length succeeded in making our house tolerably comfortable, so that the temperature inside was about $45^{\circ}$, ex- 
cepting near the enclosing walls, where it was, of course, below the freezing point; as were our cabins. The men had each a bed place with a canvas bottom, and a thrummed mat for a bed; while in addition to a blanket each, we were about to make mats as further coverings.

Our system of feeding could not be changed, for want of means, whatever we might have wished; but the men did not seem to suffer, and there was no one on the sick list but Taylor, the lame mate, and Thomas, the carpenter; our prospects had not, indeed, been brightened by the aspect of the weather in this month; but we were all in endurable spirits, and the thankful were contented with the advantages which we enjoyed.

Dec. 1 to 6 . There is little to mark the beginning of December, except that Sunday, the second, was a very stormy day, and that the mercury froze on the fourth; being four days later than in the last year at Dec. 7 \& 8 . the same date. Hence, on to Saturday night, there was a succession of storms with drift and new snow; the wind often shifting, and the ice still moving up and down the strait, so as to expose pieces of open water. From $40^{\circ}$ minus, the thermometer gradually rose till it settled at $29^{\circ}$.

Dec. 9 It was not better on Sunday, but became a perfect storm after to 15 . this; holding on with little change till the twelfth, when it fell calm; yet only to return : having produced more open water than we had yet seen, which was nevertheless covered with floating pieces of ice, and soon became sheeted with a new formation of the same now to be expected substance. The thirteenth was calm and clear, and the weather was moderate; while, after a gale on the fourteenth, the week ended with calm weather, and with the temperature $24^{\circ}$. 
The men were able to walk on Sunday, after service; and the Dec. 16 weather, having become clear, continued moderate, and unmarked all the rest of the week; when the thermometer fell to $43^{\circ}$, being the greatest degree of cold we had yet experienced. Three or four foxes had been taken in the trap at different times.

It blew fresh on the Sunday and Monday, so as to prevent the men from going out; but a fox having been taken, served for our Christmas dinner, while the men received full allowance of meat for that day, though for them as for us, there was nothing to drink but snow water. No change of weather worthy of note took place onwards till the end of the month, nor did any thing occur among ourselves to make one day differ from another, or diminish the weariness of that uniformity to which we were now tied. The month and the year ended sufficiently cold, since it was again at the freezing point of mercury.

In the course of this month it blew hard during most days, and always from the north and north-west; in consequence of which the ice was kept in violent motion. Open water was seen through all the month; and, on the last day of the year, it was visible from the beach as far as the eye could trace to the north-north-east.

The mean temperature of the month had been $1^{\circ}$ below any on record; and the cold was very severely felt by us in our frozen habitation; but by increasing the mass of snow and ice on the outside, and by flooring the house, we made it more comfortable. Half a dozen foxes were taken, and afforded us an excellent meal on Sundays and on Christmas-day; which was the first that we had spent without tasting spirits or wine: these luxuries having been now uttery exhausted, as they had long been set apart for

Dec. 23 to 25 .

Dec. 26 to 31 . 
those periods of regale, which a seaman does not easily resign, and ought not to be allowed to forget. Thomas, the carpenter, was now the only person on the sick list, and it was a matter of considerable regret to me, not less on his account than for the interests of all of us, and the credit of our medical treatment, that the scurvy under which he now at length suffered, did not yield to our great specific, lime-juice, which really seemed as if it had lost its antiscorbutic virtues, though the fault probably lay in the increase of the causes of this disease.

The aurora borealis had been seen but seldom, and was inconspicuous, while its position was generally opposed to that of the sum. But to end with the summary of this month, the weather, variable and severe as it had been, became calm and clear, though cold, and thus did we terminate the month of December, and the year 1832 . 



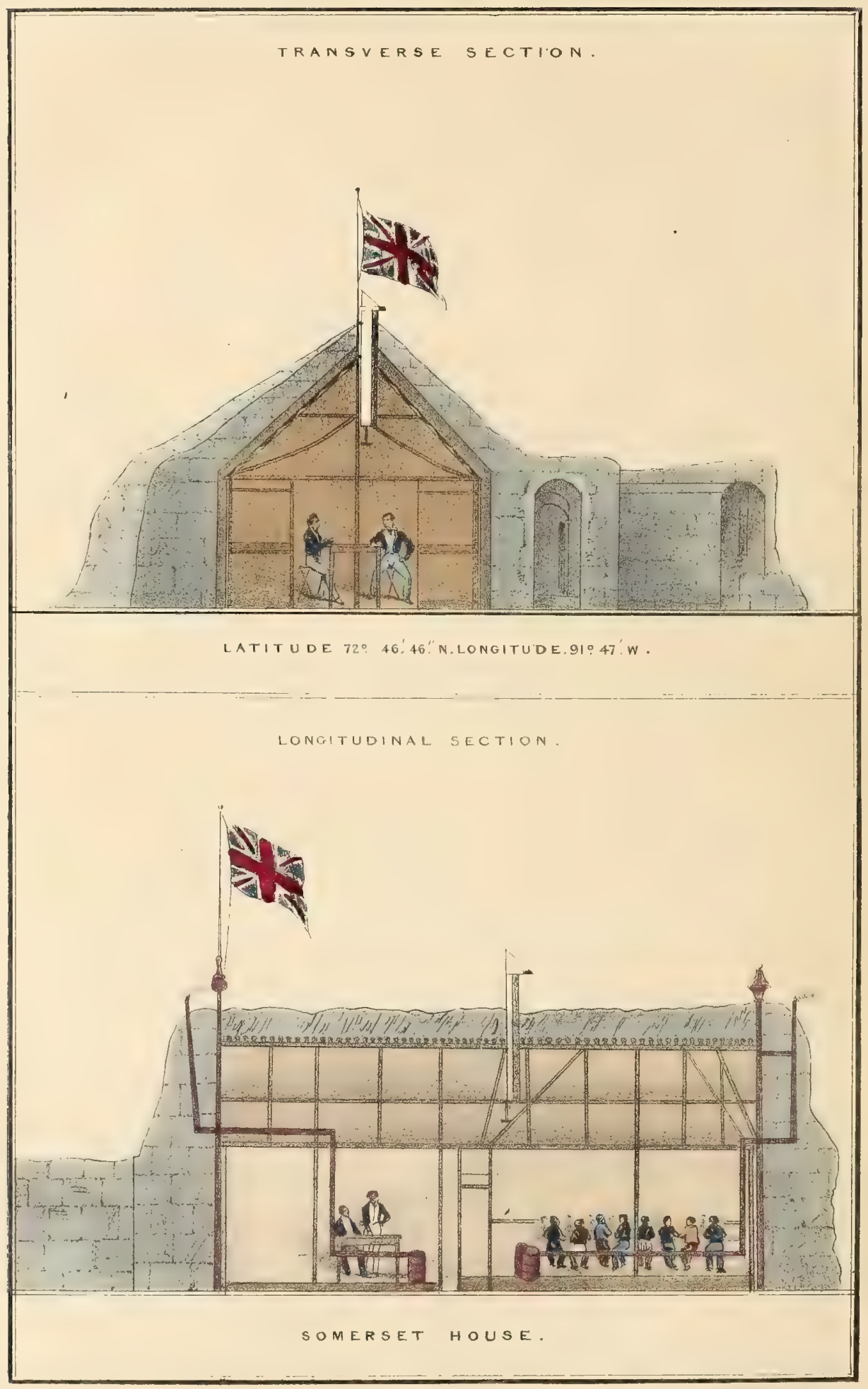


The annexed plate represents two sections of our habitations during the winters of 1832-3; the upper or transverse section shows two persons sitting at a table in the shaded part, the divisions of which show the frame, first and second roof, and the bed cabins; the blue parts represent the ice which covered the house, the passage into it, and addition which was made to keep out the cold.

The lower or longitudinal section, shows the men and officers sitting at their mess table, the fireplace, oven, and funnel, and part of the ice wall which formed an enclosure for exercise. The tube projecting through the roof is the valve to let off the foul air or vapour. 
Represents a ground plan of our winter habitation, which is fully explained in itself, excepting that the dotted line across the ice wall is meant to show the air flue leading from the outside of the house to the fireplace, the passage or entrance, though not mentioned, is sufficiently obvious. 


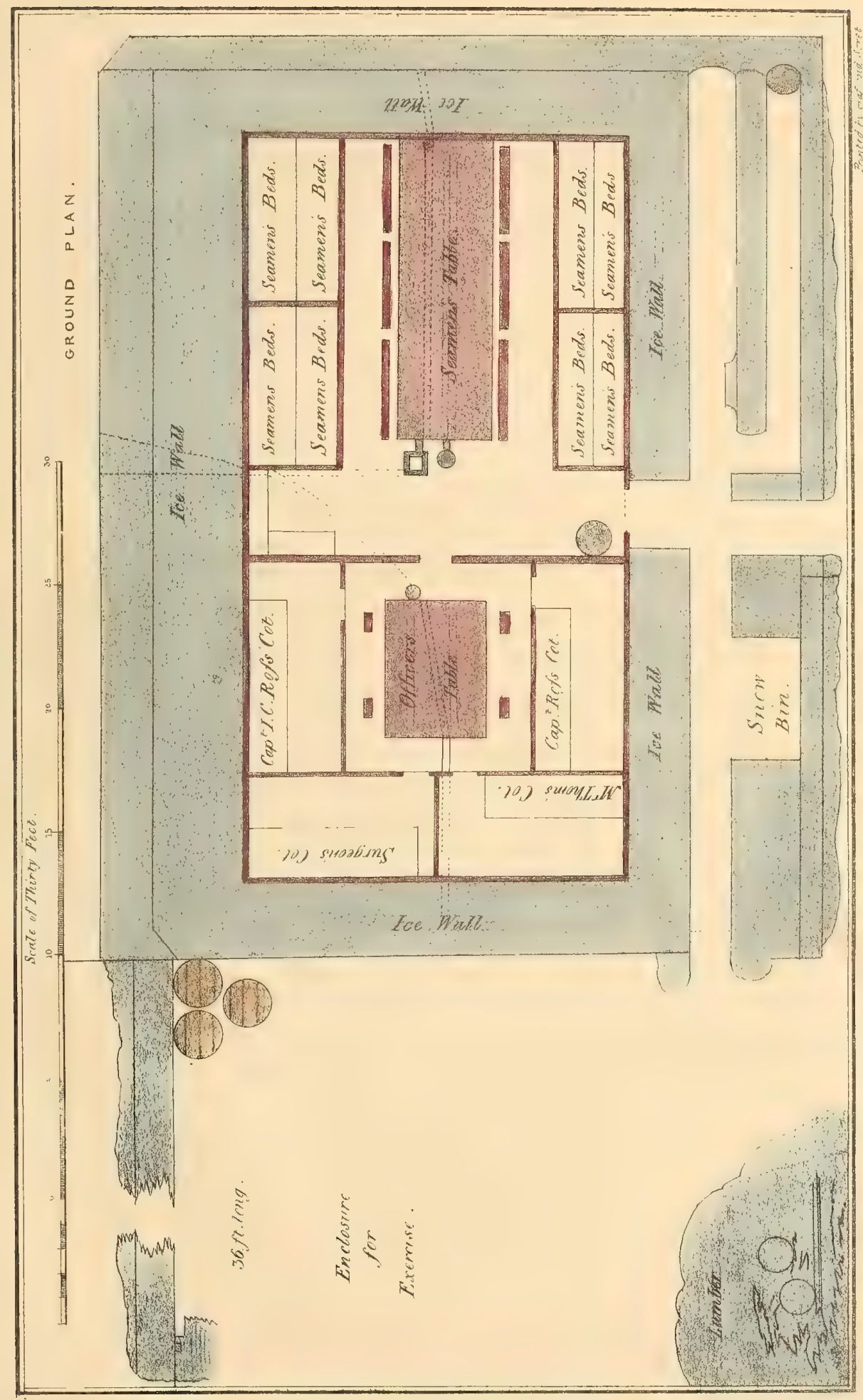





\section{CHAPTER LIV.}

THE JOURNALS OF JANUARY, FEBRUARY, AND MARCH, WITH THEIR RESPECTIVE SUMMARIES-DEATH AND FUNERAL OF THE CARPENTER.

OUR new-year's feast was like that of Christmas-day. The Jan. 1833 to 6. remainder of the week was fine, and the people were able to take exercise every day. The temperature ranged between $33^{\circ}$ and $38^{\circ}$.

A breeze came on upon Sunday, with snow-drift; and the sea, Jan. 6 to 12. which had been covered with new ice, broke up. It moderated next day; but, on Tuesday, blowing hard with the thermometer at $43^{\circ}$, it was intolerably cold. The temperature rose a little the following day, but went down to $44^{\circ}$ on the tenth. Friday and Saturday were both stormy, with the ice in violent motion; and the result of this gale was to raise the temperature to $26^{\circ}$.

This Sunday was marked by a perfect storm; yet it moderated on the next day, and still more so on the following ones, so that Jan. 13 to 19 . we could again go out during all the remainder of the week; the thermometer, which had not been very low in comparison, being then at $31^{\circ}$.

Sunday ended with a gale and drift snow, which continued the following day, and left the ice in motion on Tuesday. The weather was uncertain all the rest of the week, with strong breezes and 
calms. On Saturday the sun should have been visible for the first time; but the snow-drift deprived us of the sight: and this week produced nothing else to note.

Jan. 27 to 29 .

Jan. 30 $\& 31$.

Feb. 1 to 9 .

Feb. 10 to 16 .
It blew so hard on the first days of the week, that we could not go out. The twenty-ninth was a very fine day; and the upper limb of the sun appeared at a quarter after eleven; showing threequarters of the disk above the horizon at noon, and setting at half after one. It was the first time that we had seen it during seventyfour days. On the thirtieth, the thermometer rose to $11^{\circ}$, and the month was ended with it at $4^{\circ}$; being a great change within a very short space.

This month began, and continued for ten days, with such severity that it promised to be the coldest on record. It improved, however, about the middle, so that the mean temperature was $30^{\circ}$ minus, while the extremes were minus $4^{\circ}$ and minus $44^{\circ}$. Nevertheless our habitation was very cold and miserable; while, in attempting to warm ourselves on one side, we were frozen on the opposite, and were otherwise more than enough wearied, from the want of books or other occupation, and the impossibility of taking exercise out of doors. The crew, with the exceptions formerly noticed, were not ailing: but, of the carpenter's recovery, there was no hope.

The weather confined us for the first two days of February; but Sunday was fine, as was the next day; a violent gale coming on upon the fifth, which, after another peaceful day, recurred on the seventh, freezing the mercury, and continuing to blow with great fury till the end of the week, the thermometer then falling to $44^{\circ}$.

The carpenter being now in a hopeless state, an appropriate sermon was read on the present Sunday. On Saturday morning 
he died. This was the coldest week which we had seen, the thermometer having ranged between $44^{\circ}$ and $55^{\circ}$ : the weather had also been variable, but not marked in this respect, after what we had so often experienced.

During the whole of the subsequent week the weather was moderate but cold; and on the twenty-second, the carpenter, Chimham Thomas, was interred with the usual solemnity. It was not easy, nevertheless, to read the service out of doors, the thermometer being at $45^{\circ}$, while the ground was so hard that we had great difficulty in making a grave. This poor man had been three months ill, and his case had long been esteemed hopeless; as he was suffering from scurvy, in addition to a worn out constitution. It was the first of our losses, however, which conld, in any fairness, be attributed to the climate and our peculiar situation: the first man who died could scarcely have lived longer at home; nor was the death of the other, one that could have been delayed long, any where.

The temperature rose suddenly from minus $36^{\circ}$ to $6^{\circ}$, and then reached zero, falling again to $23^{\circ}$, till the end of the month. The Feb. 24. to 28 . first change gave us some hopes, but these did not last. In the weather, which was variable. but moderate, there was nothing to remark.

There is nothing surprising, as there is no novelty, in the retrospect of February. It could not have been much better, and it was satisfactory that it had not been worse, bad as it was. What the weather had proved, I need not repeat: but as the temperature is not discoverable from the narrative, it is necessary to say that the mean was $32.87^{\circ}$ minus; as that in the preceding Februaries were,

Feb. 17 to 23 . 
respectively, for the years; minus $29.9^{\circ}, 32^{\circ}$, and $33.69^{\circ}$. The extremes were plus $6^{\circ}$, and minus $55^{\circ}$.

The chief event was that of the death of the carpenter, Thomas; which, apart from any regret for a worthy and useful man, the more painful when we looked round on all, saw the decided illness of some, and could not easily avoid anticipating what our own fate might be, was a very serious loss ; since his assistance could scarcely fail to be required hereafter, in the reparation of the boats, and in such other matters as belonged to his profession. Respecting himself, I need only note the excellent character he had acquired, in the navy, before he joined us : but, to compensate any pain that might have been felt under the impression that this expedition had been fatal to him, we knew that his constitution had been much impaired by long service, especially on the American lakes and in the Birmese war. His age was forty-eight; and at that time of life, a seaman who has served much is an aged man, if he does not chance to be worn out.

My own condition, from the state of ancient wounds, brought into troublesome action by that tendency to scurvy which displayed itself in no other very marked way, was, at this time, somewhat threatening. I had now, indeed, some reason to suppose that I might not be ultimately able to surmount all the present circumstances; in which case, I know not that my anxiety for the fate of those who might not have very well guided themselves when I was no longer present to aid them, was not much greater than any thing which I felt on my own account.

The state of the ice could not have been worse than it was at the end of this month, and the hills were entirely covered with snow. 
It was so deep about the place of our compulsory residence, that our miserable abode was almost hidden by it, like the snow hut of an Esquimaux in winter: and, as to our course of life and feelings, these are things which poetry might tell once, but which neither poetry nor prose can repeat for ever, with the hope that any one can listen, and understand, and feel.

March began with a heavy gale of wind and drift snow, so that March I. we could not see fifty yards off. The roaring of the ice was terrific; and, on the following day, the temperature fell once more to minus $40^{\circ}$, proceeding till it reached $43^{\circ}$, on the fourth. There was no cessation of this gale till the sixth, when open water was visible to March 6 . a great extent. Two reindeer were seen on the seventh, which we March $\tau$. considered very early in the season, and on the two following days March 8 the temperature was $25^{\circ}$. \& 9.

On Sunday it blew hard from the north-east, and the thermometer, March 10. to our great surprise, rose to plus $1^{\circ}$, reaching $5^{\circ}$ on the following March 11 . day. On the twelfth, the water closed, and no more was seen this March 12 week; when it fell calm on Saturday night, having blown a hard gale during the two preceding days.

It was calm and snowy, with the thermometer at minus $5^{\circ}$, both on Sunday and Monday. The second dovekie of the season was seen feeding at a crack in the ice. During all the remainder of March 19 this week the weather was sufficiently good to enable the men to March 17 \& 18. take exercise daily out of doors.

There was a hard storm with drift snow to compensate this, Ifarch 24. which lasted the first three days of the present week; and we were March 25 very cold, as the thermometer went down to $34^{\circ}$. It moderated on the twenty-seventh, and the rest of the month, including Sunday, 
continued the same; the ground being every where deeply covered with snow.

The first eight days of March were unusually severe: the change on the ninth was great and sudden, but did not prove durable. The mean temperature thus became $20^{\circ}$, as the extremes had been from minus $45^{\circ}$ to plus $5^{\circ}$. The gales were exceedingly severe, and the last, which was just before the equinox, continued during four days.

The men had, therefore, as in the preceding month, been extremely confined; and thus the impossibility of taking exercise, added to a want of sufficient employment, short allowance of food, and the inevitable lowness of spirits produced by the unbroken sight of this dull, melancholy, uniform, waste of snow and ice, combined to reduce us all to a state of very indifferent health. Mr. Thom was ill, my old wounds were very troublesome, and two of the seamen were so far gone in the scurvy, that we were afraid they would not recover.

On this account more than any other, we had reason to lament our ill success in shooting; as it was long, too, ere we could hope for the arrival of the summer birds, to allow us to add some fresh meat to our diet. We had taken but three foxes and two hares in the whole month; which, as food, amounted to nothing.

At the end of it, after all the changes that had taken place under the gales, the ice was so rough that it was impassable on sledges, and even on foot. No aurora borealis had been seen; and, indeed, we had scarcely noticed one the whole winter.

We were indeed all very weary of this miserable home. It had been a welcome one when we first reached it ; because it was a con- 
trast to what had been much worse. It had received us, fatigued, shelterless, and half-starved, and it at least promised us comparative peace and rest. But the novelty of this feeling had long been worn out; and, for a long time now, the days had been almost without variation or mark; each duller than its predecessor, and the night returning only to tell us that another such day would come to-morrow. Even the storms were without variety, amid this eternal sameness of snow and ice : there was nothing to see out of doors, even when we could face the sky; and, within, it was to look, equally, for variety and employment, and to find neither. If those of the least active minds dozed away their time in the waking stupefaction which such a state of things produces, they were the most fortunate of the party. Those among us, who had the enviable talent of sleeping at all times, whether they were anxious or not, fared best.

That many wishes were turned towards our own English home, cannot be doubted: but it was unreasonable to indulge regret where there was nothing of which we could accuse ourselves; and they who looked forward, could feel that there was enough of exertion before them to demand all their spirit, and at least hope enough to sustain those spirits till the time should come to bring them into action. Another month would pass in the daily approaching prospect of moving: within one more, we might be in motion; and if June must still be a term of struggles and hopes, the month of July might find us in Báffin's bay.

After all, I believe, it was on those with whom the responsibility rested, that the evil sat lightest; for, in the mere sense of this, there was exertion, as the anticipation filled the mind with schemes and prospects, and even in this alone, gave it occupation. Still there was 
far more than time enough; far too much to occupy in action, and incalculably too much for thinking: and while part of our standing work was to complete the duplicates of our journals, some weary hours were filled up by noting our recollections of the natives with whom we had been so long in communication. What mine were, furnished a sketch, which I am very unwillingly compelled to defer to an appendix, gladly as I would have introduced it into this journal; which, if it may often have wearied the reader, by its unavoidable repetition of similar occurrences, cannot have tired him to one ten-thousandth part of the degree that the entry and the retrospect wearied myself. Let him who reads to condemn what is so meagre, have some compassion on the writer who had nothing better than this meagreness, this repetition, this reiteration of the ever resembling, every day dulness to record, and what was infinitely worse, to endure. I might have seen more, it has been said: it may be; but I saw only ice and snow, cloud and drift and storm. Still I might have seen what I did not; seen as a painter, and felt as a poet; and then, like painter and poet, have written. That also may be, but let painter and poet come hither and try : try how far cold and hunger, misery and depression, aid those faculties which seem always best developed under the comforts of life, and under that tranquillity at least, of mind, if not much more, which the poet and the writer require to bring their faculties into action. Our "foecundi calices" were cold snow-water; and though, according to Persius, it is hunger which makes poets write as it makes parrots speak, I suspect that neither poet nor parrot would have gained much in eloquence under a fox diet, and that an insufficient one, in the blessed regions of Boothia Felix. 


\section{CHAPTER LV.}

APRIL: THE JOURNAL AND SUMMARY-MAY: THE COMMENCEMENT

OF THE JOURNEYS INTENDED FOR THE FUTURE EXPEDITION-

JUNE: THE CONTINUANCE OF THESE ADVANCING JOURNEYS-

JULY: THE ABANDONMENT OF THE WINTER HOUSE, AND ARRI-

VAL AT THE BOATS-SUMMARY.

THE first day of April was overcast, with snow, and the tempe- 18.33. rature was at $12^{\circ}$ minus at night. There was variable weather on the two following days, but it was, on the whole, mild, so that the men could walk out. Some grouse were seen for the first time, April 4 together with two bears; and, on the fifth, the temperature rose to $5^{\circ}$ plus, continuing thus till the end of the week.

The first days of the present week afforded no variety, except that the day temperature rose to $25^{\circ}$ plus. It snowed on the tenth, and we saw two bears with two cubs, approaching, or about to pass not far from us. The hindermost was coming on alone, being the male; and, passing near to us, was killed. The last days of the week were very severe ones, with a heavy gale and drift snow; and the thermometer fell to $24^{\circ}$ minus.

Sunday was not less stormy, and no one could go out. It April It moderated towards the afternoon on Monday, but we were still all imprisoned. On the next day it was still more quiet; but there 
was no possibility of undertaking any journey till the nineteenth, when a party of men were sent forward in advance, with a sledge of provisions, and, having deposited it about eight miles off, they returned; making a second journey on the Saturday, with a similar supply, and returning at midnight.

Nothing was done to-day, and it was too cold on Monday for travelling. Our present plan now, was to carry forward in advance, to the boats which we had left, sufficient provisions to last us from the first of July till the first of October; as that was the point whence our summer journey and voyage would commence. April 23. On Tuesday, Commander Ross and the parties set off with two loads of various articles to the depot, and returned about mid-day April 24, on the twenty-fourth. In their way back, they saw a bear, and killed a seal : and, in the evening, another of the former, approaching the house, was killed. It had been at our flagstaff, which it had pulled down; and having found and eaten some bread, this was discovered on opening its stomach, which contained nothing else.

April 25 The men made another trip, but returned with inflamed eyes, so to 27 . that they were confined on the following day. On the next, the weather was fine, and the thermometer rose to $14^{\circ}$ plus, the sun being very powerful : another journey was taken to the first depot, and the thermometer rose to $17^{\circ}$.

April 28 Sunday was a day of rest; and on the twenty-ninth, another to 30 . journey completed the deposition of the provisions at the place of the boats. On the thirtieth, there was a severe gale, and we could do nothing: and, with this last labour, we ended the month of April. 
The last month was, on the whole, mild, being never less than $26^{\circ}$ minus, nor higher than $19^{\circ}$ plus; and the mean temperature was minus $4^{\circ}$, being four degrees above that at Port Bowen, and seven above that at Victory harbour in the same month of the last year.

We had succeeded in getting all our provisions forward, containing our supply from the first of July to the end of September, and were thus eight miles, or a quarter of the distance, advanced towards the place of the boats in Batty bay. The transportation of them onwards to that depot was calculated to be work enough for the next month, because the parties would be compelled to travel the same ground eight times, so as to make the distance 256 miles.

The fat of the bears which we had killed was an addition of some moment to our fuel, as the skins had their own value. Five grouse had been killed; but not a snow bunting had yet been seen. One fox only had been taken.

The men were better, except one of the scorbutic patients, John Wood, who appeared to be in a hopeless state. The sun had produced a visible effect on the snow, which was now disappearing from the tops of the hills.

The gale, which continued all this day, prevented us from carrying on our provisions : and it thus persisted until the seventh, being a continued storm, which entirely hindered us from moving during the whole of the time. The thermometer was between $3^{\circ}$ minus, and $10^{\circ}$ plus. Two bears were wounded

This day was nearly calm; and having got all our preparations ready, we set out at eleven at night; this being the best period of the twenty-four hours for travelling. On the next day, at three in 
the morning, we attained the first position; having travelled eight miles. At eight in the evening, having rested here, we set out once more with the sledges, containing six casks of bread; having left three sick men at the house to be brought up by another journey.

May 10. At noon we reached the second position in Two River bay; whence, depositing the first load, we returned ten miles to bring up another. The ice was found extremely bad, so as to compel us to keep close under the precipices. In the evening we went back to that place with the second load, arriving with it at three in the May 11. morning. At eight we returned for the third cargo, and brought May 12. it up on the twelfth, a little after midnight : going back once more May 13. to our old position for a fourth load, which was brought up on the thirteenth, about the same hour.

Not to repeat these daily proceedings, I may now say, generally, that in this advance from our house towards the boats which we had left in the preceding year, each stage of the distance required four journeys ; since, more for want of power than that of carriages, we could not otherwise transport our several stores, and, in addition to those, the men that were too ill to walk. It was not, therefore, till the twenty-fourth that we arrived with the first load near the place of the boats; which we could not at first discover, so deeply was the ground covered with snow. To dig for them and the concealed stores, occupied the greatest part of the day: while we were much impeded, and at last stopped, by a strong breeze, accompanied by a heavy snow-drift. The weather had been variable, and often very snowy during this period; and the consequence was to add much to the difficulties of this already miserable and tedious 
travelling. The range of the thermometer had been from minus $2^{\circ}$ to plus $18^{\circ}$; so that it was still very cold.

It became calm and mild on the twenty-fifth, so that the work May 25. of bringing forward the loads proceeded, both on this and the following day; on which latter I remained with the boats in May 26. Batty bay, to make observations, while the party returned to fetch up what was still left. I came back much fatigued. Sleeping here alone in the hut, about midnight, a bear pulled away the stones which supported the canvas roof, and fell in, nearly on the place where I lay. On calling out to know who was there, the creature went off to the other hut, when, as it was examining the cook's kettle, it received a shot from my gun, under which, whether wounded or not, it was soon out of sight.

The last days of this most tiresome travelling were by much the worst; as there were severe showers of snow, with very cold weather, by which the way was at last made so bad, that had it happened sooner, we should have been stopped altogether. On the twenty-ninth, all having at length been concentrated, we returned to our house on Fury beach. I killed a bear and two foxes on one of these days; the total number of the latter in this month having been twelve. The sight of some gulls twice in this month was a very welcome one.

The mean temperature of this month was lower by seven degrees than that at Port Bowen in 1824 ; it was $11^{\circ}$ plus, and the extremes plus $25^{\circ}$ and minus $3^{\circ}$. There had been no appearance of a thaw ; the ice in the offing was as bad as ever, and the two or three gulls, with a few snow buntings that we saw, without one grouse, were but feeble signs of an advancing summer. 
The fatigues of the men, of men and officers, since no one was exempted, were very great in the last twenty days of the month which our ever renewed travelling occupied; yet they had not materially suffered, though the sick continued no better.

Our allowance of provisions was as low as before, and the mode of distribution into meals the same; while the night had been made our day. The quantity of provisions that we had secured thus far on our road to the expected liberation, was sufficient to last us, on a two-thirds allowance, till the first of October.

Jume 1. Having thus carried forward to the boats all that could be spared from our actual wants, that every thing might be in readiness for moving whenever the ice should open, we had now to occupy ourselves as we best could at our "Somerset house," and to make ourselves as content as might be till it was time to move again. This apparently premature advance was absolutely necessary; because, at a later period, when it should be time for the boats to move and make the attempt to navigate the frozen strait, the roads from our winter residence to their place would not only be much worse, but might prove impassable for such loads, under the little power that we had at command. With the present arrangements, the surplus that might remain with us would be moderate, and a short time would bring us up to the boats, in readiness to sail; whereas, had this last month's work been deferred, the ice might have opened, and joined again for the winter, before we were ready to take advantage of it. The journal of this month is therefore, very generally, uniform and uninteresting. To us it was so : it cannot be otherwise to a reader. 
weather, with strong northerly winds, snow, and drift, on the three following days; but it improved as we advanced towards the end of the week, the thermometer rising to $30^{\circ}$ : notwithstanding which low temperature, the sun dissolved much of the new snow, and laid bare again some parts of the hills. Some birds were killed.

The weather continued better. On Monday a bear came to the hut, and began to devour some skins, with the carcass of the one $\& 10$. formerly shot; when it was killed; having, as it proved on examination, been formerly wounded. Some rain fell on the eleventh, for the first time, but it soon became snow ; notwithstanding which, on the following day, water was seen running down in several places, and there were many pools on the ice. Hence, on to Saturday, the weather continued variable; being sometimes fine, and at others rendered disagreeable by falling snow, while the ice was, of course, still dissolving; though the thermometer at night seldom reached the freezing point, as its highest degree in the daytime, was $52^{\circ}$.

The history of the present week is but a repetition of the same weather and the same temperatures, which, at least, were but two or three degrees higher on the average. The great work of dissolution was going on, and, it was agreed by all, much more rapidly than in the preceding year at the same time. The summer animals were now, too, increasing, and about two dozen of ducks and a goose were killed in one day, besides some other birds at various times. Some work was also done to the sledges, for our next journey, which was now near at hand.

We were enabled to give all the people a good treat of ducks on this day; being the only tolerable dinner they had seen for a long: 
time : though, on other occasions, these delicacies were reserved for

June 25 the sick. On the twenty-fifth, a party went forward with a sledgeto 29 .

load of fuel and provisions; and, on returning, they reported that the road was covered with water and soft snow. I did not find it so bad as represented, in proceeding with another load on the following day; having finished which stage, I returned to send on the others. On Saturday night, the sledges were finished. The weather during this week resembled that of the former, in its incessant changes; nor did the temperature materially improve. Many seals were seen, with some tracks of reindeer; and some birds were killed, including forty dovekies.

June 30. On this Sunday, all the party which had gone forward returned in good health. The report of the roads was more favourable; and the diurnal range of the temperature was from $32^{\circ}$ to $42^{\circ}$.

In the beginning of June the prospect was exceedingly unfavourable, as the weather was very cold, and the temperature lower than in the preceding ones at the same period. It however improved, though there was very little rain during the time, and much snow. The extremes were $45^{\circ}$ and $16^{\circ}$ plus, and the mean plus $35 \frac{1}{4}^{\circ}$.

We had advanced the tents and some stores to the second position forwards; which, though but thirty miles off, required more than a hundred miles of travelling, from the necessity of returning to bring up the loads which we could not carry on to their places in any other manner. We were still, however, encumbered by the sick, who could not walk at all ; while, unfortunately, they were the three heaviest men in the crew. Some others could barely walk, but could give no assistance in drawing the sledges. It was well 
that some appeared in good health; while all were now in hopes of a speedy embarkation, and of an ultimate escape from the miserable abode of people who had, on the whole, been sufficiently miserable in all ways.

Some of the numerous persons with whom I have conversed, since my return, on the history of our voyage, have suggested to me, on this subject, a remark which I, assuredly, did not make at the time, and should not have made now. It certainly never struck me, and I am sure it did not enter into the thoughts of one of my officers, that we had ever done, or were now doing, aught more for the sick men of our crew than was our duty, and, not less, our inclination. Undoubtedly, it was a very heavy labour to carry onwards these sick and enfeebled men, encumbered as we were: it was a far more serious matter, when even the lives of the able might be sacrificed to a duty which thus curtailed our means of conveying forward the provisions and accommodations necessary to our own existence, and what is still more, were indispensable to the accomplishment of our ultimate hopes, a return to England. It was also, as I have since been told, a great sacrifice of our own comforts, to have reserved our best and most delicate food for the sick, to have nursed and tended those who had ceased to be aught but an encumbrance, and of whom, some, as we full well knew, were not destined to survive. That may be very true: I believe, that as regarded ourselves, we did wrong; it is possible that such notions may have occurred to me for a moment or two since my return, when the ingratitude and obloquy which I have experienced from those very persons in particular has vexed me; and I believe that when the history of the wreck of the Meduse has been recited to 
me by those friends, I may have sometimes wondered why we should so far have differed; little willing as I am to remember any thing which may make humán nature appear in an evil light, or to add to the bitter feeling which England too often entertains towards its neighbour. But in spite of all that might then have occurred to our minds, though I cannot recollect that it did once occur, in spite of such inconvenience as we did really suffer, and such hazards as we did risk, and in spite of the ingratitude which I much fear I have experienced where I ought not, I imagine that I did no more than it was proper to do, and which I should do again in the same circumstances : yet is this not boasting, since I am sure that every British officer would do the same, as I know that every Christian man ought, in any situation. If it is true that France really wants such a lesson, I must be sorry; but I fear that no lesson will influence those who have not in their hearts the inclination to do right, or who are not governed by some better motive than the praise of men; in this expecting that poor reward, which, in just punishment of their motives, may even be withheld.

The wind and weather were variable during the first four days of July, but generally cold, with snow and sleet, while the thermometer at night scarcely ever rose above the freezing point. Our preserved meat was expended; and we had here, now, no other fresh animal food than what we could procure by our guns; which was not much as yet, since it consisted but of a few ducks and dovekies. Some spare grates were made for the house, and the roof was repaired and strengthened, in case we should be obliged to return to it for the ensuing winter; though somewhat at a loss to know how we were to subsist under such an unfortunate event. 
A quantity of flannel cartridges were given to the men for repairing their clothes before encountering the journey to Batty bay. An avalanche of ice from the cliffs, intermixed with rocks and water, was a novel sight, and, in this dearth of events, would have been interesting, even had it been far less splendid as a spectacle. Falling into the sea, it carried all before it; breaking the fiat ice to a great distance, and showing us, had that been now necessary, the manner in which the icebergs are sometimes found to be covered with fragments of rock and layers of earth.

So many of my countrymen have now seen the avalanches of the Alps, and so many more have read of those, in prose and in poetry, as there are some who can never forget the splendid picture of Loutherbourg on this subject, that any attempt on my part to describe such an occurrence as this must be superfluous, as it cannot fail to be feeble. Yet there was a variety in this, which, could I adequately describe it, in even the plainest prose, or represent it in the meanest drawing, would not fail to strike even those who have witnessed what Switzerland can show. It was not the snow ball, gigantic as that may be, detaching itself from the mountain summit, gaining in magnitude as in velocity during its progress, and then thundering down an irregular declivity, sliding, bounding, and breaking, till it had safely lodged itself in the valley below, or in the bed of a torrent; there perchance to obstruct a stream, be scattered over a plain, or, if even overwhelming a cottage, to fall into repose among the ice that had received it. Here, all was as instantaneous as it was unexpected. The icy mountain that had towered over our heads so long, was gone before we could say, Behold, be aware: the instant of its motion was that of its descent, 
and before it seemed to have commenced that descent, it had plunged into the sea: no, not into a sea of water, but a sea of ice; breaking up those glassy fields which had so long bound us in, as if indeed they were but a feeble mirror; scattering their fragments far and wide, with a noise exceeding thunder, and prolonged even like the reverberations of the thunderbolt, until all settled again into the dead and icy stillness of its former repose; yet to leave that new mountain in the waves, a record of this catastrophe, as long as record could be of those mountains which the sun would ere long melt, and the winds float off to other and far distant regions.

July 7. The shooting of fifty dovekies yesterday gave the men a good Sunday's dinner; and the last divine service we trusted ever to attend in this house, was performed. It was the commencement of a farewell which all hoped would be eternal; but every one must answer for the feelings under which he, for the expected last time, repeated the Lord's prayer, and heard himself dismissed in those words which promise, to those who deserve it, that peace which passes all understanding. I trust there were few who did not recollect to return their own private thanksgiving for so long a preservation amid such dangers and privations, and who did not put up their own prayers for help in the great undertaking now inpending, on the success or failure of which must turn the event of life or death to all.

July 8. On Monday, every thing was ready, and we too were as prepared as we were anxious to quit this dreary place, as we hoped, for ever. Yet, with those hopes, there were mingled many fears; enough to render it still but too doubtful in all our minds 
whether we might not yet be compelled to return; to return once more to despair, and perhaps, to return but to die. To have been able, confidently, to say, Adieu for ever, would have been indeed to render this a delightful parting; when even the shelter which we had received was insufficient to balance all the miseries which we had suffered; miseries to have extinguished every sense of regret that we could have felt in pronouncing those two words, which, it is said, have never yet, under any circumstances, been pronounced without pain. This may be true; I almost believe that it would have been true even in our case, though in parting from our miserable winter house of timber and snow, we left nothing behind us but misery and the recollection of misery ; since, in the comparison with what might have been, it was, heaven knows, a shelter from evils far greater, from death itself; and, such home as it was, a Home; that strange entity from which man never parts, bad as it may be, without reluctance, and never leaves but with some strange longing to see it again. But true as may be the pain of an adieu, or the fancy of leaving for ever a home, or true as may. be, reversely the pleasure of quitting for ever the scene of past miseries, neither the pleasure nor the pain was ours. Scarcely the feeling of a farewell, for hope or regret, for pain or for pleasure, was in any mind, when we coldly departed in the evening with our three sledges, to encounter such fate as Providence might have in store for us.

The sick; who formed our great difficulty, bore the first journey well, and we reached our first station before mid-day. It was a fine day, and the warmest that had yet occurred; the temperature being $48^{\circ}$. In the afternoon, at three, we proceeded again, with 
infinite toil, through nearly impassable ways, which were rendered more difficult to us by the care which the sick required: and so hard was the labour, that even here, and at night, we were obliged to work in our shirts. We gained but two miles by midnight, and were glad to rest.

suly 10. We recommenced with all the baggage, labouring through ways as bad, or worse, under a sun that was occasionally very hot; and at nine, reached the third position, at the cascade, which was now pouring down abundantly into a pool filled with kittiwakes; where we procured some sorrel. We found that the bears had upset a cask full of skins which we had left here, but they could not contrive to open it.

July 11. On the next day we brought forward the sick, whom we could not move together with the baggage, and then proceeded to the third position, after a very fatiguing journey, backwards and forwards, of twenty-four miles. We had lately obtained a good sup-

July 12. ply of dovekies, and could now afford every one a good breakfast; which was not less necessary than agreeable, emaciated as most of us were, and nevertheless compelled to endure this constant labour. In the afternoon, the road on the shore being better, we contrived to take most of our stores, the sick included: but it was not, finally, till after many difficulties in avoiding and traversing bad ice, that we reached the boats in Batty bay, at eight in the morning.

We found that the bears and foxes had committed considerable depredations on our stores, by destroying a cask of bread, some oil, and some sugar, and also all the leather shoes and boots they could find. The weather was very fine, and the dovekies being numerous, we killed some for our provision. Even at midnight the ther- 
mometer was now $48^{\circ}$ : it was a great revolution in the weather, and it had been a sudden one; unexpected, but not undue. 'Two light July 13 . sledges to-day brought up the few things which we had been obliged to leave at the last place, together with some sorrel for the sick; while we obtained thirty dovekies.

Sunday was made a day of rest. They who walked found the July 14 . land quite destitute of vegetation, and a considerable river running into the head of the bay. On the following day the ice was ex- July 15. amined from the hills, but was not yet breaking in the offing: the weather being calm and fine, but sometimes foggy. The men were employed in repairing the boats, and in preparations for embarking. The ice moved on the sixteenth; but the large creek was still filled, and impassable. On the two next days it rained almost constantly, and we were prisoners. About a hundred dovekies were killed, so that our supply of fresh meat was respectable, if not great.

On the twentieth, the weather became fine again; the ice con- July 20. tinued to move, and the caulking of the boats was continued. An easterly wind made the thermometer fall to $38^{\circ}$. On Sunday the July 2 to 30 . ice was reported to be broken up in the offing; but after three days, without any thing material to note, except the killing of fifty dovekies, it remained close packed on the shore, so that it was impossible for us to move. The weather, from this time, continued variable, with occasional rain and wind, together with fogs, till the thirtieth; as the only events worth noticing, were the improvement of the sick, and the killing of some more birds for our table.

We had now seen the ice leave the shore at last, but had yester- July 31. day been prevented from embarking, by a heavy fog. This ending 
in rain and sleet, with an adverse east wind, on the last morning of the month, we did not load the boats till mid-day; but as it proved, in vain, since it came to blow and rain so heavily all the afternoon and evening, that it was impossible to embark. In every way it was desirable to quit this place; as the stones had now begun to fall from the cliffs, in consequence of which two men experienced severe contusions, and one narrowly escaped with his life. Thus ended July.

Of that month, any summary is superseded by the preceding journal; it is almost sufficient to note that the mean temperature had been $36^{\circ}$, and the extremes $28^{\circ}$ and $50^{\circ}$ plus. It had not been an unfavourable one to our prospects, on the whole, while we had no right to expect an open sea in these regions at so early a period, far less in a strait which had exhibited such perseverance in preserving its ice through the whole summer, during the preceding years. That the sick had improved was a very consoling circumstance; while our situation was, at least, one of joint exertion and hope. 


\section{CHAPTER LVI.}

AUGUST-DETENTION AT BATTY BAY-THE ICE BREAKS-DEPARTURE IN THE BOATS-REACH THE EASTERN COAST OF PRINCE REGENT'S INLET-MEET WITH THE ISABELLA, AND ARE RECEIVED ON BOARD.

BETWEEN the first and the fifteenth of the month of August, the changes of the wind and the vacillations in the nature of the weather were such as I have often recorded during the past two; while the general result is all that is here worthy of notice. The prevailing nature of the former was north-easterly: and the consequence was, to block up the shore with ice, and to keep us closely imprisoned to our beach and our boats. On the third, indeed, we made. an attempt to move round the southern point of the bay: but being unable to effect this, and finding the blockade of this headland so heavy that the bay must open sooner, so as to give us notice where we might possibly pass it, we returned, as there was nothing to gain by this project.

But even this fruitless labour was not without its use. The result of it was, to do something: and, to do, even what was useless, was to keep up the spirits and hopes of the people, as it also interrupted that uniformity of idle wakefulness which led them to brood over their present condition, and to indulge in evil anticipations. 
The Highland squire who makes Boswell haul on the backstay in a gale of wind, displays more knowledge than a landsman has any right to possess.

I know not what we should have done, what would have " become of us," as the phrase is, had we not made work when we had ceased to find it. "Whe men," as they are called, are not much given to thinking, it is certain; though seamen of the present day (and I am sorry to say it), think much more than they did in the days of my junior service, and, most assuredly and certainly, are "all the worse" for it. Let my fraternity in command say whether this be true or not; and they are the bold men who will so say, despite of the paltry, fantastical, and pretending, ultra philanthropy of these days of ruinous folly. But that is an over serious matter to discuss at present. "An idle man is a pillow for the devil," says a Spanish or Italian proverb : it was not good that our men should have been pillowed in this manner: better was it that they should work themselves into utter weariness, that they should so hunger as to think only of their stomachs, fall asleep and dream of nothing but a better dinner, as they awoke to hope and labour for it, and that their sleep should be, not on the pillow of the proverb, but on a couch of snow, sufficient to impede all reflections but the wish for a better bed after a better supper, and the gnawing desire of more and better on the following day.

The shooting of waterfowl furnished indeed some occupation to those who were worthy of being trusted with powder and shot; but I believe the best occupation, to a set of such starved wretches as we were, was to eat the game, not to shoot it. Every morning now. rose on the hopes of a good supper : if that came, it was more than 
welcome; and when it did not, why then there was the chance of one to-morrow. I do not say that the supper which was missed was equivalent to the one that was eaten; since hope or expectation will not, more than wishing, fill a man's stomach; but it is certain that the sick recovered rapidly, and the well improved in strength; nor could I doubt that their present state of mind was, in this, scarcely less efficacious than the broiled ducks and the dovekie sea-pies.

To look out from the top of the hill, for the state of the ice, was another occupation for any one that chose; and it was exercise, while it served to waste the time. It was not, like Behring's unhappy men, to watch for the ship that was destined never to appear, and, when the day closed, to retire once more to darkness and despair. The day of relief might be delayed, but it was long yet before it would be time to fear that it was not to arrive; while, in every change of a breeze, in every shower of rain, and in every movement of the ice, however minute, there was sufficient to maintain hope, and to render all anxious for the to-morrow; as each, on retiring for the night, felt inclined to say, yet not under the same motives as the wretches in the Castle of Indolence, "Thank God, the day is done."

It was on the fourteenth that hope became anxiety, when a lane Angust 14. of water was for the first time seen, leading to the northward; and not many, I believe, slept, under the anticipations of what the next day might bring. On this, all were employed in cutting the ice August 15. which obstructed the shore, as early as four o'clock in the morning; and the tide having risen soon after, with a fine westerly breeze, we launched the boats, embarked the stores and the sick, and, at eight o'clock, were under way. 
We really were under way at last; and it was our business to forget that we had been in the same circumstances, the year before, in the same place; to feel that the time for exertion was now come, and those exertions to be at length rewarded; to exchange hope for certainty, and to see, in the mind's eye, the whole strait open before us, and our little fleet sailing with a fair wind through that bay which was now, in our views, England and home.

We soon rounded the north cape of Batty bay, and, finding a lane of water, crossed Elwin's bay at midnight; reaching, on the Angust 16. sixteenth, that spot to the north of it where we had pitched our tents on the twenty-eighth of August in the preceding year. I know not if all were here quite free of recollections to damp our new hopes. The difference in time was but twelve days; and should those days pass as they had done in the former, it might still be our fate to return to our last winter's home, and there to end our toils as it was but too easy to anticipate; the frrst whose fortune it should be, in a frozen grave, and the last in the maws of bears and foxes.

We found here no passage to the eastward, but the lane of water still extended towards the north; so that our stay was of no longer duration than was indispensable for rest. As we proceeded, the open water increased in breadth; and, at eight in the evening, we reached our former position at the north-eastern cape of America. A view from the hill here, showed that the ice to the northward and north-eastward was in such a state as to admit of sailing through it; but as it blew too hard to venture among it in the night, we pitched our tents for rest.

August 17. At three in the morning we embarked once more, leaving an 
additional note of our proceedings, in the same place where the former was concealed. It was calm, and we held on to the eastward by rowing, until, at noon, we reached the edge of the packed ice, through many streams of floating pieces; when we found that its extremity was but a mile to the northward. A southerly breeze then springing up, enabled us to round it: when, finding the water open, we stood on through it, and reached the eastern shore of the strait at three in the afternoon. In a few hours we had at length effected that for which we had formerly waited in vain so many days, and which, it is likely, could not have been effected in any of the years that we had been imprisoned in this country.

Accustomed as we were to the ice, to its caprices, and to its sudden and unexpected alterations, it was a change like that of magic, to find that solid mass of ocean which was but too fresh in our memories, which we had looked at for so many years as if it was fixed for ever in a repose which nothing could hereafter disturb, suddenly converted into water; navigable, and navigable to us, who had almost forgotten what it was to float at freedom on the seas. It was at times scarcely to be believed: and he who dozed to awake again, had for a moment to renew the conviction that he was at length a seaman on his own element, that his boat once more rose on the waves beneath him, and that when the winds blew, it obeyed his will and his hand.

Thus we ran quickly along the shore as the breeze increased; and, passing Eardly point, were at length compelled, by the rising of this breeze to a gale accompanied by hard squalls, to take shelter on a beach twelve miles west of Cape York; having made, on this day, a run of seventy-two miles. 
Augist 18. The wind moderating, and it at length becoming calm, we were obliged, in the morning, to take to the oars; and finding no ice to obstruct us, rowed along to the eastward, and by midnight rested for a short time at the cape to the east of Admiralty inlet. On the August 19. next day, the weather being the same, we were halfway between this place and that termed Navy-board inlet, by eight in the morning; when, the men being exhausted with nearly twenty hours' rowing, we stopped on the beach and pitched our tents. The weather had not yet become warm, clear as the water might be; since the night temperature had never exceeded $35^{\circ}$, nor that of the day $40^{\circ}$.

We were soon driven from this exposed place by the coming on of an easterly wind; and thus, taking once more to the oars, we rowed along among icebergs, till we arrived at an excellent harbour, receiving a considerable stream, where we were protected by these heavy masses, while we could, if necessary, haul the boats into a pool at the month of the river. We had thus gained five miles more; and being six or seven to the west of Navy-board inlet, were within eighty of Possession bay.

August 20. It began to blow hard last night with a north-east wind, and a heavy sea, which continued this day; blocking us up completely, but allowing us to hanl up the boats for repair. Growing worse at August 21. length, we brought them into the inner harbour which the pool formed; when, increasing to a violent gale, all the icebergs which had arranged themselves into an outer one, broke away and disappeared. There was, with this storm, a steady fall of mixed rain and snow, and the thermometer subsided to $34^{\circ}$.

August 22. It had become prudent to reduce ourselves, once more, to a two- 
thirds allowance; and thus were we imprisoned on the twenty-August 23 third and twenty-fourth, by a continuance of the gale, with fog and rain; the thermometer falling to $29^{\circ}$; a degree of cold which was severely felt by the sick people.

The wind at length abated, and the sea came down, so that we August 25. launched the boats; and it being by that time calm, we rowed to the eastward across Navy-board inlet, passing through several streams of ice; when, the men being exhausted by twelve hours' labour, we found a harbour after a progress of ten miles, and pitched our tents at the mouth of another river; there resting, and repairing the boats, which were not in the best condition.

At four in the morning, when all were asleep, the look-out man, August 26. David Wood, thought he discovered a sail in the offing, and immediately informed Commander Ross, who, by means of his glass, soon saw that it was, in reality, a ship. All hands were immediately out of their tents and on the beach, discussing her rig, quality, and course; though there were still some despairers who maintained that it was only an iceberg.

No time was however lost: the boats were launched, and signats made by burning wet powder; when, completing our embarkation, we left our little harbour at six o'clock. Our progress was tedious, owing to alternate calms, and light airs blowing in every direction; yet we made way towards the vessel, and had it remained calm where she was, should soon have been alongside. Unluckily, a breeze just then sprang up, and she made all sail to the southeastward; by which means the boat that was foremost was soon left astern, while the other two were steering more to the eastward, with the hopes of cutting her off. 
About ten o'clock we saw another sail to the northward, which appeared to be lying to for her boats; thinking, at one time, when she hove to, that she had seen us. That, however, proved not to be the case, as she soon bore up under all sail. In no long time it was apparent that she was fast leaving us; and it was the most anxious moment that we had yet experienced, to find that we were near to no less than two ships, either of which would have put an end to all our fears and all our toils, and that we should probably reach neither.

It was necessary, however, to keep up the courage of the men, by assuring them, from time to time, that we were coming up with her; when, most fortunately, it fell calm, and we really gained so fast, that, at eleven o'clock we saw her heave to with all sails aback, and lower down a boat, which rowed immediately towards our own.

She was soon alongside, when the mate in command addressed us, by presuming that we had met with some misfortune and lost our ship. This being answered in the affirmative, I requested to know the name of his vessel, and expressed our wish to be taken on board. I was answered that it was " the Isabella of Hull, once commanded by Captain Ross ;" on which I stated that I was the identical man in question, and my people the crew of the Victory. That the mate, who commanded this boat, was as much astonished at this information as he appeared to be, I do not doubt; while, with the usual blunderheadedness of men on such occasions, lie assured me that I had been dead two years. I easily convinced him, however, that what ought to have been true, according to his estimate, was a somewhat premature conclusion; as the bear-like form of the whole set of us might have shown him, had he taken time to con- 


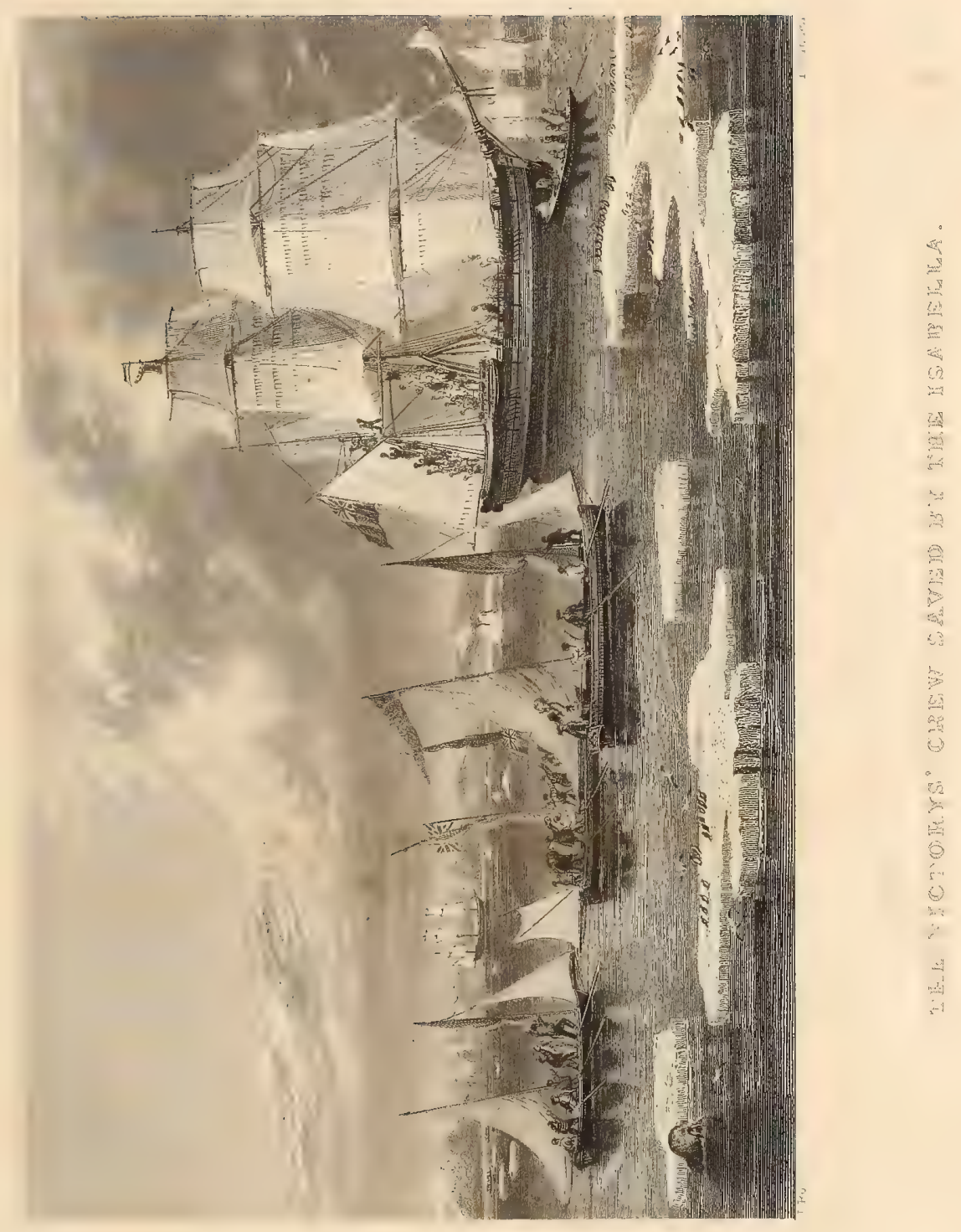



sider, that we were certainly not whaling gentlemen, and that we carried tolerable evidence of our being " true men, and no impostors," on our backs, and in our starved and unshaven countenances. A hearty congratulation followed of course, in the true seaman style, and, after a few natural inquiries, he added that the Isabella was commanded by Captain Humphreys; when he immediately went off in his boat to communicate his information on board; repeating that we had long been given up as lost, not by them alone, but by all England.

As we approached slowly after him, to the ship, he jumped up the side, and in a minute the rigging was manned; while we were saluted with three cheers as we came within cable's length, and were not long in getting on board of my old vessel, where we were all received by Captain Humphreys with a hearty seaman's welcome.

Though we had not been supported by our names and characters, we should not the less have claimed, from charity, the attentions that we received, for never was seen a more miserable-looking set of wretches; while, that we were but a repulsive-looking people, none of us could doubt. If, to be poor, wretchedly poor, as far as all our present property was concerned, was to have a claim on charity, no one could well deserve it more; but if, to look so, be to frighten away the so called charitable, no beggar that wanders in Ireland could have outdone us in exciting the repugnance of those who have not known what poverty can be. Unshaven since I know not when, dirty, dressed in the rags of wild beasts instead of the tatters of civilization, and starved to the very bones, our gaunt and grim looks, when contrasted with those of the well-dressed and well-fed men around us, made us all feel, I believe for the first time, 
what we really were, as well as what we seemed to others. Poverty is without half its mark, unless it be contrasted with wealth : and what we might have known to be true in the past days, we had forgotten to think of, till we were thus reminded of what we truly were, as well as seemed to be,

But the ludicrous soon took place of all other feelings; in such a crowd and such confusion, all serious thought was impossible, while the new buoyancy of our spirits made us abundantly willing to be amused by the scene which now opened. Every man was hungry and was to be fed, all were ragged and were to be clothed, there was not one to whom washing was not indispensable, nor one whom his beard did not deprive of all English semblance. All, every thing, too, was to be done at once; it was washing, dressing, shaving, eating, all intermingled, it was all the materials of each jumbled together; while, in the midst of all, there were interminable questions to be asked and answered on all sides; the adventures of the Victory, our own escapes, the politics of England, and the news which was now four years old. But all subsided into peace at last. The sick were accommodated, the seamen disposed of, and all was done, for all of us, which care and kindness could perform. Night at length brought quiet and serious thoughts; and I trust there was not one man among us who did not then express, where it was due, his gratitude for that interposition which had raised us all from a despair which none could now forget, and had brought us from the very borders of a not distant grave, to life and friends and civilization.

Long accustomed, however, to a cold bed on the hard snow or the bare rock, few could sleep amid the comfort of our new accommo- 
dations. I was myself compelled to leave the bed which had been kindly assigned me, and take my abode in a chair for the night, nor did it fare much better with the rest. It was for time to reconcile us to this sudden and violent change, to break through what had become habit, and to inure us once more to the usages of our former days. 


\section{CHAPTER LVII.}

PROCEEDINGS ON BOARD OF THE ISABELLA-SURVEY OF THE COAST -DEPARTURE-ARRIVAL AT HULL, AND IN LONDON.

1833. ON conversing with Captain Humphreys this morning, I found that he had taken twenty-seven fish, which was but two-thirds of a cargo, and that he purposed yet to remain out for some time. The Isabella had gone up Prince Regent's inlet, as far as Mount Sherrar, followed by the William Lee, which was the vessel that we had seen, and was now in sight; while we intended to send on board of her a part of our crew. He had made a bold attempt to cross Prince Regent's inlet to Leopold's islands, in hopes of finding some traces of us, rather than ourselves; but had been stopped at about two-thirds of the way, by a field of ice. He had run along the edge of this on the day before we crossed, and it was in this manner that we had missed him ; while it was on his return that we met, after he had examined the eastern shore for us in vain. That he had not noticed our boats, though he had seen them, arose from his having mistaken them for those of the William Lee.

Being desirous to leave, at Possession bay, a notice to any vessel which might land there in search of us, as also to verify my chro- 
nometer, I was landed for these purposes; and, after burying a bottle, with a state of the facts, at the same cairn which we had built in 1818, we returned on board and bore up. Before noon, keeping on the outside of the land ice, we had rounded Cape Graham Moore; and, after some considerable difficulties among the floating pieces and the icebergs, attained a place of safety, though continuing beset.

On Sunday, divine service was performed; giving us a now public opportunity of offering our thanksgivings for our almost miraculous deliverance.

The William Lee and some other vessels were now seen at the outward edge of the ice; but we did not ourselves get clear till the thirteenth, when, with the aid of the sails, we warped out, and, standing to the southward, fell in with the fleet of whalers on the fishing ground. From each vessel the master came on board to welcome us; and those from Hull and Newcastle in particular, brought us presents from their stock, which were very acceptable, and as thankfully received.

We were now for several days on the Isabella and Alexander banks, which had been unwarrantably expunged from the charts of my voyage in 1818. I, therefore, landed at Cape Bisson, and, by an observed difference of longitude, established the truth of my former observations. These coincided with the judgment of Captain Humphreys; and under the facilities which he afforded me, I resurveyed the coast, with several of the bays and inlets; with the intention of publishing a special chart of a place rendered so important by its abundant fishery.

Towards the end of the month the winter set in with unusual 
severity, and it became evident that we could not remain much longer in those seas. The Clarendon, which was in company, departed without taking the letters which I had intended to send by her; though, had we not been obliged to land some men in Orkney, we should have been at home as soon as that vessel.

It was on the thirtieth of September that we quitted Davis's straits; and on the twelfth of October, after only a twelve days' passage, we landed at Stromness. We were detained on the two next at the Long Hope; from which, sailing on the fifteenth, we reached the Humber on the eighteenth, and proceeded to $\mathrm{Hull}$ in the Rotterdam steam-boat.

The news of our arrival having preceded us, it was with some difficulty we could reach the inn: where we shortly received visits of welcome from the Mayor and Corporation, the officers of the 'Trinity-house, and the Philosophical Society, together with many of the principal persons of this ancient place. The freedom of the town was afterwards conferred on me; and, after a public entertainment, we all embarked in the steam-boat for London, where we arrived on the nineteenth. Here I immediately reported myself to the Secretary of the Admiralty, and on the next morning, caused myself to be presented to His Majesty at Windsor : receiving permission to dedicate my journal to him, and to add the name of William the Fourth to the Magnetic Pole. 
A D D E N D A. 



\section{A D D ENDA.}

ON my arrival in London on the 20th of October, 1833, it became my first duty to repair to the royal palace at $W$ indsor, with an account of my voyage, and to lay at the feet of His Majesty the British flag which had been hoisted on the Magnetic Pole. I had the honour of being most graciously received by His Majesty, who had always taken a deep interest in my enterprise, and who immediately granted me permission to inscribe his illustrious name, and that of Her Majesty the Queen, on my chart at the Magnetic Pole; and commanded me to place around it the names of the Royal Family, and the reigning crowned heads of Europe. On the 21 st my letter (appended) was read at the Admiralty, and subsequently published by order of the Right Honourable Sir James Graham, Bart., then First Lord of the Admiralty, with whom I had an interview immediately after his arrival in town.

The very liberal manner in which Government was pleased to reward the officers and men employed under my command will appear from the subjoined letters; but with regard to myself I was desired to wait until my case had been laid before the Cabinet; and it was not until late in February that it was intimated to me, that "His Majesty's Government considering the promotion of my nephew from Commander to Post Captain, the appointment of Mr. Thom to the Canopus, the promotion of Mr. M'Diarmid to Surgeon, and the payment of the wages of the crew, a sufficient recompense to me, and that nothing more would be given to me." Depending on the liberality of Government, I had declined receiving any of the subscriptions which had been proposed for the remuneration of my losses, and the small sum which had been subscribed at Plymouth was faithfully divided among the widows and relatives of the men who died, and one who lost his sight, on the voyage. I had no alternative but to apply to Parliament; and my case having been brought before the House of Commons by the Right Hon. R. Cutlar Fergusson, was discussed on the 17th of March, when, for the first time, I learnt that 
it was supposed my undertaking this enterprise was to recover a lost reputation. My case was, fortunately for me, submitted to a Select Committee of the House of Commons, and I had before this high tribunal an opportunity of refuting calumnies which had been industriously circulated against me, by producing documentary evidence that my conduct on the former expedition had been approved of by the Admiralty, as will appear by the following extract from the minutes of the Committee:

"Question-Did you conceive your reputation had been placed at all in question in consequence of the result of your first voyage?

"Answer-No, certainly not. The Admiralty approved of my conduct by giving me promotion subsequent to my return. When I was attacked anonymously I applied for a court-martial on my conduct, and was told by Lord Melville that I had received my promotion, and the court-martial was therefore unnecessary, and that I must not take notice of any thing that was written against me.

"Question-Did he at the same time state that you would not have received your promotion if the Admiralty had not been satisfied with your conduct?

"Answer-Yes. I have a letter from Lord Melville in proof of that fact, which I will read:

" 'I entertain no doubt whatever, from the general impression on my mind, and from reference to the dates of your promotion to the rank of Commander and of Captain, and to your employment in the intervening period, that your commission in 1818 was in consequence of former services. On the other hand, if your conduct as commander of the Isabella had been disapproved of at the Admiralty, most assuredly you would not have been promoted so soon after your return." "

The Committee having unanimously expressed their satisfaction, proceeded to inquire into my case relative to the last voyage, and made the following Report, which is extracted from the parliamentary papers :

The Select Committee consisted of-

$\begin{array}{ll}\text { Mr. Cutlar Fergusson } & \text { Mr. William Gladstone } \\ \text { Sir Robert Peel } & \text { Mr. Ewart } \\ \text { Sir Robert Inglis } & \text { Mr. Bannerman } \\ \text { Sir James Graham } & \text { Sir Andrew Agnew } \\ \text { Mr. Hutt } & \text { Mr. Edward Stewart } \\ \text { Mr. Aglionby } & \text { Mr. George Robinson } \\ \text { Mr. Chapman } & \text { Mr. Warburton } \\ \text { Sir Henry Hardinge } & \text { Lord Dudley Stuart } \\ \text { Sir Edward Codrington } & \text { Mr. Stuart Mackenzie }\end{array}$
Mr. Fox Talbot
Mr. Brotherton
Mr. Emerson Tennent
Mr. G. F. Young
Mr. Hughes Hughes
Lord Viscount Sandon
Mr. Labouchere
Mr. O'Connell

The said Committee had power to send for Persons, Papers, and Records, and five were declared to be a quorum. 


\section{R EPORT.}

Your Committee have not felt themselves either called upon by their order of reference or competent to give an opinion on the precise merits or extent of the discoveries made during the expedition commanded by Captain John Ross, whether in a geographical or scientific point of view; they have therefore confined themselves to such a general investigation into the facts, as may suffice for a decision on the main question committed to their hands, whether any reward should be allotted from the public purse, and to whom that reward is due.

In the course of this Inquiry they find that, in the year 1827, Captain Ross, stimulated by the desire of securing to this country the honour of settling the long-agitated question of a North-west Passage, proposed first to His Majesty's Government, and, on their declining to undertake it, to his friend, Mr. Felix Booth, to fit out an expedition for that purpose; that in the following year Mr. Booth, finding that the Act by which a parliamentary reward was held out for the discovery of a North-west Passage had been repealed, and that no suspicion of interested motives could any longer rest upon the undertaking, "having no other object in view than the advancement of the honour of his country and the interests of science, and to gratify the feelings of a friend," immediately agreed to Captain Ross's proposition, on condition that his connexion with the enterprise should not be made known: that accordingly, with the exception of about two thousand pounds expended by Captain Ross, Mr. Booth did actually bear all the charges of the expedition, to the amount of between seventeen and eighteen thousand pounds: that Captain Ross, being left by Mr. Booth at liberty to choose whom he pleased to accompany him, received gratuitous offers of zealous service and assistance, in any capacity, from those distinguished officers, Captains Back and Hoppner, offers equally creditable to Captain Ross and to the spirit of those who made them; but finally selected his nephew, Commander James Clark Ross, a young officer of distinguished scientific attainments, who had been employed in every previous expedition to the Arctic Seas; and having engaged Mr. Thom as purser, who, as well as Commander Ross, agreed to go without pay, and Mr. M`Diarmid as surgeon, together with a crew of nineteen men, sailed from England in May 1829: that in spite of the mutiny of the crew of a whaler, which had been engaged to accompany them with provisions, Captain Ross persevered, in reliance on finding the supplies which had been landed by the Fury, on Fury Beach, and then entered upon a course of sufferings, of dangers and discoveries, for a summary of which your Committee would refer the House to the following letter addressed by him to the Secretary of the Board of Admiralty. 
Copy of a Letter from Captain Ross to Captain the Honourable George Elliot, C.B.; dated on board the Isabella of Hull, Baffin's Bay, September 1833.

Sir,

On board the Isabella of Hull, Baffin's Bay. September 1833.

Knowing how deeply my Lord's Commissioners of the Admiralty are interested in the advancement of natural knowledge, and particularly in the improvement of geography, I have to acquaint you, for the information of their Lordships, that the expedition, the main object of which to solve if possible the question of a North-west Passage from the Atlantic to the Pacific Ocean, particularly by Prince Regent's Inlet, and which sailed from England in May 1829, notwithstanding the loss of the fore-mast, and other untoward circumstances, which obliged the vessel to refit in Greenland, reached the beach on which His Majesty's late ship Fury's stores were landed, on 13th August.

We found the boats, provisions, \&c. in excellent condition, but no vestige of the wreck. After completing in fuel and other necessaries, we sailed on the 14th, and on the following morning rounded Cape Garry, where our new discoveries commenced, and keeping the western shore close on board, ran down the coast in a S.W. by W. course, in from ten to twenty fathoms, until we had passed the latitude of $72^{\circ}$ north in longitude $94^{\circ}$ west; here we found a considerable inlet leading to the westward, the examination of which occupied two days; at this place we were first seriously obstructed by ice, which was now sure to extend, from the South Cape of the inlet, in a solid mass, round by south and east to E.N.E. Owing to this circumstance, the shallowness of the water, the rapidity of the tides, the tempestuous weather, the irregularity of the coast, and the numerous inlets and rocks, for which it is remarkable, our progress was no less dangerous than tedious, yet we succeeded in penetrating below the latitude of $70^{\circ}$ north in longitude $92^{\circ}$ west, where the land, after having carried us as far east as $90^{\circ}$, took a decided westerly direction, while land at the distance of forty miles to southward, was seen trending east and west. At this extreme point our progress was arrested on 1st October by an impenetrable barrier of ice. We, however, found an excellent wintering port which we named Felix Harbour.

Early in January 1830, we had the good fortune to establish a friendly intercourse with a most interesting association of natives, whom being insulated by nature, had never before communicated with strangers; from them we gradually obtained the important information that we had already seen the Continent of America, that, about forty miles to the south-west there were two great seas, one to the west, which was divided from that to the east by a narrow strait or neck of land. The verification of this intelligence either way, on which our future operations so materially depended, devolved on Commander Ross, who volunteered this service early in April, accompanied by one of the mates, and guided by two of the natives, proceeded to the spot, and found that the north land was connected to the south, by two ridges of high land, 15 miles in breadth; but taking into account a chain of fresh water lakes, which occupied the valleys between, the dry land, which actually separates the two oceans, is only five miles. This extraordinary isthmus was subsequently visited by myself, when Commander Ross proceeded minutely to survey the sea coast to the southward of the isthmus leading to the westward, which he succeeded in tracing to the 99 th degree, or to 220 miles of Cape Turnagain, of Franklin, to which point the land, after leading him into the \%0th degree of north latitude, trended directly; during the same journey he also surveyed 30 miles of the adjacent coast, or that to the north of the isthmus which, by also taking a westerly direction, formed the termination of the western sea into a gulf. The rest of this season was employed in tracing the sea coast south of the isthmus, leading to the eastward, which was done so as to leave no 
doubt that it joined, as the natives had previously informed us, to Ackullee, and the land forming Repulse Bay. It was also determined that there was no passage to the westward for 30 miles to the northward of our position.

This summer, like that of 1818 , was beautifully fine, but extremely unfavourable for navigation, and our object being now to try a more northern latitude, we waited with anxiety for the disruption of the ice, but in vain, and our utmost endeavours did not succeed in retracing our steps more than four miles, and it was not until the middle of November, that we succeeded in cutting the vessel into a place of security, which we named "Sheriff's Harbour." I may here mention, that we named the newly discovered continent, to the southward, "Boothia," as also the isthmus, the peninsula to the north, and the eastern sea, after my worthy friend, Felix Booth, Esq., the truly patriotic citizen of London, who, in the most disinterested manner enabled me to equip this expedition in a superior style.

The last winter was in temperature nearly equal to the means of what had been experienced on the four preceding voyages, but the winters of 1830 and 1831 set in with a degree of violence hitherto beyond record, the thermometer sank to $92^{\circ}$ below the freezing point, and the average of the year was $10^{\circ}$ below the preceding; but notwitstanding the severity of the summer, we travelled across the country to the West Sea, by a chain of lakes, 30 miles north of the isthmus, when Commander Ross succeeded in surveying 50 miles more of the coast leading to the N.W. and, by tracing the shore to the northward of our position, it was also fully proved that there could be no passage below the 71 st degree.

This autumn we succeeded in getting the vessel only 14 miles to the northward, and as we had not doubled the Eastern Cape, all hopes of saving the ship was at an end, and put quite beyond possibility by another very severe winter, and having only provisions to last us to June 1 , 1832, dispositions were accordingly made to leave the ship in her present port, which (after her) was named "Victory Harbour."* Provisions and fuel being carried forward in the spring, we left the ship on May 29, 1832, for Fury Beach, being the only chance left of saving our lives. Owing to the very rugged nature of the ice, we were obliged to keep either upon or close to the land, making the circuit of every bay, thus increasing our distance of 200 miles by nearly one half, and it was not until July 1 that we reached the beach, completely exhausted by hunger and fatigue.

A hut was speedily constructed, and the boats, three of which had been washed off the beach, but providentially driven on shore again, were repaired during this month; but the unusual heavy appearance of the ice afforded us no cheering prospect until August 1, when in three boats we reached the ill-fated spot where the Fury was first driven on shore, and it was not until September 1 we reached Leopold South Island, now established to be the N.E. point of America, in lat. $73^{\circ} 56^{\prime}$, and long. $90^{\circ}$ west. From the summit of the lofty mountain on the promontory we could see Prince Regent's Inlet, Barrow's Strait, and Lancaster Sound, which presented one impenetrable mass of ice just as I had seen it in 1818 ; here we remained in a state of anxiety and suspense, which may be easier imagined than described. All our attempts to push through were vain; at length being forced by want of provisions and the approach of a most severe winter to return to Fury Beach, where alone there remained wherewith to sustain life; there we arrived on October 7, after a most fatiguing and laborious march, having been obliged to leave our boats at Batty Bay. Our habitation, which consisted in a frame of spars, 32 feet by 16 , covered with canvas, was during the month of November enclosed, and the roof covered with snow from four to seven feet thick, which being saturated

* This has since been named Victoria Harbour, by permission of their Royal Highnesses the Duchess of Kent and Princess Victoria. 
with water when the temperature was $15^{\circ}$ below zero, immediately took the consistency of ice, and thus we actually became the inhabitants of an iceberg during one of the most severe winters hitherto recorded : our suffering's, aggravated by want of bedding, clothing, and animal food, need not be dwelt upon. Mr. C. Thomas, the carpenter, was the only man who perished at this beach, but three others, besides one who had lost his foot, were reduced to the last stage of debility, and only thirteen of our number were able to carry provisions in seven journeys of sixty-two miles each to Batty Bay. We left Fury Beach on July 8, carrying with us three sick men which were unable to walk, and in six days we reached the boats, where the sick daily recovered. Although the spring was mild it was not until August 15 that we had any cheering prospect, a gale from the westward having suddenly opened a lane of water along shore : in two days we reached our former position, and from the mountain we had the satisfaction of seeing clear water almost directly across Prince Regent's Inlet, which we crossed on the 17 th, and took shelter from a storm twelve miles to the eastward of Cape York. Next day, when the gale abated, we crossed Admiralty Inlet, and were detained six days on the coast by a strong north-east wind. On the 25 th we crossed Navy Board Inlet, and on the following morning, to our inexpressible joy, we descried a ship in the offing becalmed, which proved to be the Isabella, of Hull, the same ship which I commanded in 1818; at noon we reached her, when her enterprising commander, who had in vain searched for us in Prince Regent's Inlet, after giving us three cheers, received us with every demonstration of kindness and hospitality which humanity could dictate. I ought to mention, also, that Mr. Humphreys, by landing me at Possession Bay, and subsequently on the west coast of Baffin's Bay, afforded me an excellent opportunity of concluding my survey, and of verifying my former chart of that coast.

I now have the pleasing duty of calling the attention of their Lordships to the merits of Commander Ross, who was second in the direction of this expedition. The labours of this officer, who had the departments of Astronomy, Natural History, and Surveying, will speak for themselves in language beyond the ability of my pen, but they will be duly appreciated by their Lordships, and the learned bodies of which he is a member, and who are already well acquainted with his acquirements.

My steady and faithful friend, Mr. William Thom, of the Royal Navy, who was formerly with me in the Isabella, besides his duty as third in command, took charge of the Meteorological Journal; the distribution and economy of provisions, and to his judicious plans and suggestions must be attributed the uncommon degree of health which our crew enjoyed; and as two out of the three who died the four and a half years, were cut off early in the voyage by diseases not peculiar to the climate, only one man ean be said to have perished.

Mr. M'Diarmid, the surgeon, who had been several voyages to these regions, did justice to the high recommendation I received of him : he was successful in every amputation and operation which he performed, and wonderfully so in his treatment of the sick; and I have no hesitation in adding, that he would be an ornament to His Majesty's service.

Commander Ross, Mr. Thom, and myself, have, indeed, been serving without pay, but, in common with the crew, have lost our all; which I regret the more, because it puts it totally out of my power adequately to remunerate my fellow-sufferers, whose case I cannot but recommend for their Lordship's consideration.

We have, however, the consolation, that the results of this expedition have been conclusive, and to science highly important; and may be briefly comprehended in the following words: The discovery of the Gulf of Boothia, the Continent and Isthmus of Boothia Felix, and a vast number of islands, rivers, and lakes; the undeniable establishment, that the N.E. point of America extends to the 74th degree of north latitude. Valuable observations of every kind, 
but particularly on the magnet; and to crown all, we have had the honour of placing the illustrious name of our most gracious Sovereign, William the Fourth, on the true position of the Magnetic Pole.

I cannot conclude this letter, Sir, without acknowledging the important advantages we obtained, from the valuable publications of Sir Edward Parry and Sir John Franklin, and the communication kindly made to us by these distinguished officers before our departure from England.

But the glory of this enterprise is entirely due to Him whose divine favour has been most especially manifested towards us, who guided and directed all our steps, who mercifully provided effectual means for our preservation, and who, even after the devices and inventions of man had utterly failed, crowned our humble endeavours with complete success.

I have the honour to be, \&c.

JOHN ROSS, Capt. R.N.

Your Committee have found the statements contained in the above letter confirmed, as far as they have been examined, by the evidence which has appeared before them; and, supported by the opinions of Captain Beaufort, hydrographer to the Admiralty, of Mr. Children, one of the secretaries of the Royal Society, and of Professor Barlow, who has made the magnetic variations his particular study, they see no reason to doubt that Captain Ross nearly approached, and that Commander Ross actually reached, the Magnetic Pole.

The importance, especially to a maritime nation, of this discovery, and of the observations connected with magnetic science, arising thereout, is most highly estimated by the scientific witnesses who have been examined, and is further attested by the zeal with which this branch of science has been of late pursued by eminent men in every country, and by the expense which several foreign governments have of late years incurred for the same object.

Under these circumstances your Committee can have no hesitation in reporting, that a great public service has been performed. Independently of the demonstration that one passage, which had been considered by preceding navigators to be one of the most likely to lead from the Atlantic to the Pacific Ocean, does not exist, thus narrowing the field for future expeditions, if such should ever be undertaken; independently of the addition of between six and seven hundred miles of coast to our geographical knowledge, and of the valuable additions to magnetic science and meteorology, which this expedition will supply, your Committee cannot overlook the public service which is rendered to a maritime country, especially in time of peace, by deeds of daring enterprise and patient endurance of hardship, which excite the public sympathy and enlist the general feeling in favour of maritime adventure. Of this result they have strong evidence in the national subscription which furnished the funds for the expedition of Captain Back, in search of Captain Ross and his gallant party, to which the Government also contributed $2000 l$.

To the importance of these considerations, your Committee are happy to have to report that His Majesty's Government has not been insensible. Although Captain 
Ross's expedition was undertaken entirely on private risk, and the Board of Admiralty could not therefore be held responsible for any liabilities incurred, or be called upon in strictness to notice in any way the services of the individuals engaged in it, yet, as far as the power of the Admiralty extends, none of these services has gone unnoticed or unrewarded. It appears from a memorandum delivered in to your Committee by the Admiralty, that "all the men have received double full pay until they finally abandoned their ship, and full pay after that until their arrival in England, amounting to the gross sum of $4580 l$.; that they have besides been employed in eligible situations in the dock yards, or placed in others that will lead to promotion;" that Mr. Abernethy, the gunner, " has been promoted, and appointed to the Seringapatam;" that Mr. Thom, purser, "has been appointed to the lucrative situation of purser of the Canopus, of eighty-four guns;" that Mr. M'Diarmid, the medical officer of the expedition, " has been appointed assistant-surgeon of the navy, and, when qualified to pass his examination, will be promoted to the rank of surgeon;" that Commander Ross, to whom it appears that the greater part of the scientific results of the expedition are due, " has been placed on full pay, and appointed commander of the Victory for twelve months, that he may by that length of service be enabled to receive the rank of postcaptain, which is by a special minute of the Admiralty ensured to him at the expiration of that time;" and that Captain John Humphreys, of the Isabella, to whose persevering humanity alone Captain Ross and his party, under Providence, in all probability owe their lives, has received that remuneration for the expense of bringing them home which, upon consideration, has been thought proper by the Admiralty, and which appears to your Committee to be a reasonable compensation. Captain Ross alone, the commander of the expedition, who had the anxious and painful responsibility of the health and discipline of the party for above four years, under circumstances of unparalleled difficulty and hardship, and who had the merit of maintaining both health and discipline in a remarkable degree (for only one man in twenty-three was lost in consequence of the expedition), is, owing to his rank, not in a situation to receive any reward from the Admiralty in the way of promotion. Having incurred expenses and losses to the amount of nearly three thousand pounds, and received no more than the half-pay which had accumulated during the expedition, he remains with the same rank with which he went out. Under these circumstances, and looking to the advantages to science and the honour to his country, which have resulted from the expedition under his command; looking to the expense which the country has been willing to incur on former occasions for similar expeditions, and to the rewards which it has voted even for less important and honourable objects, your Committee hope they are not transgressing the bounds of a due regard to public economy, in recommending that a sum of five thousand pounds be voted to Captain John Ross.

To Mr. Felix Booth, to whose modest public spirit and rare munificence this expedition is entirely due, your Committee regret that they have it not in their power to propose some fit token of public acknowledgment ; but they cannot forbear offering the tribute of their admiration and respect. 
The case of a poor man afflicted with blindness in consequence of the expedition, has been brought before the notice of your Committee by a member of the House; and your Conmittee beg to recommend it to such consideration, as to His Majesty's Government, after due investigation of the facts, may seem fit.

April, 1834.

LORD VISCOUNT SANDON, Chairman.

I may here mention that no subscription has ever been received by me for my own benefit.

\title{
A P P E N D I X.
}

\author{
APPENDIX, No. 1. \\ Copy of a Letter from Captain John Ross, R. N., to Captain the Hon. George Elliot, C. B., \\ dated October 22, 1833.
}

Portland Hotel, Oct. 22, 1833.

Sir,-The expedition from which I am now returned, having been undertaken in 1829 , at my own expense, I necessarily came under certain engagements with the crew, which according to my expectation at the time, might be likely to terminate in fifteen months, and in that case I should have been enabled to fulfil those engagements; but as the absence of the men has been protracted to four years and a half, the claims upon me have greatly increased, while by the loss of my vessel the means of discharging them has been much diminished.

In venturing to request you will submit my case to the Lords Commissioners of the Admiralty, I feel assured that the public nature of the undertaking, and the unparalleled sufferings which have attended it, will bring their Lordships to the consideration of the circumstances 1 have stated, with every disposition to afford me the means of discharging obligations of so sacred a character.

It is true that according to law, the men may not be able to compel the payment of their wages after October, 1831, when all hopes of saving the vessel led to her abandonment, but a sense of what is due to my character as an officer of the navy, and a feeling of what is due to the men, whose constancy was never shaken under the most appalling prospects, and to whose fidelity and obedience I owe so much, I should be ashamed of myself if I could for a moment entertain a thought of any subterfuge, whereby I might evade the payment of their well-earned wages; I am anxious, however, with my slender means, to appeal to their Lordships in the first instance, in the confident persuasion, that an undertaking so entirely of a naval nature, will receive their countenance and support, and that under their Lordships' recommendation, His Majesty's Government will be pleased to consider the voyage as so entirely directed to public objects, as fairly to claim, under the circumstances I have described, that the payment of the officers and men should become a public charge.

As the men have most of them arrived in town, and wait the adjustment of their claims, I need scarcely add, that it is very desirable that I should, with as little delay as possible, receive an intimation of their Lordships' decision upon this application.

I have the honour to be, Sir,

$$
\begin{aligned}
& \text { Your obedient Servant, } \\
& \text { (Signed) } \\
& 5 \mathrm{~B}
\end{aligned}
$$




\section{APPENDIX, No, 2.}

Copy of a Letter from Mr. Barrow to Captain. John Ross, R.N., dated Admirally, October 25, 1833.

Admiralty, Oct. 25, 1833.

Sir, - I have received and laid before my Lords Commissioners of the Admiralty your letter, dated on board the Isabella, of Hull, in Baffin's Bay, in September last, and I am commanded to express their Lordships' satisfaction at the providential deliverance of yourself and companions from a perilous situation, unequalled in the records of navigation, and their congratulations at your safe return.

I am, \&c.

(Signed) J. BARROW.

\section{APPENDIX, No. 3.}

Copy of a Letter from Captain John Ross, R.N., to Mr. Barrow, dated October 26, 1833.

Portland Hotel, Oct. 26, 1833.

Sir,-In consequence of a verbal communication with Sir Thomas Hardy, I have the honour to transmit for the consideration of the Lords Commissioners of the Admiralty, a List (see No. 5) of the officers and men employed on the late expedition to the Arctic Seas, showing the pay due to each on the principle that I should have felt it my duty to act upon towards them, had the discharge of those claims rested with myself, instead of being taken up by their Lordships, on the grounds of the public nature of the service to which the object of the expedition was directed; and I have reason to know that the officers and men will consider themselves fully recompensed by the proposed scale of pay.

I trust I may be allowed to take this opportunity to express for myself and for every person under my command, the deep sense we have of the kind protection so cheerfully extended to us by their Lordships.

$$
\text { I am, \&c. }
$$

(Signed)

JOHN ROSS, Capt. R.N.

\section{APPENDIX, No. 4.}

Copy of a Letter from Mr. Barrow to Captain John Ross, R.N., dated October 28, 1833.

Admiralty, Oct. 28, 1833.

Sir, - I have received and laid before my Lords Commissioners of the Admiralty your letter of the 26th instant, transmitting a list of the officers and men employed on your late expedition to the Arctic Seas, showing the amount of pay due to each, according to the scale by 
which you would have felt yourself bound to remunerate them for their services, and I am commanded by -their Lordships to acquaint you in reply, that although these men have: no claim on His Majesty's Government, inasmuch as the expedition was not sent out by the Board of Admiralty, yet, in consideration of its having been undertaken for the benefit of science, of the sufferings these men have undergone, the perilous situation in which they were placed for so long protracted a period, and their uniform good conduct under circumstances the most trying to which British seamen were perhaps ever exposed; and their Lordships being moreover satisfied of your utter inability to fulfil the engagements entered into by you, and of the destitute state in which these people have providentially arrived in their native country, have been induced under such peculiar circumstances from a feeling of humanity, immediately to relieve you from your engagement, and them from pressing necessity, rather than wait till Parliament shall be assembled, to which it is intended to submit the case; their Lordships have therefore directed the Accountant-General of the Navy to advance to you the sum of $4580 l .12 s .3 d$, as the amount which by your statement you feel yourself under an engagement to pay to the persons therein named; from each of whom on making them payments, you will take a stamped receipt as a voucher in full of all demands they may respectively have upon you.

I am, \&c.

(Signed)

J. BARROW.

APPENDIX, No. 5.

List of the Names and Sums of Money paid to the Crew of the Discovery Ship Victory, Captain John Ross, R.N., by Admiralty Order, October 28, 1833.

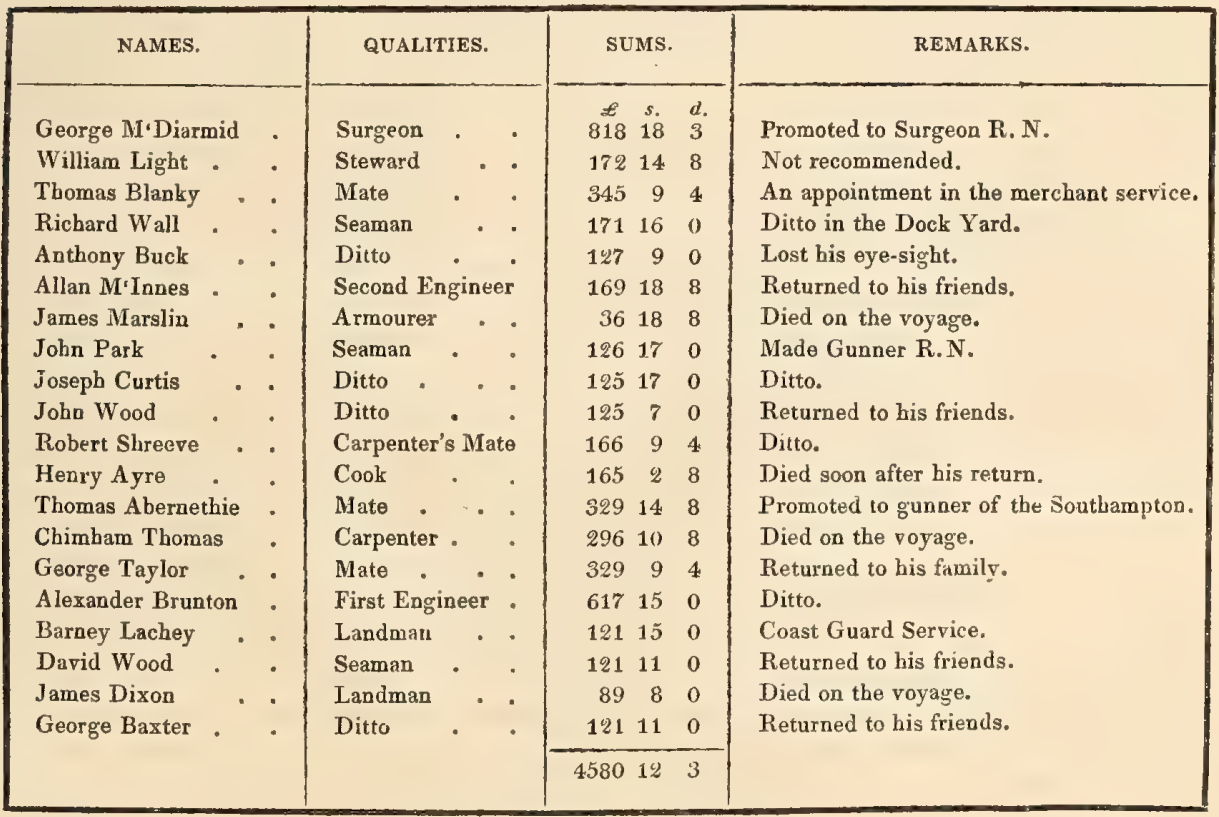


Captain Ross has produced receipts for the payment of all above sums except two (James Marslin and James Dixon, dead), whose wages have been repaid into the hands of the Treasurer. The representatives of James Marslin have made a claim for the arrears due, but it is still under consideration.
(Signed)
J. T. BRIGGS.

\section{Translation of the Esquimaux Hymn, page 76. \\ OF OUR KING. \\ Tune. - Ncellunakau tokoviksara.}

I.

Make many, O Father, the days of the king; make steadfast all his doings, preserving him on high; hear our prayers, and be gracious to our king.

II.

Let truth ever be the ornament of thine anointed, and let him every where show mildness as thou. Oh! hear our prayers, and be gracious to our king.

F I N IS.

C. WHITING, BEAUFORT LOUSE, STRAND. 


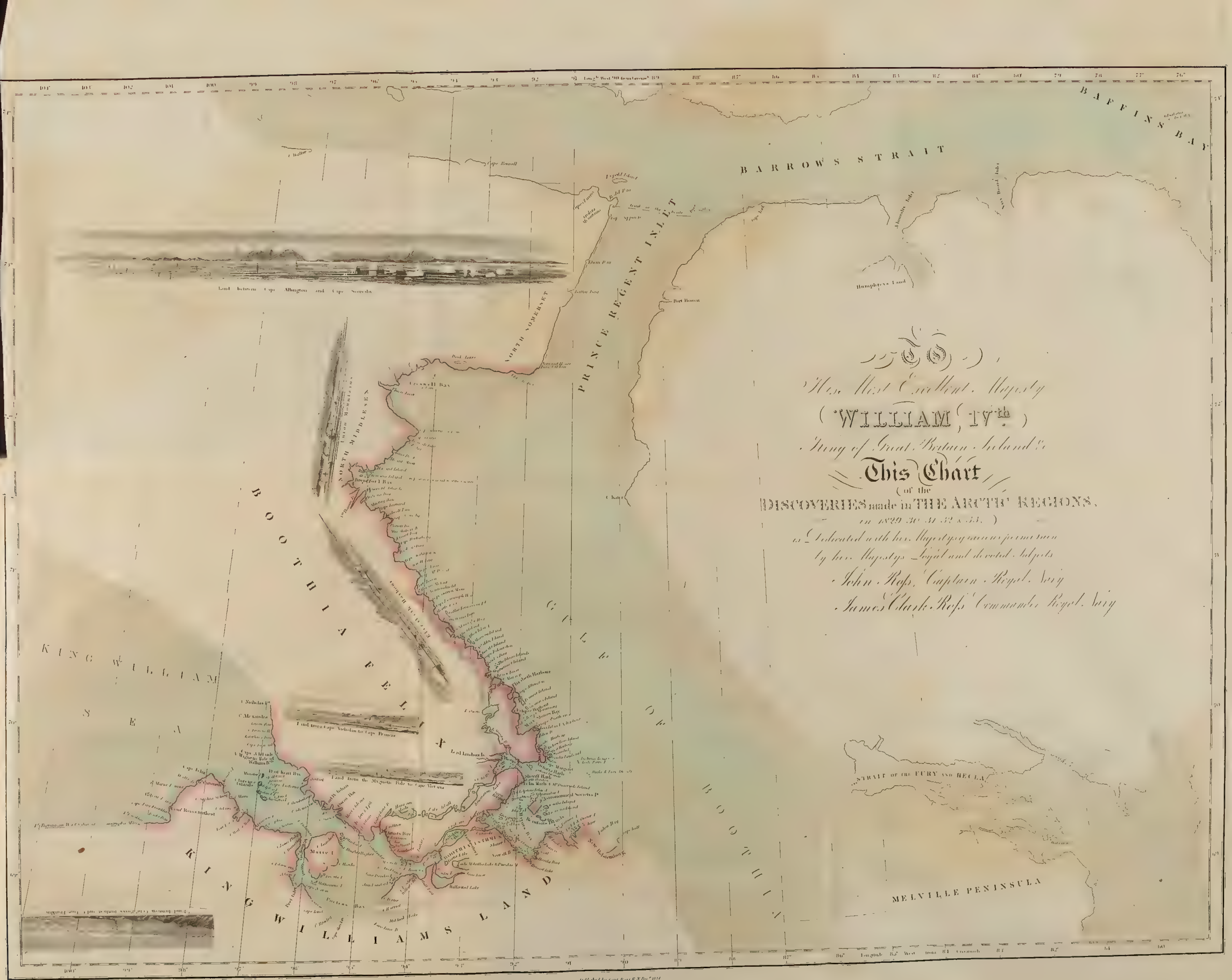






